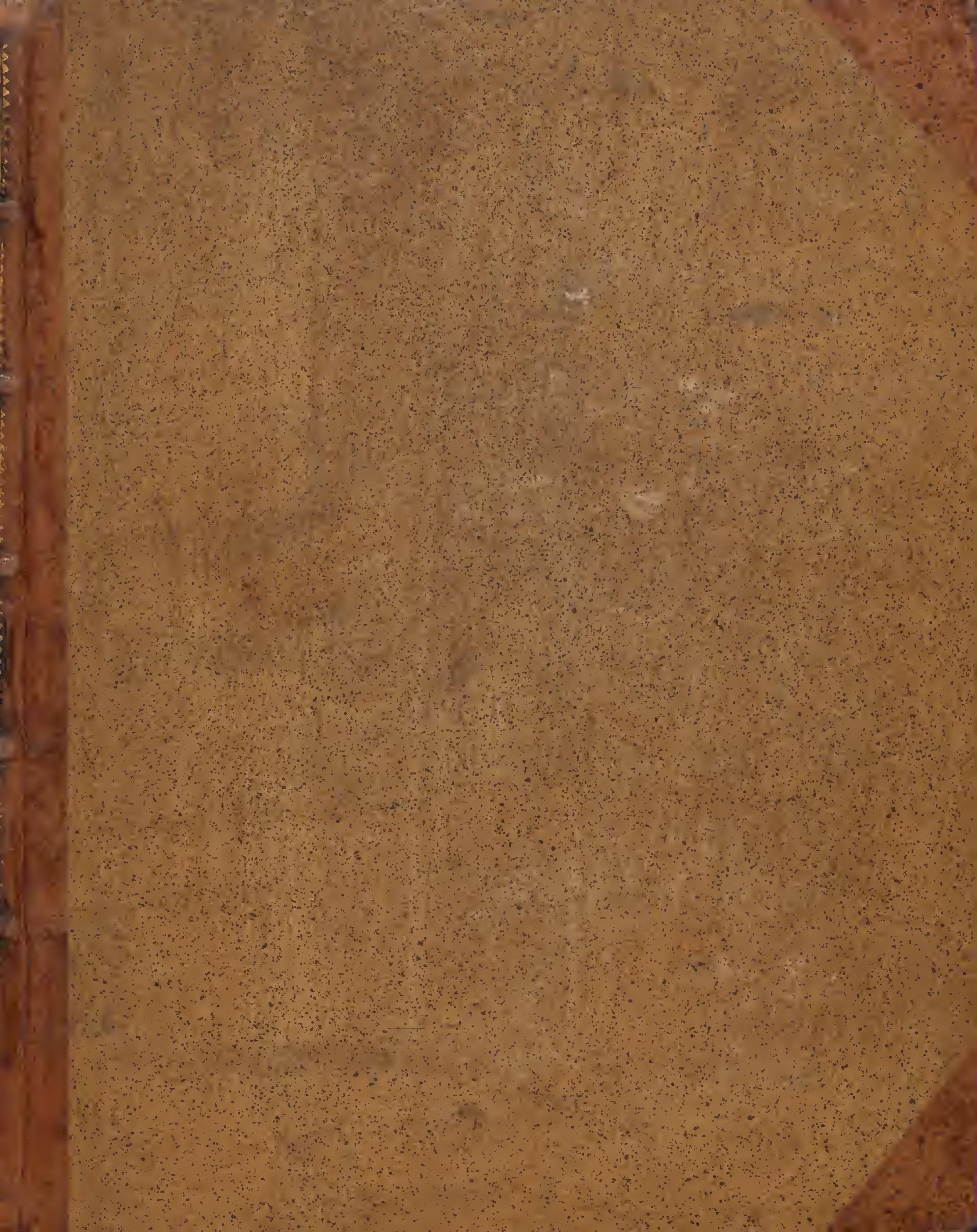








\section{DE A L G E M E N E E N B Y Z O N D E R E}

\section{NATUURLYKE HISTORIE.}

$$
\begin{array}{llllllllll}
A & G & T & S & T & E & D & E & E & \text { L. }
\end{array}
$$




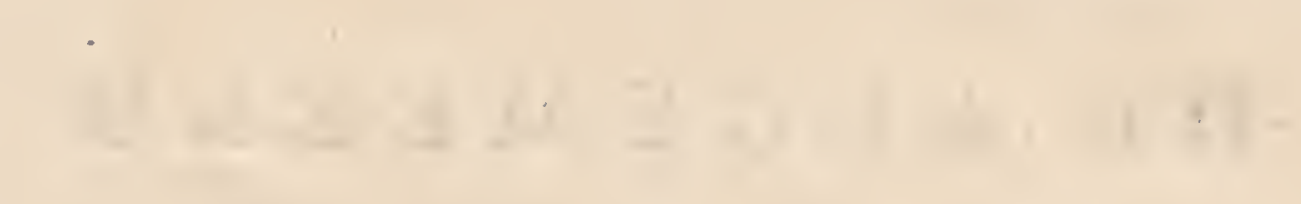

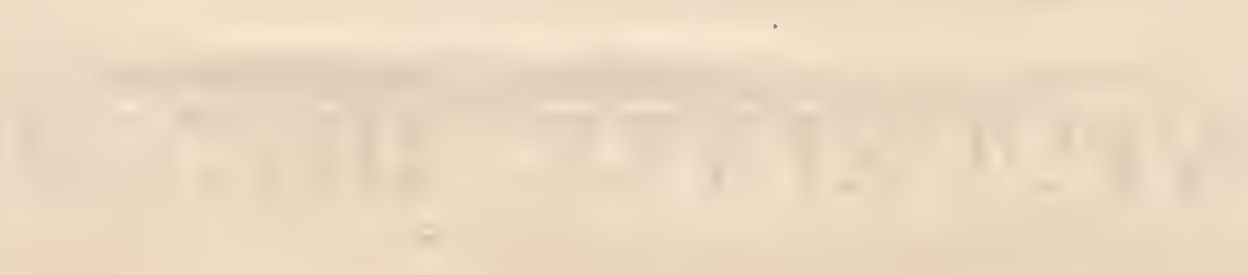


DEA L G E E E N E

E N B Y Z O N D E R E

\title{
NATUURLYKE HISTORIE,
}

\author{
$M \quad E \quad T \quad D \quad E$
}

B E S CHR Y V I G V A N

DES KONINGS KABINET.

$\begin{array}{llll}\mathrm{D} & \mathrm{O} & \mathrm{O} & \mathrm{R}\end{array}$

DE Heeren DE BUFFON EN DAUBENTON. A G T S T E D E E L.

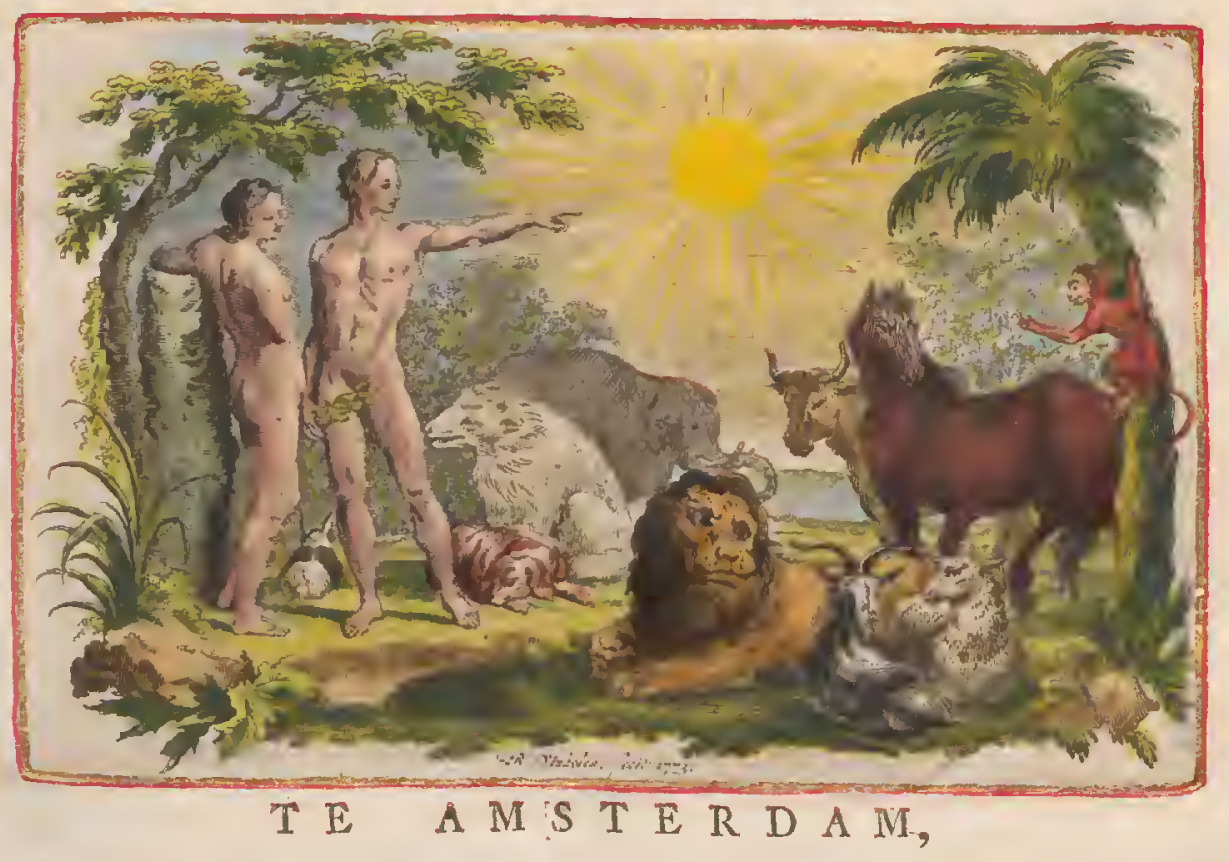

By. F. $H . \quad S \quad C \quad H \quad N \quad E \quad I \quad D \quad E \quad R$. M. D C C L X X V I.

Met Privilegie van de Heeren Staaten van Holland en Wefturiesland. 



\section{$\begin{array}{lllllllllllllllll}\text { I } & \mathbf{N} & \mathrm{H} & \mathrm{O} & \mathrm{U} & \mathrm{D}\end{array}$}

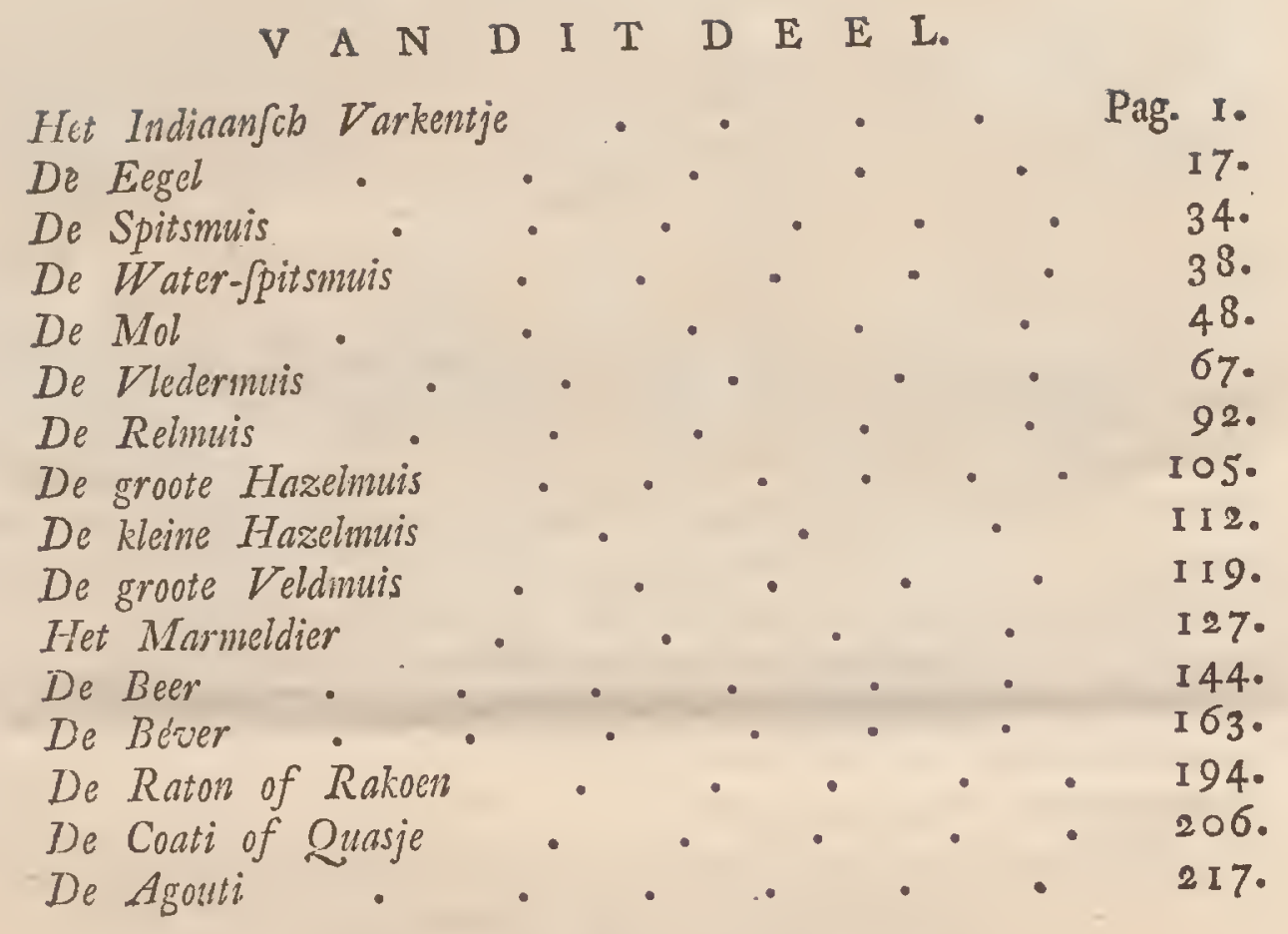

Door den Hr. DE BUFFON.

Vertaald

Door den Hr. C. van ENGELEN.

Befciryoing van bet Indianncb Varkentje . . . Pag. 4. Befcbryuing van den Eegel . . • . 20. Befcbryving van dat gedeelie van bet Kabinet, betwelk betrekking beeft tot de Natuurlyke Hiftorie van bet Indiaanfćs Varkentje en van den Eegel. 33. Befcbryving van de Spitsmuis . • • 36. leechryoing van de WTater-Spitsmuis . • • 39. Befcbryving van de Mol . • . • 52. Befcbryuing wan dat gedeelte wan bet Kabinet, betwelk betrekking beeft tot de Natuurlyke Hiftorie van de Spitsmuis, de Water-Jpitsmuis, en de Mol

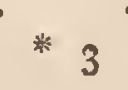


Befchryving der Vledermuizen

Befcbryving van dat gedeelte van bet Kabinet, betwelk betrekking beeft tot de Natuurlyke Hiflorie der

Befchryving van de Relmuis Vledermuizen

Befchryving van de groote Hazelmuis

Befcbryoing wan de kleine Hawelmuis

Befcbryving van dat gedeelte van bet Kabinet, betwelk betrekking beeft tot de Natuurlyke Hiftorie van de Relmuis, de groote Hawilmuis, en de klei. ne Hazelmuis

Befchryving van de groote Veldmuis

Befchryving van dat gedeelte van bet Kabinet, betwelk betrekking beeft tot de Natuurlyke Hiftorie van de groote Veldmuis en wan bet Marmeldier.

Befchryving van den Beer

Befchryving var den Béver

Befcbryving van dat gedeelte van bet Kabinet, betwelk betrekking beeft tot de Natuurlyke Hiftorie ran den Beer en van den Béver.

Befchryving van den Raton

Befcbryving van den Coati

Befchryving van den Agouti

Befchryving van dat gedeelte van bet Kabinet, betwelk be-

trekking beeft tot de Naturulyke Hiftorie van den Raton, van den Coati, en van den Agouti

Door den Hr. DAUBENTONo. 


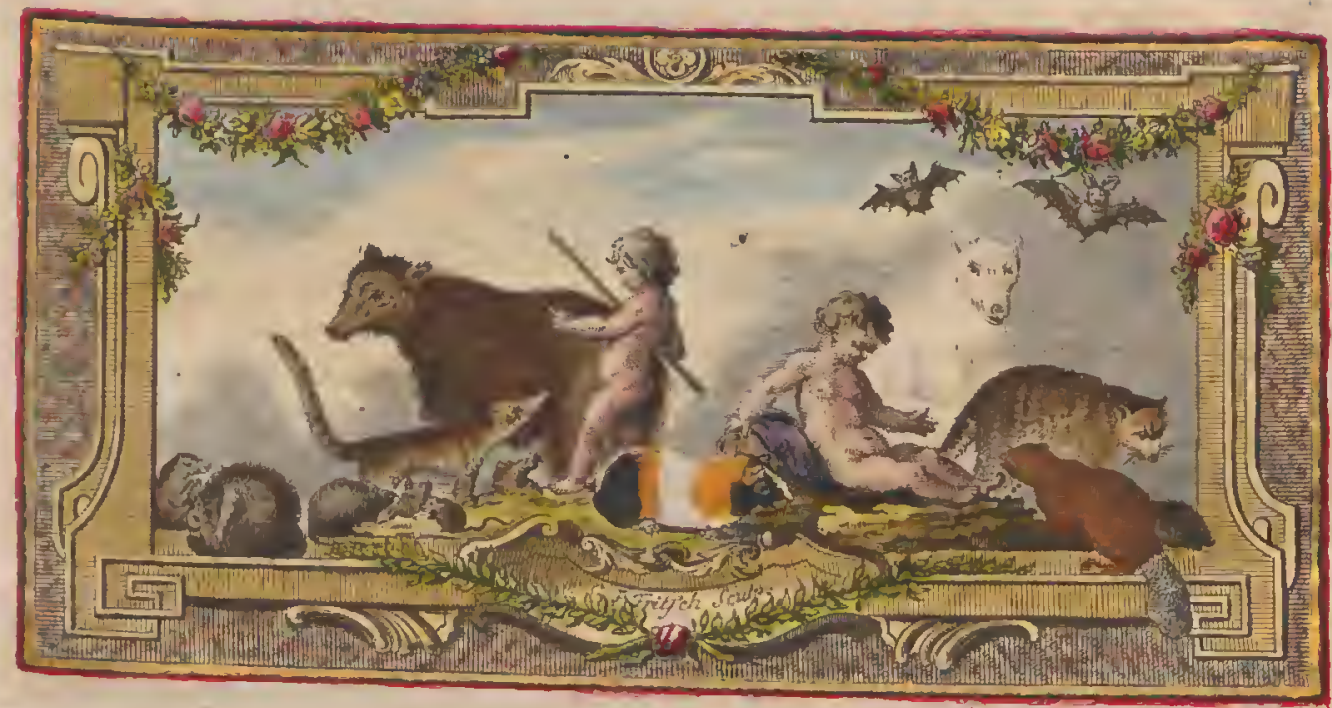

DE ALGEMEENE EN BYZONDERE

\section{NA T U URLYKE HISTORIE.}

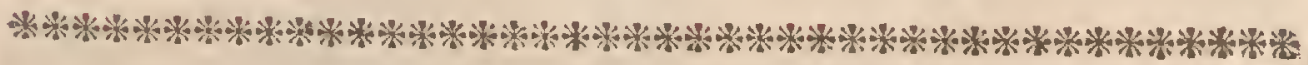

\section{HET INDIAANSCH VARKENTJE}

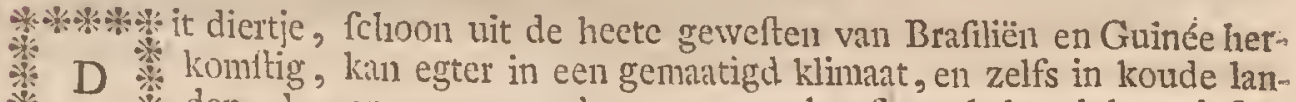

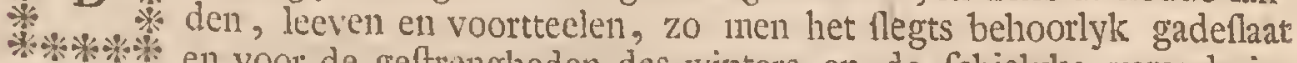
gen voor de geftrengheden des winters en de fchielyke veranderingen vin het weder beveiligt. Men fokt Indiaanfche varkentjes in Frankryl;, maar fchoon zy verbaazc1nd fterk voortteelen, 7.yn zy 'er egter in geen groot getal, omdat de zorg en oppafling, welke zy vorderen, nict vergoed worden

* Het Indiaanfch Varkentie heet in Brafiliën Cavia Cobaya; in 't Franfch Cocbon d'Inde: in 't Hoogduitch Indianifcb-Kinele, Indijcb-Säıle, Meer-Ferckel, Meer Scbruein; in 't Engelfch Guiny pig; in 't Zweedich Marfwin; in 't Poolfch Sivinka Zamorska.

Cavia Cabaya, Pison Hijt. Nat. pag. 102.

Cuniculus Indus. Gesiler Ican. Animal. Quadrup. pag. 106.

Mus, Jeu Cuniculus, Americanus $E^{\circ}$ Gunienfis, porcelli pilis E voce, Cavia Cobaya Brafilien.

Mibus diatus, Margravis. Ray Synopf. Animal. Quadrup. pag. 223.

Mius catuda, abrupta, palmis tetradncisylis, plantis tridactylis. LinNeres.

Cavia Cobaya Rrafilienfibus: quilufdam mus Pbaraonis, tactu pilojus, porcellus, mus In icus.

Kation , de Quadruped. pag. 49.

Cuniculus Indicuniculus ecoudatus, antitis, albus aut rufus, aut ex utrogue variegatus... VIII. Dre!' 
door het voordecl, dat men 'cr van bekomt: hun vel is naauwelyks van cenige warde; en hun vleefch, fchoon eetbar, is niet goed genoeg om veel gezogt te worden : het zou beter zyn, zo men hen in open perken of varanlden opvoedde, waarin zy de vrye lugt genooten, ruimte hadden on beweeging te maken, en kruiden nar humen zin verkiezen konden: de zulken, welken men onder dak in hokken opvoedt, hebben byna den zeifden flegten. fmaak als de tamme konynen, en $Z y$, die den zoner in ecn tuin hebben doorgebragt, hebben altoos een laften, maar minder onaangenaamen, fmaak.

Deze dieren zyn zo vroeg ritzig, en zo heet van geltel, dat zy malkanderen opzoeken en te famen koppelen vyf of zes wecken na hunne geboorte; zy hebben evenwel humnen volkomen groei niet, dan op de agt of negen maanden; men moet hieromtrent egter aanmerken, dat het voorllamelyk in uitwer1dige, in fchynbarre dikte en in vet is, dat zy meeft toeneemen, en dat de ontwilkkeling der vafte deelen reeds voor den ouderdom van vyf of zes mianden geëindigd is.

De wyfjes draagen flegts drie weeken, en wy hebben 'cr gezien, die op de. twee maanden na haare geboorte wierpen. Die eerfte dragten zyn zo talryk

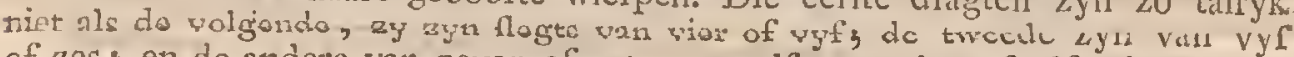
of zes; cn de andere van zeven of agt, en zelfs, van tien of elf: de moeder zoogt haare jongen maar twaalf of vecrtiell dagen; zy jaagt hen weg; zodra zy 't mannetje weder aanzockt, $c n$ dat is ten lateften drie weelken nadat zy geworpen hecft; en, zo de jongen niet weggaan, en by de moeder blyven willen, valt de vader hen op't lyf, ja mishandelt en doodthen: dus brengen deze dieren ten minften om de twee maanden voort, en gelyk de jongen op dezelfde wyze voortteelen, zo ftant men, na verloop van eenigen tyd, verbaafd over hunne fchielyke on onbedenkelyke vermenigvuldiging; van een enkel paar zoude men, in één jaar tyds, dinizend kunnen aanfolken; naar zy komen zo fchielyk om als zy in wezen raken; de koude en vogtigheid zyn hun doodelyk; zy laaten zig door de katten vernielen zonder zig te weer te ftellen; de moeders zelve fpringen niet voor hun in dc. bres; gelyk zy geen tyd hebben, om zig aan hunne jongen te verbinden, zo ftellen zy ook geene poogingen in 't werk om dezelve te behouden; de mannetjes bekonmeren 'er zig nog minder over, cn laaten zclve zig zotider weêrftand opvrecten: zy hebben geene zeer onderfcheiden aandoening of gewarwording, dan die van de liefde; dan kunnen zy toornig worden, dan vegten zy verwoed, en zy brengen zelfs malkandcren wel eens om hals, zo hunne drift aan 't zieden is, .. en. de twift het genot van cen vyfje betreft.

Zy brengen hun leeven door met flapen, koppelen, en ecten; hunne flanp is kort, matr wordt dikwils hervat; zy eeten op alle uuren van den dag cn den ungt; ell poogen zo dikwils te koppelen als zy eeten; zy drinken nooit, en evenwel pifien $z \mathrm{y}$ alle oogenthik; zy eeten allerhande foorten van groente, en vooral pieterfelie; zy verkiezen die plant zelfs boven zemelen, boven meel, en boven brood: zy houden ook vecl van appelen en andere vrugten; $z y$ ceten, met verhaafting, tennaftenby gelyk de lonynen, weinig tevens nuar zees: dikwils: zy hebben een geknor gelyk aan dat van een fpeenvarkentje; 
zy hebben ook eene foort van gekweel, waar mede zy hun vermak uitdrukken, terwyl zy by 't wyfje zyn, en een fcherpen fchreeuw, waarmede zy hume fmart te kennen geeven; zy zyn teder, huiverig, en men heeft werk om hen den winter door te krygen; men moet hen op eene gezonde, drooge, en warme, plaats houden: wanneer zy koud worden verzamelen zy zig en lluiten zig tegen malkanderen, en het gebeurt dikwils, dat zy, door de koude bevan. gen, allen te famen fterven.

Zy zyn uiteraast zagt en tam, zy doen geen kwaad, maar zy zyn even weinig gefchikt voor iets goeds; zy bebben geene verknogtheid; goedaartig door geftel, onderwerpelyk uit zwakheid, bykans ongevoelig voor alles, hebben $\mathrm{zy}$ het voorkomen van automates, van beweegende poppen, opgewonden om voortteteelen, en ecniglyk gemaakt om eene foort te vertoonen.

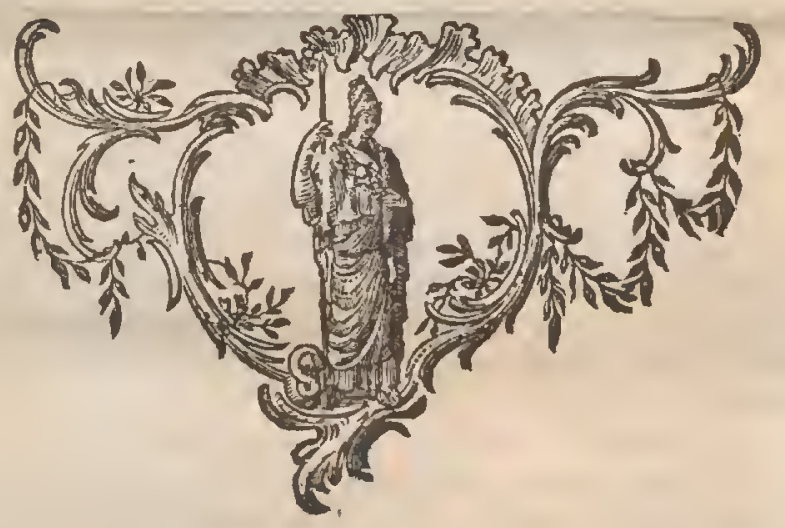




\section{BESCHR YVING VANHETINDIAANSCH \\ $V A R K E N T \mathscr{E}$.}

ज्ञ $\mathrm{D}$

it dier $(P l . I)$ is lclyk; men ziet nauwelyks deszelfs pooten; de hals verlieft zig, om zo tc ppreeken, in het ligham on den kop, welken laatiten men niet dan door de ooren bemerkt; de finuit is ftomp, en het agterfte gedeelte des lighaans loopt niet uit in een ftaat, gclyk by de meefte andere dieren: wanneer het Indiaanfch varken gaat, verlengt $z i g$ deszelfs lighaam, terwyl het ruft, trekt zig het zelve korter in, en zweltinde zyden; maar 't zy het beeft ruft of bewcegt, men onderfcheidt, in den eerthen opllag, geene van deszelfs declen, behalven de ooren, die boven aan den kop geplaatit zyn: zy zouden vry groot zyn, en hunne regtitaande plaating zoude hen vry duidelyk maken, zo het hair van het voorfte gedeelte des kops. niet byna even lang ware en dezelve voni een gedeelte hedekte; zy zyn rond. en hebben meer breedte dan hoogte.

Vall alle dieren, die reeds in, dit Werk befchreeven zyn, hebben de hass. en het konyn de meefte overeenkomft met het Indiaanfch varkentje, inzonderheid in de gedaante van den kop; die van het laatft is evenwel, naar evenredigheid, veel grooter, de ooren zyn veel korter, het voorhoofd heeft geen kromte, het einde van den bek is veel dikker dan by den has en 't konyn, en de bovenlip heeft vecl meer hoogte: fchoon dit dier den bok vanden haas heeft, is die bek egter niet gefpleeten dan ter zyner halve hoogte; de openingen der neusgaten zyn rond, verre van malkanderen af, en bygevolg zeer verfchillende van die van den has en het konyn, dic in malkandercn fchynen te loopen, en derhalven mar éne dwarfche lyn te maaken: de oogen van dit dier zyn rond, groot, en uitfpringende.

Daar zyn aan de voorfte voeten mar vier vingers $(A A, P l . I l$. $)$ drie celtagtige knobbeltjes $(B B)$ onder de agterhand, en een vierde $(C C)$ grooter dan de drie anderen, agter de voorhand; de agterfte voeten hebben maar drie vingers $(D)$ cn twee eeltagtige knobbeltjes onder den agtervoet, cn eene andere eeltagtigheid, dic de onderite zyde van den voorvoct beflaat.

Het hair is glad, en een duim lang; het is van ééne klcur van den wortel af tot aan den bovenften top; maar de varfchillende deelen des lighaams licb. hen vaalc, witte, of zwarte, vlakken, die in grootte, gedaante, en plaatfing, verfchillen, gelyk als in alle andere huisdicren: eenige Indiannfche varkentjes zyn geheel wit, andere hebben llegts witte en valle vlekken zonder zwart; daar zyn ook verfcheidenheden in de fterkte van de vale kleur; ik heb dezelve zeer lecvendig, en byna oranjeagtig, gezien in jonge. dicren, terwyl zy bleek en byna verdoofd was in de oude: de laatften zyn my ook voorgeko. men den finuit dikker en ruiger te lacbben, en daardoor lelyker te zyn, dan de jongen. 


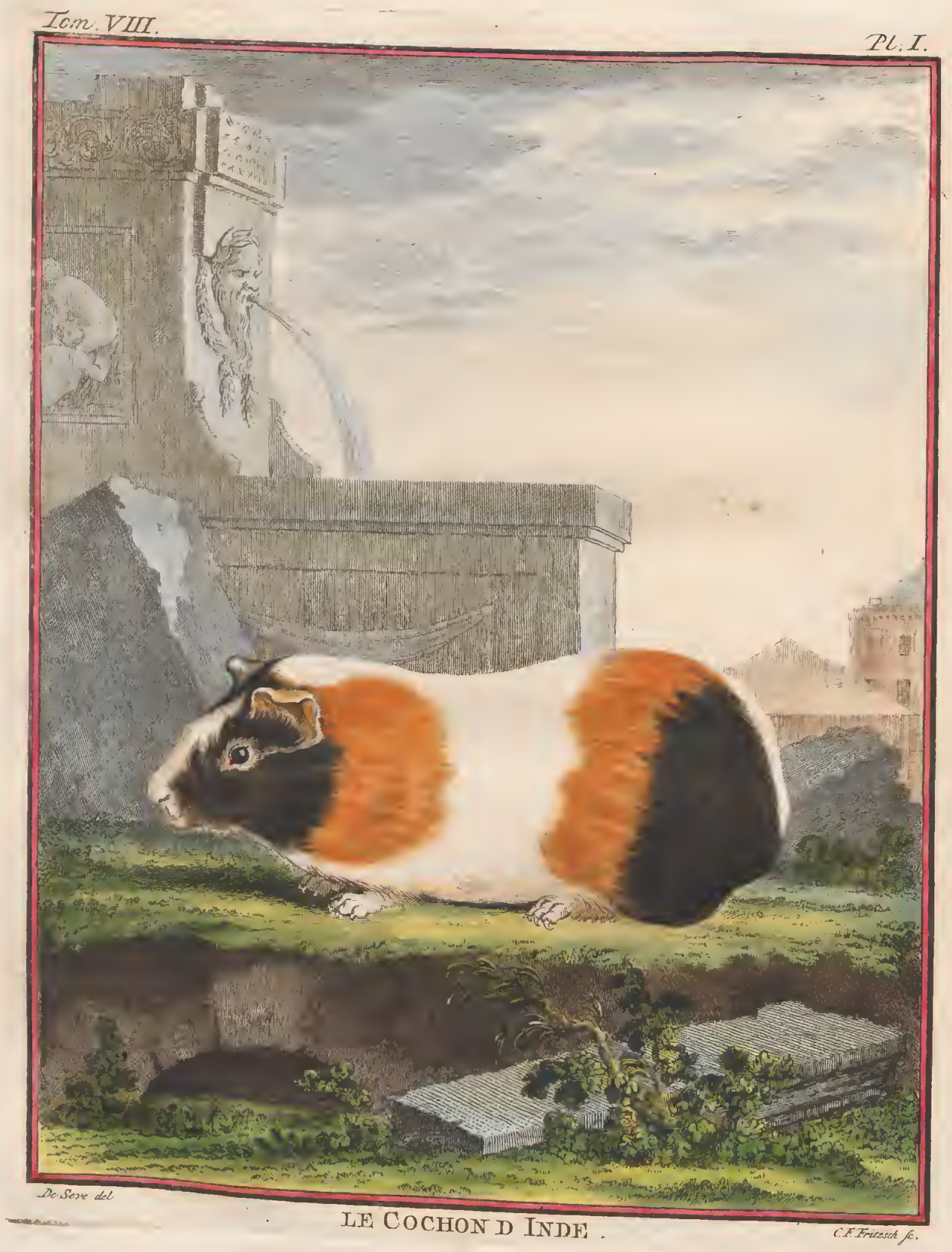




Tom VIII.

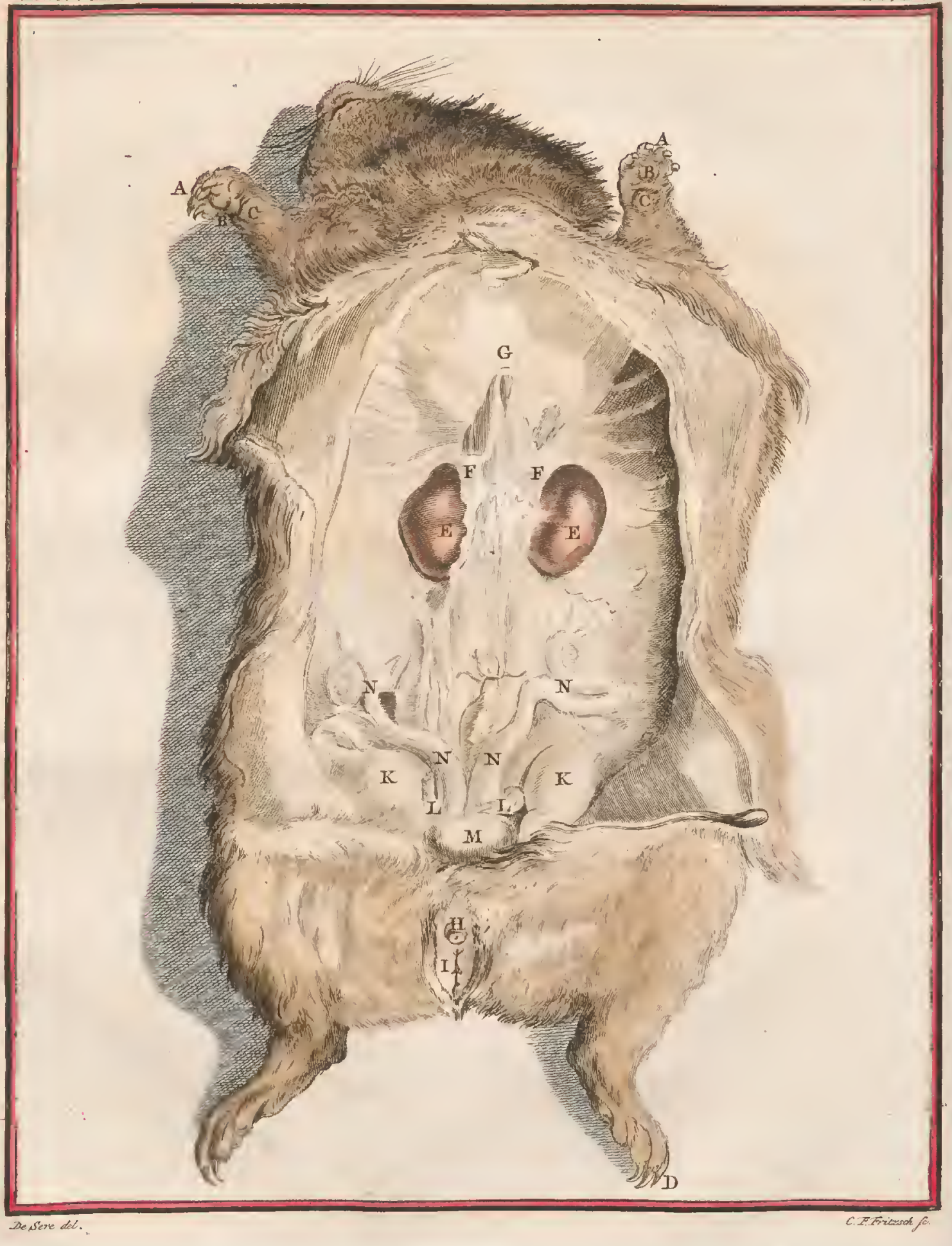




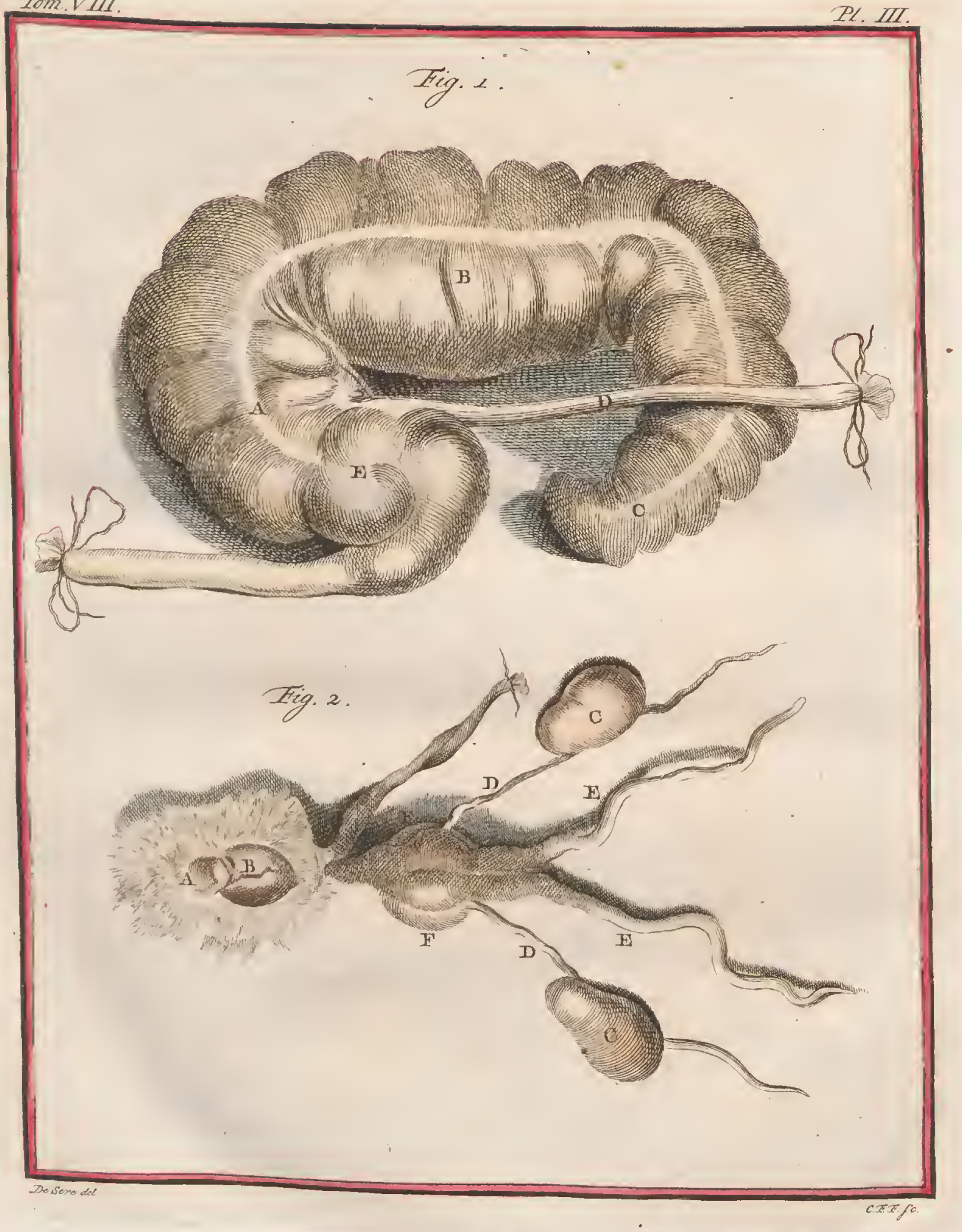




Lengte van het geheele lighaam in eene regte lyn gemeeten van het duimen, lynen.
eind van den bek tot aan den anrs

Hoogte van het voorfte ftel

Hoogte van het agterfte ftel

- 2. II.

Lengte van den kop van het einde van den bek tot ann het voorhoo $3 . \quad 3$.

Omtrek van het einde van den bek

Onitrek van de opening des monds

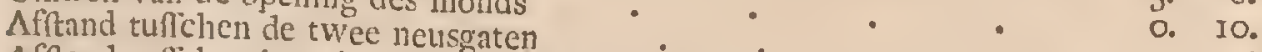

$\Lambda$ fftand tuffelien het einde van den bek en den voorften his ; $0.2 \frac{2}{2}$.

Afitand tuffehen den agterften hoek en 't oor voorften hoek van 't oog. I. 3.

Lengte van het oog van den eenen looek tot den anderen $-\quad . \quad 0.9$.

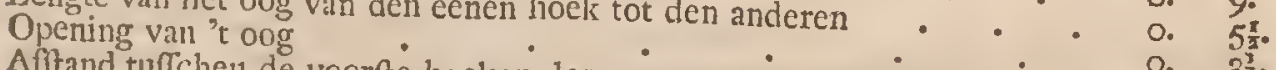

Afftand tuffchen de voorfte holken der ooren gemeeten naar de kromte van ${ }^{\circ} \quad 3 \frac{3}{3}$.
het neusheen

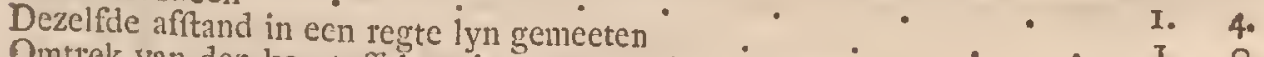

Omtrek van den kop tufichen de oogen en de ooren genomen - • . I. o.

Lengte der ooren

Omtrek van de bafis naar de uitwendige kromte $\dot{0}^{-} \cdot$ o. Io. $^{\circ}$

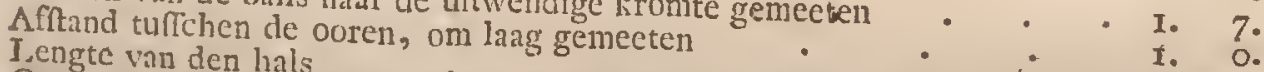

Omtrek van den hals $\quad \cdot \quad \cdot 0^{\circ}$ o. xi.

Omtrek van het lighaan agter de vooifte pooten gemeeten - - 4.5 .

$\begin{aligned} & \text { Ontrek aan de dikfte plaats gemecten pooten gemeeten } \\ & \text { Omtrek voor de agterft: pooten gemeeten }\end{aligned}-\begin{aligned} & . \\ & \text { - }\end{aligned}$

Isengte van den voorarm van den elleboug tot aan het gevirigt $\quad 5.9$.

Lengte van den voorarm by den elleboog

Dikie vin den vooram terzelfcier plaats $\quad \cdot \quad \cdot \quad \cdot \quad$ o. 8.

Omtrek van 't gewrigt - • • • o. 4 .

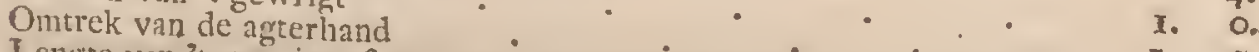

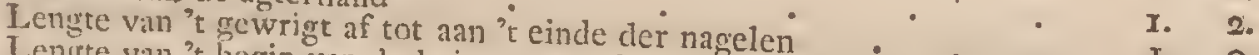

Lengte van 't begin van de knic tot aan de hiel

Breedte van 't bovente des beens $\quad . \quad 3$. 7 -

Dikte .0 .0 0. 10.

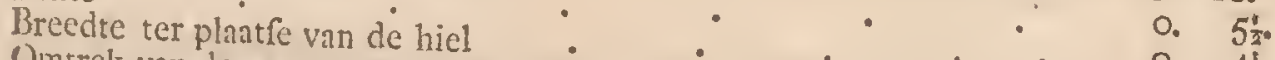

Omtrek van den agtervoet

Lengte van de hiel af tot aan 't einde der nargelen

Brecdte valn den voorften voet

Breedte van den agterften voct

Jengte van de groutfte nagelen

Breedte aan de bafis

Het Indiaanfch varkentje, waarop de afmeetingen dezer tafel genomen zyn,

heeft ook ten onderwerpe gediend voor de befchryving der inwendige dee-

len; het woog één pond en zeven oncen.

Het net was zeer kort en tegen de maag ongewonden; de lever ftrekte zig de: de blindedarm ( $A B C$,

de: de blindedarm ( $A B C$, fig. I. Pl. III.) was van groote uitgeftrektheid,
hy bellueg het giheele linker gedeelte van den onderbuik.

de zig aan cien nugterendarmagter de mag ; de onder de regter nier, en hy voeg- 
pendarm waren in den omtrek van den navel, en aan den regterkant; die van den omgeboogendarm, bevonden zig in de weeke regterzyde des buiks, het latito gedeclte $(D)$ van dit ingewand ging van de regterzyde naar den linkerkant, alwaar het uitlicp in den blindendarm $(A D C$ ), die zig van de linker in de regterzyde uitftrckte, alwaar het zig voorwalds plooide; het verlengde zig vervolgens van de regterzyde tot in de linker: het corfte gedeclte van den kronkcldarn $(E)$ ftrclite zig van den linkerkant tot in de regtcrzyde uit, langs den blindendarm, en het agterft gedeclte van den ongebocgendarm; vervolgens maakte de kromkeldarm groote omwentelingen in de regterzyde cn in de ftreck van den middel-bovenbuik, voor dat hy zig met den regten te famenvoegde; de plintfung van den blindendarm verfchilt in de verfchillende onderwerpen; ik heb gezien dat dezelse zig uitftrekte vain de linkerzyde naar de regter, garnde door de ttreck van den onderbuik, eil zig voorwands in de regterzyde verlengende.

Van weêrskanten van den aars werdt eene klier van eene geelagtige klcur gevonden, die vier linies lang, dric en ecn lialve breed, endric dik, was: de inwendige zelfftandigheid dier klieren was witagtig, en beftondt uit vecle vaiten, die zeer zigtbaar waren; zy hadden door eene wyde opening gemeenfchap met den rand van den aars: daat fypelde gcen vogt uit hunne vaatagtige zelfitandigheid, fchoon doorgefneeden; dezelve hadt ecn wcinig ftinkenden reuk.

De maag was heel ruim; de groote holte was zeer diep, en daar was, om zo te fprecken, een tweede holte, vecl kleiner dan de eerlte aan de nitwendige zyde van het regter gedeelte op cen haivenduim afftands van den portier: die zwelling werdt veroorzake omdat het gedeelte van dezen regterkant, 't welk verder dan de plooy kwam, zecr klein was naar evenredighcid van "t overige van de mag: het inwendig viles van den flokdarm eindigde, aan den rand van de boverrfte opening van de maag, in een witten en gekranften rand; het fluweelige van de maag was niet an eén ftuk vaft, het fcheen aan ballctjes geftrooid te zyn.

De dume ingewanden hadden allen tennaafteriby dezelfde dikte: de blindedarm ( $A B C$, f.r. I. Pl. III.) was groot; hy hadt drie peesagtige banden, dic zig van het cen tot het ander einde uitfrekten; de binnen-wanden waren ecuvoudig, en gelecken nict nazr dic van den blindendarm van den lias en het konyn: de kronkeldarm was zo dik als de blinde aan zyn oorfprong ( $E$ ) over de lengte van ontrent een duim, vervolgens verminderde hy allengs in dilte, en hy .wierdt in het overige van zyne uitgeftrektheid byna zo dik als de regte.

Men zou kunnen zegrgen, dat de lever uit cen enkcld ftuk beftondt, wart daar was geen plect in, die zig tot aan den wortel uitftekte, en die haar wezendlyk in verfcheiden kwabben verdeclde; zy fchecn ondertuffchen uit drie kwabben, twec groute en ecn kleine, te bcftaan, de grcotfte bevattede omtrent de twce derde deelen van de zelfitandigheid der lever, en hadt het middelite en het linkerdeel in: zy was door twee fpleeten in drie deelen gefplitft; een dicr deelen was zo groot als de twee andercn; en dat was aan de lizkcuzycie; de band, dan $2 y$ door gedrangen wierdt, lien in de fpleet, die 
tuffchen de twee klcine deelen wis, en liet galblaasje was aan het regter gedeelte valt: de tweede kwab was aan de regtcrzyde, en omvattede de nicr an haar einde: de derde kwab, die dekleinfte was, hieldt aan den wortel van de tweede, en was door cen fplect in twce declen gefplitft; de lever hadt uit-eil inwendig ecne zwartagtig roode kleur, en woog zeven gros: het galblaasje hadt de gedaante van een peer, het bevattede maar zeer weinig gal.

De milt was breed en plat; zy hadt cgter drie zyden; het beneden einde was nog breeder dan het boven-einde: dit ingewand haclt dezelfele kleui als
de lever; het woog twintig greinen.

Het alvleefch ladt eene zcer onregelmatige gedaante; het geleck eenigzins naar een doorgefnecden blad, op de agterfte zyde van de maag uitgeftrekt, welks voetje of ftceltje zeer dik ware en in den twalfvingerigendarm uitliep.

Je nieren ( $E E, P l . I I)$ waren zeer dik, zy hadden weinig diepte; do regter-inier ftak. nict meer uit dan de linker; daar was maar één tepelije in het:
bekken, dat zecr groot was; men ondericheidde niet de verfchillende zelfftandigheden van het binnenft gedeelte; men zag alleenlyk zeer blykbaare vezels, die zig van de oppervlakte vau1 de nier tot aan het bekken uititrekten.

De nicrdoosjes of bynieren $(F F)$, waren zeer groot, want zy hadders agt lynen in de lengte, zes in de breedte, cn drie in de dikte; zy waren omvangen met een dumne en gecle kortt, de zelfitandigheid van ' $t$ binnenfe was van eene zwartagtige klcur: ik heb daar geene holte in gevonden, maar allecnlyk ecre foort van langwerpige pit., die grauw was.

Het zenuwagtig middelpunt $(C, P l$. II) van het middenrif was zeer nitgeftrekt: daar waren vier kwabben in de regter-long, waarvan-drie als aan een drad geregen waren; de vierde was tufichen het breede deel van 't hart, en de wortcls van de twuede en de derde kwab, die de agterfte is: de eerfte cn do vierde waren de kleinfte, en zy liadden beiden eene byna gelyke grootte; de dric kwabben, twee froute en cen kle deelen verdeeld; de linkor long hade kwabbe vafthieldt, en die de klcinfte was dan an den wortel van de agterife gen: de agterfte kwab van de linkeizyde hadt tennan kwaben der beide lonals de agterite van de regterzyde.

Het hart was byna rond, het hadt bygevolg cen zcer-ftompe punt; het was ecn weinig naar den linker kant gedraeil, daar kwanen flegts twee tak-
ken uit het onderft van de. groote flagader.

De tong was zeer fimal in t $t$ midden en zeer breed aan haar agterfte gedeelte; de voorfte en middclfte declen waren bezet met zecr'kleine tepeltjes, en aan

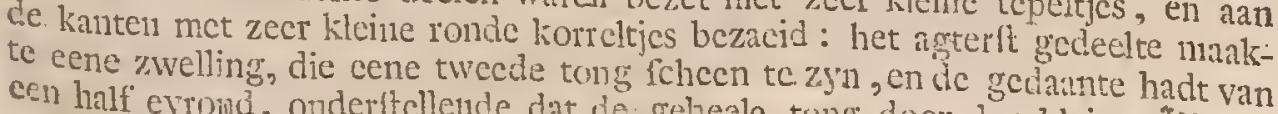
ter half eyrowd, onderftellende. dat do geheele tong door den kleinen diamezigtbare tepeltjes, en dan bepald wierdt; clic zwelling was bedekt met zeer cene ann yotere zyde; men waren op het agterft geteelte twee groote klicron, fchuinîch ycre zyde; men zag in elk dezcr klieren dric fpleeten, die zig wat

Het verhemelicen naar bimicn, en van voren maar agteren, witfrekten. leenlyk een langwerpig knobbelije in 't miduen ecnige vooren; daar was al- 
de voorfte tanden en de eerfte kiezen is, en een ander knobbeltje, watkleiner, agter de voortanden; de randen van de itrotklap waren ligtelyls getand.

De herffenen hadden geen bogtigheden, de agterherffenen waren in hun geheel agter de herffenen geplaatit, en gegroefd, gelyk in de andere dieren; de herfenen woogen twec-cn-vyftig greinen, en de agtcrherfenen agttien.

Hct Indiantich varkentje heeft maar twce mammen, eene aan ydere zyde van het agterft gedeclte van den buik, mar zy zyn zeer zigtbaar, en de te$\mathrm{pcl}$ is omringd van een kuiltjc, dat vier linies diametcr heeft.

Het heeft geen balzak, gelyk de meette andere dieren, on het kan 'er geen hebben, ondat de opening van de voorhuid $(H, P l . I L$; en $A, P l$. IlI fig. 2.) tegen den anrs aan ligt, $(P l$. . $I I$. en $P$. III. fig. $2 . B):$ de zaadballen ondertuffchen, die in de darmftrecken waren, konien uit den onderbuik te voorfehyn, en fclicten onder het vel aan de zyde vin de rocde en van den aars, elk in eenc foort van balzakjc.

Het roedchooflje $(A, P l . I V$. fig. $\mathrm{x}, 2 \mathrm{cn} 3 . B)$ was van een zeer zonderling makizcl, het bevattede cen been $(f \mathrm{~g} .4)$, dat zig van het cen cinde naar ' $t$ ander uitftrekte, en dat wat krom was; zync bolrondte was by 't voorfte van liet roedchoofdje, dat plat was op de zyden : het beneden-eindc $(A)$ van het been was by het einde van.het roedchoofdje, en hadt de gedaante vin een lepel, wiens rand met ecne kleine vleezige wrong belleed was ( $C$, fig. $\mathrm{I})$ die zig aan wêerskanten verlengde op de agterfte zyde van het roedehoofdje, en eene kloof (D) maakte van anderlualve linie lengte; de lippen van deze kloof verwyderende zag men de opening van de pisbuis; onder het overige van de agterfte zyde van het rocdchoofijje, bckleed met vafte tcpeltjes, die naar fchubben geleeken en opwands gerigt waren, was ecne vleczige fchede $(A$, fig. I Pl.IV) welker grond, by de inplanting van de voorhuict, geflooten was; de opening der fchede was gefronft, cn by den 1110nd van de pisbuis geplaatf: in den naturrlyken ftat bemerkte ik de opening dier fchede niet, mar de vlcezige zclfitandigheid van het roedehoofdje agterwards haalende, cn dezelve langs het been doende fichicten, diced ik de binnenwanden vande fchede te voorfchyn komen, en ik keerde har weder on gelyk een kous, die nen by het boveneinde van zyn becn halt; mamate ik de fchede weder omkeerde, zag ik twee punten verlchynen, die van de bimenkint te voorfchyn kwamen; en cindeljk tocn de fchedi: gehtel ontwikkcld was, zag ik twee hoornen $(A$, fig. 2 en 3), dic ann hinar ondert valt zaten, en zig langs de fohede uitfrekten; zy wiren kegelagtig; on licpen in een punt uit; zy waren twee en cen vierde linie lang, en liadden flegts ecn derde van ecn linie in dew omtrek onder aan den grond: zy waren wit, en hume zelftandigheid kwam my peesagtig voor.

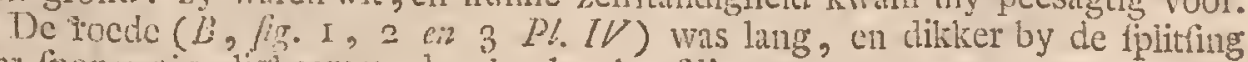
der fponse gtige lighnomen dan by het hoofdje.

De zandiballen $(K K, P l . I T$. en $C C, f g .2 . P l . M I$. $)$ waren byna rond; hume invendige zclfitundigheid hadt een witagtige kleur; zy was zagt, en door hatar te dritken, decde men "er het zaad uitypelen; de band van den opperbal was breed en "zeer dun; het knobucltie hadt weinig dikte, mar men

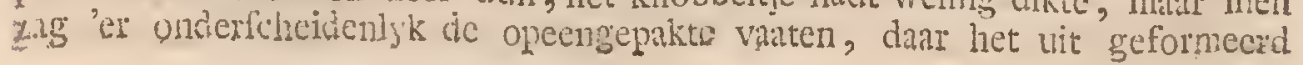




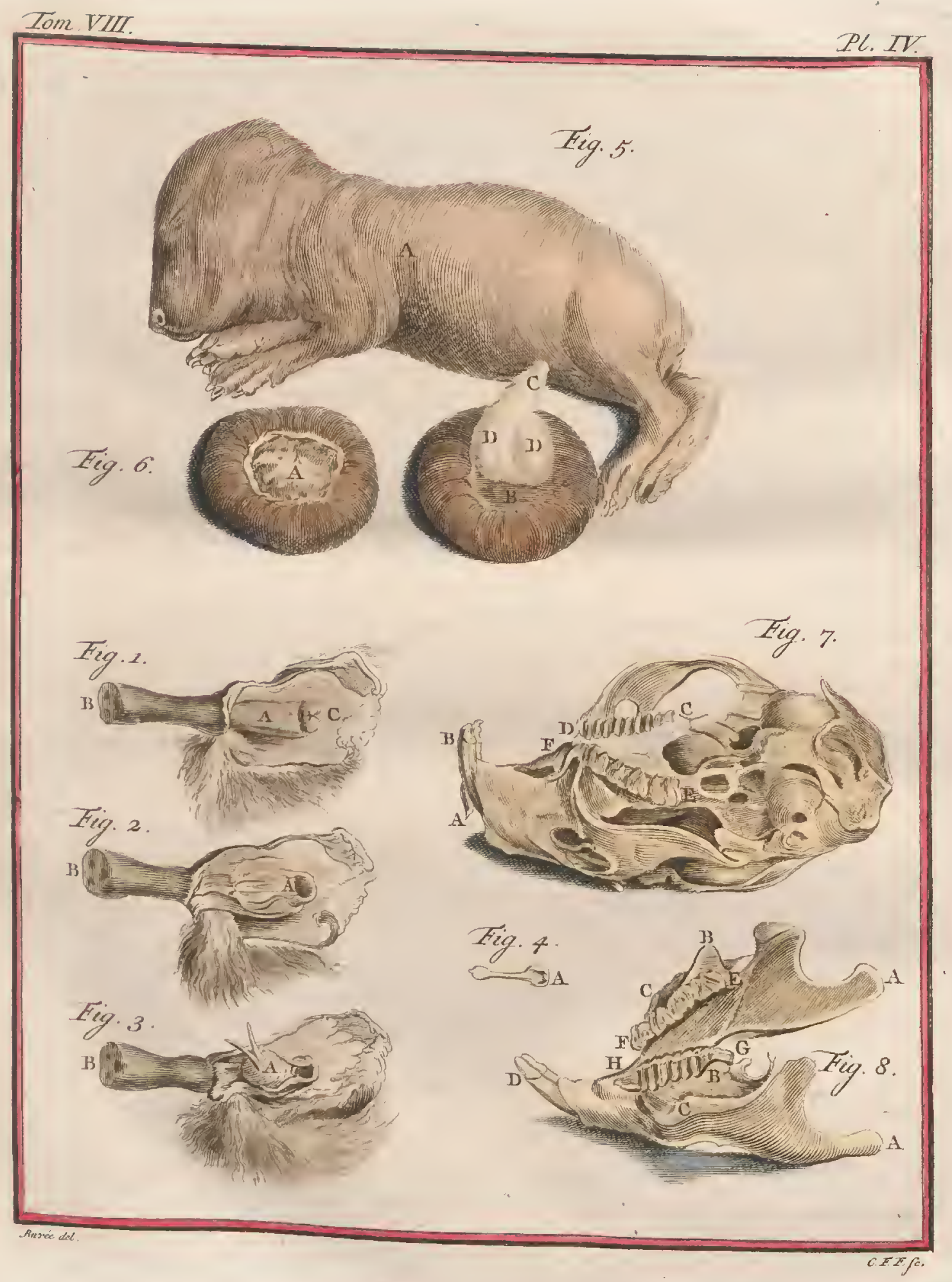





\section{BESCHRYVING VAN HET INDIAANSCH VARKENTJE.}

was; de afleidende buizen ( $L L, P$ l. Il. en $D D$, fig. 2. Pl. III) waren
dik en kort.

De blaas $(M, P l . I I)$ was byna rond: de zaadblaasjes ( $N N N N, P l . I I$, en $E E, f g .2$. Pl. III $)$ hadden de gedaante der hoornen van de lyfmoeder van een viervoetig dier; dus zoude ik, na het cerft mannetjes Indiaanfch varkentje, dat ik ontleedde, gcopend te hebben, zo ik de zaadballen nict gezien had, geloofd liebben, dat het een wyfje was, omdat de zaadblaasjes my toefcheenen de hoornen eener lyfmoeder te zyn: zy zyn elk niet dan een lange buis, die allengs in dikte vermindert van de pisbuis af tot aan het uiteinde toe, zy zitten valt aan ecn zeer dun vlies, wiens rand tegenoverftande aan die, welke an yder zaadblansje valthangt, ondat hy zo lang niet is als het blaasje, hetzelve verfcheiden bogten doet maken; die blasjes zyn doorfchyuende en gevuld met eeu wit gelei, het welk ik in de pisbuis, warvan het de gedaante hadt aangenomen, verhard heb gevonden.

De voorftanders (F F, fig. a. Pl. III) zyn, van malkander afgefcheiden, ter zyde de zaadblassjes geplaatft; dit is de reden, dat de afmectingell der voorftanders, in de volgende tafel gemeld, naar cencn enkelen voorftander genomenzyn; zy zyn zeer dun by de pisbuis, haare zelfitandigheid beftaat uit zecr duidelyke celletjes, die cen helder vogt bevatten.

Ilet wyfje, 't welk ten onderwerpe voor de befchryving der tceldeelen heeft gedicnd, was, van het einde van den bek tot aan den aars, tien duim lang,
het woog cen pond, vier oncen, zes gros.

Het liadt twee manmen, gelyk het mannetje; de lengte van de tepel was van drie linies, en het kuilje hadt vyf lynen ontrek.

De pisbuis liep uitwendig uit, gelyk in de wyfjes van de rotten, de muizc11, de veldmuizen, de waterrotten, de campaginols: het cinde van die buis fprong ecue halve linie uit, cn formecrde een kleinen kegel, geplatit by de famenvoegiug der twee dikke lippen, die de klink, den alars, en den mond van eane holte tuffich deze openingen in zig beflooten: twee dwarsloopende affchutzeis feheidden deze holte van den alrs on de klink, zo dat de opening der holte dwars was; zy hadt drie linies lengte; de kloof van de klink was ook dwars, eu vier linies lang:

De holte, die tuffchen den aars en de klink was, hadt twee linics diepte; de grond was zo lang als de opening; de twee einden dier holte hadden eene zwartagtige lileur, en men zag an yder einde dell mond van een ontlaftbuis, daar een melkagtig vogt uitfypelde; dic buis kwam van cene klier, die aan de zyde vall het einde des regtendarms was.

Het hoofdje van den kittelaar was geplatat op eene linic affands van het einde der pisbuis, en fprong ontrent eene halve linie uit. De pisbuis had cen gronte middellyti; de blias hadt byna 20 veel breedte en dikte als lengte; deszelfs twee einden liepen in een ftompe punt uit.

De fchede was zeer wyd; zy hadt een langerdiameter by de klink, dan by de lyfmoeder; niar in 't midden hamer' lengte was de diameter zo lang niet
als aan de twee cinden.

De hals van de lyfmoedcr ftak ecne linie in de fchede uit, en de randen van deszelfs mond waren gefront: de hoornen hadden een duim negen linies
VIII. Deel. 
lengte, vóbr dat zy met lugt opgeblaazen waren; toen dic daar in gebragt was heb ik gezien, dat zy verfcheiden kleine bogten makkten: door de hoornen aan het einde te trekken, heb ik dezelve byna een duim verlengd, en ik heb de bogtigheden doen verdwynen; maar myn vinger van her cen einde van yderen hoorn naar het ander ftrykende, heb ik kleine fiflingen van lugt gehoord, even als of dezelve van het eene celletje naar het ander overging; de hoornen openende, heb ik hunne vliezen dik bevonden; de wanden waren beklcedmet een fluweel, dat nitfpringende was, en dwarfiche vouwen maakte, op omtrent twce linies afitand van malkanderen geplantit: die vouwen waren ongetwyffeld verhevener toen de hoornen niet verlengd waren, en bogtigheden. makten.

De zaadballen waren omringd van een groot loofwerk, waar in ik geene: opening gezien heb; de trompet fpreidde zig daar over uit, en makte verfcheiden bogtigheden: de zaadballen hadden eene zeer onregelmatige gedaante, omdat zy byna greheel uit groote lymphatifche blaasjes beftonden.

Op den $12^{\text {den }}$ july heb ik een draagend wyfje geopend, 't welk elf en een: half duim lang was, van het einde van den bek totaan den aars; $z y$ droeg vicr vrugtjes, drie in den regter hoorn van de lyfmodder, en een in den linker; yder vrugte $(A$, fig. 5. Pl. IV.) was omtrent drie duimen lang van de kruin des. hoofds tot aan den aars: de moederkock ( fig. 6. en B. fig. 5) was eyrond, de groote dianeter was ecn duim, de kleine llegts tjen linies lang; de dikte was. van drie linies; zy hadt ecne bruin roodagtige kleur; zy was aan de lyfmoeder niet vaft dan in 't midden van hane buitenfte zyde ( fig. 6.) en hieldt daar. aan door een deel $(\Lambda)$ van die zyde, dat eyrond was, en welks groote mid. dellyn een half duim, de kleine vier en een halve linie, lang waren: de navelftreng $(C, f y .5)$ was omtrent een duim lang en zeer dik, omdat de bloedvaaten of ecnigen afitand van malkander waren: dit makkzel van de navel1treng deedt my denken, dat het pisvlies, even als by de haazen en. konynen (a), tufichen deze bloedvaten liggen zoude; om deze bedenking fneed ik de navelftreng by den navel af, en ik bragt "er cen pypje in, gerigt naar den kant vande koek; door dan lugt in te blaazen deedt ik het pisvlies zwellen ( $D D$, fig. 5.) het was kegelagtig, agt linies hoog, en hadt llegts vyf en een halve linie middellyns tegen de moederkoek: dus was de bafis van het pisvlies op verre na zo uitgeftrelkt niet als de moederkoek, gelyk dit in den haas plants heeft.

Lengte van de dunne darmen van den portier tot an den blinclenOmtrek van den twalfvingerigendarm op de dikfte plaatfen : . nimtrek op de dunfte plaatfen
Omtrek van den nugterendarm op de dikfte plaatfen Omtrek van denzelven op de dunfte plaatfen Omtrek van den omgebogendarm op de dikfte plaatfen Oratrek op de dunfte plaatfen lengte van den blindendarm Ontrek aan de dikfte plaats voeten, duimen, lyneito

(a) Zie het VI Deel vas dit Werk, Ulz, $448,149 . P l . X L D I L$.

$\begin{array}{ccc}\text { 5. } & \text { II. } & 0 . \\ 0 . & 0 . & 9 . \\ 0 . & 0 . & 6 . \\ 0 . & 0 . & 9 . \\ 0 . & 0 . & 7 . \\ 0 . & 1 . & 0 . \\ 0 . & 0 . & 9 . \\ 0 . & 4 . & 0 . \\ 0 . & 4 . & 0 .\end{array}$




\section{BESCHRYVING VAN HET INDIAANSCH VARKENTJE.}

Omtrek an de dunfte plats

: voeten, duintinen, Iyner.

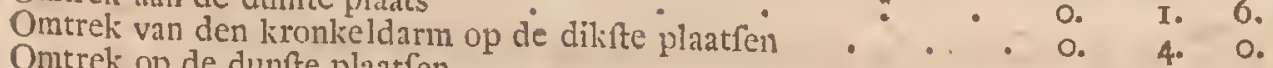

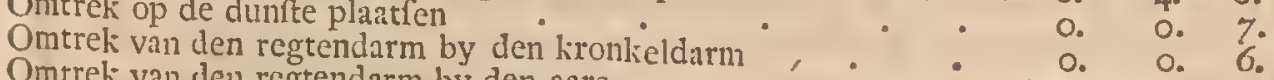

Omtrek van den regtendarm by den aars

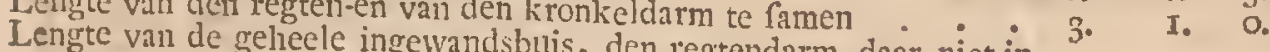
(a) niet in

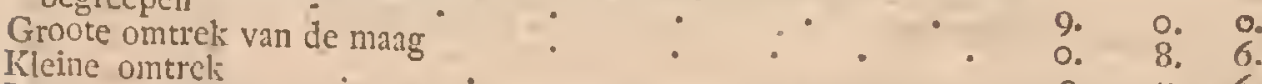

Lengte der kleine kromming van den lokdarm af tot aan den hoek, dien het regter gedeclte maakt

Lengte van den flokdarm of tot aan het einde van den grooten blindenzak

Omtrek van den flokitam

Omtrek van den portier

Lengte van de lever

Breedte

Derzelver grootite dilite

I.engte van de galblaas

Ilair grootfte tuiddellyn

Lengte van de milt

Ijtcedte van "t beneden-eincle

Breedte van 't boven-cinde

Dikte in "t midden

Dikte van "t alvleefch

Lengte van de nieren

Breedte

)ikte

Lengte van het zenuwagtig middelpunt van ke holle ader tot aan de punt

Brecite

0. $\quad$ \%. 6.

Breedte van het vleefig gedeelte tuffehen gemeld centrum en

०. 0.9 .

been

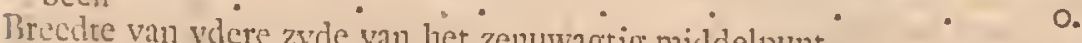

Omtrek der bafis vin liet hant zenuwagtig middelpunt • • 0 .

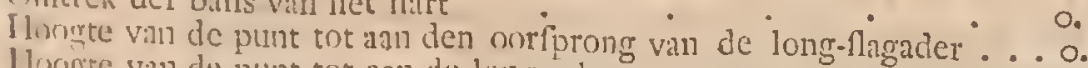

1 longete vin de punt tot aan de long-7ak

Niddellyn van de groote flagader van buiten naar buiten gemeeten.

I.mgte van de tong
Jengte vin het voorfte gedeelte van het toompje tot aan het einde.

lireedte van de tnng

lengte der herfienen

lirecite

Dikte

J.engtt der agterherffenen

Brecdie

Dikite

Afitand tuffehen den aars en de opening van de voorhuid ...$\quad 0$. horflice

Lengte van het hòorije 
Omtrek van de roede van de fplitfing der fponsagtige lighaamen af tot aan de inplanting van de voorhuid

Omtrek

L,engte der zaadballen

Breedte

Dikte

Breedte van den opperbal

Dikte

Lengte der anvoerende buizen

Omtrek in het grootfte deel van derzelver uitgeftrektheid

Groote omtrek van de blass

Kleine ontrek

Lengte van de pisbuis

Omtrek van de pisbuis

Lengte der zaadblaasjes

Middellyn by'de blaas

Middellyn aan 't einde

Lengte van elk der voorftanders

Breedte

Dilite

Aftand tuffchen den aars en de kink

Lengte van de klink

Lengte van de fchede

Omtrek aan de dikfte plaats

Omtrek aan de dunfte plaats

Groote omtrek van de blaas

IKleine ontrek

Lengte van de pisbuis

Omtrek

Lengte van het lighaam en den hals van de lyfmoeder

Omtrek

Omtrek op de dikfte plaatfen

Omtrek aan 't einde van yder hoorn
Afitand, in een regte lyn, tuffchen den bal en het eind des hoorns.

Lengte van de kromme lyn, die de trompet doorloopt

Lengte der ballen

Breedte

Dikte

Het hoofd van het geraamte $(P l . V$.$) van het Indiaanfch varkentje heeft$ veel overeenkomft met dat van het geraante van den haas; liet verfchilt 'er egter van in zeer duidelyke kenmerken; het loopt minder in 't lang; de eigenlyke neus-beenderen, fchoon minder lang naar evenredigheid van de grootte van het dier, ftrekken zig meer voorwaards, ell komen byna zo veel voornit als het been van de bovenfte kaak: dat kaakbeen maakt, tuffchen de twee fuytanden, een klein uitfteekzel $(A$, fig. $7 . D l . W$ ) opwaards gerigt; de takken van het onderft kaakebeen zyn naar evenredigheid korter dan in den hass; maar de bogt der takken heeft in het Indiandich varkentje een uit- 


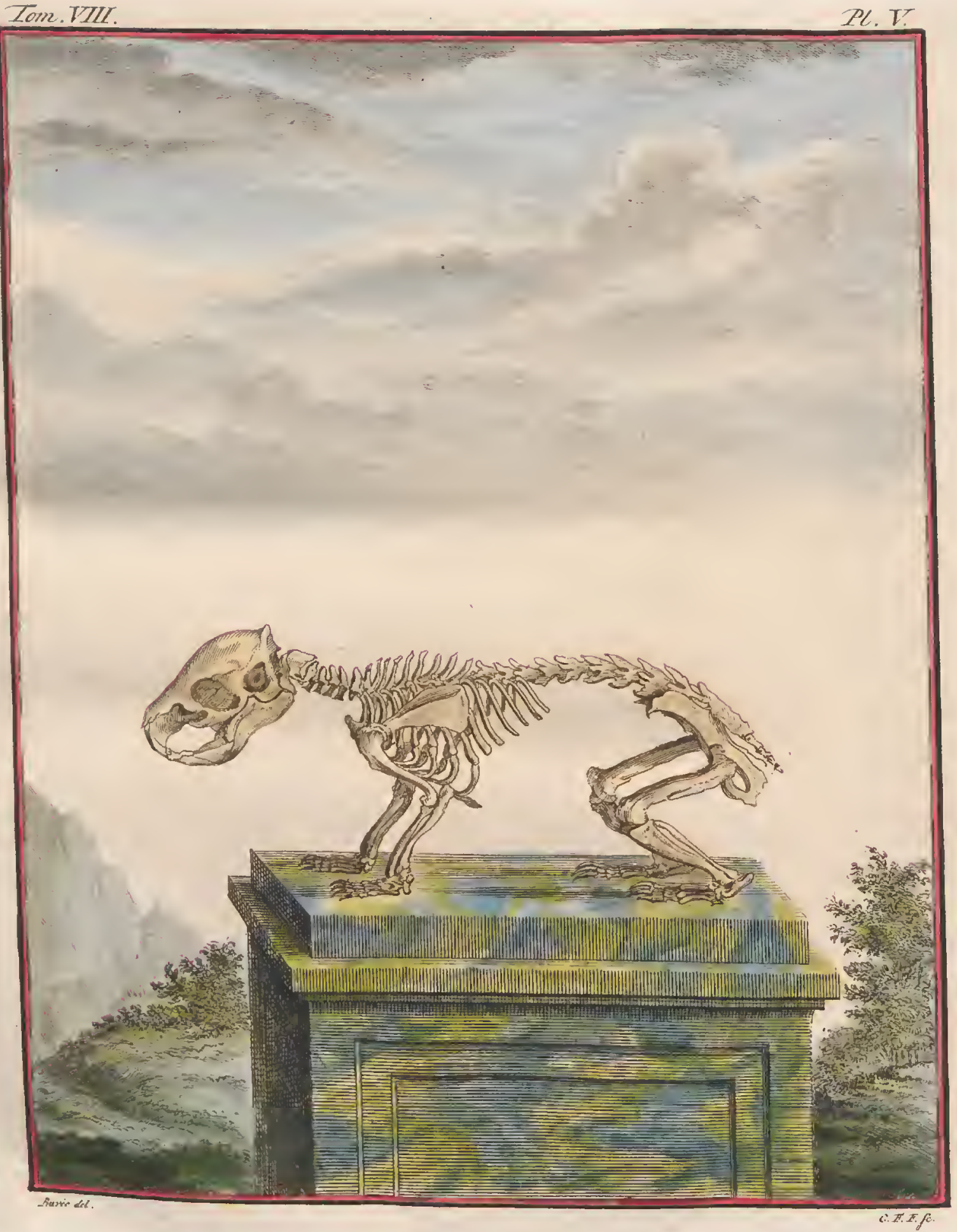



fteekzel ( $A A$, fig. 3 ) dat zeer lang is, en zig agterwaards zo verre nitftrekt als het agterhoofd: daar is een tweede uitfteckzel $(B B)$ veel kleiner by de buitenzyde van den agterften baktand van yderen kant; en een derde $(C C)$ op twee linies afftand van de buitenzyde der vier baktanden, zodat 'er eene vry diepe voor is, dic zig op de bovente zyde van het regter-en van het linkerdeel van het onder kaakebeen tegen over de baktanden uitftrekt; dus is dat kaakcheen zelf zeer dik op deze twee plaatell, welker rigting bogtagtig is: het voorhoofdsbeen heeft geen ooghols uitfteekzel, maar het knobbelbeentje maakt eenige tanding op den rand van de oogput, en daar is onder aan dat been een groot gat voor de oogput, gelyk als in de rot.

Het Indianfch varkentje heeft mar twintig tanden; twee lange fnytanden (B, fig. 7. cn D, fig. 8. Pl. IV) in yder kakebeen, gelyk als de eekhoorn, de rot, enz, en vier baktanden, ( $C D E F$ fis. 7. cn E F G H, fig. 8.) aan ydere zyde der beide kaakebeenen; de fnytanden zyn geheel wit, de bak-of maltanden hebben diepe groevingen aan de zyden; hunne bovenite gedaante is plat, maar men ziet daar voetfpooren van eenige lieine uitgroevingen, die zig van de eenenaar de andere zyde uitftrekken: die tanden zyn niet regt op en neer geplaatft gelyk als in alle de andere dieren, die in dit Werk reeds befchreeven zyn; maar die van boven ( $C D E F$, fig. 7. ) zyn fchuinfch naar buiten ge-
rigt, en die van beneden ( $E F G H$, fig.8) hebben integrendeel eene fchuin-
fche rigting nar binnen fche rigting naar binnen; ondertuffchen raaken zy malkanderen door zorden, die evenwydig zyn aan hunne lengte; dus kan het Indiannfch varkentje. het onderft kaakebeen niet ter zyde brengen, zonder het van 't bovenft te ver-
wyderen. Het tongt dik, zy maken hadt maar éne bafis en twee hoornen; de bafis was zeer hun agterit einde krakkbeenig.

Het drakbeenig.

den hals is zeer groot; het maakt cene foor der zeven wervelbeenderen van

ftompe punt uitloopt.

Daar zyn dertien rug-wervelbeenderen., en dertien ribben; zeven valfche en llegts zes waare; het doornagtige uitlteekzel van het eerite rug-wervelbeen
was byna geheel regt; die der igr volgende wervelbeenderen waren agter-
waards geboogen ; dat der tiende lielden voorwaards: het bortbeen was regt, en cindelyk die der drie laatfe cerfte ribben, cerfte ribben, é́n aan weerskanten, gełcedigden zig met het middelite gedeelte van het ecrfte been; de geleeding der tweede ribben was tuffichen het cerde vierde ribben geleedigden zir met hen tuffchen het tweede en derde been; been; eindelyk was de geleding der vyfde cn zesde gedeelte van het derde en vierde bcen: in een ander onderwerp fcheen het ribben tuffchen het derde been in twee deelen gefcheiden door eene krakbeenige lyn been vat het borft-

geleding van de vierde ribben.
De lenden

fteekzels hadden des te meerdere lengte, getale van zes; de bykomende nitbeen waren; dit been te meerdere lengte, naarmaate zy nader by het heilig- 
'er maar zes in den ftaart; zy fcheenen eene voortzetting van het heiligbeen te makken: het niterft gedeelte van het voorfte einde des heupbens liep in een punt uit.

De bovenzyde van het fchouderblad was bolrond, de onderfte zyde darentegen was holrond; de bovenfte hoek was gerond, en de onderfte maakte een punt; de doorn was gedecltelyk van het lighaams des beens los, en liep haakswyze uit, gelyk in den haas; maar die haak was naar omlang en niet nat agteren gerigt.

Het armbeen was plat op de zyden van deszelfs bovenfte gedcelte; de beenderen van den vourarm waren krom; en hunne bolrondte vertoonde zig voorwaards.

Het dijebcen was plat op zyn agterzyde, en op het benedengedeelte van de voorzyde; daar was een klein knobbeitje beneden den grooten trochanter of draaijer, en ectse foort van grant op het middelfte boven gedeelte van de nitwendige zyde: het feheenbeen was holrond op deszelfs agterte zyde, en wat bolrond van voren: het kuitbeen zilt aan het fcheenbeen met zyn beneden einde valt.

De ecrfte regel van de voorhand beftondt uit vier beenderen; dat.'t welk gemeenfichap met het fichipbeen fcheen te hebben, was buiten de ry, gelyk het erwtsgewyzc been, maar kleiner; het mann-en wiggebeen byna zo groor als hetzelve; het fchipbeen was agter het manbeen geplatit: daar waren zes beenderen in den tweeden regel van de voorhand; het eerfte was geplaatlt tegen de uitwendige zyde van het bovenft gedeelte van het ecrite been van de agterhand, en tegen het twcede been vall den tweeden regel van de voorhand, ter platfe alwaar de duim is by die der dicren, dic dezen vinger hebben; het tweede en derde been vertoonde nict dan ecie zeer kleine zyde, en waren boven het eerfte been van de agterhand; het vierde been van de voorhand was gedeelrelyk boven het eerfte been van de agterhand en gedeeltelyk boven her tweede; het vyfde been van de voorhand was boven het tweede been van de agterhand; en het zesde been van de voorhand boven het derde been van de agterlsand en boven ecn gedeelte van liet vierdc, gelyk het hakkbeen vanden menfch.

Het kootbeen, het hiclbecn, het fchipbeen, en het teerlingromig been wraren in den voorvoct van het Indianfch varken even als in dien vall den menfch geplatift: ik heb, uit dezelfde vergelyling, niet dan twee wigbeenen kunnen ontdeklien, omdat 'er niet meer dan twee waren, die olk boven een been van den agtervoet geplant waren; die beenderen waren legts ten geraJe van lirie; de twee ecrite bevonden zig elk vour ecn wiggebeen, en het derde voor het tecrlingroming been: het geen my doet denkell, dat die drie beenderen van den agervoct beantwontden an het tweede, dercie, en vierde been vanden agtervoet in die dieren, die vyf vingers of toonen hebben: bchalven de zes beenderen van den voorvoet van het Indiaanfch varkentje, diar ik zo even van gemeld heb, was 'er nog cen zevende geplantif tegen de uitwendige zyde van her voorfte gedeelte van her kootbeen, een agtite gedeeltelyk arter het cerfte wiggebeen en gedceltelyk agter het boveneinde van het eerfte beentje van den agtervoet, en cen negende tenmaltenby gelyk aan 
het agtfte, en geplaatft tcn deele agter het tcerlingsvormige en gedeeltelyk agter het boveneinde van het derde beentje van den agtervoet: ik heb nog een becntje gevonden, geplaatft an don binnenkant vall het negende, maar. het is my voorgekomen niet dan cen zaadbeentje te zyn.

Lengte des hoofds van het einde der neusbecnderen tot aan het ngtethoofd

De grootite breedte van 't hooft Lengte van het onderft kaakebeen van deszelfs voorfte einde tot aan den
agterften rand van het knokkelwyze uirfteekzel

Breedte van het onderft kaakebeen ter platife der fnytanden $\cdot$ -

Afitand tuffchen de knokkelwyze uitfteckzels

Dikte van het voorfe gedcelte van het bovent kaakebeen

Breedte van dat kaakcbeen ter plaatfe der fnytanden

Lcngte van de bovenzyde

Afftand tulfchen de oogputten en de opening der neusgaten

Breedte van deze opeling

Lengte der eigenlyke beenderen van den neus

Breedte op de breedite plaats

Middellyn der oogputten

Lengte der langfte fnytanden buiten het been

Lengtc der dikfte kiezen buiten het been

Breedte

Dikte

Lengte van de bafis van het tongbeen

lengte der hoornen

Lengte van den hals

Bengte van den hals
Lengte van het gat des eerften wervelbeens van boven naar beneden ....

Breedte van het eerfte wervelbeen op de dwarfche uitfeckzcls gemeeten.

Lengte van het gedeelte der warvelbeen-kolom, die uit de rug-wervel-

beenderen bcftaat

Hoogte van hot doornagtig. uitfeekzel van het derde wervclbecn; dat
het langfte is

Hoogte van dat van het dertiende, dat het kortffe is

Lengte der cerfte ribben

Atitand tuffchen de eerfte ribben op de breedfte plaats

Lengte van de tiende rib, die de langite is

Lengte van de langite der valfehe ribben

Breedte van de breedite rib

Lengte van het borftbeen

Tengre van het laatfe been, dat het langrt is

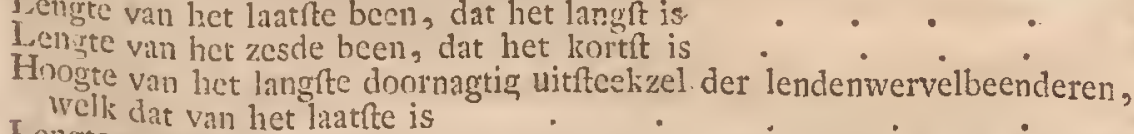
Welk dat van het latite is
Lengte van het langft bylkomend uitffeekzel, zynde dat van het laatfe wer-
velbeen

Lengte des lighaams van het vierde wervelbeen dat het langft is $: . .0$.
Lengte van let heiligbeen

Bredte van liet voorfte gedeclte.

duimen, Jynen.

2. 5

I. 7.

o. 10.

o. 4.

o. 3

o. $10^{\prime}$.

o. IO.

a. $2 \frac{1}{3}$.

0. 3 . 10.

o. $2 \frac{x}{2}$.

5. $5 \frac{3}{2}$.

o. $3 \frac{2}{3}$.

O. $1 \frac{1}{2}$.

O. $1 \frac{8}{5}$.

o. 2.

o. 4.

o. 5 .

I. 3

2.

3

2. II.

O. 5

o. $\quad 1 \frac{\pi}{2}$

०. 74

o. $\quad 4 \frac{\pi}{2}$

I. 4 .

I. 0.

o. 3

9

o. 4.

o. $\quad 34^{\frac{\pi}{2}}$

o. $3 \frac{1}{5}$

o. 5.

०. 2. 
Lengte van het eerfte valiehe wervelbeen van den ftaart, dat het langit is. 0 .

Breedte van het voorfte gedeelte van het heupbeen 0 .

Hoogte van het been, van het midden van " $t$ heupbeens-hol . . . 0 .

Middellyn van die holte

Lengte van de goot

Breedte in "t midden

Diepte

Lengte der eyronde gaten

Breedte

Breedte van het beliken

Hoogte

Lengte van 't fchoucerblad

Breedte op de breedite plaats

Breedte op de fmalite plaats
Hoogte van den doorn op de verhevenfe plaats

Lengte van den fchouder

Omtrek op de kleinfte plaats

Middellyn van "t hoofd

Breedte van 't onderft gedeclte

Lengte van de eliepyp

Lengte van den elleboogsknokkel

Lengte van het ftraalbeen

Iengte van het dijebeen

Middellyn van 't hoofd

Omtrek van 't midden des beens

Breedte van het onderfte einde

Lengte der kniefchyven

Breedte

Dikte

Lengte van het fcheenbeen

Breedte van deszelfs hoofd

Omtrek van 't midden des beens

Breedte van het onderife einde

Lengte van het kuitbeen

Breedte van het boven-einde

Breedte van liet onder-cinde

Iloogte van de voorhand

Hoogte van de voorhand
Iengte van het hielbeen
Hoogte van het eerite wiggebeen en van het fchipbeen te famen gemeeten.

Lengte van het eerfte been van de agterinand, dat het kortf is . . . o.

Lengte van het tweede been, dat het langft is
Lengte van het eerfte en van het derde been van den agtervoet, die de kortfte zyn

Iengte van het tweede been, dat het langft is -

Lengte van den eerften regel des tweeden vingers der voorfte voeten . . 0 .

Lengte var den tweeden regel

Lengte van den derden

I.engte van den eeriten regel van de middelfte toon der agterifte voeten

J.engte van den tweeden regel

Lengte van den derden

I.

6

$2 \frac{3}{2}$

०. 5

5 . 5

6.

. $3 \frac{8}{4} \cdot$

०.

0. 4 .

o. II.

o. $I_{4}^{3}$.

o. $2 \frac{1}{4}$.

I. 5 .

o. $4 \frac{\pi}{1}$.

०. $\quad 2 \frac{1}{3}$.

o. $3^{\frac{1}{2}}$

I. $5 \frac{8}{3}$.

1. $\quad 34$.

I. 2.

I. 9 .

o. I $\mathrm{I}^{2}$.

०. 7.

c. 4 .

O. $3 \frac{2}{2^{\circ}}$

०. $1 \frac{1}{4}$.

t. 8.

o. $32^{2}$

०. 6.

3.

1. 3 .

O. 2.

o. $x_{30}^{2}$

○. 5 .

$I_{2}^{2}$.

3.

4 .

o. $6:$

o. $6 \frac{3}{4}$.

O. I

o. 2.

o. 3

o. 2 .

D E 


\title{
$V$ A $N$ D D E $\quad$ N $E$ E E G
}

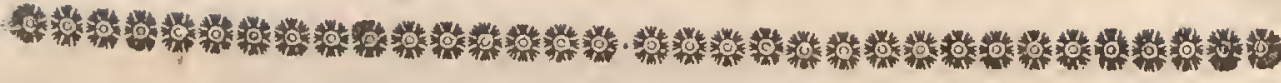

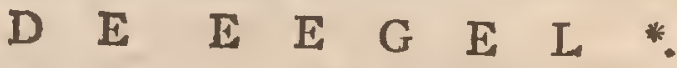

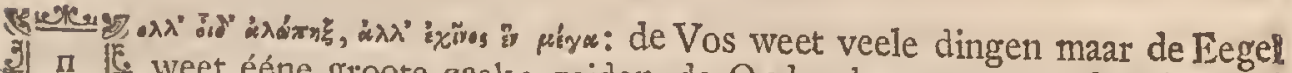
3. $\Pi$ I

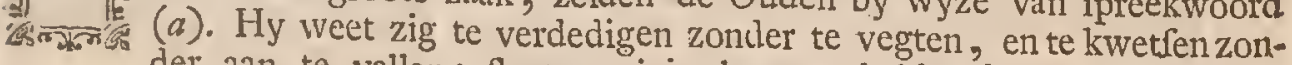
der aan te vallen; flegts weinig kragten hebbende, en met geene vaardigheid om te ontvlugten begaafd, heeft hy van de Natuur eere doornagtige wapenrulting ontvangen; $\mathrm{zy}$ heeft hem tevens het vermogen gefchonken om zig gemaklyk en vaardig als een kloot te fam te rollen, valt in eer te fluiten, en van alle kanten verdedigende wapenen aan te bieden, die yder dier, dat hem wil aantaften, fteeken, en zyne vyanden affchrikken: dit is dan ook zyn toevlugt; hoe meer hy gekweld wordt, hoe fterker hy zyne pennen opfteekt, en hoc vafter hy zig lluit: hy heeft $110 \mathrm{~g}$ een ander middel van verdediging, en dat middel is het uitwerkzel zelf der vrees, die hem prangt; hy laat zyne pis loopen, welker reuk en nattigheid, zig over zyn geheel lighaam verfpreidende, zynen vyand door die walgelykheid verder affchrikken. De meefte honden vergenoegen zig dus met den eegel aan te blaffen, en geeven zig geene moeite on hem te vatten; men vindt "er evenwel zommige, die, even als de vos, middel weeten om hem meefter te worden, en niet fchroomen zig, ten dien einde, de voeten te kwetfen, en den muil aan 't bloeden te helpen; het is tot dien prys, dat zy de overwinning behaalen; maar de eegel vreeft noch de huis-marter, noch de bofch-marter, noch de buntfing, noch de fret, noch het wezeltje, noch de roofvogels.

Het wyfje en het mannetje zyn, van den kop tot den ftart, eveneens met doornen overdekt, en het is het onderfte gedeelte des lighaams alleen, dat met hair bezet is; dus worden die zelfde wapenen, die hun zo nuttig zyn tegell andere, hun zeer ongemaklyk, wanneer zy hunne liefdedrift voldoen willen; zy kunnen niet koppelen op die wyze, zo als andere viervoetige dieren gewoon zyn, zy nweten hier toe aangezigt tegen aangezigt zyn, ' $t$ zy dat zy zig overeind houden of nederliggen.

* De Eegel heet in 't Griekfch Exuss; in 't Latyn Ecbinus, Herinaceus, Erinaceus, Ecbi. nus terriftris; in 't Italianfch Erinaceo, Riccio, Aiazo; in 'I Spsanfch Erizo; in 't Portugeefch Heyde-bog; in 't Zweedfch Igelkott; in 't Ofon; in 't Hoogduitfch Jgel; in 't Engelfch Urcbin.

"toud Franfch Equrbon.

Ecbinus terreftris. Gesves Hift. Quadrup. pag. 368.

Ecbinaceus. GeSNer Icon. Animal. Quadrup. pag. Io6.

Erinaceus fpinofins, auriculatus, Ecbinus terreftris.

Acantbion Jpinoliss, auriculatus, Ecbinus terreftris. LoINNEUs.

Erinaceus vulgaris noftras, Herinaceus, Ecbinus. KuElN de Quadrup. pag. 66.

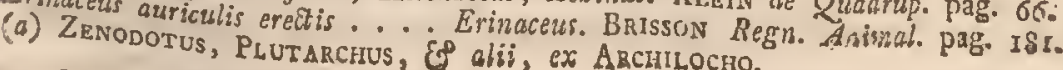
VIIT. Deel. 
Het is in de lente dat $z y$ malkanderen zoeken, en zy werpen in 't begin: van den zomer; men heeft my dikwils de moeder en de jongen in de.maand van juny gebragt; die jongen-zyn gemeenlyk drie of vier in getal, en zomtyds vyf; zy zytz, in dien vroegften tyd, wit, en men ziet op hun vel alleen. lyk den eerften oorfprong der fteekels: ik heb gepoogd eenigen diar van op te brengen, en ik heo, ten dien einde, verfcheidenmaalen de moeder met hasp: kroolt, in een ton laaten zetten, en een goeden voorraad van fpyze daar by do?n plaatfen; maar de moeder, in plants van de kleine eegels te zoogen, heeft hẹn den een 11 den anderen opgevreeten: het was geen gebrek aan voedzcl, dat har drong, want zy. at vleefch, brood, zcmelen, vrugten, en. men zou zig nooit verbeeld hebben, dat cen dier zo traag, zo log, warr aan. jiets dan de vryheid ontbrak, zo uiterft gemelyk en kwaadaartig kon worden enkel omdat het gevangen zat; de cegel is inderdaad kwaadaartig, en op de-: zelfde wyze als de aap; op zekeren dag floop 'er een in de keuken, opende. een klcin braadpannetje, halde daar het vlcefch uit, en deedt. 'er. zync vui-, ligheid in: ik lieb mannetjes en wyfjes by malkander in een.. kamer gehouden, ay zyn in 't leeven gebleeven, mar zy hebben niet gekoppeld: ik heb 'er verfcheiden in myne tuinen vly gelaten, zy doen daar weinig kwaad, en men. kan nauwelyks bemerken, dat zy 'er hun verblyf in houden; $z y$ leeven van afgevallen vrugten; $z y$ wroeten met den neus tot eene kleine diepte in den grond; zy eeten kévers, torren, krekels, wormen, en cenige wortels; zy. zYn ook zeer yrcetig narar vleefch, en eeten het gekookt of rauw.

Men vindt hen dikwils in 't veld, in de bofichen, onder de ftammen van onde boomen, ook in de klooven der rotfen, en vooral onder hoopen fteen,
die op het land of in de wyygaarden liggen; ik geloof niet dat zy de boomen beklimmen, gelyk de Natuuronderzoekers zeggen (b); noch ook, dat zy zig: van hunne ftekels bedienen, om vrugten of druiven weg te voeren; het is met den bek, dat zy aanvatten wat zy willen hebben, en fchoon 'er eene, menigte in onze boffchen zyn, hebben wy hen egter nooit op de boomen gezien: zy houden rig altoos aan den voet, in eell gat of onder de mos; zy lomen uit de ficluilplaats niet te voorfchyn zo lang het dag is, maar. zy loopen, of liever zy gaan, den geheelen nagt; zy lomen zelden digt, by de huizen, zy verkiezen de liooge en drooge plateen, fchoon men hen zomtyds ook in de weiden vindt: men vangt hen met de hand, zy vlugten niet, zy verdedigen zig niet, 't $z y$ met de voeten, 't $z y$ met de tanden, maar zy. rollen zig, zodra men hen anmaakt, als een bal in malkander, en on hèn te noodzaken van zig los te maaken en uit te fpreiden, moet men hen in 't water werpen.

Zy flaapen -des winters; dus zou de voorraad, welken men-zegt, dat zy des zomers opleggen, hen niet te pas komen: zy eeten niet veel en kunnen zig vry lang van voedzel onthouden; zy hebben koud bloed, tennaaftenby zo. als de andere dieren, die in den winter llapen; hun vleefch is niet goed on te eeten, en hun vel, daar men tegeńwoordig geen gebruik-van maakt, diende voormaals tot klcerborftels, en hekels om den hemnip door te haalen..

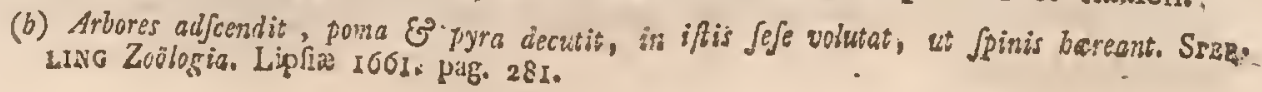




\section{A N $N$ D E $E$ N E E E G E L.}

Daar zyn twee foorten van eegels, de eene met een varkenfnuit, en de andere met een honden-bek, waar van zommige Schryvers fpreeken als van de twee foorten van daffen; wy kennen 'er maar éne, en waar in men zelfs geene verfcheidenheden in deze klimaaten aantreft; $z y$ is vry algemeen verfpreid, lyk Lapland, Noorwegen, enz: met uitzondering der koudfte landen, geMaclagaskar gelyk als in Frank, dar zyn zegt FLAcourr (c), eegels op gel gel, daar vader TACHARD van fpreekt $(d)$, komt ons voor een ander dier te zy11; en de Amerikaanfche eegel (e), de eegel van Siberie $(f)$, zyn de aangrenzende foorten van den gemeenen eegel; eindelyk de eegel van Malakka (g), fchynt nader te komen by de foort van het ftekelvarken, dan by die van den eegel.

(c) Voyage de Fuscourr, Paris 166r. pag. 152

(d) Second Voyage du Pere TACHARD, Paris I689. pag. 272.

(e) Ecbinus Indicus albus. Ray Synopf. Animal. Quadrup. p.g. 232. Ecbinus Americanus al. fss. KLEIN de Quadrup I. paj. 78. Acantbion ecbinatus, Erinaceus Americanus albus Surinamen-

(f) Erinaceus Sibericus. Al.BrRt. Sara Vol. I. pag. 66.

(f) Porcus aculeatis, feu IIzfirlx Malacenifis. ALB. Swna Vol. I. pag. 8r. Acantbion aculeis trix pedibus pentedactylis, caudd truncate. LINvaus, Erinacens, de Quadrup. pag. 60. Hi. son, Regn. Animal. pag, 183 .

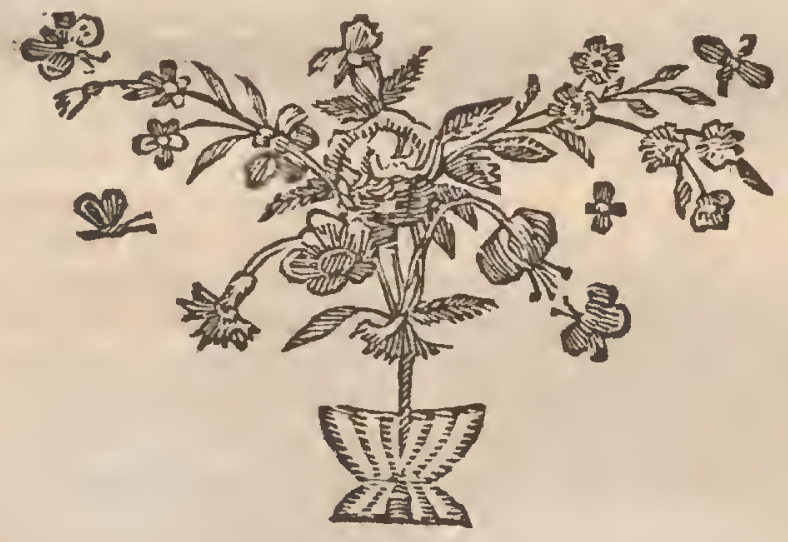




\title{
BESCHRYVING VAN DEN EEGEL.
}

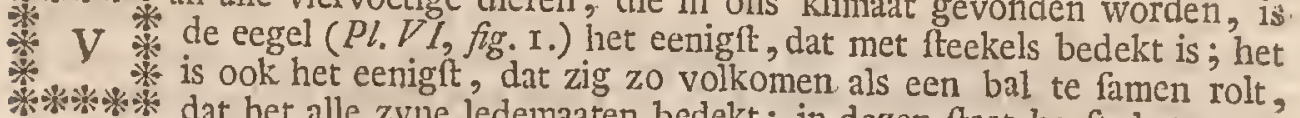
vertooning vat het alle zyne ledemaaten bedekt: in dezen ftat heeft het geene vertooning van een viervoetig dier; men ziet het niet dan in de gedaante van. cen ruig kluwen; maar dat kluwen, met punten bedekt, is niet regelmaatig; rond; het heeft op zekere wyze de figutrvan eene zeer dikke nier; deszelfs. groote bolronde kromte wordt gemakkt door den rug van het dier, . wiens lighaam derwyze gerold is dat het hoofd zig bevindt aan een der einden van de kleine holronde kromte van de nicr, en het agtertte gedeelte des lighaams aan. het ander einde; dat gedeelte en het hoofd raaken malkanderen niet onmidde. lyk; daar blyft eene ruimte over, gevuld door de fteckels van het voorhoof. en van de ftuit van den eegel, die eene holrondte maken gelyk aan het diep. zel of de invalling van cen nier; dat diepzel wordt des te fmaller naarmate. het dier meer poogingen doet om zig te. krommen en in cen bal te famen terollen; het welk gebeurt, wameer het bevreefd of gekwetft is; dan onderfcheidt men geen der deelen vail zyn lighaam; mar wanneer het gerufter is en zig niet gerold houdt dan. om. ruft te neemen, is de dieping van het kluwen, dat het makt, grooter, dat is te zeggen, dat gedeelte komt nader aan de omgekeerde lange kromte van een ellips, en men ziet den bek van het dier, die aan de twee voorfte voeten raakt; zomtyds bemerkt men ook de twee agterfte vocten, die tegen de voorfte aanleggen, en men zict tuffchen de vier voeten de opening van de voorhuid: wanneer de eegel deze houding: verlat om zig op zyne pooten te zetten verlangt hy de bolrondte van zyn rug, hy ftrekt zyn ligham vit, hy brengt zyn hoofd voorwaards, zet zig op zyn voeten en gaat gelyk andere dieren; zo men hem door eenig-geraas vervaart, zo men hem annraakt, zo men hem vat, rolt hy zig terftond weder te famen; maar die beweeging is zo fchiclyk niet, dat men daar niet verfchillende tyden in kan onderlcheiden; het dier begint met zyn rug te krommen, en zyn hoofd op de borlt te leggen; dan fluiten zig de oogen, het vel aan de zyden des lighaams ftrekt zig nar omlaag uit en omvangt de pooten; eindelyk het vel van de ftuit glydt naar beneden, en bedekt den ftart en de ag;
terfte voeten.

De eegel, fchoon overeind op zyne pooten zynde, is zeer lelyk en misvormd van ligham; het is eene langiverpige klomp van boven bolrond, van voren in een zeer fpitfen fnuit uitloopende, en op vier pooten gezet, die zo ronde, en korte ooren, kleine en uitfpringende oogen, en een zeer dunnen en zeer korten ftaart.

Men heeft in de $(2 d e f r g . P l . V I$.$) cen cegel vertoond van zyne ftekels ont-$
\end{abstract}




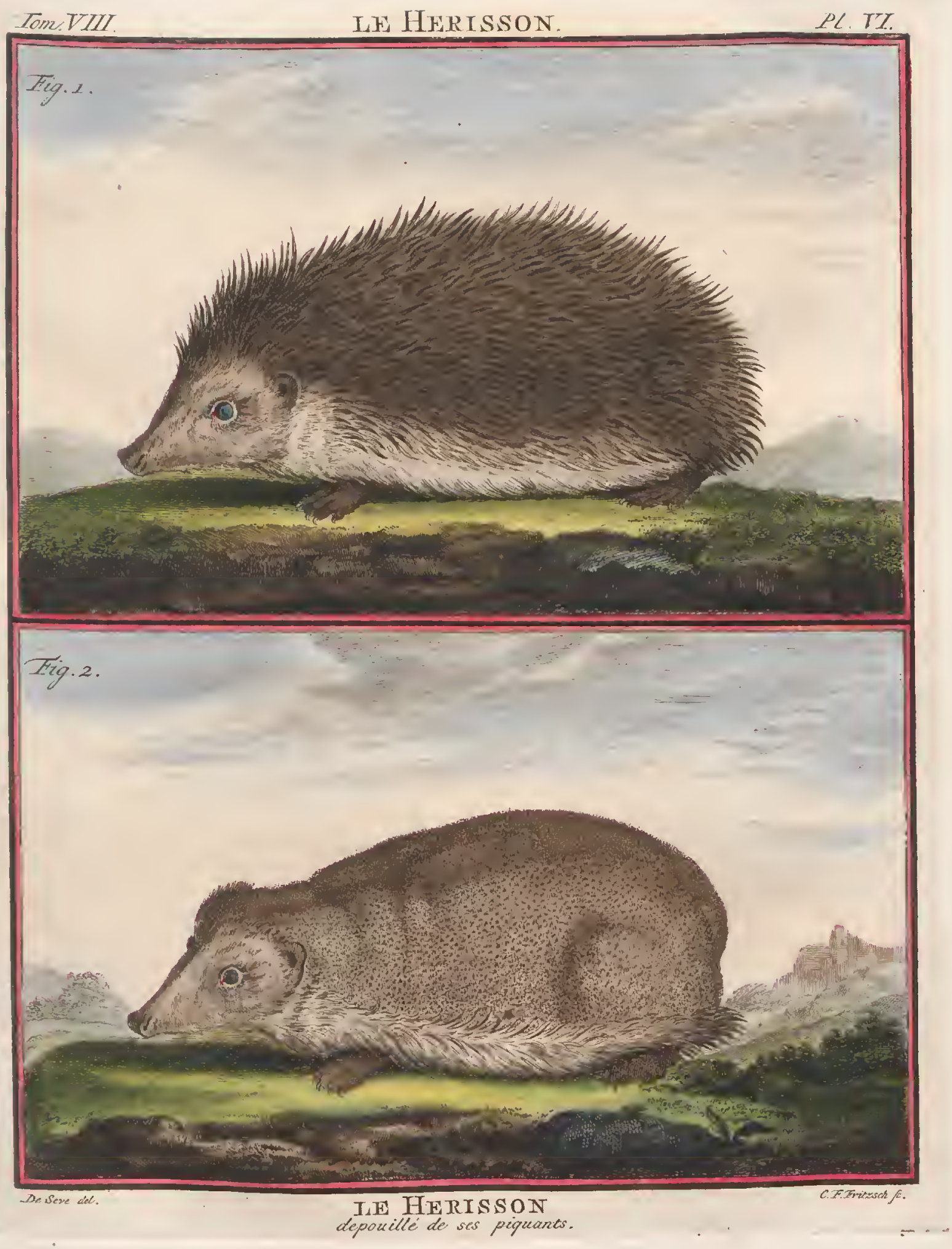



bloot, om de gedaante van deszelfs lighaan te doen zien; dit dier behieldt niets dan het hair op "t hoofd en op het onderfte gedeelte des lighaams.

De Natuuronderzockers hebben twee foorten van eegels onderfcheiden door karakters van de figuur van den bek ontleend: verfcheidene Schryvers willen, dat zommigen den fnuit van een varken, en anderen den bek van een hond hebben; maar zy hebben geene genoegzaame befchryving gegeeven, om deze byzonderheid aan te neemen, en on de karakters van deze twee gewaande foorten van eegel vaft te ftellen: de landlieden, dic in hetzelfde vooroordeel zyn, kunnen geene nauwkeurige reden van hun gevoelen geeven, wanneer men hun van naby twee eegels vertoont, die zy zeggen, dat van verfchillende foorten zyn; ondertuffchen meenen zy te meer grond te hebben voor hunne verzekering, omdat zy het vlecfch dezer dieren eeten, en meenen de voorkeur te geeven aan dat van eegels, die een varkensfnuit hebben, en dat van anderen met een hondenbek te verwerpen, als een kwaaden reuk van zig verfpreidende.

Ik heb in Bourgonje twee mannetjes eegels waargenomen, die de landlieden my zeiden.den eenen van de foort met een varkensfnuit, den andercn van die'met een hondenbek te zyn; de eerfte, in malkanderen gerold, hadt zes duimen agt linies lengte, yyf duim en twee linies breedte, en vier duimen dikte: hy woog een pond vyf oncen en twce groffen; de grootfte ftekels waren een duin lang, zy waren rond, en hadden een derde van eene linie middellyns op de grootite dikte van hunne lengte; de twee einden waren zeer dun en zeer puntig, het eind aan den kant van den wortel was krom; yder ftcekel hadt cene witagtige kleur op de punt en op twee derde declen, zyner lengte van den wortel af, en was bruin-zwartagtig of zwart beneden de punt over de lengte van omtrent twee linies; mar die kleur vertoonde zig weinig: over het lighaam van het dier, omdat de witagtige kleur de overhand hadt. i $_{i}$

De tweede eegel, famgerold zynde, was zes duim dric linies lang; vier duim en tien linies breed, en vier duim dik; hy woog cen pond, een once, en vyf en cen half gros: de fteekels hadden dezelfde lengte, dezelfde dikte, dezelfde gedante, en dezelfde kleuren als die van den anderen eegel; maar de bruinzwartagtige of zwarte kleur was donkerer en uitgeftrekter zodat $\mathrm{zy}$ de overhand hadt over de witagtige kleur: dit dier hadr eenen fterken en onaangenaamen. reuk, fchoon dezclve dien van muskus een weinig nadcrde, terwyl de andere cegel alleenlyk den reuk hadt, die van de morfigheid der dieren onaficheidbar is.

Deze twee cegels hadden fteekels over de geheele bovente opperviakte des lighaams van de kruin van den kop tot by het begin van den ftaart en aan de zyden des lighaams; de bek, het voorhoofd, de zyden des lioofds, de keei, het onder't cn de zyden van den hals, de bort, de oxels, de buik, de liezen, de billen, en de vier pooten, waren met twee foorten van hair bedekt; het een hadt dezelfde ftevigte als de varkensborftels, fchoon het veel korter was; het was witagtig met een kleurzel van geel of ros gemengd; het langtte kon zeltien linies haalen: tufichen dit borftelig hair was een zagter in geplaatit - dit was overvloediger of digter; het was kroes, en grauv, bruin of kaftanjebruin van kleur, op de voeten en op den ftaart was allecnlyk een kort. 
glad, cn weinig gevuld, hair, dat van denzelfden, aart fiheen te zyn als 'de borltels.

Deze twee dieren gelceken malkanderen volmaakt in het makzel van den bek; by was dun en liep in een zwart en gerond kaakbeen uit; de neus was grooter dan het gedeelte van deri bek, dat daar op uitliep; dezelve hadt op geenerhande wyze de gedaante van een varkensfnuit, en verfchilde veel van den neus der hunden, inzonderheid voor zo verre de neus der eegels dikker was dan het gedeelte van den bek, dat daar aanraakte, dat de opening der neusgaten verder van malkander verwyderd waren, en de buitenfte randen van yder neusgat agterwards toegevouwen:en uitgerond varen: daarenboven ftrekte de bovenfte lip zig niet tot beneden den neus uit, gelyk in den hond; dar ontbrak meer dan cen. half duim an, dat de onderfe lip zo lang niet was als de neus, het welk het onderft kaakebeen en de benedenfte zyde van den bek op. zekere wyze deedi gelyken naar het onderlt kaakebeen en de underfte zyde van den fintit eens varkens, en de dikte van den neus was eene andere gelykheid tuffchen deze ecgels en de varkens: maar het wezendlyk verfchil beftat hierin, dat de neus van den cergel zig boven het gedeelte van den bek, daar hy aanraakte, niet opwards kromde, gelyk by. het varken; dat hy miet plat .Tas van voren. en dat de openingen der neusgaten niet, voorwards gerigt waren gelyk die der varkens: ondertuffchen fcheenen deze eegels in 't algemeen meer naar een varken dan naar een hond te gelyken in de gedaante van den bek, en meer nar een hond dan, mar een varken in die van den neus, afzonderlyk befchouwd.

Ik heb verficheiden andere eegels in Bourgonje, en anderen in de parken van Verfailles en in het bofch van Compiegne gevangen, wantgenomen, en ik heb hen allen bevonden te gelyken naar die, waarvan ik de befchryving heb gegeeven; en $z o z y$ in de grootte of in de hoogere of ligtere kleuren daar een weinig vait verfchilden, is my dit verfchil alleenlyk voorgekomen als eene verfcheidenheid, die natuurlyk moet plats hebben tuffchen dieren van dezelfde foort in verfehillende ouderdommen.

De Hr. Perrault meldt egter in zyne befchryving van den eegel (a), dat hy 'er vall twee verfchillende loorten heeft ontleed; hy drukt zig in deze bewoordingen uit.

29 De Natuuronderzoekers maaken de eegels van twee foorten, welker ver, fchil door de gedaante des beks bepaald wordt, die in de eenen langpun"tig en gelyk is aan den fnuit van een varken, en korter, ftomper, en meer "naar eet hondsbek zweemende in de anderen, dic honds-eegels genaamd " worden; deze foort is de gemeene.

"Van vier eegels, welken ivy ontleed hebben, waren 'er twee van elke de"zer foorten, maar wy hebben daarin ook andére onderfcheidingen dan het "verfchil in den bek of fnuit gevonden, want zy verfchilden, ook in de kleur " van het geheele lighaam, in de dikte en in de figuur van de fteekels, maar "s, voornaamentlyk in de grootte van 't geheele dier, dat het eenige verfchi

(a) Memoire pour Servir \& 1 Hiffoire Natwrelle des animanux. Seconde Part. pag. 46. 
"2 is, "t welk Orpianus ftelt tuffchen de twee foorten van eegel daar hy van \% Preekt.

"De figuur, die wy gegeeven hebben, is die van den eegel met een honds"bek, omdat die de" zcldzaamfte is".

Die eegel met cen hondsbek moet inderdaad, zo hy beftaa, wel zeldzaam zyn, want wy hebben|hem in tien jiaren tyds niet kumen vinden, welk onderzoek wy daaromtrent gedaan-hebben: zo men de figuur (b), die de $\mathrm{Hr}$. Perrault var dit dier gegeeven heeft, -vergelykt met die, welke wy geeven $\left(P \% V I . f g . I_{\text {. }}\right.$ zal men een groot verfchil tuffchen die afbeeldingen befpeuren; mar men zal terzelfder tyd bemerken, dat de eegel van den Hr. PERRAULT niet wel geteekend is., en men zal overhellen om te denken, dat de kop en de bek niet meer naar het oorfpronkelyke gelyken "dan de pooten, waarvan het gebrek blykbaar is: daarenboven zou de befchryving van den Hr. PERRAULT omftandiger moeten zyn, om de onderfcheidene kenmerken del twee foorten met zekerheid te kunnen vaftellen.

De Hr. RAy (c) regt, dat 'er in' Engeland geen eegel met een varkensfnuit gevonden wordt., en dat hy twyffelt, of 'er wel ergens een beftar? Het is dan, volgens dezen Schryver, de eegel met den varkensfnuit, die, zo hy beftaa, de zeldzaamfte is; de Hr. Perrault integendeel denkt, dat het de gemeenfte is: die ftrydigheid van bepaaling is een nieutv bewys tegen het aanwezen van eene tweede foort van eegel, en ik vermoede, dat dezelve aangenomen is, omdat de bek van den eegel ecnige overeenkomft heeft met den fnuit van het varken, en den bek.van den hond, gelyk ik ftraks heb aangemerkt: men heeft deze karakters aan verfchillencle individu's toegefchreeven, daar zy inderdaad tot eene en dezelfcie foort. behooren. .

Lengte van het geheel lighäam; in een regte lyn gemeeten, van het einde des beks tot aan den aars

Lengte van den kop, van het cinde des beks af tot an het agterhoofd.

Omtrek van het einde van den bek

Omtrek van den bek onder de oogen gemeeten

Omtrek van de opening des monds

Aftand tuffchen de twee neusgaten

Afftand tulfchen het einde valu den bek en den voorften hoek des oogs.

Aftand tuffchen den agterifen hock en het oor

lengte van het oog van den eenen hock tot den anderen

Opening van het oog

Afitand tuffchen de voorfte hocken der oogen naar de sromste van het neusbeen gemeeton

Dezelfde affind in een regte lyn gemeeten

Omtrek van den kop tuffchen de oogen en de ooren'

Lengte der.ooren

Lengte der.ooren

Aftand tuffchen de twee ooren omlaag gemeeten

Lengte van den hals

Ontrels van den hals

ส̃uímen, lynen.

(b) Mérnoires pour Servir do l'Hiftuire. Naturelle- Ges animaux, 2. pard. Fl. 4I. pag. 33.

(c) Synopf. Anim. Quadrup. pag. 23 . 
duimen, lynter.

Omtrek des lighaams agter de voorfte pooten onder de fteekels gemeeten. 7*

Omtrek aan de dikfte plaats

Omtrek.voor de agterfte pooten gemeeten

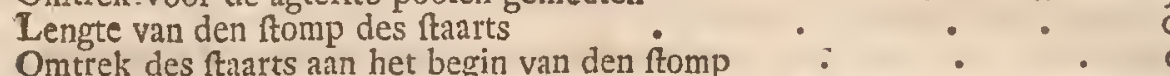

Lengte van den voorarm vall den elleboog tot aan't gewrigt . . . . 2

Breedte van den voorarm by den elleboog

Dikte van den voorarm terzelfder plaatfe

Omtrek van het gewrigt

Omtrek van de agterhand

Lengte van het gewrigt tot aan het eind der nagelen

Lengte van het been vap de knie tot aan de hiel

Breedte van het bovenft des beens

Dikte Breedte ter plaatfe van de hiel

Omtrek van den agtervoet
Lengte van de hiel tot aan 't einde der nagelen

Breedte van den vocrften voet

Breedte van den agterften voet

Lengte der grootfte nagelen

Breedte aan de bafis

De eegel, die ten onderwerpe gediend heeft voor de befchryving der weexe inwendige deelen, was negen duim zeven linies lang van het einde des beks tot aan het begin des ftarts, die tien linies lang was; hy woog een pond en vyf oncen.

Het net was zeer dun, het ftrekte zig zo verre uit als de ingewanden, die negts de voorfte helft van den onderbuik belloegen; de andere helft was gevuld door de zaadblaasjes, door de blaas, en door de ballen, die in de darmbeenftreeken geplaatit waren; men zag de mang ter linker, en het galblaasje., dat zeer groot was, vertoonde zig bloot ter regterzyde.

De twaalfvingerigedarm 1trekte zig tot in "t midden van de regterzyde uit, alwaar hy aan het zaadblaasje van dezelfde zyde raakte, en zig naar binnen te rug vouwde; al het overige van de ingewands - buis makte groote bogten en wendingen in den navelftreek, en in de regter en linkerzyde, voor dat het zig met den regtendarm vereenigde.

De groote blindezak van de maag was zeer diep en nauw van onderen; de wanden der darmen waren dun, en derzelver middellyn verfehilde op de helft van derzelver lengte.

De lever was zeer groot en zo uitgeftrekt ter linker als regterzyde; zy hade vyf kwabben; de iniddetfte was in twee ongelyke deelen gedeeld door eene diepe kloof, waarin de draagband was: het kleinft gedeelte van deze kwab was ter linker, en her grootite aan de regterzyde; het galblaasje was op het midden van het laatfte geplaatf: daar was maar éne kwab ter linkerzyde, "en deze was byna zo groot als die in 't midden; twee kleine waren ter régterzyde; de vyfde, en de kleinfte van allen was by den wortel van de middelite kwab: de lever woog een once en twee en een half gros; haare kleur was van buiten en van bimnen bruin rood. 
Het galblaasje was zeer dik en byna rond; het bevattede een fponsagtig vogt, met een ligt kleurfel van geel g'emengd, 't welk een-en-dertig greinen
wong.

De milt hadt eene kantzuilige gedaante, mar zeer onregelmaatig, want haare breedte was op twee plaatien van agt linies, terwyl het midden en de twee einden flegts zes haalen konden; haare kleur was van buiten en van bin. nen roodagtig bruin, zy woog een gros en negen greinen.

Het alvleelch was zeer uitgeftrekt en zeer dik; het maakte twee takken, warvan de kortfte zig langs den twaalfvingerigendarm tot aan het einde van de regter nier uitftrekte; de andere tak liep langs de mang, en fplitfte zig in twee deelen; het eene verlengde zig langs de milt, en het ander op de linker nier.

De nierdoosjes vertoonden zig zeer fterk, zy waren langagtig en van eene geelagtige kleur: de nieren hadden weinig uitdiepzel, en waren zcer dik nar erenredigheid haarer breedte; het bekken was groot; maar daar was maar éen tepel: de regter nier kwam de helft haarer lengte meer vooruit dan de linker nier

Het zenuwagtig middelpunt van het middelrif was zeer dun en zeer doorfchynend, mar het vleefchagtig gedeelte was zeer dik.

De long beftondt uit vyf kwabben, vier ter regter en eene ter linkerzyde; van de vier aan de regterzyde waren 'er drie als aan malkander gereegen, en de vierde was by de bafis van het hart geplaatt; de linker kwab was de grootfte van allen.

Het hart was byna rond; het bevondt zig op het borftbeen als neergelegd; en hadt eene fchuinfche rigting van de regterzyde naar de linker.

De tong was zeer dik, en bezet met byna onmerkbaare tepeltjes, en ronde witte, en wat meer zigtbaare, korrcltjes; daar waren by den wortel drie kelkwyze klieren, van ontrent eene halve linie in den omtrek, $2 y$ waren op eene kromme en dwarlche lyn geplaatit; zodat die van het midden wat verder af was dan de twee andere.

Het verhemelte was dwarfch doorfneeden met negen breede en diepe vooren; daar was eene kleine langagtige uitftecking in ' $t$ midden van ' $t$ verhemelte, de dwarfche waren krom, behalven op een na de agterfte.

De frotklap was aan de randen getand; daar wares geene bogtigheden op de agterherffenen, mar de herffenen hadden van voren twee kleine kwabben, door eene diepe voor van het overige afgefchciden; zy woogen drie-ct1-vyftig greinen, en de agterherfienen zeven greinen.

De eegel heeft tien tepels of prammen, vyf van wederzyden, twee aan den buik, en drie an de borft; zy waren alle aan de zyden des lighaams; de eerfte op de binnenfte zyde van de dy, de vierde by den elleboog, en de vyfde op de geleding van den arm met den fchouder (b).

Daar was geen balzak, het roedehoofdje $(\Lambda, P l$. VII en VIII) van den

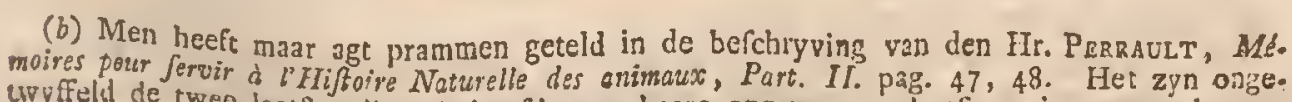
uryffeld de twee laathe, die, uit hoofde van haare ongewoone plaating, niet opgemerki zyn. VIII. Deel. 
eegel is knobbclagtig, gelyk dat van den ram en van den bok, maar van eene verfchillende figuur; het bovenft gedeelte van het einde van het roedehoofdje, daar de pisbuis is, is tuffichen twee oortjes geplaatft, en eindigt in eene punt zo dun, dat het moeijelyk zou geweeft zyn, de opening van de pisbuis genoeg te onderfcheiden, om daar een klein 1tilet $(B)$ in te brengen, zo ik 'er niet eene witte en lymagtige ftof hadt zien uitkomen; het hoofdje is de helft korter beneden, $(A, P l$. VIII.) dan boven $(A, P l . V I I)$, en zyn onderfte gedeclte maakt tivee oortjes vry gelykende naar die van het bovenite gedeelte,, en in welker midden het toompje geplateft is.

De roede $(C, P l . V I I$ en VIII) is dik, rond, en lang: de ballen $(D E)$ zyn dik, byna rolrond; zy hadden van buiten en van binnen eene geelagtige kleur, zonder eenig fpoor van den wortel des opperbals, waarvan de band: (F F Pl.ViII) die zig langs den zaadbal uitftrekte, breed en dik was; de: ballen waren, in den omtrek van den toegevouwendarm, by het heupbeen, aan de fpieren van den onderbuik vaft met een zeer fterke fpier, -die aan het: agterfte einde van yderen zaadbal hieldt: de afvoerende buizen ( $G H, P l$. $V I I, V I I I)$ waren zeer dun en zecr kort.

De zaadblaasjes waren zeer groot, en beftonden elk uit drie kwabben ( $I K$ $L)$ ten naaftenby als longen; zy hadden eene witagtige kleur: de voorftanders $(M N)$ waren onder het blaasje $(0)$; zy waren naar evenredigheid zo groot of grooter als de zaadvaatjes; zy hadden cene geelagtige kleur: daar was van weerskanten van den aars $(P)$ een klier geplaatf, gedceltelyk op het agterft einde van liet dijebeen, en gedeeltelyk op het darmbeen; deze klieren $(Q R)$. waren plat en rondagtig; zy hadden omtrent negen linies middellyns en twee: linies dikte in 't midden, en minder aan de randen; haare kleur was ninder wit dan die der zaadblansjes en minder geel dan die der voorftanders; zy hadden gemeenfchap. in de pisbuis $(S)$ by de openingen. der zaadblaajes en der voorftanders, door een buis $(T, P l$. VIII) war in ik een ftilet $(V)$ heb gebragt; deze klieren drukkende heb ik in de pisbuis een molkagtig vogt doen. vloeijen, het welk dezelfic vertooning hadt als dat, 't welk uit de zaadvaaten te voorichyn kwam; het vogt der voorftanders was klaar en. geclagtig: de: buizen, daar de zaadblaasjes uir beftonden, hadden op zommige plaaten omtrent eene linie midddlyns; zy waren allen zeer zigtbaar en makten bogten gelyk aan die van de herfenen, en ande fingeringen van de ingewanden: fchoon de buizen der klieren, an de zyden van den arars geplaatft, kleiner waren clan die der zaadblaasjes, heb ik haar egter ook zeer onderfchoidenlyk be. merkt; zy waren in verfcheiden rigtingen gekluwend: de buizen der voorftanders makten duntze tukfehictingen, en zy. waren doorfehynende, ongetwyfletd. ondat zy een helder vogt bevatteden.

De figuuren, dic in de ( $V I I$ en $V I I I P l$.$) vertoond worden, z y n$ van natuurlyke grootte; de inwendige deelen der voortteeling zyn kleiner in de een dan in de andere plaat, omdat de. eegels war naar de tekeningen gemaakt zyn, van verfchillenden ouderdon waren.

Die, welke voor de befchryving: van de vrouwelyke teeldeelen: gediend heeft, was agt en een halven duim lang van het einde des beks tot aan den ars gemeeten; zy woog twee pond en én once. 



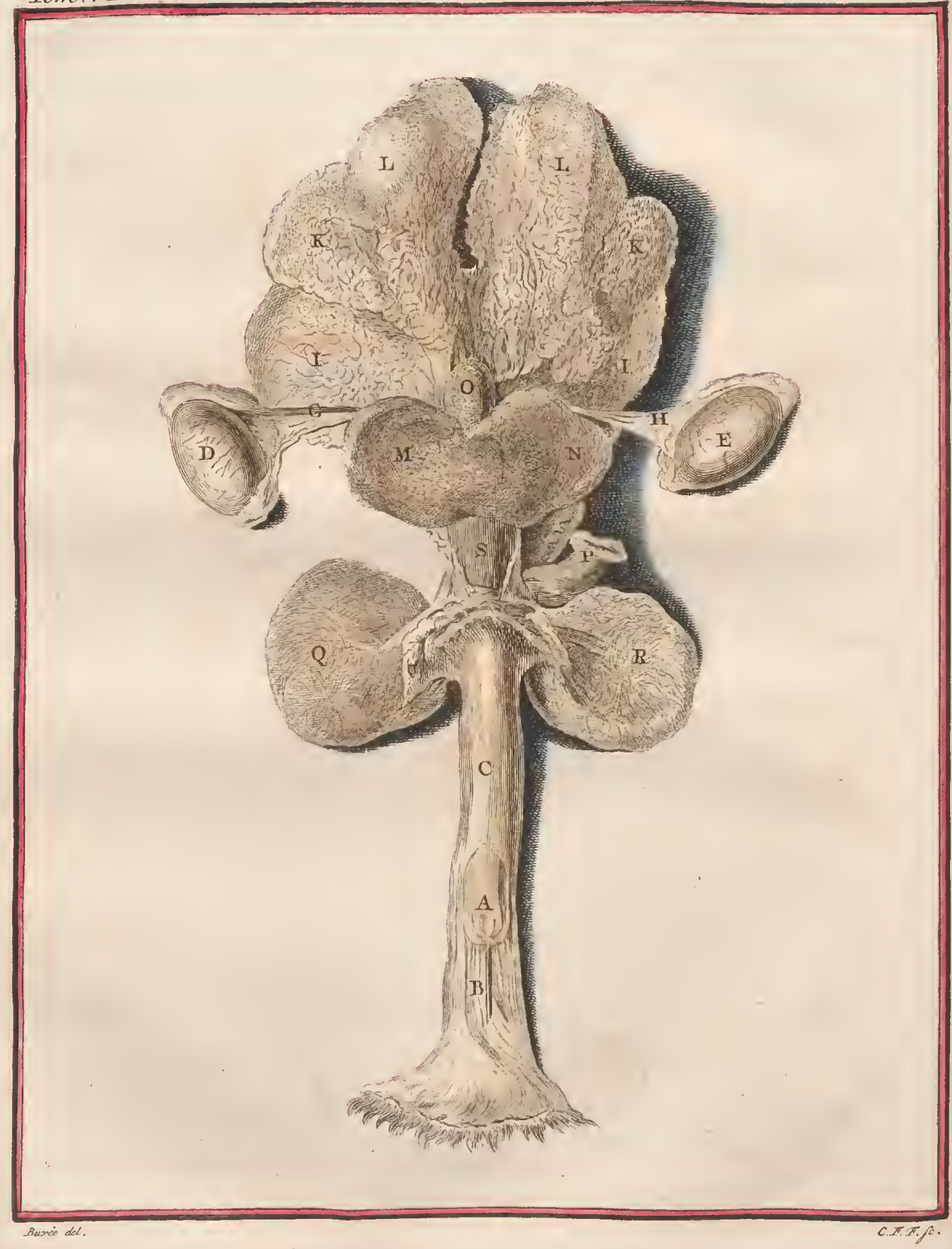




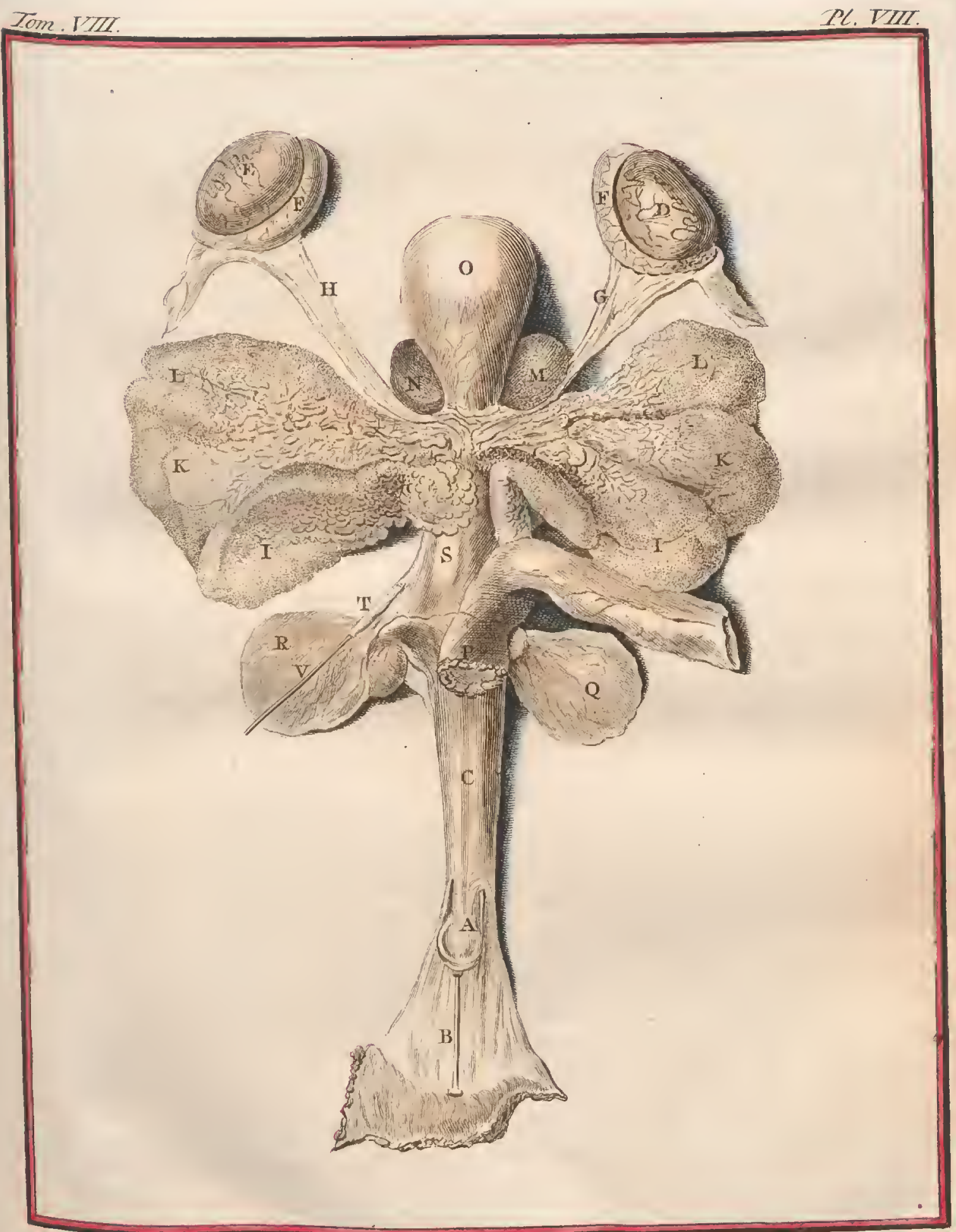

Niurie del. 

De klink was zeer groot; men zag nauwelyks den kittelaar; de fchede was zeer lang; de inwendige opening van de lyfmoeder maakte een groote knobbel aan het onderft van de fchede; de hoornen der lyfmoeder hadden, op. verfchillende plaatfen, verfchillende dikten, inzonderheid de linkerhoorn, die veel dikker was dan de regter; de zaadballen. beftonden uit knobbeltjes; die naar druiven-korrels geleeken.

voeten, duimen, lynen.

Omtrek op de dikfte-plaat

Omtrek op de dunfte platten

Groote omtrek van de dmata.

Kleine omtrek van de kleine kromming van den flöidarm af tot an den hoek welken het regtergedeelte malkt

welken het regtergedeelte makt
Lengte van den llokdarm tot aan het einde van den grooten blindenzak.
Omtrek van den flokdarm

Omtrek van den portier

Lengte van de lever

Breedte

Haare grootfe dikte

Lengte van het galblaasje.

Deszelfs groote middellyn

Lengte van de milt

Breedte van het onderfte einde

Jreedte van het bovenfte cinde

Breedte in " $t$.midden

Dikte

Dikte van het alvleefch

Lengte van de nieren

Breedte

Dikte

Lengte van het zenuwagtig middelpunt van de holle ader tnt aan

de punt

Breedte van het vleefchagtig gedeelte tuffchen het zenuwagtig mid-

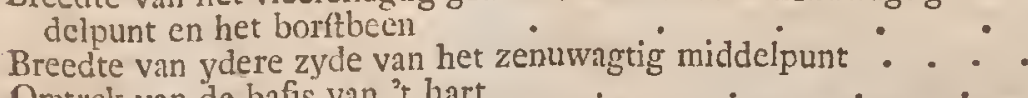

Omtrek van de bafis van " $t$ hart

Hoogte van de punt af tot aan den oorfprong van de longflagader.

Hoogte van de punt af tot aan den longezak

Hoogte van de punt af tot aan den longezak
Middellyn van de groote flagader van buiten naar buiten gemeeten.

Lengte van het voorfte gedeelte van het toompje af tot aan het einde. o.

Brcedte van de tong

Breedte der vooren van het verhemelte

Hoogte van de randen

Lengte van de voorherffenen

Breedte

Dikte

Lengte van de agterherfienen

Breedte

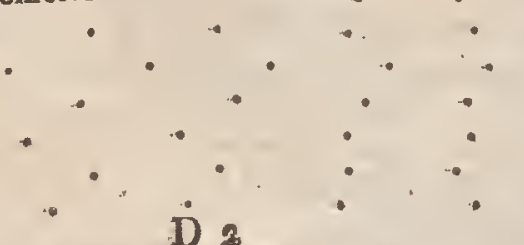

$\begin{array}{lll}5 . & 4 . & 0 . \\ 0 . & \text { I. } & 6 .\end{array}$

o. 0.9 .

a. 6. 6.

5. 3 .

o. 0.8 .

o. I. 0.

o. o. 8.

o. 2. 9.

०. 3. 0 .

0. $0.7 \%$

a. c. II.

0. 0.9 .

o. 2. $\quad \%$

o. 0.6 .

o. 0.6 .

o. 0.6 .

o. 0.3 .

o. $0 . \quad$ I.

o. I. C

o. 0.7.

o.

0. 7

(0.

0. 3.

०. 2. 5.

o. O. II.

o. 0.9 .

o. $I^{*}$

I. 5.

o. 0.80

०. 5 .

o. o. $1 \frac{k}{3}$.

o. o. $\frac{2}{3}$.

o. 0.9 .

o. $\quad$. 9.

o. 0.5 .

o. $0.4 \%$

o. 
Dikte

voeten, duimen, lynets:

Afftand tuffchen den aars en de opening van de voorhuid . '

o. 0.2 .

Afftand tuffchen de randen van de voorhuid en het einde van de roede

Lengte van het lioofdje

Omtrek

Lengte van de roede, van cle fplitfing der fponsagtige lighamen af tot aan de inplanting van de voorhuid

\section{Omtrek}

luengte der zaadballen

Breedte

Dikte

Lengte van den opperbal

Dikte

I.engte der afvoerende vaaten

Middellyn

Groote omtrek van de blaas

Kleine omtrek

Lengte van de pisbuis

Omtrek van de pisbuis

Lengte van de zaadvaatjes

Breedte

Dikte

I.engte der voorftanders

Pireedte

Afitand tuffchen den aars en de klink

Leugte van de klink

Lengte van de fchede

Omtrek aan de dikfte plaats

Groote omtrek van de blaas

Kleine omtrek

Lengte van de pisbuis

Omtrek

Omtrek

Omtrek op de dikfte plaaten

Ontrek op de dunlte plaats

Afftand tuffchen den bal en het einde van den hoom in een regte lyn

Icengte van de kromme lyn, die de trompet doorloopt .

Iengte der ballen

Broedte.

Dikte

De kop van het geraante van den eegel ( $P l . I X)$ heeft, in deszelfs voornaame evenredigheden en in de uittteekzels van het agterhoofd, cenige overcenkomft met dien der buntlings en der fretten: de putten der oogen ftuiten. vis agteren niet, zơdat zy zig zouden fchynen uit te ftrekken van het jukbern tot aan den hoek, dien het jukbecnig uitfeekzel van het flapbeen mot 


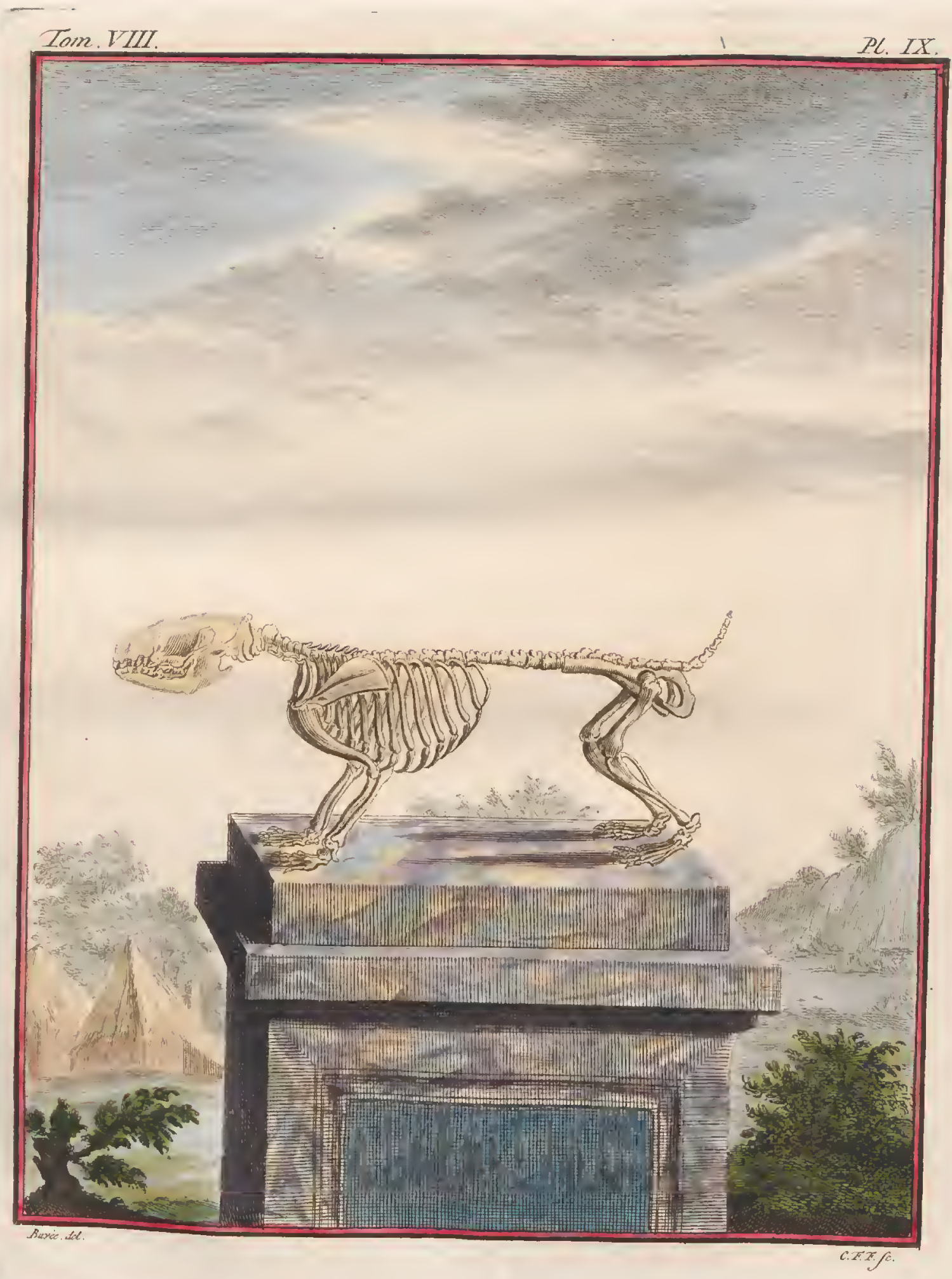


lighaam van dit been maakt, zo men het kronnswyze uitfteekzcl van het onderft kakbeen in het agterft gedeelte van deze ruimte niet befpeurde: de eigenlyke neusbeenderen zyn zeer fimal, en ftrekken zig niet zo verre voorwaards uit als het bovent kaakbeen: daar is van onderen, aan de agterfte zyde der takken van het onderft kaakbcen, een uitfteekzcl, dat zig agterwaards uitftrekt, en dat opwaards is gekromd.

De eegel heeft zes-en-dertig tanden, twec van voren in yder kaakbeen, die fimal en de langfte van allen zyn; vicr baktanden aan ydere zyde van yder kaakbeen; vyf kleine tanden geplaatft tuffchen de kiezen en den voorften tand, aan wederzyde van het bovenft kaakbeen, en drie kleine tanden ook geplaatif tuffchen de kiczen en den vooriten tand van het onderft kaakbeen : de tweede der baktanden, of kiezen, is de grootfe; de laatfte is de kleinfte; daar zyn zeer verheven punten op de onderzyde del boventanden, en op de bovenzyde van de onder-tanden: van vyf kleine tanden van het bovenft kaakbeen makken de vicr cerften elk flegts een punt; de vyfde lieeft 'er dris, en zoude onder het getal der kiezen kumnen geplaatft worden: van de drie kleine tanden van het onderit kaakbcen heeft de cerfte den wortel agterwaards fchulinfch gerigt op dien van den voorften tand: de wortel van den. tweeden der klente tanden is ook agterwaards gerigt, maar minder fchuinfech dan dic van den cerften; zy hebben alle drie ecne verlenging naar voren, die in de twce lantften van her overige des lighaams ran den tand onderfcheiden wordt door eene klcine voor; het welk twee kwabjes makkt, welker een veel kleiner is dan de andere, en zig boven den wortel bevindt.

Het tongbeen beftondt uit negen beentjes meer of min. krom, het beentje van 't midden van de vork hadt weinige lengte; de takken en de tweede beentjes waren de langfte.

Het doornagtig uititeckzel van het tweede wervelbeen van den hals gelykt nan dat van het Indiannfch varkentje; de onderfte tak der dwarfche uititeekzels van het zesde wervelbeen is breed eil plat.

Daar waren vyfticn rug-wervelhecnderen en vyftien ribben, agt wate en zeven valfche; de doomagtige nitteckzels van dezc wervelbeenderen waren allen agterwards geboogen, met uitzondering van dic der drie lantfe; alle de zyden waren zeer breed mar evenredigheid van bet ligham des diers, uirgezonderd de latefe der valiche ribben: het bortbeen beftondt liegrs uit vyf breude en dikke beenrjes; het eerite hadi van voren twee korte takjes, dar de twee ecrlte ribben, cene aan ydere zyca, op uitlicpen: dic twcede ribben geledigden zig tuffehen het cerfte cin tweede beentje; de derde tusfchen het tweede en derde beentie, cn cus vervolgens tot aan de zesde ribben, die zig met het middelite redeelte van het vytile becntje geledigden; de geleding der zevende en agtfe ribben was an liet agterfe einde van dit vyfde en latite beentje van het borftheen.

De lenden wervelbecncieren waren ten getale val zes; humne bykomende nitflekzels hadden weinig lengte; het heiligbeen beftond uit drie vallihe wervelbeenderen en de ftart uit dertien.

Het voorfe gedectte van het heupbeen hadt cene figunt, die nar kmang lig geleek; de guot van 't bckken was zeer kort en zeer diep.

D 3 
De bovenfte rand van 't fchouderblad-was bolrond, de agterfte regt en de woorfte holrond: het ravenbeks-gewyze uitteekzel was kort, maar het fchouderbeenshoofd hadt veel lengte en brecdte, en twee takken, waarvan de een zig geledigde met het fleutelbeen, en de ander benedenwards liep: de lleuitlbeenderen hadden maar weinig kromte.

Ilet ambeen was dik, dat van de dy hadt weinig lengte; de beenderen van den voorarm waien wat bolrond van voren over de lengte van hun onderft gedeelte: het ficheenbeen was lang; en heţ kuitbeen was daar aan valt van het midden zyner lengte tot aan zyn onderfte einde.

De eerite regel van de voorland beftondt uit vier beentjes; dat, 't welk aan het fchuitbeen fcheen te beantwoorden was buiten den regel, gelyk ook het erwtsgewyze been, maar het hadt minder dikte; de twee anderen waren elk beneden een der beenderen van den voorarm: de tweede regel van de voorhand beftondt uit vyf beentjes; de drie eerfte waren boven de drie eerfte beentjes van de agterhand; het vicrde beentje van de voorhand boven het vicrde en een gedeelte van het vyfde beentjc van de agterhand; het vyfde beentje van de voorhand gedeeltelyk aan de buitenlte zyde van het vierde beentje van de tweede ry, en van her tweede beentje van de eerfte ry; eindelyk was 'er een zesde beentje, gedeeltclyk tufichen het tweede en derde van de eerite ry en gedeeltelyk tufichen het derde en vierde van de tweede ry geplaatit.

De voorvoct beftondt uit zeven becnderen gelyk dic van den menfch; het tweede wigbeen van den ecgel xvas vecl kleiner dan de twee andere.

De beenderen van de agterhand en de regels der vingeren van de voorfte voeten waren tennattenby 20 lang, marr dikker, als die van den agtervoet en der regels van de vingeren der agterfte.voeten; cle nagels dier voeten waren langer.

Lengte van den kop van het einde des bovenften kaakebecns tot aan het agterhoofd

De grootfte brecdte van den kop

Lengtc van het onderft kaakbeen van deszelfs voorfte einde tot aan den agterften rand van het knokkelwyze uititeekzcl

Breedte vall het onderft kaakbecn ter plantíc van de fnytandena ${ }^{*}$

Afftand tufichen de knokkelwyze uitfteekzels

Dikte van het voorfte gedcelte van het:bovenft kaakbeen

Breedte van dat kaakben ter plaatfe der fnytanden

Lengte van de bovenfte zyde

Lentand tuftchen de oogputten en de opening der neusgaten
Lengte van die opening

Breedte

Breedte aan de breelite plats

Hoogte der oogputten

I engte der langite finyranden buiten het been

Lengte der dikfte kiezen buiten het been

Lengte der twee voornaame ftukken van het tongbeen

duimen, fyneno

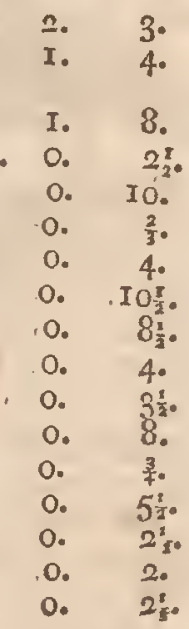


duimen, lynén.

Lengte der tweede beenderen

Lengte der derde beenderen

Lengte van het middelft been

Lengte der takken van de vork

Lengte van den hals

Brecdte van het gat des eerften wervelbeens van boven naar beneden.

Lengte van de eelie zyde tot de andere

Breedte van het eertte wervelbeen, op de dwarfche uitfteekzels gemeeten. 0 .

Lengte van het gedeelte der wervelbeen-kolom, die uit de rug-wervel-

beenderen beftaat

Lengte van het doornagtig uitfeelizel van het derde wervelbeen, dat het

langft is lighams van het laatfte wervelbeen, dat het langft is . . o.

Lengte der eerfte ribben

Affand tuffchen de cerfe ribben aan de breedfte plats

Lengte van de zevende, die de langfte is

Iengte van de laatfe der valfche ribben-

Breedte van de breedite rib

Lengte van het borftbeen

Lengte van het eerfte been dat het langft is

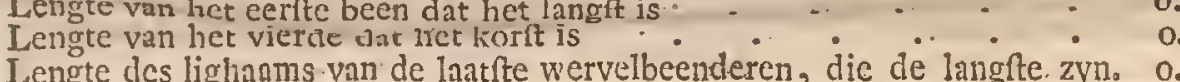

Lengte van het heiligbeen

Breedte van het voorfte-gedeelte

Breedte van het agterft gedeelte

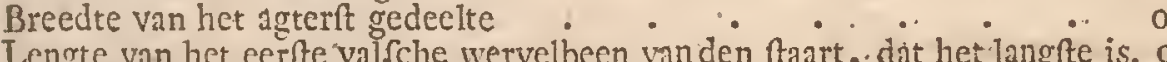

Breedte van het vourfte gedeelte van het heupbeen

Hoogte van het been van het midden der knokkelwyze holligheid . . . . I.

Midclellyn van die holligheid

Lengte van de goot

Breedte in ' $t$ midden

Diepte

Breedte

Breedte van bet bekken

Hoogte

Lengte va: 't fchouderblad

Breedte op de breedifte plaats

Breedte op de finalfte plaats
Hoogte van den doorn op de verhevenifte plaats

Lengte der fleutelbeenderen

ILengte van den fehouder

Omirek op de kleinfte plaats

Middellyn van deszelfs hoofd

Breedte van het onderfte gedeelte

Lengte van de ellepyp

Liengte van den elleboogsknokkel

Lengte van het ftralbeen

Lengte van het dijebeen

Middellyn van het hoofi deszelven

Omtrek van 't midden des beens

Ereedic van het onderfte einde.

o. $\quad 3 \frac{2}{2}$.

0. $2 \frac{\pi}{2}$.

o. $3 \frac{1}{2}$.

o. 10 10

o. $2 \frac{1}{3}$.

3.

o. 3.

$2 \frac{\pi}{2}$.

\%.

7.

$r$

1.

5 .

41.

3.

9.

4站.

政.

$2 \frac{1}{3} \cdot$

4.

$3 \frac{1}{2}$

6

IO.

4.

3.

7

I. 2.

7.

8

3 .

- 7

o. 6.

. $\quad 3 \frac{3}{5}$

o. 5 .

I. IO.

0. 4.

I. 4.

o. $2 \frac{\pi}{2}$

o. $6 \frac{2}{3}$. 
Lengte der kniefchyven Breedte

Diktc

Iengte van het 't fcheenbeen

Breedte van 't hoofd deszelven

Omtrek van 't midden des beens

Omtrek van het onderft cind des genomen

Lengte van het kuitbeen

Omtrek aan de dumfte plaats

Hoogte van de voorhand

Lengte van het hielbeen
Hoogte van het eerfte wigge-en fchuit-been te famengenomen

Lengte van het eerfte been van de agterhand, die de kortfte is

Lengte van het derde been dat het langfte is

Lengte van her ecrfte been van den agtervoet, dat het ${ }^{\circ}{ }^{\circ}$

Lengte van het tweede been, dat het langfte is

Lengte van den eerften regel des middelften vingers van de voorfte voeten

Lengte van den tweeden regel

Lengte van den derden

Lengtc, van den eerften regel van den duim

Lengte van dęn tweęden

Lengte van den eerften regel des middeliten vingers van de agterfte voetell

Lengte van den tweeden regel

Lengte van den derden

Lengte van den ecriten regel van den duim

Lengte van den twceden duimen, lynen.

o.

o. 2 .

o. 2 .

I. IO.

o. 4 .

o. 4 i.

4.

I. 9.

o. 2.0

o. $2 \frac{\pi}{10}$.

o. 6 .

o. $3 \frac{1}{\mathrm{x}}$

o. 2?.

0. 6 .

O. $2 \frac{x}{3}$.

o. 6!

o. $2 \frac{1}{2}$.

o. 2.

o. 2.

o. I⿳⺈.

D. $I \frac{1}{2}$.

o. $2 \frac{1}{2}$.

o. I

o. 2\%.

$0 . \quad I_{8}$,

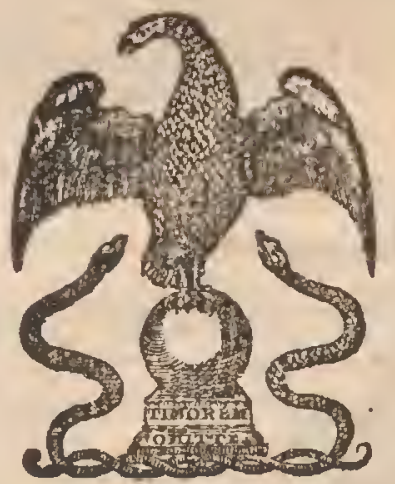




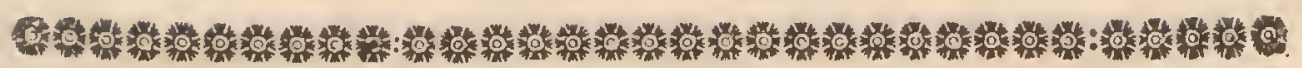

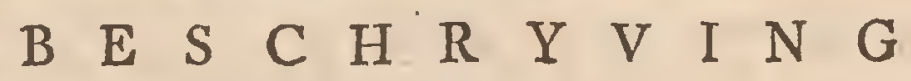

VAN DAT GEDEELTE VAN HET KABINET;

HETWELK BETREKKING HEEFT TOT DE NATUURLYKE HISTORIE

VAN HET INDIAANSCH VARKENTJE IN VAN DEN

E E G E L.

No. DCCLVIII. Drie Indiaanfcbe Varkentjes opgezet.

Deze drie dieren zyn van verfchillende grootten, en verfchillend gevlakt met wit, vaal, en zwart.

No. DCCLIX. Het geraamte van cen Indiaan fch varkentje.

De lengte van dit gernamte is van tien duimen en vyf lynen, van het voorfte gedeelte des boveniten kaakebeens tot aan het agterlt gedeelte der heupbeenderen; de kop is twee duim vyf lynen lang; en heeft drie duim en tien lynen in den omtrek, op de jukbeenige uitfteekzels en op de hoeken van het onderft kaakbeen gemeeten; de omtrek van het koffer, aan de dikfte plaats genomen, is van zes duim en twee lynen.

No., DCCLX. Het tongbeen van een Indiaan/ch varkentje.

De befchryving van dit been maakt een gedeelte uit, van die van het ge: ramte van het Indiaanfcl varkentje.

No. DCCLXI. Het been van de roede van een Indiaanfch varkentje.

Dit been is zes lynen lang, ééne lyn aan zyn onderfte einde breed; en llegts twee derde van een lyn aan zyn bovenite einde, dat de gedaante van een klaverblad heeft.

No. DC.CLXII. Drie opgezctte cegels.

De eerfte is zeer jong, de tweede en de derde zyn volwaffen: de tweede is gedeeltelyk faamgerold, en de derde is geheel uitgeftrekt, gelyk andere viervoetige dieren.

No. DCCLXIII. Het geraamte van een eegel.

Dit geraamte is agt duim negen lynen lang van het voorfte gedeelte van het bovenit kakebeen tot aan het agterit gedeelte der heupbeenderen : de lengte van den kop is twee duim twee lynen, en de omtrek drie duim negen lynen aan de dikite plaats; het koffer heeft zeven duim en eene lyn omtrek.

No. DCCLXIV. Het tongbeen van een cegel.

De befchryving van dit been wortt in die van het geramte van den eegel gevonden.

IIII. Deel. 


\section{E I S P I T $S$ M U I $S$ :}

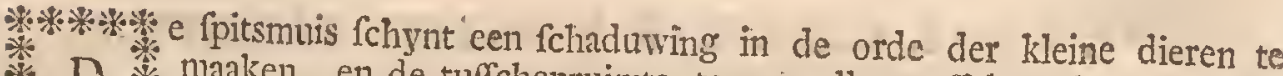

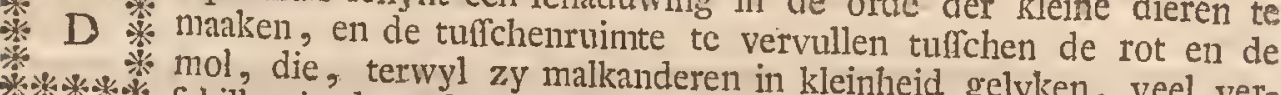

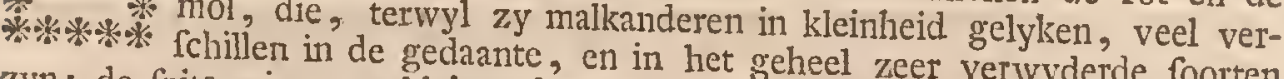
zyn: de fpitsmuis, nog kleinex dan de muis, gehel zeer verwyderde foorten hebbcude den neus veel langer dan de kaakbecnen; in de oogen, die, fchoon dier, en veel kleiner zyn dan die ke zy vyf aan alle de voeten heeft; in den th; in 't getal der vingeren, welde agterite, welke zy korter heeft dan den taart, in de pooten, byzonderlyk lyk in de tanden.

Dit zeer klein dier heeft en en die de katten tegen ftat; $z y$ zecr fterke lugt, die het byzonderlyk eigen is, maar zy eeten haar niet gelyk de muis: het op de fpitsmuis, zy dooden haar, en die tegenzin der katten, dar het vooroordeel uir geboren lie lelyke reuk, inzonderheid voor de paarden; ondertuffs gevaarlyke beet voor het vee, en in ltaat on te byten, want het heeft de opening noch venynig, noch zelfs. noeg om de dubbelde dikte van het vel van een van den bek niet groot gehet welk evenwel volftrekt noodzaaklyk is om te kunnen byten: der paarden, welke het gemeen aan den tant der fpitsmuis toefchryft ie ziekte zwel, eene foort van anthrax of negenoog, die uit eene inwendige is eengevoortkomt, en geene betrekking heeft met de beet, f men fleck van dit diertje.

Het onthoudt zig gcmeenlyk, byzonder des winters, op de hooizolders? in de ftallen, in de fchutren, in de mifthoopen; het eet graanen, infekten,

* De fpirsmuis heet in 't Griekfch Muranỳ; in 't Latyn Mus araneus, Mus cecus; in 't Italiaanfch Totoragno; in 't Spaanfch Murganbo; in 't Franfch Mufaraigre; in 't Hoogduitfch

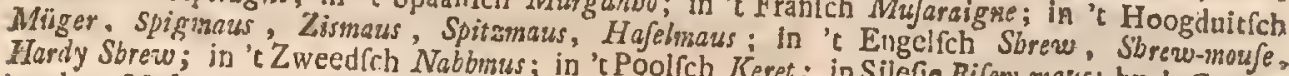
bunders Mufarring; in Swiffelland Miotrer: in Savoye Muset, in Silefic Bifem-maus; by de Grauwfersm, Muzeraigne, Mufet, Mufeire, Sery Sri. Mufaraneus. GESNGR ITifor. Que, Sery Sri.

Mus Mocbics, com hat hor. Qundrup. pag. 747. (uadrup. pag. $\$ 16$.

Mujoraneus. Rsy Synopf. Animal. Quadrup. pag. $239-$
Sorex Mujaraneus. LiNNASus.

Mufaraneus roftro productiore; Mus venenofus. KLLIN de Quadrup. pag. 58 :

Mufaraneus Jupra ex fufco rufus, infra albicans..... Mufaraneus. BRIsson.
pag. 178 .

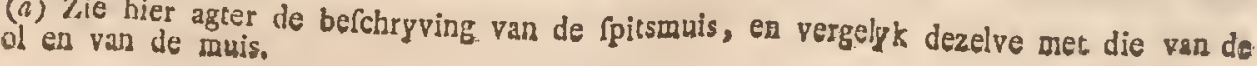


en gerot vleefch; men vindt het ook dikwils in de velden, en in de bofrchen, alwaal het van zaaden leeft: het verbergt zig onder de mos, onder de bladen, onder de ftammen van boomen, of zomtyds in de gaten, die door de mollen verlaaten zyn, of in andere kleinere gaten, welken het voor zig zelven maakt, door de aarde met zyne nagels en fnuit door te graven.

De fpitsmuis brengt veele jongen tevens voort, in even grooten getale, zegt men, als de muis, maar niet even dikwils: zy heeft een veel fcherper fchreeuw dan de muis; maar zy is, op verre na, zo vardig en behendig niet als deze; men vangt haar ligtelyk omdat zy kwalyk ziet en kwalyk loopt.

De gewoone kleur der fpitsmuis is bruin met ros gemengd; maar daar zyn ook afchgraauwe, en byıa zwarte, en alle zyn zy meer of min witagtig onder den buik.

Zy zyn zeer gemeen door geheel Europa, maar het blykt niet, dat men haar in Amerika wedervindt: het dier van Brafilie, daar MARcgrave (b) onder den naam van pitsmuis van gewaagt, en 't welk hy zegt, dat een zeer pitfen bek, en drie zwarte ftreepen op den rug heeft, is grooter, en fchynt tor eene andere foort dan die van onze fpitsmuis te behooren.

\section{(b) Marcgrayin Hiftor. Brafilo pag. 229.}




\section{$B E S C H R Y V I N G V A N D E S P I T S M U I S$.}

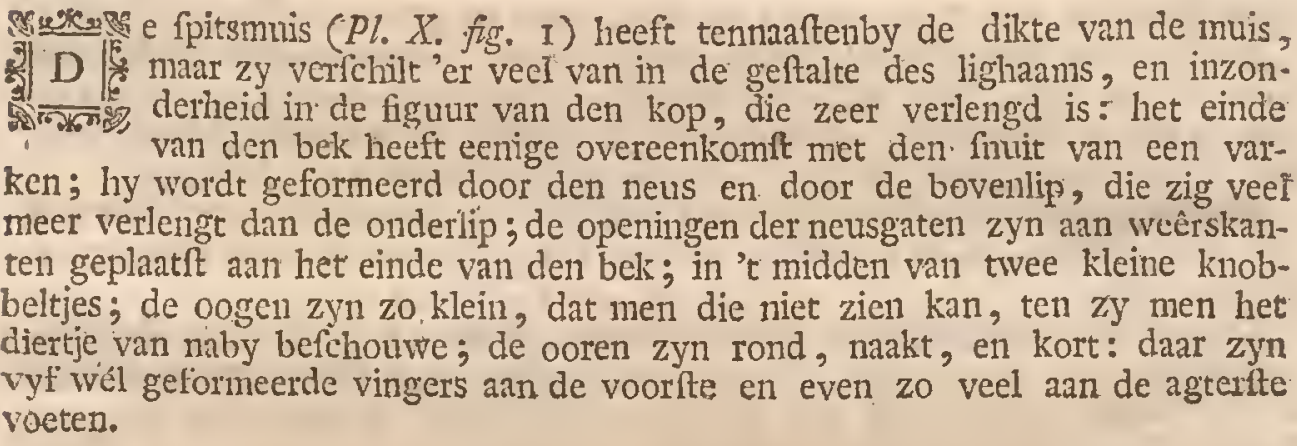

Lengte des geheelen lighaams, in een regte Iyn gemeeten van het einde van den bek tot aan den aars . . . 2. II.

Lengte van den kop, van het einde van den bek tot aan het agterhoofd. . . O. II I $\mathbf{z}^{\text {F* }}$

Omtrek van den bek op het einde van de onderfte lip gemeeten . . . o. 8.

Omtrek aan het einde van den bek
Omtrek van de opening des monds, van de fplyting der lippen tot aan die van de andere zyde

Afftand tuffchen de twee neusgaten

o. 3.

Afftand tuffchen het einde van den bek en den voorften hoek van het oog. 0.

Afitand tuffchen den agterften hoek en het oor . . . o. 4:

Lengte van het oog van den eenen hoek tot den anderen . . . 0. s.

Opening vant het oog

Afitand tuffchen de voorfte hoeken der oogen in een regte lyn gemeeten. o. 3.

Omtrek van den kop tuITchen de oogen en ooren genomen . . . I. 40

Lengte der ooren

Lengte van de bafis op de uitwendige kromte gemeeten

Afftand tuffehen de beide ooren om laag gemeeten.

Lengte van den hals

Omtrek van den hals

Omtrek van het lighaam agter de voorfte pooten gemeeten

Omtrek aan de dikite plaats

Omtrek voor de agterfte pooten

Lengte van den ftomp des ftaarts

Dmtrek van den ftaart aan 't begin van den ftomp

Lengte van den voorarm, van den elleboog tot aan het gewrigt . -0 .

Omtrek van den voorarm aan den elleboog

Omtrek van het gewrigt

Omtrek van de agterhand

lengte van het been van de knie af tot aan de hiel

Omtrek van het bovenft des beens

Breedte ter plaatfe van de hiel

Omtrek van den agtervoet 


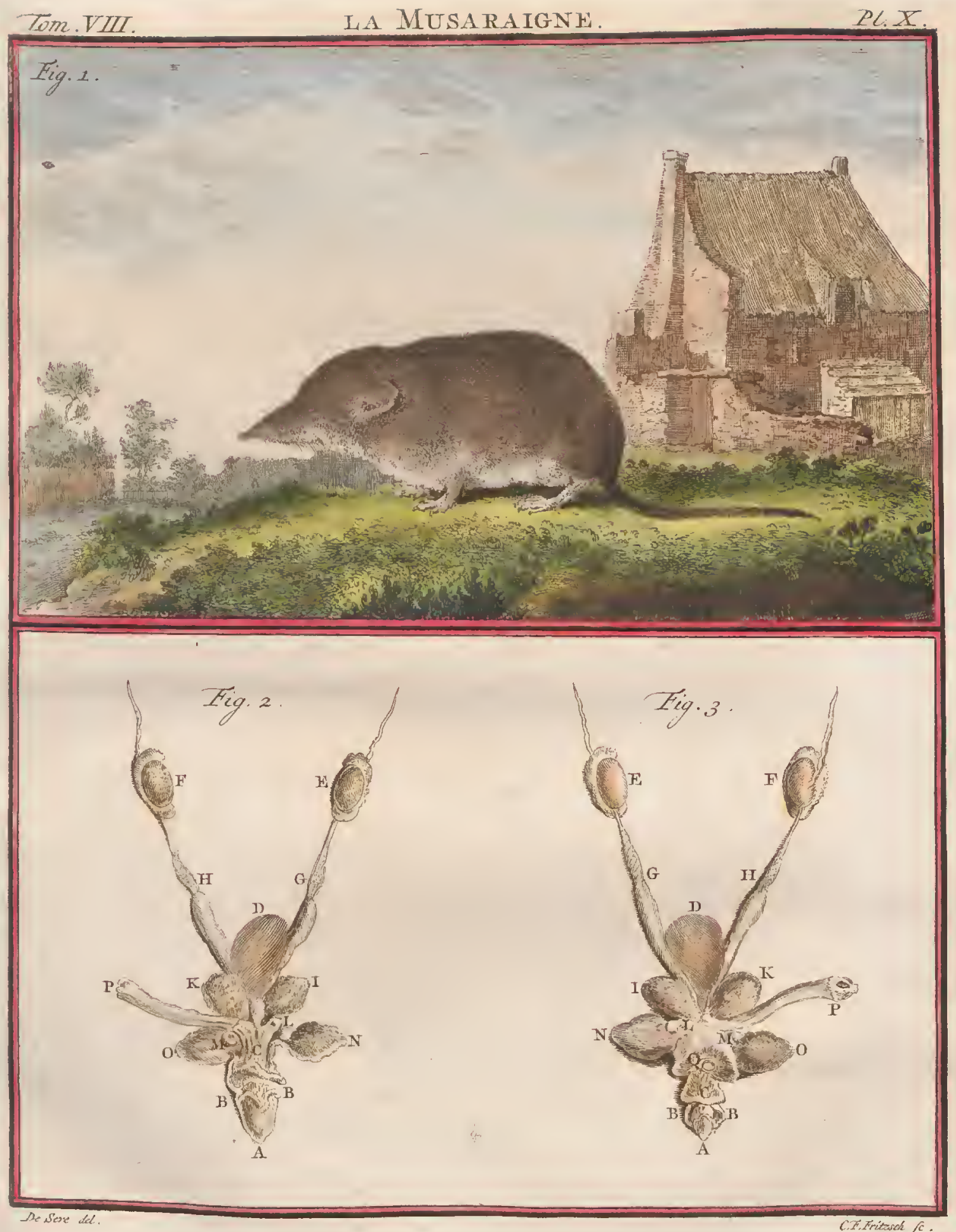



Lenfte van de hiel tot aan "t einde der nagelen duimen, lyner.

Breedte van den voorften voet

Breedte van den agterften voet

Lengte der grootfte nagelen

Breedte aan de bafis

De fpitsmuis, die ten onderwerpe voor de befchryving der inwendige deelen gediend heeft, was twee en een half duim lang van het einde van den bek tot aan den ftaart; $2 y$ woog twee gros en zes-en-veertig greinen; de milt drie greinen, de herffenen twee en een half grein de agterlherffenen cén grein.

Dit dier ontleedende heb ik yder deel nauwkeurigr vergeleeken met dat, " $t$ welk daar ann beantwoordde in de water-fpitsmuis, waarvan de befchryving op deze volgt, en ik heb deze twee dieren bevonden zo fterk 11anr malkanderen te gelyken, dat ik geoordeeld heb, dat het genoeg zonde zyn de befchryving te maaken, en de maten op te geeven, van de ingewanden des grootfen diers, het welk de water-fipitsmulis is, on ook een regt denkbeeld van het kleiner te kunnen vormen; dus wyze ik naar de befchryving van de water-fpitsmuis, die vervullen zal't geen hier ontbreekt: ik zal alleenlyk annmerken, dat de matag en de darmen van de fpitsmuis, naar evenredigheid, een weinig grooter en langer waren dan de mag en de darmen van de waterfpitsmuis, cn dat de eerfte geen zenuwagtig middelpunt in het middelrif hadt.

Nen kan geene mammen aan de fpirsmuizen bemerken, dan by dic, welke vol melk zyn; ik heb 'er twee in dezen ftaat waargenomen, en ik heb nlegts zes tepeltjes kunnen vinden, op het agterfte gedeelte van den buik, drie van weerskanten geplaatf; de twee eerite waren ann de zyde van de klink.

Het cerfte dezer wyfjes droeg vyf vrugtjes, drie in den regter hoorn van de lyfmoeder, en twee in deil linker; het ander hadt zes vrugtjes, drie aan elke zyde: de moederkoek was rond in den omtrek, bolrond, en van eene roodagtige kleuir; zy hadt drie en een halve lyn middellyns: de lengte der vrugtjes was vyf of zes lynen van den aars tot aan de kruin des hoofds; men onderfcheidde reeds hunne voornanme ledemaaten; die twee wyfjes zyn geopend den 12 april en den 10 juny.

Het geraamte van de fpitsmuis verfchilde niet van dat van de water-fpitsmuis, dan in de grootte der beenderen en der tanden, enl in 't getal der valfche wervelbeenderen van den ftant, 't welk negts zeventien was in de fpitsmuis. Dewyl men de verfchillende grootte van de voornaame becndercn dezer twee dierert kan beoordeelen uit de tafels der afmeetingen van de uitwendige deelen, is 't my voorgekonen, dat het genoeg ware de befelryving te maaken, en de afmeetingen te geeven van het geraamte van de water-fpitsmuis, omdat deze, grooter zynde, de figuur der beenderen duidelyker doet zien: ik wys derhalven naar de befchryving van de water-fpitsmuis om de befchryving. der beenderen en tanden van de fpitsmuis, welken ik hier, even als de ingewanden, voorby gaa, te vervullen. 


\section{DE W A T E R-S P I TS M U I S*.}

at ewyl dit dier, fchoon in ons klimat naturlyk thuis hoorende, by * $D$ To geen Natuuronderzoekers bekend was, en de Hr. Daubentos de a die cerfe is geweeft, die het ontdekt heeft, zo wyze ik voor alles, * fchryving, welke hy hier agter van het zelve geeft. In ' $t$ vervolg van dit Werk zal ik dikwils gelegenheid hebben op dezelfde wyze te handelen, uit hoofde van de onvergelykelyke naarftigheid, waarmede gemelde Heer de dieren onderzoekt, en de menigvuldige ontulekkingen, welke hy gedaan heeft, van verfcheidene foorten, die voorheen of onbekend waren, of verward wierden met die, welken men kende: alles wat ik ten opzigte van de water- fpitsmuis kan zeggen, is dat men haar, by 't op-en ondergaan der Zon, aan den oarfprong der fonteinen vangt; dat zy zig overdag in de klooven der rotfen, of in gaten onder den grond, langs kleine beekjes, verbergt; dat zy in de lente werpt, en gemeenlyk negen jongen ter wereld brengt.

* De Water-fpitsmuis heet in 't Franfch Mufaraigne d'Eau; Mémoires de l'Académie des seiences, Anné $\mathbf{7 5 6}$. Mémoire Jur les Mujaraignes, par Mr. Daubentọ.

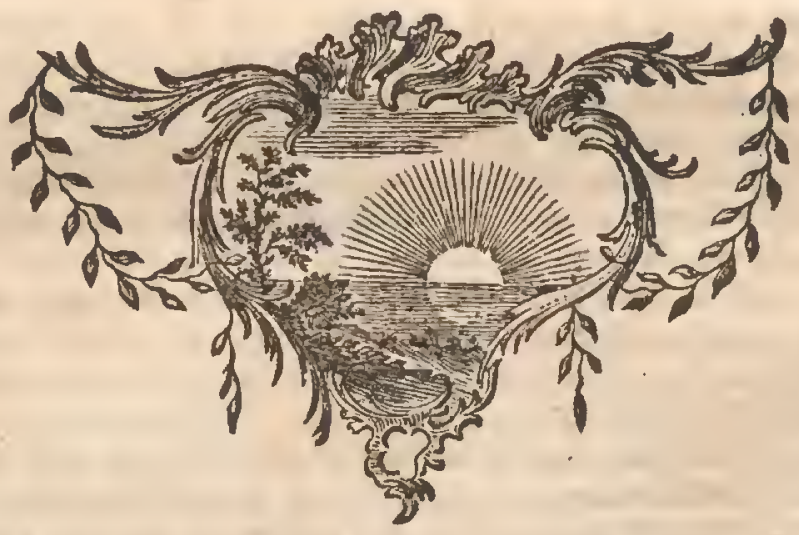




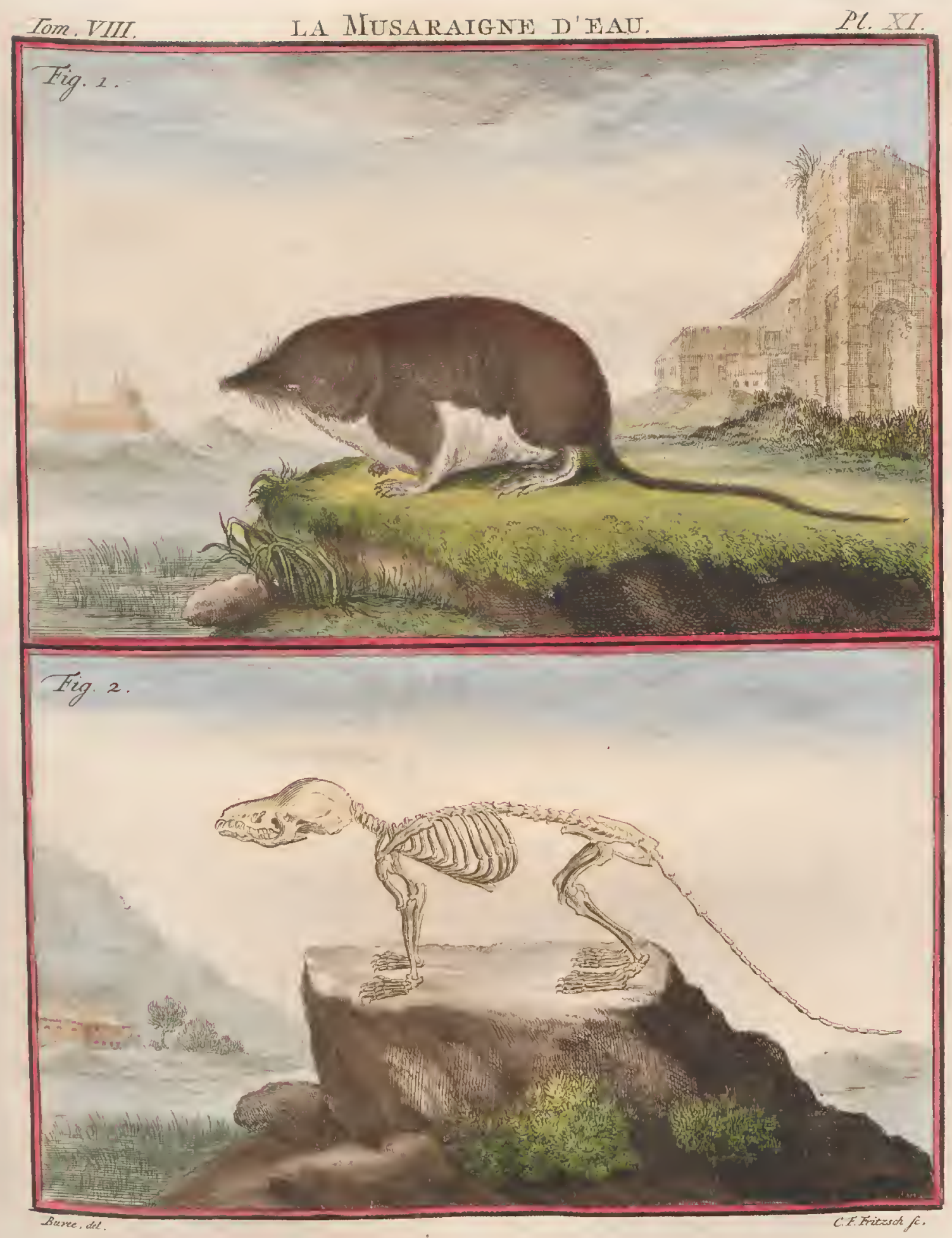





\section{BESCHRTVING VAN DE WATER-SPITSMUIS.}

$\mathrm{k}$ vond voor twee of drie jaaren de water-fpitsmuis (Pl. Xl. fig. I.) die door geene Natuuronderzoekers nog wargenomen is $(a)$. Dewyl zy een tweeflagtig diertje is, heb ik haar water-fpitsmuis geheeten, om haar van de reeds bekende fpitsmuis te onderfcheiden.

De water-fpitsmuis is grooter dan de fpitsmuis; zy heeft wat dikker bek, de ftaart en de pooten zyn langer en meer van hair voorzien; de kleuren van de water-fpitsmuis zyn verfchillende van die der fpitsmuis, want het bovenft gedeelte des lighaams, van het einde van den bek tot aan den faart, is van eene zivartagtige kleur, met een zweemzel van bruin gemengd; en het onderfte gedeelte heeft fchaduwingen van vaal, van grauw, en van afchgrauw, omdat het einde der hairtjes valal of grauw is, en het overige van eene afchgrauwe kleur tot aan den wortel: de ftaart is graus, hy is byna naakt, met uitzondering van de benedenfte zyde, die van het een tot het ander einde een kort witagtig hair heeft; de vingers hebben aan de zydeu ook hair, 't welk by de fitsmuis geen plaats heeft.

Lengte van het geheele lighaam in cen regte lyn gemeeten van het duimen, lynen:

einde van den bek tot aan den aars
Lengte van den kop, van het einde van den bek tot a an het agterhoofd. $\stackrel{3}{\mathrm{I}}$.

Omtrek van den bek, op het einde van de onderfte lip gemeeten . . .

Omtrek aan 't einde van den bek
Omtrek van de opening van den bek van de fplyting der lippen van

een einde tot het ander

Afitand tulfichen de twee ncusgaten

Afrtand tuffchen het cinde van den bek en den vooriten hoek van 't

oog aftand tuffchen den agterften hoek en 't oor

Lengte van het oog van den eenen hoek naar den anderen .....

Opening van het oog

Afitand tuffchen de voorite hoeken der ongen in een rente lyn gemeeten.

Omtrek van den kop tufíchen de ooren en de oogen . . . . : 1 .

L.engte der ooren

lengte van de bafis, op de uitwendige kromte gemeeten ${ }^{*} \cdot{ }^{-} \quad{ }^{\circ}$

Aftand turfchen de twee ooren, om laag genomen . . . . $\quad$.

Lengte van den hals

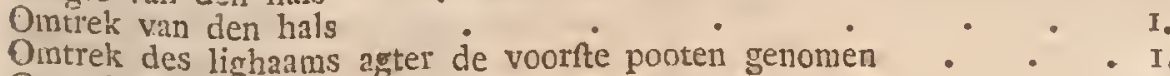

Omtrek aan de dikite plaats

Omtrek voor de agterfte pooten

Lengte van den ftomp des ftarts

- .2 .3$.

Omtrek van den ftart, aan 't begin van den ftomp' . . . 0 .

Lengte van den voorarm van den elleboog tot aan th gewrigt ${ }^{\circ} \cdot \dot{*} 0_{0}$

(a) Zie Mémoires de l' Académic Royals des Sciences., amnée 2756. 
Omtrek van den voorarm aan den elleboog duimen, lynea,

Omtrek van de vuift

Omtrek van de agterhand

Lengte, van de vuift tot aan 't eind der nagelen

Lengte van den poot, van de knie tot aan de hiel

Omtrek van het bovenite van den poot

Breedte ter plaate van de hicl

Omtrek van dey agtervoet

Lengte van de hiel af tot ann 't einde der nagelen

Breedte van den voorften voet

Breedte van den agterftell woet

Lengte der grootfte nagelen

Breedte anil de bafis

De water-fpitsmuis, die ten onderwerpe voor de befchyving van de inwendige weeke deelen gediend heeft, was drie duim lang van het einde van den bek tot aan den aars; 2 y woog vier gros en vyf grein.

Het netvlies was verborgen agter de maag, die aan de linkerzyde geplaatf was; de lever ftrekte zig cent weinig naar dezelfde zyde uit: de omwentelingen van de darm-buis begonden in de regtezyde, vervolgens befloegen $z y$ de navelftreek, en de linkerzyde, voordat ay den regtendarm formeerden; het linker gedeelte van de maag was veel dikker dan het regter; de darmbuis hadt omtrent dezelfde dikte van den portier af tot aan den aars: het eerfte gedeelte van die buis was van eene geelagtige kleur over de lengte van twee of drie duim, en fcheen dikker vliezen te hebben, dan in het overige zyner uitgeftrektheid, alwaar de vliezen zo dun waren, dat zy niet beletteden de ftoffen, die zy bevatteden, daar door heen te zien; daar was geen blindedarm.

De lever beftondt nit vyf kwabben; een der grootften was agter " $t$ midden van 't middelrif geplaatit, $z y$ bevattede het galblaasje en zy was aan den draagband vaft; daar was een kwal ter linkerzyde, tenmaaftenby zo groot als die in 't midden, en twee aan de regterzyde, war van de eerfte tennaaftenby dezelfde grootte hadt als die van ' $t$ midden; de tweede aan de regterzyde was wat kleiner dan de cerfte en bevattede het voorfte einde van de nier; eindelyk de vyfde kwab hieidt vaft aan 't nidden van den wortel der lever; dit ingewand woog twee-en-twintig greinen; het hadt van buiten en van binnen eene zwartagtig roode kleur.

Het galblaasje van eene water-fpitsmuis openende, vond ik het vol kleine witagtige korrelige lighaampjes, die ik eerft als een zetzel van het galvogt befchouwde; ik nam "er eenigen met de punt van, een mes uit, ell ik doopte hen in water; aanftonds verlieten $z y$ het mes, fcheidden zig van malkanderen af en vielen op den bodem van het vat, dat een glaazen bakje was; toen zag ik ondericheidenlyk, dat zy allen eene zelfde figuur hadden; $z y$ waren plat en zeer dun; zy hadden flegts eene halve lyn lengte, en eene derde van eene lyn breedte, aan de breedite plaats; het een der einden was puntig en het ander gerond; daar was in 't midden een kleine vlak van eene geelagtige kleur: dewyl alle die kleine lighamen ftandvaftig dezelfde gedaante 


\section{BESCHRYVING VAN DE WATER-SPITSMUIS.}

hadden, die in hunne kleinheid, niet veel verfchilde van die der botjes, die men in de lever van de fchaapen, en van verfcheiden andere lieren, vindt, zo vermoedde ik, dat zy ook wel eene foort van wormen zouden kunnen zyn: dus nam ik anderen op de punt van het mes en ik dompelde hen in lauw svater; zy verlieten het mes gelyk als de cerften, maar ik zag hen geenerleie beweeging maaken, waar uit blyken konde, dat het bezielde wezens waren: terwyl ik hen befchouwde bemerkte ik vyf of zes lighaampjes, die zekerlyk bezield waren, want zy zwommen in tegenftrydige rigtingen van malkanderen met herhaalde fprongen, vry fchielyk, ent tennaftenby gelyk de jonge kikvorfchen, terwyl $\mathrm{zy}$ nog in den ftaat van bobbelkoppen $\mathrm{zyn}$; $\mathrm{zy}$ hadden "er ook de figuur van, want hun agterft gedeelte was dumner dan het voorfle, cn liep in een ftaart uit; maar zy hadden eene witagtige kleur en waren zo klein, dat men hen van naby moet befchouwen on hen te bemerken.

De milt was van buiten en binnen van cene roodagtige kleur; zy woog anderhalf grein.

Het alvleefch was groot, het ftrekte zig uit dwars anter de mag van den twaalfvingerigendarm tot aan de milt: het linker-einde liep nit in twee kleine takjes, waarvan het een zig van voren tufichen de maag en de milt, en het ander van agteren tuffchen de nier cn de milt uittrekte.

Het middelrif was zeer dun; het zenuwagtig middelpunt ftrekte zig onlaas tot het borfthcen, en van agteren 1legts ter linkerzyde, uir.

De long beftondt uit vyf kwabben, vier aan de regter en flegts eén aan de linkerzyde; drie aan de regter waren aangeregen, de derde was de grootite van de vyf; de vierde was de kleinfte van allen; zy was by de bafis van 't hart.

Het hart was in 't lang, puntig, en lag fchuinfeh van voren naar agteren en van de regter naar de linkerzydc.

De tong was dik, van eene byna kegelagtige gedaante, en puntig- aan het eind, zy hadt cene linie breedte aan de balis: het verhemelte was dwarfch doorfinecden met negen of tien vooren; ik hob derzelver indrukzel zomtyds op de dikfte phats van de tong gezien.

Daar waren geene bogtigheden in de voorherfenen; zy woogen twee en een half grein, en de agterherffenen éćn grein.

De fpitsmuizen hebben geen balzak, en de opening van de voorhnid is yoor den aars geplaatft; daar is van buiten llegts ééne opening; dezelve verwydende ziet men een middelfchot, welker rand nict $z 0$ verheven is als die van do buitente opening; het middelfchot fcheidt den aars van de opening der voorhuid.

Het hoofdje der roede $(A, f g .2 \mathrm{en} 3 . P l . X)$ is breed, plat, en van cone zecr Onregelmaatige gedaante; het heeft blaadjes $(B B)$, éen aan weerskantcn, die zig vitfrekken over een gedeelte van deszelfs binnenzyde, onderltellende, dat dezelve voorwaards gerigt is; dit hoofdje eindigt in een wit, en kraakbeenig knobbeltje: de opening van de pisbuis is op de onderfte zyde van het hoofdje, by het knobbelije, tufichen ongelykheden of kleine verlengingell, die deze opening boorden; de roede (C) was platagtig van boven en benden: de blaas $(D)$ hadt eene cyronde gedaante.

VIII. Deel. 
De zaadballen $(E F)$ waren byna rond van eene geelagtige kleur van buiten, en eene witagtige van binnen; de anvoerende buizen ( $G H$ ) geleeken naar de hoornen en de trompetten van eene lyfimoeder, want zy waren zeer dun by de zaadballen, en zeer dik in het overige van derzelver uitgeltrektheid, uitgezonderd het einde, dat by de pisbuis was; de zaadblaasjes ( $I K$ ) hadden weinig fevigte, zy waren zeer dun by de pisbuis: ik heb geen voorftanders gezicn, maar alleen eene ronde kijer $(L M)$ en eene andere $(N O)$ veel grooter, en plat aan weerskanten van den regtendarm $(P)$ by den aars $(2$, fig. 3.)

De water-fpitsmuis, die teri onderwerpe voor de befchryving van de teelcicelen van het wyfje gediend heeft, hadt dric duim en vyf lynen lengte, van bet einde van den bek tot aan den aars, en twee duimen drie lynen van den. yars tot aan 't einde van den ftaart; $z y$ woog vyf gros en vier-en-twintig greinen.

$\mathrm{Zy}$ hadt ticn mammen op den buik, vyf aan ydere zyde; de twee cerfte waren aan den kant van de klink, en de laatlte by de kraakbeenderen der valfche ribben; de tepels waren blykbaar omdat dit wyfje drangende was, man het is niet mogelyk dezelve op een anderen tyd te onderfcheiden.

De klink en de aars zyn alleenlyk gefcheiden door een middelfchot dat van buiten niet zigtbaar is, dan wanneer men deze openingen verwydert: de klink selykt naar de opening der voorhuid van het mannetje; men herkent dezelve daar aan alleen, dat men 'er geene roede kan doen uitkomen, en dat men "er die niet in vindt.

De opening van de lyfmoeder was omringd van kleine knobbeltjes; de pisbnis hadt weinig lengte en omtrek: de blaas geleek tennnaftenby naar die van het mannetje; de hoornen van de Jyfmoeder waren kort in vergelyling van de lengte der fchede, zy rankten aan de ballen.

Den 20 may heb ik een water-fpitsmuis geopend, die negen vrugtjes droeg; vyf in den regterhoorn van de lyfmoeder en viex in den linker: fchoon $z y$ nog staar vicr lynen lang waren van de kruin des hoofds tot aan 't begin van den ftart, onderfcheidde men daar aan reeds de voornaame leden, en de oogen waren met zwarte ftippen geteekend: de moederkoek geleek naar die van de rot; zy hadt eene en eene halve lyn middellyn.

er grte van de darmbuis van den portier tot ann den ans lynen. Omtrek op de dikfte plaaten Ontrek op de dunfte plaatfen

Groote omtrek van de maag

Kleine omtrek
Lengte der kleine kronite van deii if kdarmi af tot aan den hoek, welken het regter gedeelte makt . . . Lengte vin den flokdarm af tot aan den grond vain den blindenzak ... Omtrek van den fokdarm Omtrek van den portier Lengte van de lever Breedte
Derzelver grootrte dikte

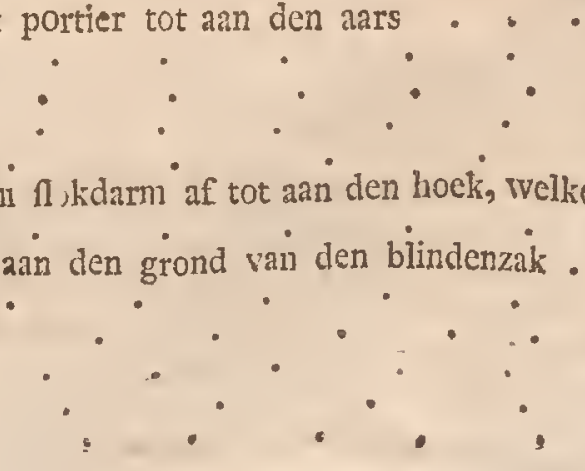

9. 6. ०. 7. o. 4. I. 4. I. I. 2 o. 2. ०. 3. o. II. 
Lengte van het galblaasje

Deszelfs grootfte middellyn

Lengte van de milt

Breedte van het onderft einde

Breerte in 't midden

Breedte aan het boven-einde

Haare grootfte dikte

Dikte van het alvleefch

Lengte der nieren

Breedte

Likte van het zenuwagtig middelpunt van $\dot{d e}$ holle ader af tot an de punt

Breedte

Breedte van ydere zyde van het zenuwagtig middelpunt

Qmitrek van de bafis van 't hart
Hoogte van de punt tot aan den oorfprong van de longflagader . .

Hoogte van de punt af tot aan de longezak

Middellyn van de groute llagader van buiten naar buiten genomen. . . o

Lengte van de tong van het voorfte van het toompje tot aan 't einde : . .

Breedte der vooren van' $t$ verhemeite $. . . . \quad . \quad 0$

Lengte van de voorherffenen

Breedte

Dikte

Lengte van de agterherffenen

Breedte

Dikte

Afitand turtchen de randen van de voorhuid en het einde van het

duimen, lynts. hoofdie

Lengte van het hoofdje

Breedte

Dikte

Lengte van de roede van de fplitfing der fponsagtige lighaamen af tot

aan de inplanting van de voorhuid

Breedte van de roede

Dikte

Lengte der zaadballen

Breedte

Dikte

Breedte van den opperbal

Dikte

Lengte der afvoerende vaaten

Breedte aan de dikfte plaats

Dilite

Groote ontrek van de blaas

Kleine omtrek

Lengte van de pisbuis

nmtrek

Lengte der zaadvaatjes
Breedte

Dikte

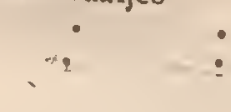




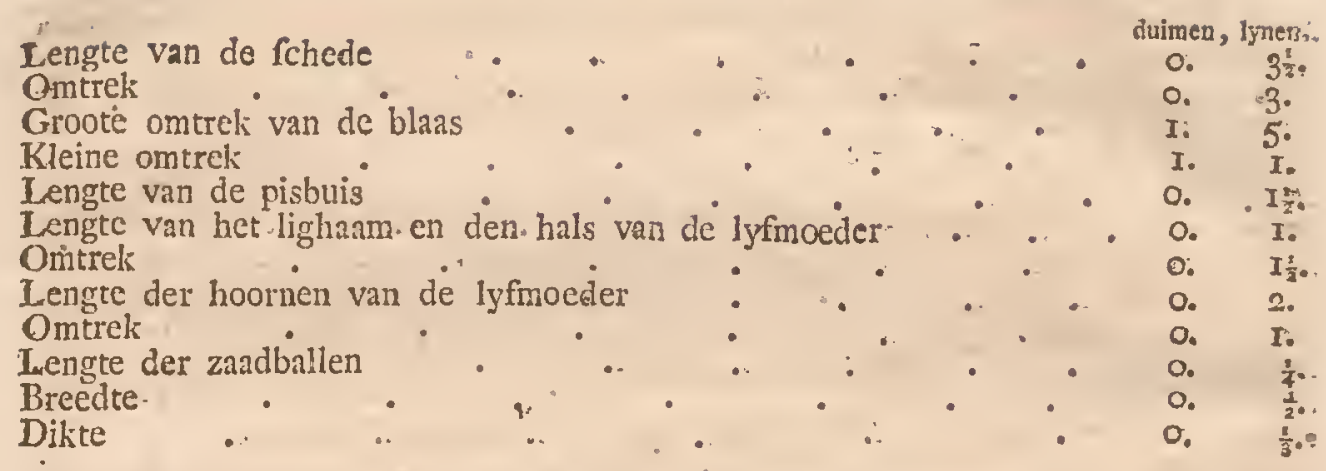

De kop van het geraamte ( $P l . X I$. fig. 2). van de.water-fpitsmuis is zeer langagtig; het gedeelte egter, dat uit de twee wandbeenderen en lietagterhoofdsbeen beftat, is rond; het vcorhoofd heeft weinig, breedte en de bek is zeer lang; ce oogputten zyn in cene uitfnyding, die aan weerskanten van, 't hoofd is, en in welker midden het kroonswyze uitfteekzel van het onderit. kaakbeen. zig byna zo hoog verheft als het voorhoofdsbeen: het voorfte gedeclte dier uitfnyding makt de ongput-, die men in 't gernamte nauwelyks.bemerkt, on]dat dezelve zeer klein is, en alleenlyk van voren in een beenagtigen rand uitloopt : de eigenlyke neusbeenderen, fchoon zeer lang, zyn veel minder voorwaards nitgeftrekt, dan liet bovenft kaakbeen.

De fpitsmuis heeft met den eegel eenige overeenkomften in de figuur en. plaatfing der tanden, voor zoverre gcene derzelven, eigenlyk gefprooken, , noch dlagtanden noch hondstanden $z y n$, voor zo verre de wortels der meeften agterwaards hellen, en de twee cerfte tanden van yder kaakebeen langer zyn dan de andere; de twee lange tanden van 't bovenft kaakbeen zyn binnenwaards gekromd, en die van het onderft knakbeen zyn wat om hoog s'ekromd, zotht de bolronde zyde van het einde der twee beneden tanden rakk aan de holronde zyde der boven-tanden: belalven deze vier lange tanden zyn 'er zeven: andere aan wcerskanten van het bovenft kaakebeen, en vyf aan weerskanten van het-onderf, het welk in alles agt-en-twintig tanden makkt: de vier voor: the waren van oene zeer donkere oranjelkleur aan ' $t$ einde (b).

Het tongbeen beftondt uit negen beentjes, gelyk als in de meefte dieren, die in dit Werk reeds beichreeven zyn; het middelite been hadt geene merkbaare kromte, darentegen waren de takken van de vork bolrond van voren.

Het doornagtig titituekzel van het tweede wervelbeen van den hals hadt de gedaante van, cen kam, en ffrekte zig byı even verre voorwards als ag-terwaards uit: de andere wewelbeenderen hadden green doomagtig uitfteek2ul; de onderfte tak van het fchuinfch uitfeekzel van het zesde wervelbeen: was lang, en ftrekte eig veel-meer agterwards dan voorwaards nit:

Daar waren derten rug-wervelbeenderen en dertien ribben, zeven ware en: zes valfhe: de ecrtte wervelbeenderen hadden geene doornagtige uitfteekzels, en die der laatfle waren weinig zigtbaar: het borftbeen beftondt uit zes beens:

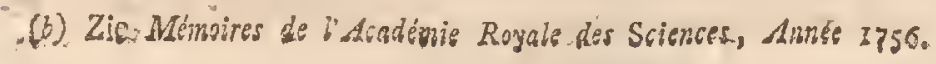


tjes; de eerfte ribben, ecne aan wederzyden, geledigden zig met het voorfte gedeclte van het eerfte been; de geleding der tweede ribben was tuffchen het cerfte en tweede been; die der derde ribben tuffchen het tweede en derde, en dus vervolgens tot aan de zesde en zevende ribben, die zig tuffehen het vyfde en zesde been geledigden.

De lenden.wervelbeenderen waren ten getale van zes; hunne doornagtige uitfteckzels hadden niet veel meer lengte dan die der latifte rugwervelbeenderen, en de bykomende uitfteekzels der lenden-wervclbeenderen waren nict langer dan de doornagtige.

Het was moeijelyk de valfche wervelbeenderen, die aan het heiligbeen be hoorden, te onderfcheiden van die, welke cen gedeelte van den ftaart uitmaakten; daar waren 'er in alles twee-en-twintig van het voorfte gedeclte van het heiligbeen if tot aan het einde van den ltaart: het waren de vyf eerften alleen, die doornagtige uitfeekzels hadden, en dic uitfteekzels hingen aan malkanderen valt, zodat zy in zommige onderwerpen, die ik heb waargenomen, eene doorgaandekam lings die vyf wervelbsenderen makkten: ik hcb evenwel uit de voetfpooren der gaten, welken ik heb bemerkt, opgemaakt, dat 'er. maar drie valfche wervelbeenderen waren, die tot het heiligbeen behoorden: in dit geval zouden 'er negentien in den tzart geweett zyn.

Schoon de ftant van de water-fpitsmuis flegts tivee wervelbeenderen mecr hadt dan die van de andere fpitsmuis, was hy egter zeven lynen linger, omdat yder wervelbeen np zig zelven langer was, ten opzigte der lengte van het lighanm des diers.

Het heupbeen geleek naar dat van de rot, van de muis, enz; maar daar was vry wat verfehil in de fchatmbeenderen, want dic van de fipirsmais waren op meer dan twee lynen affinds van malkanderen gefcheiden; dus maakte het ongenamde been geen goot:- de eyronde gaten waren zecr groot:

Het fichouderblad hadt 20 weinige breedte, dat het ligham van dit been zig wcinig vertoonde; men zag met den eerfen opflig van "t oog nict dan den doorn, die zeer groot was in vergelyking van het overige des beens; hy was gedeeitclyk los van het lighaam. des becus, en liep uit in twee takken, welker langlte zig met het llentelbeen seledigde, en de andere butenwaards gerigt was: de lourelbeenderen waren hrom, hume boliundte was op hume onderfte zyde.

Het bovenft gedeelte van het armbeen was. breed en agterwaards gekromd; het hadt drie verhevenbeden in de lengte, eene op het midden van den voorften kant, en eene aan elke zyde: de knnkkels waren plat, en hadden eene beenagtige varlenging an ydere $2 y d e$ van het onderft einde hes beens:

De bovenite zyde van het lijebeen was zo bieed als die van het armbeen, ondat 'er eene beenagtige kam onder.den grooten draijer' was: dhar was ook wen kam voor het bovenil gedeelte van het fuhcenbeen; die kam was nat butten gekromd, zodit zy een goot op de nitwenüige. zyde van het been makite : het kuitbeen was van het feheenbeen niet afgefcheiden. dan van deszelfs middeifte gedeele tot an het boveneinde.

Ik heb llegis drie beanderen in de certte ry van de voorhand, en vier in de:

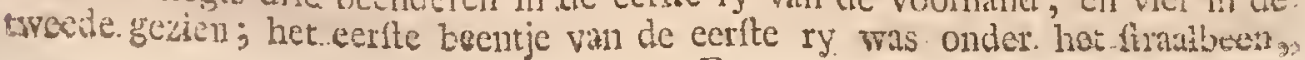


het tweede onder de ellepyp, en het derde buiten de ry, gelyk als het erwtgelykend beentje van den menfch: het eerfte beentje van de tweede ry van c.e voorhand was gedeeltelyk boven het eerfte van de agterhand en gedeelteIyk boven het tweede; het tweede beentje van de voorhand was boven het tweede van de agterhand, het derde beentje van de voorhand boven het derde beentje van de agterhnind; en het vierde beentje van de voorhand gedeeltelyk boven het vicrde, en gedeeltelyk boven het vyfde, beentje van de agterhand.

De voorvoet beftondt uit zeven beentjes: het eerfte wiggebeen was het grootft van de drie, en het tweede het kleinft.

Lengte van den kop, van het einde des onderften kakakeens tot het agterhoofd. lynen.

De grootite breedte van den kop

Lengte van het onderft kaakbeen tot aan den agterften rand van het knokkelwyze uitfteekzel

Breedte van het onderft kaakbeen ter plate van de voorfte tanden

Breedte van het bovent kaakbeen terzelfder plaats

Affand tufichen de oogputten en de opening der neusgaten

Lengte van deze opening

Breedte van de langfte voortanden buiten het been

Lengte der twee voorname deelen van het tongbeen

Lengte der tweede beenderen

Lengte der derde beenderen

Lengte des beens van 't midden van de vork

Lengte der takken van de vork

Leirgte van den hals
Lengte van het gat des eerften wervelbeens van boven naar beneden

Lengte van de eene zyde naar de andere

Lengte van het gedeelte der wervelbeenkolom, die uit de rugwervelbeenderen beftaat

Lengte der eerfte ribben

Afitand tufichen de cerfte ribben an de breedrte plaats

Lengte van de langfte

Lengte van de laatite der valiche ribben

Lengte van het borfbeen
Lengte van het eerfte been dat het langft is

I Lengte van het lighaam des vyfden lenden-wervelbeens, dat het langft is.

Lengte van het heiligbcen

Breedte van het voorfte gedeelte

Brcedte van het agterfte gedeelte
I.engte van het zesde valfche wervelbeen van den ftart, dat het langfte is.

Lengte der cyronde garen

Breedte

Breedte van het bekken

Lengte van het fchouderblad

Breedte aan de breedifte plaats

Lengte der fleutelbeenderen

Lengte van den fchouder

Breedte van het boveneinde 


\section{BESCHRYVING VAN DE WATER-SPITSMUIS. 47}
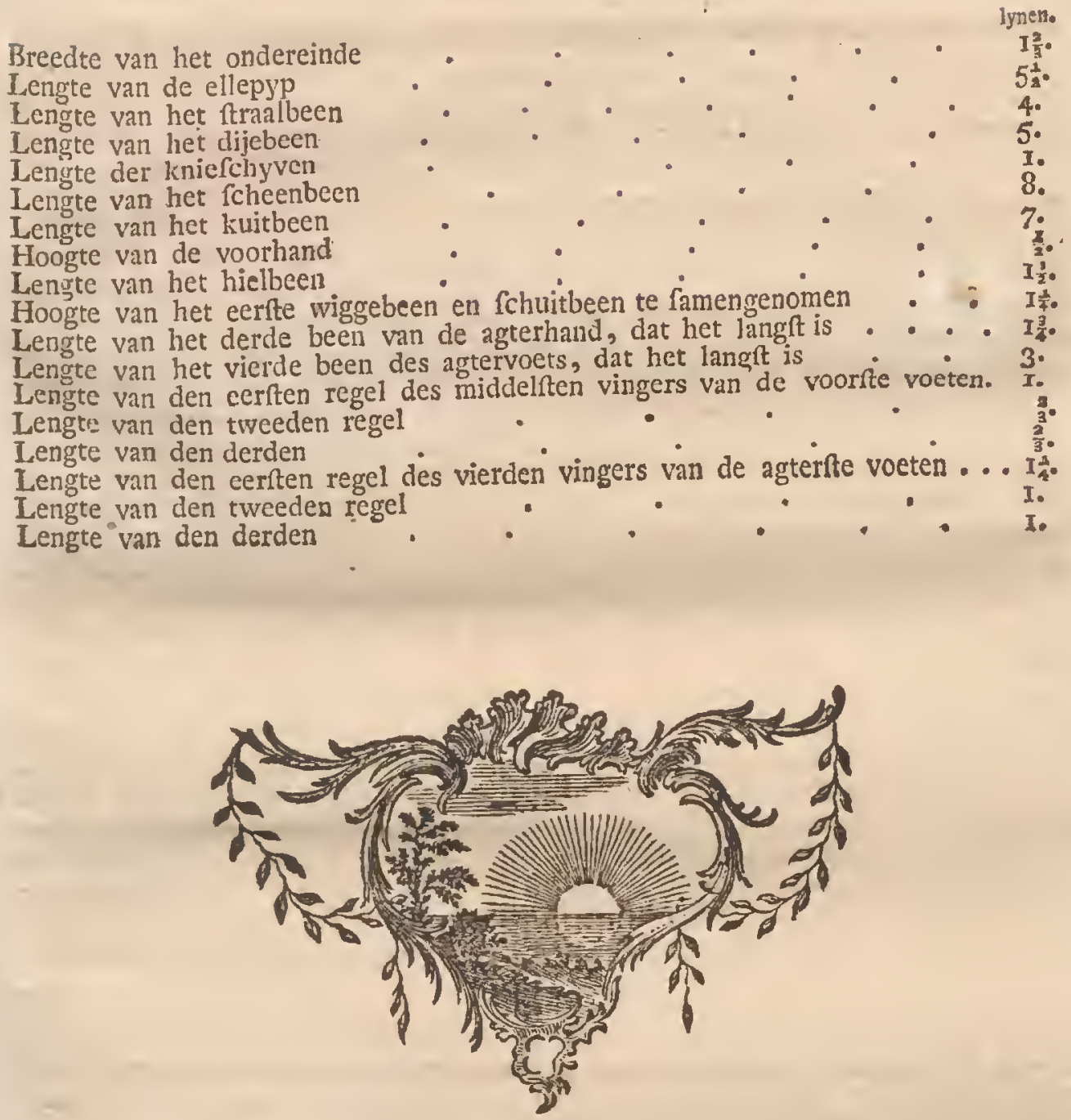


\title{
D E $\quad \mathrm{M} \cdot \mathrm{O}$ I
}

\begin{abstract}
3. S D dat zy weinig gebruik van het zintuig des gezigts kan maken; in * D Deryoeding van dat gemis heeft de Natuur han het genot van het

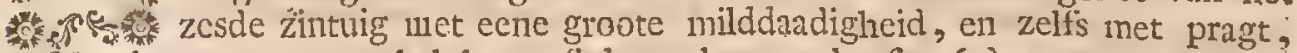
gefclionken : een opmerkelyke tocitel van bewarplaten $(a)$, cn vaaten, cene verbaazende menigte zaadvogt, byfter grootc zaadballen, cen tecllid vail cene zonderlinge lengte; dit alles heimelyk binnen in 't lighaam verborgen, en bygevolg veel warmer en vecl wcrkzanucr dan het anders wczen zoude.: dat dicr is inderdaad van alle dieren, die wy kennen, liet gunftigft bedeeld, het beft voorzien van werktuigell, en bygevolg van gewaarwordingen en aandoeningen, die daar toe betreklyk zyn; liet heeft daarenboven een tedcr gevoel, zyn vel is zo zagt als zyde; het heeft een zeer fcherp gehoor, en kleine handjes met vyf vingeren, zeer verfohillende van het einde der vocten van andere dieren, en byna gelyk aan der menfehen handen; het is zeer fterk nar den omtrek zyu's lighaams, hceft een ftevig vel, ecne ftandvaftige lyvigheid, eene leevendige en wederkcerige verknogtheid van het mannetje en wyfje, vrees of afkeer voor alle andere maatchappy, de zagte gewoouten van ruft en afzondering, de konft van zig in -veiligheid te ftcllen, van zig in een oogenblik eenc wykplats te bereiden, eene wooning toc te ruften, het gemak van dezclve uit te breiden, en "er een overvloedig bctaan te vinden, zonder verpligt te zyn daar uit te komen. Zie daar de natuur, de zeden en talenten van de mol; zeden en talenten ongetwyffeld varkieslyk boven hoedanigheden, die wel veel fehittercnder, mair die tevens met het we. zendlyk gcluk onbeftanbaarder zyn, dan in de dicpfte duiftcrnis te leeven.
\end{abstract}

-

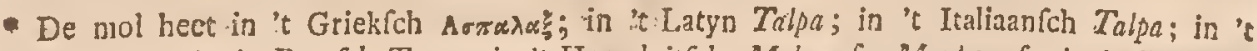
Spaanfch Topo; in 't Franfch Tause; in 't Hoogduitch Mulwirf, Maulwurf; in 't Engelfch Mole, Moldward, Want; in 't Zweedfch Mullwad; in 't Poolfch Kret.

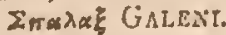

Talpa. Gesner. Hift. Osbatrup. pag. 931. Icon. Animal. Quadrup. pag. IIb.

Talpa. Rsx. Synopf. Aizinal. Quadrup. pag. 236.

Talpa condata. L.INNTES.

Talpa noftras, nigra communiter. KearN de Quadrup. pag. 60.

Tulpa catudala nigricans, pedibus anticis $\mathrm{E}^{2}$ pofticis pentadadylis .... Talpa vulgaris. Bris. son. Regn. Animal. pag. 230.

(a) Tefles maximos, paraftatas ampliflmas, novum corpus feminale ab bis diverfum ac fepara. tum... penem etiam omnitsm, ni fallor, animalium longiflimum, ex quibus coliigere eft ma. ximam pra reliquis omnibus animalibus voluptatem in coîu boc atjectun Eo vile animalculam perci. pere, ut babeat quod ipfi invideant, qui in hoc fuprenas wite fua delicias collocant. RAY Synogs. Arimal. Quadrup. pag. 23\% 


\section{$\checkmark A \quad N \quad D$ E $M O L$ L.}

De mol fluit den ingang van haare wykplaats, komt 'er byna nooit uit, ten zy daar toe genoodzaakt door de overvloedige zomerregens, wanneer haar verblyf onder water raakt, of deszelfs gewelf door den voct des hoveniers wordt ingedrukt; zy maakt zig een rond gewelf, of ecn foort van koepel, in de.weiden, en vry gemeen een lange gang of buis in de tuinen, omdat het gemaklyker is eene loffe en beteelde aarde te verieclen en op te werpen, dan vafte zooden, die, met de wortels van het gras doorgroeit, veel taajer famenhangen; zy houdt haar verblyf niet in flykerige oorden, noch ook in faamgepalkte, al te harde en fteenagtige, gronden; zy moet cene zagte goede aarde hebben, wél voorzien van fappige wortels, en vooral wél bevolkt net infekten en wo:men, daar zy haar voormamfte voedzel van makt.

Dewyl de mollen maar zelden uit haare onderaardfche wooning te voorfchynk komen, zo hebben zy weinig vyanden, en ontfnappen ligtelyk aan de roofdieren: haare grootlte geefiel is de overftrooming der rivieren; meri ziet haar by het aanwaffen van ' $t$ water in menigten zwemmende vingten, en alle mogelyke poogingen aanwenden om hoogere landen te bereiken; maar de meefte komen on, zo wel als haare jongen die in de gaten blyven; buiten dit middel van verdelging zouden hanre groote talenten tot de voortteeling ons zeer laftig worden. Zy koppelen teger het einde van den winter; $\mathrm{zy}$ draagen niet lang, want men vindt reeds veele jongen in de mand van may; daar zyn gemeenlyk vier of vyf in ydere dragt, en het is vry gemaklyk onder de hoopen, cile zy opwrocten, de zulle te onderfcheiden, onder dewelke zy haare jongen werpen; die hoopen zyn met veel konft gemaakt, en zjon doorgaands grooter en verhevener dan de andere: ik geloof, dat deze dieren meer dan eens in 't jaar voortbrengen, mar ik kan het niet verzekeren; vaft gaat het ondertufichen, dat mer jongen vindt van de maand april af, tot in auguifus toe, ' $t z y$ dan, dat $z y$ meermaalen werpen, ' $t z y$ dat zommige vroeger, andere lanter, koppelen.

Het verblyf, alwaar $z y$ jongen, zoude cene afzonderlyke befchryving verdienen; het is met cen zonderlinge ichranderheid vervaardigd: zy beginnen met de aarde voort te duwen, op te wrocten, en "er een vry hoog gewelf van te maken; zy laaten middelfchutten, of eene foort van pilairen, op korte affanden Itaan, om het gewelf te onderfteunen; zy drukken en flaan de aarde, vermengen dezelve met vortels en planten, en maaken har van onderen zo hard en ftevig, dat het water door het gewelf, ter oorzaake van deszelfs rondte en ftevigte, niet kan indringen; zy werpen vervolgens onder dat gewelf een klein heuveltje op, op welks kruin zy gras of andere groente en bladen brengen, om daar een bed voor hare jongen van te maken: in deze plaatfing bevinden zy zig boven het waterpas van den grond, en bygevolg in veiligheid voor de gewoone overftroomingen, en terzelfder tyd voor den regen bedekt door het gewelf, dat over het heuveltie, waar op zy liggen, heen ligt, en hetzelve rondom bellui: : dit heuveltje is rondom doorboord met rerfcheiden fchuinfch afloopende gaten, dic laager nedergaan, en zig allerwegen uitfrekken, als zo veele ondernardfehe wegen, diar de moeder-mol kan VIII. Deel, 
deraardfche gangen zyn ftevig, en vaftgeflaagen, om niet in te ftorten, ftrek: ken zig tot twalf of vyftien ichreeden uit, en loopen allen, als ftralen uit het middelpunt naar den ontrek eens cirkels, op het hetveltje of het hoofdverblyf uit; men vindt in dezelve, zo wel als onder het gewelf, overblyfzels of afval van tyloozen-bollen, die warfchynlyk het eerfe voedzel uitmaaken, dat zy aan haare jongen geeft.

Men ziet uit alle deze fchikkingen, dat de mol zig nooit op een grooten afitand van hare woonplats verwydert, en dat de eenvoudigfte en zekerfte wyze om hat met haare jongen te vangen is, rondom die woonplaats eene kleine loopgraf te maken, die dezelve gelieel oniringt, en alle gemeenfchap der onderfcheidene kanaalen affindt; maar dewyl de mol op het minfte gerugt wegvliedt en haare jongen poogt mede te neemen, zo dienen 'er drie of vier menfchen klaar te ftaan, die, gezamentlyk met de fpade werkende, den geheelen hoop te gelyk opneemen, of in een oogenblik eene loopgrave rondom dezelve maken, en die haar vervolgens vatten, of aan de uitgangen warrneemen.

Zommige Schryvers (b) hebben verkeerdelyk gezega, dat de mol en de das. den geheelen winter door flaapen zonder voedzel te gebruiken: de das, gelyk wy gezegd hebben (c), komt in den winter, zo wel als in den zomer, uit haar hol, om har onderhond te zoeken, en men kan dit met zyne oogen zien uit de fpooren, welken zy op de fneeuw agterlat; de mol llaapt zo weinig, geduurende den geheelen winter, dat $\mathrm{zy}$ in dat faifoen, everi als in den zomer, de aarde opwroet; cn dat de landlieden een fpreekwoord, of ftelregel, liebben. De mollen wroeten, de dony is naby. Zy zoeken inderdaad de warmtte plaatlen; de Tuinlieden vangen haar dikwils rondom hume broeibedden in de maanden van december, january, en february.

De mol wordt natwweiyhs elders dan in beteelde landen gevonden; daar zyn 'er geene in de dorre woeftynen noch in de koude klimaten, alvanar de aarde geduurende het grootfte gedeelte van 't jaar bevroozen is. Het dier, 't welk men Siberiiche mol genoemd heeft (d), "t welk groen en goud geel hair heeft, is van eene verfchillende foort van onze mollen, welke men niet overvloedig vindt, dan van $Z$ weeden $(e)$, tot in Barbarije $(f)$; want het ftilzwygen der Reisbefchryvers doet ons vermoeden, dat zy in de heetere klimaten niet gevonden worden: die van Amerika zyn ook verfchillende, de Virginifche mol. $(g)$ is evenwel vry gelyk aan de onze, uitgezonderd de kleur van "t hair, die met donker purper gemengd is; maar de roode Amerikanfche mol (b), is een ander dier: daar zyn flegts, twee of drie verfcheidenheden in de gemee:

(b) Urfus, meles, Erinacequs, Talpa, Vefpertilio, per byemem dormiunt abftemii. Linsas Fauna Suecica, Stockholmia 1746 . pag. 8.

(c) Zie bet Artikel van de Das, VII Deel van dit Werk, blz. 68 .

(d) Alb. Seba Amft. 1734. Vol. I. pag. 5.

(e) LiNNAe Fiaun. Suecic. Stockholm I7t6. pag. 7.

(f) Voyages du Dr. SHaw, Amit. I743. Tom. I. pag. 322.

(g) ALB. SeBa, Vol. I. par. 5.

(b) Idem, ibidem. 


\section{$V A N D E$ M O L. 5I}

ine foort van onze molken; men heeft 'er meer of minder bruine, en meer of minder zwarte; wy hebben 'er gezien, die geheel wit waren, en SeBA maakt gewag (i), en geeft de figuur van eene mol, die zwart en wit gevlakt is, welke men in Ooft-Friesland vindt, en die een weinig grooter is dan de gewoone mol.

(i) Deze mol is in Ooft.Friesland op den grooten weg gevonden: $z y$ is wat langer dat de gewoone mollen, waarvan $z y$ voor het overige niet verfchilt dan door haar vel, ' $t$ welk op den rug, en onder den buik, geheel gemarmerd is inet witte en zwarte vlekken, waarin men evenwel min of uneer eene vermenging van gryze hairtjes, zo fyn als zyde, onderfcheidt: de fnuit van dit dier is lang en met een lang ruig hair bezet; de oogen zyn zo klein, dat men moeite beeft or de opening der ongappelen te ontdekken, ALB. SERA Fol. 1. pag. 68 .

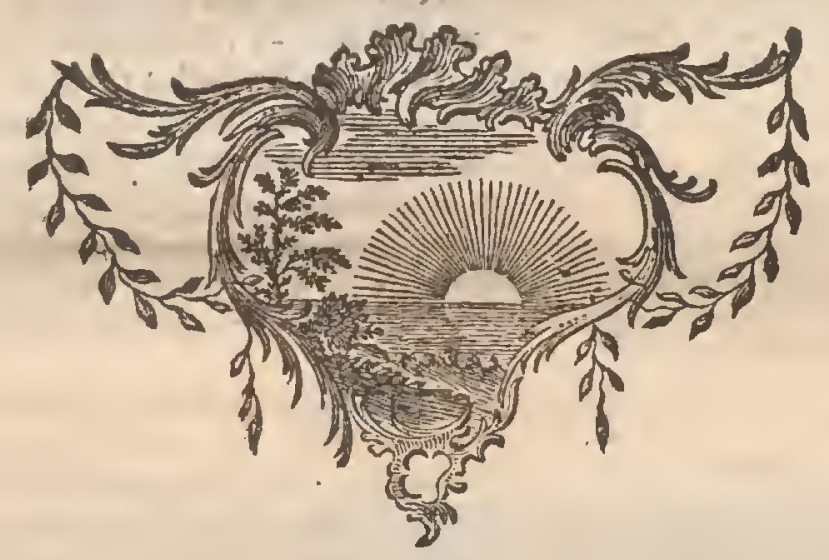


e mol (Pl. XII. fig. I) heeft veel gelykenis met de fpitsmuizen, en inzonderheis met de water-fpitsmuizen, in den bek en in 't hair, maar zy verfchilt 'er in andere opzigten van, inzonderheid in de.poo. ten en in den ftaart: het lighaam van de mol fchynt zeer mismaakt; het is langagtig en byna rolrond; het ruft op de aarde, en men onderfcheidt daar niet aan dan van voren. een puntigen bek, van agteren een zcer korten. ftart, en ain de beide zyden de voeten, die onniddelyk aan "t lighaam fchynen vaft te zitten; en de voorfe voeten fchynen zelfs tel zyde en onder het hoofd geplaatit: het einde van den bek ftrekt zig drie en een halve lyn buiten het onderft kaakbeen en de fnytanden van het bovenft kaakbeen uit; het eindigt, gelyk dat van het varken, in cene foort van. fchrobber, waarin de openingen der neusgaten zyn.

De bovenfte lip ftrekt zig van den fchrobber tot de fnytanden uit; $z y$ is dubbeld, want daar is een vliezig blad, dat zig van die lip, ter plaatfe van de eerfte baktanden, los makkt, en dat rondom de hondstanden en de fnytanden beweegt; dit blad fpringt weinig voor de middelfte fnytanden uit; maar voor de andere fnytanden en de hondstanden daalt het tot dè-onderlip neder: dewyl de bovenlip een gedeelte van het einde van den bek uitmakt; zo moet de mond zig openen terwyl het dier den fchrobber beweegt om in de aarde te wroeten; mar dan zou 'er aarde in den mond komen, zo het viiezig blad, dat op de tanden is, zulks niet belettede, want daar is ecne ledige ruimte tuffchen de eerfte baktanden en de hondstanden, ter plaatfe alwaar het blad. het laagft nederdaalt.

De oogen van de mol zyn ten uiterften klein; men ziet dezelve niet, dan terwyl men het dier van zeer naby warneemt, en de rigting van het hair niet verward is; alsdan bemerkt men dat. het hair twee ydels maakt, die zeven lynen van de hocken van den nond af, cen weinig hooger in eene fchuinfohe lyn gevonden worden: men bemerkt te dezer platte, tuffchen hct hair, op het vel, ecin zwart en glinfterend 1tip, dat het oog is, en dat het middelpunt aanwyft van eene ruimte zonder hiir, dic omtrent twee lynen middellyns lieeft.

De ooren ftaan niet fchelpswyze of hebben geene lepels; zy zyn van buiten niet getekend dan door de opening van den uitwendigen gehoorweg, wiens rand in het onderft gedeelte van den cirkel, dien hy maakt, wat uitfipringt buiten het vel: de opening van het oor is ten naftenby op een gelyken atiland van het oog gepliatit, als die, welke tuffchen het oog en den fchrobber is; om deze opening te zien, moet men het hair, dat dezelve omringt en geheel bedukt, verwyderen.

De voorite voet is veel dikker dan de agrerfte voet, en hy heeft in zyne gedaante meer overeenkomft met eene land dan met een voet: hy is derwy- 


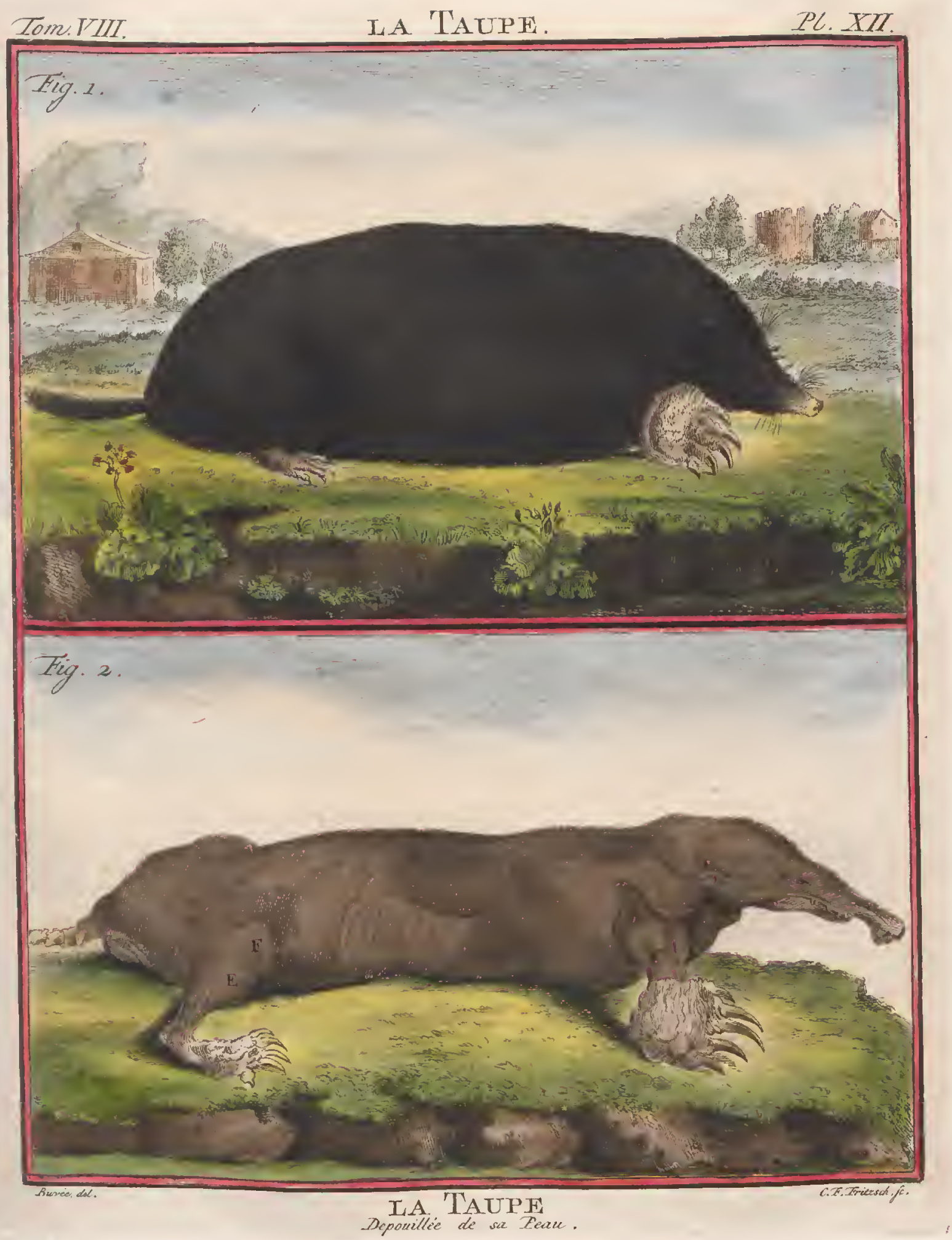



ze geplaatft, dat de palm agterwaards gedraaid is, en dat de vingers fchuinfch naar buiteri en omlaag gerigt zyn: het gewrigt is onder het vel verborgen en heeft weinig dikte; de agterhand is zeer lang; zy fchynt droog en zenuwagtig; de vingers zyn zeer kort, maar de nagels zyn zo lang als de vingers; de agterfte voet gelykt naar dien van de rot.

De ftart is fchubagtig gelyk die der rotten, mar van een langer hair voorzien: de aars is uitfpringende, en zeer verre af van den oorfprong van den ftart.

Het hair van de mol is zagt, glinfterende, en van eene afchgrauwe kleur, die verfchillende fchaduwingen aanneemt, naarmate men het dier onder verfihillende oogpunten ziet: wannecr men de mol van voren, van den kop tot aan den ftaart, befchouwt, fchynt het hair, agterwaards liggende, van cene heldere en glinfterende afchgrauwe kleur; wanncer men haar integendeel van agteren, van den ftart naar den kop, befchouwt, fchynt het hair zwart, zonder glinfterende te zyn; maar het is alleenlyk zwartagtig op de borft en aan den buik, en het heef een zweemzel van vaal op het onderft kaakbeen, cn op het midden van den buik.

Men heeft ( $P I . X I I$. fig. 2.) eene gevilde mol van natuurlyke grootte vertoond, om te doen zien de plaatfing der deelen, dic onder het hair en onder het vel verborgen zyn, gelyk als het oog $(A)$, de opening van het oor $(B)$, den voorarm $(C)$, den elleboog $(D)$, den poot $(E)$, de knie $(F)$, de dije $(G)$.

Lengte van het geheele lighaam in cen rogte lyn gemeeten, van het düimen, lynen.

einde van den finuit, of deszelfs rand, tot an den aars
Lengte van den kop, van den fnuit tot tuffechen de ooren

Omtrek van den finuit op den rand gemeeten $. \quad . \quad 0_{0} 6_{0}$

Omtrek van denzelven agter den rand, op de dunfte plaats gemeeten. o. 5 :

Omtrek op het einde vau de onderfte lip gemeeten . . . I. I:

Bogt van de opening des monds, van de fiplyting der lippen van de eene

tot de andere zyde

Afftand tuffchen de twec neusgaten $\cdot \quad \cdot{ }^{\circ} \cdot 0_{0}$

Afitand tufichen den fiuit en den voorften hoek van't oog: ${ }^{*} \cdot 0_{0}$

Afitand tuffchen den agterten lioek en het oor . . . o.

Breedte

Aftznd tuffchen de voorfte hocken der oogen, in een regte lyn gemiceten $\quad . \quad . \quad 0$.

Ontiek van den kop tuffchen de oogen en de ooren genomen . . . 2.

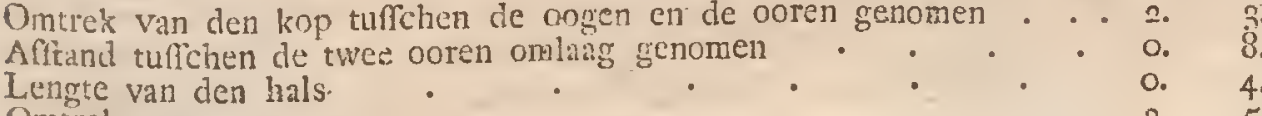

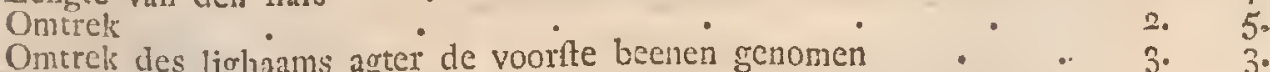

Omtrek an o lin a

Omtrek voor de dikfte plants

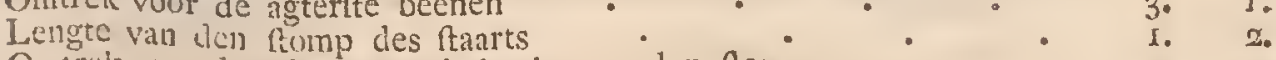

Omtrek van den tant aan 't begin van den ftomp : ${ }^{\circ} \cdot 0^{\circ} 4$.

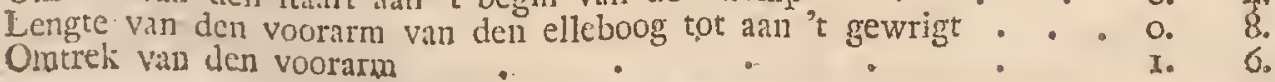

G 3 
Omtrek van 't gewrigt van de hand

Omtrek van de agterhand

Lengte van 't gewrigt af tot an

aluimen, lyners.

- I. 2.

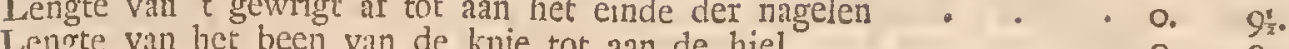

Ontrek van het bovenit des beens

Breedtc ter plate van den enkel $\quad$ : $\quad$.

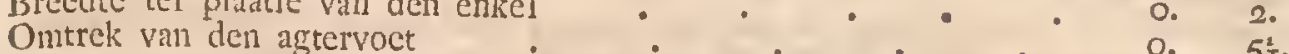

Lengte van de hiel tot aun 't einde der nagelen .: . .

Breedte van den voorften voet

Breedte van den agteriten voet $\quad . \quad: \quad: \quad$ o. $3-$

Lengte van de grootfte nagels der voorfte vocten $\quad \cdots \quad \cdots \quad 0.3^{\frac{\pi}{2}}$.

Brecdte an de bafis.$\quad \cdots \quad$ o. I. $_{0}$

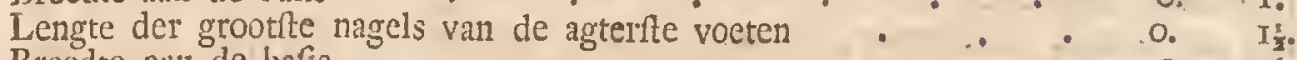

Breedte aulis de bafis .

De mol., die ten onderwerpe gedicnd heeft voor de befchryving der inwendige wecke declen, was, van het einde van den bek tot an den oorfprong van den ftart, vier duim en agt lynen, en tot aan den pars legts vier duim en ééne lyn, lang; zy. woog.cen once en drie groffen.

Het netvlies ftrekte zig tot aan het cinde van den onderbuik uit, maar het was zo dun, zo fyn, dat men het op de ingesvanden niet bemerken konde; men zag het niet, dan wanneer men het met een tangetje opligtede.

De twalfvingerigedarm ftrekte zig in de regterzyde tor de nier vit; hy vouwde zig weder binnenwards, en verlengde zig naar voren, om zig te voegen ann den nugterendarn, dic zyne onwentelingen in den eigenlyk gezegden bovenbuik, onder die maag, en in de navelitreek, maakte : het vervolg der darmbuis ftrekte zig uit in de linkerzyde en het week van den buik aan dien kant, in den eigenlyk gezegden onderbuik, in de regterzyde en het week van deil buik aan den regterkant, alwaar het zig weder binnenvaards v ouwde voor zig met den regtendarm tc vercenigen.

De maag was meer naa de linker dan naar de regterzyde geplaatft, en de lever ftrekte zig nict veel meer nar de regter dan nanr de linkerzyde uit: maar deze plaatfing verfoliilt, want in andere onderwerpen was de lever veel meer naar de regter dan naar de linkerzyde: de mang hadt zulke dumnc vliezen, dat zy niet beletteden de ftoften te zien, die daar in bellooten waren: dit ingewand ( $f$ g. I. Pl. X 1/I.) was van een zeer byzonder maakzel; het was zeer verlengd, zyne groote kromte $(A B)$ hadt vier duin en vier lynen lengte van den grond van den blindenzak $(C)$ tot aan den portier $(D)$; de flokdarm $(E)$ was tennaaltenby in 't midden van de kleine kromte geplatat, zodat de groote blindezak $(F)$ veel diepte hadt; het regtergedeelte $(G)$ van de maag formeerde geen plooy.

De darmbuis hadt ten naaftenby den zclfden ontreik of dezelfde middelIyn in hare geheele uitgeftrektheid, uitgczonderd by den portier, daar zy dikft was.

De lever (by haarc voorfte zyde, fir. 2 . en by hare agterfte zyde, fig. 3 . pl. XIII. gezien) beftondt flegts uit vier kwabben, cn zelfs waren 'er, itrikt gefproken, mar drie, zo inen niet voor onderfcheidene kwabben rekent dan 


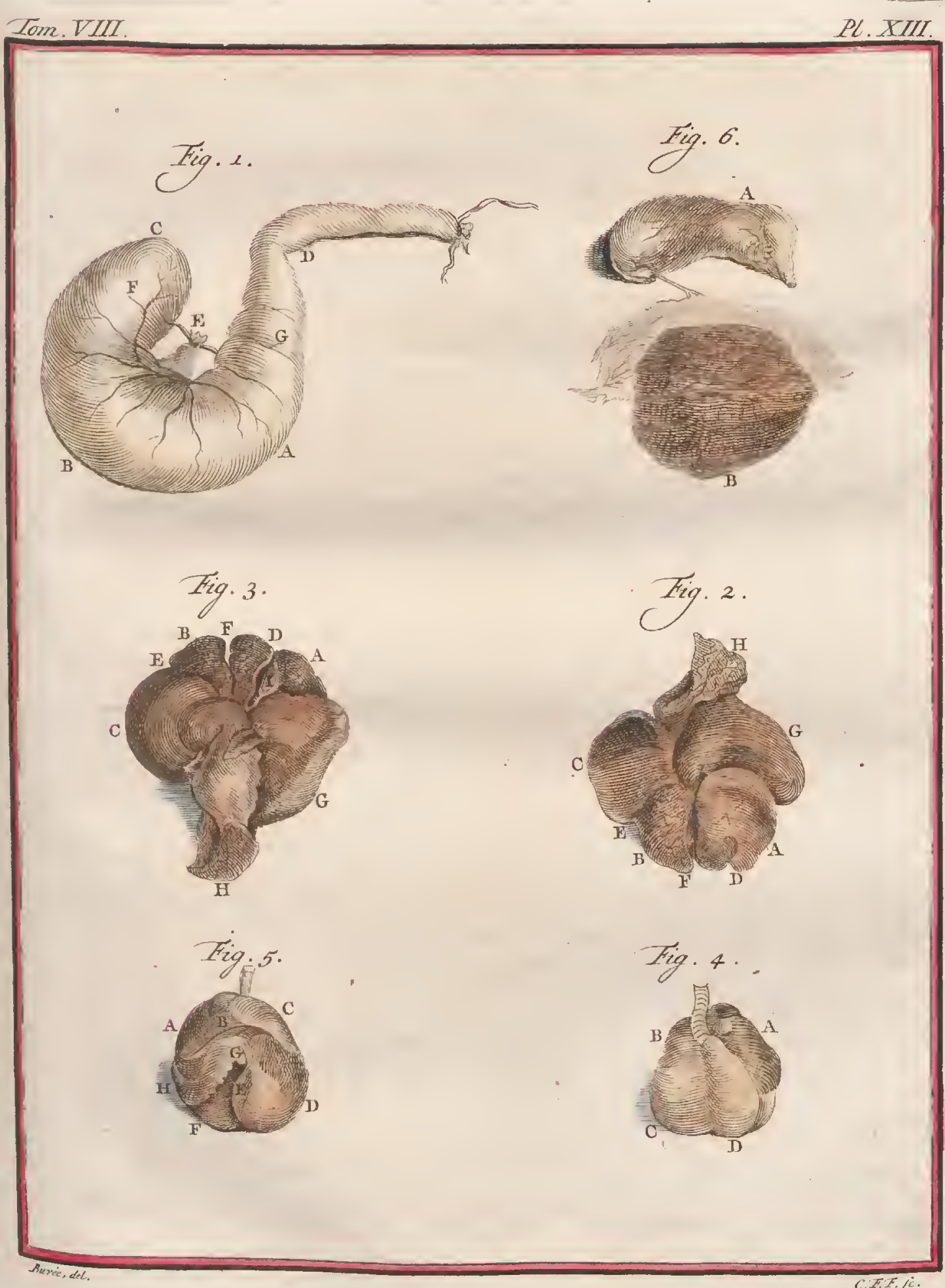

C.R.j. 

बie, welke afgefcheiden waren door fpleeten, die zig tot aan den wortel van dat ingewand uitftrekten: de grootfte kwab formeerde het middelfte, en het geheele linker, gedeelte van de lever; zy was in drie deelen, $(A B C$, fig. 2 en 3.) die tennarftenby gelyk waren, onderfcheiden; de band, die haar droeg, (F) was aan de voorfte zyde van het middelfte gedcelte vaft; het galblaasje was in de regter filyting $(D)$ geplaatit; daar was een kwab $(G)$ aan den regterkant, die niet veel minder uitgeftrekt was dan de eerfte, en eene andere kleinere $(H)$, die an den wortel van de lever vafthieldt; $z y$ hadt drie verlengde deelen, waarvan twee de nier omvatteden, het derde ftrekte zig te. gen den flokdarm uit: dit derde gedeelte makt in de meette dieren een afgezonderde kwab, maar in dit fchynt het cen deel van de derde kwab uit te maaken; de lever hadt van buiten en van binnen eene roodagtig bruine kleur; $\mathrm{zy}$ woog vier-en-dertig greinen: het galblansje $(I, f g .3)$ was byna rond, het bevattede maar zeer weinig vogt.

De milt was in 't lang uitgeftrekt en hadt drie zyden overiangs, gelyk als in de mcefte dicren met gefpleeten voeten; haare kleur was uit-en inwendig vermilioen rood; zy woog drie en een half grein.

Het alvleefch was zeer dik, zcer vaft, en van eene witagtige kleur; het hadt twee takken, waarvan de langfte zig langs den twaalfvingerigendarm uitftrekte, de ander liep an het onderft cinde van de mile uit.

De regter nier fprong de helft hanrer lengte meer voorwaards dan de linker nier; zy waren beide zo dik als breed; zy waren verlengd, en hadden weinig diepzel; de verfcheiden zelfftandigheden waren wél onderfcheiden, en het bekkentje was klein en hadt maar ééne tepel; de nicrdoosjes waren zeer zigtbaar en vóór het diepzel der nieren geplaatit; zy hadden eene geclagtige kleur, en waren twce lynen lang, éne lyn breed, en cene halve lyn dik.

Men zag geen zenuwagtig middelpunt in het middelrif; het was byna ge. heel doorfchynend over zywe gehcele uitgeftrektheid.

De longen (aan haare boventte zyde gezicn, fig. 4, en aan haare onderfte zyde, fig. 5 . Pl. XIII.) beftonden nit vier kwabben aan den renter en twee aan den linker kant, gelyk by de meefte dicren plats heeft; mar de buiten. gewoone platfing van it hart vin de mol hadt veel invlocil op de plaatfing en figuur van verfcheiden long $\mathrm{kwabben}$ : het hart $(A, f i g .4 \mathrm{en} 5$. .) was zeer verlengd en geheel aan de linkerzyde geplaatf; het raakte aan de ribben van zyne bafis af tot ann de punt: de twreede kwab ( $B$, fig. 5.) van de regter long was niet dan voor cen gedeelte tuffchen dê ecrite ( $B$, fig. $4 . \mathrm{en} C$, fig. 5) en tuffchen de derde $(C$, fig. A. on $D$, fig. 5) geplatit: zy ftrekte zig ter linkerzyde uit over den kant van " $t$ hart, dic overltondt aan dien, wclke aan de ribben raakte; de viercle kwab ( $E$, fig. $E$ ) die de kleinlte vinl alle was, was plat tuffehen de agterfte linker kwab ( $D$, fig. 4. eq $F$, fig. 5.) en de agterfte regter ( $C$, fig. 4. en D, fig. 5.), wclker einde verdeeld was door eene diepe fpleet, die zig in eene kromme lyn op den onderkant.uitftrekte: de andere kwab ( $\mathrm{G} \mathrm{H}, \mathrm{fg}$. 5.) van de linkerzyde, die eer de ondertte dan de voorfte gentamd moet worden, fcheen aan de voorfte linker kwab van ande. te dieren te beantwoorden, en door het hart buiten hare plats gẹragt te zyn; zy was krom gelyk eene romeinfche $S$ : het grootite gedeelte var deze: 
kwab vondt zig geplaatit tuffchen het hart en de agterfte kwab; het regtereinde $(G)$ was omgevouwen op de vierde regter $\mathrm{kwab}$, en het linker einde (H) was ook op de punt van "t hart omgevouwen.

De tong was zecr lang, fmal en dun aan 't einde; daar waren op het agterft gedeelte twee kelkswyze klieren naaft malkander geplaatit; al het overige was doorzaaid met zeer kleine ronde en witte korrels, en met allerfynfte tepeltjes, die nauwelyks zigtbaar waren, bedekt.

De ftrotklap was kort en ligt uitgediept in "t midden; elk der randen van den ingang van het ftrottenhoofd hadr eene verlenging in de gedaante van een lelletje aan de buitenite zyde van zyn boven einde; die twee lelletjes fcheenell met de ftrotklap een buis te maken, waar van de rand op verfcheiden plaatfen was uirgefineeden.

Het verhemelte was met negen vry wyde vooren doorfneeden: de randen van de middelite formeerden twee bolrondte's, eene van voren en eene van agteren.

De voorherlfenen waren driehoekig gelyk het hoofd; daar waren geene bogtigheden in, zy woogen agttien greinen: de agterherfenen hadden dezelfde plaatfing en dezelfde gedaante als by de meefte andere vicrvoetige dicren, maar men onderfcheidde geene groevingen op de oppervlakte; zy woogen vier grein.

De mol, die ten onderwerpe veor de befchryving der mannerjes tecldeclen gediend heeft, was van dezelfde grootte als die, waar van de nuaten in de voorgaande tafel zyn bygebragt: de voorhuid kwam uitwendig te voorichyn ter lengte van drie lynen, en mankte eene kleine kegclagtige fchede, dic maar eene lyn middellyns ann de batis hadr, cu dic in ecn bosje hair uitliep; het hoofdje van de roede was zeer dun en zeer lang, het hadt eene kegelagtige, en bygevolg verlengde, gedaante; het was puntig en eindigde in cen zeerklein beentje: de roede was naar eventedigheid veel dikker dan het hoofdje; de twee takken van de vorkswyze fpliting der piponsagtige lighamen hadden elk twee lynen lengte; zy liepen uit op het agterfte cinde der fehambecnderen, dic van malkanderen afftenden, gelyk als in de fpitsmurs.

Daar waren, even als in de rot, aan weerskanten van de roede, twee klieren, die elk twee en ecne halve lyn lengte, ecne en cen halve lyn brcedte, en éene lyn dikte hadden; zy hadden met den rand van de voorhuid gemeenfchap elk door middel van een uitwerpbuis, dic vier lynen lang was.

De zaadballen waren rond, van eene weeke zelfftandigheid en van cene roodagtige kleur, zo wel uitwendig als inwendig; ik heb hen klein gevonden in vergelyking van den ontrek, dien Schtelnawick hun geeft; want hy berigt (c) dat zy grooter zyn dan de nicren; integendeel in het onderwerp, dat wy onderhanden hebben, waren de nieren een en cen halve lyn langer, een vierde lyn breeder, en eene lyn dikker chan de zaadballen, gelyk men in de volgende tafel zien kạn.

De blaas was byna rond, en derzelver vliezen hadden zo weinig dilkte, dat

(c) Ephem. de l'Académie des Cur. de la Nature.Dec. II. Anm. I, Zie la Colleq. Acak. Tom. III. pag. 5io. enz. 
zy doorfchynende waren; men zag 'er eenige vleezige, zeer fyne, vezels aan.

De afvoerende vaaten hadden weinig lengte en waren zeer dun: daar waren by den hals van de blaas twee klcine knobbelties, die de pisbuis van weerskanten omringden; zy zyn my voorgekomen zaadblaasjes te zyn, omdat de afvoerende vaaten daar op uitliepen: deze knobbeltjes waren zo klein, dat het onmogelyk was derzelver inwendig makzel te onderfcheiden; $z y$ waren nauwelyks anderhalve lyn lang en eene. halve lyn breed.

Eene lyn verder dan. deze kuobbeltjes, ann do zyde van de roede, was een ander op de onderite zyde van de pisbuis, dat ook anderhalve lyn lang en eene lyn breed was: dit knobbeltje kwam my voor de voorftanders uit te maaken, omdat het meer zelfftandigheid hadt dan de andere, en door een kleine voor, in 't langloopende, in twee. kwabben verdeeld was.

Schoon ik eene menigte mollen van verfchillende leeftyden, en in verficheiden faifoenen, ontleed heb, vermoede ik, dat ik cvenwel nog geene in den tyd hunner koppeling heb aangetroffen: de waarneemingen van SCHELHANER, die, in zyne bcichryving van dit dier, een breed verllag geeft van den toeftel der mannetjes teeldeelen, doet my denken., dat het met de mol is, gelyk als met de relmuis, by welke ik de zaadballen en zaadblaasjes veel grooter gevonden heb op het einde van de maand juny, dan op andere tyden, waarin ik dit. dier ontleed heb: ik zal de mol ook in zulk een gunftigen tyd voor de bcfchryving der. mannetjes teeldeelen poogen te betrappen, en 'er dan in het vervolg van dit Werk de befchryving van mededeclen: de befchryving, welke ik hier gemakt heb, zal ten minften de verfcheidenbeden doen zien, die op verfchillende tyden tuffchen deze deelen gevonden worden; maar het komt my niet voor, dat die verfcheidenheden invloed kunnen hebben op de lengte van de roede en van het hoofdje: die twee deelen, aan malkanderen gevoegd, hadden flegts een vyfde van de lengte des diers, van den rand des fchrobbers tot. aan den aars gemeeten; de mollen, welke Schelinanier heeft ontleed, waren derhalven, in dit opzigt, zeer verfchillend gemaakt, dewyl hy meldt dat deze deelen byna de helft der lengte van het geheele dier hadden.

De mol, die ten onderwerpe voor de befchryving der wyfjes teeldcelen gediend heeft, hadt vier duim en tien lynen lengte, van den fnuit tot aan den zars; ik heb de mammen niet kumnen ondericheiden, wclke voorzorgen ik ook genomen heb met het hair, en zelfs de opperhuid, weg te neemen; ik nan1 dezelve naderhand waar in een wyfje, dat jongen zoogde: de pisbuis maakte buiten het lighaam eene fchede van eene kegeligtige gedante, gclyk de voorhuid van " $t$ mannetje; maar die fchede hadt in het wyfje flegts twee lynen lengte, en eene halve lyn middellyns aan de bafis, dus kan men aan het uitwendige het wyfje niet gemaklyk van het mannetje onderfihciden, dan voor 20 verre het de bilnaad veel korter heeft.

De klink was zeer klein, en geplaatft agter de kegelswyze fchede door de pisbuis geformeerd; daar waren aan weerskanten van de fchede en van de pisbuis twee klieren gelyk aan die, welke aan de zyde van de mannetjes roede gevonden worden: die van het wyfje hadden drie en eew halve lyn leng: $r$, twee lynen breedte, en twee derde van eene lyn dikte.

VIII. Dee!. 
De blaas was tennaaftenby van dezclfde grootte en zo doorfchynende als die van het mannetje, maar zy hadt eene eyronde gedaante; de pisbuis ftrekte zig langs de fchede uit, gelyk als in de rot, de muis, de veldmuis, enz: zonder dezelve te doorbooren, en zy kwam naar buiten te voorfchyn, gelyk reeds gezegd is.

De fchede was zeer lang en evenredig met de lengte van de roede en derzelver hoofdje van het mannetje: de lyfmoeder hadt geene inwendige opening of mond; men herkende het lighaam van dit ingewand niet dan door zyne dikte, en door de fplitfing der hoornen: de fchede en de lyfmoeder formeerden van bimen niet dan eene doorloopende buis, die gemeenfchap hadt met de twee hoornen van de lyfmoeder; zy hadden tennaaftenby een even groote middellyn als de fchede, en zy maakten bogtigheden gelyk als in de zog: de vliezen van de fchede, van de lyfinoeder, en van de hoornen waren teu. maftenby zo dun en zo doorfchynende als die van de blaas.

De zaadballen rakten aan het einde der hoolnen; zy waren omvangen van eene foort van loofiverk waar op men de trompetten zag liggen, die evenwel zo fyn waren, dat men moeite hadt om dezelve te onderfcheiden: de zaadballen waren zeer dik en gerond, zy hadden van buiten en van binnen cene roodagtige kleur.

lk heb, op 't einde van april, eene mol geopend, die twee vrugtjes droeg;, een $(\Lambda, f i g: 6, P l . X I I L)$ in yderen hoorn van de lyfmoeder; $z y$ waren omsrent cen duim lang van de kruin des hoofds tot aan den aars; de moederkoek (B) was byna rond; hy hadt agt of tien lyn middellyns, hy was van eene roodagtige kleur met cenig zweemzel van grauw vermengd.

Op den I I may heb ik eenc andere mol geopend, die drie vrugtjes hadt, twee aan de regter en een aan de linkerzyde; $z y$ waren van dezelfide grootte als die, warvan zo aanftonds melding gemaakt is,

Lengte van de darmbuis van den portier tot aan den aars : voeten, duinen, lynen: Omtrek op de dikfte plaatfen

Omtrek op de dunfte plantfen

Groote onitrek van de maag

Kleine omtrek

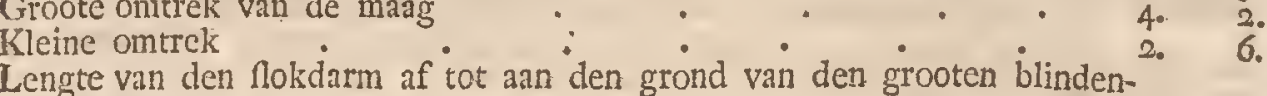

Omtrek van den nokdarm

Omtrek van den portier

Lengte van de lever

Breedte

Haare grootte dikte

Lengte van het galblansje

Zyn groothe middellyn

lengte van de milt

Breedte van hot onderf einde

Breedte van het bovent einde

Diktc in ' $t$ midden 
Dikte van het alvleefch

Lengte der nieren

Breedte

Dikte

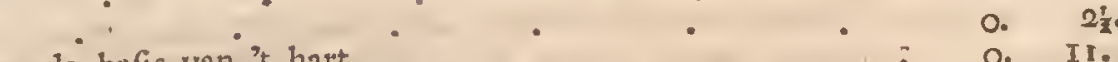

Qmtrek van de bafis van 't hart orfprong van de longllagader....$o_{0}$. II.

Hoogte van de punt tot aan den longezak . . . 0.4 .

Middellyn van dc groote flagader van buiten naar buiten gemeeten. $0 .{ }^{\frac{2}{5 *}}$

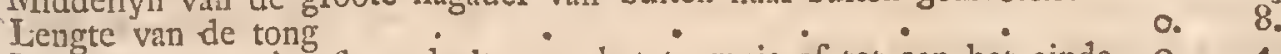

Lengte van het voorfte gedeelte van het toompje af tot ann het einde. O. 4 .

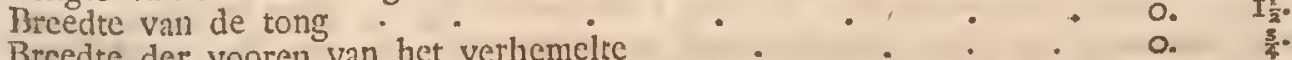

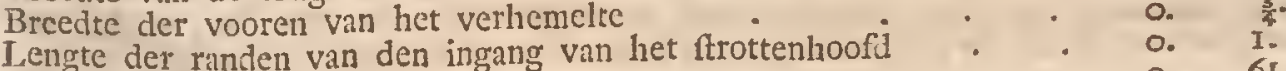

Lengte der voorherfenen

Brecdte

Dikte

Lengte der agterherflenen

Breedte

Dikte Aftand tuffehen den aars en de opening van de voorhuid . . . .

Lengte van het hoofdje

Lentrek van de roede van de fplitfing der fonsagtige lighanmen af tot

Len inplanting van de voorluid 0.

Omtrek

Lengte der zaadballen

Brecute

Dikte der zandballen

Lengte der afvoerende vaaten

Groote omtrek van de blaas

Klcine omtrek

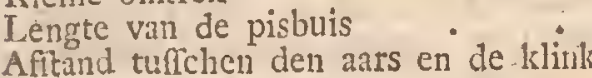

Lengte van de feliede en van het lighaam van de lyfmoeder ... . I. 2.

Omtrek Ontrek by de fplitfing der hoornen

Groote omtrek van de blaas

kleine omtrek

Lengte van de pisbuls

Lnirek der hoornen van de lyfmoeder

Omtrek op de dikfte plaatfen

Omtrek aan het einde van yderen hoorn

Lengte der zaadballen

Breedte

Diktc

De kop van het geraamte van ce mol ( $P$ l. XID) hadt ten naaftenby dezelfde gedaante als die van het geramte van de fpitsmuis; het voorfte gedeelte $\mathrm{H}_{2}$ 


\section{0

$$
\text { D. E N A TUURLYKE H I T T R I E, }
$$

egter van het bovenft kaakbeen en de opening der neusgaten waren breeder in de mol; het vitfteekzel van het jukbeen vereenigde zig met dat.van her llapbeen om een zeer dunnen boog te maaken, die eene groote ruimte befloeg, in welker midden het kroonswyze uitlteekzel van het onderft kaakbeen zig bevondt; de oogen waren niet in de oogputten gezonken, gelyk die van andere dieren, daar in dit Werk reeds melding van gemaakt is; zy waren geplaatif boven het voorfte gedeelte van de ruimte door den jukbeenigen boog gemakt, zodat een fpeld, die men ter plaatfe van het oog inftak, in het hoofd, agter het jukbeen ging.

Daar waren vier-en-veertig tanden; twee-en-twintig in yder kaakbeen: zo men den naam van hondstanden niet moet geeven, dan aan die, welke de langfte zyn onder de fnytanden en de baktanden of kiezen, dan waren 'er agt finytanden in het onderft kakbeen, want de vyfde was veel langer, dan de vier eerften van ydere zyde: het is waar, dat de vierde van de drie anderen verfchilde, voor zo verre hy puntig en wat fchuinfch buitenwaards gerigt was, maar hy wass niet langer: de zes voorlte fnytanden van 't zelfde kaakbeen waren allen ten naatenby van dezelfde breedte; daar waren maar zes fnytanden in het bovenft kakbeen, maar de twee middelfte waren breeder dan de vier anderen : de twee hondstanden van boven waren langer maar minder breed aan de bafis dan die van onderen, die byna zo breed als lang waren: daar waren zeven balktanden aan ydere zyde van het bovenft kaakbeen; de drie eerften waren zeer klein; de vierde, fchoon veel langer, hadt maar cene punt, gelyk de drie andere; de drie laatfte varen de dikfte, en hadden elk drie punten, twee op den buitenften, en een op den binnenften rand: de onderfte baktanden waren ten getale van zes aan ydere zyde; de twee eerfte waren de kleinfte en hadden maar een punt; de derde was grooter; hy hadt een zeer blykbaare punt boven het lighaam van den tand, en men bemerkte twee andere, zeer kleine, punten, een aan weerskanten van de bafis:" de drie laatfte tanden waren de dikfte van dit kaakbeen; zy hadden elk vyf punten, twee groote op den buiten-en drie kleine op den binnenrand.

Het eerfte, der zeven nek-wervelbeenderen hadt een klein doornagtig uitfteekzel; dat van het tweede wervelbeen was zeer breed en ftrekte zig naar agteren uit, de andere wervelbeenderen hadden "er geen: de onderite tak van het fchuinfch uitfteckzel van het zesde was zeer breed en :ftrekte zig evenveel naar voren als naar agteren uit.

Daar waren veertien rug-wervelbeenderen en veertien ribben, agt waare en Zas. valf che; de doomagtige uitfteckzels der eerfte wervelbeenderen waren ten uiterften gering, en dic der andere waren insgelyks zeer kort: men zag egter, dat het doarnagtig uitfteckzel. van het agtite wervelbeen agterwaards helde, dat die van het negende en tiende regt waren, eindelyk dat die der dric laatfe voorwaards lelden: het borftbeen beftondt uit vyf beentjes, waarvan het eerft ( $f$ ig. $1, P l . X V$ warin het van ter zyde gezien wordt) zeer lang en dik was, ten naaftenby gelyk liet borltbeen der vogelen; het ftrekte zig onder her vierde wervelbeen van den hals uit: de twee eerfte ribben, cene aan weerskanten, geledigden zig met het agterft gedeelte (A) van dit eerfte been; 



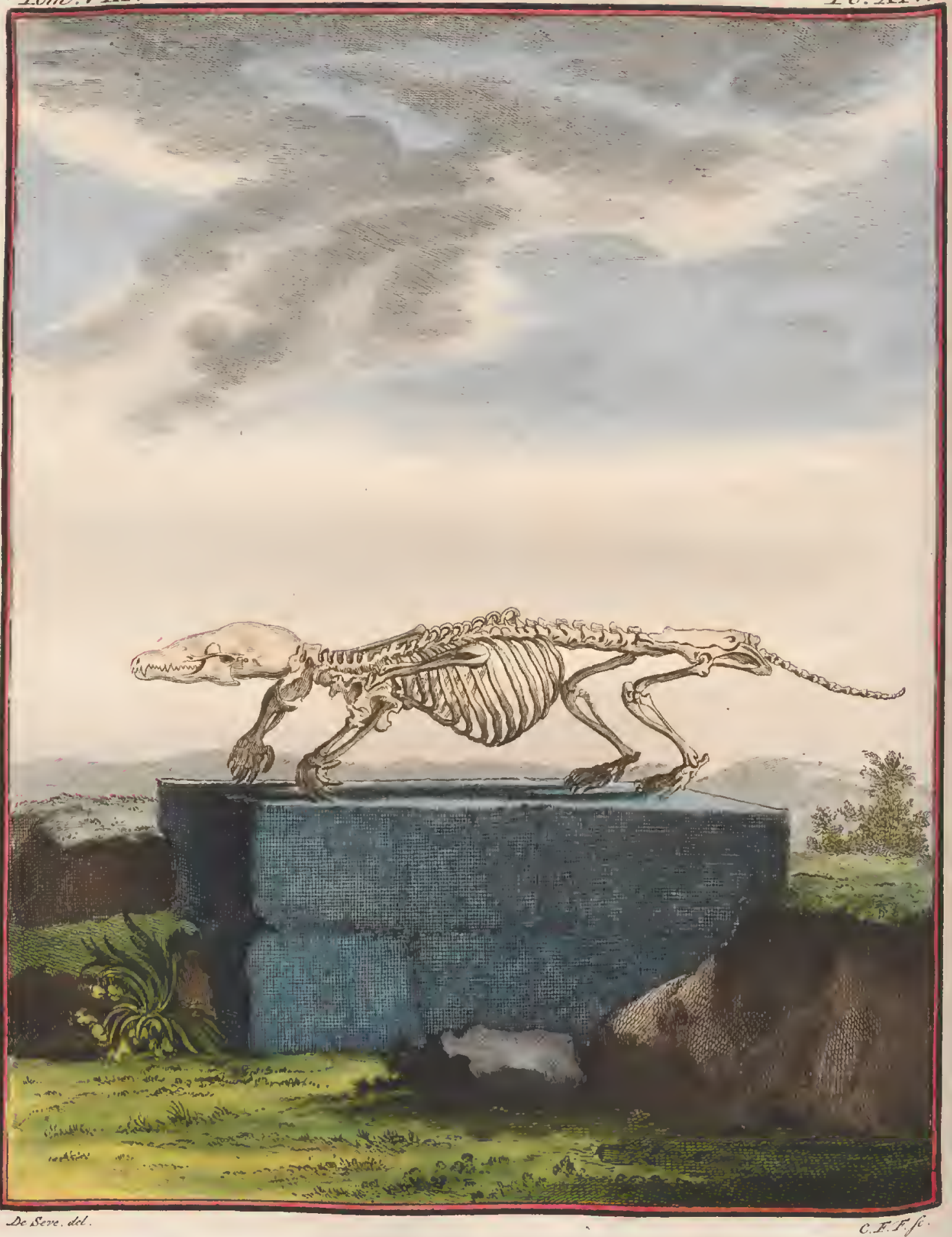




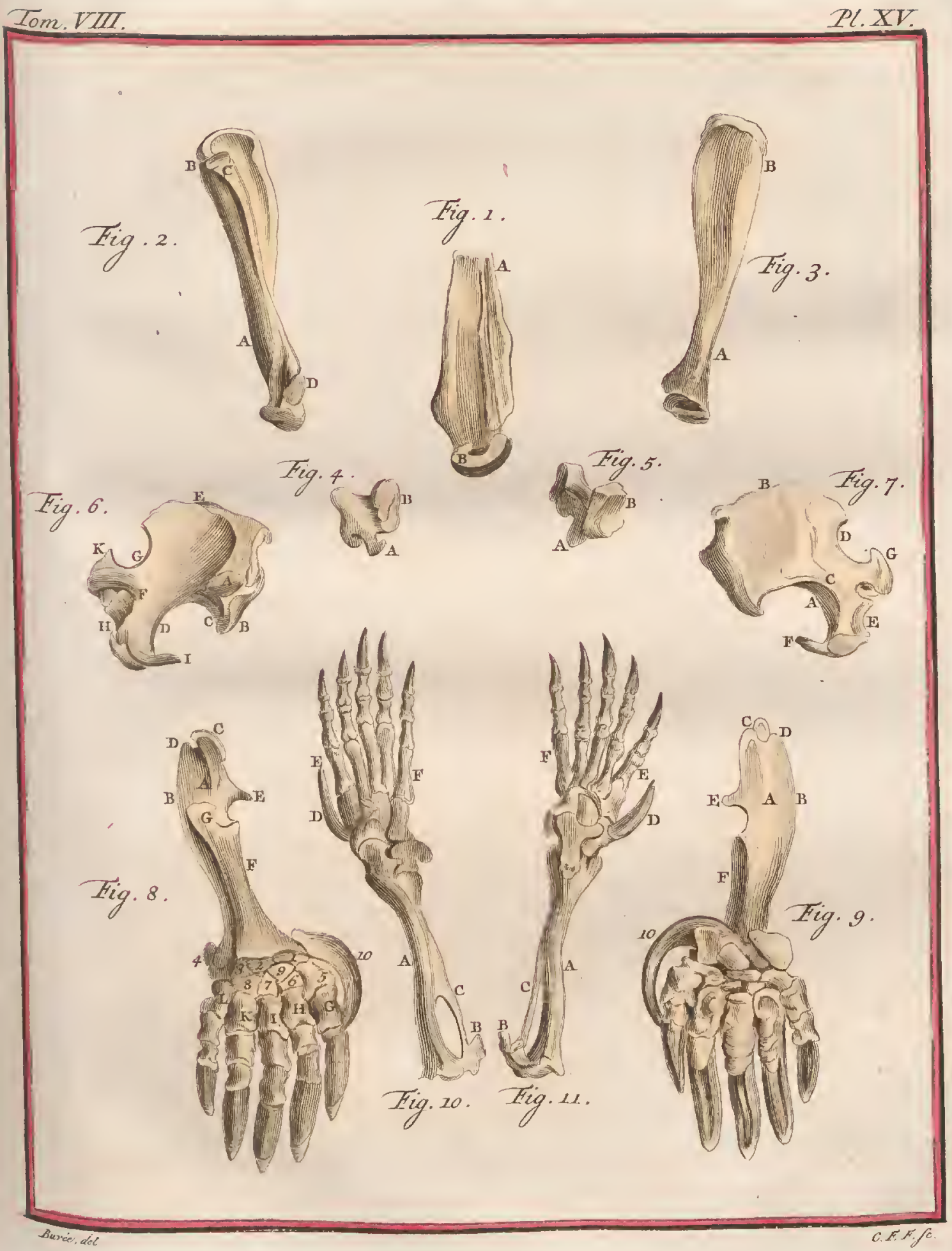





\section{B.ESCHRYVING VA N DE M OL.}

de geleding der'tweede ribben was tuffchen het eerfte en tweede been; die der derde ribben tuffchen het tweede en derde been; die der vierde ribben tuffichen het derde en vierde been; de vierde en vyfde ribben geledigden $\mathrm{zig}$ met het middelfte gedeclte van het vierde been; de geleding der zevende en agtfte ribben was tuffchen het vierde en vyfde beentje van het borftbeen.

De lenden-wervelbeenderen waren ten getale van vyf: de twee ecrfte hadden het doornagtig uitfteckzel voorwaards gebogen, en de bykomende uitfteekzels agterwaards gerigt; de andere hadden het doornagtig uitfteckzel breed en regt, en de bykomende voorwaards gerigt.

Het heiligbeen beftondt uit vyf valfche wervelbeenderen, waar van het laatfte zeer lang was; het eerfte was zonder doornagtig uitfteekzel; die der vier andere valfche wervelbeenderen, waren met malkander vereenigd, en maakten eene beenagtige kam: daar waren twaalf valfche wervelbeenderen in den ftaart.

De fchaambeenderen waren van malkanderen af verwyderd gelyk in de fpitsmuizen, en daar waren drie lynen afftands tuffchen beiden.

Het fchouderblad, (van zyne uitwendige zyde, fig. 2. Pl. XV, en van zyne inwendige zyde fig. 3 gezien) was zeer lang en zecr fmal aan zyn voorite gedeelte $(A)$; het agterfte $(B)$ hadt wat meer breedte: de doorn $(C$, fig. 2.) was wel geteekend op dit deel; mar men bemerkte dezelve nauwelyks op 't midden van het been; hy liep op het voorfte deel uit met een knobbeltje $(D)$, het welk men als een fchouderbeens-hooft.moct befchouwen, fchoon het niet aan het fleutelbeen rakkte, dewyl het dat door een band ophicldt.

De fleutelbeenderen (van humne voorfte $z y d e$ fig. 4 en van hunne agterfte, fig. 5. gezien) waren zeer dik en zeer kort; zy hadden een uitfteekzel $A$ op 't midden van hunne onderfte zyde; het buitent einde geledigde $2 \mathrm{ig}$ onmiddelyk in het armbeen met ecne zyde $(B, f i g .5)$ veel grooter dan die $(B, f i g$. 4) van het ander einde, het wclk raakt aan het voorlte gedeelte $(B, f g$. I ) van het eerfte beentje des borltbeens.

Het armbeen (van zyne bovenfte zyde, fig. 6 . en van zyne onderfte:zyde, fig. ? gezien) hadt eene zeer onregelmaatige en zeer lelyke gedante; het hoofd egter $(A, f g .6)$ van dit been was evenredig aan het overige van het geraamte, maar daar was onder het hoofd eene groote zyde $(B)$, die de geleding van het lleutelbeen maakte: daar wierdt agter deze zyde eene groote holte gevonden, waarvan de opening $(C)$ onder den kop van het been aan de voorfte zyde was: die zyde $(D, f i g .6$ en $B$, fig. 7.$)$ was zeer holrond over haare lengte; de agterfte zyde ( $E$, fig. 6. en $B$, fig. $\left.7_{*}\right)$. was integendeel bolrond langs het middelft en het bovent gedeelte van het been, welke gedeelten zeer breed, en van boven en van onderen platagtig, waren: het middelite onderfte gedeelte $(F$, fig. 6. en $C$, fig. 7 ) was veel minder breed en hadt byna zo veel dikte als breedte; de agterfte zyde $(G, f i g .6$, en $D, f i g .7)$ van dat gedeelte des beens was holrond; het onderft gedeelte $(H, f i g .6$. en $E$, fig. 7.$)$ was breed, ell eindigde aan weerskanten in cen puntig en opwaards gerigt uititeekzel; het voorte ( $1 ;$ fig. 6 . en F, fig. 7.$)$ was. linger dan het agterite $(K$, fig. 6 , en $G$, fig. 7$)$. 
De ellepyp; aan haare voorfte zyde ( $A, f$ ig. 8 en aan haare agterfte $A$, fig. 9. gezien) hadt eene verhevenheid (B) lang's de uitwendige zyde van haar middelft, en yan haar bovenit gedeelte; de elleboogsknokkel was zeer breed van voren naar agteren, en liep an ydere zyde uit in een puntig uitfteekzel, $(C D)$; daar was een ander uititeekzel $(E)$ op den binnenkant, boven de geleding van het armbeen.

Het ftralbeen ( $F$, fig. 3 en 9) was dik en geledigde zig met het armbeen $(G$, fig. 8 ) het welk op de bovenzyde van zy'n bovenft einde was.

Het dijebeen hadt onder den grooten draaijer cen uitteckzel, dat zo dik was als de kleine draijer, en op dezelfde hoogte geplatit.

Het bovenft gedeelte van het fiheenbeen (aan deszelfs voorfte zyde, $A$, fig. 10. en aan de agterite zyde $A$, fig. I I. gezien) was bolrond van voren en van binnen; daar was op de buitenzyde van het hoofd van dit been een lang uitteckzcl $(B)$ agterwaards gekromd.

Het kuitbeen (C, fig. I0 en II) was aan het fcheenbeen vaft van zyn onderlt einde tot in ' $t$ midden zyncr lengte; daar waren op het bovenit einde twee uitfteelizels, het een agter, het ander op de buitenzyde; dit latite was in thang van boven mar bencenen, en bevondt zig op gelyke afftanden van het agterit uitfteekzel van het zelfde been en van dat van het fcheenbeen.

De voorhand beftonde uit tien beentjes, warvan agt twee rijen, yder van vier, makten: daar waren in de eerfte ry twee beentjes ( 1 en 2. fig. 8 ) beneden het 1traalbecn, tennaftenby gelyrk het fchuitbeen, en het manswyze been, van den menfch; een derde (3) beneden de ellepyls, in plats van het wiggebeen, en een vierde (4) aan, de buitenzyde van het einde der ellepyp; het was buiten de ry, en fcheet1 door deze platting betrekking te hebben tot het erwtsgewyze beentje, fchoon het hooger geplatit was: de vier beentjes $(567,8)$ van de tweede ly van de voorhand der mol, waren boven de vier cerfte bcentjes van de agterhand geplaatti, ten naaftenby gelyk het tafolbcentje en ruitwyze beentje het groot en haakswyz.c been van den menlch, uitgezonderd dat het vierde beentje van de mol zig niet boven het vyfde beencje van de agterhand uitftrekte, ggelyk het haiksgewys been van den menfch: het negende beentre (9) van dc voorhand van de mol was geplaatit tulfchen de twee rijen beneden het eerfte been van de eerfe ry, en gedeeltelyk tufficlicin het tweede en derde been van de tweede ry: het tiende (Io fig. 8,9 ) was zeer lang, en hadt de gedaante vall een krom 111es; het lieidt aan de binnenzyde van het onderft einde, des fraalbeens; zyne bolrondte was van buiten, en het liep uit op de geleding van het. eerfe been van de agterhand met den eerften regel van den voorften vinger.

De vyf beentjes ( $G H I K L$, fig. 3 ) van de agterhand waren zeer kort; zy hadden byna 7.0 veele breedte als lengte: de twee eerfte regels van de vingeren, en de eerfte van den duim der, voorfte vocten, waren ook zeer kort, maar het agterfte van den duim en van de vingeren was integendeel zeer lang.

Daar waren zeven beenderen in den voorvoet, die, in lunne fchikking, ten naatenby aan die van den wenlch benntwoordden, en een agtite beenje ( $D$., fig. Io en $I I$ ) 't welk overeenkomft liadt met het tiende been van de vool- 
fiand, voor zo verre het zeer veriengd en wat krom was, mar het hadt minder lengte en minder kromte; het geledigde zig aan zyn agterft einde tusfchen het fchuitbeen en het eerfte wiggebeen, en het ftrekte zig van voren evenwydig uit met de buitenzyde van het eerfe been van den agtervoet.'

De beenderen van den agtervoet $(E F)$ ivaren nict kort, gelyk dic van de agterhand; man zy hadden eene lengte geëvenredigd aan die der regelen.

Lengte van den kov van het bovent kakbeen tot aan het agterhoof duimen, Iynen

De grootte breedte van den kop

Lengte van het onderft kakbeen tot aan den agterften rand van het knokkelwyze vitfteekzel

Breedte van het onderft kaakbeen ter plaatfe van de fnytanden ${ }^{\circ}$. o. ro

Breedte van het bovenft kaakbeen ter plaatfe van de houdstanden $0_{0}, 0_{0}{ }_{2}^{\frac{2}{3}}$

Afitand tufichen de oogputten en de opening der neusgaten . . . . . o. 5 .

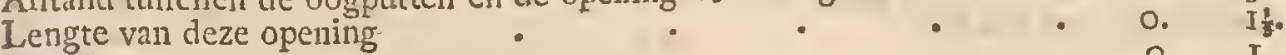

Breedie

Lengte der langfte fnytanden buiten het been . . . . $0_{0} I_{1}^{\frac{1}{2}}$.

Lengte der twee voornaame deelen van het tongbeen $\quad . \quad . \quad 0$.

tengte der tweede beenderen

Lengte der derde beenderen

Lengte van het midden-been

Lengte der takken van de vork

Breedte van het gat van het eerte weivelbeen

Breedte van de eene zyde naar de anvelbcen van boven naar beneden. 0

Lengte van het gedeelte van de wervelbeens kolom, die uit de rugwervelbeenderen beftaat

Lengte der eerfte ribben
Afltand tufichen de cerfte ribben op de breedife plats
.

Lengte van de agtfte rib, die de langfte is

Lengte van de lastite der valfche ribben

Lengte van het borftbeen

Lengte van het eerfte been, dat het langfte is

Lengte van het derde been, dat het korft is

Breedte van het eerfte been, dat het breedit is

Dengte des lighaams van het vyfde lendenwervelbeen, dat het langft is.

Lengte van het heiligbeen

Breedte van het voorite gedeelte

Breedte van het agterfte gedeelte

Lengte van het vyfde valfiche wervelbeen van den ftaart, dat het langft is.

Lengte der eyronde gaten

Breedte

Lengte van het fchouderbiad

Breedte aan de breedfte plaats.

Lengte der fleutelbeenderen

Lcngte van den fchouder

Breedte

Lengte van de ellepyp

Lellgte val het ftrailbeen

Lengte van het dijebeen 
Lengte der kniefchyven

Lengte van het fcheenbeen

Lengte van het kuitbeen

Hoogte van de voorhand

Lengte van het hielbeen

Hoogte van het cerfte wiggebeen en van het fchuitbeen te famengenomen. 0

Lengte van het eerfte been der agterhand, dat het langft is

Lengte van het vyfde, dat het kortit is

Lengte van het vierde been van den agtervoet, dat het ingft is ${ }^{\circ} \cdot$

Lengte van het eerfte, dat het kortft is .

Lengte van den eerften regel des middelften vingers van de voorfte voeten. 0 .

Lengte van den tweeden regel

Lengte van den derden

Lengte van den cerften regel van den vierden vinger der agterfte voeten.

Lengte van den tweeden regel

Lengte van den derden duimen, lynew.

c. 2.

o. 9 .

๑. 9 .

o. I $\quad$ :

o. $2 \frac{2}{2}$.

व. $I^{2}$

o. I.

2 .

o.

o:

o. 1.

○. 1.

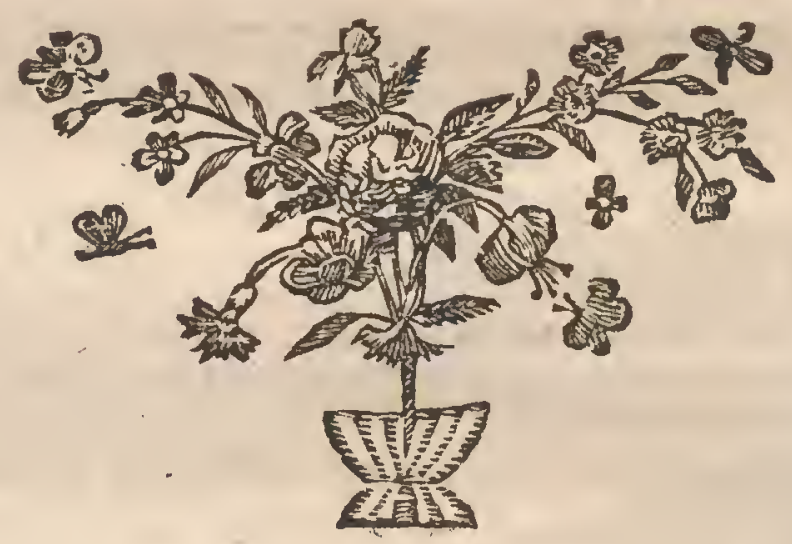

D E 


\section{$\begin{array}{llllllllllllllllllllll}B & E & S & C & H & R & Y & V & I & N & G\end{array}$}

\section{VAN DAT GEDEELTE VAN HET KABINET,}

\section{HETWELK BETREKKING HEEFT TOT DE NATUURLYKE HISTORIE}

\section{VAN DE SPITSMUIS, DE WATER-SPITSMUIS,}

$$
\text { E N D E M O L. }
$$

\section{No. DCCLXV. Een Spitsmuis.}

Dit diertje is in wyngeeft beward.

No. DCCLXVI. Het geraamte van eene fpitsmuis.

De lengte van dit geramte is van twee en een half duim van het einde des bovenften kaakbeens tot het agterft einde van de fchaambeenderen; het hoofi heeft agt en een halve lyn lengte, en tien cn een halve lyn omtreks aan de dikfte plats op de kruin genomen.

No. DCCLXVII. Het tongbeen van eene Jpitsmuis.

Het gelykt naar dat van de water-fpitsmuis, daar in de befchryving van het geraamte van dit dier gewag van gemaakt is.

No. DCCLXVIII. Een vater-fpitsmuis.?

Dit dier is, even als de fipitsmuis, ftraks gemeld, in wyngeeft bewaard.

No. DCCLXIX. Het geraamte vian eene vuater-piismuis.

Dit geraamte heeft eene lengte van twee duimen elf en een halve lyn, van het einde des bovenften kaakbeens tot aan het agterft einde der fchaambeenderen; de kop heeft negen en een halve lyn lengte, en dertien lynen omtrek, an de dikfte plats op de kruin gemeeten.

No. DCCLXX. Het tongbeen van de water.Jpitsmuis.

De befchryving van dit been heeft een gedeelte litgemaakt van die van het geraamte van de wvater-fpitsmuis. Zie blz. 44 van dit Deel.

No. DCCLXXI. Drie vrugtjes van eene mol.

Deze vrugtjes zyn in wyngeelt, elk met zyn navelftreng en moederkoek; zy hebben veertien lynen lengte van het einde van den bek tor aan het begin van den ftaart.

No. DCCLXXII. Eene mol.

Deze mol heeft de gewoone kleur van de dieren van deze foort; $z y$ is in wyngeeft bewaard.

No. DCCLXXIII. Eene upgeatte mol.

De lengte van deze mol is van vier duimen drie lynen, van het einde van den bek tot aan het begin van den ftant; haare kleur is een mengzel van wit en geelagtig.

VIII. Deel. 
No. DCCLXXIV. Eene andere opgeatte mol.

Deze mol heeft vyf.duimen lengte van het einde van den bek tot het begin. van den ftaart; haare kleur is wit met geelagtige fchaduwingen op den bek en afchgrauw langs den rug en op de finuit: zy is door. den Hr. SAIERNE ten. gefchenke gegeeven.

No. DCCLXXV. Eene andere opgezette mol:

De lengte van deze mol is van zes duim en drie lynen van liet einde des. bets tot aan het begin van den ftart; $z y$ is in 't geheel van. eene geelagtige. ilcur; $z y$ is door den Hr. Graaf de Tressan uit Lotharingen gezonden.

No. DCCL.XXVI. Het geraamte van eene mol.

De lengte van dit geraamte is van vier duimen negen lywen van het cinde des bovenften kaakbeens tot aan het agterfte einde der fchambcenderen; de: liop is een duim en vier lynen lang, en heeft een duim en zeven lynen. omtrch an de dikfte plants op de kruin gemeeten.

No. DCCLXXVIr. Het tongbeen van eene mol."

Het beftat uit negen beentjes; de twee eerfte waren korter dan die van de. fitsmuis, en de twec takken van de vork waren daar en tegen langer; zy waren breed en ingedrukt aan hot einde, dat overftondt tegen dat, 't welk aan : et middenbeen hieldt.

No. DCCLXXVII. Het roede-been van een mol.

Dit been is zeer dun en heeft maar céne lyn lengte.

No. DCCLXXIX. Ilet been van den voorarm, wan de voorband, vars de poot, ens van den voorvoet van de mol.

Deze beenderen $2 y n$ op een effen vlak aan malkanderen vaftgemaakt en ge. gelulit in de oris, wans in dezclve in liet dier gevonden worden.

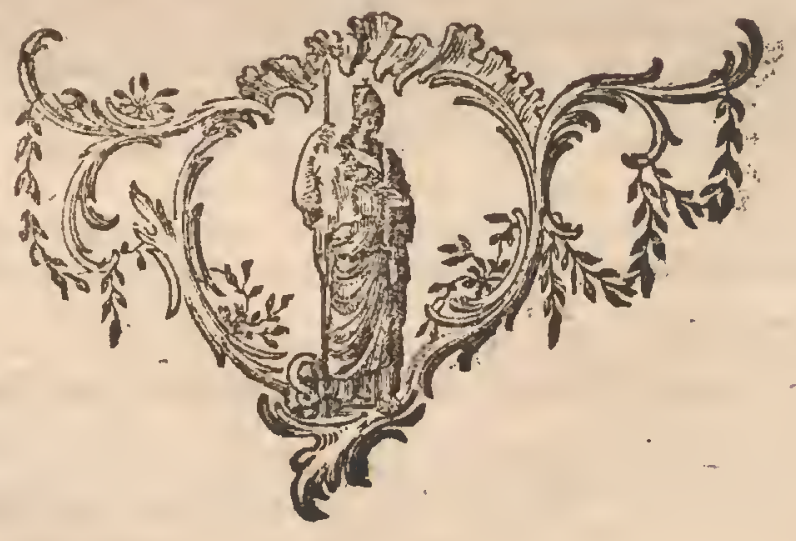




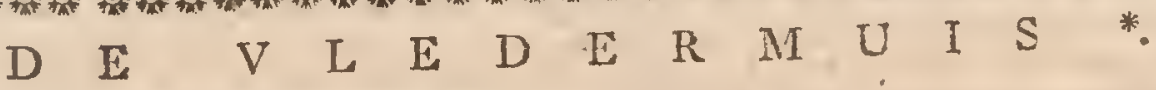

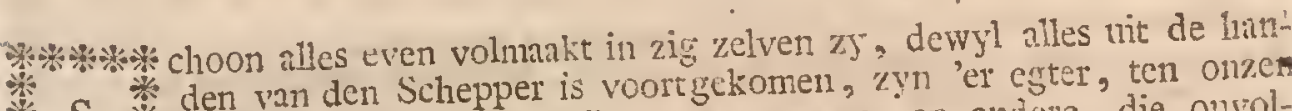
$\mathrm{S}$ 粼 den van den Schepper is voortgekomen, zyn 'er egter, ten onze.

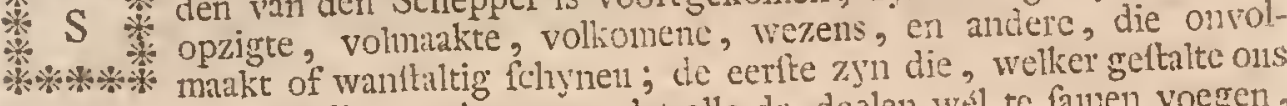
aangenaam en volledig voorkonu, ondat alle de deelen wél tc fanen voegen en een juift geheel makken, omdar het ligham en de ledemaaten eene neite evenredighcid tot mikanderen hebbell, omdat de beweegingen greichikt, alle dc verrigtingen gemaklyk en natuurlyk 7.jn : de andere, die ons lelyk en ysfelyk toefchynen, zyn dic, welker hoedanigheden ons nadeelig zyn, die, welker natuur zig van de gewoone naruur verwydert, en weller gadante at te veel verfchilt van de gewoone geftalten, daar wy de eerte gcwarwordingen van ontvangen en de denkbeelden van gekreegen hebben, die ons tot voorichriften, tot modellen, in onze beoordeclingen dienen. lien menfchelyik hoofd op een paartenhals, het lighram met veleren bedekt, en in den fairt van cen vifch uitloopende, vertoonen ditarom alleen eene fchildery van de tilterfte nismaktheid, ondat in desclve die dingen vercenigd worden, die de Natuur verft van malkanderen verwyderd heeft, en wy zegrgen, in dien zin, dat zulk eene vertooning onnatuurlyk, dat zy monterigtig, is. Een dier, 't welk, gelyk de vledernuis, half viervoetig, half vogel, is, cn 't welk, over het geheel, noch tot het een, noch tot het ander gelriagt kan worden, is, on zo te firecken, een monfter-wezen, voor zo verre het, de cigenfchappen van twee zo verfchillende geflagten vereenigende, nar geene der modellen gelykt, welke de groote klaffen der Natuur ons vertoonen; het is flegts onvolmaakt viervoetig, en het is nog onvolmakkter vogel. Een viervoetig dicr moet vier voeten hebben; een vogel heeft vederen en vleugels; by de vledermuis zyn de voorte voeten noch voeten noch vleugels, fchoon zy 'er zig van bedient on te vliegen, en 'er rig ook van kan bedienen om zig voort te feepen; het zyn inderdand wantaltige uitcinden, welker beenderen monfteragtig verlengd, en vereenigd zyn met een vlies, 't welk noch met vederen, noch zelfs net hair, gelyk het overig gedeeite des lighnams, bedekt is; het zyn eche foort van vinnen, of, zo men wil, gevleugelde pooten, waar nan men niets ziet, dan de nagel van een korten duim, cn welker vier andcre, zeer lange, vingers niet dail te famen kimnen werken, en geene eigene be

* De vledermuis of vleermuis, heet in "t Griekfcl Nuxzipis; in 't Latyn Vefpertilio; in "

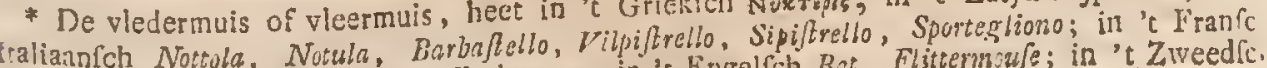

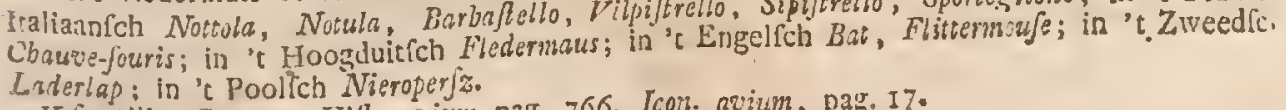

Vefrertilio. GLang R Hijt. avium pag. 766. Icorr avium, pag. 17.

Vefperilio. RAY Syzopf. Animal. Ounitrup. pag. 243 .

Vefpertilio caudatus, ore naforue fomplici. LiNN玉US.

Verperitio vulgari., KLEIN de Ouadrup. pag. 6r.

De gronte vledermuis van ons land. Vefpertilio marini coloris, pedibus omnibus pentadactylis, suriculis fimplicibus .... . Vefpertilis major. BRIssox. Regrb. anim. pag. 224. 
weegingen, noch afzonderlyke verrigtingen hebben; het zyn eene foort van handen tienmaal grooter dan de voeten, en in 't geheel viermaal langer, dan het gantfche lighaam van het dier; het zy11, met én woord, deelen, die eerder het voorkomen van een grillig gewrogt, dan van een regelmaatig voortbrengzel hebben: dit vlies bedekt de armen. maakt de vleugels of de handen van het dier, vereenigt aig met het vel van zyn lighaam, en omvangt terzelfder tyd zyne pooten, en zelfs zyn ftaart, die door deze miffelyke famen. voeging, om zo te fpreeken, een zyner vingeren wordt: voeg by deze ongelykheden de onevenredighcid des lighaans en der ledematen, de lelykheid van den kop, die nog treffender is; want, in. zommige foorten, is de. neus nauwelyks zigtbaar, de oogen. zyn ingezonken tot byna aan den voet van de fchelp van. 't oor, en verwarren zig met de wangen; in andere foorten zyn de ooren zo lang als 't lighaam, of wel het gelaat is als een paardehoef gedraaid, en de neus met eene foort van kam overdekt: de meefte hebben vier ooren op den kop; alle hebben zy kleine, donkere en bedekte oogen, ongefchikten grooten neus, of liever neusgaten, den muil of bek van het: cen oor tot het ander gekloofd; alle zoeken zy zig ook te verbergen, vlieden. het licht, onthouden zig niet dan in duiftere plaatfen, komen. daar niet dan des nagts uit te voorfchyn, en begeeven zig tegen dat de dag aankomt daar. weder in, om tegen de muuren valtgeplakt te zyn: haare beweeging in de lugt is minder eene vlugt dan eenc foort van. onzekere rukken en fprongen, welke zy niet dan met mocite en zonder bevalligheid vitvoeren: zy hebben werk on zig van de aarde te verhoffen, zy vlicgen nooit op eene groote hoogte, $2 y$ kunnen humne vlugt nict dan zcer gcbrekkelyk verhaaften, verflauwen, of befticren; die vlugt is noch zeer fncl, noch zeer regt, zy gefchiedt door fchielyke lingeringen in eene fchuinfche en bogtige rigting.

Al vliegende laaten $z y$ niet na zommige vliegjes, muggen, en vooral de ragt-vlinder's, die niet dan by den. duifter vliegen, in het voorbygaan op te vangen; zy likken dezclve, om zo te fpreeken, in haar geheel door, en men ziet in hare nitwerpzelen de ftukken en brokken der vleugelen en andere drooge onverteerbaare declen dezer infekten. Op zckeren dag in de grotten. van d'Arcy zynde om de ftalaktiten te onderzoeken, ftond ik verbaald van. op eell grond, schecl met albaft bedekt, en in zulk eenc donkere en dicpe plats, eene foort van aarde te vinden die van een gelieel verfchillenden aarc was: het was cen dikke hoop, verfcheiden vocten breed, van eene zwartagtige ftof, byna. geheel beftande uit broklicul van vleugels on pooten van muggen en kapellen, even als of deze infekten zig in cindelooze nienigte in deze plats verzameld hadden, om daar te famen on te komen en te rotten; ondertuffchen was het niets anders dan de drek van de vledernuizen, warichyn. lyk een recks wan jaaren op de plats dezer onderaardiche gewclven, daar $\mathrm{zy}$ zig by voorkeur onthiclden, opgehoopt; want in den geheelen ontrek dezer grotten, dic van meer dan een halfkwarticr van ecn myl is; zag ik geenen anderen hoop van eene dergelyke ftoffe, en ik befluot, dat de vledermuizen hier byzonderlyk haare gemeene woonplaats geveftigd. ladden, omdat er nog eenig. fauw licht door de opening inkwam, en zy waarfchynlyk niet verkiezen zouden, dieper in te dringen in eene plaars van volltrelkte duilternis. 
De vledermuizen zyn wezendlyke viervoetige dieren, zy hebben niets gemeen met de vogelen dau de vlugt; maar gelyk de werking van vliegen eene zeer groote fterkte in het bovenfte gedeclte des lighaams en in de voorfte leden onderftelt, zo hebben zy de borft-fpicren veel zwanter, vleeziger en fterker dan eenige der viervoetige dieren, en men kan zeggen, dat $\%$ y ook daar in naar de vogejen gelyken; zy verfchillen 'er van in al het overige van haar makkzel, zo wel uit-als inwendig; de longen, hẹt laart, de teeldeelen, alle de andere ingewanden, zyn gelyk aan die der viervoetige dieren, met uitzondering van de roede, die neerhangende en afgefcheiden is, het welk byzonderlyk tot den menfch, tot de aapen, en tot de vledermuizen behoort: $z y$ brengen, even als de viervoetige dieren, luunne jongen lecvende voort; eindelyk zy hebben, even als deze, tanden en borften; men verzekert, dat zy niet meer dan twee jongendraagen, dat zy dezelve zoogen, en zelfs vliegende vervoeren.

Het is in den zomer, dat zy koppelen en werpen, want des winters zyn zy verftyfd; de eene bedekken zig met haare vleugelen als met een mantel, haaken zig met de agterpooten aan het gewelf haarer oncleraardfche wooning vaft, en blyven dus hangen; de andere plakken zig tegen de muuren, of verbergen zig in gaten: zy voegen zig altoos in een zeker getal by malkander, om zig voor de koude te beveiligen; alle brengen zy den winter door zonder van haare plats te komen, en zonder te eeten, zy worden niet wakker dan in de lente, en gaan zig tegen het cinde van den herfft op nieuws verbergen.

Zy kninnen beter tegen het vaften dan tegen de koude beliaan; zy kunnen verfcheiden dagen zonder eeten doorbrengen, en evenwel behooren zy onder de vlecfcheetende dieren, want $\% 0 \mathrm{zy}$ in een keuken of bewarpliats van het vleefch kunnen komen, hegten zy zig aan de zyden fpek, die daar ophangen; ook ceten zy vleefch rauw of gekookt, verfch of bedorvent.

De Natuuronderzockers, die voor ons gefchreeven hebben, kennen maar twee foorten van vledermuizen, de Hr. Dsubenton heeft 'er nog vyf ardere gevonden, die, zo wel als de twee eerlte foorten, in ons klimaat natuurlyk thuis hooren; zy zyn daar zelfs vry gemeen, vry overvloedig;, en het is zonderling, dat geen Waimcemer haar hecft gade geflaagen: die zeven foorten zyn zeer onderfcheiden, zeer verfchillende van Inalkanderen, en onthouden zelfs zig nooit in dezeirde plants.

De eerfte foort, die beliend is geweeft, is de gemeene, of de cigeniyk genoemde vledermuis, warvan ik in het begin van dit artikel de henamingen heb gegeeven, en waarvan men ook de befchryving en de figuur hicr agter zien kan.

De tweede is de vledermuis met groote ooren, welke wy de Oreillar, of de groot-nor zullen nocmen, dic ook door de Natuuronderzoekeren opgemerkt, en door de Naamlyitmakkers angeweezen is $(a)$. De groot-oor is mis-

(a) Vefpertilio. Aldrovaxd. Hifl. avium pag 571.

Vejpertilio auriculis quaternis, Jongst, Hija. avium pag. 34:

Vejpertilio vulgaris, auriculis duplicibus. KI.eIN de Quadr. pag. 6t.

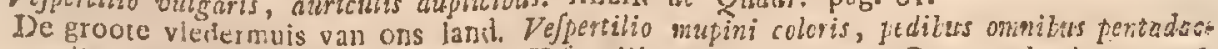

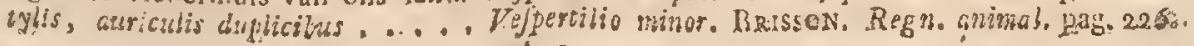


fchien gemeener dan de gewoone vledermuis, $z y$ is kleiner van lighaam, $z y$ beeft ook veel korter vleugelen, minder dikken en puntiger fnuit, ooren van eene buitenfpoorige grootte; gelyk men uit de befchryving en de figuur hier agter geplaatft, zicn kan.

De derde foort, welke. wy de Noctiile, van het Italianfche wcord Notula. of de Nagt-rlieger zullen noemen, was niet bekend; ondertuffchen is zy in Frankryk zeer gemeen, en men ontmoct haar zelfs meer, dan de twee voorgande foorten; men vindt haar onder de daken, onder de loode gooten van gioote landhuizen, van kerken, en ook in oude holle boomen: $z y$ is byna $z 0$ groot als de vledermuis, zy heeft korte en breede ooren, rosagtig hair, een fcherpe en finydende ftem, die vry gelyk is aan het geluid van. een yzeren. klok; zie verder de befchryving en de bygevoegde figutr.

Wy zullen de vierde foort, die geheel niet bekend was, Serotina noemen; zy is kleiner dan de vledermujs en de noctule; zy heeft ten natitenby de grootte van den oreillar, maar $z y$ verfchilt 'er van in de ooren, die zy kort en puntig heeft, en in de kleur' van 't hair; $z y$ heeft de vleugels zwart, en het hair van een donkerer bruin: zie de befchryving en de figuur.

Wy zullen de vyfde foort, die ook nict bekend was, pipiftrelle heeten, van het Italiannfch woord pipiftrello, 't welk ook, vledermuis betekent; de pipiftrelle is, op verre ma, zo groot niet als de vledermuis of de noetule, nocla zelfs als de ferotine of de orcillar; van alle de vledermuizen is zy de lileinfte en de minft lelyke, fchoon.zy de bovenfte lip zeer gezwollen, de oogen ceer klein, zeer ingezonken, en het voorhioofd zeer ruig, heeft: zie hier agter do befchryving, en de figuur.

De zesde foort, die mede onbekend was, zal Barbaftule gehleeten worden, van het Italiaanfich rvoord barbaftello, 't welk al mede vledermuis betekent: dit dier heeft ten naaftenby de grootte van den oreillar; het heeft de ooren even breed, maar minder lang, de naam van barbaftelle paft haar te beter, omdat zy eene groote knevel ichynt te hebben, die egter niet dan fchyn is, en cen gevolg van het zwellen der wangen, die eene wrong boven de lippen makken; zy heeft den finuit zeer liort, den neus zeer plat, en de ongen bykans in de ooren, zie de betihryving cn de figuur.

Eindelyk zullen wy eene zevende foort, die geheel nict bekend was, Hoefjaer noemen; zy is zeer treflende door de zonderlinge mismakitheid van haar geliat; warvan de blykhaarte en duidelykite trek een wrong is, in de gedante van cen hoefyzer, rondom den neus en op de bovenfte lip; men vindt har zeer gemeen in Frankryk in de muuren en kelders van oude verlaaten kafteelen: daar zyn . Fleine en groote, maar die voor het overige zo gelyk zyn in geftalte, dat wy har geoordeeld hebben van dezelfde foort te zyn: dewyl wy egter veele gezien hebben, zonder cene middelfoort tuffchen de groote en de. kleine te vinden, zo durven wy niet beflifien, of de ouderdom : alleen die verfehillen voortbrenge, dan of het eene ftandvadtige verfcheidenheid in dezelfde foort zy? zie ook de befchryving en de figumren.

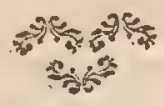





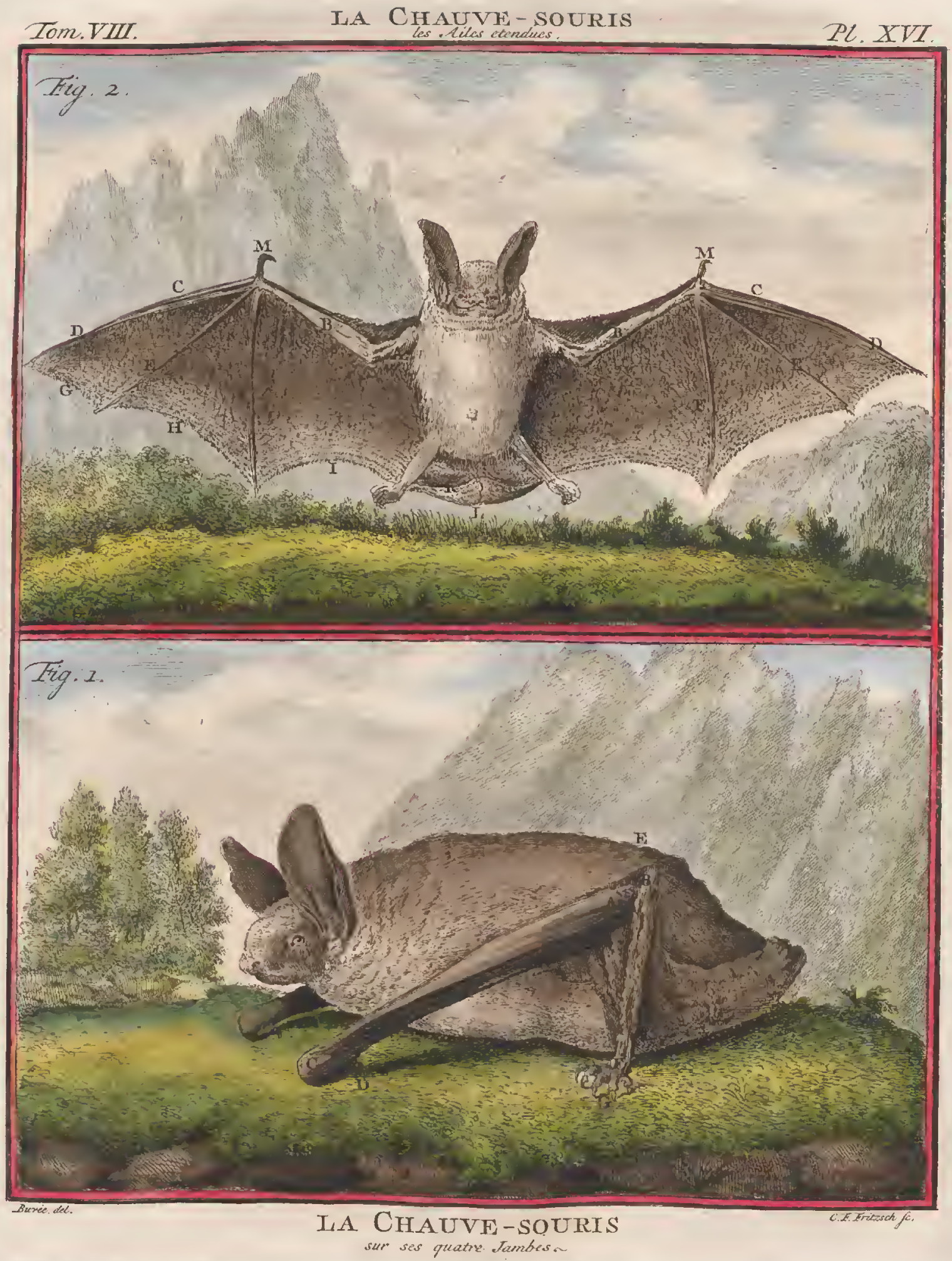




\section{BESCHRTVING DER VLEDERMUIZEN.}

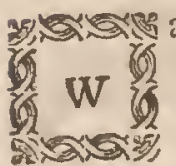

anneer men de vledermuizen by het flauwe licht der. fchemering heen en weêr ziet vliegen, zou men vit de gedaante harer vleugeLen haar ligtelyk voor vogelen befchouwen, maar ik ben verwonwaarneemen, de kenmerken der viervoetige dieren, welken deze dieren hebben, niet bemerkt, en zig derwyze vergift hebben, dat zy hen in den rang der vogelen hebben geplaatt: alle de figuuren, die wy van de vledermuizen. hebben, zelfs in Werken van de Natuurlyke. Hiftorie, vertoonen haar met uitgefpreide vleugelen: hadr men nooir opgemerkt, dat die vlengels pooten 2y'n, wanneer het dier in ruft is, en dat het vier beenen heeft, gelyk andere viervoetige dieren; lat ons. dan beginnen met de vledermuis te befcluryven in den ftant van ruft ( fig. I. Pl. XVI) voor dat wy haar doen zien in dien ftant, warin haare twee voorfte pooten vleugels worden, die.. hair in . de lugt ophouden ( fig. 2).

De beenen der vledermuizen fehynen volftrekt verfchillende van die van arderc viervoetige dicren, en zy zyn inderdaad op eenc zeer zonderlinge wyze gerigt en gemakt: de ellcboog. $(A)$ is by de knie $(B)$; de voorarm $(A C)$ is zeer lang, cn ftrekt zig fchunich van boven naar bençen, en vall agteren naar voren, zo verre als de neus van het dier, .uit: het gewrigt $(E)$ draagt op de aarde, en men ziet in de voorfte voeten flegts cenen vinger $(D)$ dat de duim is, en die zig agterwarrds uiltrekt; de knie (B) is zo verheven als het onderft $(E)$ van liet kruis; her been $(B F$ ) heeft een loodregte rigting van boven naar beneden, en de vyf vingers van den agterften voct, zyn nar buiten gerigt, en allen even lang: de arm is van agteren naar voren regt uitge1trekt, en de dij ftat van boven naw beneden. loodregt: de arm is.agter den voorarm, en de dije agter den poot verborgen; zy zj'1l daarenboven met den. yoorarm en het been irgewikkeld in gefronzelde vliezen, die. den ftart, en: byna het geheele agterfte gedeelte van het ligham des diers bedekken.

De verfchillende declen der beenen van de vledermuis, op zulk cene.buitengewoone wyze gerigt, kondigen geen gemakkelyken gang aan; ook. fleept dit dier zig meer dan dat het gai, ondertufichen drangt het zyn ligham, door middel van zyne vier bcenen, van voren, op zyde en vast agteren: in den ftat van ruft fteunen de borft, en de buik op de aarde, zonder dat de vier vocten het gewigt des lighams onderfeunen; $\angle y$ belctten hot alleenlyk te: rwaggelen en op zyde te villen.

On voorwaards te gann ligt de yledermuis de beide voorte voeten te gclyk op g. en zet dezolve op ecu kleinen aftand van de plats, dar zy warn, neder; terzelfder tyd rigt zig de duim van yderen voet naar buiten, cn let dier hakt zig met den nagel vait aan 't fteunpunt, dat het ontmoet; het ftrelit de twee agterfte voeten agterwaterds uit, op eene. Wyze, dat de vyt vingeis van ydeIed yoet ook agterwards gerigt $2 y \_$; let fteunt op den bul van den voet, eax? 
ftevigt zig door midclel van de nagels der vingeren: dan heft het zyn lighaam op de voorpooten op, $\mathrm{cn}$ het brengt zig voorwaards door den arm op den voorarm te buigen; die beweeging wordt bevorderd door de uitftrekking der agterite pooten, die het lighaam insgelyks voorwards brengen : om ecn twecden pas te doen brengt de vledermuis de agterfte voeten terzelfder tyd als de voortte naar voren, laatende fteeds de vingers der agterfte voeten naar agteren gerigt: die wy<e van gaan, fehoon zwaar, omdat het lighaam op yderen ftap weder op de aarde valt, is zomtyds vry vaardig, wanneer de voeten telkens een goed fteunpunt ontmoeten; maar het gebeurt dikwils, dat de duim der voorite voeten een lighaam annvat, dat te rug wykt, als dan doen de agterfte voeten, door het wyken van den duim mede uirglydende, eene vrugtloo* ze pooging; zo een der voeten op een vaft punt heeft gedragen, en het ander niet evenecns houdt, zo doet het dier een valfchen ftap; insgelyks is het behulp der agtervocten seer onzeker, omdat de nagels naar agteren gerigt zyn, en het dus mar de bal van den voet alleen is, die tot fteunpunt dienen kan om het lighaam voorwaards te brengen, en de voet dikwils agterwaards glydt, wanncer het bcen zig tiitltrekt om het lighaan voort te werken: ik heb ook vlcdermuizen gezien, die de voorfte en de agterfte voeten én voor één naar voren bragtcn, gclyk, de andere viervoetige dieren.

Wannecr de vledermuis zydelings wil gaan, verwydert zy van dezelfde zyde cen haarer voorite voeten door dien van den anderen af tc brengen, en ligt zig dus op de twee beenen van de eene zyde op: door deze beweeging raakt het voorfte gedeelte des lighaams ter zyde, omdat het op een gelyken afitand tuffchen de twee voorfte voeten nedervalt: om agterwaards te loopen begint de vledermuis met de agteríte beenen agterwards te brengen, vervolgens ligt $z y$ het lighaan op de voorfte beenen op, terwyl de anderen het, door zig te buigen, agterwaards trekken; die lantite gang is vry gemeen aan zekere vledermuizen, die de vingers der agterte voeten mect agterwaards gerigt hebben; zy hangen zig op door zig net deze vingers valt te makken, en verkiezen die plaating om te ruften: ik heb llegts eene enkele foort gezien die dit verkoos, de andere blyven op humne vier pooten, en verzamelen zig by malkanderen om eche onderlinge warmte te ontvangen en mede te deelen; dit doen $\mathrm{zy}$ inzonderheid wanneer zy zig in koude platefen bevinden.

Gelyk de gang der vledermuizen altoos zwaar, en dikwils zeer traag is, zo verlchile dezelve weinig van lummen ftat van ruft; ook neemen zy deze bewceging niet dan wanneer $z y$ verdoofd of vcrmoeid zyn; of wanneer het fterke licht haar niet toelatat uit hase af\%ondering te voorfelnyn te komen of de voorwerpen te bemerken; maar zodra het licht evenredig is aan de zrvakheid haarer oogen, en de hocdanighcid van de lugt, de gekorvenen, die haar tot voedzel verítrckken, in beweeging brengende, haar begunftigt, dan fpreiden zy hare lange vleugels uit, zy neemen vlugt, heffen zig in de lugt op, daa. len weder, en doorloopen lange aftanden met een vry fnelle vaart.

Wy moeten tot de vledermuis in haren ftant van ruft wederkeren om de ontwikkeling haarcr vleugelen te ricn: ik heb reeds gezegd, dat men in de vonrfte pooten mar énen vinger zag, die de duim is, daar zyn daarcnbo. wen vier zeer lange vingers, tegen den voorarm uitgeftrekt, met hun einde 
by den elleboog toegevouwen en in ecn gefronfeld vlics bewonden: wanneer de vledermuis haare vlugt wil neenien verwydert $z y$ haare vier vingers van malkander, het vlies, dat dczelve omvat, fpant zig uit en maakt een vleugel; dataelfde vlies verlengt zig buiten den vierden vinger tot aan het lighaam des diers, omvangt den arm en de dij, en ftrekt zig verder totagter den ftaart uit, welken het insgelyks omvangt, gelyk ook de vier beenen en de vier vingers van den voorften voet.

Het vlies van de vledermuis is buigzanm, en heeft zo weinig dikte, dat het half doorfchynend is; het is zo fterk, dat men moeite heeft om het te fchelren: door het zelve heen ziende bemerkt men daarin eenige bloedvaaten en fpieragtige vizels, die het fronlelen, wanneer de vleugels toegevouwen zyn, en die daar, in dezen ftat, holten makken, op reijen geplaatit gelyk de maazen van een net: dit vlies fcheurende, ontrifelt men de witagtige vezels, die het weefzel, dat het vlies niankt, anıwyzen.

De arw ( $A A$, fig. $2, P l . X V I)$, de voorarm $(B B)$, de rier vingers $(C C$; $D D, E E, F F)$, van de voorfe vocten, de dij enl het been hebben 1maar weinig vleefch, en gelyken nar de deelen van een geraante, in krip bewonden: de eerfte vinger $(C)$ is by den taveeden $(D)$ geplatift; daar is veel meer af. ftands tufichen den tweeden en den derden vinger $(E)$ dan tuffchen den eerften en dent tweeden; de derde is nog verder af van den vierden $(F)$ dan van den tweeden: de agterfte rand van het vlies makt aan weerskanten van het dier vier uitfnydingen, de eerfte $(C)$ tuffchen den tweeden en derden vinger, de tweede $(H)$, tuffchen den derden en vierden; de derde $(I)$ tuffchen den vierden vinger en liet been, en de vierde $(K)$ tuflichen het been en den farrt $(L)$, warvan het laatfte valfche wervelbeen gedccltelyk van het vlies los is: deze regelmaatige uitinydingen zyn door de tekenaars nagevolgd, en dicnen tot fieraaden in de kardoezen en andere loofwerken.

Wannecr de vledermuis ophoudt te vliegen en zig op de aarde nedcrzet, rouwt zy haale vier voorfte vingers langs den voorirm 2 en $z y$ fteunt op den duin $(M M)$ en op het gewrigt.

Het hoofd van dit dier fchynt met het lighaam verward te zyn; men ziet 'er niet van dan den bek en de ooren, die zeer groot zyn; men bemerkt nauwelyks de oogen, bykans verborgen in thair, dat zeer lang is by alle foorten van vledermuizen. De Schryvers van de Natumrlyke Hiftoric, die gewag van dezc dieren gemakt hebben, hebben tot hier toe flegts een of twee foorten gekend in ons klinıat; ik heb 'er egrer met gemak veel meer gevonden, zodia ik begonnen heb dezelve war te neemen; en in vier jaaren tyds heb ik let $z o$ verre gebragt, dat ik zeven zeer verfchillende foorten heb verzameld, Warvan ik reeds de kenmerken lieb opgegeeven in eene memoric over de vledermuizen in de Kcninglyke $\Lambda$ kaderuie der Weetenfchappen roorgeleezen (a): de meeften dier kenmerken hangen af van het getal der tanden, van de grootte en de gedaante der ooren, cu van den bek, en zyn in de volgende bef hryving" van ydere foort van vledermuis voorgedrangen.

De remeene Vladermuis.

De vledermuis (fig. I, Pl. XVI.) heeft een dikken en verlengden bek, bree-

(a) Zie les Mimoires de l'Academie royale des Șciences, année 1759. VIII. Deel. 


\section{DE NATUURLYIE HISTORIE,}

den neus, zeer grooten mond, groote ooren, en kleine oogen; het onderft gedeelte der uit-en inwendige randen van de fchclp van 't oor maakt van weerskanten een kwabbetje, en daar is tuffchen deze twee kwabbetjes ecn uitfpringend lelletje voor de opening van den uitwendigen gehoorweg: hetzelve heeft wcinig breed. te maar deszelfs lengte evenaart byna de helft van die van de fchelp of lepel van 't oor; de vyf vingers der agterfte vocten zyn de eene byna zo lang als, de andere.

De kruin des hoofds, het bovenft van den hals, de fchouders, de rug, de ftuit en de dijen waren van eene blecke afchgrauwe kleur; met eene ligte fchaduwing van geelagtig: het hair verwyderende zag men eene zwartagtige kleur, die hetzelve over het grootfte gedeelte van deszelfs lengte, van den wortel af, hadt: de keel, het onderft van den hals, de oxels, de borft, de huik, en het geheel ondertt gedeelte des lighaams, hadt eene witte kieur, met eenige ligte fchaduwingen van geelagtig gemengd: men zag ook eene swartagtige kleur, wanneer men het hair verwyderde, ondat hetzelve even als het hair van het bovenft des lighaanis, die kleur over het grootit gedeelte zyner lengte, van den wortel af, liadt.

De lippen en het onderft kakbeen waren ros; de neus en de ooren hadder. eene grauwe kleur naar zeer helder bruin trekkende; het vlies van de vleugels en van den ftaart, de beenen en de voeten hadden gedeeltelyk diezelfde kleurfels, en waren gedeeltelyk zwartigtig: het hair van dit dier was omtrent drie lynen lang; de ltaart was, tot aan het einde, in zyn vlies ingewilkkeld.

De Oreillar of Groot-oor.

De oogen op dit dier ( $f \mathrm{~g} . \mathrm{I}, P l . X V I I$ ) ) laande, ziet men, dat het geen beter naam lian lacbben, dewyl deszelfs ooren uitermaaten groot zyn; hunne lengte is gelyk an dic des geheelen lighaams van de bafis der ooren af tot aan den ftaart gemeeten; zy: zyn ook zeer breed, want hunne breedte maakt meer dan twee derde van hunne lengte: deze ooren zyn dun, byna doorlchynende, en ten naaftenby van eene eyronde gedaante; zy maken, op eeligen afftand van hunnen voorften rand, een vouw in de lengte en die voorwards uitfpringt; daar is eenig hair langs deze vouw. : daar was een kwabbetje op den binnenrand, op eenigen afftand van 't hoofd; de twee. ooren rakten inalkanderen aan! het onderft gedeelte. van hunnen binnenrand, en vereenigden zig ann malkanderen door een vlies, dat eene lyn hoog was boven 't voorhoofd. Alle de deelen van zulk een nitgeftrekt oor moeten zeer zigtbaar zyn; ook heeft hetzelve eene uitipringende. lelle, geplaatit voor den gehoorweg, dic zo groot is, dat zy een tweede oor fchynt te zyn; zy is lang, fmal, en. puntig aan 't einde: het oor heeft eene zcer merkbaare beweeging; het vouwt en verlaagt zig naar buiten, zodat deszalfs einde den fchouder nadert, en de beide ooren, in deze plaatfing, ten naaftenby de gedanate van ramshoomen neemen : men ziet in hun weefzel dwarfche vezcls, op eenigen afitand van malkanderen geplantit, die rimpels maken.in dezelfde-rigting, wannecr het oor zig. thevouwt: de ongen zyn klein, rond, en voor de ooren geplantf; de finuit is lang, puntig, en tuffchen de oogen met lang hair bedekt.

De vleugels hebben weinig lengte en zyn van cene bruin-of zwartigtige: Heur: het thart-vlies is my, mar evenredigheid, grnoter voorgekomen dan de vleugcls; het hadt dezelfde kleuren : het hair van "t bovenft van den bek, van den, hals, van. de. fchouderen, en van het lighaam, was ecne vermengde zwart 


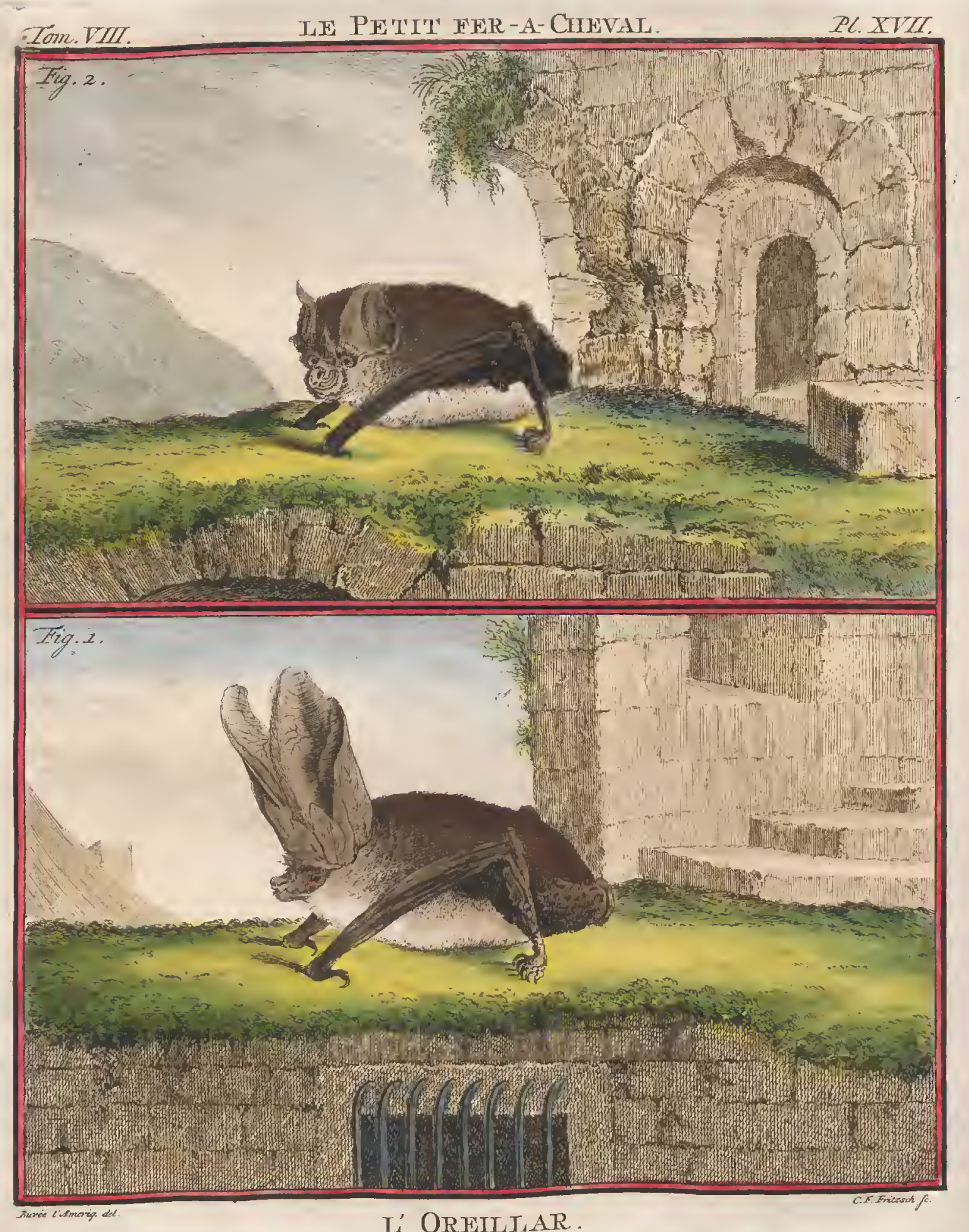




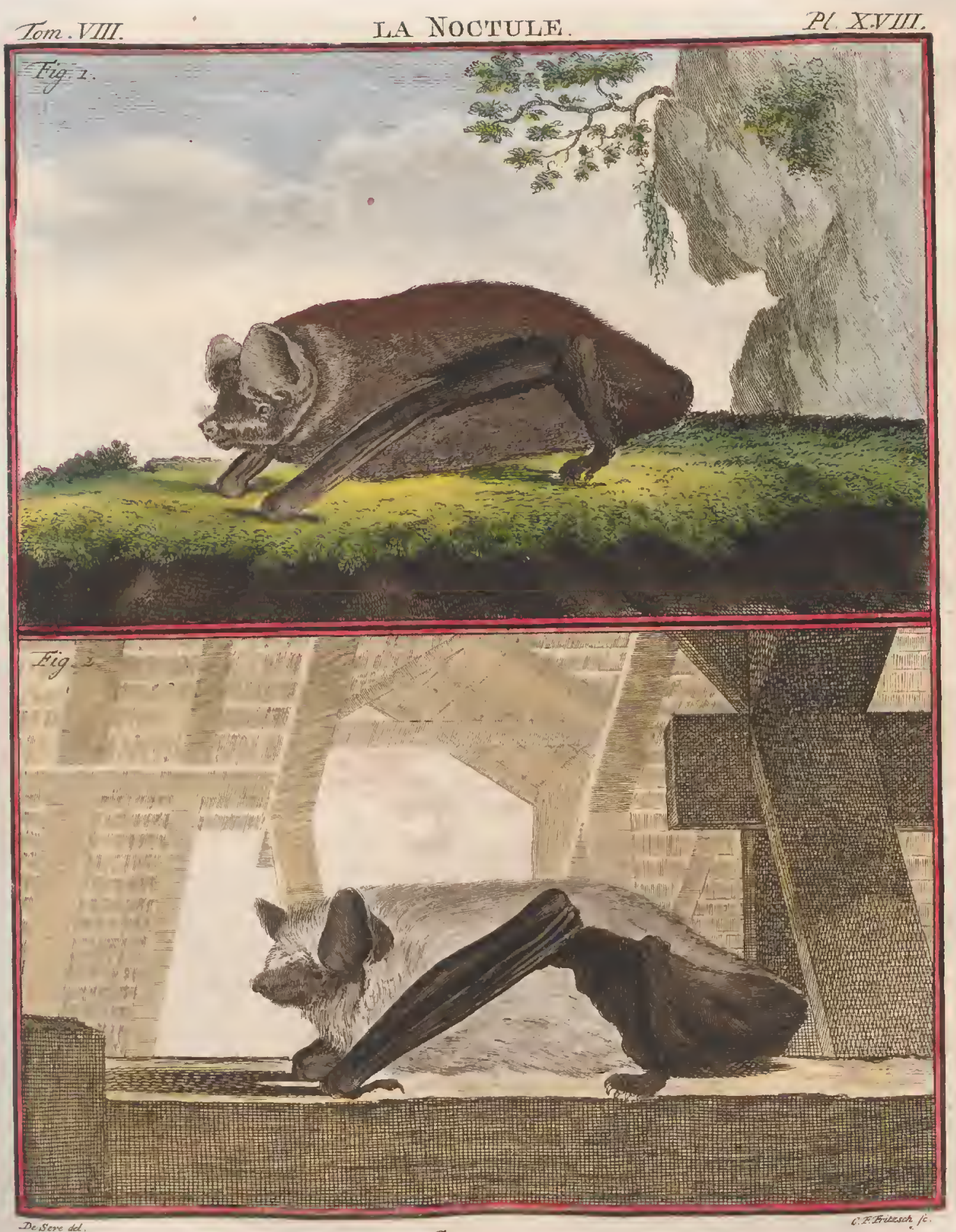

LA SEROTINE. 
agtige en rosagtig grauwe kleur, omdat yder hairtje zwartagtig was van den wortel af over het grootft gedeelte zyner lengte; daar was eene rosagtige kleur boven het 2wartagtig, en de punt was bruin : het bovenft van het lioofd, van den hals, van de fchouderen, en van het lighaam, hadt eene kleur van vermengd zwartagtig en gramw, ondat het hair gedeeltelyk zwartagtig en gedeeltelyk grauw was; mar de zwartagtige fchaduwing van het boventt des lighaams was, eigenlyk gefprooken, niet dan een rosagtig grauw, enhet grauw van het onderit des lighams was ook wat rosagtig : het hair van dit dier was lang, het haalde omtrent drie lynen.

\section{De Nocíule of Nagt-vlieger.}

De nagt-vlieger ( $f$ ig. I , Pl. XVIII) is ten minften zo groot als de gemeene vledermuis, maar zy heeft korter beenen, wat min verlengden neus, en mi1der bolrond voorhonfd: de ooren zyn vry wat minder lang, fchoon byna even breed; hun einde is gerond; $2 y$ hebben op het onderft gedeelte van den binnenrand, by het oog; een rondagtig kwabbetje en op het onderft gedeelte van den buitenrand, by den hoek van den mond, cen ander kwabbetje van eune zeer onregelmaatige gedante: daar is, voor de opening van den uitwendigen gehoorweg ecne zeer korte en rondagtige lel: de oogen zyrr zeer klein en geplaatit beneden de voorfte hoeken der ooren: het hair van dit dieis twee lynen lang, en heeft eene vale kleur met bruin gemengd; het einde var den bek, de vleugels, het ftaart-vlies, en de voeten zyu van eene zwartagtige kleur.

De ferotine ( $f i g .2, P l . X V I I l)$ is ten naaftenby van dezelfde grootte als de hoefyzer, waarvan de afmeetingen in de volgende tafel zyn gemeld: $z y$ heeft een verlengden bek; de ooren zyn kort en breed, hunne buitenrand heeft eene uitfnyding, dic onder an het einde gerond is; daar is voor den gehoorweg een zeer korte lel: het hair van de bovenzyde des lighaams is bruin met val gemengd, niet donker; de onderzyde heeft 1 og bleeker kleuren, geelagtig en zeer helder afchgrauw: het vlies der vleugelen en van den ftart heeft eene zwartagtige kleur.

De pipiftrelle ( $f i g . ~ I, P l . X I X)$ is zeer klcin; het hoofd is wél geëvenredigd naar het overige des lighaams, en de ooren, of fchoon groot, zyn het niet overmaatig: de neus is klein, mar de bovenlip makt eene zwelling aan weerskanten van het kaakbecn: de oogen zyn rond, zeer klein, en gezonkeir tuffchen de opzetting van de lip en het oor: het voorhoofd is bedekt met vry lang hair, dat het hoofd dikker makkt; de ooren zyn breed, aan de einden gerond, en aan de buitenzyde uitgefneeden, terwyl de binnenfte een uitfpringenden hock maakt: daar is van binnen in de lepel van het oor een uitTpringend gedeclte of lel, die zig duidelyk vertoont, en voor de opening van den buiteniten gehoorweg geplaatl is.

Het hair van het boventt des hoofds en des lighams is van eene bruine kleur, met een zwecmzel van geelagtig; het hair van het onderft des lighaams heeft neer geelagtig on minder bruin, maar wamnecr het opgeftreeken is, fchynt het byna geheel zwartagtig bruin, omdat het grootfte gedeeltevan yder hairtje deze

$$
\mathrm{K} 2
$$


kleur heeft, en het einde alleen geelagtig is; de langfte hairtjes zyn van twe en eene halve lyn: de neus, de lippen, de ooren, de beenen, de ftaart, en. het vlies der beenen en van den ftaart, zyn zwartagtig.

De Barbaftelle.

Dc barbaftelle (fig. $2, P l . X I X$ ) heeft lange en breede ooren, die met het onderft gedeelte van hunnen binnenjand aan malkanderen raaken, zodat mell, dit dier van voren befchouwende, noch voorhoofd noch hoofd verneemt; de bek is zeer kicin, men bemerkt denzelven onder de binnenranden der ooren: de neus inakt cen plat knobbeltje en is onmiddelyk boven den mond seplatit; de openingen der neusgaten zyn agter den bovenften rand van dit knobbeltje; het neusbeen is ingedrukt, en van hair ontbloot van de neusgaten af tot aan de ooren; die ruimte is van eene bruin-zwartagtige kleur: daar zyn van wecrszyde twee kleine vooren, die op ydere opening der neusgaten uitloopen, zodat, wanneer men den bek van het dier lluit, de voorfte voor van ydere zyde zig over haare lengte toevouwt, en een buis makk, waarvan de rand aan die der opening van het neusgat raakt; de wangen zyn dik en gezwollen, en fchynen op het eerfte aanzien, knevels te zyn, die over de lipm pen hangen; de oogen zyn zeer klein, rond, en voor de fchelpen der ooren seplatitt: ydere fchelp is dubbeld, omdat 'er cenc lel is voor aan de fchelp in " $t$ midden, tuffchen het oog, en de opening van den buitenften gehoorweg; die lel heeft omtrent de halve hoogte van de fchelp:

Het hair van de barbaftelle is van eene bruin-zwartagtige kleur over het gebecle lighaam, uitgezonderd op de keel, de borft, en den buik, alwar het een gemengd grauw en bruin is; het langfte hair is op den rug, alwaar het tot vyf lynen haalen kan; de ftart fteekt maar weinig uit buiten het vlies, sat hem omvangt.

De Hoefyzer.

Het vreemd mankzel van het aangezigt dezes diers geeft hetzelve eerr zeer lelyk aanfichouwen; het fchynt op den bek het afbeeldzel van een hoefyzer te hebben, daar het ook zyn naam naar heeft: ik heb in een geruimen tyd van deze dieren geene gevonden dan van eene middel-grootte (Pl. XVII, fig. 2) ruffchen de pipiftrelle en de barbaftelle; eindelyk heb ik zommige gezien, die veel grooter waren; dewyl zy in zommige opzigten van de eerften, die ik in grooten getale had wargenomen, verfchilden, zo heb ik de eene en andere afzonderlyk befchreeven, en ik begin met de befchryving der kleine.

De bolronde rand van het vlies, dat de figuur van een hoefyzer makkt, was boven de bovenfte lip geplaart; yder tak verlengde zig ter zyden de neusgaten, die agter den holronden rand waren; dit vlies hadt omtrent eene Iyn breedte over zyne gehecle lengte: het middelichot der neusgaten ftrekte zig van weerkanten boven hunne openingen uit, zodat hetzelve eene ronde en holronde bovenzyde hadt: op het agterft einde van die zyde verhefte zig een limal en puntig plaatje; agter hetzelve was. een ander ten naftenby vierknnt, 't welk met bet fmalle één lighan makte, en loodregt langs het neusbecn liep; het hadt omtrent eene lyn hoogtc; uit de bafis van dit tweede plaatje kwan cen ander driehoekig vlies te voorfchyn, 't welk zig fehuinfch naar agteren uititrekte; het hadt twee en een halve lyn lengte en eene en een halve lyn breedte omlang. 



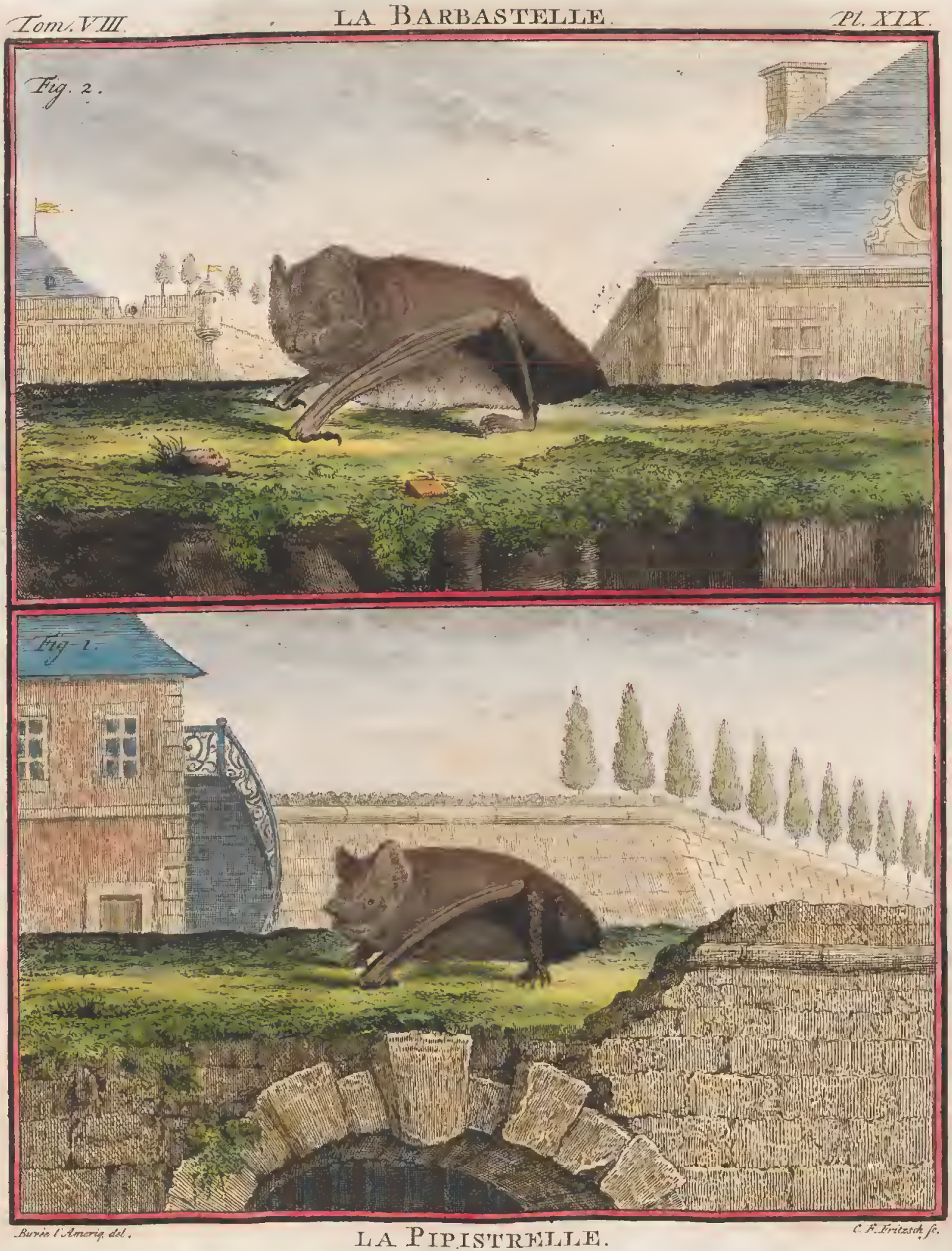




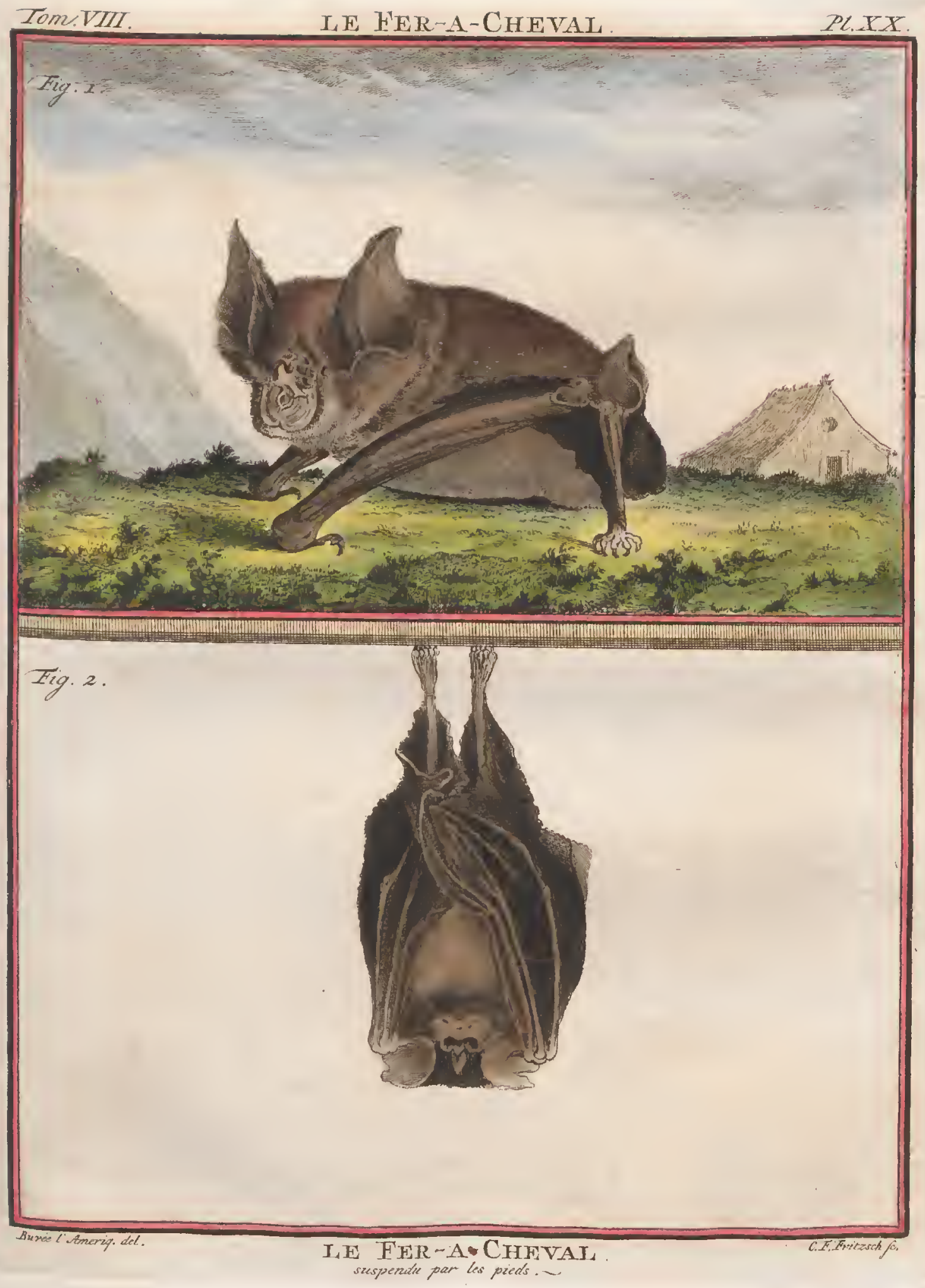



De oogen waren zeer klein en zeer gezonken, zy waren elk tuffchen het oor, en het drielhoekig plaatje, daar van gemeld is, geplaatft: de ooren waren groot, breed aan de balis, en liepen uit in een punt, die wat buitenwaards gekromd was; de binnenrand van het oor was bolrond, de buitenfte was holrond beneden de punt, en bolrond by de bafis van het oor; hy formeerde vall voren een groot kwabbetje, maar daar was geen lel.

Het hair was zeer zagt, en vier lynen lang; de onderite zyde des lighaams hadt eere vuil witte kleur; de bovenkant hadt dezelfde kleur met fchaduwingen van afchgrauw-bruin; de ooren en het vlies der vleugelen en van den ftaart waren van eene zwartagtige kleur.

Deze dieren bleeven den geheelen dag aan hunne agterfte pooten hangen., en hunne vleugelen ingervikkeld, (zie Pl. XX, fig. 2.)

Men heeft'er gevonden in een kelder valn het kafteel van Montbard, die veel grooter waren $(P l . X X, f i g$. I) dan die, waarvan ik de befchryving gegeeven heb; zy hadden ten naaltenby dezelfde grootte als de gewoone vledermuis en de nagt-vlieger: hunne afnceetingen zyn in de volgende tafel bygebragt; voor het overige verfchilden zy van de kleine niet dan in ecnige fchaduwingen van kleur, en in eenige beter ontwikkelde deelen in de vliezcn die $o p$ den neus, op het neusbeen, en voor op het voorhoofd waren, ongetwyffeld omdat deze dieren ouder waren: het vlies, 't welk het hoefyzer maakte, hadt anderhalve lyn breedte op de breedfte plaatfen, het was op 't midden var zyn voorften rand uitgefnecden; het driehoekig plaatje, datzig fchuinfch naar agteren uittrekte, hadt drie lynen lengte, de lengte by de balis was van drie en eene halve lyn: daar waren op de voorfe zyde van dat plantje zes holligheden, drie aan weerskanten, op zulk cene wyze geplaath, dat de twee eerfre zig bevonden op eene lyn beneden cie punt van den drichoek, en, niet dan door een zeer dun middelifchot, van malkanderen afgefcheiden waren: de beide tweede waren van de eerfie en van de beide derde, insigelyks niet dan door een zeer dun middelichot afgefthciden; mant daar was een lyn afftands tuffehen de beide tweede en tufichen we beide derde, die aan de batis van den drieloek waren.

Het hair hadt tot vyf lynen lengte; het onderft gedcelte des lighaams was van eene grauwe, met geelagtig gemengde, kleur; het bovenft des lighams was helder afchgrauw en ros gemengd, ondat het hair, over bet grootite deel zyner lengte heider afchgrauw of grauv err aan het einde rosagtig was : danr was ook een bruine ftreep, die zig aan weerskanten van het cor tot tuffchen de fchouders uirftrekte, en een derde, dic zig van tuffchen de fchouders tot langs dan rug verlengde; die ftreepen wicrden veroorzalakt door chat het einde van het hair bruin was.

Een dezer dieren was een wyfje, en hadt binnen korten geworpan, want haare tepels waren zeer groot; zy hadden tot twee lynen lengte en eene lyn breedte; zy waren zeer dun en geleeken naar de tepeltjes van een. runder pens; zy waren ten getale van vier, twee op het agterft gedeelte van de borit, een aan weerszyden in 't midden van een kuiltje' zonder hair, 't welk drie lynen omtrek hacir; cn twee andere geplatif voor de fehamelheid, op twee lyren affiand van de klink, en llegts ééne lyn van malkanderen. af.

$$
\text { II }
$$




\section{VAN VERSCHILLENDE SOORTEN.}

Lengte van ' $t$ geheele lighaam in eene regte lyn gemecten van het cinde van den bck tot aan den aars

Met uitgefpreide vleugelen gemeeten .

Lengte van het hoofd van het einde van den bek tot aan het agterhoofd

Omtrek van het einde van den bek . -

Omtrek van den bek onder de oogen geno-

men
Omtrek van de opening des monds : :

Afftand tufichen de peide neusgaten Afftand turfchen het cinde valn den bek en den vooriten hoek van 't oog . . •

Afiland tuffchen den agterften hoek en ' $t$ oor vain het nan den eenen hoek Lengte van het

Opening van't oog

Affand tuffchen de voorfte hoeken der oogen volgens de kromte van het neusbeen

Dezelfile affand in eene regte lyn gemee-

ten
Omtrek van het hoofd tuffchen de oogen en de ooren genomen

Lengte der ooren
Breedte van de bafis op de uitwendige Bromte gemeeten

Afitand tufichen de beide ooren omiag ge-

nomen
I,engte van den hals

Omtrek van den hals

Omtrek des lighaams agter de voorfte pooten dwars donor de vleugelen genomen...

Omtrek aan de dikfte plaats genomen ...

Omtrek by de agterfte pooten gemeeten -

Lengtovan den ftomp des ftaarts

Omtrek van den ftaart an 't begin van den ftomp den voorarm van den elleboog Leligte van den voorarm van den elleboog
tot aan ' $t$ gewrigt

Breedte van den voorarm by den elleboog.

Dikte van den voorarm terzelfder plaats.

Jengte van 't gewrigt van de hand . . .

Dikic van 't gewrigt Zengte van 't gewrigt af tot aan 'teinde der :vingeren

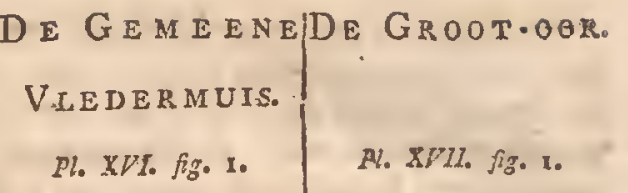

veten, duimen, lynen. |vocten, duimen, lynez.

\begin{tabular}{|c|c|c|c|c|c|}
\hline & \multirow{2}{*}{\multicolumn{3}{|c|}{ o. I. 8.}} \\
\hline $\begin{array}{l}\text { o. } \\
\text { I. }\end{array}$ & $\begin{array}{l}2 . \\
3 .\end{array}$ & $\begin{array}{l}7 \cdot \\
3 \cdot\end{array}$ & & & \\
\hline ๖. & I. & 0. & o. & o. & 8. \\
\hline & \% & & 0. & 0. & \\
\hline 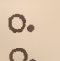 & I. & 4. & o. & o. & 9. \\
\hline & I. & o. & O. & o. & 7 \\
\hline & 0. & $I^{\frac{2}{3}}$ & 0. & 0. & $\frac{1}{I_{4}}$ \\
\hline & o. & 5. & 0. & 0. & 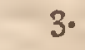 \\
\hline o. & 0. & 3. & o. & o. & $I_{*}^{z}$ \\
\hline 2. & c. & I. & o. & o. & \\
\hline 2. & o. & $\frac{8}{x^{*}}$ & o. & o. & $\frac{3}{4}$ \\
\hline o. & o. & 6. & o. & o. & 3. \\
\hline o. & o. & $4 \frac{1}{2}$. & 0. & 0. & $2 \frac{2}{3}$ \\
\hline o. & I. & 8. & o. & O. & \\
\hline o. & 0. & 10. & o. & I. & \\
\hline o. & 0. & 7 & o. & ๑. & II. \\
\hline 0. & o. & $6 \frac{x}{2}$ & ○. & o. & \\
\hline o. & $\begin{array}{l}\text { O. } \\
\text { I. }\end{array}$ & $\begin{array}{l}3 . \\
3 .\end{array}$ & $\begin{array}{l}\text { o. } \\
\text { o. }\end{array}$ & $\begin{array}{l}\text { o. } \\
\text { o. }\end{array}$ & 6. \\
\hline o. & 2. & 10. & o. & I. & 8. \\
\hline 0. & 2. & 4. & 0. & I. & \\
\hline o. & I. & 6. & o. & I. & \\
\hline o. & 2. & I. & o. & I. & Io. \\
\hline c. & o. & $3 \cdot$ & o. & o. & I \\
\hline o. & 2. & 4. & 0. & I. & \\
\hline o. & o. & s. & o. & 0. & \\
\hline O. & o. & $x_{5}^{1}$ & o. & 0. & \\
\hline ๑. & o. & $1 \frac{3}{4}$. & o. & o. & \\
\hline o. & o. & $I_{1}^{\frac{1}{3}}$. & o. & 0. & \\
\hline o. & $3 \cdot$ & 8. & o. & 2. & 3 \\
\hline
\end{tabular}




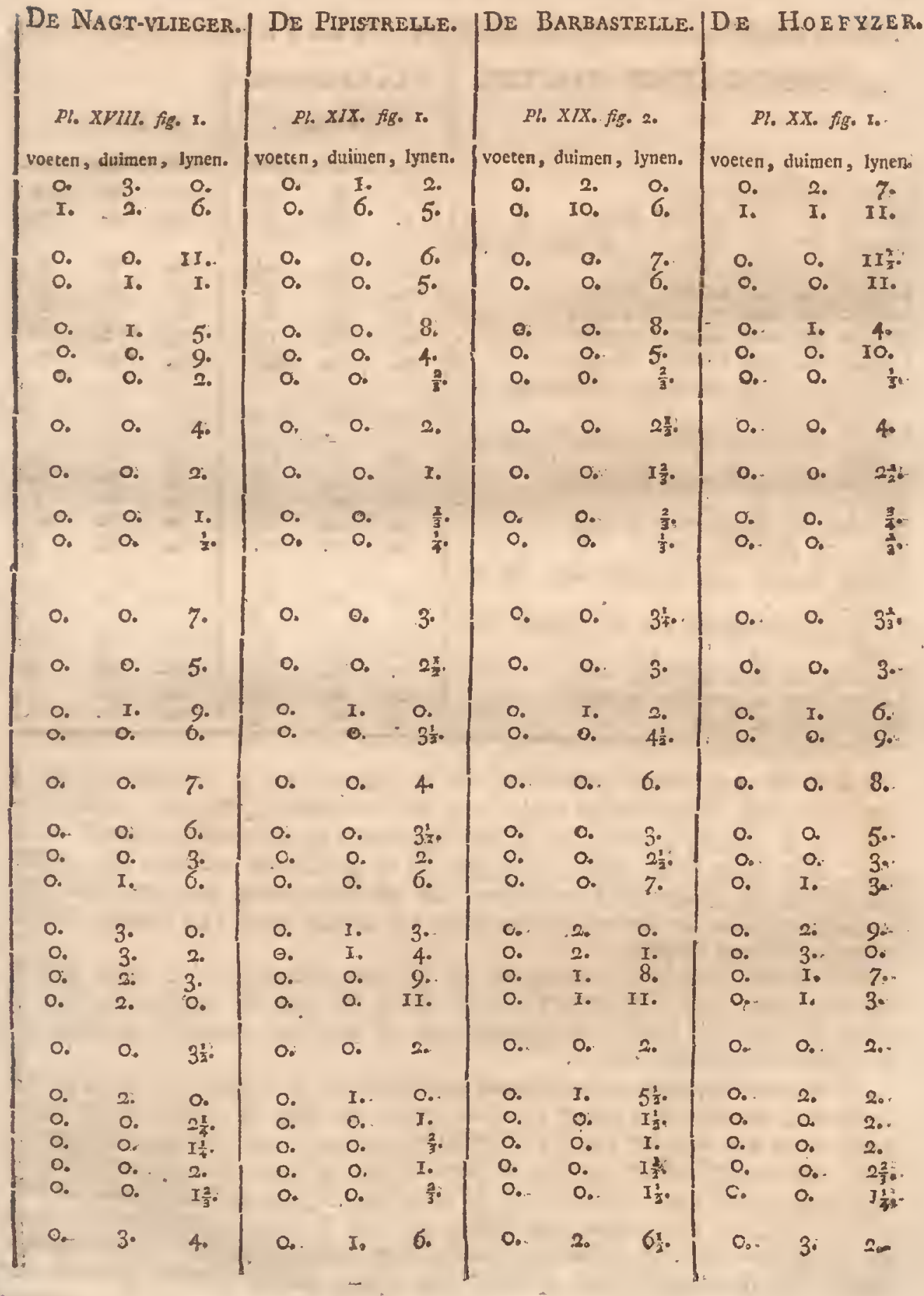




\begin{tabular}{|c|c|c|}
\hline & & \\
\hline VAN VERSCHILLENDE SOORTEN. & VIEDERMUIS. & \\
\hline & vocten, duimen, lynen. & \\
\hline engte van den vleugel & o. $7 . \quad 0$. & 0.4 \\
\hline $\begin{array}{l}\text { te plaats } \\
\text { der voorfte voeten }\end{array}$ & $\therefore$. & o. \\
\hline rels & o. $\quad 0$. & 0. \\
\hline engte van & -0. & Oa \\
\hline angte van den & 0. & 0. \\
\hline te van den derden vinger & o. & o. \\
\hline Lengte van den vierden vinger a de & 10. & o. \\
\hline van de knie tot an de & o. $\quad 0$. & $\mathbf{r}_{2}^{\prime}$. \\
\hline & $I I_{\frac{3}{3}}^{2}$. & o. \\
\hline reedte van liet bovenft des beens : & $I \frac{3}{4}$. & . \\
\hline kte ${ }^{\circ}$ vhat $c^{\circ}$ van de hiel & $\begin{array}{l}I_{4}^{\frac{1}{4}} \\
I_{0}\end{array}$ & $\begin{array}{l}0 . \\
0 .\end{array}$ \\
\hline $\begin{array}{l}\text { c op dezelfde plaats } \\
\text { tte van de hicl aan het eind } \dot{d} \text { der na- }\end{array}$ & 0. & 0. \\
\hline vingeren van de agtcrite voe & o. $\quad$ o. & o. \\
\hline & o. & o. \\
\hline & o. & 0. \\
\hline an & $1 \frac{7}{3}$. & $1 \frac{3}{4}$. \\
\hline edte an de bafis & & o. $\quad 0$. \\
\hline
\end{tabular}

Ik.heb de nagt-vlieger gekoozen, om de befchryving te maken en de afmeetingen van de inwendige deelen der vledermuizen te neemen, omdat van alien dic ik dikwils genoeg, en in genoegzaamen getale, hebbe kunnen bekomen, deze foort de grootite, en bygevolg de gefchilkfe was om ten onderwerpe voor de befchryving te dienen : het mannetje woog een once en vieren-twintig grein, en het wyfje een once en veertig grein; zy badden beiden veertien duimen vlugts.

Het net was tufiches de mag en de darmen verborgen: de lever ftrekte zig cven verre, en zelfs verder aan de linker als an de regterzyde uit; de maag was aan den linkerkant geplaatif, en de milt hadt dezelfde platating als in andere viervoetige dieren.

De darmen muakten cenige groote wendingen in de regterzyde $\mathrm{cn}$ in de 11:velftreck, en zy waren gerigt op eene wyze, dat men de declen van de darmbuis, waar aan men den naam van twalifvingerigen, van nugterendarm geef, $\mathrm{cnz}$, niet onderlcheiden konde, te meer ondat 'er geen blindecharm was; de darmbuis ftrekte zig, zo als zy uit de mang kwam, van de linker naar de regterzyde uit, en zy mankte twee flagen van een krullyn, vervolgens vouwde zy zig weder over, en makte nogmaals twee krullyn flagen in tegenftrydige rigting met de vorige, mal op zulk eene wyze, dat dit tweede gedeelte der 
$$
1
$$ 


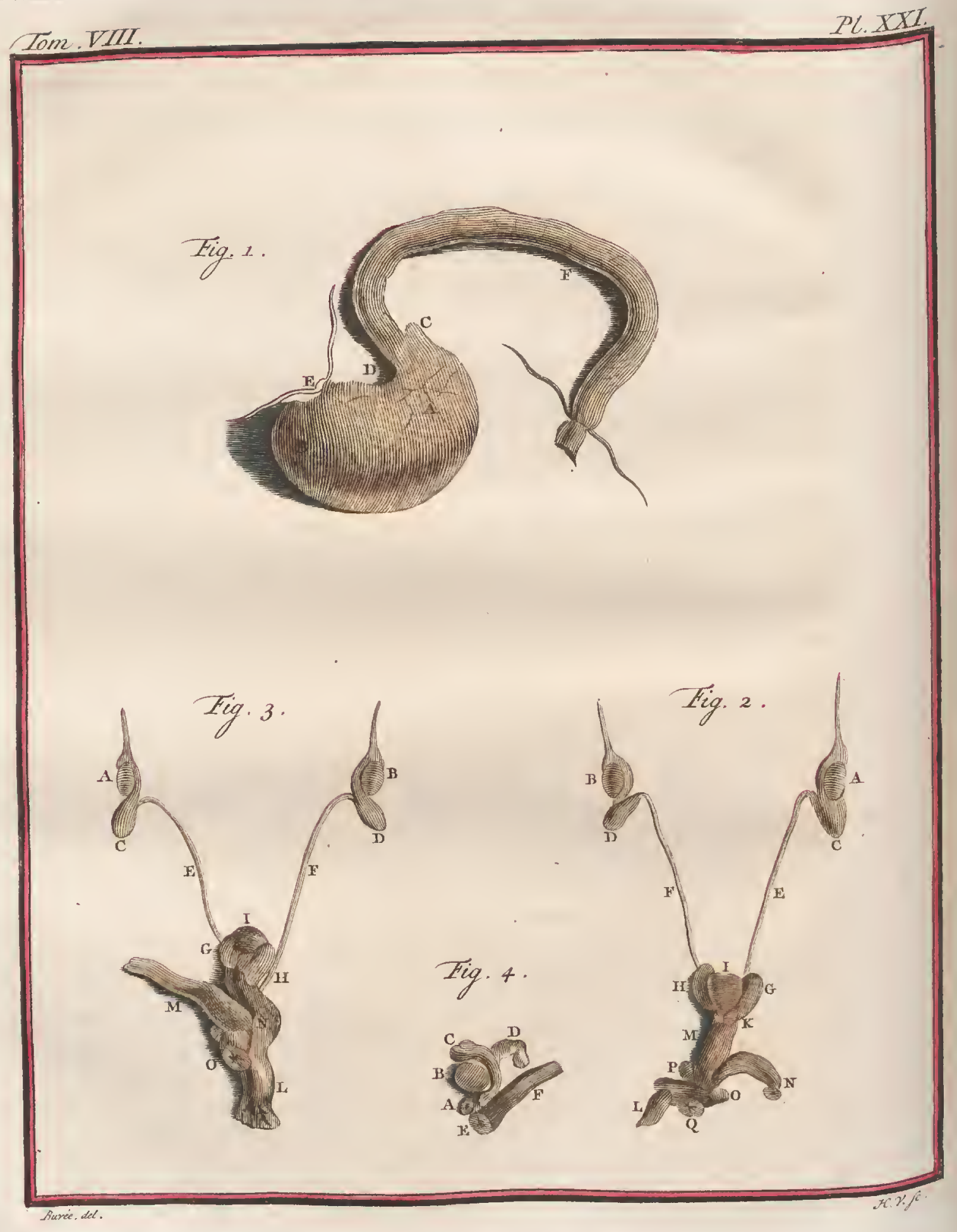




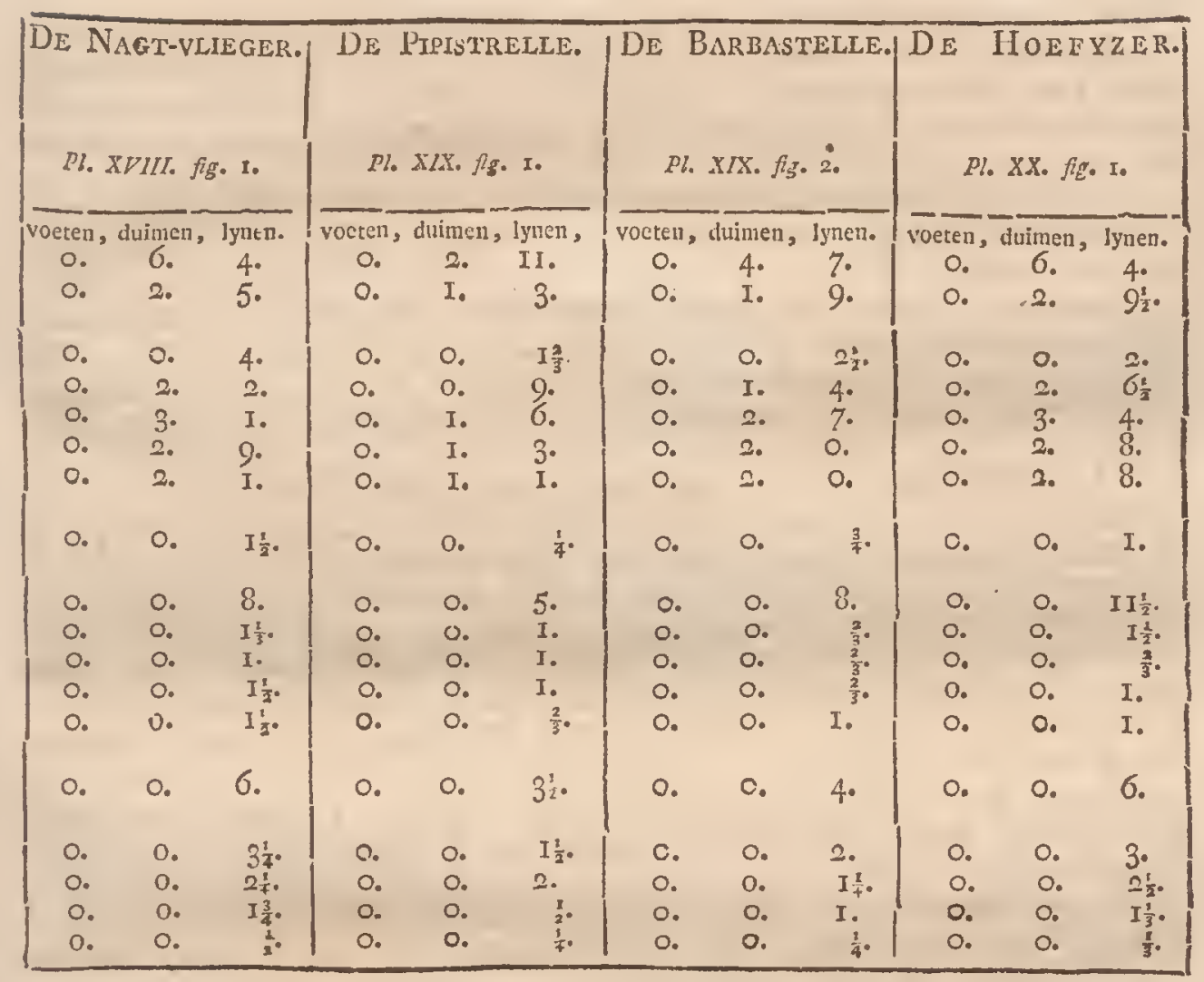

darmbuis zig langs de lenden-wervelbeenderen verlengde en op den aars uitliep.

Daar was aan weerskanten van den regtendarm by den aars, eene eyronde klicr, welker grootfte middellyn een en een halve lyn lang was.

Het regter gecleclte $(A, f i g . I, P l . X X I)$ van de mang was zeer groot naar cvemreclighcid van het linker gedcelte $(B)$; het regter gedcelte was egter weinig verlengd buiten den"hock, dien het makte; daar was cene zwelling $(C)$ by den portier $(D)$ : men ziet in deze zclfde figutur een gedeclte $(E)$ van den flokdarm en het begin $(F)$ van de darmbuis: die buis vermindert allengs in dikte van de mang af tot ann den aars: hatre rokken waren zo dik, dat meg dezclve byna niet konle uitzetten met "cr lugt in te blazen.

De lever hadt gecn draggband; zy beftondt uit drie kwabben, de grootfte bevondt zig gedeeltclyk ter linkerzyde, en gejeeltelyk agter het midden van het middelrif; ; de tweede kwai was kluiner dan de eurfte, en door cene drepe fplyting in twee declen verdeeld, wanr uit het galblaasje te voorfillyn kwan; het linker gedeclte was gehecl an de regterzyde, en het ander gedeelte was byra gehecl tuffehen het midden van het middelrife en het regter gedeelte van de eerite kwab; de derde kwab was de klcintte van allen, zy I'III. Deel. 


\section{DE NATUURLYKE HIS TORIE,}

was vaft aan den wortel van de lever, en ftekte zig tuffchen de bovenfte dee- len der twee andere kwabben uit: de lever hadt eene roodagtige kleur, $2 y$ woog vier en-twintig en een half grein; het galblasje was rond, cn het bevattede een geclagtig vogt, met een ligt kleuriel van groen, dat omtrent een half grein woog.

De milt was langagtig en kantzuilig, gelyk in de meefte andere dieren; zy hadt eene roode kleur, zeer donker van buiten en van binnen; zy woog wat meer dan twee greinen.

De regter nier fprong wat meer voorwaards dan de linker; $z y$ hadden cene onregelmatige gedaante en lagen weinig diep; het bekken was groot, daar was een tepel, die zig meer vertoonde dan de andere, en die van ee. ne geelagtige kleur was; de verfchillende zelffandigheden waren zeer onder-. fcheiden.

De regter long en de linker long waren niet verdeeld in verfcheiden kwab. ben gelyk in de meefte andere dieren; daar waren alleenlyk uitfrydingen in de linker long, zonder eenige klieving; mar daar waren twee klievingen.in. de regter long, die eventvel niet diep genoeg waren om 'er drie kwabben van te makken toen de longen opgeblaazen waren.

De.tong was zeer dik; het voorfte gedeelte fcheen glad voor 't oog, mar men zag met een ligt-vergrootglas daar op kleine knobbeltjes als op fegry11; het agterft gedeelte fchecin dubbeld te zyn en eene klcine tong te hebben, die op de groote geplakt was; men bemerkte danrop kleine tepeltjes op den \%oom, dic deze verhevenheid makte: daar waren in 't midden twee kleine kelk-klieren, naaft malkanderen geplaatft, en de vertooning van eene overlingfche voor.

Het verhemelte was met zes, vooren doorfneeden, waarvan de randen in 't midden afgebrooken waren, mat uitzondering van den vooriten rand van de cerfte voor; zy waren alle wat bolrond van voren: de ftrocklap fprong zo weinig voortuit, dat men denzelven niet onderfcheidde, ten zy men zesr nautwkeurig toezag; hy was puntig aan.'t einde.

De agterherfenen, waren byna zo groot als de voorherfenen; men zag daa. cen dik knobseljje in 't midden, dwarfeh getand, en van andere kleinere snobbeitjes, op de zyden en van voren omringd: daar waren gecne bogtigheden in de kiwabben van de voorherfenen; zy woogen dric en een haif. grein, en de agterherfunen twee grein en een vierde.

Daar waren mar twee tepelijes op de borlt; aan wecrskanten é́n.

De zazdballen ( $A$ B fig. 2 en $3 P \%$. XXl) waren an weerszyden van den ars geplant: en de knobbeljes ( $C$ D) van den opperbal aan weerskanten. van het begin des ftarts; die lnobbeitjes hadden mear dikte dan de zadbalien, zodat men, het dicr. van burten aaprakende, dezelve voor zaadballen jam: de afiorende vaten ( $l i j$ ) maikten over let groofte gedeelic hunIfor lengte, ktohe bogtigheden en $z y$ liepen in het agrerft gedeulte van de: buitenzyde der zadblaasjes $(G H)$; die zaadblasjes waren langagrig en vry, dik naar evenredigheid van her lighaam des dicrs; de hals van de blaas ( $I$ ) was ouningl van een wrong, $(K$, fig. 2$)$. van ecna vufte zeltítndigheid, 
die my voorkwam de voorftanders te makken; de pisbuis was van het een einde tot het ander van een vry dikke fpier omringd.

De roede was niet vaft an den onderbuik, gelyk in cle meefte viervoetige dieren; zy was geheel uitfpringende tot an het fchambeen, gelyk als in den menfch; met het vel bekleed zynde en in de voorhuid eindigende was zy vier lynen lang van her fchaambeen af tot aan de voorhuid, die een punt maakte; zy hadt evenwel omtrent vier lynen omtrek in 't midden der lengte van het hoofdje (L) 't welk zeer dun was, en geleek naar eene fpeld of een doomtje, met een zeer dikken kop; want dit hoofdje $(K, f i g .3)$ was dik aan de bafis, zecr klein in al het overige van deszelfs lengte, puntig aan het einde, vaft en fteckend, omdat het door een been geformeerd wierdt: men zict in de gemelde figuturen die de natuurlyke grootte der deelen vertoonen, de roede ( $M$, fig. $2, L, f_{i g} .3$ ) den regtendarm $(N$, fig. 2 en $M, f i g .3)$ de klieren $(O P$, fig. 2 en $N$, fig. 3 ) die ter zyde van den aars zyn, en den aars $(Q$.
fig. 2,0 fig. 3$)$.

De klink $(A, f i g .4, P l . X X I)$ was rond; daar waren eenige vertooningen van een kittelanr by de randen, op eenc lyn afftands van de pisbuis: de blaas (B) geleek ten naatenby nar die van het mannetje; de randen van de opening der lyfinoeder fprongen in de fchede uit; de hoornen $(C D)$ hadden weinig lengte; zy raakten aan de zaadballen: men ziet in dezelfde figuur, die de natuurlyke grootte vertoont, den aars $(E)$ en den regtendarm $(F)$.

Lengte van de darmbuis van clen portier tot aan den ars $\quad$ duimen, lyncu.

Omtrek op de dilifte plasten

Omtrek op de dunfte plaatfen

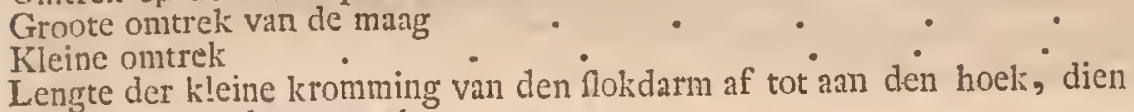

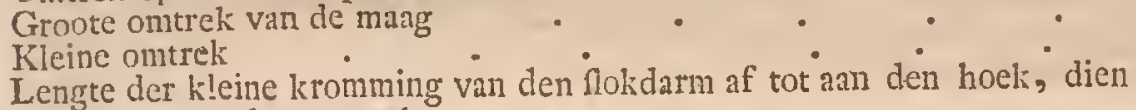

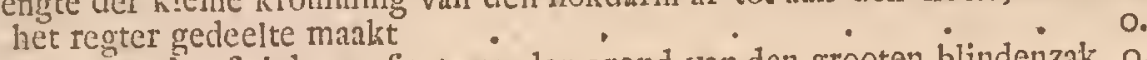

I,cngte van den nokdarm af tot aan den grond van den grooten blindenzak. 0 .

Omtrek van den flokdarm
Omtrek van den portier

Lengte vail de lever

Breedte

Hare grootite dikte

Lengte van het galblaasje

Zy'n grootite omtrek

Lengte van de milt

Breedte van het onderft einde

Breedte van het bovenft einde

Dikte in ' $t$ midden

Lengte der nieren

Breedte

Dilite

Breedre
Breedte van het vleezig gedeclte tufichen-het zenuwagtig middelpunt en liet borftbeen

$$
\text { L } 2
$$

7.0.

0. $4 \frac{1}{2}$.

o. $2 \frac{1}{2}$.

I. Io

r. 6 .

o. $42^{2}$

O. $\quad I_{2}^{2}$.

o. 3 .

o. 9.2

o. II.

o. 2.

o. 2.

o. $I_{2}$.

o. 9 .

0. 2.

o. I $\frac{1}{2}$.

O. I.

o. 4.

o. $\quad 2_{2}^{x}$

c. 2 .

2.

o. I票. 
Breedte van ydere zyde van 't zenuwagtig middelpunt $\quad . \quad . \quad . \quad 0.030^{\circ}$
Omtrek van de bafis van 't hart

Hoogte van de punt af tot aan het begin van de longfiagader :

Hoogte van de punt af tot aan den longenzak

Middellyn van de groote flagader van buiten man buiten $\cdot c_{0}$

Lengte van de tong

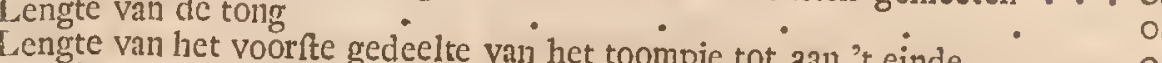

Breedte van de tong

Lengte der voorherffenen

Breedte

Dikte

T.engte der agterherffenen

Breedte

Dikte

Afftand tuffehen den anrs en de opening van de voorhuid
Afitand tuffchen de randen van de voorhuid en het einde van het hoofdje.

I,engte van het hoofdje

Omtrek

Lengte van de roede, van de fplitzing der fponsagtige lighamen af, tot aan de inplanting van de voorhuid

Omtrek

Lengte der zaadballen

Breedte

Dikte

Breedte van den opperbal

Dikte

J.engte der aanvoerende vaaten

Groote omtrek van de blaas

Kleine omtrek

Lengte van de pisbuis

l.engte der zaadblaasjes

Breedte

Dikte

Afitand tuffchen den aars en de klink

Ontrek van de klink

Iengte van de fohede

Ointrek

Groote omtrek van de blaas

Kleine omtrek

I.engte van de pisbuis

Omtrek

Jengte van den hals en het ligham van de lyfmoeder

Omtrek

1.engte der hoornen van de lyfinoeder

Ontrek op de dikfte plattien

Omtrek aan "t einde v'an yderen hoorn

l.engte van de kromme lyn die de tronpet doorloopt

Lengte der zaadball th

Jireeste

Dikte 
Daar was boven het agterhoofd des kops van het geraamte van dc vledermuis een punt, geformecrd door den famenloop van drie sanden, warvan de eene zig uitftrckte op de kruin van 't-hoofd, $c n$ de andere op de zyden van het agterhoofdsbeen: de oogputten cindigden van voren in het julibecn; $z y$ makten flegts een klein gedeelte uit van eene groote opening, van buiten geflooten door den boog, dien de uitfteekzcls van het jukbeen en van het flaapbeen door hunne vereeniging maakten: de eigenlyke neusbeenderen ftrekten zig veel minder voorwaards uit dan het bovent kaakbeen, dat ook minder vitfprong dan het onderft.

De tanden waren ten getale van agt-en dertig, agttien in het bovenft kaakbcen, en twintig in het onderft: daar waren zes fnytanden in het onderft kaakbeen, die brced en ten naaftenby aan malkanderen gelyk waren, en flegts vier in het bovenft, aan wecrszyden twee: de twee eerfte ftonden ontrent eene lyn van malkanderen af; die vicr tanden eindigden in een punt; de fnytanden van het onderft kaakbeen waren als in twee kivabben verdeeld, die hen de gedaante van een hart gaven: yder kaakbeen hadt twee hondstanden; die van boven waren langer dan de onderfte, en agter geplaatit, wanneer de mond gellooten was: de boven baktanden waren ten getale van zes aan weerskanten; de eerfte hadt flegts eene punt, de tweede was zo klein, cn vertoonde zig zo weinig, dat men hem nauwelyks bemerkte, en dat hy een ydel boven zig liet tuffehen den certen en den derden tand: die latete was zeer breed aan de bafis, en hadt een lange punt, op zyn voorfte gedeelte geplantft; de drie andere tanden hadden elk verfcheiden punten: daar waren aan weerskanten van het onderft kaakbeen zes tanden verder dan de hondstanden; de drie eerften hadden mar én punt; de derde was lunger dan de eerfte en de tweede; de drie laatfen hadden verfcheiden punten, mar zy waren minder breed dan de boventte; ook vielen du\%, wanneer de mond geflooten was, van buiten orer de onderite tanden heen.

Het doornagtig uitfeekzel van het tweedc nck-wervelbeen was breed en verheven; men zag "er niets van op de vyf eerfe wervelbecnderen : daar waren elf rug-wervelbeenderen cn elf ribben, zes ware cu ryf valfche; de doornagtige nititeckzels der cerfe en der Iathe wervelbednderen waren duidelyk, de andere vervelbeenderen hadden 'er geen; het borttbecin beftonde flegts uit twee becnderen; het eerite was het mintt ling marar het brectit; het hindt twee lange en breede takken, dic zig fchuintch van buiten en van voren vitftrekten, en die \%ig met de lleutelbeenderen en de cerfte ribbe ann weerskanten ge!edigden: de geleding der tweede ribben was tiffichen het cerfee en tweede been vin her bortivecn; dx de:te, vierte, vycte, cn zesde, ribhen geledigden zig met het mildelfte gredeclte van het twec.se been, 't welk zig nog twee lynen verder dan de zesde ribben uitirelse, en dat aan zyn agterit cinte breeder was dan an 't overige zyner uirgettrektheid.

Daar waren llegts vyf lenden wervelbeenderen; lume niflteeky ls waran zeer kolt; het heiligbeen ficheen te buftan wit vier valiche wewelbecnderen, en daar waren 'w in den ftart mar tien, wasr van het lateft de minfte, cn het zesde da meefte, lengte hadt; liet voorite gedeeite van lact heupbesn wis L 3 
driehoekig; de fchambeenderen hadden cen zeer blykbaar nitfteekzel op de randen van het bekken onder de knobbelwyze holligheid; die beenderen raakten malkanderen, om zo te fprecken, negts in éen punt.

Het fchouderblad ( $P l . X X I l \wedge A$, fig. I ) van het geraamte van de nagtvlieger, in zyne natuurlyke grootte op de vier beenen gezien, ( cn in fig. 2 , van hetzelfde geraamte, in 't klein en met de becnen uitgefpreid gezien) was groot en van cene zouderlinge gedaante, het hadt veel meer breedte dan longte; het maakte in zekcren zin cen lang vierkant, welks groote zyden ( $B C$, fig. I ) byna gelykwydig waren met de wervelbeen.kolom: de doorn (D) was weinig verheven en begon ten naftenby in 't midden van de voorfte helft van de groote boven-zyde, welke men als de bafis van het 1chonderblad kan bclchouwen; dic doorn ftrekte zig fchuinfch en omlaag uit tot den onderften en voorften hoek van het vierkant: het grootft gedeelte $(A)$ van dit vierkant was dan agter den doorn; dit gedeelte hadt verfchillende vlakten, het was bolrond aan zyne buitenzyde by den kleinen agterften kant $(E)$ van het vierkant, en het hadt by den doorn eene holrondte, geformeerd door eene voor, die met het eene einde tritliep op den rand van de panswyze holligheid, en met het ander einde op de bafis van het fchouderblad, ten naaftenby op een gelykc1 aftand van den doorn cn van den boventten en agterften lioek van 't vierkant: dit vicrkant was nict regelmaatig, want het hadt drie ftompe en geronde hecken, en fchoon de vierde $(F)$, alwar de geleding van den arm plaats hadt, niet ftomp wis, zo was dezelve egter niet minder onregelmaatig; de bimenzyde van het fchouderblad hadt holronde en bolronde kromningen, die ån de bolronde en holronde krommingen van de buitenzyde beantwoordden: de doorn was los van het lighaan des beens by den rand van de panswyze holligheid, en makte een tak, die bolrond was van voren, en in cen fchouderbeenshoold uitliep: het fchouderblad hadt ecn ravenbcks-uit1teek7.cl, dat zecr lang ell weinig krom was.

De fleutelbenderen ( $G G$, fig. I, en $B$, fig. 2) warcu lang breed en van voren over humne lengte bolrond.

Het ambeen (H, fig. I, C C , fig. $n, P l$. XXII en A, fig. I, pl. XXIII warin de beentjes van den wootfen linker poot met den voet eens zo groot als natumilyk vertuond worden) was lang, ten naafenby regt, en over het grootl gedeelte zyner lengte rolrond; dan was cenc beenagtige kam in 't lang voortoopcude, op de onderfte zycie van het voorfte gedecltc, en eene knobbelagtigheid aan weerskanten van het hoofd, dat geen hals hadt.

Daar was maar één been ( $I I$, fig. I, $D D$, fig. 2 , Pl. XXIl cn $B$, fig. $I ., P l . X X I I l)$ in den voonarm; het is my uit deszelfs platting, en uit deszelfs geledingren met het armbeen en niet de voorhand, voorgekomen, dat het aan het tralbeen van andere diercin beantwoordde: dit been was zeer lang, byna rolrond over zyne geheale uitgeltrektheit, en wcinig bolrond oin hoog an zyn middelite agterf gedeclte.

Het dijcbeen $(K$, fig. I, $E L$, fig. $2, P l . X X I I$ en $A$, fig. $2, P l . X X I I I$ wiain de beendereil van het agterft linkerbeen en den voet cens zo groot als 3ntuuriyk vertoond worden) was kort, regt, en byna rolrond over zyne ge heele nitgeltrektheid, uitgezonderd aan de beide cinden. 


$$
\text { Fig. } 2 .
$$

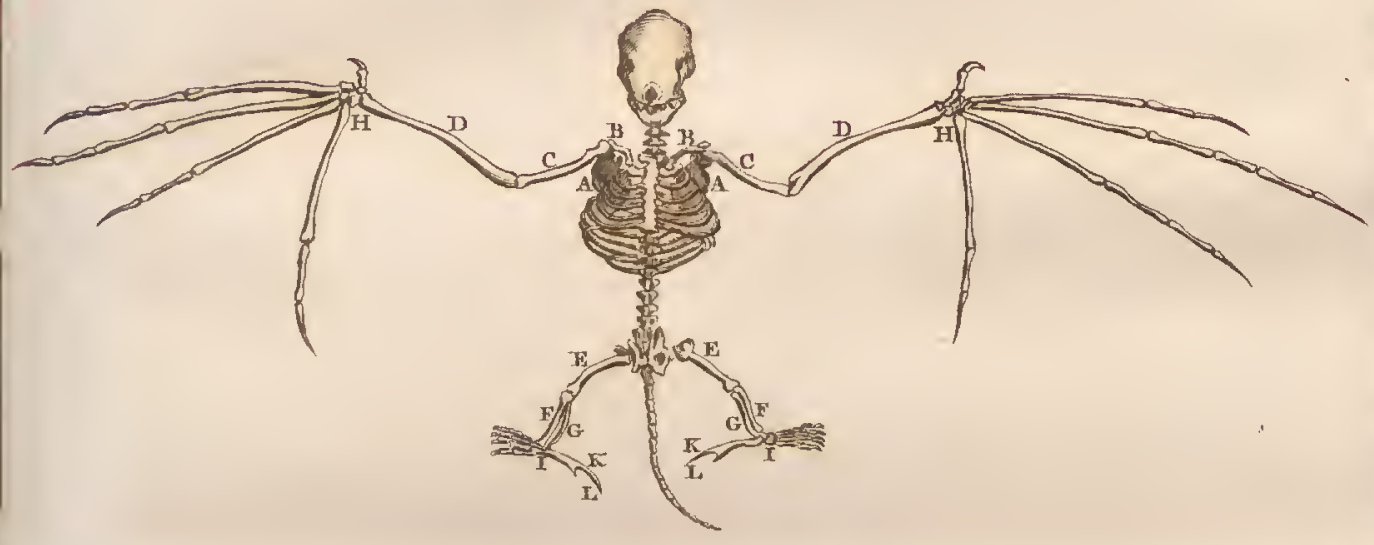

$$
\text { Fig. I. }
$$

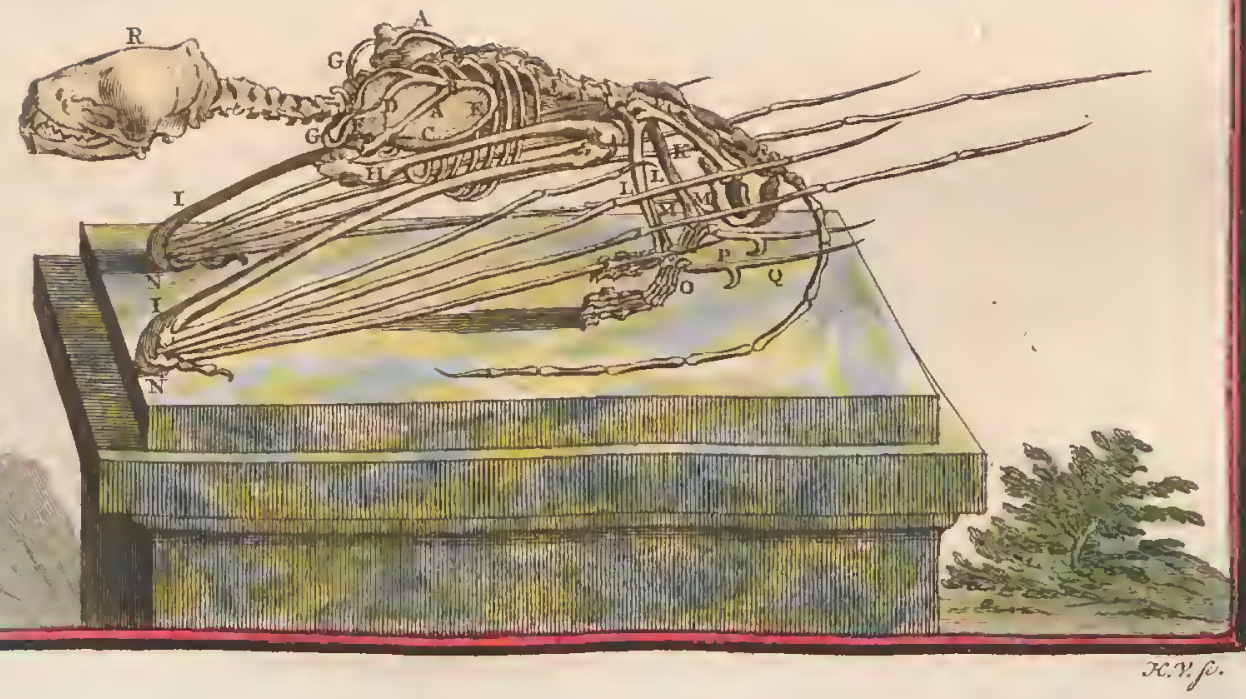




Tom VIII.

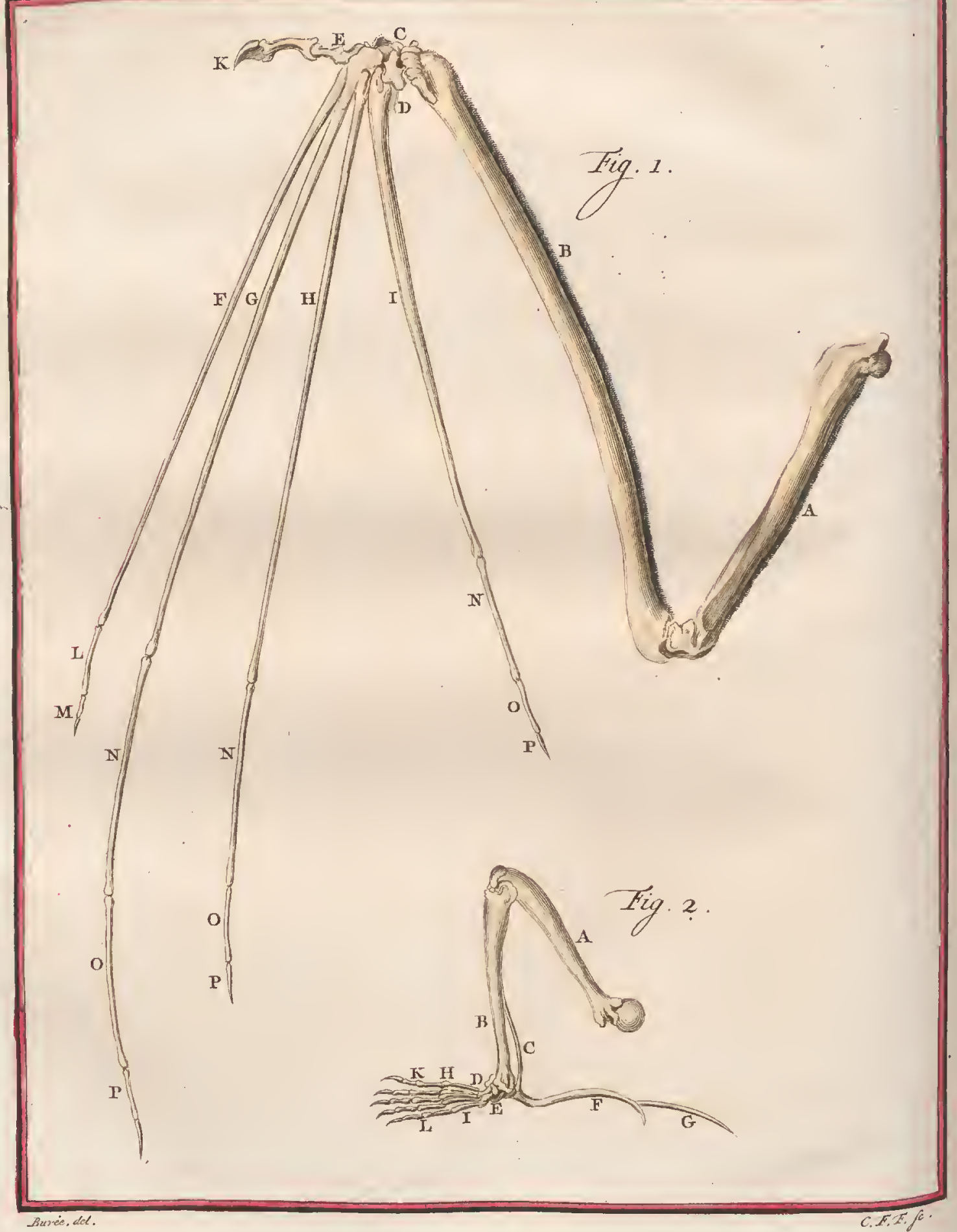


Het fcheenbeen $(L L, f i g . I, F, F, f i g .2, P l . X X I I$ en $B, f i g .2, P l$. $X X 1 I I)$ was langer dan het dijebeen, regt, en byna rolrond in zyne geheele lengte, met uitzondering der beide einden.

Het kuitbeen (MI M, fig. I, G G, fig. $2, P$. XXIl en $C$, fig. 2, Pl. XXIII) was zo dun als een zeer fyne draad; het hadt evenwel wat meer middellyns aan zyn onderft dan aan zyn bovenft gedeelte.

lk heb maar drie beentjes in de eerfte ry van de vocrhand $(N N$, fig. I, $H \mathrm{H}$, fig. $2, \mathrm{Pl}$. XXII en C D, fig. $\mathrm{I}, \mathrm{Pl}$. XXIII) gezien; én groot, dat voor het been van den voorarm geplaatit, en fchuinfeh gefehikt was van boven naar beneden, en van buiten nar binnen, en een klein aan weerszyde van het groot: darar waren in de tweede ry vier beentjes, ten maaftenby van dezelfde grootte; de drie eerfte waren elk voor een van de drie eerfte beenderen van de agterhand; het vierde beentje van de tweede ry van. de voorhand was gedeeltelyk voor het vierde beentje van de agterhand, en gecleeltelyk voor het vyfde.

De voorvoet $(O, f i g .1, I I, f i g .2, P l . X X I I$ en $D E$, fig. $2, P l . X X I I I)$ beftondt uit zeven beentjes gelyk de voorvoet van den mentch; daar was daarenboven een lang en kron been $(P, f g$. I, $K K$, fig. : , $P$ l. XXIl en $F$, fig. $2, P l . X X I I I)$ t welk aan het agterft gedeelte van het hielbeen vaft was, en een ander ten naaftenby van dezelfde lengte en dezelfde gedaante, $(Q, f i g$. I $L L, f i g .2, P ! . X X I I$, en $G$, fig. $2, P l . X X I ! I)$ 't welk ant het ecrite by. deszelfs agterft einde vaft was.

Van vyf beenderen van de agterhand was het cerfe $(F, f i g .1, \eta \% . X X I I)$ alleen geëvenzedigd aaı de grootte van het dier; de vier andere ( $F G H I$ ) waren uitermaaten lang: het derde $(G)$ en het vierde $(H)$ hadden ten matten. by ecne gelyke lengte, en zy waren langer dan het tweede $(F)$ en het vyfde (l) die alle beiden even lang waren.

De duim hadt zyne twce regels en een nagel $(K)$, die wel geformeerd was; ik heb flegts twee regels $(L M)$ in cen eeriten vinger gezien, maar de drie anderen hadden elk drie regels. $(N O P)$; de vier vingers hadden geen nagels, het einde van humnen laatien regel verdween in het weefzel van het vlics der vleugelen.

De beenties van den agtervoet $(H I, f i g .2, P l . X X I I I)$ en der vingeren $(K L)$ van de agterfte voeten, waren van eene grootte evenredig' met die van het dier, en yder vinger hadt een wél geformeerden nagel, mar die minder dik en wat langer was dan die van den duim der voorste voeten.

Het bekkeneel van den kop van den groot-00r hadt geene beenige grnaten 2 : de tanden van het bovenft kakbeen waren ten getale van 7eflien; te weeten twee fnytanden aan weersyde, een hondstand. on vyl baktanden; de eerfte finytand hadt twee punten, en de tand, die zig agter den hondstand bevondt, was zeer lilein: dar waren in het onderit kakbeen twinig tanden, gelyk in de vledernuis, 'c welk in alles 'zes.en dertig tanden makte; de zes fintanden van dit kakbeen liadden elk mar twee of drie kwabben; het heiligbeen beftondt uit vier valfche wervelbeenderen, en de ftaart uit negen.

Het hould des geramtes van de.nagt-viliegers, (fig. I, P..XXI1) was veel 
minder lang dan dat van de vledermuls; de kruin $(R)$ van den kop was wat holrond in plats van bolrond te $2 y_{11}$; de bek hadt veel meer breedte dan lengtc: de opening der neusgaten was, naar evenredigheid, zo breed als de bek, en bygevolg waren de twee eerfe finytanden van het bovenft kaakbeen meer van malkanderen verwyderd dan by de genneene vledermuis; hetcerte dezer tanden en de vier hondstanden waren ook veel grooter en dikker, en de zes onderfte finytanden waren in dric of vier kwabben verdecld, en om zo te fpreeken gefeftomeerd of gekranfd; dewyl de beide kaakbeenen korter warcn dan by de gemeene vledermus, waren 'erook minder baktanden van boven en beneden; daar waren 'er maar vicr' aan weerszyde van het bovenft kaakben, en vyf aan ydere zyde van het ondert; ik heb geen klcinen tand agter de bovenfte hondstanden gezien, gelyk in de gemeene vledermuis, en ik hej maar twee kleine tanden met cen cnkcle punt geteld tuffehen de onderfte hondstanden en de drie gronte baktanden: dus hadt de nagt-vlieger ntaar tree-cndertig tanden, veertien in het bovenft kaakbeen, en agetien in het onderft; daar waren vier valfche wervelbeenderen in het heiligbeen en tien in den ftaatt.

De ferotine liadt aan weêrskinten van het bovenlt kaakbeen twee finytanden, een hondstand, en vier baktanden; de eerlte der finytanden was breed aan 't einde, mar" de tweede was puntig en zeer klein; de finytanden van het onderft kakbeen waren ten getale van zes, en daar bevonden zig aan weerszyde een hondstand en vyf baktanden, het welk in alles twee-en-dertig maakt: fchoon die van de nagt vilieger ten zelfden getale zyn, zo verfchillen cvenwcl de tanden van de fcrotine van dezelve in de gedaante van den eerfen fnytand aan wecrskanten van het bovenf kakbeen, dic aan het einde breed is in dit dier en puntig in de magt vlieger.

Het bovent kikkbeen van de pipiftelle hadt aan weerzyden twee puntige finytanden, warvan de eerfte de langfte was, een lionistand en vyf baktan. den, waarvan de cerfte maar één punt hadt; de finytanden van het onderit kaakbeen waren ten getale van zes, die elk drie of vicr kwabben hadden; daar was vervolgens aan weerszyde cen liondstand en vyf baktanden, warvan de ecrfte en de tweede mari én punt hadden, en de tweede langer was dan de ecrite; het heiligbeen hadt vier valfhe wervelbeenderen cn de fiart agt.

Het hoofd van liet geranute van de hoefyzer hadt can becnagtige graat, die dun en feherp was en zig van het voorhoofd tot het agterhoofd uitftekte; en ecn minder verheven en dwarfiche grat op het agterhoofdsbeen: de bek was zeer breed, de opening der neusgaten hadr veel uitgelerelitheid, cn de eigenlyke newseenderen waren rond en formecrden eene ditke boliondte bovende opening der neusgaten : daar waren gene firytanden in het bovent kaakbeen; daar waren an weerszyde cen honlstand en vier baktanden, warvan de cerfte twee punten hadt, de twee andere hadden "er drie: danr waren in her onderít kankbesn mar vier finytanden, die elk drie kwabben makten, cen hondstand aan weerszyde, die minder dik was dan de bovenfte, en vyf baktanden; de eerfte was de kleinfte, hy hadt maar één punt. 
Lengte van het hoofd van het einde des onderfen kaakheens tot aan 't

duimen, lynen:

De agterhoof

De grootite breedte van 't hoofd
Lengte van het onderft kaakbeen tot aan den agterften rand van het knokkelwyze uitfteekzel

Breedte van het onderft kaakbeen ter plaatfe der fnytanden

Breedte van het bovent kaakbeen ter plaatfe der fnytanden

Afrtand tuffchen de oogputten en de opening der neusgaten

Breedte van deze opening

Lengte der langfte hondstanden buiten het been

Lengte der bafis van het tongbeen -

Lengte der hoornen

Lengte van den hals

Lengte van het gat des ceriten wervelbeens wan boven naar beneden.

Lengte van de eene zyde naar de andere

Lengte van het gedeelte van de wervelbeens-kolom, die uit de rugrvervelbeenderen beftat

Lengte der eerfe ribben
Afftand tuffchen de eerfte ribben an de breedfte plaat

Lengte van de zesde, die de langfte is

Lengte van de laatfe der valfche ribben

Lengte van het borftbeen

Lengte van het laatfte beentje dat het langft is

Breedte van het eerite beentje dat het breedit is

Lengte van het lighaam des vyfden lenden-wervelbeens, dat het langft is. 0 .

Lengte van het heiligbeen

Breedte van het voorfte gedeelte

Breedte van het agterfte gedeelte
Lengte van het zevende valfche wervelbeen des ftaarts; dat het lang-

fte is

Lengte der eyroinde gaten

Breedte derzelver

Breedte van het belken

Lengte van het fchouderblad

Breedte

Lengte der fleutelbeenderen

Lengte van het fchouderbeen

Lengte vas het voorarm-been

Lengte van het dijebeen

Lengte der kniefchyven

I.engte van het fcheenbeen

Lengte van het kuitbecn

Iloogte van de voorhand

Lengte van het hielbeen

Hoogte van het eerfte rviggebeen en van het fchipbeen te famengenomen.

I.engte van het eerfte beentje van de agterhand

I.engte van het tweede

I-engte van het derde

Lengte van het vierde

Lengte van het vyfde

Lengte van het vierde beentje des agtervoets VIII. Deel o. $I I I^{\circ}$

o. $6 \frac{6}{2}$.

0.

o. $\quad I \frac{\pi}{3}$.

c. 2.

o. 3 .

If

o. It:

o. 3.

o. 3.

5

o. It.

०. 9.

o. 3

o. 4 .

o. 3.

o. 7.

o. 5 .

o. $5 \frac{2}{3}$.

o. 4t.

o. I $I_{2}^{1}$.

o. II

o. 4.

o. 2

o. 2

o. 8.

o. $3 \frac{2}{3}$.

o. 7 .

I. 3 .

2. 3 .

O. 9.

o. IO 10

o. 9 .

o. I.

o.

O. II

2. 0 .

2. 2.

2. $\quad I_{2}^{x}$

2. 0 .

०. I I 
Lengte van den eerfen regel des duims van de voorfte voeten . duinen, lynen. Lengte van den tweeden

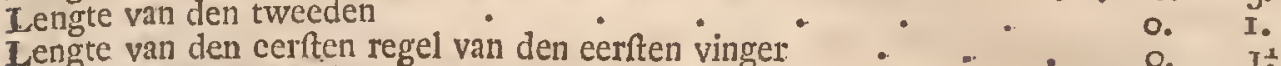
Lengte van den tweeden Lengte van den eerften regel van den tweeden vinger Lengte van den tweeden Lengte van den derden Lengte van den eerften regel van den derden vinger Lengte van den tweeden Lengte van den derdẹn Lengte van dell eerften regel van den vierden vinger Lengte van den tweeden Lengte van den derden Lengte van den eerften regel van den vierden vinger der agterfte voeten Lengte van den tweeden. Lengte van den derden

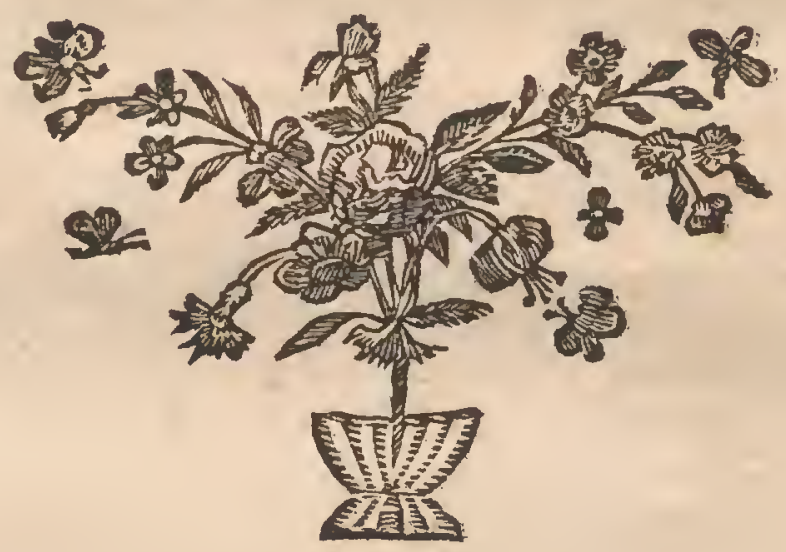


VAN DAT GEDEELTE VAN HET KABINET, HETWELK BETREKKING HEEFT TOT DE NATUURLYKE HISTORI:

DE R V L E D E R U I Z E N.

No. DCCLXXX. Een gemeene vledermuis.

No. DCCLXXXI. Een groot-oor.

No. DCCLXXXII. Een nngt-vlieger.

No. DCCLXXXIII. Een ferotine.

No. DCCLXXXIV. Een pipifrelle.

No. DC.CLXXXV. Een barbaficlle.

No. DCCLXXXVI. Eene groote en kleine boefyzer.

Deze agt dieren zyn in wyngeeft bewaard.

No. DCCLXXXVII. Het geraamte van een gemeene vledermuis.

Dit geraamte is twee duim en tien lynen lang, van het einde des onderften kaakbeens tot aan het agterfte einde der heupbeenderen; de omtrek van den kop, aan de dikfte plats genomen, is van een duim en vyf lynen.

No. DCCXXXVIIl. Het geraamte van een groot-oor.

De lengte van dit geraamte is van een duim en zeven lynen, van ' $c$ cinde des onderifen kaakbeens tot aan het agterfte einde der heupbeenderen; de omtrek van het hoofd, op de dikfte plaats gemeeten, is van een duim en eene lyn.

No. DCCLXXXIX. Het geraante van een nagt-vlieger.

Dit geraamte is twee duim agt lynen lang van het einde des onderften kaakbeens tot alun het agterfte einde der heupbeenderen; de omtrek van het hoofd is van een duim en zes lynen aan de dikfte plaats.

No. DCCXC. Het tungbeen van een nagt-vlieger.

Dit been beftat llegts uit éne bafis en twee hoornen, gelyk dat van de rot, van de muis, enz; maar de bafis heeft veel meer kromte, en heeft geene meerdere dikte dan de takken.

No. DCCXCl. Het roede-been ean een nagt-vlieger.

De lengte van dit been is van drie lynen; het onderft einde is zeer dun en puntig; het ander einde, dat aan de roede valt was, is veel dikker, het heeft een halve lyn middellyn.

No. DCCXCIl. Het geruamte van eene pipifrelle.

De lengte van dit geraamte is van een duim zeven lynen van het einde des onderften kaakbeens tot aan het agterfte einde der heupbeenderen; het hoofd heeft tien lynen omtreks aan de dikfte plaats gemeeten.

No. DCCXCIII. Het gernamte van eene hoefyzer.

Dit gerammte heeft twee duim vyf lynen lengte van het einde van het onderit kakbeen, tot aan het einde der heupbeenderen; de omtrek van het loofd is van cen duim vyf lynen, aan de dikite plaats genomen.

$$
\text { M } 2
$$



geheelen winter flaapen, namelyk de relmuis, de groote hazelmuls, en de kleine hazelmuis: de relmuis is de grootfte van de drie, de: kleine hazelmuis is de kleinfte: verfcheiden Auteuren hebben de eene dezer foorten met de twee andere verward, fchoon zy alle drie zeer onderfcheiden zyı, en men-dezelve gevolgelyk met weinige moeite herkennen cn uit malkanderen houden, kan; de relmuis heeft ten naftenb́y de grootte van een eekhoorn; zy heeft, even als deze, den' ftart met lang hair bedekt; de groote hazelmuis is niet zo groot als de rot, zy lieeft den ftaart met zeer kort: hair bedekt, met een pluim van lang hair nan 't einde; de kleine hazelmuis is. niet grooter dan de muis, haar ftaart is met langer hair bedekt dan die van. de groote hazelmuis, maar korter dan die van de relmuis, met een groote pluim lang hair ann't einde: de groote hazelmuis verfchilt ook van de' twee andere door de zwarte ftippen, die zy by de oogen heeft, en de kleine hazelmuis door de blonde kleur van haar hair op den rug: alle drie zyn zy wit of witagtig onder de keel en den buik; mar de groote hazelmuis is van eene fchoone witte, de relmuis llegts van eene witagtige, kleur, terwyl de kleine hazelmus eer geelagtig dan wit is in alle de onderfte deelen van het ligTraam: zie hier agter de drie figuuren en de befchryvingen.

Het is oneigenlyk uitgedrukt, dat deze dieren den geheelen winter flaapen; hunne itaat is niet die van een natuurlyken laap; het is eene verftyving, ee* ne verdooving der ledematen en zintuigen, en die verdooving wordt door. de verkouding van het bloed voortgebragt: deze dieren hebben zo weinig inwendige warmte, dat dezelve die van de lugt, warin zy leeven, weinig overtreft: wanneer de warmte der lugt tien graaden boven 't vriespunt op dem thermometer tekent, zo is de warmte dezcr dieren ook flegts van tien graaden: wy hebben den-bol van een kleinen thermometer in het lighaam van verfcheiden leevendige relmuizen gehouden, en bevonden, dat hetzelve van binnen ten naaltenby even warm was als de lugt; zomtyds zelfs is de ther* mometer, fchiclyk in het ligham gedompeld, ell op het hart, om zo te fpree-ken, vant het dier gehouden, een halven graad of een graad gevallen, ent terwyl dezelve in de lugt op els hadt geftaan, in het- lighat11 van het dier tot:

* De relmuis heet in 't Grokfch Muwços volgens GesNer; Exciós volgens de Taqlkenners.' in 't Latyn Glis; in 't Italiaanlch Galero, Gliero, Gbiro; in 't Spaanfch Liron; in 't Franfch" le Loir; in 't Hoogduitfch Siebensflalafer volgens KLEIN; en Greul in zomnige andere plaatín,

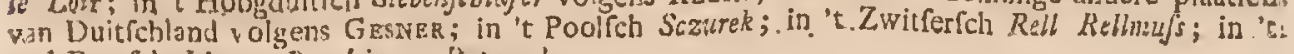
aud. Franfch Liron. Rat-Liron, Rat-ueute.

Glis. Gesner. Hiftor: Quadrup. pag. 550: Icon. Quadrup. pag. 109.

Glis. Aldrovann. Ilijt. Quadrup. digitat. pag. 409.

alis Jugra. obfchro cinereus, infra ex allo cinerejgens. BRIsson Regn+ Anim. pago.I6ou 
tien gezakt: nu weet men, dat de warmte van den menfch, en van de meeste dieren, die vleefch en bloed hebben, op alle tyden dertig graaden te boven gat; het is derhalven geen wonder, dat deze dieren, dic in vergelyking van anderen 20 weinig warmte hebben, in een ftat van verftyving: of verdooving vallen, zodra die weinige inwendige warmte door de uitwendige warmte der lugt niet meer onderfteund en geholpen wordt, en dat gebeurt wanneer de thermometer niet meer dan op tien of elf graaden boven 't vriespunt is : dit is de ware oorzaak van de verdooving dezer dieren, "eene oolzaak, daar men onkundig van was, en die zig egter algemeen uititrekt tot: alle dieren, die, geduurende den winter, flaapen; want wy hebben dezclve waargenomen in de relmuizen, in de eegels, in de vledermuizen; en fchoon wy geene gelegenheid gehad hebben om dit op het marmeldier te beproeven, ben ik egter overtuigd, dat hetzelve een koud blocd heeft, gelyk de andere, nardien het even als deze, aan denzelfden täăat van verdooving, geduu rende den winter, onderheevig is.

Die verdooving duurt zo lang als de oorzalk anhoudt, die dezelve voortbrengt, en eindigt met de koude: eenige graden warmte boven de tien of twaalf zyn genoeg om deze dieren weder leevendig te makken, en zo men hen, des winters, in eene zeer warme plats houdt, verftyven zy in 't geheel niet; zy gaan en komen, zy ceten cn flaapen alleenlyk van tyd tot tyd, gelyk alle andere dieren. Wanneer zy de koude voelen, fluiten zy zig in een, en rollen zig als tot ecn bal, om minder oppervlakte aan de lugt te bieden, en een weinig warmte te behouden: het is dus, dat men hen des winters vindt in de holle boomen en in de gaten der muuren, die op 't zuiden ftaan; zy. liggen daar in als ballen, en zonder eenige beweeging, op mofch en bladen, men vat hen, men houdt hen, men rolt hen, zonder dat zy zig beweegen, zonder dat zy zig uitftrekken; nicts kan hen uit hume. verdooving doen herkomẹn, dan cene zagte, en langzaam aangezette, warmte; zy fterven, wanneer men hen eenskiaps by 't vuur brengt. men moet, om hen te doen leeven, hen trapswyze daar toe. doen naderen. Schoon zy in dezen ftant zonder eenige beweeging zyn, fchoon zy de. oogen gellooten hebben, en van alle gebruik der zintuigen beroofd fchynen, voelen zy egter de fmart, zo die zeer leevendig is; het kwetfen, het branden, doet hen eene beweeging van famentrekking.maklen, en cen kleinen doffen fchreeuw nitgeever1, welken zy zelfs. verfcheidenmal herhaales: de inwendige gevoeligheid blyft derhalven beftan, zo wel als de werking van het liart en de longen; het is cvenwel te vermoeden, dat die leevensbewceging in dezen ftat van verdooving niet met dezelfde kragt, en hetzelfde vermogen, werken, als in den gewoonen ftat; de omloop heeft waarfchynlyk geen plats dan in de grooute vaten, de ademlaaling is zwak en traag, de affcheidingen zyn zeer flauw en wcinig, en daar hebben geene uitwerpzels plaats: de doorwaafleming ftat ook byn ftil, dewyl zy verfelheiden manden zonder ceten doorbrengen, het welk nict zoude kumnen gefchieden, $20 \mathrm{zy}$, in dezen tyd viln vaften, naar evenredigheid, zo veel.van hunne zelfitandigheid verlooren als op andere tyden, waarin zy dat verlies door het neemen van voedzel herfellen: $z y$ verliezen 'er egter jets van, dewyl $z y$, in al te lange winters, in husM 3 . 
ne gaten fterven; doch miffchien is het ook niet de langere aanhouding, maar de meerdere geftrengheid, van de koude die hen duet omkomen, want zo men hen voor eene fterke vorft bloot legt, fterven $z y$. in korten tyd: het geen my zou doen denken, dat het niet het al te groot verlies van zelfftandigheid is, waardoor $\mathrm{zy}$ in zwaare winters onkomen, mar dat dit meer aan de al te ftrenge koude moet toegefchreeven worden, is, dat zy in den herfit ten uiterfen vet zyn, en dat $z y$. het nog zyn, wamneer $z y$ in de lente weder leevendig worden: die overvloed van vet is een inwendig voedzel, 't welk genoeg is om hen te onderhouden, en om te vergoeden wat zy door de uitwaafeming verliezen.

Voor het overige, gelyk de koude de eenige oorzalk van hunne verdooving is, en $z y$ in dezen ltaat niet vallen, dan wanneer de warmte van de lugt beneden de tion of twaalf graaden is verminderd, zo gebeurt het dikwils, dat $z y$ des winters wederom leevendig worden; want daar zyn uuren, dagen, en zelfs anhoudende dagen, in dat jargetyde, waarin de thermometer op twaalf, derticn, veertien, en zelfs meer graaden, boven 't vriespunt ftaan blyft, en geduurende dat zagte weder komen de relmuizen uit haare holen te voorfchyn, om de leevensmiddelen te zoeken, of liever, zy eeten den voorraad, welken zy in den herfft verzameld, en war heur winter-verblyf gebragt, heb. ben. ARISTOTeles heeft gezegì $(a)$, en alle de Naturonderzoekers hebben het 11 ARISTOTriss gezegd, dat de relmuizen den winter zonder eeten overbrengen, en dat $z y$, in dezen tyd zelven van hun vaften, ten uiterften vet worden, dat de flaap alleen hen meer voede, dan de fpyze andere dieren voedt; het ftuk is niet alleen niet waar, mar de onderftelling zolve van het ftuk is onmogelyk : de relmuis, vier of vyf manden in een ftaat van verdoo. ving doorbrengende, zoul niet vet kunnen worden, dan ran de lugt, die zy inademt: lat ons, zo men wil, eens toegeeven, en dar is vecl te veel tnegegeeven, dat een gedeelte van die lugt tot voedzel overgant, $z$ ll daar uit zulk eene aanmerkelyke vermeerdering geboren worden? zal dat, zo ligte, voedzel zelfs genoeg kunuen zyn voor het geduurig verlies, dat door de doorwatfeming gemalkt wordt? het geen Aristoter in in deze dwaling hecf kunnen doen vallen, is, dat de relmuizen in Griekenland, alwaar de winters gematigd $2 y^{\prime} n$, inct aanhoudend flanpen, en dat zy telkens, wanneer zy door de warmte wakker gemaakt of verleevendigd worden, voedzel, en miffchien wel wat rykelyk, gebruikende, zeer vet zullen gervorden, of liever gebleeven, en coor ARISTOTELEs, in haaren ftaat van verdooving zelve, zodanig gevonden, zyn; wat men lier omtrent als waar en zeker kan ter nederitellen, is, dat zy op alle tyden vet zyn, en vetter in den herfit dan in den zomer.

Het vlcefch dezer dieren is vry gelyk aan dat van het Indiaanfch varkentje: de relmuizen makkten een gedeelte van de goede fier by de Romeinen uit; zy fokten dezelve by menigten. Varro geeft de manier op, hoe men de relmuizen in perken kan houden, en ApIcius die, om "er lekkere ragouts van ta maken : dat gebruik is niet gevolgd geworden, "t zy dat men een afkeer van

(a) HIiftor. Animal, lib. VIII, cap. I7. 


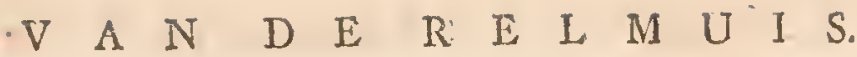

deze dieren hebbe, omdat zy naar de rotten gelyken, 't $z y$, dat hun vleefch inderdaad niet aangenaam van fmank $z y:$ ik heb boeren, die het gegeeten hadden, hooren zeggen, dat het weinig beter is dan dat van de waterrot; voor het overige is de relmuis alleen eetbar; de groote hazelmuis heeft een flegt vleefch, en dat zeer onangenaam riekt.

De relmuis gelykt vry wat naar den eekhoorn in zyne gewoonten en leevenswyze; zy onthoudt zig, even als deze, in de buflichen, zy kloutert op de boomen, en fpringt van tak tot tak; niet zo varrdig evenwel als de eekhoorn, die langer van pooten, minder dik van buik, en zo mager als de relmuis vet, is; ondertufichen leeven zy beiden van het\%elfde voedzel; beuken, hazelnooten, kaftanjes, en andere wilde vrugten, maken hunne gewoone pyze uit: de relmuis eet ook kleine vogeltjes, dic zy jil humne neften vangt; zy makt rig geen verblyf van lcem boven in de boomen, gelyk de eekhoorn, maar zy vervaardigt zig een bed van mos in de holle tammen; zy legert zig ook in de fplecten van hooge rotfen, eil altoos in drooge platien; zy vreeft de nattigheid, drinkt weinig, en komt zelden op de arde neder; ook verfchilt zy hier in van den eekhoorn, dat deze zig gemaklyk laat temimen, daar zy altoos wild blyft.

De relmuizen koppelen tegen het einde van de lente, zy werpen in den zomer, de dragten zyn gemeenlyk van vier of vyf; zy groeijen fchielyk, en men verzekert, dat zy maar zes jaar leeven: in Italie, alwaar men nog het gebruik heeft van haar te eeten, maakt men greppen in de boffchen, welke men met mos bekleedt, en met ftroo bedekt, en warin men beuken werpt; men verkieft een drooge plaats, onder de befchutting van een rots, die op het zuiden ftaat; de relmuizen begeeven $\mathrm{zig}$ in menigte derwands, en men vindt haar aldar verftyfa tegen het einde van augutuss; dat is de tyd, waarin zy beft te eeten zyn.

Deze kleine dicren zyn moedig en verdedigen hun leeven tot het latifte uiterfte; zy hebben zeer lange en zeer fterke voortanden, ook byten zy geweldig; zy vreezen noch het wezeltje, noch de kleine roofvogels; zy ontfnappen aan den vos, die hen niet tot boven in de boomen volgen kan; hunne grootfe vyanden zyn de wilde-katten, en de bofch-marters.

De foort dezer dieren is niet heel zeer verfpreid; men vindt hen niet in zeer koude klimaten, gelyk Lapland en Zweeden; ten minften de noordfche Natuuronderzoekers fpreeken 'er niet van; de foort van relmuis, die zy aanduiden, is de kleine hazelmuis, de kleinfte van de drie: ik vermoede ook, dat men haar niet vindt in de zeer heete landen, dewyl de Reisbelchryvers 'er geen gewag van makels: ook zyn 'er weinige of geene relmuizen in de open landen, gelyk Engeland; zy moeten een gemaatigd klimaat hebben, en een land met boffchen beflaagen: men vindt haar in Spanje, in Frankryk, in Griekenland, in Italie, in Duitfchland, in Zwitferland, alwanr zy zig in de boffchen op de heuvels, en niet boven op de hooge bergen, verhouden, gelyk de marmeldieren, die, fchoon onderheevig om door de koude te verftyven, de fneeuv en yffel egter fchynen te zoeken. 


\section{BESCHRTVING VAN DE RELMUIS.}

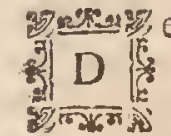
e relmuis ( $P l . X X I V$. fig. I.) heeft veel overeenkomft met den eekhoorn, voor zo verre de geitalte des lighaams betreft, en vooral die van den ftaart, die, van het een tot het ander einde, met lang hair bedekt is; maar zy verfenilt 'er op eene zeer blykbare wyze van door de grauwe kleır, die alleen genoeg is om haar van den cekhoorn te onderfcheiden, als welke val is, of flegts ecn ligt zweemzel heeft van grauw, en zomtyds van bruin met vaal gemengd; daarenboven is de reimuis wat kleiner dan het eekhoorntje: de beide dieren ondertuffehen worden in de bosfchen gevonden, beklautercn de boomen, en loopen of fpringen de een byna zo vaardig als de ander van tak tot tak: wanneer men hen van naby waarneemt, bemerkt men ligtclyk dat de relmuis een minder breeden kop en bek heeft, dat de oogen kleiner zyn en minder uitfpringen, dat de ooren langer, dumner, en byna kaul, de beenen, de voeten, de vingers en de nagels kleiner, ell de hairen van den faart minder lang zyn.

De oogen van de relmuis, die ten onderwerpe voor deze befchryving gediend heeft, waren met zwart geboord; de bovenfte zyde van den bek cn van den kop, en een gedeelte der zyden van den kop, de bovenkant, en de zyden van den hals en van het lighaam, de fchouders, de buitenkant van den arm, en van den voorarm, van de dije en van het been, en byna de gehcele ftart liadden ecn grauwe kleur, met zwart en silverkleur gemengd; het hair was afchgrauw, over het midden zyner lengte byna van den wortel af; het overig gedcelte hadt cenc zeer fchitterende grauwe kleur tot aan de punt; dit hadt by de meeften dezer dieren plaats; anderen evenwel hadden aan "t einde zwart boven het grauw; het midden der bovenzyde van 't gewrigt der hand en van de agterhand was zwartagtig; een gedeclte der zyden van het hoofd, het onderfte kaakbeen, de hals, de benedenzyde van den hals, de borft, de oxels, de binnenkant van den arm en van den voorarm, de voorfte voeten, de buik, de liczen, de binnenzyde van de dije en van het been, de zyden van den agtervoct, en de vingers der agterftc voeten, hadden eene wirte kleur, op zommige plaatien ligtelyk met cen zwcemzel van grauw gemengd, en op eenige hairtjes verzilverd; de zelfde witte kleur was 'op de onderfte zyde van den ftart by zyn begin, en trekte zig langs ảen ltomp over de helft van deszelfs lengte uit.

1) knevels wilren van eene zwartagtige kleur en twee duimen lang; het hair des lighaams hadt vyf of zes lynen lengte, en dat van den ftaart ontrent een duim: de voorfte voeten verfehilden niet van die van den eekhoom, dan voor zo verre men ter plate van den duim niets zag dan zeer onvolmaalite overblyfzels -van nagels: daal waren zes ecltagtigheden onder de agterfte voeten vier aan het begin der vingeren, en twee meer naar agteren.

De voeten van de relmuis zyn dikker dan die van de rot; het is gemaklyk de relmuis vande rot, en van de waterrot, die ten naltenby van dezelfde dilite 


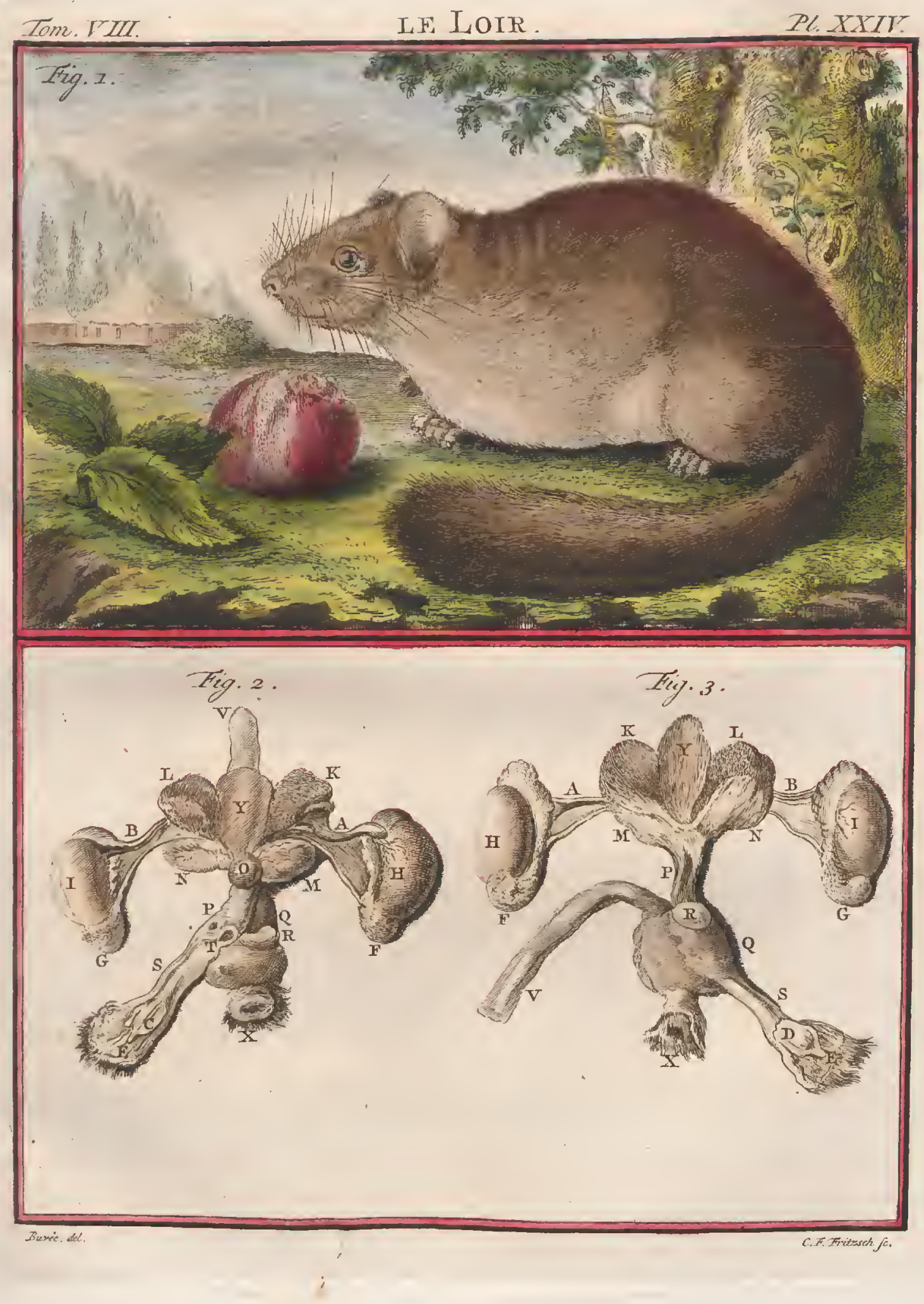


dikte zyn, te onderfcheiden door de gedaante van den ftaart, die zeer ruig is by de relmuis, en byna kaal in de twee andere dieren.

duimen, Jynen:

Lengte des geheelen lighaams, in een regte lyn gemeeten, van het einde

van den bek tot aan den aars
Lengte des hoofds van het cinde van den bek tot aan het agterhoofd.

Omtrek van het einde van den bek

Omtrek van den bek, beneden de oogen genomen ${ }^{-}{ }^{-}$.

Ontrek van de opening des monds

Afitand tuffchen de twee neusgaten
Afftand tuffchen het einde van den bek en den voorften hock van 't oog. 0 .

Afitand tuffchen den agterften hock en 't oor . - . . - o.

Lengte van het oog van den eenen hoek tot den anderen

Opening van het oog

Afltand tuffchen de voorfte hoeken der oogen volgens de kromming van het neusbeen gemeeten

Dezclfule afftand in een regte lyn gemeeten

Omtrek van het hoofd tufichen de oogen en de ooren

Lengte der ooren
Breedte an de bafis op de buitenfe kromre gemeeten

Aftand tuffehen de beide ooren om lang genomen

Lengte van den hals

Lengte van den hals
Omtrek van den hals

Omtrek des lighaams agter de voorfte pooten genomen

Ontrek aan de dikfte plaats genneeten

Omtrek voor de agterfte pooten gemecten

Lengte van den ftomp des ftaarts

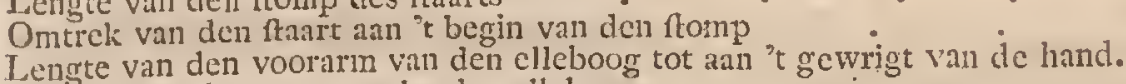

Breedte van den voorarm by den elleboog

Dilite van den voorarm terzelfder platfe

Ontrek van "t gewrigt van de hand

Omtrek van de agterhand

lengte van het gewrigt af tot ann het cinde der nagelen

Lengte van het been valn de linie a
Breedte van het bovenft des beens

Dikte

Breedte ter plaatfe van de hiel

Omtrek van den agtervoet

Lengte van de hiel af tot aan 't einde der magelen

Brecdte van den voorften voet

Bicedte van dell agterfien voct

I. engte van de grootite nagelen

Breedte aan de bafis

De relmuis, die ten onderwerpe voor de befchryving der weeke binnendeelen gediend heeft, was, van het einde van den bek tot an den aars, zes VIII. Deel. 


\section{DE NATUURLYKE HIST ORIE,}

duim lang; de ftart was vier en een haif duim lang tot aan het einde van den ftomp, en vyf duim drie lynen tot aan het einde van het bair; hy woog
twee oncen zeven gros.

By het openen van den onderbuik vondt men twee vette blatdjes vall eene lyı dikte, die aan weerskanten een. der ingewanden bedekten; in de imagere relnuizen hebben deze blaadjes marr weinige dikte, en zyn in de zyden van het vouwde zig tuffchen den: het net was zeer dun en zeer weinig uitgebreid; na zo veel ter linker als ter regterzyde; kerkant, en de milt aan de linkerzyde de andere dieren met gekloofde voeten. De twanlfvingerigedarm ftrekte zig tot in. ' $t$ midden van de regterzyde uit; hy vouwde zig binnenwards, en verlengde zig naar voren, om zig te verde zyden maakte: die van den die zyn omwentelingen in de navelftreek en in in. den eigenlyk हezegden onderbuik voorwaards langs den twaalfvingerigendarm, en vous ftrekte 'zig de darmbuis. voordat hy op den regtendarm uitliep, die in vouwde zig agter de maag, den aars ging.

Daar was a van eene eyronde gedaante van den regtendarm, by den aars, eene klier: deze klieren waren vervuld van een de groote ontrek drie lynen lang was;

De nuang liep zeer in 't lang, en melkig en witagtig vogt. beid, langer dan het linker; zodat de rlogter gedeelte was, naar evenredighoek, dien het regter gedeelte maakte middellyns als het overige van de darmb re twalvingerigedarm hadt zo veel grootte verfchilde.

De lever hadt vyf kwabben; de grootfte was, in haar geheel, ann de linkerzyde geplaatf; de middelfte kwab was in twee ongelyke deelen gefcheiden door een diepe fplitfing daar de draagband doorging; het kleinfte gedeelte van deze kwabbe was geplateft vóúr de linker kwabbe; het grootft gedeelftrekte zig verder dan de randen van de kwabe uit de onderfte fplyting, het be waren ter regterzyde, en de vyfde an den wit; de derde en vierde kwabHokdarm: de lever hadt van buiren en den wortel van de lever by den. kleur; zy wootg een half gros en dertig greinen.

Het galblaasje was zeer groot en byna eyrond, het hadt eene groenagtige Xleur, die kwam van "t vogt dat daar in bevat was.

De nilt hadt dric zyden, zy liep in 't lang', en was van eene donker roode kleur van buiten cn van binmen; haar. ondert gedeelte was wat breeder

Het alvleefch was zcer breed, en het ftrekte zig dwars van de milt af tot aan den twaalfvingerigendawn uit.

De regter-niel ftak omtrent de helf haarer lengte meer vooruit dan de linker, zy waren langagtig, en hadden weinige uitfingding; het bekken was vry. 
groot, maar daar was maar ééne tepel; de verfcheiden zelfftandigheden van het binnenft waren zeer duidelyk te zien.

Het zenuwagtig middelpunt van het middelrif was zeer doorfehynend, en het vleezig gedeelte hadt weinig dikte:

De linkerlong hadt maar eene kivab, en de regterlong hadt "er vier, waarvan drie aangeregen waren: de vierde bevondt zig by de bafis van " $t$ hart, en was, naar evenredigheid der andere, dikker dan zy gemeenlyk is in de dieren, die vier kwabben in de regterlong hebben; de meefte longe-kwabben van de relmuis hadden noch fplytingen noch uitfnydingen.

Het hart was weinig verlengd; de bafis was in 't midden van de borft, en de punt liep fchuinfch ter linkerzyde en naar agteren.

Het cinde van de tong was breed en zeer dun; het overige hadt meer dikte; het voorfte gedeelte was voorzien van bykans onmerkbaare tepcltjes, met kleine witte korreltjes doorzaaid, en in 't midden over de lengte gevoord; op het agterft gedeelte waren dikker tcpeltjes agterwiards gerigt, en drie kleine kelkklieren, hoekswyze gefliikt, cenc van agteren en twee van voren.

Het voorfte gedeelte van 't verhemelte was doorfneeden door drie brecde vooren, en daar waren 'er vier op het agterft gedeelte tuffehen de baktanden; die laatite voorcn waren minder brced dan de cerlte, zy hadden minder verheven randen, die bolrond van binnen $c n$ in 't midden afgebroken waren, met uitzondering van den laatften; de ftrotklap was zeer dun.

Daar waren geene bogtigheden op de voorberfienen; de agterherfenen waren agterwaards geplaatit, en hadden dezelfde figuur als dic der meefte andere viervoetige dieren; de voorherffenen woogen een-en-twintig grein en de agterherffenen zeven en een half grrein.

De relmuis heeft zo veel overcenkomft met de groote hazelmuis, dat 'er alle reden is om te dcnken, dat de inwendige deelen der voortteeling van het mannerjc op verfchillende tyden des jaars meerderen of minderen omtrek krygen, gelyk ik in de groote hazelmuis heb waargenomen; dewylik geen relmuis heb gevonden, welker zaadballen, zaadblaasjes, voorftanders, enz, niet zeer klein waren in vergclyking van de dikte, die deze zelfde deelen hadden in een groote hazelmuis, dic ik in het gunftig jargetyde ontleed heb, als zyllde deze dieren gemaklyker te bekomen dan de relmuizen, zo gaa ik hier de befchryving der teeldeelen van de mannet,es relmuis voorby, omdat die' be1chryving onvolkomen zoude zyn, en vervuld kan worden door de befehryving der teeldeclen van de groote hazclmuis, welke ik gedaan heb naar een onderwerp, waarin deze deelen in alle humne grootte waren $(a)$; des te meer omdat de teeldeclen van een mannetjes relmuis my voorgekomen zyn zeer te gelyken naar die van de groote hazelmuis, dezelve met den anderen vergelykende toen zy nog niet al den ontrek hadden, dien zy op een anderen tyd moeften krygen.

(a) Zie de befchryving van de hazelmuis, welke op die van de relmuis volgd.

$N_{2}$ 
Het wyfje, 't welk ten onderwerpe voor de befchryving der teeldeelen gediend heeft, was van dezelfde grootte als het mannetje, waar naar de voor* gaande befchryving is gedaan.

Dit wyfje hadt, even als het mannetje, tien manmen, vyf aan weerszyde; twee op de borft, en drie aan den buik.

De kittelaar was zeer weinig zigtbaar, maar men zag onderfcheidenlyk de dicping van de voorhuid; de blaas hadt eene eyronde gedaante, de loornen van de lyfmoeder waren zeer lang, legt en hingen aan den onderften rand van elk der bladen van den onderbuik vaft; de zaadballen hadden zo weinig dikte, dat men dezelve nauwelyks onderfcheidde van het vet der bladen: de. trompetten waren niet gekluwend gelyk die der.rotten.

Lengte van de ingerwandsbuis van den portier tot aan den aars voeten; duimen, lynen, Ontrek op de dikfte platen

Omtrek op de dunfe plaatfen

Groote omtrek van de maag

Kleine omtrck

Lengte der kleine kromining van den foldarm af tot aan den hoeik, dien het regter gedeelte maakt Lengte van den lokdarm tot aan-den grond van dei grooten blinden-

Onitrek van den flokdarin

Omtrek van den portier

Lengte van de lever

Breedte

Haare grootfte dikte

Lengte van het galblaasje

Zyn grootfte middellyn

lengte van de milt

Breedte aan het ondereinde

Breedte aan het boven-einde

Dikte in 't midden

Dikte van 't alvleefch

Lengte der nieren.

Breedte

Dikte

Lengte van het zenuwagtig middelpunt van de lolle ader tut ain de punt

Breedte

Breedte van het vieczig gedeelte tuffchen het zenuwagtig middelpunt en het borftheen

Breedte aan: weerszyde van het zenuwagtig middelpunt . . . .

Omtrek van de biffis van " $t$ hart
Hoogte van de punt af tot. aan den oorfprong van de longhag-
ader

Hoogte van de punt tot aan den longezak
Middelyn van de groote llagader van buiten naar buiten ge-

meeten

Lengte van de tong 
Lengte van het voorfte gedeelte van het toompje tot aan. 't einde.

Breedte van de tong

Lengte der voorhermenen

Breedte

Dikte

Lengte der agterherfenen

Breedte

Dikte ${ }_{\text {Aftand tuffchen den aars en de opening vall de voorhuid }}^{\bullet}$

Afttand tuffchen de randen van de voorhuid en het einde. van het roedenhoofdje

Lengte van het hoofdje

Lmirek van de roede van de fplitfing der fponsagtige lighaamen tot aan de inplanting van de voorhuid

Onitrek

Afitand tuffehen den aars en de klink

Lengte van de klink

Lengte van de fchede

Omtrek aan de dikite plaats

Omtrek ann de dunfte plaats

Groote onitrek van de blans

Kleinc omtrek

Lengte van de pisbuis

Omtrek van den hals en het lighaam van de lyfmoeder

Omtrek

Lengte der hoornen van de lyfmoeder

Omtrek op de dikite plaatfen

Omtrek op de dikfte plaatfen
Omtrek op het einde van yderen hoorn
Aftand in eene reggte lyn tufichen de zadbailen en het einde van

\begin{tabular}{|c|c|}
\hline o. & \\
\hline & 0. \\
\hline O. & O. \\
\hline 0. & o. \\
\hline O. & O. \\
\hline $\begin{array}{l}\text { O. } \\
\text { O. }\end{array}$ & 0. \\
\hline o. & o. \\
\hline 0. & o. \\
\hline
\end{tabular}

Lengte van de kromme lyn die de trompet doorloopt :

Lengte van de liromme lyn die de trompet doorloopt ${ }^{\circ} \cdot{ }^{\circ}$

Breedte

Dikte

1) kop van Het gernamte van de relmuis is minder verlengd en naar evenredigheid brecder dan die van de rot; de bels is ook minder lang en makt met het voorhoufd en de kruin een krommere oppervlakte: dit hoofd heeft vecl overeenkomft met dat van de waterrot, zo wel tell opzigte zyner lengte en breedte, als in de kronming van cle jlakte, die zig. van het cinde der neusbeenderen tot het agterhoofd uitftrelit; ondertulichen waren de beenige randen van het agterhoofd minder nitpringende dan in de waterrot, de bek was linger en minder breed, de trkken van het ondert' kaakbeen waren minder dik, en het uitfteckzel van hume bogt hadt meer lengte: de eigenlyke neusbeenderen waren, even als die van de rot, veel verder uitgeftrekt nas. wuren dan het bovent kakbeen. 
Daar waren twee lange tanden voor in yder kaakbeen; de bovenfte waren loodregt gelyk in de rot, en de onderfte waren wat meer holrond van boven, de buitenfte zyde dier vier tanden was van eene bleeke oranjekleur; daar waren in yder kaakbeen ftangruimtens, gelyk als in het paard, de rot, de waterrot, enz: dat is te zeggen eene lange ruimte zonder tanden, tuffchen de voorfte tanden en de baktanden in: die laatite waren ten getale van vier, aan weerszyde der beide kakbeenen, zy geleeken veel meer naar de baktanden van de rot dan naar die van de waterrot, fchoon zy wat dikker waren: daar waren in alles twintig tanden.

Het doornagtig uitfteekzel van het tweede nek-wervelbeen hadt de gedaante van een kam, het was minder vèrheven dan dat van de rot, en ftrekte zig: meer naar agteren dan naar voren uit: de vyf wervelbeenderen hadden geen döornagtig uitfteekzel; de onderfte tak van het fchuinfche uitfteckzel van het zesde was zeer kort.

Daar waren maar dertien rug-wervelbeenderen en dertien riblen, zeven ware en zes vallche: de doornagtige uitfteekzels der agt eerfte wervelbeenderen waren agterwaards gehogen, die van het negende was regt, en die der vier andere helden naar voren; alle deze uitfteckzels hadden weinig lengte: het borftheen beftondt nit zes beentjes; de ecrfte ribben, een aan weerszyde, geledigden zig met het voorfte gedeelte van het eerfte beentje; de geleding der twecde ribben was tuffchen het eerfte en tweede beentje; die der derde tusfehen het tweede en derde beentje, en zo vervolgens tot aan de zesde en z.evende ribben, welker geleding was tuffohen het vyfde on zesde beentje.

"De lendenwervelbeenderen waren ten getale van zes; de doornagtige en bykomende uitfteekzcls del cerften hadden minder lengte, dan die der laatite; zy waren alle voorwawds hellende: het heiligbeen beftondt uit drie valfche wervelbeenderen en de ftaart uit vyf-en-twintig.

De eyronde gaten waren naar evenredigheid breeder dan die van de rot; het fchouderblad hadt minder breedte, en de bafis was korter; de voortte rand van lict armbeen was op het boven gedeelte in plaats, van op het middelgedeelte te zy11: voor het overige is my het geraamte van de relmuis nict voorgekomen van dat van de rot te verfchillen dan in de maaten, warvan men zal kunnen oordecletr door de volgende tafel te vergelyken met die der maten vall de beenderen van eene rot $(b)$. Lengte van den kop van het eincle der neusbeenderen tot liet agter-
loofd

De grootfte breedte van den kop • • •

Lengte van het onderft kankbeen van deszelfs voorfte cinde tot an den ag- ${ }^{\circ}$ Io:

terften rand van het lnolkclwyze uitftekzel ${ }^{-} \cdot{ }^{-}$.

Breedte van het onderft kaakbeen ter plaatfe der finytanden
Breedte van het bovenft kaakbeen ter plaatfe der finytanden
*

Afitand tuffchen de oogputten en de opening der neusgaten $\bullet \quad \cdot \quad 0^{\circ}$.

(b) Zie het VII Decl van dit Werls, blz. 184, enz. 
Lengte van deze opening

Breedte

Lengte der eigenlyke neusbeenderen

Breedte aan de breedifte plaats

Lengte der langfte finytanden buiten het been

Léngte der langfte baktanden buiten het been

Lengte der twee voornaame deelen.van het tongbeen

Lengte der tweede beenderen

Lengte der derde beenderen

Lengte der takken van de vork

Breedte van het gat des cerften wervelbeens van boven naar beneden.

Lengte van de eene zyde tot de andere

beenderen beftaat
Lengte van het lighaam des lantften wervelbeens, dat het langft is.

Lengte der eerfte ribben

Afitand tuffehen de cerfte ribben aan de breedfte plaats

Lengte van de negende rib, die de langfte is

Lengte van de laatre der valfehe ribben

Lengte van het borftbecn

Lengte van het ecrfte been dat het langft is

Lengte van het vyfde been dat het kortit is

Lengte van het lighaam van het vyfde lendenwervelbeen dat het langft is

Lengte van het heiligbeen

Breedte van het voorfte gedeclte

Breedte van het agterfte gedeclte

Lengte van het twaalfde valfche wervelbeen des ftaarts, dat het langft is.

Lengte der eyronde gaten

Breedte van het bekken

Hoogte

Brecdte aan de breedfre plaats

Breedte aan de fmalfte plaats
Hoogte van den doorn aan de verhevenfte plaats.

Longte der fleutelbeenderen

Lengte van den fchouder

Lengte van de ellepyp

Lengte van den clleboogsknokkel

Lengte van het ftraalbeen

Lengte van de dije

Lengte der kniefchyven

Lengte van het fcheenbeen

Lengte van het kuitbeen

Hoogte van de voorhand

Lengte van het hielbeen

Hoogte van het eerfte wig-en fchuitbeen te famengenomen

Lengte van liet eerfte been van. de agterhand dat het kortut is

aluimen, lynes.

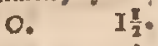

o. It:

o. $6 \frac{1}{2}$

o. 1.

O. 32.

o. 2.

o. It.

O. 3.

o. I.

$0 . \quad x^{\frac{\pi}{2}}$

o. I

o. 2.

I. 5.

o. 2.

D. 2 .

o. 4.

$0.10_{3}^{2}$

○. 7.

1. 3

O. $\frac{1}{2}$

o. 2

$5 \frac{3}{4}$

$3 \pi^{\circ}$

$2 \frac{1}{3}$.

3 t.

$3 \cdot$

2.

$3 \frac{15}{5}$

$7 \frac{1}{2}$

4.

I

5 .

9.

$\quad I \frac{2}{2}$

9 .

.

I.

I. $\frac{1}{2}$.

o. I

०. 3.

o. Io.

o. I. I. 
Lengte van het derde been dat het langft is

Lengte van het eerfte been van den agtervoet, dat het kortit is ${ }^{*}$

Lengte van het vierde been dat het langft is

Lengte van den eerften regel des middelften vingers van de voorfte voeten

Lengte van den tweeden regel

Lengte van den derden

Lengte van den eerften regel des viẹden vingers van de agterfte voe-

Lengte van den tweeden regel

Lengte ven den derden

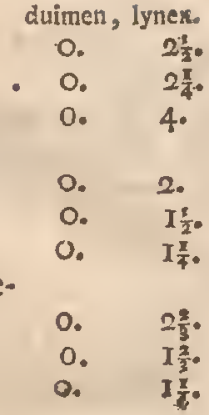

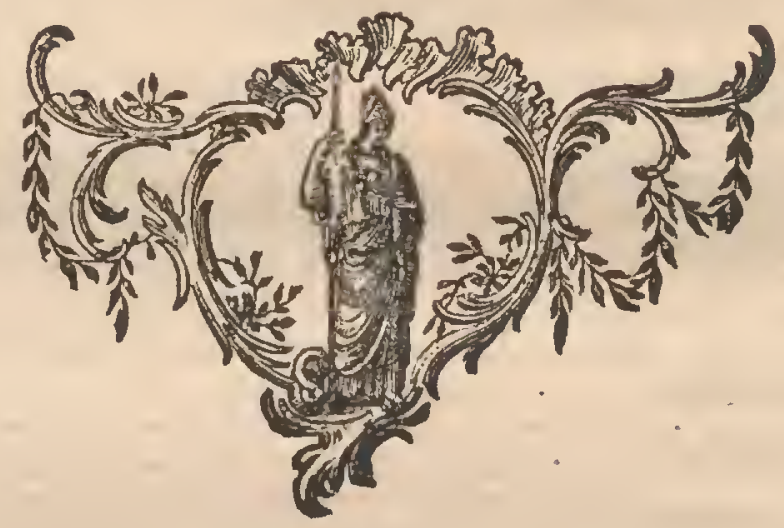

D E 


\section{E G R O O T E H A Z E L M U I S *.}

絭湴橉

relmuis onthoudt zig in de boffchen, en fchynt onze woonplaat fen te fchuwen; de groote liazelmuis integendeel bewoont onze tuinen, en wordt zomtyds in onze huizen gevonden; de foort der laatfte is talryker, algemeener verfpreid, en daar zyn weinige tuinen, die "er niet van geplaagd worden: zy neftelen in de gaten der muuren, zy loopen op de leiboomen, kiezen de befte vrugten uit, en ontginnen die alle in den tyd, dat dezelve beginnen te rypen; zy fcliynen de perfikken by voorkeur te verkiezen, en zo men die wil behouden moet men 'er de groote hazelmuizen zorgvuldig afweeren: zy klauteren ook op de peerenboomen, de aprikoozenboomen, de pruimboomen; en zo de zoete vrugten har ontbreeken, eeten zy amandelen, hazelnooten, nooten, en zelfs meelagtige zaaden; zy brengen dit alles in groote hoeveelheid naar hare verblyfplaatlen, welke zy in de aarde maken, byzonderlyk in tuinen die gefpit, of gefchoffeld en geharkt worden, want in boomgaarden, alwaar de grond niet geroerd wordt, vindt men har dikwils in oude holle boomen; zy maken zig een bed van groente, mos, en bladeren: de koude verdooft haar, en de warmte doet haar herleeven; men vindt 'er zontyds agt of tien op dezelfde plaats, alle verdoofd, alle in een bal faamgerold, in 't midden van haaren voomaad van nooten en hazelnooten.

Zy koppelen in de lente, werpen in den zomer, en brengen vyf of zes jongen ter wereld, die fchielyk groeien, marr die evenwel zelve niet dan in 't volgende jaar teclen. hun vlecich is niet ectbar, gelyk dat van de relmuis: zy hebben zelfs de kwaade lugt van de huiskat, terwyl de relmuis in 't geheel niet riekt; zy worden zo doorvoed niet, noch krygen die bladen of laa. gen vet, welken men in de relmuis vindt, en die de geheele malfa harer ingewanden omvangen, gelyk men uit de befchryving van de relmuis en de groote hacelmuis, met malkanderen vergeleeken, zien zal: daar zyn hazelmuizen in alle de gemaatigde geweften van Europa, en zelfs in Polen en Pruilien, maar zy fchynen in Zweeden of in de Noordelyke landen niet geronden te worden.

* De groote hazclmuis wordt in 't lirafch Lérut geheeten; we'ke nzam warlahynlyk komt van Lotrut, of kleine Loir, door welk la:tite woord men gezien heeft dat de relinuis wordt uitgedruke, en ferot zegt dan miffchien 70 veel als kleine relmuis; de gronte hazelmuis is inderdaad kleiner dan de relmuis: ook noeme men ic groote hizulnuis witte rot; en gelyk dezelve gemeener is dan de relmus, en te naan van re'muis bek:n.'er is dan dic van groote hazelinuls, zo geeft men ook dikwils den nam van relmuis uan de groo:e hazeimuis; in Bour. Eonje noemt men de groote hazelmuis $V_{0} i f f u$, of Vonfieu; in 't I.atyn heet dit dier Sorex Plisig volgens GesNer; in 't Hoogduit'ch Injelmouss; le Danizik noemt men het Grauwert, volgens KLeIN; in 't Engelfch tbe greater Dorwotife of Bepper, volgens RAY: in 't Vlaamich Jaeg. "a!e volgens Geren; in 't Poolich Mivzorzecbeswa, Kofzatka volgens Rzaczinski.

Mus avellanarim" major. GesNeR Hijt Quadrup. pag. 735. Icon. Quadruped. pag. II5.

Mass avellanarum major. liay Synopf. Antmal. Quadrup. pag. 219.

Loir. Il Joire de l'Academie royale des Sciences, Tom. III. Part. III. pag. $4^{\text {to. }}$

Glis jupra obfruse cinereus, infra ex abbo cinerafients, macula ad oculos nigra. Baisson. Regn. Animal. pag. $10 \mathrm{r}$.

Dill. D.eO\% 


\section{BESCHR XVING VAN DE GROOTE HAZELMOIS.}

* * * * * $\mathrm{D}$ * van eene verfchillende kleur, mar het onderfcheidend kenmerk van * deze tivee dieren is in de gedaante van den ftaart: die van de rel****** muis is, van het een. tot het ander einde, met lang hair bedekt; terwyl de ftart van de groore hazelmuis over- het grootft gedeelte zyner leug; te, flegts kort hair heeft, en an het cinde alleen in een kwasje of pluimpje van lang hair uitloopt: de groote hazelmuis is korter van. lighaam en kop, heeft langer ooren, en wat puntiger bek dan de relnuis.

De oogen van de groote hazelmuis, die ten onderwerpe-voor deze befchrvving gediend heeft, waren omringd van cene zwarte ftreep of band, die zig van voren tot aan de knevel uitftrekte, en van agteren tot voorby het oor; daar beneden langs loopende, voortging; daar was ook een weinig zwart boven het oor tegen het onderfte: het voorhoofd, enl het laager gedeelte van dell kop nar voren, was van eene vaale kleur; de kop en het bovenft van den hals, de fclouderen, de buitenzyde van den arm, en van cen gedeelte van den voorarm, de rug, de ribben des lighaams, de finuit, de buitenzyde van de dije van het been, hadden ook eene vaale kleur, mer afchgrauw en zwartagtig bruin gemengd, ondat het hair van eene afchgrauw-bruine kleur was over het grootfte gedeelte zyner lengte; daar wis grauw boven het afchgrauw, en vaal aan de punt; eenige hairtjes waren van eene afchgrauw-zwartagtige kleur van het cen tot het ander einde; die om laag aan de buitenzyde van het been waren, hadden niet dan deze kleur, maar dezelve frekte zig niet tot op den agtervoet uit gelyk by de relmuis: een gedeelte van de zyden des hoofds, het onderft kaakbeen, de keel, het onderft en de zyden van den hnls, de borft, de oxels, het binnen. gedeelte van den arm en van den voolarm, een gedeclte der buitenzyde van den voorarm, de buik, de liczen, het binnen gedeelte van de dije van liet been waren van eene witte kleur, net geelagtige en afchgrauwe lchaduwingen :vermengd; want het hair, hadt over het grootlte gedeelte zyner lengte eene afchgrauwe kleur en eene witte of geelagtige kleur aan de punt: de vier voeten waren met kort wit hair gedekt: het. langite hair van het lighaam was.van zeven lynen, en de. knevels waren een duim en zeven lynen lang.

Lengte des geheclen lighaams in een regte lyn gemeeten van het einde .

duimen, lynes.

van den bek tot an den aars.
lengte van den kop van het einde van den bek tot aan het agterhoofd. Omtrek van het einde van den bek Omtrck van den bek onder de oogen gemeeten Smtrek van de opening des monds Afitand tulfchen de beide neusgaten
Antand van het einde van den bek tot and den voorften hoek van 't ${ }^{\circ}$ oog

$\begin{array}{cc}\text { 4. } & 5 \\ \text { I. } & 5 \\ \text { I. } & 3: \\ \text { I. } & \text { I. } \\ \text { O. } & 6 . . \\ \text { O. } & \text { I. } \\ \text { O. } & 6\end{array}$




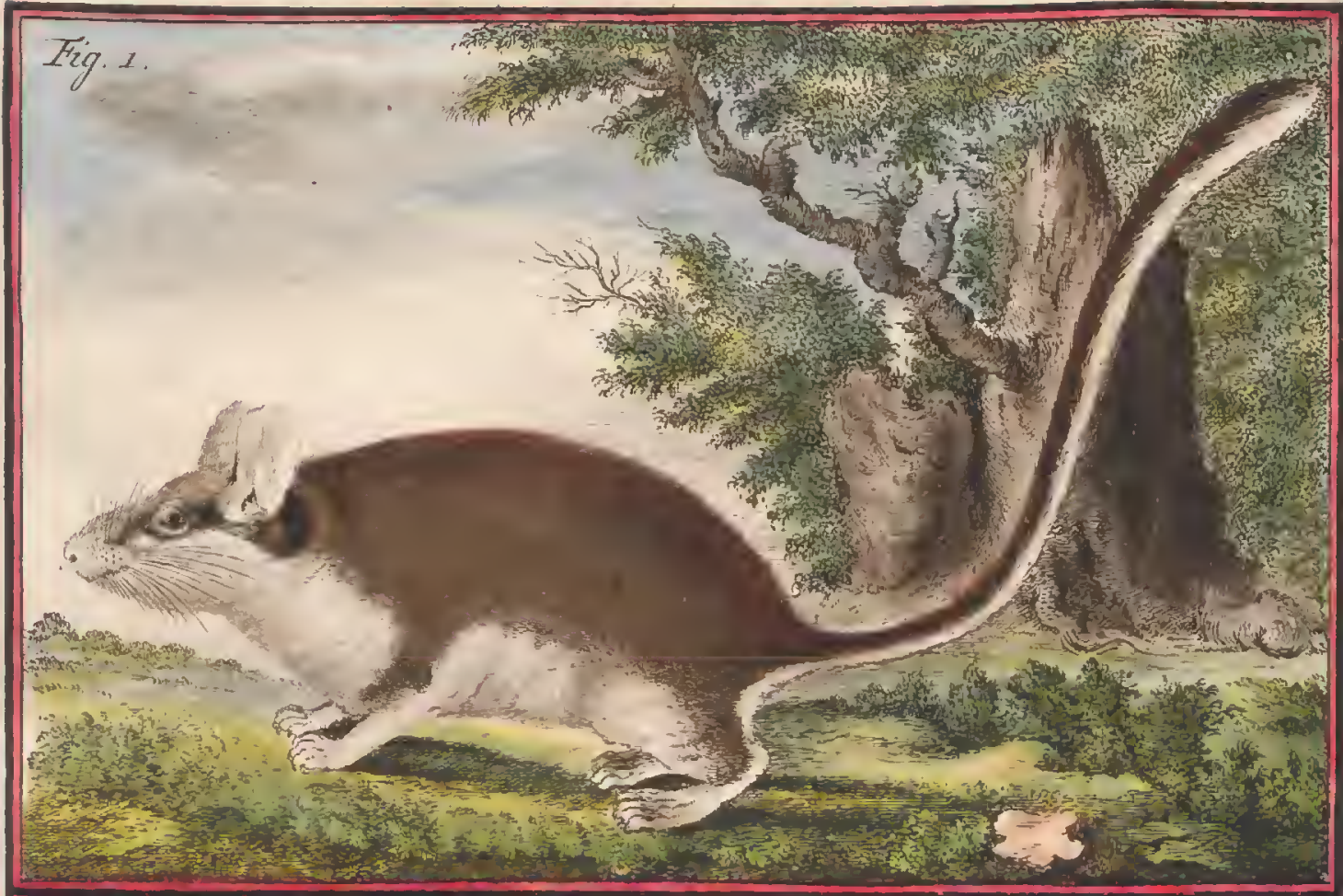

Fig. 2.

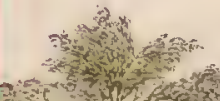

for

Hot on

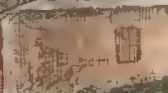

1. $\left.x^{2}+x^{2}+3\right)$

tais -1

totes ot.

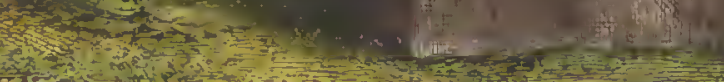

Duree, dal.

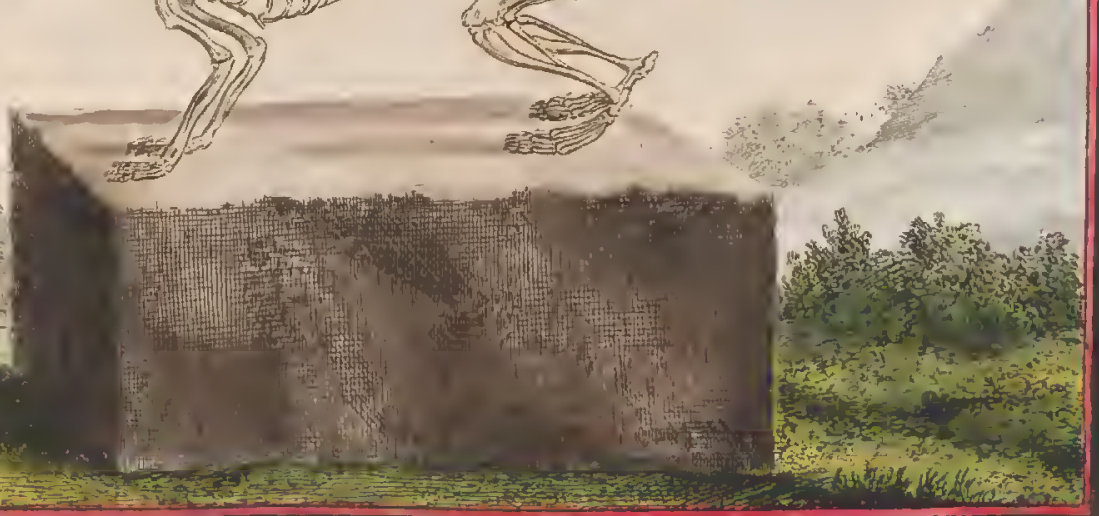

c.F. Fritural fa. 

Affand tuffchen den agterften hoek en 't oor
Lengte van het oog van den eenen hock tot den anderen
Opening van het oog

De groote hazelmuis, dic ten onderwerpe voor de befchryving der weeke binnenfte deelen gediend heeft, was vier en ecn half duim lang van het einde van den bek tot aan den aars, en woog een once vyf en een half gros.

By het openen van den orderbuik zyn 'cr geene blaadjes, aan wederzyde geplatit, gevonden, gelyk als in de relnuis, maar het netvlies ftrekte zig tot de fchamelheid uir; het was ten uiterfen dun en zat aan de darmen vaft; de lever, de milt, het alvleefch, de magg en de darmen hadden dezelfde platefing als in de rclmuis, mar zy waten dikker: de maag hadt eene verfchillende figuur van dic vall de relmuis, want zy was dikker en minder verlengd; de groote blindezak hadt meer diepte, en daar was minder afftand tuffchen den flokdarm in den hoek dien het regter gedeelte makkt.

De lever beltondt wit het zelfde getal kwabben, en hadt dezelfde figuur als: die van de relmuis, maar haare kleur was van buiten en van binnen van een blecker rood; zy woog een half gros en zes-en-twintig greinen.

Het galbiasje was veel kleiner dan dat van de relmuis, het hadt dezelfde $\mathrm{O} 2$ 
gedaante maar zyn kleur was roodagtig, omdat het vogt, daar in bevat, minder met groen gekleurd was dan in het galblaasje van de relmuis.

De milt was verlengd en driehoekig gelyk die vande relmuis, mar zy hadt, in zommige dieren, dezelfde breedte aan 't een einde als aan 't ander; haare kleur hadt een fterker zweemzel van rood; zy woog vyf greinen.

De regternier fprong niet meer vooruit dall de linker, zy waren breeder dan die val de relmuis; voor het overige geleeken zy dezelve zo wel uit-als in-

Het vleezig gedeelte van het middelrif hadt zo weinig dikte, dat het meer dan half doorfchynende was, maar het zenuwagtig middelpunt was het byna geheel; het hart en de longen geleeken naar dic van de relmuis.

Het agterft gedeelte vall het verhemelte val1 de groote hazelmuis was flegts doorfneeden van drie kleine vooren in plaats van vier, die in de relmuis waren; voor het overige geleek het verhemelte, de tong, de ftrotklap, de voorherffenen en de agterherfenen van de groote hazelmuis naar die zelfde deelen. in de relnuis gezien: de voorherfenen van de groote hazelmuis woogen zeventien en een half grein, en de agterherffenen vyf.

De groote hazelmuis, die ten onderwerpe voor de befchryving der teeldeelen gediend heeft, was vier duin ell elf lynen lang van het einde van den bek tot aan den ftaart; hy was op 't einde van juny gedood.

Schoon deze groote hazelmuis dik en vet was, hadt zy egter geen balzak, ook waren de afvoerende buizen $(A B, f g .2$ en $3 P$. $X X I V)$ zo kort, dat zy de zaadballen niet tot buiten den onderbuik fcheenen te kunuen volgen, en ik heb gevonden, dat de knobbeltjes van den opperbal. aan de randén van
het bekken vaft hingen.

Het roedenlicofdje ( $C, f \mathrm{~g} .2 \mathrm{en} D, f \mathrm{~g}: 3$ ) was dik en hadt eene zonderlinge gedaante; het liep uit in een bek ( $E, f$ f. 2 en 3 ) anderhalve lyn lang, die aan het cinde naar omlaag gekrom, en aan het einde van de bovente zyde $(C, f g .2)$ van het hoofdje geplaatit was; men. voelde binnen. in dezen bek een been, dat zig langs het roedenhoofdje uitftrekte, cn het. einde van den bek wierdt geformeerd door dat van de pisbuis; het overige val1 het hoofdje hadt
eene byna rolronde gedaante; de onderfte zyde $(D, f f g .3)$ was met kleine ron-
de en witte kliertjes bedekt; de voorfte de en witte kliertjes bedekt; de voorfte. zyde, die beneden den bek was, was

De knobbeltjes van. den opperbal ( $F G$, fig. 2 en 3 ) waren dik en beftonden uit fam gekluwende viaten, die zo doorlchynende waren als in de rot: de zaadballen ( $H I$ ) waren ook zeer dik; mar het is nier in alle jaargetyden, of ten miniten.niet in alle leeftyden van het dier, dat de. inveudige deelen der voortteeling zo dik zy'1, want ik heb geene dan deze cenige groote liazelmuis gezien, by wie dezclve zo wel geformeerd waren.

De znadvaatjes $(K L)$ fcheene11, nar de klcur te oordeclen, uit twee zelffandigheden te beftan; het gedeelte $(M \cdot N)$, dat zig digft by de pisbuis bevondt, was witugtig, en het ander $(K L L)$ hadt eene geelagtige kleur; wallneer men dezelve egter,'van naby befchouwde, zag men overal hetzelfde maak. $z e l$, en, om zo te fipreeken, hetzelfide weefzel, van vaaten: het is my voorgekomel1, dat zy, in een gedeelte der zaadvaatjes, geene witte kleur. hadden, 
dan omdat zy vol zaadvogt waren; de voorfanders $(0, f g .2)$ waren veel kleiner in de rot, maar op dezelfde plaats gefchikt.

Daar waren aan de zyden van de pisbuis $(P, f g .2$ en 3 ) agter de opregtende en verfnellende fpieren $(Q)$ twee geelagtige klieren $(R)$ van eene eyronde gedaante, welker groote middellyn drie lynen en de kleine twee lynen lengte hadt; zy bevatteden cen melkagtig vogt: men ziet daarenboven in deze twee figuuren, die van natuurlyke grootte zyn, de roede $(S)$, de doorfnydingren $(T, f i g .2)$ van de wortels der fponsagtige lighamen; een gedeelte $(V$, fig. 2 en 3 ) van den regtendarm, den aars $(X)$ en de blaas $(\mathcal{Y})$.

De groote hazelmuis, die ten onderwerpe voor de befchryving van de wyfjes teeldeelen gediend heeft, woog een once drie gros, en hadt ten naftenby dezelfde grootte als die, welker afmeetingen in de eerfte tafel van deze befchryving zyn bygebragt: de kittelaar was zeer zigtbaar cn de voorhuid zeer groot, gelyk ook de fchede, naar evenredigheid van het lighaam des diers; integendeel was het lighaam van de lyfmoeder zeer klein, haare opening en haar hals vertoonden zig nauwelyks; de hoornen waren beide in eene regte lyn gerigt, en makten met het lighaam van de lyfmoeder en de fchede een $\checkmark$; de trompetten waren aan de zyden der zaadballen, die zeer klein waren, gekluwend.

voeten, duimen; lynen.

Omtrek op de dilite plaatfen

Omtrek op de dunfle plaatfen

Groote omtrek van de maag

Kleine omtrek

Lengte van de kleine kromming van den flokdarm af tot aan den hoek, dien het regter gedeelte maakt

Lengte van den flokdarm af tot op den grond van den grooten blindenzak

Omtrek van den nokdarm

Omtrek van dell portier

Lengte van de lever

Breedte

Haare grootfte dilite

Lengte van het galblaasje

Zyn grootfte omitrels

Lengtc vall de milt

Breedte an het onderit einde

Breedte aan het bovenfte einde

Dikte in ' $t$ midden

Dikte van het alvleefch.

Lengte der-uicren

Breedte

Dikte

Lengte van het zenuwagtig miduelpunt van de holle ader af tot aan de punt

Breedte van het vleezig gedeelte tuffchen het zenuwagtig middelpunt en het boxftbeer.

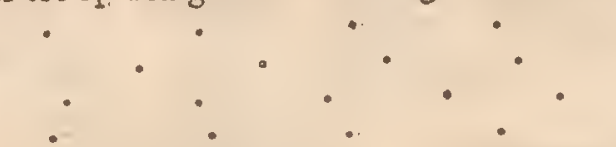

o. 0.4 .

○. ․ $\quad 5 \frac{\pi}{2}$

०. ०. 3.

o. o. 6.

o. O. II.

O. I. 4 .

o. 0.3 .

o. c. $3 \frac{1}{2}$.

o. 0.2 .

o. I. I.

ค. $0.3 \frac{1}{2}$

०. o. $3^{\frac{1}{2}}$

0. $0 . \quad J_{*}^{2}$

o. 0.1

o. 0.6

०. 0.4

o. 0.3 .

o. o. 3 .

o. o. 3

o. $\quad 0 . \quad 3$. 
Breedte van weerszyde van het zenuwagtig middelpunt Omtrek van de bafis van 't hart

Hoogte van de punt af tot aan "t begin van de long-nagader

Hoogte van de punt af tot aar den longezak . . . 0.

Middellyn van de groote đlagader van buiten genomen.$\cdots \quad$ o.

Lengte van de tong

Jengte van het voorfte gedeelte van het toompje tot aan' ' $t$ einde.

Breedte van de tong

Lengte der voorherffenen

Breedte

Dikte

Lengte der agterherfenen

Breedte

Dikte

Afftand turfchen den aars en de opening van de voorhuid

Afftand tuffchen de randen van de voorhuid en het cinde van het roedenhoofdje

Lengte van het hoofdje

Omtrek

Lengte van de roede van de fplitfing der fponsagtige lighaamen af tot an de inplanting van de voorhuid

Omtrek

Lengte van de zaadballen

Breedte

Dikte

Breedte van den opperbäl

Dikte

Lengte der afvoerende buizen

Omtrek over het grootit gedeelte haarer uitgeftrektheid . . .

Groote omtrek van de blaas

Kleine omtrek

Lengte van de pisbuis

Lengte van de zaadblaasjes

Breedte

Dikte

Lengte van de voorftanders

Breedte

Dilite

Afitand tuffehen den aars en de klink

Lengte vant de klink

Lengte van de fchede

Omtrek aan de dikfte plaats

Omtrck aan de dunfte plats

Groote omtrek van de blazs

Kleine ontrek

Lengte van de pisbuis

Omtrek

Omtrek

Lengte van de hoornen der lyfmceder

Omtrek op de dikfte plaatfen

Ontrek aan 't einde van yderen hoorn

O. 4 .

I. 2 .

o. 4 is

o. I.

o. 9.

o. $3 \frac{1}{2}$.

०. 2.

o. 5 .

o. $6 \frac{\pi}{2}$.

o. $\quad 3 \frac{1}{2}$

o. 3.

o. 5 .

O. -4.

O. O. I I

o.

O. 4.

0.

o. 4 .

o. 0.8. 
Aftand in een regte lyn tuffchen de zaadballen en het einde van den

hoorn
Lengte 'van de kromme lyn, die de trompet doorloopt Lengte van de zaadballen

Breedte

Dikte

veten, duimen, lynct.

Het geraamte van de groote hazelnuis ( $P l . X X V$, fig. 2) vergelykende met dat van de relnuis, heb ik daar niet dan zecr kleine verfchillen in opgemerkt; het zal genoeg zyn daar eenige van by te brengen, zonder in eene volledige befchryving te treeden, of de maten der beenderen te geeven; men kan hunne grootte, met betrekking tot die der beenderen van de relmuis beoordeelen uit de tafels, waar op de maaten der uitwendige deelen van deze twee dieren gevonden worden.

De kroonswyze uitfteekzels van het onderft kaakbeen waren wat kleiner dan in de relmuis; daar waren in den ftart twintig wervelbeenderen; de agterfte hoek van 't fchouderblad fyrong meer uit dan by. de relmuis.

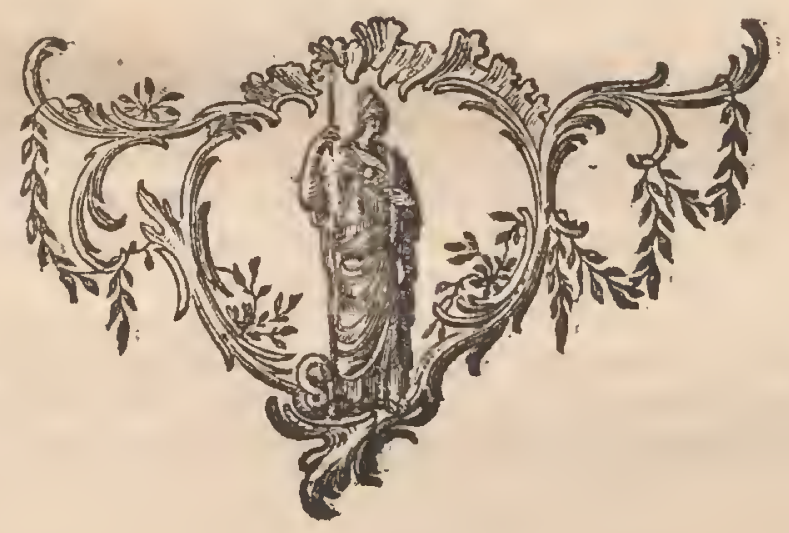




\section{DE I L E I N E H $\Lambda$ Z E L, M U I S *.}

25 kleine hazelmuis is de minft lelyke van alle rotten; zy heeft glin-<smiles>[R]C1CCCCCC1</smiles>

6. fterende oogen, een ruigen ftaart, en haar hair is van een onder1. fcheiden kleur; zy is meer blond dan ros; $z y$ houdt haar verblyf S5y nooit in de huizen, en wordt, gelyk de relmuis, meeft in de bosfchen gevonden, alwaar zy zig in oude holle boomen verbergt: de foort is, op verre na, zo talryk niet als die van de groote hazelmuis; men vindt haar bykans altoos alleen in haar hol, en wy hebben veele moeite gehad om "er eenige magtig te worden; zy fchynt evenwel vry gemeen te zyn in Italie, en zelfs in de Noordfche klimaten gevonden te worden, dewyl de Hr. LiNNeus haar begrcepen heeft in de lyft (a), welke hy van de Zweedfche dieren heeft gegeeven; daarentegen nag men met grond vermoeden, dat zy in Engeland niet gevonden wordt, want $\operatorname{RAY}(b)$, dic haar in Italie gezien hadt, zegt, dat de kleine 1lapp-rot, die men in Engeland aantreft, niet ros is op den rug, gelyk als die van Italie, en dat zy wel van eene andere foort zou kunnen zyn: in Frankryk is zy dezelfte als in Italie, en wy hebben gevonden, dat Aldrovanuus (c) haar wél heeft angeduid; mar die Schryver voegt 'er by, dat 'cr twee foorten in Italie zyn; ecne zeldzaame, waarvan het dier den reuk van muskus heeft, eene andere, die gemeener is, waar van het dier gehecl zonder reuk is; cn dat men die beide foorten te Boulogne kleine hazelmuizen noemt, ter oorzake van de gelykheid, welke $\mathrm{zy}$, zo wel in geftalte als in dikte, met malkanderen hebben: wy kennen flegts ééne der foortell, en die is de tweede, want onze kleine hazelmuis heeft gecne lugt, noch aangcnaame, noch onaangenaame; haar ontbrecken, even als an de groote hazelmuis, die vettige blacien, dic de ingewanden van de relmuis omvangen; ook wordt 7.y \%o vet niet als deze, en, fchoon zy gecne kwaade lugt lieeft, is $z y$ egter niet goed om te eetcn.

De kleine hazclmuis verityft, of wordt verdoofd, door den flaap, en lerte zig als cen kloot in malkander, gelyk als /c relmuis en de groote hazchmuis; zy verlcevendigt, even als deze, in annhoudend zagt weder, en doct ook een voorrand op van hazcluooten en andere drooge vrugten: zy makt har

nefít

* De kleine hazelnuis wordt in 't Franfch Mufcardin geheeten van haren Italiaanfchen naan Mojcaritino; men noenu has ook Ratior, of Ruthort, in Bumronje; en in 't Engelfch Durmaus of heeper; aile welke vier woorden zo veel als $\int$ la $x p$-rot, of $\int$ hap-muis, uithrukiken.

Mus avellanarum minor. A lonov. Hiftr. Quadrup. Wigit. pag. 440.

Mus avellanarum minor. RAY Synoff: Animal. Quadrup. pag. 220.

Mus caitd longd, pilojâ, corpore rufo. gula albicante. LiNNisus.

Glis jupra rufus, infro albicans. Le Croque-nuix. Brisson. Regn, Anim. pag. I62.

(a) Zie Linkas Fauna Suecica, pag. I.L.

(b) Zie Ray Synopf. Anima!. Ouadrut. pag. 220.

(c) Zis Alurov. Hiflor. Quadrus. Digit. pag. 440. 


\section{VAN DE KLEINE HAZELMUIS. IIS}

neft op de boomen, gelyk de eekhoorn, maar zy plaatft het gemeenlyk laager, tuffchen de takken van een hazelnootenboom, in een kreupelbofch, enz: het neft is gemaakt van gras of andere groente, door malkauderen heen gevlogten, het heeft omtrent zes duimen in den omtrek, en is niet dan van boven open. Verfcheiden landlieden hebben my verzekerd, dat zy die neften in hakhout en heggen gevonden hadden, dat dezelve van bladeren en molch omvangen zyn, en dat men drie of vier jongen in elk neft aantreft: zy verlaaten het neft zodra zy groot genueg zyn, en zoeken tene legerplaats in het hol of onder den ftam van oude boomen, en het is daar dat zy haare ruft neemen, dat zy haaren voorrad opdoen, en dat zy haaren winterlaap vol. brengen.

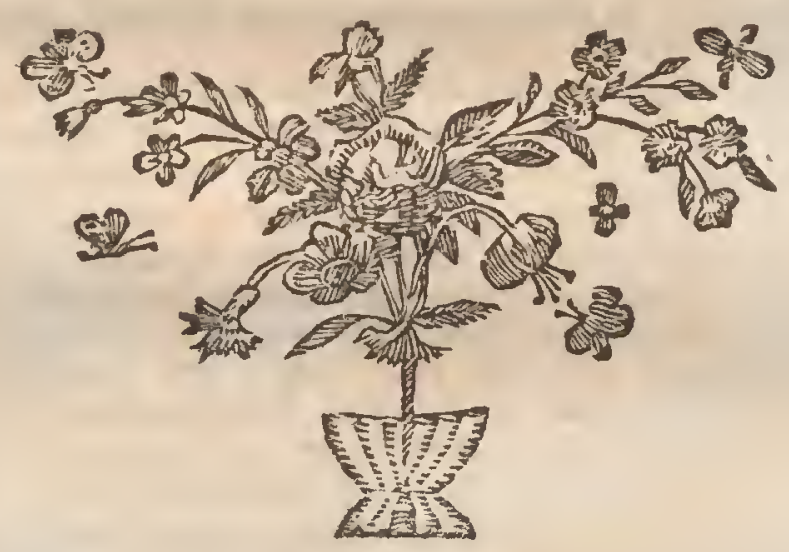

FIII. Dee?. 


\section{BESCHRTVING VAN DE KLEINE HAZELMUIS:}

kleine hazelmuis ( $P l . X X V I)$ is kleiner dan de groote hazelmuis, byna in dezelfde evenredigheid als de groote hazelmuis kleiner is dan de relmuis; zy is wat dikker dan de muis, en zy heeft een breeder kop, meer verlengden bek, grooter oogen en korter ooren; het voorhoofd is verhevener dan dat van de relmuis en de groote hazelmuis, maar de ooren hebben ten naaftenby dezelfde gedannte, en dezclfue grootte als die van de relmuis; zy zyn van buiten en van binnen met kort hair bedekt: de ftart is ook bcklced met hair op de zyden gefchikt, gelyk op den ftart van. de relmuis, maar het is vecl korter, want het kan llegts tweelynen in de lengte haalen: het hair van den ftaart is genoeg om de kleinc. hazelmuis van de veldmuis en de muis te onderfcheiden; zy zyn alle drie ten naftenby van de-. zelfde grootte, en $z y$ hebben den ftaart even lang, maar die van de veldmuis en de muis is kaal; de kleine hazelmuis heeft den kop, den bek, en de. ooren meer verlengd dan de veldmuis.

De zyden en het onderft van den bek en van den kop, dè ooren, de zyden van den hals, defchouders, de buitenzyde van de vier pooten, en de fthart met uitzondering allcen van de punt., waren van eene heldere vale en blonde kleur by de klcine hazelmuis, die ten onderwerpe. voor deze bcfchryving gediend heeft; hot bovenft en de zyden des lighaams en het einde van den ftart hadden eene vale kleur met een zweemzel van bruin: de borít, de buik, en de binnenzyde der pooten waren. van eene greelagtige kleur; het onderft van den hals en de keel, tot aan 't einde van 't onderlt kaakbeen, hadden wit hair; het ander hair van. 't overige des lighaams, nitgezonderd dat van het einde des beks, der ooren, der voeten, en van derr.ftaart, was, over: het grootf gedeelte zyner lengte, van eene afchgrauwe klcur, en hadt geen. val of geelagtig dan aan de punt; de lengte van het langfte hair was van vier lynen, en de knevels konden een duim en twee lynen haalen.

Men heeft onder op de XXVI Plaut de kleine hazelmuis vertoond in de houding die zy lapende heeft.

Lengte van 't geheele lighaam, in cen regte lyn gemeeten, van het

duimen, Jynem.

einde van den bek tot an den aar's.$\quad 3$.

I.cngte van den kop, van't einde van den bek af tot op het agterhoofd. 0 . II.

Omirek van het cinde van den bek . . . 0 . II。

D.ntrek van den bek onder de oogen gemecten - . . . . 1. $=$

Giutrek van de opening des monds

Afitand tufichen de twee neusgaten

$A$ frand tuffilen het cinde van den bek en den voonften hock van 't oog.

Afitand tuffehen den agterften hoek en "t oor

1.engte van het ong van den cenen hock tot den anderen

Opening van het oog 


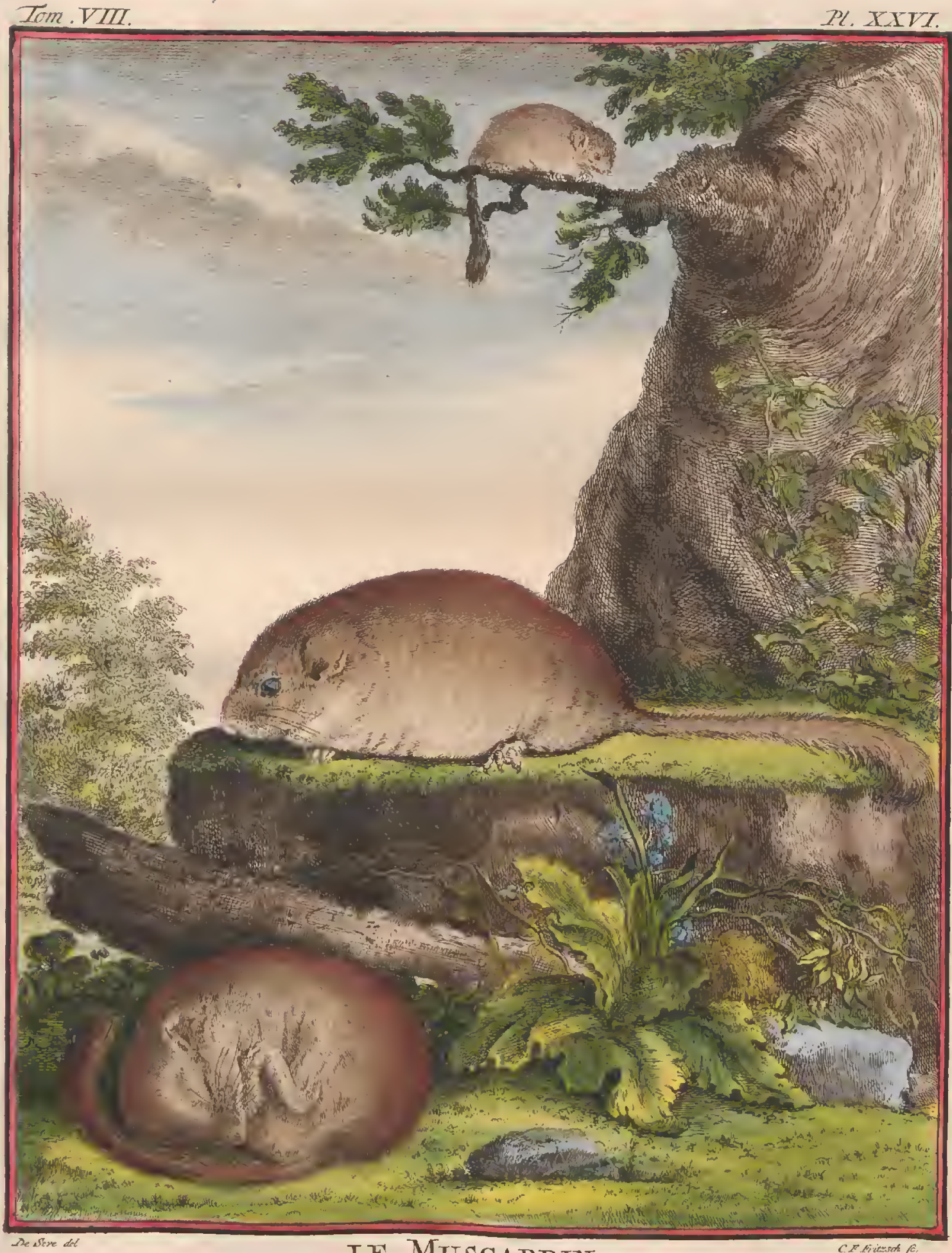

\section{IE MUSCARDiN.}



Afitand tuffchen de voorfte hoeken der oogen volgens de kromming van het neusheen gemeeten

Dezelfle afftand in een regte lyn gemeeten

Omtrel van den kop tuffchen de oogen en de ooren gemeeten

Lengte der ooren

Breedte van de bafis, op de uitwendige krnmming genomen

Afitand tuffchen de twee ooren omlaag gemeeten

Lengte van den hals

Omtrek van den hals

Omtrek vin 't lighaam agter de voorfte pooten gemeeten

Ontrek aan de dikife plaats genomen

Omtreli voor de agterte pooten gemeeten

Lengte van den ftomp des ftaarts

Omtrek van den ftart aan 't begin van den ftomp'

Lengtc van des voorarm van den elleboog af tor aan ' $t$ gewrigt van de hand

Breedte van den vonrarm by den elleboog

Dikte van den voorarm ter zelfder plaats

Omitrek van 't gewrigt van de hand

Omtrel van de agterhand
Lengte van "t gevrigt tot an 't einde der nageien

Lengte van het been van de knie tot aan de hiel

Breedte van 't bovent des beens

Dikte

Breedte ter plaatfe van de hiel

Omtrek van den agtervoet

Lengte van de hiel tot aan 't einde der iagelen

Breedte van den voorften voet

Breedte van den agterfter voet

Lengte der grootite nagelen

Breedte aan de bafis

duimen, lyner.

Dezelfde kleine hazelmuis, daar de afmeetingen in de bovenftaande tafel gemeld, naar genomeri zyn, heeft ook ten onderwerpe gediend voor de befchryving der inwendige weeke deelen.

By het openen van den onderbuik zyn 'er geene vette blaadjes gevonden selyk in de groote hazelmuis, en het netvlies was tuffchen de mang en de darmen verborgen: de ingewanten hadden dezelfde plaatfing als die van de relmuis en de groote hazelmuis; de maag en de darmen hadden dezelfde gedaante als in de groote hazelnuis.

De lever geleek naar die van de relmuis en van de groote hazelmuis; zy was van buiten en van binnen donker-rood van kleur, gelyk de lever van de relmuis; $z y$ woog dertien greinen; het galblaasje verlchilde niet van dat van de relmuis; de milt was verlengd en driehoekigg gelyk de milt van de relmuis en van de groote hazelmuis, zy was van een zwartagtig rood en woog één grein.

De nieren gelecken meer nar die van de relmuis, dan naar die van de groote hazelmuis, zo ten aanzien van hare ligging, als van haare gedaante cen makizel. 
- Het middelrif, hethart, de longen, de tong, het verhemelte, de ftrotklap. de voorherffenen en de agterherffenen geleeken naar die zelfde deelen, in degreinen en de agterherfenen twee en een half grein voorherffenen woogen agt

Tuffchen de teeldeente grem.

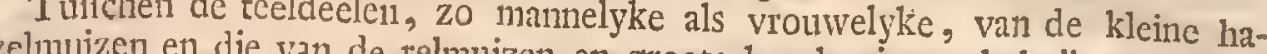
zelmuizen en die van de relmuizen en groote hazelmuizen, heb ik geen verfchil kunnen metken: de zaadblaasjes en voorftanders van de mannetjes kleine hazelmuizen waren zeer klein: derzelver afmeetingen heb ik in de volgende tafel uitgelaaten, omdat ik geloofde, dat $\mathrm{zy}$ alle haare grootheid niet hadden, die $z y$ in een ander faizoen zouden kunnen verkrygen, even als die van de.
groote hazelmuis.

Iengte van de darmbuis van den portier tot aan den aars. voeten, duimen, lynetle. Omtrek op de dikfte plaatfen Omtrek op de duntte plaatfen

Groote omtrek van de maag

Kleine-omtrek

Lengte der kleine kromming van den flokdarm af tot an den hoek,
dien het regter gedcelte maakt

Lengte van den flokdarm af tot op den grond vari den grooten
blindenzak

Omtrek van den nokdarm

Omtrek van den portier

Lengte van de lever

Breedte

Haare grootife dikte

Lengte van het galblaasje

Deszelfs grootite middellyn

Lengte van de milt

Breedte van het benedenft einde

Breedte van het bovenft einde

Dikte in 't midden

Dikte van het alvleefch

Lengte der nieren

Breedte

Likte van het zenuwagtig middelpunt van de holle ader tot aan de

punt

breedte van het vleezig gedeelte tuffchen het zenuwagtig middelpunt

Lengte aan weerskanten van het zenuwagtig middelpunt . . :

Omtrek van de bafis van "t hart

Hoogte van de print af tot aan den oorfprong der longflagader ${ }^{*} o_{0}$

Hongte van de punt af tot aan den longezak
Miiddellyn van de groote fagader van buiten naar buiten gemeeten.

Lengte van de tong einde

Breedte van de tong. 


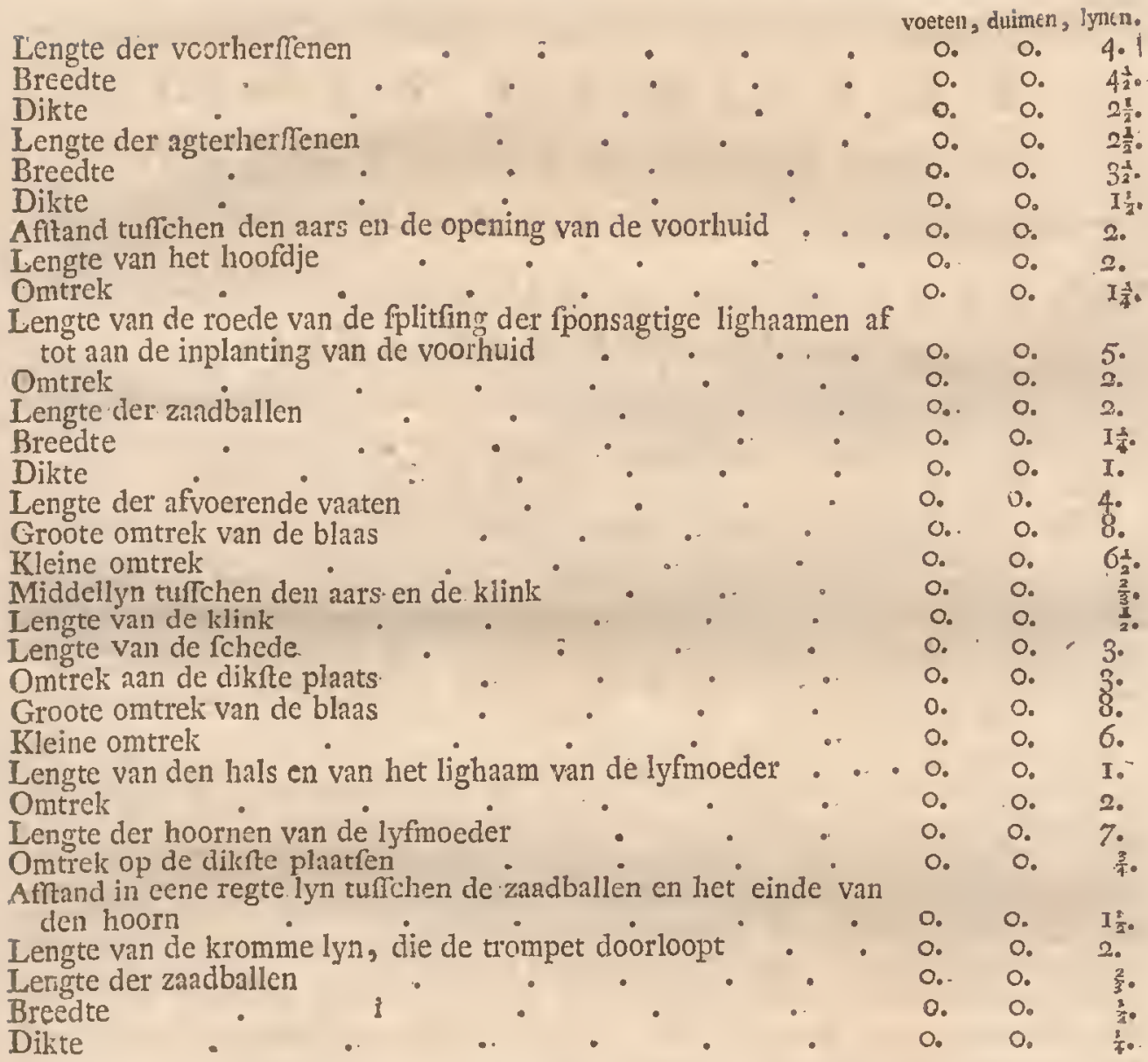

Het geraante van de kleine hazelmuis, hadt zo veele gelykenis met dat van de groote hazelmuis, als 'er tuffchen het gernamte van de groote hazelmuis en dat van de relmuis gevonden is; ik laat hierom ook de befchryving en de maaten der beenderen van de kleine hazelmuis, even als die der beenderen van de grooie hazelmuis, agterwege: ik zal alleenlyk aanmerken, dat de kroonswyze uitfteekzels van het onderft kaakbeen evenredig kleiner waren dan: die van de groote hazelmuis: daaz waren in den ftaart drie-en-twintig valfche wervelbeenderen; de voorfte zyde van ' $t$ fchouderblad is my bolronder voorgekomen dan in de groote hazelmuis.

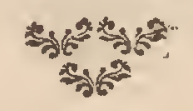




\section{$\begin{array}{lllllllllll}B & E & S & C & H & R & Y & V & 1 & N & G\end{array}$}

VAN DAT GEDEELTE VAN HET KAHINET,

\section{HETWELK BETREKKING HEEFT TOT DE NATUURLYKE HISTORIE}

\section{VAN DE RELMUIS, DE GROOTE HAZELMUIS, EN DE KLEINE HAZELMUIS.}

No. DCCXCIV. Een relmuis.

No. DCCXCV. Een groote bazeimuis.

No. DCCXCVI. Fen kleire barelmuis.

Deze drie dier-jes worden in wyngeeft bewaard.

No. DCCXCVII. Drie junge kleine bszelmuizer.

Zy zyn flegts een duim en agt lynen lang van het einde van den bek tot aan den oorfprong van den ftart; heur hair is van cene vaalbruine kle ur, het helderval en blond der volwaflenen vertoont zig niet dan op zommige deelen des lighaams; $z y$ zyn, even als de drie vorige, in wyngeeft.

No. DCCXCVIII. Het geraume san eene relmuis.

De lengte van dit geritumte is zoven duim negen lynen van het einde der neusbeenderen tot aan het agtert cinde der heupbeenderen; de kop heeft twee duim vyf.lynen omtrek, aan de dikfte plats gemeeten.

No. DCCXCIX. Het tungheen vas eene relmuis.

Dit been beltaat tit negen ftukken, warvan de twee eerfte, aan weerszyden één, veel langer zyn dan eevige der andere.

No. DCCC. Het raede-been van een relmatis.

De lengte van dit beentje is flegts van twee lynen, het einde, "t welk aan de pponsagtige lighanmein valt was, hecf anderhalf lyn breedte, de breedte van ${ }^{\prime} t$ ander einde is flegts van cene halve lyn.

No. DCCCl. Het geraante van een groote bnzelmuis.

Dit gerante heeft vier duim zes lynen lengte van het einde der neusbeenderen tot aan het agterft einde der heupbeenderen: de ontrek van den kup, aan de dikfte plaats gemeeten, is van twee duimen.

No. DCCCII. Het tongbeen van cene groote bazelnuis.

Dit becn gelykt nar dat van een relmuis.

No. DCCCIII. Het riede beemic van een groote bazelmuis.

De lengte van dit beentje is flegts van twee lynen.

No. DCCCIV. Het geraams van een kleine baxelmuis.

Dit geraante heefit drie duim vier lynen lengte van het einde der neusbeenderen tot aan het agterfte der heupbeenceren: de kop heef een duim en vyf lynen omtrek, an de dikfte plants genomen.

No. DCCCV. Het tongbeen van een klcine bazelmuis.

Dit beentje geiykt nar dat van de relmuis en van de groote hazelmuis.

No. DCCCV!. Het roede beentje van een kleine bazelmuis.

De lengte van dit beentje is llegts van anderhalve lyn. 


\section{E G R O O T E V E L D M U I S *.}

a geeven den nam van groote: veldmuis aan eene nieuwe foort van $W$ T veldmuis, die niet dan fints eenige jaren is bekend gerveeft; geen 1. Natuuronderzoeker heeft van dit dier gefprooken, behalven alleen den $\mathrm{Hr}$. Brisson, die, het onder het gellagt der rotten bevattende, het daarom ook rat de bois, of bo/cb-rut genaand heeft: maar gelyk het even zeer verfchilt van de rot als de veldmuis en de muis, die haare eigen byzondere naamen hebben, zo moet men het billykerwyze ook met een onderfiheiden naam aanduiden, en die van furmulot, als of men zeide groote mulot, of groote veldmuis, is ons de natuurlykfte voorgekomen, omdat dit dier inderdaad zo wel in kleur als in wyzen van doen en leeven meer nar de veldmuis dan naar de rot gelykt; de groote veldmuis is fterker en kwaadaartiger dan de rot; zy heeft ros hair, een zeer langen en kalen ftart, haar ruggegraad is gekromd gelyk dic van den eekhoorn, mar haar lighanm is veel dikker, en zy heeft knevels gelyk een kat; het is niet meer dan negen of tien jairen geleden $(a)$, dat deze foort van dieren zigin den omtrek.van Parys verfpreid hebben; men weet niet van waar zy gekomen zyn, max zy hebben verbaazend fterk toegenoomen, en men zal zig daar over niet verwonderen, zodra men weete, dat zy doorganns twalf of vyftien jongen werpen, diliwils zeftien, zeventien, agttien, ja zelfs tot negentien: de platen, daar zy het eerit verfcheenen zyn, en daar men haar welhatt heeft opgemerkt, door de vernielingen, dic zy anmegteden, zyn Chantilly, Marly-la-Ville, en.Verfailles. De Hr. LE ROY, Opziener van het pirk, heeft de goedheid gehad ons dezelve in eene goede menigte te zenden, zo wel leevende als doode; hy heef ons zelfs de waarneemingen medegedeeld, welke hy over deze nieuve foort van dieren gemaakt heeft: de mannctjes zyn grooter, ftouter, en kwandaartiger dan de wyfjes; wanneer men hen vervolgt, en denkt te vatten, draaijen zy zig on en byten in den ftok of in de land, die hen wederitant; hume: beet is niet flegts gerveldig, manr zelfs gevaarlyk; zy wordt fchielyk van eene vry sroote zwelling gevolgd, en de wonde, fchoon klein, heeft langen tyd noodig, eer zy fluiten wil: zy teclen driemanl in ' $t$ jaar, dus brugt én parar van deze dieren ten minften zes-en-dertig van humne foor in een jaar tyds in wezen: de moeders bereiden een bed vor hare jongen; dewyl zommige der geene, die men ons leevende gezonden bak, werkelyk droegen, en wy dezelve in kooijen bewarden, zo hebben wy de wytjes, twee of drie dagen voor dat zy wierpen, de houten vloer van hare kooy zien knabbelen, daar eene menigte fpanders van makien, en haar dezelve zien uitlirekken, en fchikken, om tot een bed voor hatre jongen te dienen.

De groote veldnuizen hebben cenige natuurlyke hoedanigheden, die haar

*. Rat de bois. Mus cauda longidond fupra dilute fulous, infra albicans . . Mís fylves. sris. Brisson. Regn. Animal. pag. 170, in 't Franich Suminilot.

(a) De Hr. DE Buron heeft dit in 1757 of 1758 gefchreeven. 
cenigzins tot de waterrotten fchynen te brengen; fchoon zy zig overal nederflaan, fchynen $z y$ egter de oevers der wateren te verkiezen : de honden maaken "er jagt op", gelyk op de waterrotten, dat is te zeggen met eene woede, die narr dolheid gelykt: wanneer zy bemerken, dat $\mathrm{zy}$ vervolgd worden, en de kenze hebben om zig in 't water te ftorten, of in een doomenbotich in te dringen, dat op een gelyken afftand van haar af is, verkiezen zy het water, loopen daar onbefchroomd in, en zwemmen met eene verwon.lerlyke gamaklykheid: dit doen zy inzonderheid wanneer zy haare holen niet kunnen wedec winnen, want zy graaven zig, gelyk de veldmuizen, onderataflche verbıyfplateen, of zy legeren zig in die der konynen: men kan ie groote veldnuizen met fretten in haare holen vangen; deze vervolgen haar gelyk de konynen, en fchynen haar zelfs met meer drift te zoeken.

Deze dieren brengen den zomer in 't veld door, en fchoon zy zig voornaamlyk met vrugten en koorn voeden, laaten zy egter niet na ook zeer vleêfchvreetende en verflindende te zyn: zy eeten de lampreirjes, de jonge patrysjes, en ander klein gevogelte, en zo zy in een hocnderhok komen, houden zy "er byna op dezelfde wyze huis als de buntfings, zy brengen 'er veel meer om hals dan zy ecten kunnen.

Tegen de maand van november -verlaten de moeders, de jongen, en de onvolwafenen, het veld, en begeeven zig troepswyze naar de ciluuren, alwaar zy zeer groote fchade doen, $2 y$ byten het ftroo ftutk, verllunden veel graan, en befmetten al het overige net haare vuiligheid: de oude mannerjes blyven in 't veld; elk hunuer woont afzonderlyk in zyn eigen hol; zy doen daar, gelyk de veldnuizen, geduurende den herfit een voorraad op van eekels, van beuken, enz.: zy vullen hum verblyf tot den rand toe, en blyven zelve op den bodem; zy verftyven daar nict gelyk de relmuizen, zy komen 'er des winters uit ta voorfchy11, inzonderheid by mooy weder: zy, die zig in de fchuuren verhouden, verdiyven de muizen en.rotten, men heeft zelfs opgemerkt, dat de rotten, zedert dat de groote veldmuis zo taterk rondon Parys vermenigvuldigd is, daar veel minder geneen zyn, dan zy te voren svaren.

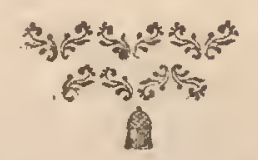


• 


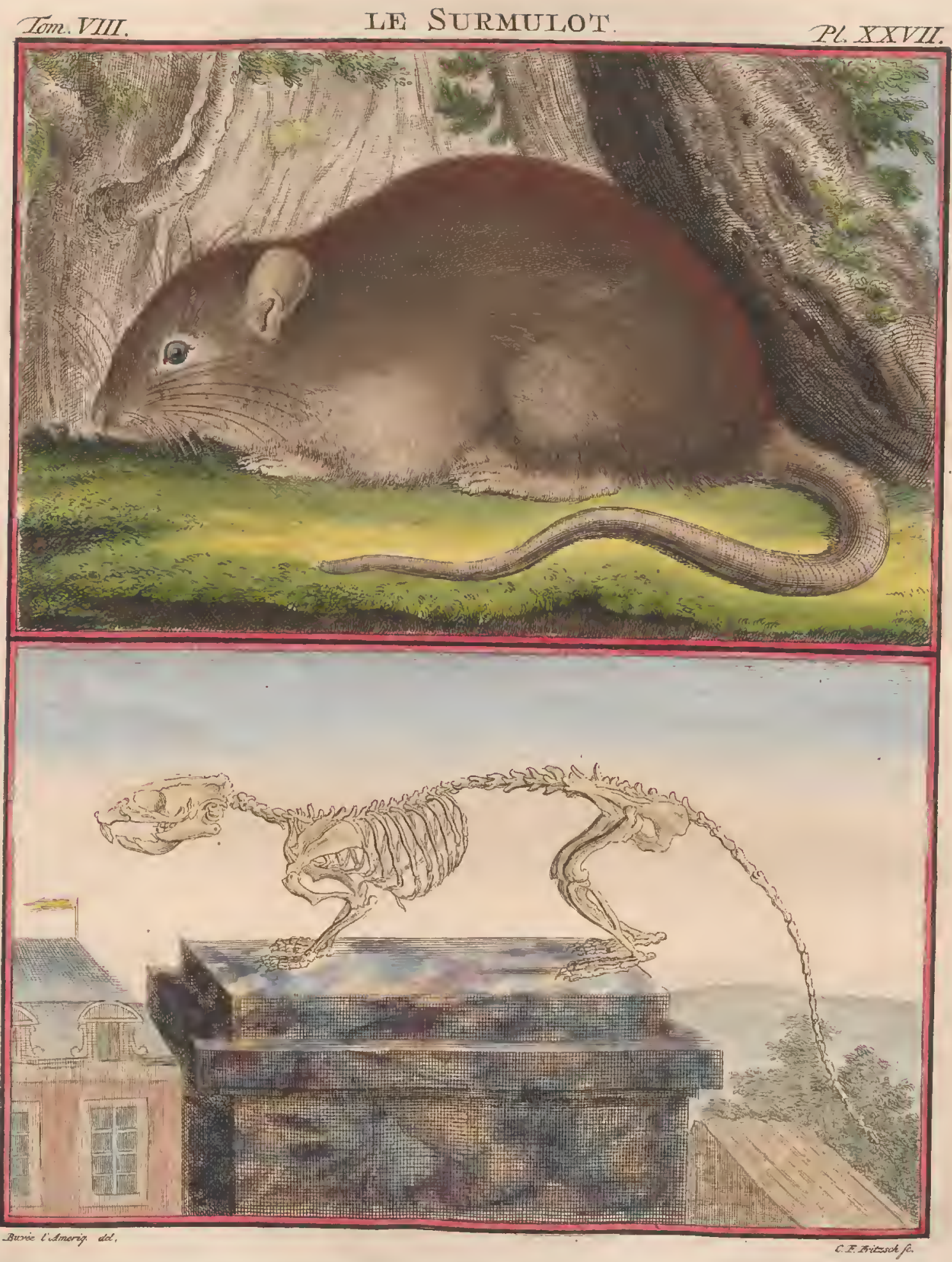




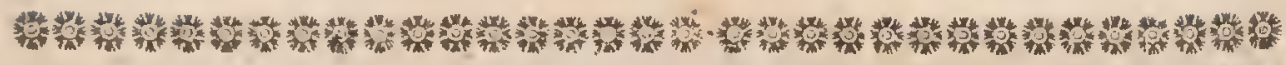

\section{BESCHRTIING VAN DE GROOTE VELDMUIS.}

$\mathrm{D}$

Dre gronte veldnuis (Pl. XXVIT, fig. I) geiykt naar de rot in de ge9. ftalte cies lighaams, maar zy is veel grooter; de rug makt dikwils 6. een bolronden boog, die aan den oorfprong vali den ftaart begint, 3. dier is lang, het heeft een dunuerr bel en het onderft kaakbeen zeer kort; de ooren zyn breed en gerond; de oogeil zyn zwart, groot, rond, ell zeer uitfpringende: het hair van de groote veldmuis, die ten onderwerpe voor deze bechchryving gediend heeft, hadt verfchillende zweemzels van bruin, van vaal, van afchgrauw, en van grauw, maar zo, dat het bovent van den kop en van den hils, de rug; de lendenen, en het kruis, met bruin, vaal, en grauw genengd waren, ondat het eind der hairtjes van eene bruine kieur was, ondiat'er yaal op het bruin volgde, ell het overig gedeelte van yder hairrje eene afchgrauwe kleur hadt: de zyden van liet hooft, van den hals, en van 't lighaan, litdkn eene geelagtige kleur met grauw, en afchgrauw-bruin, gemengd; de keel, de borf, en de builk waren vuil wit met cen ligt zweemzel van afchgrauw : hat Jangite hair konde manr ontrent een duin halalen, en het grof hair der knerels was twee duin lang' 3 de voeten waren wit en met zeer kort hair bezet: de ftaart is bedekt met kleine fchubbetjes op de eigen wyze als die van de rot gefchikt, en daar zyn tuffchen die lchubbetjes eenige korte hairtjes; ik heb tot twee honderd fchubagtige ringen op den ftaast van eene groote veldnuis geteld, fchoon hy maar zes anim en drie lynen lengte hadt: de duim der voorfte voeten is zo kort als die van de rot, de duim der agterfte voeten is wél geformeerd; de knobbeltjes van de plant der voeten zyn ook in kleinen getale, en in dezelfde fchikking gils die van de rot.

Lengte van 't geheele lighaam, in een regte lyn gemeeten van het einde van den bek tot an den aars

Lengte van den kop van het einde van den bek tot an 't agterioof

Omtrek van den bek aan 't einde van de onderite lip gemeeten ${ }^{\circ} \cdot{ }^{\circ}$
Omtrek van de opening des monds van de eene fplyting der lippen tot aan de andere

Afitand tuffichen de twee neusgaten

Affand tuffehen het einde van den bek en den voorften hoek van 't oog.

Afitand tuffchen den agterfen hoek en 't oor
Lengte van het oog van den eenen hoek tot den anderen

Opening van 't oog Omtrek van den kop tuffchen de oogen en ooren genomen - . 4 Lengte der ooren

Breedte van de bafis op de uitwendige kromming genomen

Aftand tuffchen de twee ooren, onlang genomen

Lengte van den hals WIIL. Deel:

duimen, Iynen.

9. 3.

2. 3

2. 4 .

I. 0 .

o. 2.

I. 0 .

o. IO.

o. 3.

o. 2.

7.

4. 0

8.

०. 8.

o. II.

○. $\%$ 
Omtrek van den hals

Omtrek des ligliaams agter de voorfte pooten

Omtrek aan de dikfte plaats gemeeten

Omtrek voor de agterfte pooten genomen

Lengte van den ftomp des ftaarts

Omtrek van den ftaart aan "t begin des ftomps

Lengte van den voorarm van den elleboog af tot aan 't gewrigt van de
hand

$$
\text { hand }
$$

Omtrek van den voorarm by den elleboog

Omtrek van 't gewrigt van de hand

Omtrek van de agterhand

Lengte van het gewrigt af tot "aan 't eind der 11agelen

Lengte des beens van de knie tot aan de hiel

Omtrek van het bovenft des beens

Breedte ter plaatfe van de hiel

Omtrek van den agtervoct

Lengte van de hiel af tot aan 't einde der nagelen
Breedte van den voorften voet

Breedte van den agteriften voet

Lengte der grontite nagelen

Breedte aan de bafis

De groote veldmuis, waarop de afmeetingen in de voorgaande tafel bygebragt, genomen zyn, woog dertien oneen vyf en een half gros: het netvlies was zeer dun, en ftrekte zig tot in 't midden van den onderbuik uit.

De twaalfvingerigedarm ftrekte zig uit in de regterzyde en weeke buikzyde, alwaar hy zig binnenwaards vouwde; hy verlengde zig naar voren, en voegde zig vervolgens an den nugterendarm, die zyne draajingen in de navelftreek en in de zyden maakte; die van den omgebogendarm waren in de darmbeentreeken en in den eigenlyk gezegden onderbuik; de omgeboogendarm voegde zig in die ftreck aan den blindendarm! de blindedarm ftrekte zig in de linkerzyde uit, en vouwde zig weiler over in de navelftreek; maar die plaatfing is niet fandvaftig, want ik heb hem in andere onderwerpen voorwaards in ' $t$ midden van den onderbuik vitgeftrekt gezien: de kronkeldarm ftrekte zig in de regterzyde uit, hy vouwde zig agter de lever onder den twaalfvingerigendarm, hy liep agter de maag en voegde zig eindelyk aan den regtendartin.

De maag geleck nar dic van de rot; de darmen hadden dezelfde gedaante en dezelfde plaatling; de lever beftondt uit even veel kwabben als in dit dier, maar zy hadt eene bleckroode kleur van buiten, en was nog bleeker van binnen; zy wog vier gros en veertig greinen: daar' was geen galblasje.

De milt ftrute zig fchuinich, van boven naar beneden en van voren naar agteren, in de linkerzyde uit; $z y$ was verlengd even als die van de rot, en $z y$ hadt ook drie zyden, twee binnen en eene buiten; het onderft gedeelte hadt de meefte breedte, en het midden was fmaller dan het bovenft gedeelte: dit ingewand hadt van buiten en van binnen eene donker-roode kleur; het woog
twee-en-dertig greinen.

Het alvleetib formeerde negts kluwentjes van klieren, gelyk als in de rot, 
en de nieren verfchilden niet van die van de rot, dan voor zo verre de" regter-nier haare gehecle lengte meer vooruittak dan de linker: de nierklieren hadden dezelfde kleur als die van de rot, maar zy hadden drie lynen lengte, twee en eene halve lyn breedte, en eene lyn dikte; de zelfitandigheid van 't bimnenft was van eene bleckroude kleur, uitgezonderd in 't middelpunt, alwaar de kleur grauw was.

Het zenuwagtig middelpunt van het niddelrif was weinig nitgeftrekt, en het vleezig gedeelte hadt weinig dikte: de longen geleeken naar die van de rot: het hart was zeer dik en byna rond; daar kwamen drie takken uit den boog van de groote flagader.

De tong, liet verlicmelte, de ftrotklap, de voorherfenen, en de agterherffenen gelecken naar die zelfde deelen in de rot gezien; de voorherfenen woogen een half gros en de agterherfienen twaalf grein.

De groote veldmuis heeft twaalf mammen, zes aan weerszyde, drie op de borft, en dric op den buik; ik heb eci wytje gezien, dat"er marr elf hadt; de derde van de linkerzyde van de borft ontbrak.

De balzak was zeer dik; het roedenl1ofdje, de roede, de klieren, die in de voorhuid, ter zyde van het hoofdje, waren, de zaadballen, de opperbal, de afvoerende vaten, de zaadblaasjes, en de voorftanders, verfchilden nict van die zelfde declen, in de rot gezien, dan in de grootte; de klieren in de voorhuid hadden in de groote veldmuis elf lynen lengte, vier.lynen breedte in het bovenft gedeelte, en eene en een halve lyn dikte.

Daar waren tuffehen de voórltanders en de blas tivee celagtige lighaamen, ran cene zeer wceke zelfitandigheid, die door een celagtig weefzel aan de, pisbuis vafthingen; $z y$ hadden elk tien lynen lengte, vier lynen breedte, en: anderhalve lyn dikte; zy liepen, aan de zyde van de pisbuis, in een punt uit, en waren ann het ander einde gerond.

Daar was, aan de buitenzyde van ydere afvocrende buis, by de zadblaasjes, een klein witagtig en gekorreld lighaampje, dat ontrent twee lynen lengte, een lyn breedte, en een halve lyn dikte hadt.

Het wyfje, dat ten onderwerpe voor de befclryving der teeldeelen gediend heeft, was agt en een, half duim laing van het einde van den bek tot aan het begin van den ftaart; de omtrek van den kop was van drie en een half duin; liet lighaan hadt vier duim drie lynen ontrek agter de voorfte pooten, zes duimen in 't midden op de dikfte plaats, en vier duin agt lynen voor, de agterite pooten.

De kittelaar was niet in de klink, hy rvas voorvaards geplaatft gelyk die van 't ivyfje van de rot; de buis, die de voorhuid van de wyfjes groote veldmuis formecrle, was op dric lynen affands van de.klink; eindelyk alle de teeldcelen, zo wel in ais uitwcndige, verfchilden in deze twee wyfjes niet dan in grootte.

lik heb vier drangende wyfjes van de groote veldmuis geopend; het dikfte woog een pond en een once; harre lengte van het einde van den bek tor ann het begin van den ftaart was van negen duim en tien lyncu: elk dezer vier wyfjes hadt twalf nuammen gelyk in de befchryving van het mannetje gezegd is; de tepels van het dikfte wyfje hadden tot zes lynen lengte, wanneer mit 
dezelve uittrok; dit wyfje droeg elf vrugtjes, zes in den linkerhoorn van de lyfmoeder en vyf in den regterhoorn: het tweede en derde wyfje hadden elk twaalf vrugtjes by zig, zes in yderen hoom, mar ik heb 'er maar tien in het vierde gevonden, vyf aan weerszyde : een ander wyfje droeg zeven vrugtjes in den linkerinoorn, zonder dat "er een in den regterhoorn ware.

De meederkoek van yder vrugtje was bolrond van buiten, vlak van binnen, en van eene gemengde roodagtige en zwartagtige kleur op de beide $z y$. den; in het dikfte wyfje hadt ydere moederkoek zes lynen miduellyns en hanre grootfte dikte was van anderhalve lyn: de navelftreng liep op het middelpunt van de moederkoek uit en was elf lynen lang; men bemerkte daar de drie bloedvaaten als roodagtige draadjes: deze vrugtjes hadden een duim lengte van de kruin des hoofts tot aan het begin van den ftart; wanneer $z y$ vyftien lynen lang zyn, zyn zy nog niet naby den tỷi der geboorte.

Lengte van de dunne darmen van den portier af tot aau den blinden- vocten, duimen, lynenor

darm $\quad$ d d d

Omtrek van den twaalfvingerigendarm op de dikfte plats.

Omtrek op de dunfte plaatien

Omtrek van den nugterendarm op de dikfte platefen . - .

Omtrek op de dunfte plantfen

Omtrek van den omgebogendarm op de dikite plaatfen

Omtrek op de dunfte plantfen

lengte van den blindendarm

Omtrek op de dikfte pliats

Omtrek op de dunite plants.

Omtrek op de dunite platifen

Omtrek tan den regtendarm by den kronkeldarm

Omtrek by dell aars

Lengte van den kronkeldarm en den regtendarm te famengenomen.

Lingte van de geheele darmbuis, dell blindendarm daar niet in begrecpen

Groote omtrek van de maag

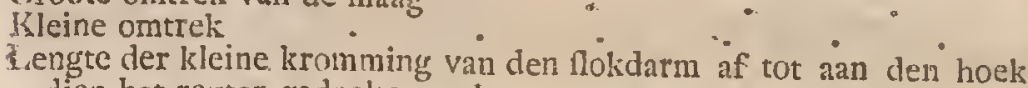

dien het reyter gedeelte makt
Lengte van hei linker gedeelte van den flokdarm af tot aan den grond van den grooten blindenzilk

Omtrek van den llokdarm

Ontrek van dell portier

Lengte van de lever.

Breedte

Haare grootfte dikste.

I,engte van de milt

Breedte van bet onderft ein ile

lireedte van het bovenft einde

Breedre in ' $t$ midden

Dikte

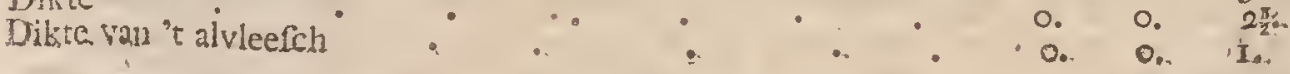

\begin{tabular}{rrr} 
5. & I. & 0. \\
0. & 0. & 10. \\
0. & 0. & 7. \\
0. & 1. & 0. \\
0. & 0. & 9. \\
0. & I. & 0. \\
0. & 0. & 7. \\
0. & 2. & 3. \\
0. & 2. & 8. \\
0. & I. & 6. \\
0. & 2. & 0. \\
0. & 1. & 0. \\
0. & I. & 3. \\
0. & 0. & 10. \\
\hline & 0. & 0.
\end{tabular}

I. 0.0 .

6. I. 0 .

०. 6.6 .

o. 3.6 . 6.

o. $0 .: 3$.

o. I. S.

०. $0 . \quad 6$.

o. 0.

o. 2. 4.

o. I. 9 .

o. 0.7 .

०. 2. 4.

०. ०. 5 .

०. ०. 4.

o. o. 3 .

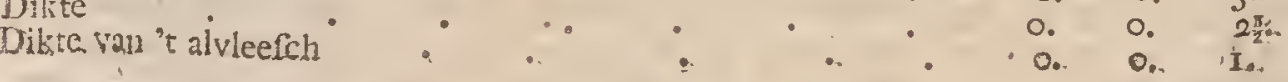


Lengte der nieren

Breedte

Dikte

Lengte van liet zenuwagtig niddelpunt van de liolle ader af tot aan de punt

Breedte
Breedte van het vlcezig. gedeelte tuffchen het zenuwagtig middel-

punt en het borftbeen
Breedte van weerszyde van het zenuwagtig middelpuit

Omtrek van de bafis van 't hart

Hoogte van de punt af tot aan den oorfprong van de lonflagader.

Hongte van de punt tot aan den longenzak

Middellyn van de gronte flagader van buiten naar buiten gemeeten.

Lengte van de tong

voeten, duimen, lynemi einde

Breedte van de tong

Lengte der voorherffenen

Breedte

Dikte

Lengte der agterherfenen

Breedte

Dikte

Afitand tuffchen den aars en den balzak

o. O. II.

o. o. 7 .

o. 0.5 .

Hongte van den balzak

Afrand tuffehen den balzak en de opening van de voorhuid . . 0 .

Aftand tuffchen de randen van de voorhuid en het einde van de. roede

Lengte van het hoofdje.
Omtrek

Lengte van de roede van de fplitfing der foonsagtige lighaamen af tot aan de inplanting van de voorhuid

Omtrek

Lengte der zaadballen

Brcedte

Dikte

Breedte van den opperbal

Dikte der afvoerende vaten

o. 0.6 .

o. 0.5 .

Middellyn op het grootft gedeelte hunner uitgeftrel.theid . . . o.

Middellyn by de blaas

Groote omtrek van de blaas

Kleine omtrek

I,engte van de pisbuis

Omtrek

Lengte der zaadblaasjes

Breedte

Dilite

Lengte der voorftanders

Breedte

०. 3 . 3

o. 2.

o. . O. II.

o. 0.7 .

o. O. It.

o. I. 3 .

Dikte

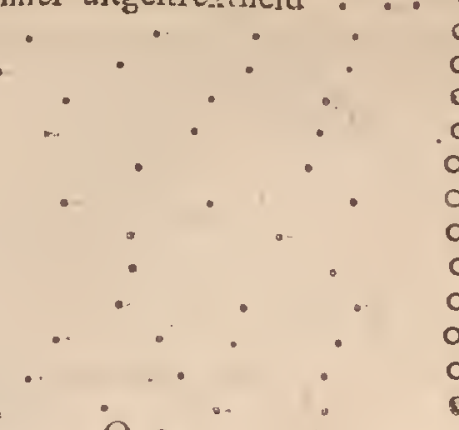

o. o. 3:

०. ०. 6.

8.

c. 3.

o. o. 8.

०. 8.

o. 4.

o. 5

C. 3.

0. 2

o. 7.

o. 5 .

o. IO.

O. 4 .

o. II.

0. 5 .

o. 4 .

0.

2. 8.

०. $\frac{2}{3}$.

I. $6^{13}$

I. 4.

o. 6

I. ?:

o. 2 . 2

0. 4.

o. 2 .

o. $I_{3}^{\prime}$.

Q 3

c. 0.5 . 


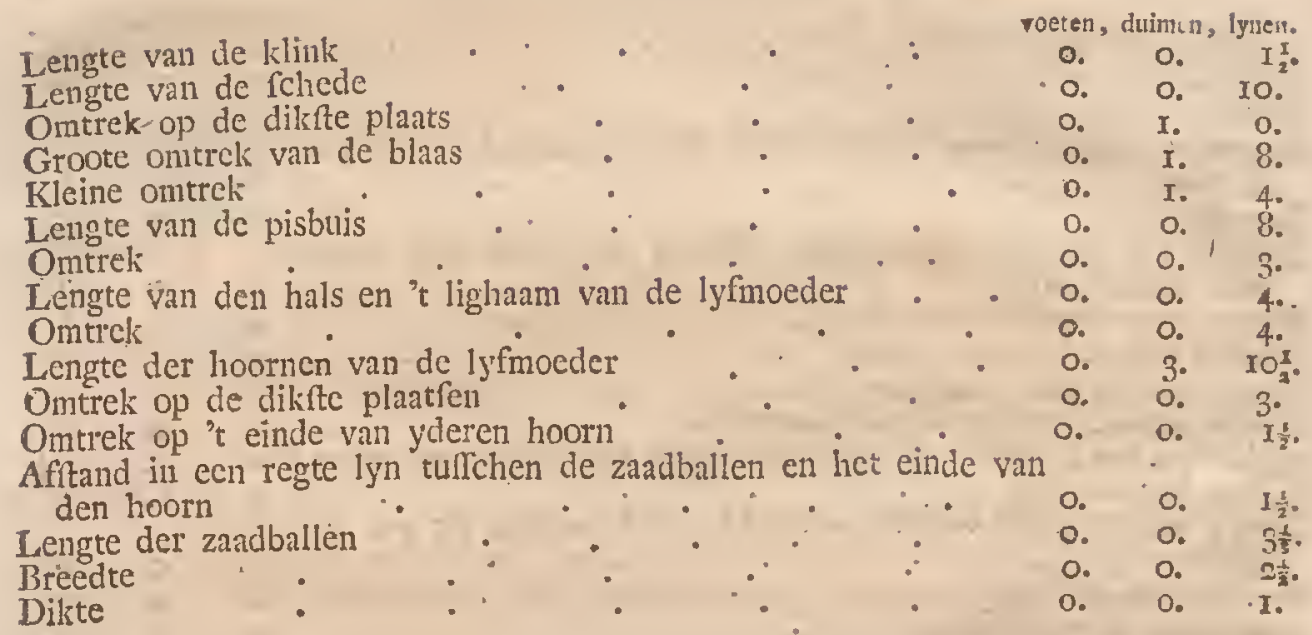

Het geraamte van de groote veldmuis ( $P$ l. $X X V I I$, fig. 2 ) gelykt byna geheel naar dat van de rot in het getal, de figuur, en de fchikking der beenderen en der tanden, nitgezonderd het getal der beenderen van het borftbeen en van de valfche wervelbeenderen van den ftart; ik heb zeven wel onderfcheiden beentjes geteld in het borftbeen van de grootfe en oudfte groote veldmuizen, mar in de andere waren het vyfde en zesde beentje met malkanderen verward, gelyk als in de rot: wanneer "cr zeven becntjes in liet borftbeen waren, was 'er ook eene valfche ribbe meer, want de zesde ribben geiedigden zig tuffchen het vyfde en zesde beentje, en de zevende en agtfte ribben tusfchen het zesde en het zevende. beentje, van het borftbeen; daar zyn dertig valfche wervelbeenderen in den ftart gevonden.

De befchryving van de rot, in het zevende Deelvan dit Werk te vinden, kan die der beenderen van de groote veldmuis, gelyk ook die der ingewanden, vervullen; ook laat ik de tafel der maaten van de beenderen van dit dier agter, omdat men de verfchillen van grootte, die tuffchen deze bcenderen en die van de rot plaats hebben, kan beoordeelen door de tafel der afmeetingen van de uitwendige deelen van de groote veldmuis te vergelyken met die der zalfde deelen, op de rot gemeaten. 


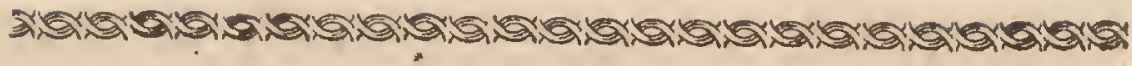

\section{HE T M A R M EL D I E R *.}

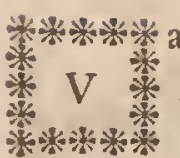

an alle hedendaagfche Schryveren, dic over de Natuurlyke Hiftorie gefchreeven hebben, is GESNER die, welke, ten opzigte van het byzonder verflag van zaaken, deze weetenfchap den grootften dienft 潘㴽㴽棌 gedaan, en dezelve meeft bevorderd, heeft; hy paarde een juift oordeel, en zuivre bedoelingen, met eene groote geleerdheid; ArDrovandus is weinig meer dan zyn Uitlegger, en de Natuuronde1zockers van minder naam zyn niet dan zyne Uitfchryvers: wy beraaden ons niet om de byzonderheden, raakende het onderwerp der nuarmeldieren, van hem te ontleenen; het waren dieren van zyn land $(a)$, welken hy beter kende dan wy, fchoon wy 'er eenigen, gelyk hy, in huis hebben opgevoed: dewyl dat geen, 't welk wy hebben waargenomen, juift overeenkomt met het geen hy daar van zegt, zo geeft ons dit een billyken grond van vertrottwen, dat al het overige, 't welk: hy meer heeft waargenomen, even vaaragtig en juift is.

Het marmeldier, jong gevangen, is gemaklyker te temmen dan eenig ander wild dier, en wordt byna zo volkomen tam als onze huisdieren; het leert ligtelyk een ftok aanvatten, gebaarden maken, danfen, en aan de ftem van zynen meefter gehoorzaamen; het heeft, even als de kat, een natuurlyken afkeer van den hond; zodra het gemeenzaam in huis begint te worden, en gelooft op zyn meefters hulp te mogen vertrouwen, valt het, in zyne tegenwoordigheid, de grootfte en fterkfte honden moedig aan, en byt dezelve geweldig; fchoon het niet volkomen zo groot is als een haas, is het egter gedrongener, en part veele fterkte nict veele lenigheid.

Het marmeldier heeft de vier vooríte tanden van het kaakbeen vry lang, en fterk genoeg on wreedelyk te kwetfen; het taft egter nienıand dan de honden aan, ell doet geen menich kwand ten zy het getergd worde; zo men 'er niet op paft knabbelt het de huisgeraaden, de ftoffen, de matten, en doorboort zelfs het hout, zo het opgenooten is: dewyl het zeer kort van dijen is, en de vingers der vocten omtrent eveneens heeft als de beer, zo zit het dikwils, en loopt, gelyk de beer, gemaklyk op de agterfte pooten; het brengt de din-

* Het maruneldier heet in 't Latyn Mus Mipinus Pliniz; in 't Italiannfch Murmont, Marmota. Marmontam, en in zommige ftrceken van Italie Varofa, volgens GesNer; in "t IHoogduitfl, en in 't Zwiterfch Murneltbier, Murmentle, Miflbullerle, volgens GesNer; by de Grauwbünders Montanella volgens Gesner; in 't Poolich Bobak, Swiflez, vo'gens RzaczYng.

I1; in 't Franfch Marmotte; in 't nud Franfch Marmontain, Marmotaine, Marmotan.

Mus Aipinus, Geser Hift. Qundrup Mag. 743. Icon. Animal. Quadrup. pag. ios.

Mus Alpinus Plinit, Marmota lialis. IR a Syyusf. Aninal Quatrup. pag. 22 r.

Mus cauda elangatâ, nuda, copore nfo: Mameta. LiNNeưs.

Glis, Marmota Inalis; Miss Alpinus Plinii. Kuein de Quadrup. pag. 56.

Glis pilis e fujco Eे flavicante mixtis, veftitus; Marmota Alpina. BRtsson. Ragn. Animal.

(a) GesNer was een Zwitrer, en warlyk een dier mannen, die hunue Natie luífer by. 2etten, 
gen, die het met de vooritc pooten heeft aangevat, naar den bek, en eet overeind gelyk als de eekhoorn; het loopt fchielyk genoeg in 't opklimmen, maar vry langzaam op dc vlakte; het klautert op de boomen, het kruipt tusfchen de wanden der rotien, of tuffchen twee angrenzende muuren, op, en het is van het marmeldier, zegt men, dat de Savoyands geleerd hebben in de fchoorfteenen op te klauteren, on dezelve te veegen.

Zy ceten van alles, wat men hun gceft, vleefch, brood, fruiten, wortels, moeskruiden, kool, kevers, fpringhaanen, enz; maar zy zyn greetiger naar melk en boter, dan natr eenig ander voedzel; fchoon mincer dan de kat gencigd om te fnoepen $c^{\prime}$ tc theelen, poogen zy cgter in die platfen in te fluipen, daar men de melk bewaart, cn zy drinken dezelve in groote menigte al morrelende, dat is te zeggen, een klein geknor van genoegen maakende, gelyk de katten gewoon zy11, wanneer men haar een goeden brok naar haar genoegen geeft: voor het overige is de melk het cenigft vogt dat hun behaagt, zy drinken maar zelden water, en weigeren wyn.

Het marmeldier heef, tell opzigte van de geftalte des lighiams, ecn weinig, van den beer, en een weinig van de rot: het is evenwel de aretomys, of beer-rot, der Ouden niet, gelyk zommige Schryvers, en onder anderen PerRAuLT, gemeend hcbben; het heelt den neus, de lippen, cn de gedaante van den kop, gelyk als de haas; het hair en de nagels van den das; de tanden van deıl béver; de knevels van de kat, de oogen van de relmuis; de voeten vall den beer; cen kurten flaart en afgeftompte ooren: de kleur van zyn hair op den rug is ros bruin, dat meer of ninder donker valt; dat hair is vry ruw, maar dat van den buik is rosagtig, zagt, en gevuld.

Het dier heeft, terwyl het fpcelt, of terwy] men 't liefkooft, de ftem en het gemorrel van een hondje; maar zodra men het tergt of bang makt, makt het al blaazende zulk een ficherp en doordringend geluid, dat er het trommelvlies door beledigd wordt: het bcinint de zinlykheid, en loopt, gelyk de kat, agter af om zyne uitwerpzelen te loozcn; maar. het heeft, even als de rot, vooral in den zomer, eeil terke lugt, die het zeer onaangenaan makt: in den herfft is het zeer ver: behalven ecn zeer groot net, heeft het, even als de relmuis, twce zeer dikke vetbladen; het is evenwel niec even vet over alle de deelen van het lighaam; de rug en de nieren zyn.meer dan het overig gedeelte belaader1 met cen vaft en ftevig vet, vry gelyk aan het uiërvleefch van de lioe; dus zou het marmeldier vry goed on te eeten zyn, zo het niet altoos eene zekele lugt hadr, die men nier verbergen kan, dan door het met zeer fterke kruiderijen, of andere inmengzelen toe te makken.

Dit dicr, "t welk zig in het geweft van fneeuw en ys vermaakt, "t welk men niet dan op de hoogfte bergen vindt, is evenwel meer dan eenig ander onderhevig om door de koude te verdooven: het is doorgands op het einde van feptember of in het begin van october, dat het zig in zyne afzondering gaat verbergen, oin daar niet dan in april weder uit te voorfchyn te komen; die wykplaats of afzondering, is met voorzorg genaakt, en met lonft gemenbileerd, zy is voor ecrit zeer ruim, minder breed dan lang en zeer hoog van verdicping, waardoor $z y$ een of meer dezer dicren kan bevatten, zonder dat 'er de lugt bederve; lumpe voeten en nagels fchynen gemaakt on de aarde te 
krabben, en $z y$ graven dezelve inderdaad met eene verwonderlyke fnelheid uit; $z y$ werpen den uitgegraaven grond agter zig naar buiten; het is niet een gat, een buis, die regt of bogtig voortloopt, het is eene foort van galery in de gedaante van eene kapitaale $\mathbf{Y}$ gemaakt, waarvan de beide takken elk hunne opening hebben, en beiden uicloopen in het voet-of ftamftuk van de $Y$, dat is te zeggen in de galerije, die van agteren digt $i_{\text {s, }}$ en die eigenlyk de verblyfplaats uitunaakt: dewyl alles op de ichuinfte van den berg is uitgegra1ven, en het underfte gedeelte van de $\mathrm{X}$ of de galery alleen horizontaal of waterpas ligt, zo is de benedenfte tak of opening naar onderen af hellende; het is in dit lang en fchuins afloopend gedeelte van de wooning, dat zy humne uitwerpzelen bergen, waarvan de vogtigheid rig dus van zelve naar buiten loott; de bovenite tik van de $\mathrm{Y}$ is hooger dan al het overig gedeelte van 't verblyf, en helt nuar hetzclve toe; dit is lumne poort diar zy door inkonen, en uitgaan. De plaats van 't verblyf is niet flegts beftrooid, maar dik bedekt met mofch en looy, zy doen daar des zomers een grooten voorraad van op; men verzekert zelfs, dat dit op gemeene koften, of liever met gemeenen arbeid, verrigt wordt, dat de cenc het fynite gras afbyten, dat de ande. re het verzamclen, en dat zy beurtelings voor voertuig dienen om het naar de legerplatats te brengen; de eene, zegt men, legt zig op den rug, laat zig niet hooy belaften, fpreidt zyne pooten uit, on voor regels te dienen, en laat zig vervolgens voortfleepen door de anderen, die dit zonderling rydtuig by den faart van het dier trekken, en terzelfder tyd zorg draagen, dat de laft niet omwippe; het is, volgens dit berigt, door de menigvuldige vryving, dat zy meeft allen het hair op den rug hebben afgefleeten: men zou daar evenwel eene andere reden van kunnen geeven, te weeten, dat zy hun verblyf onder den grond houdende, $c_{n}$ onophoudelyk bezig met in de aarde te granven, dit alleen genoeg is, om hunnen rug tc ontblooten: wat hier ook vall wezen noge, het is zcker, dat zy te famen blyven, en dat zy in 't gemeen aan hunne wooning arbeiden; zy brengen drie vierde gedeelten van lum leeven in dezelve door, zy wyken derwalrds by ftorm-weder, by regen, of zodra zy eenig gevar vernecuren; zy komen 'er zelfs niet dan in de fchoonIte dagen uit te voorfchyn, en gaan 'er niet verre van daan; een hunner houdt, ap een verheven rots gezeten, de wagt, terwyl de anderen zig verluftigen nuet in het gras te fpeelen, of zig bezig houden met hetzelve af te finden om 'er hooy vall te maken; cn zudra hy, dic de wagt hondt, een menfch, een arend, een hond, enz, verneemt, geeft liy, door een kort geblaas, daar van berigt aan de anderen, dic dan op mar binnen trekken, en dan vin den fchildwagt, die de laatfe buiten blyft, gevolgd worden.

Zy doen geen voorraad voor den winter op, zy fchynen te voorzien, dat dezelve hun nutteloos zoude zyn; mal de eerite aannaderingen van het jargetyde, dat hen moet verdoovell, voelende, gaan zy aan't werken, om de twee deuren hunner woonplants te fluiten, en zy doen dat met zo veele zorg en zo valt en ftevig, dat men de aarde genaklyker overal elders dan ter plaatfe, alwaar zy die hebben toegenuurd, han openen; zy zyn dan zeer vet, men vindt 'er onder, die tot twintig ponden toe weegen; zy zyn drie manI'III. Die?. 


\section{DE NATUURLYKE II ISTORIE,}

den daar na nog wél in 't vleefch, maar allengs vermindert hunne lyvigheid, en op ' $t$ einde van den winter zyn zy mager.

Wanneer men hen ontdekt, vindt men hen als een bal te fam gerolu en: in het hooy beftommeld; men neemt hen dus verdoofd weg, zonder dat $z y$ ergens van weeten; men kan hen zelfs dooden zonder dat zy het fchynen te voelen. Mlen verkieft de vetfen om te eeten, en de jongften oin tam te maaken; eene trapswyze opklimmende warmte doet hen herleeven, gelyk de relmuizen, en die, welken men in huis onderhoudt, worden, zo men hen in zeer warme plaatfen doet leeven, nict verdoofd, en zyn zelfs zo leevendig. als op andere tyden: wy zuilen, by de verdooving van het marmeldier, niet herhaalen wat wy onder het artikel van de relmuis gezegd hebben; de verkouding des bloeds is daar de eenige oorzaak van, en men hadt al voor ons waargenonien, dat de omloop in dien tyd der verdooving zeer langzaam ging; dat alle de affcheidingen zeer traag gefchiedden, en dat hun bloed, door geene nieuwe chyl aangevuld wordende, byna zonder ecnige weingtiglicid was (b). Voor het overige is het niet zeker, dat zy altoos en ftandvaltig geduurende zeven of agt maanden in 't jaar verdoofd zyn, gelyk bykans alle: Schryvers beweeren: hunne holen zyn diep, zy woonen daar in getale by: een, daar moet derhalven in de cerfte dagen vry wat warmte blyven, en zy kunnen daar eeten van het gras, dat zy verzameld hebben: de Hr. ALTALANN zegt zelfs in zyne verhandeling over de dieren van Zwitlerland, dat de jaagers de mameldieren drie weeken of een mand in hunne kelders laaten, voor dat zy hunne ruft gaan ftooren; en dat zy zig wel wagten van te graaven, terwyl het zagt weder is, of een warme wind waait, dewyl deze diertjes als dan wakker worden, en dieper op graaven zouden, maar dat men hunne wykplaatfen in den tyd der grootfte koude openende, hen dermaate verdoofd en bedwelmd vindt, dat men hen ligtlyk wegneemt: men kan derhalven zeggen, dat zy in allen opzigte zyn gelyk de relmuizen, en dat, zo zy langer tyd verdoofd blyven, de reden daar van is omdar $z y$ in een klimaat leeven, waar in de vinter langer duurt.

Deze dieren brengen flegts ééns in 't jaar' voort; de gewoone diragten zyn maar van drie of vier jongen, hunne groei is vaardig, en hunne leevensdunring is legts van negen of tien jaar; dus is de foort noch talryk, noch zeer verfpreid; de Grieken kenden har niet, of hebben 'er ten minten geen gewag van gemakit: ondcr de Latymen is PLinsus de eerfte gewceft, die dit dier heeft angeduid onder den naam van mus Alpinus, of Alpifche bergrot; en inderdand fchoon "er verfcheiden andere foorten van rotten in de Alpen. gevonden worden, verdient geene egter meer opnerking dan het marmeldier; geen der andere houdt har verblyf op de kruinen der hoogfte bergen: de andere blyven in de vlakten, of wel op de helling der heuvelen en der eerfte bergen, manr geene klinimen zo hoog' op als 't marmeldier; daarenboven komt het nooit van de hoogtens neder, en fchynt byzonderlyk aan den keten der Alpiliche bergen bepald te zyn, alwaar het zig eene ligging op her Zuiden en Gotten, by voorkeur boven die van 't Noorden of Weiten, fichynt

(b) Zie Tranfari. Puilof hib. No. 397. 
te verkiezen; men vindt hen evenwel ook in de Apenynfche en Pyreneefche gebergten, en in de hoogfte gebergten van Duitfchland: de Bobak van Poolen (c) waaraan de Hr. Brisson (d) en na hem de Hren. Arnaut de Noblem VILLE en SALERNE (e) den naam van marmot of marmeldicr gegecven hebben, verfchilt van dit dier niet nlegts in de kleuren van ' $t$ hair, maar ook door 't getal der vingeren, want het heeft vyf vingeren aan de voorfte voeten; de nagel van den duim komt buiten het vel uit, en men vindt van binnen de twee phalanges of regels van dezen vyfden vinger, die by het marmeldier gcheel ontbreekt: dus zyn de Bobak of het Poolfch marmeldier, de Monax of het marmeldicr van Kanada, de Cavia of het marmeldier van Baha. $\mathrm{ma}$, en de Cricet of de Straatsburgfche maimot, alle vier verfchillende foorten van het marmeldier der Alpen.

(c) Zie Autuariam Hijt. Nat. Polonia, Auth. RzaczYnskr, pag. $32 \%$.

(d) Brisson. Regn. Anim. pas. 165.

(e) Hiffoire Naturelle des Animaux, par Mrs. Arnaut de Noblemblese E SalerNe, Parif r756. Een nuttig Werk, en warrin de byzonderheden met zo veele zorgvuldigheid als oordeel verzameld zyn.

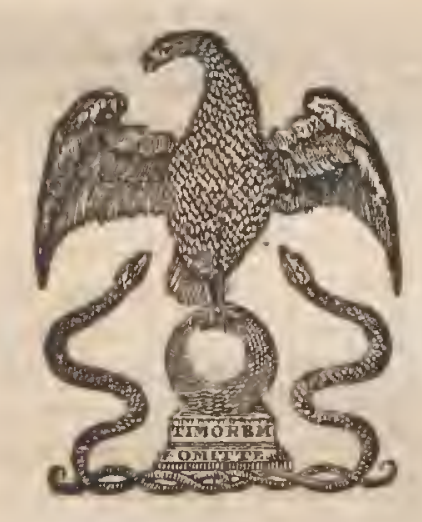

$\mathrm{R} \approx$ 


\section{BESCHR TVING VAN HET MARMELDIER.}

औै $\mathrm{S}$

choon het marmeldier ( $P l . X X V I I I)$ gedulrende den winter flapt, gelyk als de relmuis, de groote hazelmuis, en de kleine hazelmuis, zo verfchilt het egter in het makzel der inwendige deelen van deze fchen is het in meer dan van de rot, de muis, de veldnuis, enz; ondertusals van de cerftgenoemde als van de ceritgenoemde, gantich verfchillende: het mameldier heeft eenige overeenkomit met den haas en het konyn door dell bek, die kort en dik is, en door de gedaante van den kop, die verlengd ell, ter platife van het voorhoofd, geboogd. is; het voorhoofd evenwel en de kruin des hoofds zyn breeder en platter; de oogen zyı aan de zyden des hoofds geplaatf: gelyk die van den haas; de bovenlip makt by het marmeldier in zekeren zin een haazenbek, want die lip is gedeeltelyk gefpleeten en tot aan het middelfchot der neusgaten geboord; maar de ooren zyn geheel verfchillende van die van den haas en van 't konyn; zy hebben nog minder lengte dan die van de rotten, nauwlyks komen zy buiten "t hair te voorfchyn, het welk egter maar weinig lengte heeft op den kop, uitgezonderd aan de wangen, daar het veel langer is; dit verfchil van lengte maikt aan weerszyde van den kop den valfchen fchyn van wangen : de onderite lip is veel korter dan de bovenite; de hals heeft zcer weinig lengte: het lighaam is dik en zeer gevuld; het agterftel is verlaagd en zeer afgenomen; de ftart heeft dikwils van agteren eene rigting regt waterpas; hy is met lang hair bekleed: de beenen zyn kort en fchynen het nog meer, omdat zy nooit wel uitgeftrekt zyn, en ondat de voorhand en de voorvoet geheel op de aarde draggen: de voorlte voeten zyn wat binnenwaards gekeerd, en hebben flegts. vier' vingers; daar zyn 'er vyf ann de agterfte voeten, die integendeel wat buitenwards gekeerd zyn; wan. neer het dier ophoudt en ruft, kluwent het zig, gedeeltelyk in malkanderen, de rug maakt een boog, de buik en het begin van den ftart drangen op den grond, de kop is in de borit gebogen, de bek rakkt de voorfte voeten en de 1 taart is ter zyde van het lighaam gevouwen : dikwils verlat het dier deze houding voor een gedeelte, en heft het hoofd op; als dan fchynt het eenige flimheid in het gelat te hebben, fcitoon zyn groote bek altoos domheid. fchynt an te duiden.

De kruin van 't hoofd, het bovenft van den hals, de fchouderen, de Iug, en de weeke buikzyden, van. het mameldicr, dat ten onderwerpe voor deze hefchryving heeft gediend, waren zwart met zweemzels van grauw el van afchgrauw, ondat 'er twee foorten van hair waren, het een langer, fteviger, en zwart, het ander korter, zagter, en grauw of afciggrauw, dat eene foort van donshiti: was; aan de zyden des hoofd was het hair gedeeltelyk granw en gedeeltelyk zwartagtig; de ooren waren grauv, het einde van den. bek, het onderit vau het onderit kaakbeen en van den hals, de voorite hee- 


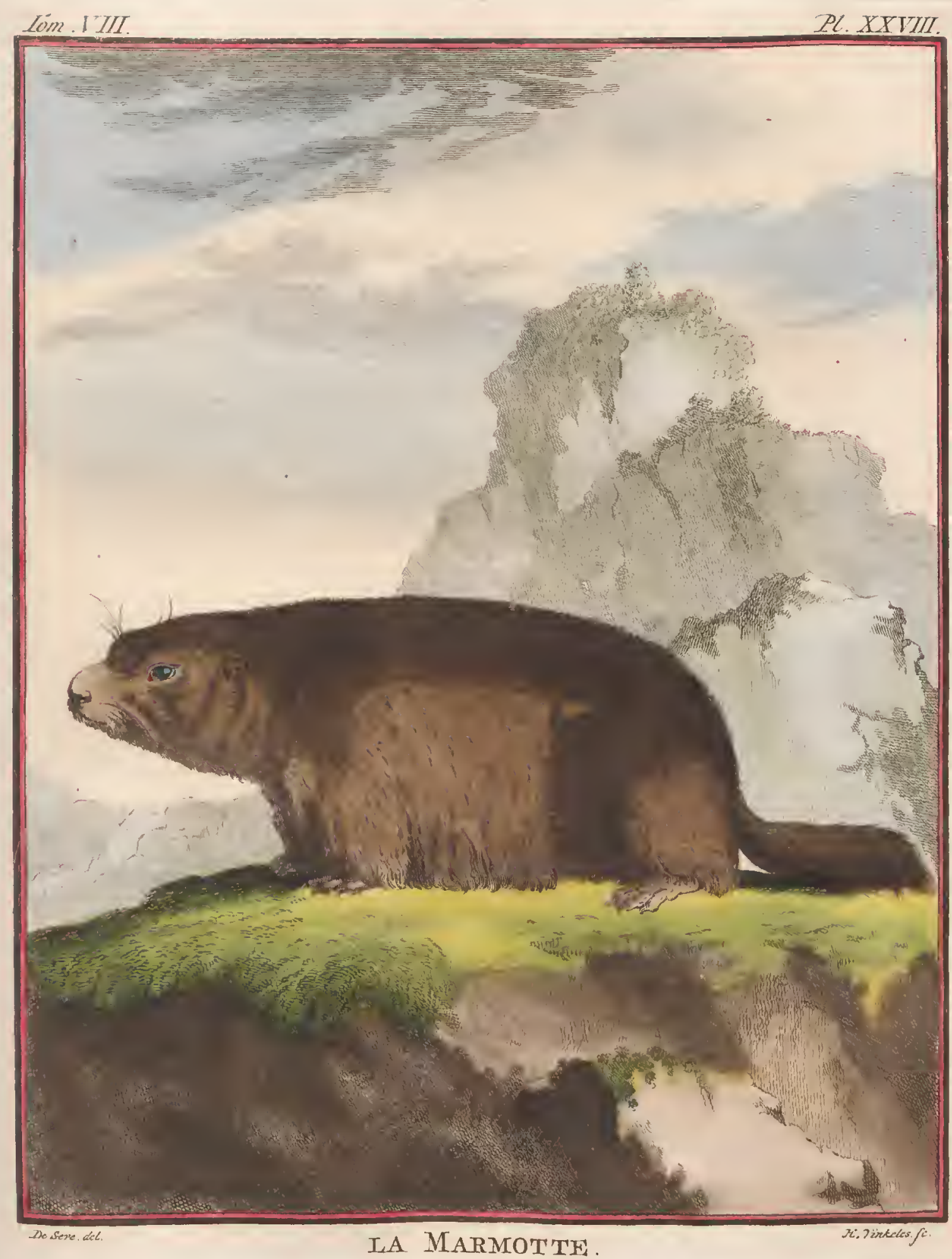



nen', het onderft en de zyden van de borft, de buik, de binnenzyde van dedije en van 't. been, en de vier voeten, hadden eene roffe kleur; met zwart, grauw, en zelfs afchgrauw, gemengd, omdat het donshair afclggrauv was, en het ftevig en lang hair zivart, grauw, en vaal hadt; de ftuit, en de buitenzyde van de dije en van 't been waren van eene bruin-rosagtige kleur; het hair van dell ftaart hadt eene zwarte kleur met bruin-rosagtig, op zommige plaatfen, gemengd; dit hair was niet in zyn gehecl; het langite hair was boven de fchouders, en hadt anderhalf duim lengte; de nagels waren lang, zeer puntig en zwartagtig; daar waren dikke knobbeltjes onder de voeten, drie agter de vingers der voorfte voeten, twee onder de voorhand, het een ter zyde van het ander, en vyf onder den agtervoet.

Lengte des geheelen lighaams in cen regte lyn gemeeten van het einde van den bek tot aan den aars

Hoogte van het voorftel

Hoogte van het agterftel

Lengte van den kop van het einde van den bek tot aan het agter-

hoofd.
Omtrek van den bek an het einde van de onderfte lip genomen.

voeten', duimen, lyneni:

Bogt van de opening des monds van de eene fplyting der lippen tot de andere

Afitand tuffchen de twee neusgaten
Afitand tuffchen het einde van den bek en den voorften hoek van

't oog Aftand tuffchen den agterften hoek van 't oog en 't oor . • : Lengte van het oog van den eenen hoek tot den anderen. :

Opening van het oog
Aftand tuffchen de voorfe hoeken der oogen in een regte lyn gemeeten

Omtrek van den kop tuffchen de oogen en de ooren genomen.

Lengte der ooren $\quad . \quad . \quad \cdots \quad$.

Breedte van de bafis op de uitwendige kromming gemecten $\ldots$. . o.

$\Lambda$ fitand tuffchen de beide ooren om laag gemeeten . . .

Lengte van den hais

Omtrek van den hals

Ontrek des lighaams agter de voorfte pooten gemeeten " .

Omtrek an de dikfte plaats

Omtrek voor de agterfte pooten

Lengte van den ftomp des ftaarts

Omtrek van den ftaart aan 't begin van den ftomp ${ }^{\circ}$ "

Ointrek van den voorarm. tot an den elleboog $\quad$.

Ontrek van 't gewrigt van de hand

Omtrel: van de agterhand

Lengte van "t gewrigt af tot ann 't einde der nagelen

Lengte van het been van de knie af tot aan de hich

Omtrek van het bovenft des beens

Breedte ter plaate van de hiel

Oratrek van don agtervoet

1. 3. 0

०. 5. 0.

०. 4,6 .

०. 3. $\quad$ 5.

○. 3. 0.

०. 0.3 .

I. 9.

I. 2.

0. 7 .

o. $\quad 3^{\frac{1}{2}}$

I. IT.

5. 6.

○. 5 .

o. IO.

I. 9 .

I. 0.

9. 6.

o. II. 6.

ก. 9. 0.

०. 2.6 . 6

o. 3. 0

०. 3. 8

०. 5. 6 .

०. 2. 0 .

o. 5. 0 .

०. 3. 6

o. 4. O.

0.2 .3$. 


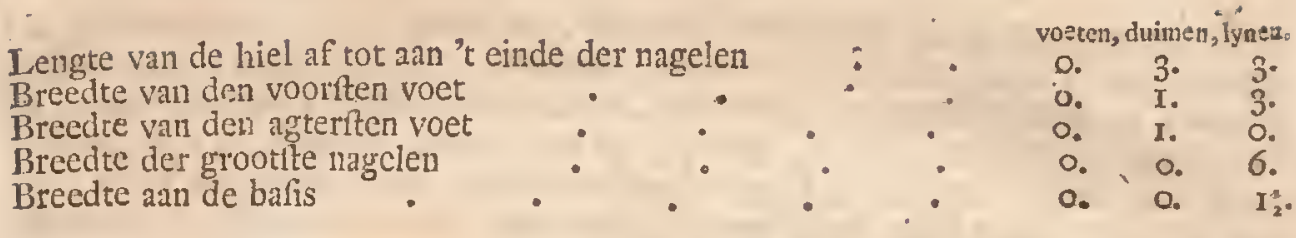

Het marnaeldicr, 't welk voor de befchryving der wecke binnen-deelen gediend heeft, was anderhalf voet lang van het einde van den bck tot an den aars; het woog zes pond; het was een wyfje gelyk alle de marmeldiercn, welken ik hier te lande gezien hcb; wy hebben nog geen mannetje kunnen vinden.

Het netvlies ftrekte zig wat meer ter linker dan ter regterzyde uit; het was gedeeltelyk agter de mang omgevouwen; ontwikkeld en uitgeilagen zynde was het groot genoeg om alle de darmen te bedekken, onderftellcnde dat het dicr op den rug lage. Daar waren ook, gelyk als in de groote liazelmuis, twee netten of panden aan wcerszyde van den onderbuik, die, volgens den $\mathrm{Hr}$. Perrault, (a) twee andere netvliezen zyn; zy hadden, even als die, welke door gemelden Schryver zyn waargenomen, omtréint vyf duim lengte en vier duim breedtc; manr zy waren nict zeer met vet beladen; men zag dar plaatfen, dic alleenlyk door een zeer fyn vlies geformeerd wicrien; hot gewoone netvlies hadt veel gelykenis met dezelve: ik hch geen vicrde netvlies gezien van het groore afgefuchiden; wel is waar, dat een gedeelte van dit latife zig voorwaards uiiftrekte, het grootfte gedeelte van de lever, cnz, bedekte, en dat 'er vet was aan de inplantingen van het middelrif en van de divarfe fpicren van den onderbuik.

De twaalfvingerigedarm ftrckte zig in de regterzyde uit, en kromde zig naar binnen: dc nugteredarm maakte zyne omwentelingen in de navelftreek en de omgebogendarm in de zyden; de blindedarm was geplatatit in de navelftreeken en den eigenlyk gezegden onderbuik, en agterwaards gcrigt; hy vouwde zig naar de linkerzyde en voorwards: de kronkeldarm ftrekte zig voorwands uit, vouwde zig regts om, en makte groote omwentelingen in de regterzyde en wceke buikzyde; vervolgens liep hy agter de maag, maakte eenige bogtigheden in de linker weeke buikzyde, en vocgde zig eindclyk aan den regtendarm.

De maag was verlengd on byna gcheel ann de linkerzyde gelcgen: de dunne darmen hadden ten nafienby dezclfdc dikte over lumne geheelc uitgeftrektheid; de blindcdarm $\left(A B C, l l . X X \angle X^{*}\right.$ ) was groot cn gelcek in zyne gedaante naar dien van de rot: de kronkeldarm was ten naftenby 7.0 dik als de blinde an zyn oorfprong $(D)$, hy verminderde zagtelyk in dikte over de lengte van drie duimen, en geleek hier in nar den lironkeldaim van de rot, maar hy verfchilde daar vail in dit zelfde gedeelte voor zo verre hy geene blykbaare fchuinfche vczels hadt: het overige van den kronkcldarn en de rcgtedarm hadden ten naftenby dezelfde dikte; ik heb gecn klieren op dcu twallvingerigendarm, gelyk als op dien vall de rot, gezien.

(a) Mimoire pour fervir a l'Hiftoire Natarelle des Animaux, Part. III. pag. 35,36 . 


$$
\mathscr{2}
$$


Daar waren op den rand van den aars drie openingen op eene zelfde kringswyze lyn gefchikt; de randen dier openingen waren wit, en daar was in de opening zelve eene verdikte fnotterigheid van dezelfde witte kleur en van een zecr onaangenamen reuk: clk diel openingen liadt gemeenfchap met een zak van omtrent twee lynen dikte, die geformeerd wierdt door een witten kelk van binnen met dezelfde finotterigheid bedekt, die zig op de randen van de opening vertoonde.

De lever hadt vyf kwabben, twee aan de linker en drie aan de regterzyde: de bovenfte linker kwab was de kleinfte van allen, en de onderfte de grootfte; de onderfte kivab van de regterzyde ftrekte zig een weinig ter linkerzyde uit, zy was in drie deelen gefcheiden door twee fplitfingen, de band was in de linker fplitfing en het galblaasje in de regter: de lever hadt cene roodzwartagtige kleur van buiten, en was byna geheel zwait van binnen; zy woog drie oncen en vyf gros.

Het galblaasje bevattede vyftien greinen gewigt van eene oranjekleurige gal, deszelfs gedaante was tell naltenby rond.

De milt was kantzuilig, wat breeder aan't boven cinde dan over het overige haarer lengte; zy woog een gros en agttien grein; haare kleur was dezelfde als die van de lever.

Ik heb maar twee takken in het alvleefch gezien; de een ftrekte zig ter linkerzyde uit. en was de korttte; de andere volgde den twaalfvingerigendarm en was zeer lang; daar waren daarenboven cenige verlengingen, die zig naar het galblaasje nititrekten.

De regter nier fprong omtrent een vierde harer lengte meer voorwards uit dan de linker; die laatite was dikker clan de eerlte: zy hadden byna scene uitdieping; de zelfftandigheden van binnen waren wól onderfcheiden; daar warcn llegts ecnige tepels in het bekken.

Het zenuwagtig middelpunt van het middelrif hadt veel uitgeftrektheid : de longen beftonden uit vyf kwabben, vier ter regter, en eene ter linkerzyde; die latifte was byna zo groot als de vier andere, die ten naftenby dezelfde platfing en dezelfde figuur hadken als in de meefte andere dieren.

Het hart was lang, daar liwamen twee takken uit cen boog van de groote flagader.

De tong was zeer dik; haar voorfte gedeelte fcheen, door eene voor over de lengte, in twee gelyke deelen gefcheiden; daar waren zulke fyne tepeltjes $o p$, dat men dezelve nauwelyks bemerkte; onderfcheidenlyker zag men eenige kleine ronde knobbeltjes, op cenigen afitand van malkanderen geplantft: dar waren op het agterlt gedcelte drie kelkswyze klicren, op cen regte dwars. lyn gefchikt, eene in 't midden en een van weerskanten.

Daar waren op her verhemelte twaalf of dertien vry onregelmatige vooren; die van het agterft gedeelte waren in ' $t$ mididen haarer lengte afgebroken; het verhemelte was gedeeltelyk zwart en gedeeltelyk wit: de ftrotklap was dun, rond, en tot op de randen gckorreld.

De voorherffenen waren zo breed als lang; derzelver oppervlakte was glad, en in plats van de gewoone bolligheden zag men daar llegts eenige klcine 


\section{i36 DE NATUURLYKE H I S T O R I E,}

putjes in; zy woogen twee gros en twintig grein: de agterherffenen geleeken naar die van andere dieren, en haar gewigt was van vier en-veertig grein.

Daar waren tien mammen; vyf aan weerszyde, twee op de borft en drie op den buik.

Het lighaam en de'hoornen van de lyfmoeder en de zaadballen waren aan de zyden van den onderbuik vaft aan twee netten, waarvan reeds melding gemaakt is: zo men den naam van netvlies. daar aan wil geeven, makten zy maar één, het welk van de eene zyde tot de andere onder de lendenen liep, en de nieren en de lyfmoeder ophieldt.

Het hoofdje van den kittelaar was zeer kort dun en hard; het is my beenagtig voorgekomen; de ftomp en de takken ftrekten zig langs de fchede, over de lengte van veertien lynen, uit: het lighaam van den kittelaar hadt on. trent eene lyn omtrek, het maakte eenige kleine bogtigheden, dic zig van binnen in de fchede als knobbeltjes vertoonden.

De blaas was byna rond, en haare vliezen hadden weinig dikte; de hals en het lighaam van de lyfmoeder fcheenen verward; de zaadballen hadden eene omregelmatige gedaante; men zag 'er kleine korreltjes op, dat lymphatifche biaasjes waren.

voeten, duimen, lyner.

Lengte der dunne darmen van den portier tot aan den blindendarn. 7.9 .90 Omtrek van den twaalfvingerigendarm op de dikfte plaatfen . . o. I. 5 .

Omtrek op de dunfte plaatfen

Omtrek van den nugterendarm

Omitrek van den omgebogendarm

Lengte van den blindendarm

Omtrek op de dikfte plaats

Omtrek op de dunfte platats

Ontrek van den kronkeldarm op de dikfte platen

Omtrek op de dunfte plaatfen

Omtrek van den regtendarm by den kronkeldarm

Omtrek by den aars

Lengte van de geheele darmbuis, den blindendarm daar niet mede onder begreepen

Gronte ontrek van de maag

Kleine omtrek
Lengte der kleine kromining van den flokdarin af tot aan den hoek,

dien het regter gedeclte makt
Lengte van het linker gedeelte van den fioldarm af tot aan het einde van den grooten blindenzak

Lengte van de lever

Breedte

Hare grootite dikte

Lengte van het galblasje

Deszelfs groottte midclellyn

Lengte van de milt

Breedte van het ondereinde

Breedte van het boveneinde

Breedte in 't midden

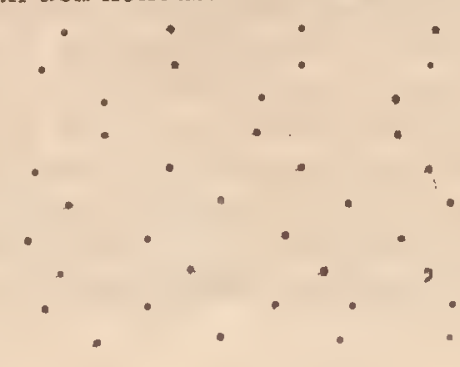




\section{.}




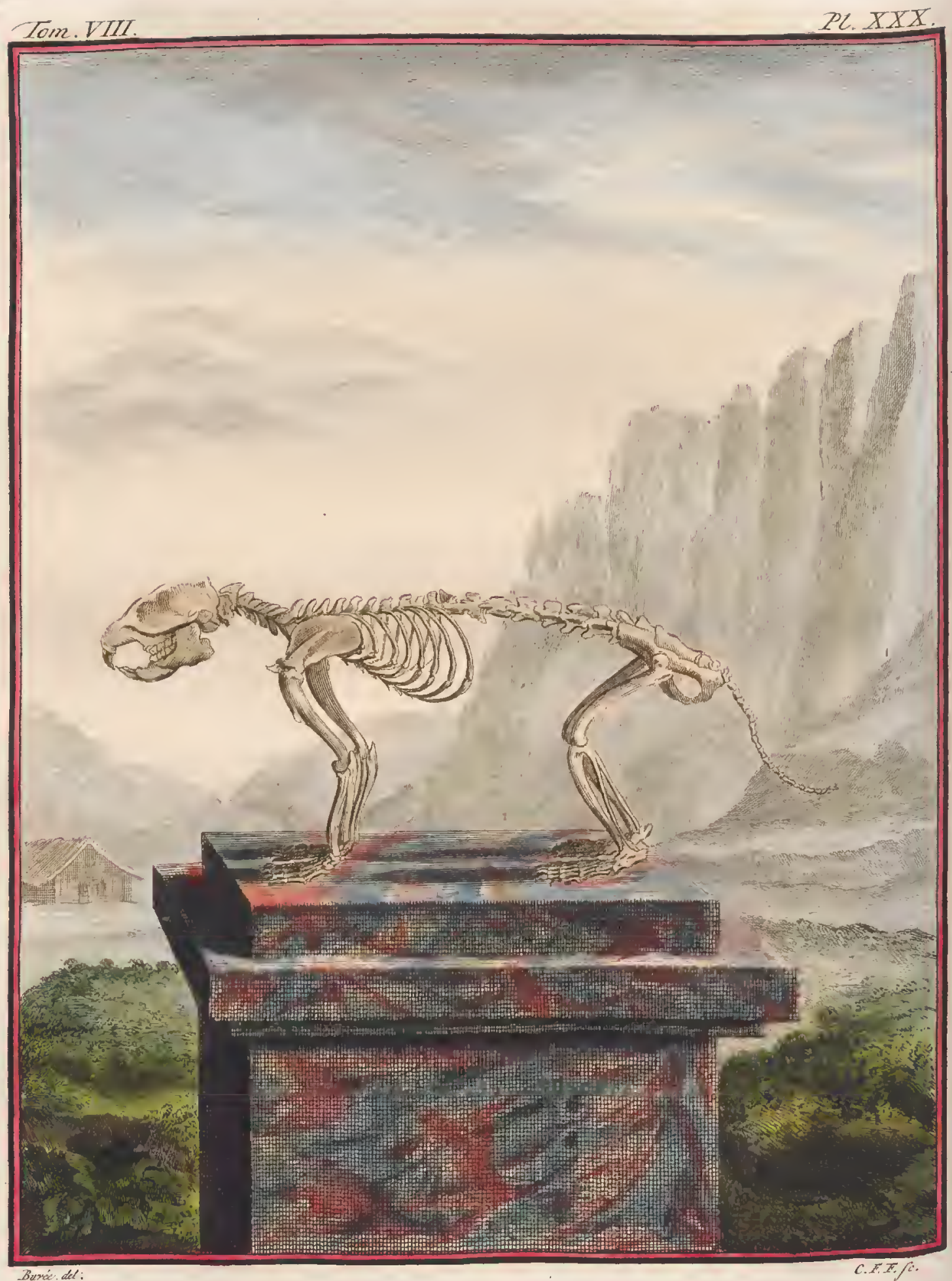




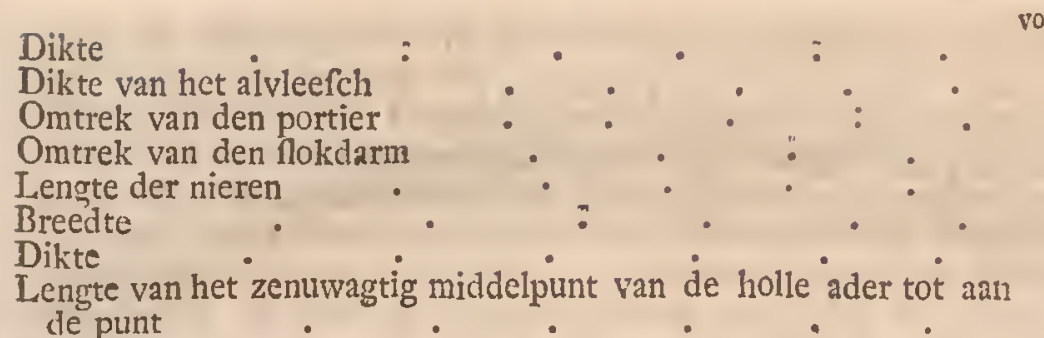

voeten, duimen, lynen.

Dikte van het alvleefch

Omtrek van den portier

Lengte der nieren

Breedte

Lengte van het zenuwagtig middelpunt van de holle ader tot aan de punt

Breedte

$\begin{array}{rrr}0 . & 0 . & 3 . \\ 0 . & 0 . & 2 . \\ 0 . & 0 . & 10 . \\ 0 . & 0 . & 9 . \\ 0 . & 1 . & 1 . \\ 0 . & 0 . & 9 . \\ 0 . & 0 . & 6 .\end{array}$

Breedte van het vleezig gedeelte tufichen het zenuwagtig middelpunt en het borftbeen

Breedte aan weerszyde van het renuwatig middelpunt -

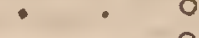

O. I. I.

Omtrek van de bafis van "t hart

Hoogte van de punt af tot aan den oorfprong der longflagader.

Hoogte van de punt af tot aan den longezak

Middellyn van de groote flagader van buiten genomen : .

Lengte van de tong

Breedte van de tong

Breedte der vooren van 't verhemelte

Hoogte van de randen

Lengte der voorherffenen

Breedte

Dikte

Lengte der agterherfenen

Breedte

Dikte

Lengte van de klink

Lengte van de fchede

Ontrek op ile dikfte plaats

Omtrek op de dunfte plaats

Groote ontrek van de blas

Kleine omtrek

Lengte van de pisbuis

Omtrek

Lengte van den hils en 't lighaan van de lyfmoejer

Omtrek.

Iengte der hoornen van de lyfmoeder

Omtrek op de dikfte plaatfen

Omtrek aan "t einde van yderen hoorn

Affand in een regte lyn tuffchen de zaadballen en het einde van den hoorn

Lengte van de kromme lyn die de trompet doorloopt ${ }^{\bullet}$.

I.engte der zaadballen

Breedte

Dikte

De kop van het geraamte van et marmeldier $(P l . X X X)$, hecft veel overecukonit met dien, van de waterrot, den campaguol, de relmuis, de grnote VIII. Deel. 


\section{${ }_{13}^{8}$ DENATUURLYKE HISTOR I E;}

hazelmuis en de kleine hazelmuis, zo wel in de voornatme gedaante der beenderen als in het getal, de figuur en de plaatfing, der tanden : daar is op ' $\mathrm{t} a \mathrm{~g}$ terhoofd eene dwarfche zeer uitfpringende verhevenheid en twee andere veel kleiner, op de kruin; zy ftrekken zig fchuinfch agterwaards uit van de oogputten af, en $z y$ vereenigen zig op 't agterhoofd tot eene enkele die op de dwariche verhevenheid uithoopt : het voorhoofdsbeen is breed en holrond; het heeft aan weerskanten een lang en puntig uitfteekzel, 't welk een gedeelte der randen van de oogput maakt; de eigenlyke neusbeenderen zyn lang en breed, hun voorfte einde is wat omlaag gebogen en verlengt zig 20 verre naar voren als het bovenft kaakbeen; daar is geen kaakbeensgat voor de oogput; het zelve is boven een klein uitfteekzel, dat aan de zyde des wortels van den eerften baktand geplantlt is: de bogt der takken van het onderft kaakbeen makt een groot uititeekzel agterwaards gerigt.

Daar zyn voor in yder kakbeen twee lange fnytainden; die van boven zyn wat korter dan de onderfte, alle hebben zy de voorfte zyde van eene oranjekleur : het bovenft kaakbeen heeft aan weerskanten vyf baktanden, en het onderfte flegts vier, het geen in alles twee-en-twintig tanden maakt; de onderfte baktanden hebben minder punten dan de bovenfte.

De niekwervelbeenderen hadden byna geene doornagtige uitfeekzels, uitgezonderd het tweede, dat 'én zeer groot hadt, meer agterivaards dan voorwaards hellende: de onderfte tak van het dwarfch uitfteekzel des zesden wervelbeens ftrekte zig agterwaards onder het dwarfch uirfeekzel van het zeven. de uit.

Daar waren twaalf lenden-wervelbeenderen en twaalf ribben; zeven waare en vyf valfche; het doornagtig uititeekzel van het eerfte wervelbeen was regt, die der agt volgende wervelbeenderen waren agterwaards hellende; het doornagrig vititeekzel van het tiende wervelbeen was regt, en die der twee laatften helden voorwards, en waren breed en kort: het borltbeen beftondt uit vyf beenderen, het voorfte gedeelte van het eerfte been was zeer breed en geledigde zig met de eerfte ribben, eene ann weerszyde; de geleding der tweede ribben was tuffchen het eerfte en tweede beentje; die der derde tuffchen liet tweede en derde beentje, en dus vervolgens tot de vyfde, zesde en zevende, ribbein, die zig tuffchen het yierde en vyfde beentje van het borltbeen geledigden.

De lenden-wervelbeenderen waren ten getale van zeven: zy hadden breede en. korte donrnagtige uititeekzels, het eerfte wervelbeen hadt geene bykomende uitteckzels: die der andere waren fchuinfch naar voren gerigt, en des te langer als zy zig nader by het heiligbeen bevnden: dit beell hadt vyf valfche wervulbeenderen, en de ftart twee-en-twintig, die alle zeer lort waren.

Het voorfte gedeelte van het heupbeen was ivat buirenwaards gekromd; het hadt drie zyden, eene binnen en twee buitell: de eyronde gaten waren groot, en de grot hrit veel breedte en diepte.

Her lihoulerblad geleck byna geheel naar dat van den eekhoorn (b); het

(b)'Zie het VII Deel van di: Wẹrk, blz. 167 . 
Lengte van de eene zyde naar de andere

duimen, lynen.

Breedte van het cerfte wervelbeen op de dwarfche nitfeckzels gemeeten.

Lengte der vyf laatite wervelbeenderen

O. 4.

Lengte van het gedeelte der wervelbeens-kolom, die uit de rug-wervelbeenderen beftant

Hoogte van het doornagtig uitfeekzel van het tweedc wervelbeen dat het langft is

Hoogte van dat van het twaalfile dat het kortte is

Lengte des lighaams van het laatfte wervelbeen dat het langft is

Lengte der eerfte ribben

Afitand tuffchen de eerfte ribben an de breedfte plaats ${ }^{\circ}$ -

Lengte van de negende rib, dic de langfte is

Lengte van de laatite der valfche ribben

Breedte van de breedfte ribbe

Lengte van het borftbeen

Jengte van het eerfte beentje, dat het langft is

Lengte van het vierde beentje, dat het kortft is

Iloogte vam het langfte doornagtig uitfteekzel van de lendenwervelbeende-

ren, dat het laatft is
Lengte van het langft bykomend uitfeekzel, hetwelk dat van het laatfte

wervelbeen is

Lengte van het heiligbeen

Breedte van het voorfte gefteclte

Breedte van het agterfte gedcelte
Lengte van het agterfte wervelbeen van den ftart dat het langft is.

Breedte van het voorite gedeelte van het heupbeen

Hoogte van het been van het midden van de knokkelwyze hoiligheid.

Mišlellyn van die holligheid

Tengte van de goot

Breedte in ' $t$ midden

Dicpte

Lengte van de eyronde gaten

Breedte

Breedte van het bekken

Hoogte

Breedte aan de breedfte plaats

Breedte aan de fmalfte plaats
Hoogte van den doorn ann de verhevenfte platits

Lengte der feutelbeenderen

Lengte van den fchouder

Omirek aan de kleinfte plats

Omtrck van den kop
breedte van liet oncicrite gedeclte

Lengre van ủe ellepyp

Lengte van de ellcboogsknokkel

Lengte van het ftralbeen

J.en rte vin het dijebeen

Omirek van het hoofd

Untrisk van 't midden des beens 
Breedte van het onderfte einde

Lengte van de kniefchyven

Breedte

Dikte

L.engte van het fchecnbeen

Breedte van het hoofd

Omtrek van ' $t$ midden des beens

Breedte van het onderft einde

Lengte van het kuitbeen

Omtrek aan de dunfte plaats

Breedte van het bovenite einde

Breedte van het onderfte einde

Hoogte van de voorhand

Lengte van het hielbeen

Hoogte van het eerfte wiggebeen en van het fchuitbeen te famen-

genomen
Lcngte van het vicrie beentje van de agterhand, dat het kortfte is.

Lengte van het tweede beentje dat hict langft is

Lengte van het cerfte beentje valu den agtervoct, dat het kortfe is :

Lengte van het vicrde beentje, dat het langft is

Lengte van den cerften regel des tweeden vingers der voorfte voeten.

Lengte van den tweeden regel

Lengte van den derden

Lengte van den vierden regel van den vierden vinger der agterfte voeten.

Lengte van den tweeden regel

Lengte van den derden

Lengte van den eerften regel van den duim

Lengte van den tweeden duim: $n$, lynen.

o. $7 \frac{1}{2}$

o. 4.

o. $\mathbf{I}_{4}^{\circ}$

o. 3 . 8 .

o. 9.

o. 4 .

2. 9.

o. $33^{*} \cdot$

o. 3 .

o. $3 \frac{1}{2}$.

o. $3 \frac{3}{10}$

o. $3 \frac{1}{3}$

o. 7.

o. $8 \frac{\pi}{2}$.

o. 7 .

D. II.

o. $5 \frac{\pi}{20}$

o. $3 \frac{2}{3}$

o. $4 \frac{1}{2}$

o. 6.

0. 4;

o. 420

o. $4^{\frac{1}{2}}$

o. 4 .

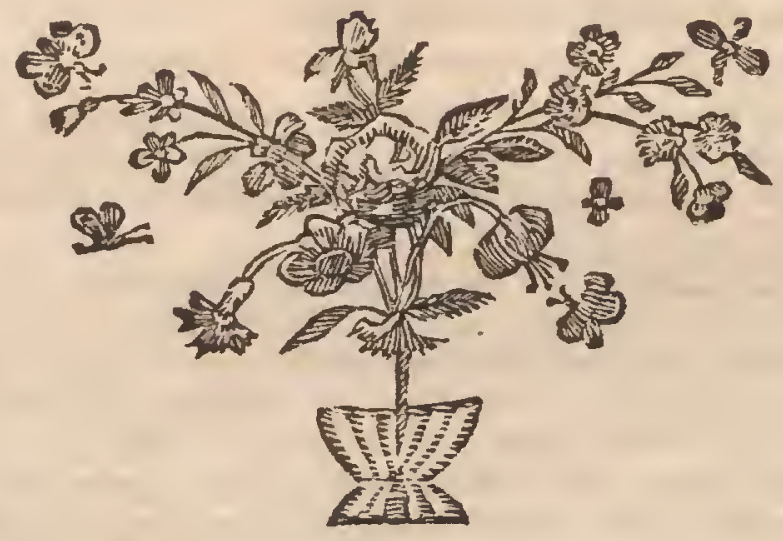


No. DCCCVII. Een groote veldmuis in wyngeefo.

No. DCCCVIII. Drie opgezette gronte veldmuizen.

Deze drie dieren hebben de verfchillende houdingen die hun de gewoonfte zyn.

No. DCCCIX. Het geruamte van een groote veldmuis.

De lengte van dit geraamte is agt duim, van het einde der neusbeenderen tot aan het agterft einde der heupbeenderen; de kop heeft twee duim agt lynen omtrek aan de dikfte plaats op de jukbeenige boogen gemeeten.

No. DCCCX. Het tongbeen vain een groote veldmuis.

Dit beentje beftaat llegts uit eene bafis en twee takken gelyk dat van de rot.

No. DCCCXI. Het roedebeentje van een groote veldnuis.

De lengte van dit beentje is van vier lynen.

No. DCCCXII. Een marmeldier van Piemont.

Dit marmeldier is opgezet; het heeft de gewoone grootte en kleuren van de dieren van deze foort; het komt uit het Graaffchap Nice, vier mylen van Barcelonnette in den omtrek vain St. Dalmas, alwaar veel marmeldieren gevonden worden.

No. DCCCXIII. Een narmeldier van Dauphiné.

Het is alleenlyk het opgezette vel met de vier voeten in 't geheel; de ooren zyn hart en krom geworden door de werking van 't vuur, en het droogen in den oven: het fchynt dat dit droogen, gevoegd by den zwaveldamp, waaraan dit vel dikwils is blootgefteld, de kieuren van 't hair ook veranderd heeft; want ry zyn zeer bleek; men ziet 'er niets op dan grauw, en zelfs witagtig grauw, met eenige zweemzels van geclagtig en van bruin; wanneer men evenwel het hair verwydert, vindt men het vlashair of dons, van eene bruine of zeer donkere afilgrauwe, kleur; de ftaart heeft ook zwart met grauw ge- 
mengd, ten naaftenby gelyk die van den wolf: dit marmeldier is door den Hr. Dagreu uit Dauphiné gezonden.

No. DCCCXIV. Het geraamte vas een marmeldier.

De lengte van dit geraamte is van één voet, drie duim agt lynen van het einde der neusbeenderen tot aan ' $t$ agterft einde der heupbeenderen; de kon heeft zes en een half duim omtrek, op de dikfte plaats gemeeten.

No. DCCCXV. Het tongbeen van een marmeldier.

Dit been kwam my in 't eerft voor llegts uit zeven ftukken te beftaan; drie aan weerszyde en én in 't midden, dat het vorkbeen en deszelfs twee takken bevattede; doch nader toeziende heb ik evenwel gemeend eenige voetfpooren té bemerken van de geleding der takken van de vork met het middenbeen.

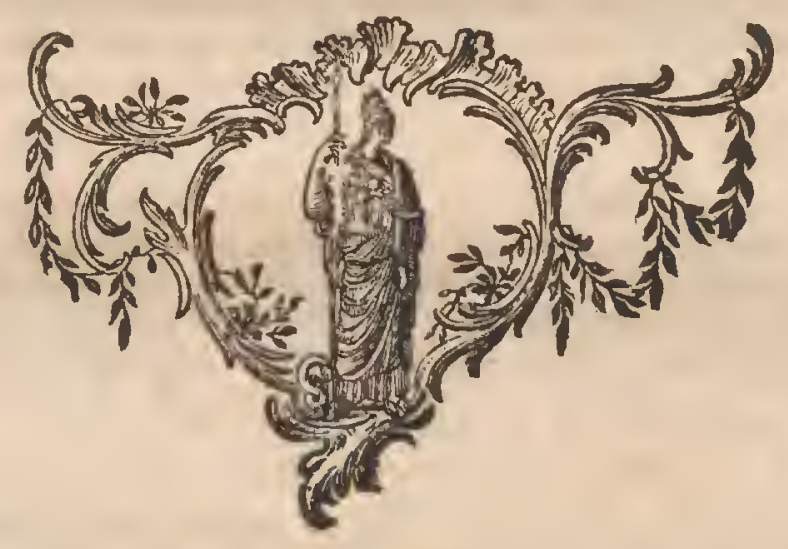




\section{D $\quad E \quad$ B. E E E R *.}

3. D kend zyn, waar omtrent de Schryvers van de Natnurlyke Hifo2is zo veel verfchillen als over den beer; hunne onzekerheden, en

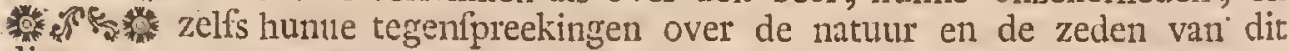
dier, zyn my voorgekomen hier uit haren oorfprong te neemen, ondat zy de foorten niet genoeg onderfcheiden, en zontyds tot de eene foort brengen. 't geen tot de andere behoort: voor cerft moet men den landbeer niet verwarren met den zeebeer, gemeenlyk witte beer, yslandfche beer, geheeten; dit zyn twee zeer verfchillende dieren, zo wel ten opzigte van de lighaamsgeftalte, als ten opzigre van de natuurlyke neigingen en gebruiken; vervolgens moet men tw'ee foorten in de landbeeren onderfcheiden, de brune en de zwarte (a); dewelke niet dezelfde neigingen, dezelfde natuurlyke luften, hebbende, niet als verfibeidenheden van eene en dezelfde foort befchotwwd kunnen worden, mar twee onderfcheidene en afzonderlyke focrten vitmaaken; daarenboven zyn 'er ook landbeeren, die wit zyn, en dic, fchoon in kleur naar de zeebeeren g'elykende, in al het overige daar zo veel van verfchillen als de aṇdere beeren: men vindt leze witte landbeeren in groot Tartarije (b), in Muskovie, in Lithuuwen, en in de andere Noordfche gewesten : het is niet de gettrengheid van het klimant, die hen des winters doet wit worden, gelyk de hermelynen, en de haazen; mar die witte beeren worden wit geboren, en blyven op alle tyden wit: men zoude hen dan nog als een vierde foort mocten befchouwen, zo men ook geene beeren vondt met bruin en wit hair vermengd, hetwelk een tuffchenfoort tuffichen den witten, en den bruinen of zwarten, landbeer anduidt; bygevoly is de witte landbeer nict dan eene verlchnidenheid van de ecne of andere dezer foorten.

Men vindt in de Alpifche grebergten den bruinen beer vry gemeen, en den zwarten beer zeldzaan, die daarentegen in grooten getale in de Noordiche boffchen van Europa en Amerika gevonden wordt; de brine is woeft en verfcheurende; de zwarte is allenenlyk wild, en weigert volitandig vlecfch te ee-

ten;

* De Peer hect in 't Griekfoh "A Spaanfch O/Jo; in 't Franfch Ours; in 't Huogduitfch Baer; in 'c Engelfci Beer; in 't Zweedich Bioern; in 't Poolf:h $H_{t}$ tver, Nierizuieds.

U:jus. GusNrR 11ift. Otuadrup. pag. 941. Icoit. Quadrup. pag. 65.

Uifus. Rat Syungl. Aimal. Quadrup. pag. I71.

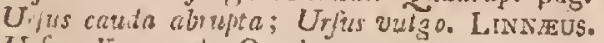

Urfus. KLEIN de Queadrup. pab. \&2.

Uritus niger coula wnicolore ... .urfus. Briscox, Regn. Animal. pag. 258.

(a) Men leite op, dat wy hier onder den naan $\mathrm{v}$ dn bruine heeren dezulken begrypen, die bruin, vaal, ros, roodagtig, zgn, en onder dien van zwarte beeren, ile zulken die zwartagtig, zo ruel als die, welke geheel zivart, zyn.

(b) Réation de la grande Tatiarie, Aunterd. 1737, 120, pag. 8. 


\section{$\begin{array}{lllllllllll}V & A & N & D & E & N & B & E & E & R\end{array}$}

ten; wy kunnen 'er geen netter en verfcher getuigenis van geeven dan dat van den Hr. DU PRATz; zie hier wat hy, in zyne Hiftorie van Louifianc, daarvan (zegt (c). „De beer, (men begrype, dat hier van den zwarten, " en niet van den bruinen, beer gefprooken wordt) vertoont zig des win"ters in Louifiana, omdat de fneeuw, dic de landen van 't Noorden be" dckt, hem belettende zyn voedzel te vinden, en hem noodzaakt de Noord"fche landen te verlaaten; hy leeft van vrugten, onder anderen van cekels " en wortels, en zyne lekkerfte geregten zyn de honing ell de molk; zo hy " die kan bekomen, zou hy zig liever laaten dooden dan daarvan afitaan; " in weerwil van 't vooroordecl, waarin men is, dat de beer verlindende $z y$, "houde ik, met allen dic in deze Provintic en in de nabuurige ftreeken be"kend zyn, ftannde, dat hy het geenszins is : liet is nooit gebeurd, dat deze " dieren cen menfch hebben verlonden in weerwil van hunne groote menigte ", en den alleruiterften honger, dic hen zomtyds prangt; dewyl zy, -zelfs in ", dit geval, het vleefch van cene flagting, dat zy aantreffen, niet eeten; in "s den tyd tocn ik te Natchés woonde, was 'er zulk een ruwe winter in de "landen van het Noorden, dat deze dieren in groote menigten afzakten; zy "waren zo gemeen, dat zy malkanderen het voedzel onttrokken en honger " deeden lyden; ook waren zy zcer mager; die groote honger decdt lien uit "2 de boffchen, dic langs de rivier ftan, te voorfchyn komen, men zag hen , des nagts in de menfchelyke wooningen dringen, op de platten loopen, ", die niet wél geflooten waren; zy vonden 'er vleefch, voor de koelte al", daar geplaatft, maar rakten 'cr nict aan, het waren alleen de graanen, die " $z \mathrm{y}$, zo zy ciezelve belomen konden, giectig aten : het zoude zekerlyk in "zulk eene gelegenheid, $c n$ in zuik eene dringende bchoefte, hebben moe"ten zy11, dat zy humne vernhindende woede zouden hobben moeten open"baaren, zo zy iets van dic genartheid gehad hadden, of eenigzins vleefch"vreetende dieren geweeft waren : zy hebben nooit dieren gedood om hen " te verflinden, en zo zy cenigzins vlecfchvreetende waren, zouthen zy gee" ne landen, met fnecuw overdekt, alwar zy menfchen en dicren nari wel"gevallen behomen konden, verlaten, on in verre alliggende ftreeken vrug" ten en wortels, cen voedzel, "t welk verfindende dicren ftandvaftig wei"g geren te eeten, met mocite te gaan zocken". De Hr. Du PraTz voegt "er in cene noot by, dat hy, zedert dat hy het bovenftande gefchreeven hadt, met zekerheid hadt vernomen, dat "er in de gebergten van Savoye, twee foorten van beeren zyn, de cenc zwart, gelyk die van Louifiane, die geen vleclch ecten, de andere rood, die zo vertcheurende zyn als de wolven; de Baron DE LA HoNTAN zegt $(d)$, dat de beeren van Kanada ten uiterlten zwart maar weinig gevaarlyk zyn; dat zy nooit de menfchen aantaften, ten zy men op hen fchiete, cn hen kwetfe: insgelyks zegt liy (e), dat de roodagtige beeren kwaadaartig zyn, dat zy de jigers onvervard komen anvallen, daar de zivarten integendeel voor huil vlugten. (c) Li Hiffoire de la Louifauze par Mr. LE Page DU Pratz, Paris 1758. in I20. Tom. II. pgg.
77. env.

(d) DE LA HONTaN, Voyages Tom. I. pag. 86.

(e) Idem, Tom. II. pag. 40. VIII. Deel. 
Wormus heeft gefchreeven $(f)$, dat men drie foorten van beeren in Noorwegen kende; de cerfte Brefsdiur, die zeer groot, die niet: geheel zwart, maar bruin, en die niet zo fchadelyk is als de andere, leevende alleenlyk. van kruiden en boombladeren: de tweede foort, Ildgiersdiur, is kleiner, zwarter, verfcheurender dan de eerfte, en taft dikwils de paarden cn andere dieren an, vooral in den herfft: de derde, Myrebiorn, die de kleinfte foort van. drie is, laat egter niet na fchadelyk te zyn; deze beer, zegt hy, vocdt zig mct micren, en fchcpt vermak in. micren-neften om te wroeten: mon heeft wvaargenomen, voegt hy 'er, zonder bewys, by, dat deze drie foorten onderling vermengen, cn tuffchenfoorten met malkanderen voortbiengen; dat dezulke, die verlindende $z y n$, de troepen anntaften, dat zy, even als de wolven, alle de beeften van die trocpen om hals brengen, en 'er flegts. een of, twee opvrceten; dat zy, fchoon vleefchrrectende, ook wilde vrigten eeten, en dat, wanneer "er cene groote hoeveelheid forben-vrugten valt, deze dicren meer te vreezen zyn dan anders, omdat die fcherpe vrugt hun de tanden zo, zoor maakt, en prikkelt, dat zy dit ongemak, 't wclk hen bclet te eeten, nict dan door bloed en vet verhelpen kunnen; maar de meette dier byzonderheden, door Worntus bygebragt, komen my zeer twyffelagtig voor, want daar is geen voorbeeld, dat dieren, wclker trek ftandvaftig verfchillende is, gelyk in de twee eerfte foorten, wanrvan de eene niet dan groente en bladen eeten, terwyl de andcre zig met vleefch en bloed voedcn, zig met malkanderen vermengen, en eene:tuffchenfoort voortbrengen; daarenboven het zyn hier de zwarte beeren, die vleefclivicetende zyn, en de bruine, die van gewaffen leeven, het geen volltrekt ftrydig met de waarheid is: daarenboven, de vader Rzaczynski $(g)$ cen Pool, en de Hr. Klein van Dantzik, (b) die van de beeren van hun land gelprooken hebben, maaken llegts van twee foorten gewag; van de zwarte en de bruine of roffe, en onder dic laatten van de grooten en de kleinen; zy zeggen, dat de zwarte beeren de zcldzaamfte, dat de bruine darentegen zcer gemeen, zyn; dat het de zwarte beeren zyn, die de grootfte vallen, en die de mieren eeten; en cindelyk, dat de groote bruine of roffe beeren de fcluadelykfte en de verniclendfte zv11: deze getuigeniffen, zo wel als die van den Hr. DU PRATz en van den l3aron DE LA HoNTAN, zyn, gelyk. men ziet, geheel ftrydig met dat van WORMIUs, 't welk ik hch bygebragt: het fchynt inderdand zeker, dat de roode, rolle, of bruine bccren, die niet legts in Savoye, maar ook in de hooge gebergten, in de grootc wouden, en in bykans alle woeftynen van de wereid, gevonden worden, de dieren leevende verlinden, en zelfs de allervuilite lingting-platatfen doorwrocten, en het finkendit vlcefch datar van esten; de zwarte beeren onthouden zig weinig anters dan in de koude landen, maar men vindt bruine of roffe beeren in de koude en in de gemaatigde oorden, en zelfs in de Zui. delyke geweiten: zy warea gemeen by de Grieken: de Romeinen licten hen van Lyhie (i) komen, om in humue fchouwpelen te dienen; men vindt

(f) Zie Mujeum Worm. pag. 318.

(F) Auctuar. Hifor. Natural. pag. 32.

(b) De Quadruped. pag. 82.

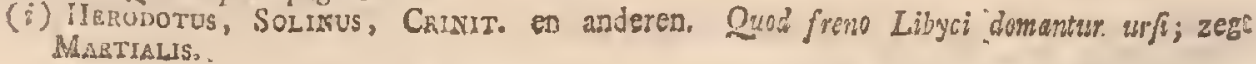


hen in China $(k)$, in Japan ( $l)$, in Arabie en Egypte, en tot in het eiland van Java $(m)$. Aristoteles (n) fpreckt ook van witte landheeren, en befchouwt dat verfchil van kleur als toevallig en voortkomende, zegt hy, van een gebrek in de voorttesling: daar zyn derhalven beeren in alle landen, die woeft, bergattig, of met boffchen beflagen, zyn; maar men vindt 'er geene in de welbevolkte ryken, noch in opene en beteclde landen; daar zyn 'er geene in Frankryk, even weinig als in Engeland, ten zy mogelyk eenige weinige in de minft bezogte gebergten.

De beer is niet alleen wild, maar ook eenzaam; hy ontvlugt, uit der aart, alle matfchappy; hy verwydert zig van de platefen daar de menfch toegang toe heeft; hy is niet naar zyn zin dan in die oorden, die nog tot de onde Natuur bchooren; een oud hol in ongenakbaare rotfen, cene grot door den tyd in den ftam van een ouden boom geformeerd, in 't midden van een digt bofch, dienen hem tot huisvefting; hy gaat zig daar alleen verbergen, brengt 'er een gedeelte van denwinter, zonder vourraad, door, en komt daar, in verfeheiden weeken, niet uit te voorfchyn: hy is evenwel niet verdootd noch van gevoel ontbloot, gelyk de relmuis of het marmeldier, mar gelyk hy natuurlyk vet is, en gelyk hy dat ten hoogften is op 't einde van den herfit, den tyd, waarop hy zig gaat verbergen, zo ftelt die overvloed van vet hem in ftat om die lange onthouding te kumnen doorftaan, en hy komt uit zyn hol nict te voorfcly'n, dan wanneer hy voelt, dat hy uitgehongerd is: men beweert, dat let na verloop van ontrent veertig dagen is $(0)$, dat de mannetjes uit hunne fchuilplantien te roorlchyn komen, mar dat de wyfjes daar vier manden in blyven, omdat $\mathrm{zy}$ daar haare jongen werpen: ik kin bezwarlyk gelooven, dat zy daar niet alleen zouden kumen beftan, maar zelfs haare jongen voeden, zonder zelve, geduntende zulk een Jang beftek van tyd, cenig voedzel te nuttigen; ik erken, dat $z y$, terwyl zy draagen, ten uiterften vet zy"1, dat zy diarcnboven met eene zeer dikke vagt bekleed zynde, den meetten tyd flaapende doorbrengende, en zig geheel geene beweeging geevende, zeer weinig toor de doorwalliening verliezen moeten; maar zo het waar $z y$, dat de mannetjes ma verloop van veertig dagen te voorfehyn komen, omdat zy gedrongen worden door de behoefte van voedzel te noeten gebrni$\mathrm{ken}$, zo is het niet natuurlyk zig te verbewden, dat de wyfjes door diezelfde behoefte niet nog fterker gedrongen zouden worden nadat zy geworpen hebben, en terwyl zy hame jongen zoogen, door welke dubbelde nitpurting zy nog meer gुcbrck aan eeten moeten hebben dan de mannetjes, ten zy men wilde onderftellen, dat $\mathrm{zy}$ eenigen humner jongen, met de bekleedzelen, en al het verdere overtollige voortbrengzel haarer werping, opvreeten, iets, het welk my niet waarfchynlyk voorkomt, in weerwil van het voorbecld der katte1], die zomtyds hare jongen opvreeten: voor het overige fprecken wy hier

(k) Hiftoire générale des Toyages, par Mr. l'Ablé Prevôt, Tom. IIT. pag. 492. IIjzoire Naturelle du Fason par KAEMFER, Tom. I. pag. IOy.

(i) Strazo lib. XVI. Prosezr Alpizus, pag. 233.

(n) Voyage autour du Monde, jar LR Gentur. Poris 1725. Tom. III. pag. 8.

(n) Aristoteles de Almirandis. crp. 140. d: Genér. Anim, lib. $V$. cap. 6.

(o) Idem, Hiforice Anim. lib. VIIL. cap. x7. 


\section{$\$ 48$ DE N A T U UR L Y K E H IS T ORIE,}

alleenlyk van de bruine beeren, waar onder de mannetjes de jonggebooren beeren inderdaad opvreeten, zo zy hen in hun neft vinden, maar de wyfjes integendeel fchynen hen tot woede toe te beminnen: zy zyn, nadat zy geworpen hebben, woefter, en gevaarlyker, dan de mannetjes; zy vegten, en ftellen zig voor alles bloot om hunne jongen te behouden, die by hunne geboorte niet lelyk en onzienlyk zyn, gelyk de Ouden gezegd hebben, en die na hunne geboorte, ten naaftenby zo fchielyk groejjen als de andere dieren; zy zyı volmaakt geformeerd $(p)$ in het lighaam liaarer moeder, en zo de vrugt, of de jonge beeren, in den eerften opflag mismaakt fchynen, het is omdat de volwaffen beeren dat insgelyks zyn door hunnen grooten klomp, en door de dikte en onevenredigheid des lighaams en der ledematen, en men weet, dat, by alle foorten van dieren de vrugt, of de jonggeboorne, minder geëvenredigd is dan het volwaffen dier.

De beeren zoeken malkander in den herfft: het wyfje is, zegt men, driftiger dan het mannetje; men wil, dat het zig op den rug nederlegt om zyne liefkoozingen te ontvangen, dat zy hem nauw omhelft, dat zy hem lang vafthoudt, enz, maar het is zekerer, dat zy op de ivyze der viervoetige dieren koppelen: men heeft gevangen beeren zien koppelen en werpen, alleenlyk heeft men niet waargenomen hoe lang de tyd van het draagen aanhoude? ARIsTOTELES zegt $(q)$, dat de dragt flegts dertig dagen duurt; dewyl niemand deze byzonderheid heeft tegengefprooken, en wy geene gelegenheid gehad hebben dezelve nader te onderzocken, zo kunnen wy het noch ontkennen noch verzekeren; wy zullen alleenlyk aanmerken, dat het ons twyffelagtig voorlomt; voor eerft ondat de beer een groot dier is, en de dieren, naarmante zy grooter zyn, ook meer tyd noodig hebben om in het lighaam hunner moeders geformeerd te worden. Vervolgens omdat de jonge beeren vry langzam groeijen, en de hulp humner moeders een jaar of twee noodig hebben: wyders omdat de beerin llegts weinige jongen werpt, één, twee, dilie, vier, en nooit meer dan vyf; cene eigenichap, welke zy gemeen heeft met alle de groote dieren, die niet veel jongen brengen, en dezelve lang draagen : eindelyk, cmdat de heer twintig of vyf-en-twintig jaar leeft, en de tyd van de dragr en den groei doorgaands evenredig zyn met de duuring des leevens: uir deze overeenkomften, die my zeer gegrond voorkomen, zoude ik dan gelooven, dat de tyd vall de dragt by de beeren ten minften van eenige nianden is; hoe het $z y$, de moeder fchynt zeer groote zorg voor liaare jongen te draagen, $z y$ bereidt hun, in $t$ diept van har hol, een bed van mos en gras, en zoogt len tot cat zy met har kumen uitgan, zy werpt in den winter, en hare jongen beginnen bar in de lente te voigen: her mannetje en wyfje woonen niet te fame:, zy heboen elk hume alizonderlylie wykplaats, die zelrs vry verre van malkander af is: 20 zy geene rots kunnen vinden om zig te legeren breeken en verzanclen zy hout on zig eene hut te maken, welke zy zo digt met groente en blaceren overdeklen, dat $z y$ ondoordringbaar voor het water is.

(p) In Mufeo Llluffr. Senatus Bononïenfis urfulluin a cefo matris utero extractum, Eo omnibus

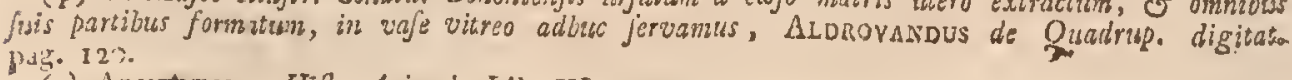

(a) Aristoteles Hif. Animal. Lib. VI. cap. 30. 


\section{$V A, N \quad D E N \quad N \quad B \quad E E R$.}

De ftem van den beer is een geknor, een grof gemorrel, dikwils gemengd met tandenknarfen, 't welk hy vooral doet hooren, wanneer men hem tergt; hy is zeer vatbaar voor toorn, en zyn toorn heeft altoos iets van woede, en dikwils van grilligheid; fchoon hy zagt, en zelfs gehoorzaam fchynt voor zyin meefter, wanneer hy getemd is, moet men zig egter altoos van hem wantrouwen, hem met onizigtigheid behandelen; en hem vooral niet op het einde van zyn neus flaan, noch aan zyne teeldeelen raaken. Men leert hem om zig overeind te houden, om poetfen te maiken, om te danfen; hy fchynt zelfs naar het geluid der inftrumenten te hooren, en de maat ruwelyk te volgen; maar om hem deze foort van opvoeding te geeven moet men hem jong vangen, ell hem zyu geheele leeven lang onder bedwang houden; de beer, die oud is, wordt niet tam, en laat rig niet meer bedwingen; hy is natuurlyk onverfaagd of ten minften onverfchillig voor gevaar: de wilde beer gat niet uit $2 y n$ weg, vlugt niet op 't gezigt van eell menlch; men wil egter, dat men hem door het blaazen op een fluit $(r)$ verbaaft, en zodanig verwonderd kan maaken, dat hy blyft ftaan, en zig op de agterfte pooten ftelt; ditis de tyd, dien men moet waarneemen on hem te fchieten, err die fchoot moet hem dooden; want zo hy alleenlyk gekwetft is, komt hy zig met eene woede op den fchieter werpen, en, hem met zyne voortte pooten omvattende, zou hy hem verftikken $(f)$ zo 'er niet fchielyk ontzet kwame.

Men jaagt en men vangt de beeren op verfcheidenerhande wyzen in $Z$ weeden, in Noorweegen, in Poolen, enz; de minft gevaarlyke manier, zegt men, om hen te vangen $(t)$, is hen dronken te maken door brandewyn te gieten op den honing, daar zy veel van houden, en diell zy in de boomitammen zoeken: in Louifiann en Kanada, alwaar de zwarte beeren zeer gemeen zyn a en alwaar zy niet neftelen in holen, mar in onde boomen, die op den ftam geftorven, en in het Inirt verrot, $7 \mathrm{~J}^{\mathrm{n} n}$, vangt men hen door humne verblyfplaatfen in brand te fteeken $(v)$ : dewyl zy de boomen zeer gemaklyk beklimmen kunne11, zo legeren zy zig zelden gelyks gronds, en zontyds is huin verblyl wel dertig of veertig vocten hoog : zo het eene moeder met laare jongen is, klimt zy het ecrt af, men doodt haar vóór clat zy op de aarde kome; de jongen daalen vervolgens neder; men vangt hen met hen eell touw om den hals te doen, en men leidt hen wey om hen org te voeden of te eeten, want het vleefch van een jongen beer is lekker en goed; dalt van een beer of beerin is eetbar, maar om dat het met eet olyagtig vet gemengd is, zo zyn het byna de voeten alleen, welker zelfftandigheid valter is, die men een lekker vleefin kan noemen.

De beerenjagt is, zonder zeer gevaarlyk te z:m, zeer nuttig, zo men dezelve met eenig geluk doet: her vel is de waardigtte van alle rnwe pelterijen, en de hoeveelheid olie, welke men van een enkelen beer bekont, is zeer aanmerkelvk: men doet eerlt het vlecich en vot te famen kouken, het vet

(r) Toyages de Rigyarn, Ton. I. pag. 37,38 .

(f) Idem ibil. Hijlt. de ia Louijiane, puT Mr. LE PAG

(t) Voyages de Reg.vard. Tom. I. pai. 53.

(v) Menoires fur la Louifiane, par Dumonts. Paris 1753. pag. 75. Stbiv. Hifloire de la Lotijiane, par M. LE. PAgE du PaAT, Tón. pag. 8z. 
fcheidt zig af, en vervolgens, zegt de Hr. DUPRATZ $(w)$; , zuivert men het " dool daar, terwyl het gefmolten en zeer heet is, eene goede hoeveelheid "zout en water, al fprengende, by te doen, daar kont cene losbarfting, of , ontulofling van, en daar ftygt een dikke rook op, die de kwaade lugt van't " vet nede voert: zodra de rook ophoudt, en terwyl het vet nog meer dan "lanw is, ftort men het in een pot, waar in men het agt of tien dagen ftaan "laat, na verloop van wolken tyd men daar eene heldcre olie op ziet dryven, " die men 'er met een lefel afneemt: die olie is zo goed als de bulte olyvenolie, , en dient voor dezelfde gebruiken; onder dezc olic heeft men een reuzel, zo " wit als de varkensreuzcl, mar wat weeker; zy dicnt voor de keuken, en " lieeft geenerhanden kwaaden fnaak of reuk". De Hr. Dusont ftemt in zyne Memories over Louifinn met den Hr. Du PRATz overeen, en hy zegt daarenboven, dat men van een enkelen bcer zomtyds honderd twintig potten van deze olie of reuzel krygt; dat de Wriden darr veel in handelen met de Franfchen; dat die olie zecr fehoon, zeer gezond, en zear goed is; dat zy niet dan by zeer groote koude dik wordt, dat zy, zo dit gebeurt, gehcel aan korrels, eu van eene fchittercnde blankheid, is; en dat men hatar dan als boter op het brood funeert: onze kruideniers houden geen beeren-olic, mar zy Jaaten uit Savojen, uit Zwitforland, of van Kanada, vet of reuzel komen, die niet gezuivert is. De Schryver van het Diatinnnaire du Commerce zegt zelfs, dat het beeren-vet, om goed te zy'11, grysigtig, taay, en van cen flegten reuk moct wezen, en dat men dat, liet welk al te wit is, vervalfcht en met ongel vermengd heeft: men gebruikt dit vet als cen plaatfelyk niddel tegen breuken, verkouwdheden, enz, en veele lieden verzekeren daar goede uitwerking van gehad te hebben.

De menigte vet, daar de beer mede bezet is, makt hem zeer ligt in 't zwemmen; ook trekt hy, zonder vermoeijenis, mecren en rivieren over. , De "beeren van Louifinna, zegt de Hr. Dunont $(x)$ die van eene zcer fchoo", ne zwarte kleur zyn, trekken de rivier in weerwil haarer groote breedte " over; $7 y$ zyn zeer greetig nar de vrugt der plaqueminiers, zy klimmen op " die boomen, zetten zig fchreilings op een tak, en terwyl zy zig met den ec" nen poot vafthouden, gebruiken $z y$ den anderen om de takken te buigen, ", en de plaquenines nader by te brengen: ook komen zy zeer dikwils uit "s de boffchen te vootlihy 1 , om in de wooningen te fuuffelen, en de patates ", en het mäys, dat zy vinden, op te eeten". In den herfit, wanneer zy het uiterf hnmner vettigheid bereikt hebben, hebben zy byna de kragt niet om te gaan $(y)$, of ten minften $\% y$ kunnen zo hincl niet loopen als een menfch $(z)$; zy hebben zomtyds tien vingeren dikte $(a)$ vet aan de ribben en dijen, het onderfe hunner vocten is dik en gezwollen, zo men in het zelve fnydt, loopt daar een wit en melkagtig fap uit; dat gedeelte van hun lighaam fchynt te be-

(iv) Memoire fur la Louifinne, Tum. II. pag. 89, 90.

(x) Ibidem, pog. 76

(y) Voyage du Bron de la Hoxtan, pag. 86.

(๘) Hlifoire de la Louifiane pap M. DU PRATZ, pag. 83.

(a) Extrait d'un aturage banois, cité par Mrs. ARNault de NodLeyille \& SalkrNe, llifoire Natur, des animanx, Parie I757. Ton. VI. pag. 376. 


\section{$\begin{array}{lllllllllll}V & \text { A } & N & D & E & N & B & E & E & R . & 15 z\end{array}$}

ftaan uit kleine kliertjes, die als zo veele tepeltjes zyn, en dit is de reden, dat zy des winters, in hunne afzondering, geduurig op humne pooten zuigen.

De beer heeft zecr goede zintuigen van gezigt, gehoor, en gevoel, fchoon hy, in evenredigheid van den ontrek zyns lighaams, een zecr klein oog, korter ooren, een dikke huid, en een zeer ruige vagt, heeft; by heeft een uitmuntenden reuk, en miffchien fyner dan eenig ander dier, want de binnen-oppervlakte van dit zintuig is zeer verre uitgeftrekt; men telt 'er (b) vier rijen platte beenagtige laagen, die door drie regt opłtainde vlakten van malkanderen onderfcheide11 zyn, hetwclk de oppervlakten, bekwaam om de indrukzels der reukdeeltjes te ontvangen, verbaazend vermeerdert.

De beer lseeft de voor en agter-pooten vleezig, gelyk de menfch; het hielbeen is kort en maakt een gedeelte van de plant des voets nit; daar zyn vyf groote toonen tegen de hiel overftaande, aan de agtervoeten; de beenderen. van de voorhand zyn in de voorvoeten eveneens; mar de duim is niet afgefcheiden, en de dikfte vinger ftaat, aan deze foort van hand, naar buite11, terwyl hy aan dic van den menfch naar binnen is: de vingers zyn dik, kort, en tegen malkanderen geflooten zo aan de handen als aan de voeten; de nagels zyn zwart en van eene eenlagtige, zeer harde, zelfitandigheid: de beer flat met zyne:vuiften, gelyk de menfch met de zyne doet; maar die ruwe overeenkomften met den nicnfch maken hem llegts te lelyker, en geeven hem geene meerderheid boven de andere dieren.

(b) Stephanus Lourentinus, Ephem. illem. Dec. T. Ann. IX en X. pag. 403. aange-

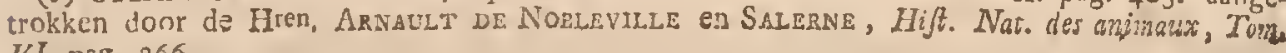
$V I$. pag. 366 .

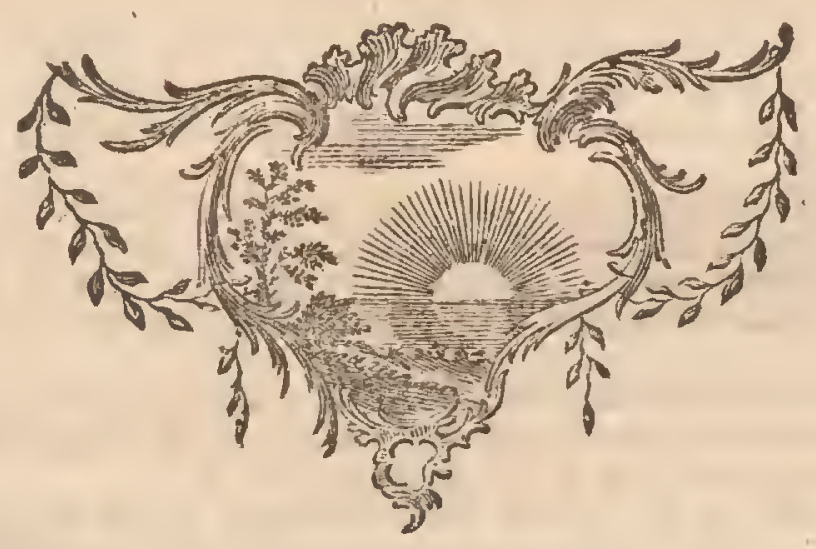




\section{I52 DE NATUURLYKE HISTORIE,}

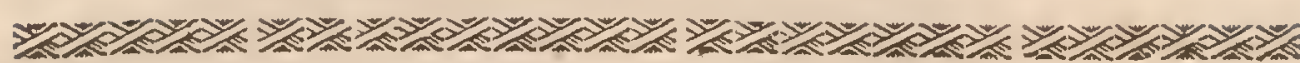

\section{$B E S C H R \Upsilon V I N G \quad V A N$ DEN BEER.}

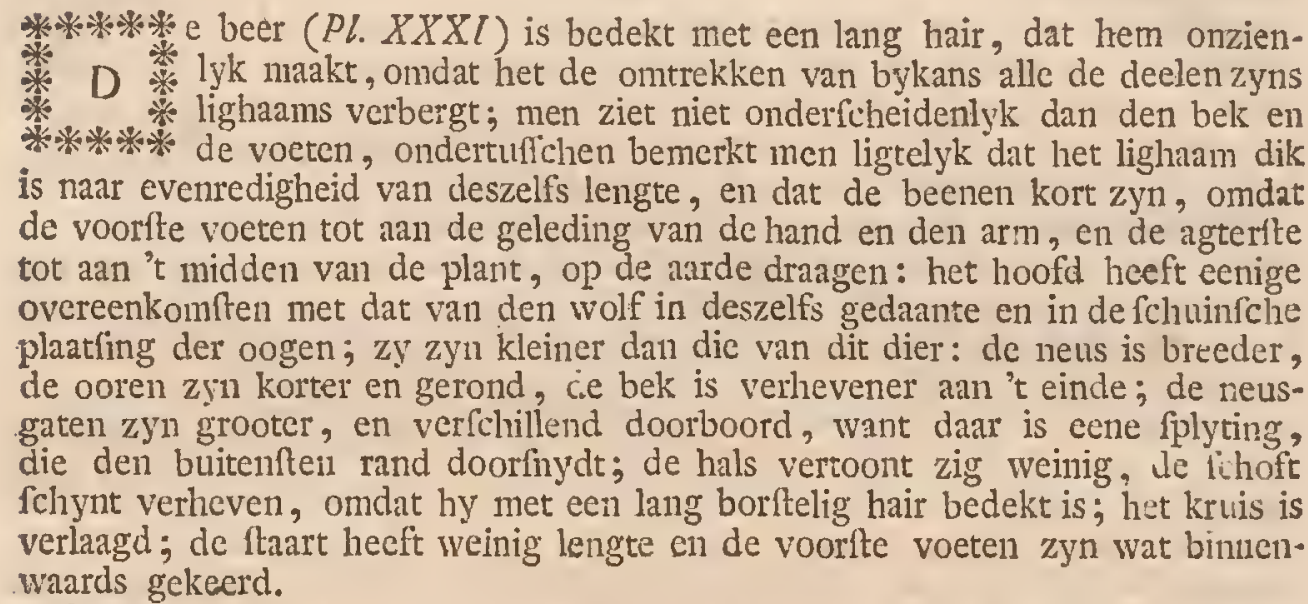

Daar zyn tegenwoordig te Parys, in het gebouw, alwaar men het Gemeen de gevegten van beeften vertoont, drie beeren, die in de kleur van 't hair een weinig van malkanderen verfihillen; een van de drie komt uit Savoye: Inen zegt dat hy vier jaar oud is: hy heeft het bovenft van den bek van eene conker vaale kleur, den fithoft en het onderit der vier pooten zwart of zwartagtig; al het overige des lighaams is cen mengzel van bleck vaal en afchgrauwbruin, ondat het hair eene afchgrauw-hruine kleur heeft over het grootf gedeelte zyner lengte en eene bleekvale kleur aan de punt: de beer, die in de $X X X I$ plaat vertoond wordt, liadt ten naaftenby dezelfde zweemzels van kleur, fchoon hy jonger was; wy hebben hem in Bourgonje gekogt, werwaards men hem uit de Alpen gebragt hadt; zyn geleid rer verzekerde ons dat hy geen twee jaar oud was: de manten, in de volgende tafel bygebragt, zyn naar dezen beer genomen.

De tweede der drie beeren, die voor de gemelde gevegten dienen, kont, even als de eerite, uit Savoye; men denkt dat hy tien jnar oud is; zyn kleur is bruin zwartagtig over het geheele lighaam, uitgezonderd den fchoft, het voorite der fchouderen, de oxels en de borft, die een zweemzel van vaal hebben.

De derde beer komt uit. Zwitierland: men noemt hem vergulden beer, omdat hy de fchaduwingen van vaal aan den kop en op 't ligliaam klaarer en leevendiger heeft; men zegt dat hy agt jaaren oud is.

De beer, die in de XXXII plaat vertoond wordt was geheel wit, met nitzondering van het kraakbeenige van de neus en van de nagelen, die zwartagtig waren: de oogen hadden eene afchgrauwe kleur en wierden blauw, wanneer het dier zig boos makte: hy was tennaaftenby van dezelfde grootte als die van $P$. XXII. fchoon by in de figuur grooter lichynt. 


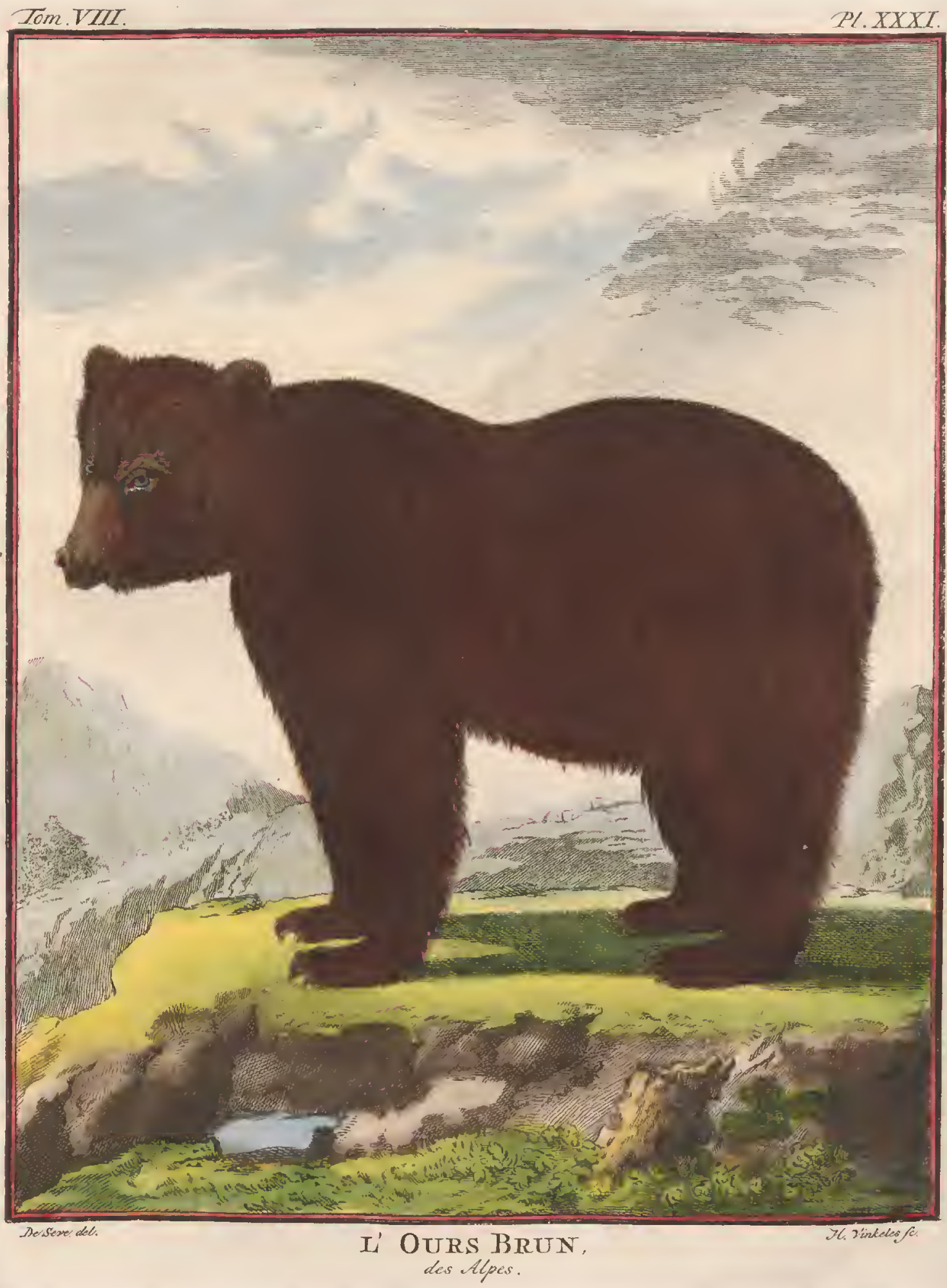




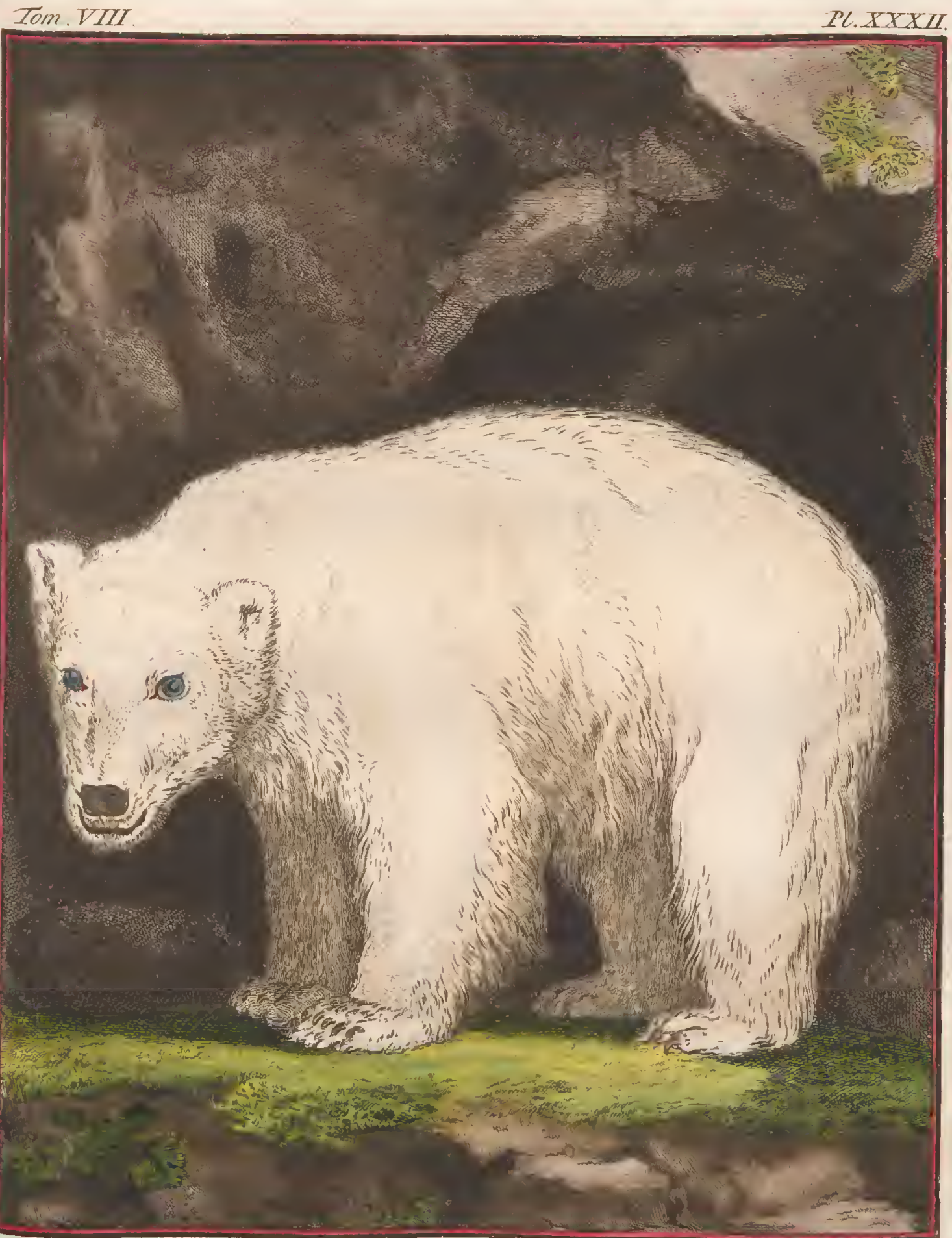

Dewerea del.

I' OURS BIANC

T. Jinkeles f. Terrestre! 
Al het hair van den beer is niet ftevig en gianzig' aan 't einde, de langfte hairen zyn 't alleen, tuffchen welken eene foort van vlashair gevonden wordt; de cerfte zyn drie of vier duim, het ander omtrent twee duim lang.

Lengte des geheelen lighnams in eene regte lyn gemeeten van hoeten, dutimen, lynen. einde van den bek tot aan den aars

Hoogte van het vooritel

Heogte van het agterftel

nmtrek van het einde van den bek

Omtrek van den bek onder de oogen genomen

Bogt van de opening des monds van de eene fplyting der lippen tot ann de andere

Afftand tuffchen de twee neusgaten

Afftand tuffchen het einde van den bek en den voorften hoek van 't oog

Affand tuffchen den agterften hoek van 't oog en 't oor . . D.

I.engte van het oog van den cenen hoek tot den anderen ... .

Opening van het oog

Afftand tufchen de voorfte heeken der oogen volgens de kromming van'het meusbeen gemeeten

Dezelfile affand in een regte lyn gemeeten $\quad . \quad \quad . \quad$.

Omtrek van den kop tuffichen de oogen en ooren gemeeten . . I.

Lengte der ooren

Breedte van de bafis op de uitwendige kromming gemeeten ${ }^{*} . .0$.

$\Delta$ fftand tuffchen de bcide ooren omlang gemeeten . . . o.

Lingte van den hals

Omtrek van den hals

.

Omtrek des lighaams agter de voorfte pooten gemeeten $\bullet^{-} \cdot{ }^{-}$

Omtrek an de dikite plaats gemeeten

Ontrek voor de agterfte pooten genomen

ontrek 2.

Hoogte van den buik baven den grond aan de buikzyden • $\quad$ I. 5 .

Dezelfue hongte onder de borft

Lengte van den ftomp des ftaarts
Omtrek van den ftaart aan 't begin van den ftomp
Lengte van den voorfen arm van den elleboog tot het gewrigt van

de hand

Breedte van den voorarm by den ellebong

Dikte van den voorarm ter zelfder platie

Ontrek van 't gewrigt van de hand

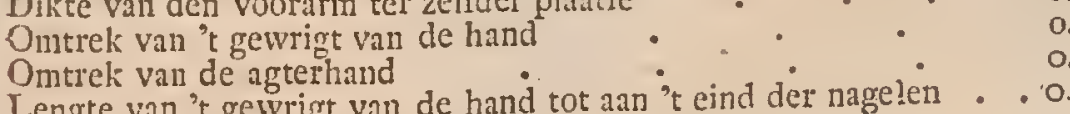

Lengte van het been van de knie af tot an 't eind der nagelen . . o

Breedte van het bovenit des beens . . .

Dikte

Brecdte ter plaatfe van de hiel

Omtrek van den agtervoet

Lengte van de hiel af tot aan 't einde der nagelen

Rreelte van den voorften voct

Breedte van den agterften voet

Lengte der grootfte nagelen

Breedte aan de bafis VIII. Deel.

4. 2. 0 .

2. $5 . \quad 0$.

2. 3.

०. 11.6.

I. I. 0 .

8. 4.

a. $3 \frac{\pi}{2}$

5. 0.

5. 0.

०. $\%$.

o. $3 \frac{\pi}{2}$

3. 0.

8.6

4. 6

3.30

6. 0.

8. 6

9. 6

3.6

o. 3. 0.

o. 5. 6 .

O. TI. O.

o. $5 . \quad 0$.

4. 4.

8. 6.

8.0

10. 6.

5. 0.

3. 6.

. 3.6 .

. 6.6

9. 6

0. 4. 0.

0. 3. 5 .

०. 2. 6.

०. 0.3 . 
I54 DE NATUURLYKE HISTORIE,

De beer-der Alpen, wat op de maten der uitwendige deelen genomen zyn, heeft ook:gediend ten onderwerpe voor de befchryving der invendige weeke deelen; wy lieten hem dooden in de mand van april; hy woog honderd een-en veertig pond; het was een wyfje.

De.Hr. Perraul' liet het vel van cen beer afftroopen, en liet denzelven. in dezen gevilden ftant tekenen en fnyden (a) om de ware gedaante van het. lighaan dezes diers te doen zien; wy hebben hem alleen van zyne hairen ontbloot, om hem dus zonder hair: te vertoonen, ( $f g . \mathrm{I}, \nu l: X X X I I t)$ op een tafel neergelegd : men ziet in deze figuur dat de lop zo groot niet is als hy zig met het hair vertoont; en dat de ooren en de hals langer zyn; de ftaart $(A)$, fchoon zeer kort, vertoont zig egter: de borft was zeer nauw; en bygevolg waren de fchouders digt by malkanderen geplatit; de voorfte.pooten waren: langer dan de agterfte: de elleboog. $(B)$ de voorarm $(C)$ het gewrigt van de hand $(D)$ de knic $(E)$ her been $(F)$ en de hiel $(G)$ waren wél gemiakt : de voorhand $(D)$ en de agterhand $(H)$ hebben eene grootte geëvenredigd aan die van het dier, maar de vingers zyn zeer kort, de duim is van de andere vingeren niet onderfcheiden : de palm van de hand was met eene celtagtigheid bekleed $(I)$, die zeer dik en geplaatif was op het voorfte gedeelte der beenderen van de agterhand en op het agterite gedeelte van die der voorite regels; dezelve hadt drie en cen half duim lengte, twee duim breedte an de breedite plaats, en agt lynen dikte: daar was eene andere eeltagtigheid $(K)$ in de gedaante van een knobbeltje van omtrent negen. lynen middellyn op het. binnenfte gedeclte van de voorhand an de lruitenzyde, en eindelyk vyf an. dere eelagtigheden ten naftenby van dezelfde dikte, eene op elke.van de latite regels der vingeren van onderen.:

De voorfte beenen waren veel dikker, vleeziger, en fchecnen veel fterker dan de agterfte, welker plaating daarenboven belemmerd en onvoordeclig fchecn te. moeten zyn, omdat de voet, dic, van de hiel tot aau t einde der vingeren, agt en een half duin lengte hadt, niet meer dan-zeven duim op de aarde draagen konde: de hicl $(G)$ bleef anderhalf duim of twee duim van den grond af; datar. was onder den agtervoet eene eeltagtigheid $(L M)$ van vyf. duimen lengte, en van drie duimen breedte aan de breedfte plaats; zy droegr met haare gehecle lengte van de buitenzyde op de aarde, en was holrond in 't midden v'an haare binnenzyde. :

By het openen van den onderbuik vondt men, onder de huid, eene foort van fpek, dat tot e'n duim dikte hadt, cu dat zcer blank was op den onderbuik, daar was onder de fpieren valn den buik vet, dat met vlokjes gef́cinkt was; het ftrelste zig uit van het burtbeen tot an het fchambeen in de gedaante van cen titreep of band, die op de witte lyn was, en die.triec of drie duim breedte, en een of twee duim dikte hadt; malr de grootfte hoeveelheit yan dit vet w's by het borftbeen; het hadt ecne, fchoone witte kleur.

Het netwlies ftrekte zig an de regterzyde tot in 't midden van den onderbuik: tit, en hot ging i.nis de linkerzyde niet verdel dan de ribben, het vouwde zig tuffehen de darmen, en het was zeer ruim en wyd toen men het hadt:

(a) Minoire pour ferois d l'Hifloire Naturelle des abimaux., Part. I, pag. 83. Pl. IXest. 


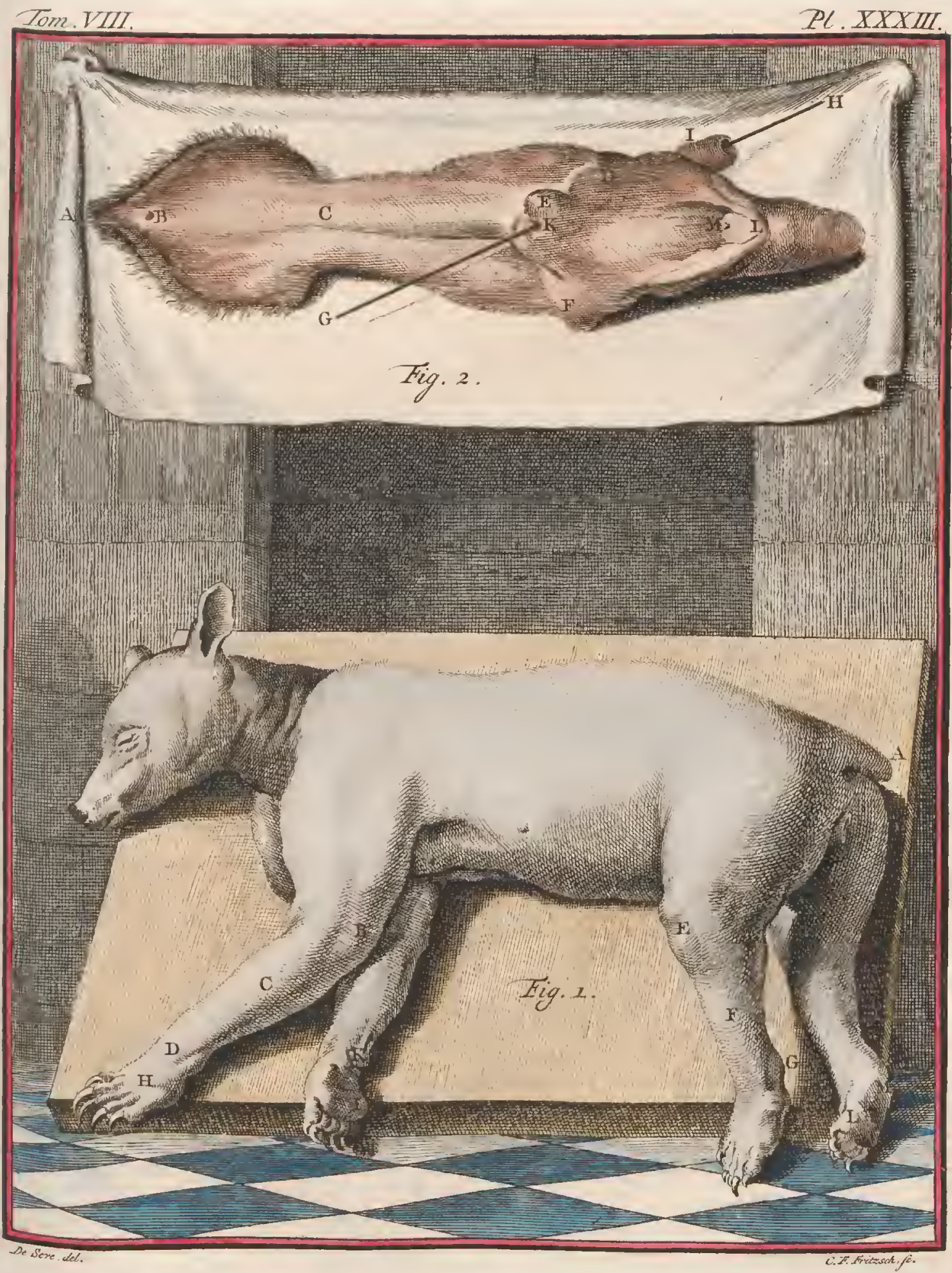



uitgeftrekt; het hadt drie lynen dikte op de vetfe plaatien, maar daar bleef nog even veel doorfchynende ruimte over, als 'er met vet bedekt was.

De twalfvingerigedarm vouwde zig binnenwaards op een kleinen affand van de maas, en ging ter linkerzyde voort, de nugteredarm makte ayne omwentelingen in 't midden van den onderbuik en aan de regterzyde; die van den omgebogendar'm waren aan dezelfde zyde, in den eigenlyk grezegden onderbuik en in de linkerzyde, vervolgens verlengde hy zig agter de maag, in de linker buikzyde, voor dat hy zig ant1 den regtendarm voegde.

De maag was meer ter linker dan ter regterzyde geplaatlt; zy was klein in vergelyking van de dikte van het dier; zy geleek naar de maag van den hond, inzonderheid in het regter gedeelte; de groote blindezak was byna niets; de vernauwing welle de portier makte, was fehuinfch op den darm, zodat de twaalfvingerigedarm eene foort van elleboog by den portier aan de zyde der kleine kromming van de mag makte; ik heb noch van buiten noch van binnen aan dit ingewand die veruauving gezien, daar de Hr. PkrRault in zyne befchryving van den beer gewag van maakt $(b)$ : het breedfte gedeelte van de mang in ons onderwerp was ter plantfe van den flokdarm, gelyk de Hr. PerRAULT heeft angemerkt, man zig ter regterzyde uitfrelkende verminderde dezclve in dikte, ten naaftenby gelyk de maag van den hond en van andere

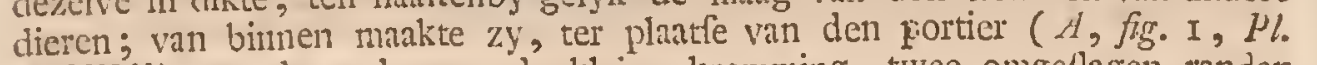
$X X X Y$ ) aan de zyde van de kleine kromming, twee omgellagen randen $(B B, C C)$ en haare vliczen hadden te dezer plaatfe $(D D)$ byna een duim dikte: byna de geheele helf $(E)$ van dit ingewand, ann de regterzyde, was bekleed met een vlies zo glad als dat van den twaalfvingerigendarm $(F)$ : men zag daarenboven in den twa:lfvingerigendarm eene fluweeligheid in de ge. daante van zeer fyne en zeer lange ciraadjes, die duidelyk vlotteden op het water, 't welk men daar op wierp om hen fichoon te maken: het gehecle linker gedeelte van de maag was onelien van binnen door vry groote plooijen ( $G G G G$ ), die in verfchillende rigtingen elkanieren kruiften, en eene foort van onregelmaatig net makten, maar zeer verfchillende van dat der muts in de herkauwende dieren; deze vouwen zouden cer nar die van de lebbe geleeken hebben, zo zy meer uitfpringende waren geweeft: men ziet, in dezelfde figuur, een gedeelte van den flokdarm $(H)$ en de bovente opening $(I)$ van de magg.

Daar was'geen blindedarm; de darmbuis was ten uaftenby van dezelfle dikte over hare geheele lengte, uitgezonderd by den aars alwar zy meer dikte hadt.

De lever geleek nar die van den lond in het getal en de pjlating der kwabben, maar zy verfchilde darvan in de figuur; haare randen waren ninder gerond en fcherper; zy hadden max weinig uitdieping en de bovente regter kwab was, naar evenredigheid, veel kleiner dan in den hond, zodat zy in den beer nict veel dikker was dan de bovenfte linker kwab; het geen iny doet denken, dat de beeren, door den Hr. Perrault ontleed, van den onzen verfeliilden in de betrekkelyke dikte der kwabben van de lever, dewyl hy

(b) Memoire pour fervir a lififoire Naturelle des animaux, Part. I. pag. 87. 
meldt, dat flegts éne der kwabben veel kleiner was dan de andere, daar ik; 'er twee even klein gevonden heb; de lever hadt van buiten eene bleek roode kleur, en die van binnen was niet veel donkerer; zy. woog twee pond en een gros.

De milt was breeder aan de beide einden dan in 't midden, en het onderft einde liep uit in een foort van punt, een weinig nar onlang en voorwards gekromd: dit ingewand was zwartagtig van buiten, en roodbruin van binnen; het woog vier en een half once.

Het alvleefch was van eene zeer onregelmatige gedaante, maar men onderfcheidde daar twee. voornaame takken aan, waarvan de. een zig langs do kromming van den twalf vingerigendarm onder. de regternier uitftrekte, en de ander zig verlengde tot onder de linkernier; de regter tak was korter en dikker, de ander hadt nucer lengte en breedtc.

De nieren ( $f \mathrm{~g} g .2 \mathrm{e} / \mathrm{3}, \mathrm{Pl}$. $X X X I V$ ) beftonden uit verfcheiden gedeeltens in, de gedaante van knobbeltjes, gelyk die der runderen; ik heb 'er omtrent vyf-entwintig in ydcre nier geteld; terwyl de gehcele nier ( fig. . 2) nog omvangen was in het vlies, dat alle haare knobbcltjes met malkanderen gemeen hadden, vertoonden zig de meefte wat bolrond aan de buitenfte oppervlakte van de sier, even gelyk die der runderen; maar nadat ik het vlies, dat niet flegts de nier in haar geheel bedekte, maar dat zig ook tufichen elk der gedeeltens, daar zy uit beftondt, inwikkelde, had weggenomen, is my de uitwendige oppervlakte der knobbeltjes plat voorgekomen ( fig. 3) gelyk ook de zyden, daar zy malkanderen mede raakten; de regter nier fiprong llegts een half duim meer voor uit dan de-linker; men heeft in de, ( 2 figuur) een nier vertoond, van haare voorfte zyde gezien, en in de ( 3 fg. ) van haare agterfte zyde, de nier-flagader en, uitmelkende aders worden in de ( 2 en $3 . f g$.$) . onder (\Lambda B)$ en de pisbuis met $(C)$ aangeweezcn:

Het zenuwagtig iniddelpunt van het middelrif was gerond; het vleezig gedeelte hadt omtrent eene en eene halve lyn dikte.

De. long was ten naaftenby van maakzel als by den hond; daar waren vier. kwabben aan de regter en twee aan de linkerzyde: de punt van 't hart was ftomp en agterwaards gerigt; de groote flagader verdeelde zig in drie takken.

De tong gelcek veel naar die van den hond, inzonderheid in hanre gedaante, tepcltjes, enz, maar zy verfchilde daar van door verfeheiden klieren, van ecn kelk omringd, die op het agterf gedeelte van de tong geplaarft en byna in een halien cirkel gefchikt warren, waarvan de bolronde zyde agterwaards gekecrd wis; dar. was. in 't midden éne klier, die dikker was dan de andere, derwyze geplatet, dat zy een hoek in den.lialven . kring makke.

Het verlremeltc was-dourlizeden met tien of twanlf vooren, die bolrond vain voren waren; het igterft gedeelte vall het verhemelte tuffchen de baktanden was knobbelig: de voorherffenen woogen zeven oncen éćn gros en vyftien greinen, en de agterherficuenıéén once vicr en een half gros.

Daar wareil zes mimmen; vicr op de borft, ann ydere zyde twee, en de twee andere voor de fihamelheid, op vyf duim afftands van de klink.

De lippen van de klink waren zeer uitfpringende, en de onderfte fplyting liep in cen punt uit $(A, f g .2, P l . X X X I I)$ het hoofdje van den kittelaas. 


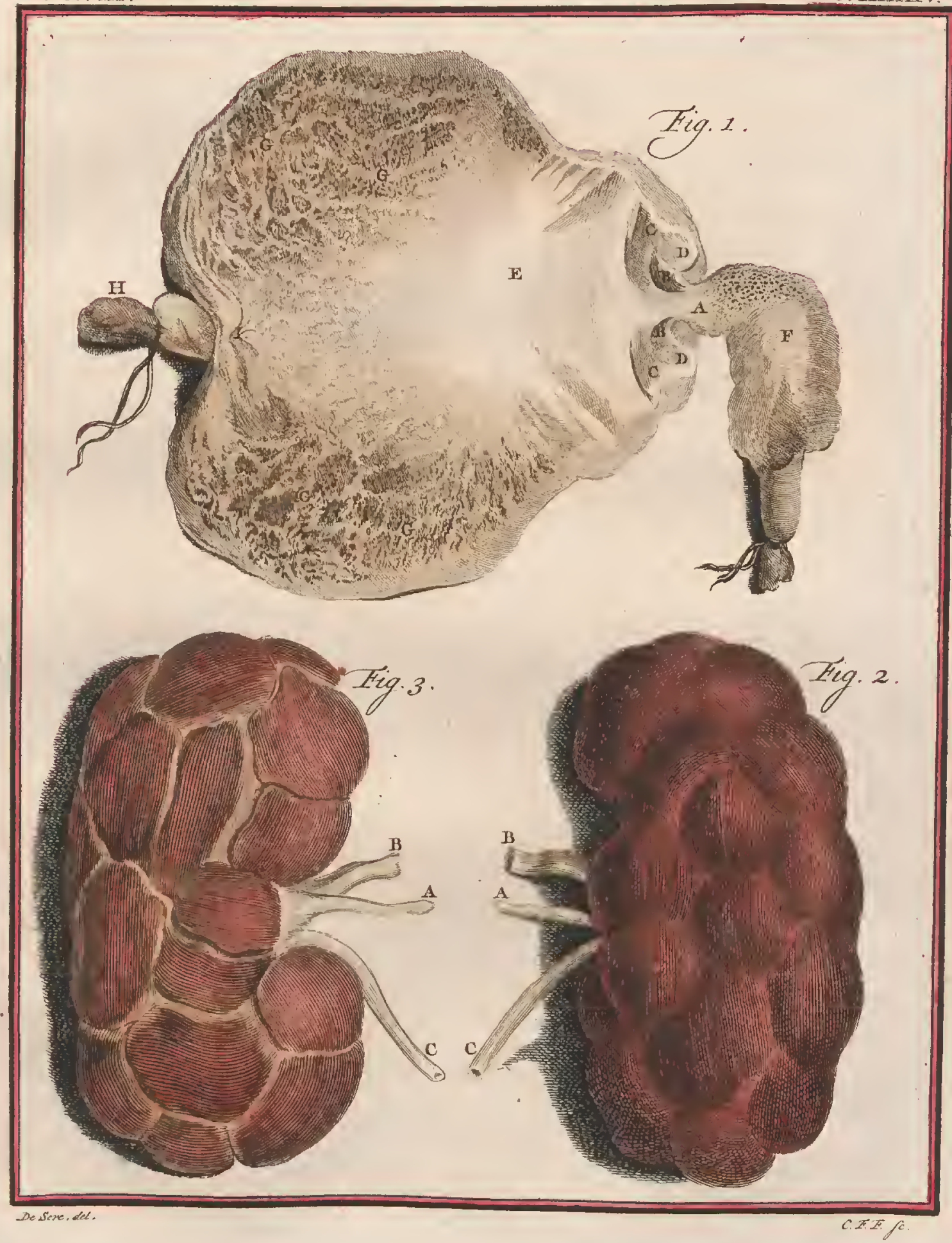



was zeer weinig merkbar, men herkende het niet dan door eene holligheid (B) welke de voorhuid maakte: de fchede $(C)$ was zeer nauw, en fcheen uitwendig gezwollen ter platfe van de opening van de pisbuis; geopend zynde heb ik gezien, dat deze opzwelling gemaakt wierdt door een omgellagen kringswyze rand $(D E F$ ), beftaande uit knobbeltjes, dis de fchede van binnen omliepen; de opening van de pisbuis was in den omgetlangen rand, en was insgelyks met knobbeltjes omvangen; ik lieb een ftilet $(G H)$ in de pisbuis $(I)$ gebragt om derzelver opening $(K)$ aan te wyzen: de hals $(L)$ van de lyfmoeder kwam mecr dan een half duim voorwaards in de fchede uit, en haare opening $(M)$ was omringd van knobbeltjes: de hoornen van de lyfmoeder makten een zeer fcherpen hoek aan hunne fplitfing, en ftrekten zig in eene. regte lyn uit; de zaadballen warerr rondagtig en wat plat; daar waren binnen in dezelve eenige witagtige knobbeltjes, die van buiten door de alchgrauwe kleur van cen zaadbal zigtbaar waren:

Lengte van de darmbuis van dèn portier tot aan den aars . vocten, duimen, lyneraio

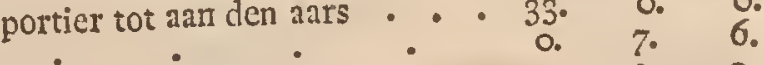

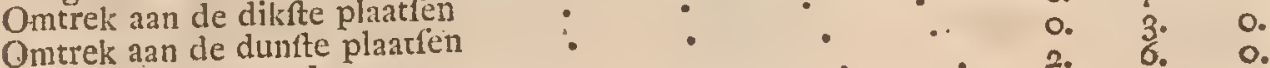

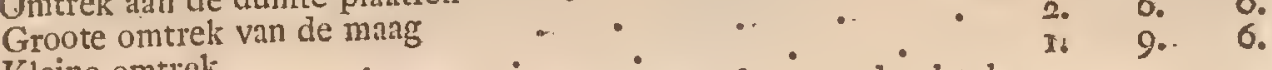

Kleine omtrek dien het regter gedeelte makt

Lengte van het linker gedeelte van den flokdarm af tot aan den grond van den grooten blindenzak

Omtrek van den flokdarm

Omtrek van den portier

lengte van de lever

Breedte

Haare grootite dikte

Lengte van het galblaasje

Zyn grootfte middellyn

Lengte van de milt

Breedte van het onderfte einde

Breedte van het bovenitte einde

Dikte in " $t$ midden

Dikte van het alvleefch

Lengte van de nieren

Breedte

Dikte $\quad \cdot{ }^{\circ}$ middelpunt van de holle ałer tot aan de

Lengte van het zenuwagtig middelpint van de holle ater tot an de o. 3. 0. punt

Breedte
Breedte van het vleezig.geileelte tuffchen het zenuwagtig mididolpunt

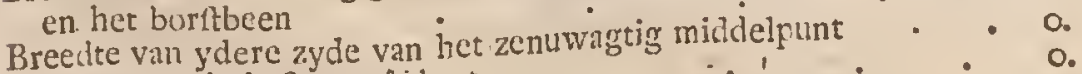

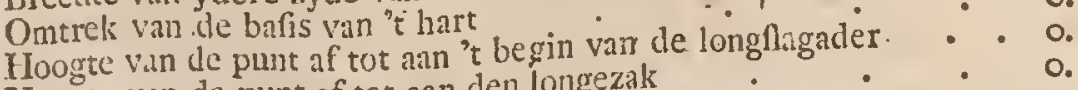

Hongte van de punt af tot an den longezak

Lengte van de tong' 
Lengte van het voorfte gedeclte van, het toompje af tot aan 't voeten, duimen, lyner. einde

Breedte van de tong

Breedte der vooren van het verliemelte

Hoogte van de randen

Lengte der voorherffenen

Breedte

Dikte

I.engte der agterherfenen

Breedte

Dikte

Affitand tuffchen den aars en de klink

Lengte van de klink

L.engte van de fehede

Omtrek aan de dikfte plaats

Omtrek aan de dunfte plaats

Groote omtrek van de blaas

Kleine omtrek

Lengte van de pisbuis

Omtrek van den hals en het lighaan der lyfinoeder

Omtrek

Lengte der hoornen van de lyfmoeder

Omtrek op de dilite plaatfen

Omtrek op het einde van yderen hoorn

Afitand in een regte lyn tuffchen de zaadballen en het cinde van den hoorn

Lengte van de krommic lyn, die de trompet doorloopt

Lengtc der zaadballen

Breedte

Dikte

De kop van 't geramte van den beer (Pl.:XXYV) heeft :veel gelykenis naar dien van den wagthond en den wolf, fchoon de bek van den beer naar eventedigheid breeder, de neusbeenderen meer voorwards uitgettrekt en ver'hevener, het voorhoofd breeder, en de priemswyze uitfteckzels der 1laapbeenderen grooter zy'n: daar zyn ter plate van den bogt, dien yder tak van "t onderft kakbecn makt, twec uitfteckzcls agterwaards gerigt; het voorfte is het kleinfte en op omtrent cen duim affands van het agterfte geplaatit; de voorhoofds-boezems zy'n zeer groot, en daar is een beenig plaatje van byna een duim breedte, dat uit het agterhoofdsbeen uitfteckt, en dat zig tuffchen de voorherifenen en de agterherffenen uitftrekt.

Het geriamte $(p l . X X X V)$ dat ten onderwerpe voor deze befchryving gediend. heeft, is zeer groot, gelyk men zien zal uit de maten in de volgende tafel bygebragt; daar zyn zes finytanden en tweehondstanden vitn voren in elk der kaakbeenen, en vyf baktanden aan weerszyde van het onderit kaakbeen: alleen blyven de dric agterfte baktanden van het bovenfte kaakbeen aan weerszyde over, maar men ziet daar dric tandkaftjes, ook van wecrzyde, die de plaats van drie Mlcine baktanden aanwyzen: dcze bcer hadt dan twaalf baktanden in het bo- 


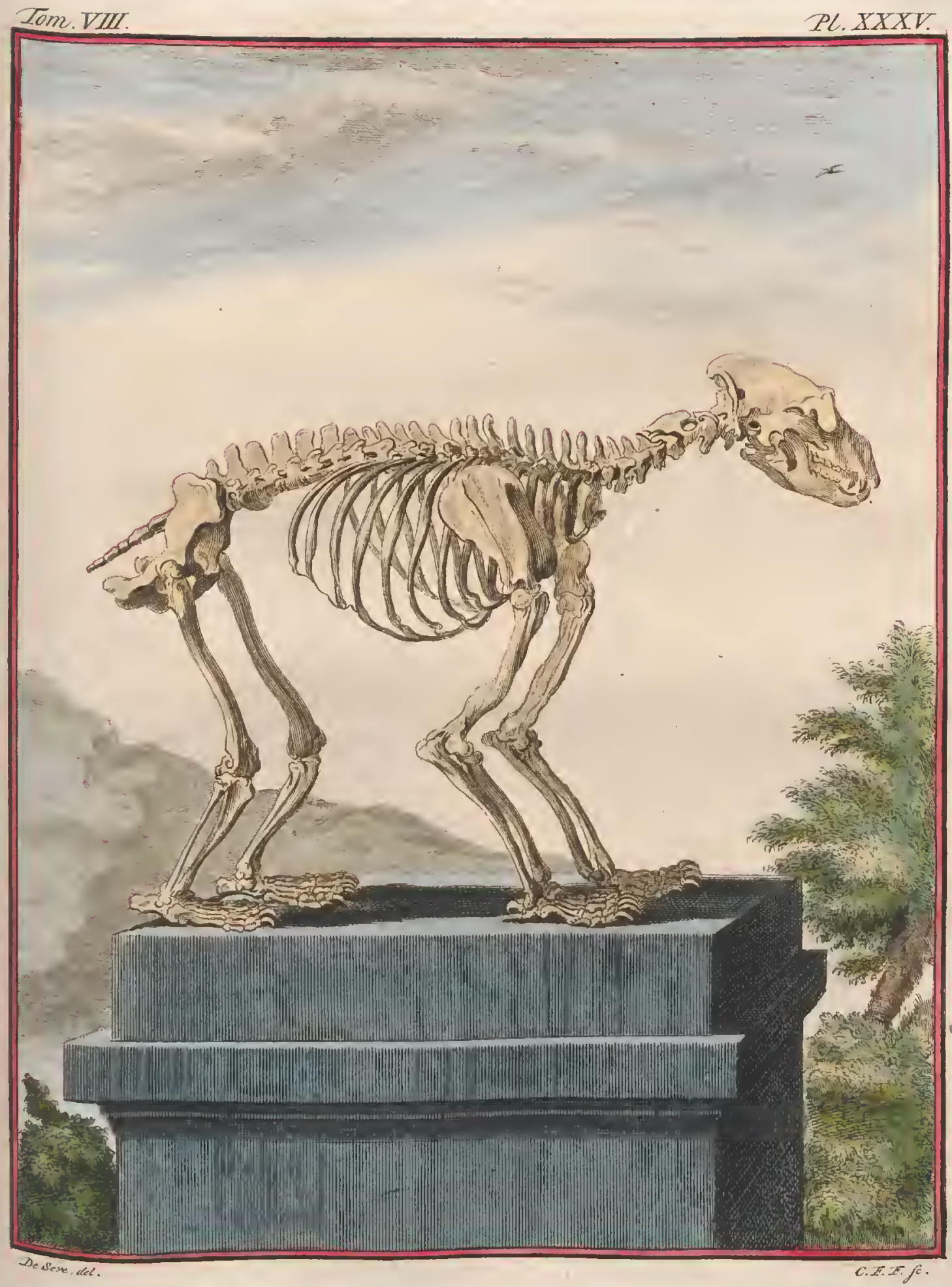





\section{BESCHRYVING VA N DE N BEER. 159:}

venft kaakbeen, "t welk in alles agt-en dertig tanicn maakte: het geraante egter van den beer, dien ik ontleed heb, cn die ten onderwerpe voor de befchryving der weekc deelen heeft gediend, heeft llegts vier tanden aan weerzyde van het bovenkaakbeen, en men ziet 'er geen voetfpoor van tandkaftje, daar men een grooter gretal van tanden uit kan opnaaken; die beer hadt dan maar vier-en-dertig tanden: wy weeten, dat hy uit de Alpifclte gebergten kivam; het was cen bruine becr. Zo het groot geraamte, dat ik in het Kabinet heb gevonden, van een beer van de foort der zwarte beeren van 't Noorden was, zoude men cen kenmerk te meer hebben on deze twee foorten te onderfcheiden, dewyl zy in 't getal der tanden van malkanderen verfehillen zouden: de fitytanden dier twee geramenten zyn alle half verleeten; de hondstanden gelyken nar die van don hond en den wolf; de eerfte baktand van het onderft kaakbeen is zeer: klein, en agter den hondstand geplantt; daar is ecne ledige ruimte tuffclren den eerften en tweeden baktand, die veel dikker is datn de cerfte, maar die flegts eenen wortel heeft; de drie lastfte zyn zeer dik, vooral op cen na de laatfte; de laatlte van het bovent kaalibeen is de grootfte vanallen, dic in het bovent en onderft kaakbeen zyn; zy hebben geen punten gelyk die van de baktanden van den hond en den wolf, en zy gelyken daar op geenerlande wyze naar.

Het doornagtig uitfteekzel van het tweede nekwervelbeen verfchilt niet:van dat van den hond en den wolf, dan voor zo verre hetzelve mecr agtersiaards uitgeftrekt is, en het derde wervelbeen in "t geheel bedekt: de doornagtige uitfteckzels van het vierde en vyfde wervelbeen zyn langer dan in den hond en den wolf, en de dwarfche uititeckzels van het derde, van het vierde, cn van het vyfde wervelbeen hebben geene takken, die zig voorwands nitftrekkèn, gelyk als in deze dieren; mar de dwarfche uitfteekzels van het viertie en van het vyfde wervelbeen hebben een onderiten tak, die zo lang is als de bovenfte.

Daar zyn veertien lendenwervelbeenderen en veertien ribben aan weêrzyde, negen ware en vyf vallche; de doornagige uitftekzels der cerlic wervel-: beenderen zyn regt, en de andere zyn agterwards gebogen, uirgezonderd het laatfte dat regt is: het borfibeen beliondt wit negen beenderen; de ecrite ribben, eene an wecrzyde, geledigden zig met het voortte midden gedeclte van het ecrite dier beendaren; de geleding der tweede ribben was tuffehen het eerfte en tweede; die der darde ribben tufichen het tweede en derde der beenleren, en clus vervolgens tot de negende ribben, die zig. tuffchen het agtlte: cu negende.been geledigden.

De lendenwervelbecnderen zyn ten getale van zes; liunne. uitfteckzels hebben ten naaftenby dezelfde evenredighcden als die van den houd en den wolf; het voorfte gudcelte van het heupbeen heeft mear breedte, en de goot dour het ongeramde been geformeerd, is dieper dan in deze dieren: daar waren vyf valliche wervelbeendercn in het heiligheen: de ftart was niet gehecl in let geramte, war maar deze befohrying gemankt is.

Het. 1chouderblad is byna vierkint; de dooru is ten naftenby als de hoek: lyn van dat vierkant geplantít; $Z y$ verdcels het fchouderhlad in twee ongelyke

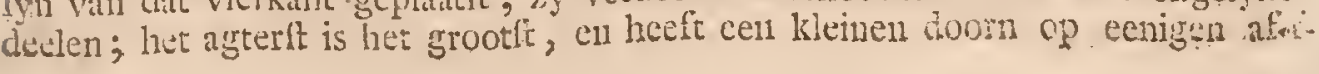


ftand van zyn agterften rand-geplaatit, die in het.onderfte gedeelte uitgefneeden is.

Het armbeen was van voren bolrond over de lengte van het onderfte micdelgedeelte; twee graaten of kleine verhevenheden vereenigden zig op deze bolrondte; de eene ftrelite zig uit op het voorfte van het been tot aan deszellis boveneinde; de andere was fchuinfeh, en verdween op de buirenzyde van liet boventt middel-gedeelte van het been.

De ellepyp was over haare lengte bolrond naar voren, en het armbeen was bolrond over zyne bimnenzyde, hetzelve onderltellende in een ftat van vooroverbuiging te zyn, zo dat deszelfs onderlt gedeelte gelyklynig of evenwydig ware met de ellepyp; en het bovenft gedeelte was fchuinch naar voren van dit been gerigt.

Het dijebeen is zeer lang maar evenredigheid der beenderen van den poot; daar was een graat op de binnenrand der agterfte zyde; het fcheenbeen en het kuitbeen zyn zeer kort.

Daar zyn drie beenderen in den eerften ry van de voorband; het grootit was onder het ftralbeen, het tweede onder de ellepyp, en het derde buiten den ry: de tweede ry beftondt uit vier beenderen; de drie eerften bevonten zig elk boven een der drie eerfte becnderen van de agterhand, en het vierde been van de voorhand gedeelrelyk boven het vierde en gedeeltelyk boven het vyfde van de agterhand.

De voorvoet heeft zeven beenderen, even als by de meefte dieren geplaatit.

De beenderen van de agterhand en der vingeren van de voorfte voeten zyn ten naaftenby zo lang en zo dik als die van den agtervoet en der vingeren van de agterite voeten.

Lengte van den 'kop van 'het einde des bovenften kaakbeens tot ain"t agterhoofd

De grootfte breedte van den lop
Lengte van het ondert kaakeen van zyn voorfte cinde tot aan den agterften rand van het kinokliclwyze uitfteekzel

Breedte van het onderft kaakbeen ter plaate van de hondstanden.

Breedte ter plaatfe valn den bogt der takken

Afftand tuffehen de knoklielwyze uitfteelizels

Altan van het.voorfte redeelte van het bovent kaliheen ${ }^{*}$

Dikte van het-voorte gredeelte van het bovent kithkeen $\cdot \cdot \cdot 0$.

Breedte van dit katkbeen ter platefe der inytanden

- Breedere ter plaatfe van de hondstanden

Iengte van de bovenfte zyde

Lengte dezer opening

Breedte

Breedre aan de breedite plaats

Breelte der ougputten

Lengte der langfte fnytanden buiten het been

Breedte aan de balis

voeten, duimen, lynen.

\begin{tabular}{ccc} 
I. & 0. & 9. \\
0. & 7. & 0. \\
0. & 8. & 6. \\
0. & 1. & 10. \\
0. & 2. & 11. \\
0. & 2. & 6. \\
0. & 0. & 3. \\
0. & 1. & 8. \\
0. & 2. & 10. \\
0. & 5. & 0. \\
0. & 2. & 7. \\
0. & 1. & 9. \\
0. & 1. & 10. \\
0. & 2. & 9. \\
0. & 0. & $8 \frac{1}{2}$. \\
0. & 1. & 30 \\
0. & 1. & 10. \\
0. & 1. & 4. \\
0. & 0. & 10. \\
& \multicolumn{3}{c}{ Lengte }
\end{tabular}


Lengte van de dikfte baktanden buiten het been voeten, duimen, lynen.

Breedte

Dikte

Lengte van den hals

Lengte van de eene zyde naar de aridere

Breedte van het eerfte wervelbeen "op de dwárfche uitfteekzels.

Lengte van het gedeelte der wervélbeenskolom, 'die uit rugwervelbeenderen beftaat

Hoogte van het doornagtig uitfteekzel van het vyfde wervelbeen dat het langfte is

Hoogte van dat van het dertiende dat het kortite is

Lengte des lighaams van het laatfte wervelbeen dat het langft is.

Lengte der eerfte ribben

Afftand der cerite ribben aan de brèedfte plaats

Lengte der tiende ribbe, die de langfte is

Lengte der laatte van de valfche ribben

Breedte aan de breedifte plaats

Lengte van het borftbecn

Lengte van het agtite been dat het kortit is

Hoogte van het langfte doormagtig uitfteckzel der lendenwervelhecnderen, het welk dat van op een na het laatfle is .

Lengte van het laatfe bykomend uitteekzel zynde dat van het laat-

fte wervelbeen

Lengte des lighiaams van het vyfde wervelbeen, dat het langft is.

L.engte van het heiligbeen

Breedte van het voorite gedeelte

Brcedte van het agterfte gedeclte
Breedte van het voorfte gedcelte van het heupbecin

Hoogte van het been, van her midden der knolkelwyze holligheid. o.

Middellyn van deze holligheid

Lengte van de goot

Breedte in 't midden

Dicpte

Lengte der eyronde gaten

Brecdte

Breedte van het beklien

Longte van het fchouderblad

Breedte aan de breedifte plaats

Breedte aan de finalfte plaats

Hoogte van den doorn aan de verhevenfte plaats

L.engte van den fchouder

Omtrek aan de kleinfte plaats

Middellyn van het hoofd des beens

Breedte van het onderit gedeelte

L.cngte van het elleboogsbeen

Lengte van den elleboogsknokkel

Lengte van het fraalbeen

Lengte van het dijcbeen

Mididellyn van het hoofd

$$
\text { VIII. Deel }
$$

O. O. 3 .

o. 0.7 .

०. 7.8 .

c. 50

I. 4. 8.

o. 2. 9 .

o. I. 3 .

०. J. 3.0

O. 3. II

- 3.7

I. 2. 7

०. 9. I0

o. 0.8

$\begin{array}{rrr}0 . & 2 . & 6 .\end{array}$

o. 2. 0 .

o. I. 9.

o. T. 6 .

5. 3.

10.

r. 8.

4.75

2. 5 .

- 3.9 .

3. 6.

2. 9.

I. 10.

3. 0.

3. 10.

2. 0.

c. 4. ?

I. 8 .

I. 6

०. 4. 6 .

o. I. 9 .

०. 3. 2.

o. II. II.

o. 2. 0.

०. IO. 0.

I. 2. 0 . 
Omtrek van het midden des beens voeten, duimen, jynem, Breedte van het onderft einde Lengte der kniefchyven Breedte

Dikte

Lengte van het fcheenbeen

Breedte van het hoofd

Omtrek van 't midden des beens

Breedte an het onderft einde

Lengte van het kuitbeen

Omtrek aan de dunfte plaats.

Breedte aan het bovenfte einde

Breedte aan het onderft gedeelte

Hoogte van de voorhand

Lengte van het hielbeen

Hoogte van het eerte wigge-en het fchuitbeen te famengenomen

Thengte van. het eerfe been van de agterhand dat het kortfe is ....

Lengte van het derde been dat het langft is.

Lengte van het vierde been dat het langfte is.

Lengte van den eerften regel des middeliten vingers van den voorften voet

3.engte van den-tweeden regel

Lengte van den derden

Lengte van den tweeden Lengte van den tweeden
voeten

Lengte van den tweeden regel

Eengte van den derden

Lengte van den eerften regel van den duim

Lengte van den tweeden regel

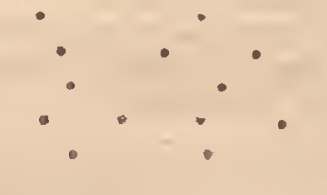

$\begin{array}{lll}0 . & 1 . & 2 . \\ 0 . & 0 . & 9 \frac{1}{2} . \\ 0_{0} & 1 . & 4 \cdot \\ 0 . & 1 . & 2 . \\ 0 . & 1 . & 3 .\end{array}$

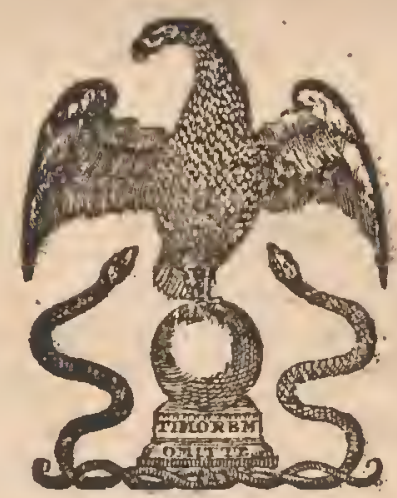




\section{A N D. E N B E' V E R. . T63}

\%

\section{E $\mathrm{E} \quad \mathrm{E} \quad \mathrm{V} \quad \mathrm{E} \quad \mathrm{R}$ *.}

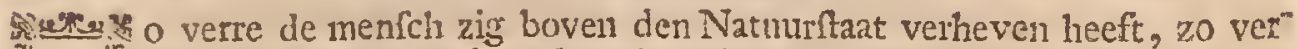
8. $Z$ lo re zyn de dieren beneden denze!ven gedaald; onderworpen en in (1) flaverny gebragt, of als oproerigen behandela en door het geweld verfpreid, hebben $\mathrm{zy}$ geene matichappyen meer, hun vernuftis nutteloos geworden, hunne zwakke konften zyn verdweenen, ydere foort hecft haare algemeene hoedanigheden verloren, en allen hebben zy geene andere eigenfehappen belouden dan welke zy hoofd voor hoofd bezitten, en die in de cene volmaakt geworden zyn door bet voorbeeld, de navolging, de opvoeding; en in de andere door de vrees en de noodzanklykheid, daar zy zig in bevinden, on geduurig voor hunne veiligheid te waken. Welke uitzigten, welke bedoelingen, welke ontwerpen, kan men verwagten van flaaven zonder ziel, of bannelingen zonder magt? te lkrtipen of te vlugten, en altoos op eane eenzaame wyze te beftan, nicts te ftigten, niets voort te brengen, niets aan de nakomelingfchap na te laten, fteeds in rampen te kwynen, van hunnen oorfprong te vervallen, of hunne bont te rckken zonder te vermenigvuIdigen; in ééll woord, door de duuring zo veel, ja meer, te veriiezen, dan zy door len tyd verhreegen hadden.

Dus blyven "el" van humne verwonderlyhe kloekhcid geene andere voetfpooren over dan in die verre af zynde en woefte lancien, daar de menfell, eeuwen agter malkanderen, geenen toegan o toe gehad heeft, daar ydere foort van dieren hunne natuurlyke talenten in vryheid oeffenen konde, eil dezelve in ruft volmaaken, door zig in eene mantfliappy te vereenigen, die door ons geflagt niet telkens overvallen wierdt: de hevers zyn mogelyk het eenigft voorbceld, 't welk als een gedenkftuk van die foort van veritand in de dieren beftaat, 't welk, fchnon in zyn beginzel oneindig beneden dat vanden menfch, egter gemeene ontwerpen, en betreklyke oogrierken onderftelt; ontwerpen, die de matichappy ten grondilage, en het leggen van een dyk, het ftigten van een vlek, het veftigen van eene foort van Gemeenebeft, ten voorwerpe hebbende, ook eenige wyze onderftellen van malkanderen te verftaan en gemeenfchaplyk te werken.

De bévers, zegt men, zyn onder de viervoetige dieren het geen de bijen onder de infekten $z y^{\prime}$; weik een verfchil ondertulichen! Daur zyn in de Naturu, zo als dezelve tot ons gekonen is, dric foorten van matfchappyen,

* De Béver heet in 't Grielifch Kárng; in 't Italiaanfich Bivaro, Bevero; in 't Spaanfch Be. varo; in 't Eranfcls Caftor of Bieure; in 't Hoogdutich Biber; in 't Lingelfch Beaver, in ": Zweedfch Baefwer: in 't Poolfch Bobr.

Cajlor. Gesner Hiftur. Qualrup. pag 300. Icon. Qualrup. pag. 84.

Cajor five Fiber. Ria Synopf. Animal. Quidrup. Paj. 209.

Caftor cauda aqatd, plana, fiber. Linsaus.

Cofor, Fiver, Kueis de Quadrup. pog. QT.

Cajtor caftcnei coloris, canda borijontaliter planb. Caffor five Fiber. BaIssoN, Regn. Animab, pag. 133 . 


\section{${ }_{064}$ DE N A T UURL Y KE H ISTORIE,}

dewelke men moet befchouwen vóór dat men dezelve vergelykt: de vrye matfchappy van den menfch, waar van hy, naaft God, alle zyne magt ontleent; de gedwongen matfchappy der dieren, altoos vlugtende voor die van den menfch, en eindelyk de gedwongen matifchappy van eenige kleine diertjes, die, allen in den zelfden tyd en indezelfae plaats geboren wordende, genoodzaakt zyn te famen te blyven. Een individu, op zig zelven alleen geno. men, zo als het eerft uit de handen der Natuur te voorfchyı komt : is llegts een onvrugtbaar wezen, dat niets vermag, en wiens vernuft zig tot het enkeld gebruik zyner zintuigen bepaalt; de menfch zelf, in den louteren $\mathrm{N}_{2}$ tuur-1taat, ontbloot van kundigheden, en van allen onderftand der matichap$\mathrm{py}$, brengt niets voort, itigt niets; alle matfchappy integendeel wordt, lioe toe, vallig, hoe blind, dezelve wezen moge, noodwendig vrugtbaar, mits dat zy uit wezens van dezelfde natuur belta; door de enkelde noodzaklykheid van malkanderen te zocken of te vermyden zullen zig daar gemeene beweegin. gen formeeren, weiker uitllag dikwils cen werk zal zyn, 't welk het voorkomen zal hebben van met verftand ontworpen, beleid, en uitgevoerd te worden: dus zyn het werk der bijen, die, in cene gegeeven plats, . gelyk een korf of den ftam van een hollen boom, elk har celletje maken; , het werk der vliegen van Cayenne, die niet alleen. ook haare celletjes maaken, mar zclfs de korf, of zo gy wilt, het vertrek, vervaardigen, watain die celletjes bevat moeten worden, louter werktuigelyke verrigtingen, die geen vernuft, geen beraamd ontwerp, geene algemeene bedoeling, onderftellen; verrigtingen, die enkel het voortbrengzcl zynde van cene natuurlyke noodzaaklykheid, en het onvermydelyk gevolg. van gemeene bewecgingen $(a)$, altoos op dezelfde wyze, in. den zelfden tyd, en.op dezelfde plaats, worden uitgevoerd door eene menigte, die zig niet uit verkiezing in mantfhappy heeft famgevoegd, maar die door de kragt der natuur by malkanderen geplatift is: het is derhalven niet de maatfchappy, het is 't getal alleen, 't welk hier werkt; het is eene blinde magt, welke men niet kan vergelyken by het. licht, waardoor alle maatfchappyen beftierd worden: ik fpreek niet van dat zuiver licht, van die goddelyke ftranl, die niet dan den menfch alleen, befchynt en leidt; de bévers zyn daar gewiftelyk, gelyk: als alle andere dieren, van beroofd; mar omdat hunne matchappy niet. cenc gedwongen vereeniging is, mar integendeel met eene foort van verkiezing wordt angegaan, en ten minften een algeneenen famenloop, gemeene bedoetingen in hun, die zig in dezclve begeeven, onderfelt, zo moet men. daar in ten minften een blyk van vernuft erkennen, " $t$ welk, fchoon in zyn beginzel zeer verfchillende van het menfehe. lyk verfand, egter uitwerkzelen voortbrengt, die overeenkomf genoeg hèben on dezclve met malkanderen te kunnen vergelyken, niet in eene voliomene en magtige maatfchappy, zodani: als dic beftant onder Volkeren, dic fints eene recks van eeuwen als befchaafde Volkcren hebben geleefd, maar in ce pas opkomende matchappy der Wilden, dewelke alleen, nari billylhoid, met dic dir dicris kan vergeleeken worden.

(a) Zie ds ophelderingen en bewyzen hier van in het IV. Deal van dit. Werk, in de Wege bandeling orer de Nacuur d̈̈ Dieren. 
Laat ons dan het voortbrengzel van de eene en de andere dezer maatfchappyen zien; laat ons zien, tot hoe verre de konit van den béver zig uitftrekke, en waar die van den Wilden zig bepaale? Fen tak te breeken om zig daar een ftok val te maaken; eene hut te bouwen, dezelve met loof en bladeren te beleggen om zig voor den regen te beveiligen; mofch of hooy by malkander te halen, oin zig daar cen bed van te vervardigen; zie daar de verrigtingen, die het dier en de Wilde gemeen heeft; de beeren manken hutten, de anpen hebben ftokken, verfcheiden andere dieren maaken zig een net, zin'lyk, gemaklyk, verblyf, dat ondoordringbaar voor 't water is: een fteen te vryven of te flypen, om hem fcherp te maaken, zig daar van een byl te ver: vaardigen, zig van denzelven te bedienen om te fnyden of te hakken, om het hout van zyn baft te ontblooten, om pylen te punten, om een vat vit te holen, een dier te villen om zig met zyn vel te kleeden, deszelfs zenuwen te bezigen om'er het koord eens boogs van te maalien, die zelfde zenuwen aan eenen harden doorn te hegten om zig van het een en ander als van een naald en draad te bedienen, dit zyn verrigtingen; die enkelyk tot elk menfch, op zig zelven alleen, en hoofd voor hoofd befchouwd, behooren; verrigtingen welke de menfch in de volftrektfte eenzaamheid alle kan uitvoeren, zonder van anderen geholpen te worden, naardien zy het gebruik van de hand alleen onderftellen; maar een grooten boom om te hakken en te vervoeren; eene groote welgedekte hut te bouwen, eene lange kanoe of fchuit te vervaardigen en te water te brengen, zyn werkingen, die noodwendig een gemeenen arbeid en beraande ontwerpen onderftellen : die werken zyn ook de eenige gevolgen van eene pas opkomende matfchappy onder wilde Volkjes, gelyk de werken der bévers de vrugten van eene nieer gevorderde mantfchappy onder deze dieren zyn; want men moet anmmerken, dat zy niet denken om te bouwen, ten $2 y$ zy een vry land bewoonen, en eene volkomen ruft genieten : daar zyn bévers in Languedok, op de eilanden van de Rhone, daar zyn 'er in grooteren getale in de Noordche Provintiën van Europa, maar gelyk alle deze ftreeken bewoond zyn, of ten minften veel door menfchen bezogt worden, zo zyn dar de bévers, even als alle andere dieren, verfpreid, eenzaam, vlugtende, of houden zig in ecn hol verborgen $(b)$; men heeft hen

(b) Min beweert, dat deze foort van eenzaame bévers ook in den Rhyn zyn, doch zeer zeldzaain: daarentegen wil nien, dat zy in een grooter getal huisvelten, in de rivier de lippe, die by Wezal in den Rhyn valt, en ontrent Lipftat vecle vy"ers maakt; dat zy daar zelfs nog eenige gebouven optimmeren, niet in die iyvers van de sivier, maar onder de aarde aan die vyvers: men vindt 'er ook op de hufen van Pommeren, "an Denmuaken, Sweden, enz; gelyk ook deze cenzaame en vlugtentie bévers in de Ntderlauden in de.rivieren, de Mas, de Waal, den YTEl, cnz, te vinten ayn: maar zaldzaan,

Zie her wat de Hr. vaN ner. HaAr, Stads Ileeineefter van's Hertogenbofte, Lid van de Matfchappy te Haarlem, de goedheid heeft gehad, ons ineede te deelen, van een léver, den 10 E) art 1770 , ain de Mass, by buiter.geincen hoos water, gedood:

"Nadat men cedert eenyse jataren, zo in le Maas, Waal en Yifel, nu en dan een bever. ge.

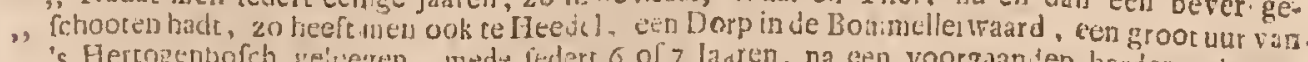
"s Hercngenbofch geicegen, mede federt 6 of 7 Jarien, na cen voorgan en harden wints, 3. zulk ean dicr ontekt, en dikwils van zyne wooning, in een Rycwasrd aan de Maas gemalit,

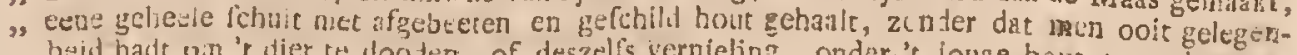
", heid hadt vin 't dier te doodert, of deszelis vernieling, onder. 't jonge-hout te verhocden. 
daar nimmer zig zien vereenigen, nimmer iets onderneemen of bouwen; terwyl in die woelte landen, daar de mentch in matfchappy niet dan zeer laat is doorgedrongen, en daar men te voren niets dan eenige voetitappen van den wilden menfch vondt, overal vereenigde bévers gevonden zyn, die maatfchappyen hadden opgeregt, en welker werken men niet konde nalaaten te bewonderen: wy zullen ons toeleggen, om geene andere dan oordcelkundige, onwraakbaare, getuigen by te brengen, en wy zullen geene andere ftukken voor zeker opgeeven, dan die, waarin zy allen overeenftemmen: misfchien minder dan zommigen hunner tot verwondering geneigd, zullen wy ons het twyffelen, en zelfs het beoordeelen veroorloven, over alles, wat ons al te moeijelyk te gelooven zal voorkomen.

Allen konien zy hier in overeen, dat de bevers, tvel verre van eene blykbaare meerderheid van vernuft boven de andere dieren te hebben, integendeel beneden zommigen van dezelve fchynen te zyn in de hoedauigheden, die hun hoofd voor hoofd eigen zyn; en wy hebben gelegenheid om dit ftuk te beveftigen, dewyl wy nog tegenwoordig een jongen leevenden bever hebben die ons van Kanada is toegezonden (c), en welken wy federt byna een jaar bewaaren: liet is een vry zagtaartig, bedaard, redelyk genneenzaam, dier, een weinig droevig, zelfs wat klaagende, zonder geweldige driften, zonder fterke neigingen, zig weinig beweeging geevende, geene poogingen, voor wat het wezen moge, aanwendende; het toont cgter een ernitig verlangen naar zync vryheid, door de deuren zyner gevangenis van tyd tot tyd af te kuabbelen, maar zonder woede, zonder verhantting of drift, cn alleen met oogmerk om daar eene opening in te makien, en 'er uit te konnen; voor het overige is het vry onverfinilig, zig ann nienand verbindende $(d)$, niet zoelende te befchadigen, en weinig poogende te behagen: hy fchynt in de betreklyke hoedanigheden, die hem nader by den menfch zouden brengen, beneden den hond te zyn; hy fichynt noch gemaakt on te dienen, noch om te beveelen, noch zelfs on ongang met eenige andere foort dan zyne eigen te hebben; zyn vernuft, in zig zelven befooten, opesıaurt zig niet volkomen

" eindelyk ontielite men, by de tegenwoordize honge Rivier den ro maart 17\%o, dat een be"ver twee roeien boven 't water op den Itam van cenen Wilgenboom zat, alwaar hy, uit ", een fchuit, met een vuuroer getood en herwasts gebragt werdt: hy woog 40 ponden, "Was kaftanjebruin, en, van 't uitterlte van desı ftart tot aan zyne geele ndgtanden, ountrent " 4 voeten larg, vry vet, ei fteris gepiend: onder het vel tulfchen zyne agterfte pnocen "vondt men twee blaajes ieder ter grontie van een hoender-ey, mot redelyk geele Cafin", retur gevuld: weegende beiden 4 oncen: het ovir gevan zyne ingewanden kwam zeer wel over ", een met de berchryving en afbeelding welke ue Hiren. SE liuFron en DAOBrenton in hunne "Ilifoire Naturelle Yone VIII pagina 138. Anfterdamiche Editic daarvan geeven. Sehoon " dit dier aan Neterland niet eigen ichyms, en vermoedelyk in den winter tnet het $y$ s van el. "ders overkomit dryven, blykt het nugthans, dat ze hier vry wal tieren, en gepaard zymie "wel ligtelyk zonden kumnen vernenigvuldigen; althans zy verdienen mede ecne plauts in de "Nituurlyke Hiltorie van Nederland: het vel van den béver is vervolgens opgezat, en wordt " in het Kabince van den Pins Erfitadhouder beward.

(c) Dez teérer, die jong gevangen is, is my in 't begin van 't jaar I758 roegezonden; donr den IIr. Ine MonTablinad, Kapitein in de Antillerie Royale.

(id) De Hr. Kusin heeft evenwel gefchreeven. dat hy er cen verfcheiden jaaren lang onderhouden hadt, die hem volgde, in hem kwam opzoeken, gelyk da honden bunne meeftrs gan opzoeken. 


\section{$\begin{array}{lllllllllllll}V & A & N & D & E & N & B & E & V & E & R . & & 167\end{array}$}

dan by zyns gelyken; alleen heeft hy weinig perfoonlyke fchranderheid, nos minder loosheid of liften, zelfs geen ivantrouwen genoeg om plompe ftrikken te vermyden; wel verre van andere dieren an te vallen, weet hy zelfs zig niet wel te verdedigen; hy verkiclt de vlugt boven het gevegt, fchoon hy fel en met woede kan byten, wanneer hy rig door des jagers hand voclt aangevat: 20 men derhalven dit dier in zyn natuurltat, of liever in zyn taat van eenzaamheid en verftroojiling, befchouwt, fchynt het, wat de inwendige. hoedanighedell betreft, niet boven andere dicren te $2 y n$; het heeft geen meer geeft dan de hond, geene meerdere fcliranderheid dan de olyfant, geene. meerderc liftigheid dan de vos, enz: het is meer opmerkelyk door het zonderlinge van zyn uitwendig makzel, dan cloor de fchynbare meerderheid. zyner inwendige hoedanigheden: het is het eenigtt onder de viervoetige dieren, dat een platten, eyronden, en met fchubben bedekten, ftari heeft, waarvan hy zig als van een roer bclient, om zig in 't water te fturen; hy is de eenigfte, die vinnen aan. de agterpooten, en tcrzelfder tyd gefcheiden vingers aan de voorpootell, heeft; welke laatfen hy als handen gebruikt om naar zyn mond te brengen; hy is de eenigfte; die. in de voorfte declen van zyn lighaam naar de landdieren gelykende, in. de agterfte deelen terzclfder tyd naar de watcrdieren zweemt: hy makt de fchaduwing of overgang van de viervoetige dieren tot de vilfchen, gelyk de vledermuis die der viervoetige dieren tot de vogelen maakt: maar die zonderlingheden zouden meer gebreken dan volmaktheden zyn, zo het dier uit dit makzel, 't.welk ons zo vreemd en grillig toefchynt, geene voordeelen wift te halen, die hetzelve alleen eigon zyn, en die het boven alle andere dieren verheffon:

De bévers beginnen met zig in de mand juny of july te: verzamelen om zig in matfchappy te verecnigen; zy. komen in grooten getale, en van verfcheiden kanten, famen, en makken welhaaft eene hende van twee of drie hondcrd uit; de plats der byeenkomit is gemeenlyk de plaats daar zy zig nederflaan, en dat is altoos.ann de oevers der wateren; zo- het een. vlak. Watcr is, en dat altoos op diczelfde hoogte blyft, gelyk in een meir, ontilaan $2 y$ zig van de moeite on cen dyk te leggen; maar in ftroomende wateren, en. die onderhevig zyn om te ryzen of te daalen, gelyk in de beeken en rivieren, leggen zy eene hoogte of dyk, om den ltroom te ftuiten, en door die ftuiting maken zy cene foort van konl, of poel, wan van het water zig altoos op dezelfite loogte houdt: de dyk loopt dwars door de rivier, gelyk: een fuis, en reikt van den eenen oever tot den anderen; hy is dikwils tagtig of honderd voeten lang, en hecft aan zyne bafis tien voeten breedte of clikte: dit werkftuk komt verbaazend voor, en fchynt geene cvenredigheid te hebben met de weinige grootte dezer dieren, dcwyl de grootlte bévers. maar vyftig of zeftig pond weegen, en, van het einde van den neus tot ann het begin van den ttaart, weinig meer dan drie voeten lang zyn; let onderftelt inderdaad cen oncindigen arbeid, mar de vafheid, waarmede het werk gemaakt word, verwondert nog meer dan deszelfs grootte: zy zoeken doorgains eene weinig diepe plats in de rivier om daar humen dyk te leggen; Zo 'er een groote boom op den oever ftaat die in 't water kan vallen, begimnen $2 y$ met denzelven neer te vellen, om daar her voormame ftuk van. lun. werk. van. te mas 
ken: die boom is dikwils dikker dan het lighaam van ecn menfeh; zy zagen, zy knabbelen, hem aan zynen voet, en zonder eenig ander gereedfcliap dan hunne vier fnytanden, kerven zy hem in vry korten tyd door, en doen hem overvallen maar die zyde die hun behnagt, dat is te zeggen dwars over de rivier: vervolgens kerven zy de takken van de kruin van dien grevallen boom af, om denzelven waterpas met don ftroom te leggen, en overal gelyk te doen draagen: die verrigtingen gefchieden in 't gemeen; verfcheiden bévers knabbelen gelykelyk den boom om hem te doen vallen, verfchciden gaan ook gezamenlyk de takken daar af fnyden, nadat hy gevallen is; anderen doorloopen terzelfder tyd de oevers van de rivier, en hakken mindere boompjes om, de cenen zo dik als een been, de andere als eene dij; zy fplyten en zagen dezelve op eene zekere lengte, om 'er paalen van te makken; zy brengen die ftukken hout eerft over land nar den oever der rivier, en vervolgens te water natr de plants van hun gebouw; zy maken daar cene foort van geheidpaal-werk van, dat zy wel vaft fluiten, en nog dieper in den grond werkey en fteviger maken, terwyl zy daar takken tuffchen in vlegten: deze bewerking onderftelt., dat 'er veele moejjelykheden te overwinnen waren en overwolmen zyn; want om die palen te fihiken, en dezelve ten naftenby loodregt te ftellen, moeten eenigen het dikfte cinde met de tanden tegen den oever van de rivier of tegen den boom, die dwars over dezelve ligt, ophetfen en regt over einde houden, terwyl anderen terzelfder tyd naar den grond des waters duiken, om daar met hunne voorfte pooten een gat te graven, daar zy de punt van den paal inbrengen, opdat dezelve vait ftaan, en zig regt op houden, moge; op deze wyze zetten zy verfcheiden ryen paalen, en naar maate een deel van den troep daar mede bezig is, gaat een ander gedeelte klei-aarde haalen, die zy met de voeten kneeden, en met den finart flann, om dezelve des te vafter te manken; zy brengen die in hunnen bek, en met de voorfte pooten, in zulk eenc groote hoeveelheid aan, dat zy daar alle de tuffehenruimten tuffchen het palwerk in mede vervullen: dit palwerk beltaat, gelyk ik zeide, uit verfcheiden ryen paalen, allen van cene gelyke hoogte cu allen tegen malkanderen aan geplant; het ftrekt zig van de eene zyde van de rivier tot de andere uit; het is overal gevuld en gemetzeld: de paalen zyn loodregt ingeftooken aan den kant daar het water van daan kome, of aan de bovenzyde van de rivier; het geheel werk daarentegen heeft eene opgaande fchuinfe ann de 'zyde die ten lalt moet draagen; zodat de dyk, die tien of twaalf voet onder aan zyne bafis breed is, boven ain den kruin tot twee of drie voeten breedte toeloopt; hy heeft dus niet alleen alle de noodige dikte en ftevigheid, maar ook de gevoegelykite gedaante om het water te keeren, om het te beletten door te dringen, zyne zwarte te wederitaln, en zyne kragt te breeken.

boven ann den dyk, dat is te zéggen, aan dat gedeelte, alwar dezelve de minte dikte heeft, maken zy twee of drie afhellende openingen, die zo veele verlaten zyn om het water door te laaten, en welke zy verwyden of vernauwen., naarmate de rivier rytt of daalt: en zo 'cr door fchielyken, of al

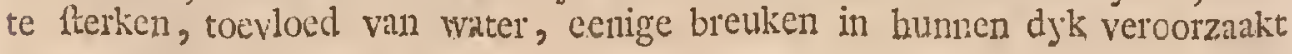




\section{$\begin{array}{llllllllllllll}V & \Lambda & N & D & E & N & B & E & V & E & R\end{array}$}

worden, weeten $z y$ die te herftellen, en begeeven zig ten dien sinde, zodra het water gevallen is, op nicuvs aan 't werk.

Het zoude, nadat wy dit berigt wegens den arbeid, dien zy aan hunne gemeene werken befteeden, gegeeven hebben, overtollig zyn van hunne byzondere gebouwen te fpreeken, zo men in eene Hiftorie geene rekenfehap van alle de ftukken, die daar toe behooren, verfchuldigd ware, en zo dit cerfte groot werk, 't welk \%y met zulk cen algemeenen yver hebben toegefteld, niet ten doelwit hadt om hunne kleine wooningen gemaklyker te maken. Die kleine wooningen inderdand zyn hutten, of liever een foort van huisjes in het water op een geflooten en vercenigd paalwerk, aan den kant van hunne lom of meir, zo als thans de rivier ten humen opzigte by'na geworden is, gebouwd; zy hebben twee uitgangen, de eene on zig te lande, de andere om zig te vinter, nar buiten te begeeven: de gedante van dit gebouw is bykans altoos eyrond of rond: daar \% yn "er grooter en kleiner. van viar of vyf, tot agt of tien, voeten in den omtrek; men vindt 'er zomtyds ook, die twee of drie verdiepingen hebben; de wanden zyn tot twee voet dik, .,y zyn loodregt opgreharld op het geflooten en vol.geheid paiwerk, het welk tevens voor fordament, en voor vloer, van het huis dient: zo het gebouw maar éne veldieping lieeft, loopen de wanden hlegts eenige voeten regt op, war boven dezelve eene kromte krygen en een gewell maken in de gedante van het liandvatzel of het oor eener 111ande; dar gewvelf betluit het gebouw, en dient het voor bedekzel.

Het zelve is van een ftevig metzclwerk te fanengefteld, en van buiten en biinen zinnelyk beftreeken: het is ondoordringbaar voor den fterkften re. gen, en wederftaat aan de geweldigfte winden; de rranden zyn met een foort van ftukadoorfel belegid, zo wel beflaigen, en 70 net geftreeken, dat men dalr het werk van den menfeh in vermoeden zoude, de ftart dient hun voor truffel on dit pleifter., 't welk zy met himme roeten kneeden, over te ftrylien.

Zy gebruiken rerfcheidene foorten van werkftoffen, hout, fleenen, en zandagtige aarde, die niet onderhevig is zig in het water te ontdoen; het hout, dat zy gebruiken, is bykans altoos ligt en week; het zyn elzen, populieren, wilgen, die natuurlyk aan de ocvers van 't warer groeijen, en die gemaklylier te fchillen, te vellen, en te vervocren zyn, dan boomen van zwater of harder hout: zo zy een boom aantaften verlaaten zy hem niet voor dat hy geveld, gefchild, vervoerd, $z y:$ : zy kerven hem altoos op een voet, of anderhalf voet, boven den grond if; $z y$ werken zittende, en belulven het voordeel van deze gennklyke plaating, hebben zy nog het vermak van geduurig de fchors en het hout, van welken zy veel werk 1naalen, te knabbelen, want zy verkiezen den verfchen baft, en het tedere hout boven de meefte der gewoone voedzels; zy doen daar ecn rumen voorrad van op on dien des winters te nuttigen (c): zy houden niet v'un droog hout; het is in 'c water, en

(e) De vonrral voar agt of tion bévers is van vyf-en-twintig of dertig voeten in 't vierkint, tegen agt of tien voeten in de diepte; zy lirengen dat hont niet in hunne huccen vons dat het klein gekapt on in Itaat is on gegeeten te worden: zy houden mier van het verfche dan van het gevlome hout, en gaan, greduurende den winter, van tyd tot tyd in de boffchen eeten, Memoire de l'Académie des Sciences, Amée i 7os. Mémoire de Mr. Sarrasin.

$$
\text { VIII. Deel. }
$$




\section{1\% DE NATUURLYKE HISTORIE,}

by humne wooningen, dat zy hun magazyn opregten; ydere. hut heeft 'es. een, dat grooter of kleiner wordt aangelegd naar evenredigheid van "t getal der bewooneren, die daar alleen een gemeen regt op hebben, en nooit hunne buureh gaan befteelen: men heeft gehugten van twintig of vyf-en-twintig wooningen gezien; die groote veftingen zyn evenwel zeldzaan; en deze.foor van Gemeenebeften zy11, doorgaands minder talryk; zy beftaan veelal flegts uit tien of twalf wyken, warvan elk zyn kwartier, zyn magazyn, zyne afzonderlyke wooning, heeft:.zy dulden niet,. dat vreemdelingen zig binnen den omtrck van hunnen ftaat komen nederzetten: de kleinfte hutten bevatten twee, vier, zes; en de grootfe agttien, twintig, en zelfs, zegt men, tot dertig bévers, altoos in effen getale, en evenveel wyfjes als mannetjes: dus mag men, fchoon men zelfs vry wat aflag op deze rekening toeftaa, vryelyk ftellen, dat hunne matfchapwy dikwils beftat uit honderd vyftig of twee honderd vereende werklieden, die allen eerft gezamenlyk, in én lighaam, geïrbeid. hebben om het groot gemeen werk te vervaardigen, en vervolgens in gezelfchap ow hunne byzondere wooningen te bouwen.

Hoc talryk deze mattchappy moge iveze, daar hecrfcht egter een diepe en ongeftoorde vrede; de geneenfchaplyke arbeid heeft den band hunner vereeniging toegetrokken; de gemakken, welken zy zig bezorgd hebben, de overvloed van leevensmiddelen, wclken zy verzamelen, en met nalkanderen nutttgen, dienen om dien vrede te onderhouden; hunne gematigde begeerten, hunne eenvoudige fmak, hunne afkeerigheid voor vleefich en bloed, weeren: zelfs het denkbeeld van roof en oorlog uit hunne maatichappyen; zy genieten alle de voordeelen, welken de menfch alleenlyk weet te verlangen : vrienden onder malkanderen kumen $z y$, zo zy cenige vyanden van buiten hebben, dezelve vermyden; zy waarfcliouwen malkanderen door een lag met hunnen ftaart op 't water te doen, die zeer verre door alle de gewelven der wooningen klinkt; elk kieft zyn party, 't zy van zig in 't water te ftorten, 't zy van zig bin-' nen zyne mumen te bergen, die nicts dan 't vuur van den hemel of 't ftaal. van den menfch, te dugten hebben, c11 welken geen dier durft openbreeken : of onverre werven.

Deze wykplaatfen zyn nict alleen zeer veilig, mar ook zecr zinlyk en zeer gemaklyk; de vloer is met groente bedekt; kleine takjes van palm-boomen en farren-boomen diencn hum voor tapyt, daar zy nooit eenig vuil op brengen, noch dulden, dat het "er op gebragt. worde; het venfter, 't welk op het water uitziet, dient hun voor balkon, daar $z y$, geduutende het grootlt gedeelte van den dag, de friffche lugt gann genieten en het bad gebruiken: zy houden zig diar regt op, met het hoofd en de vourfte deelen des lighanns overeinde, en alle de anterfte declen in 't water: dit venfter is wederom net eene oplet. tende voorzorg: en overleg gemaakt; de opening is juift zo hoog genomen, dat dezelve door let ys niet geftopt kan worden, het welk in de klimaten, har de bévers bouwen, zomtyds twee of drie voet dik wortt; zy verlangen tin de rigchel met de pailen, daar dezclve op was, in de fichuinte door te fnyden, en matken zig dus een uitgang tot het water, dat onder het ys is: die vloeibaare hoofdftof is hun zo noodzaaklyk, of liever geeft hun zo veel vermak, dat $z y$ dezelve niet fchynen, te kunnen milien; zy begeeven zig 


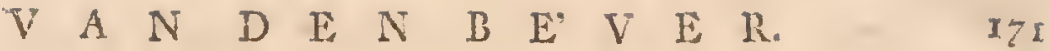

zomtyds vry verre onder het ys, en dan kan men hen ligtelyk vangen, met de hut aan te taften, en hen terzclfder tyd op te wagten by een gat, 't welk men op eenigen affand in het ys makt, en alwaar zy verpligt zyn te komen, oin te ademen.

De gewoonte, welke zy hobben, om den ftart en alle de agterfte deelen ties lighaann, gedunrig in 't water te houden, fchynt de natuur vain hun vleefch veranderd te hebben; dat ler voorfte deelen tot an de nieren, heeft de hoedanigheid, den fmakk, de vaftheid, van he: vleefch der land-en lugt-dieren: dat van de dijen en den traart heeft den reuk, den finak, en allc de loedanigheden, van vilch; die ftaart, cen voet ling, een duins dils, en vyf of zes dum breed, is zelfs een uitcinde, cen werendlyk gedeelte, van vifch, an het lighaam van enn vicrvoctig dier gehegt; het is ten cencmaal met fichubben bedekt, en lietvel is grclyk aan dat der groote viffchen: men kan die fchubben wegneemen door dezelve met een mes opwards te fchraapen, en madat zy daar af zyn, zict men derzelver indrukzel nog op het vel, gelyk in alle onze vifichen.

Het is in 't begin van ilen zomer, dat de bévers zig verzamelen; zy befteeden de maanden van july en auggitus om hunnen dyk en lunne wooningen te maken; zy doen liunnen voorrad van baft en hout in de mand van feptember op; varvolgens ruften zy van humen arbeid, genieten het lecven, en fmaken de huiffelyke vermaken; die tyd van rut cn huiffelyk vermak is tevens de tyd hunner verliefdheid: malkanderen kennende, door den omgang, door de vermaken en de mocijelykheden van een gemeenfchaplyken arbeid voor malkanderen ingenomen, voegt yder paar zig niet by enkeld toeval te fanen, noch koppelt door ecnc loutere noodzakilykheid der Natuur, maar bepaalt zig met keus, cll vereenigt zig nit finaak; zy brengen den herfft en den winter te famen door; met malkanderen voldaan verliaten $\mathrm{zy}$ den anderen niet vecl; gelyk $z y$ het te huis nar hunnen zin hebben, komen zy daar niet uit dan om aangenaame en nuttige wandelingen te doen ; zy brengen dan verfche fchorfen mede, welke zy boven dezulke verkiezen, die droog of al te veel met water doortrokken zyn.

De wyfjes zegt men dat vier manden drangen; zy werpen op 't cinde "van den winter, en brengen gemeenlyk twee of drie jongen voort; de mannetjes verlaaten har ten naaltenby on dezen tyd, zy begeeven zig reldwaards, om de aangenaanheden en vrugtei van de lente te gaan genicten; zy keeren van tyd tot tyd tot de wooning te rug, mar zy blyven dar niet: de moeders integendeel blyven darr nog seluisveft, en houden zig berig met het zoogen, bezorgen, en opvoeden, harer jongen, dic, na verloop van eenige weeken, in ftaat zyn han te volgen; zy galn dan op haare beurt hare wandelingen doen, zig in de viye lugt herftellen, vifch en krecten zoeken, nieuwe fchorfen ectell, en brengen dus den zomer in 't water en in de boffchen door; zy verzamelen niet wedcr dan in den herfit, ten $z y$ de vreritroomingen hunnen dyk omgekeerd, of hunne huten venield hebben; want dan komen zy vroegtydig smen, om die breuken te herftellon.

Daar zyn platten, daar zy eene byzondcre verkiezing voor hebben om 'er hun verblyf te veftigen, en alwar men gezien heoft, dat zy, nadat men hun 


\section{DE NATUURLYKE H I T ORIE;}

werk verfcheidenmaal verdelgd hadt, yderen zomer weder kwamen, om het op nieuws te herbouwen, tot dat zy eindelyk door die vervolging vermoeid, en door het verlies van verfcheidenen hunner verzwakt, het befluit namen, om van verblyfplaats te veranderen, en verre af in de diepfte eenzaamheid te wyken.

Het is voornaamlyk in den winter dat de jagers hen zoeker, omdat hun bont in dat jaargetyde alleen volkomen goed is; en zo het gebeurt, dat zy,

- na derzelver veltigingen vernield te hebben, eene groote menigte vangen, zo herftelt zig de matfchappy, nu tot een al te klein getal gebrigt, niet langer; de weinigen, die den dood of der gevangenis ontkomen zyn, worden vlugtende; hunne vermuftigheid, door de vrees gekluifterd, komt niet meer te voorfchyn, zy begraaven zig zelven en allc humne talenten in een hol, alware $z y$, tot den ftat van andere dieren verlaagd, een vreesagtig leeven leiden, zig niet anders dan mer de dringendfte behoeften bezig houden, geene andere van humne bekwaamheden te werk ftellen dan dic hen alleen en op hun. zelven leevende, betreflen, en de gezellige hoedanigheden, daar wy ons zo billyk over verwonderden, onherftelbaar verliezen:

Hoe verwonderlyk inderdaad, hoe verbaazend, de dingen mogen fchynen, welken wy wegens de matfchappy en de gemeene zo wel als byzondere werken onzer béver's verhaald hebben, durven wy egter zeggen, dat men aan derzelver wezendlykheid niet-kan twyffelen: alle de berigten op vorfchillende tyden, door cene groote menigte ooggetuigen, gegeeven $(f)$, komen in alle de byzonderheden; welke wy gemeld hebben, overeen; enzo ons verhaal van dat van zommigen humner verfchilt, is het alleenlyk in die punten, war in het ons is voorgekomen, dat zy het verwonderlylie zogten te vergrooten, dat zy de waarheio opbliezen, of voorby liepen, ja zomtyds de warifchynlykheid zelve uit het oog verlooren; want men hecft zig niet vergenoegd met te zeggen, dat de bévers gezellige zeden, en blykbaare bekwaamheden voor de bouwkunde, hebben, mar men heeft ook verzekerd, dat men hun de algemeene begrippen van Staatkunde en Regeeringsvorm niet konde weigeren; dat zy, nadat hunne matichappy eens. getormeerd was, de reizigers en vreenrdelingen tot flaven wiften te maken; dat zy dezelve gebruikten on hunne aarde aan te brengen, hun hout te llcepen, enz; dat zy de luijaards onder hen, die niet-wilden, en de ouden, die niet konden, werken, op dezclfde wyze bchandelden, to weeten, dat zy hen op den rug lagen, en hen

(f) Zie over de Hiftorie der beszers, Ola'15 Manvos in de befchryving der Noordfche landen; les loyages du Baron de ca Hontas, Tun. II. pag. 155. enz. Miefeun Wormtanum.

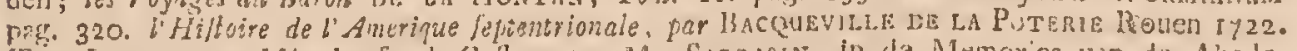
rorz. 1. pag. 133. Minzoire fur le Caltar, pas Mr. Sarrasin, in de Memories van de Alsidemie des Sciences, Anné 1704. La relation d'wi Voyage en Acadie par. Difrull. Ro Ron 1703. pas. I25. env. Los noncelles, dicouventes doms iAmerique jefertionale, Paris 1697. pag.

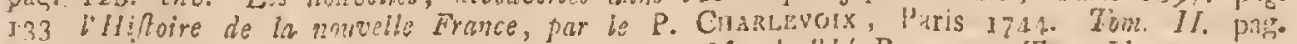

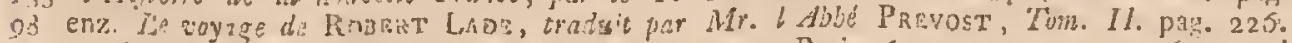

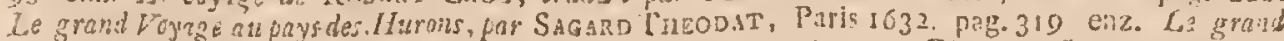

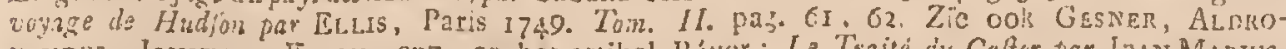
vanis, Jorston, KI.eln, enz, op het artikel Béver; La Traite du Cafor par Jean Matius, Paris 1746. LiH:foire de in Virginie, traduite de l'Anglois, Orleans 1707, pag. 400. L'His. soise Nabirlle du Pere Reaczraskx, ap het artikel van béver, enz. 
Toor voertuig gebruiliten, om hunne bouwftoffen voort te fleepen; dat deze Republikeinfche dieren nooit dan in onelfenen getale verzamelden; op dat "er in hunne raadsvergaderingen altoos eene beflificnde ftem mogte overblyven; dat de geheele maatichappy een voorzitter hadt; dat ydere wyk zig een befichikker verkoos; dat zy fchildwagten plaatiten om het Gemecrebeft-te bewa.. ken; dat zy vervolgd wordende niet nifteden zig de zaadballen af te byten, om aan de greetigheid der jagers te voldoen, en dat zy zig dus verminkt aan hun vertoonden om genade in hunne oogen te vinden, enz, $(g)$. Zo verre als" wy af zyn on die fabels te gelooven, of die vergrootingen aan te neemen, zo moeijelyk of onbillyk komt het ons ann den anderen kant voor, duidelylyke, wél beveftigde, en ontwyffelbaare, byzonderheden te verwerpen, of zelfs te aarzelen om die toe te ftemmen: men heeft de werken der bévcrs duizendmaal gezien, herzien, omgekeerd, verdelgd; men heeft dezelve gemeeten, afgetekend, gegraveerd; eindclyk, het geen alle tivyffeling wegneemt, het geen fterker is dan alle de voorgaande getuigeniffen, is, dat wy nog tegenwoordig verfche, en iverkelyk beftande, blyken van dit alles hebben, dat 'er nog tegenwoordig van die zonderlinge werken beftaan, die, fchoon minder gemeen dan in de eerfte tyden der ontdekking van Noord-Amerika, nog in genoegzaamen getale egter gevonden worden, dat alle Zendelingen, alle Reisbefchryvers, zelfs de allernieuwite, die in.de landen vain. 't Toorden' zyn ingedrongen, verzekeren dezetve ontmoet te hebben.

Allen ftemmen $\mathrm{zy}$ overcen in te zeggen, dat men, behalven de bévers , die zig in maatfchappy begeeven, allerwegen in het zelfde llimaat, ecnzanane bévers aantreft, dewelke, uit hoofde hunner gebreken, vit de marfehappy, zeggen $z y$, verworpen, aan geene van derzelver voordeelen deel mogen hebbell, en dus noch een huis noch een magazyn bekonten, manr even ais de das onder de arde in eenig hol hun verblyf houden moeten: men heeft deze eenzaame bévers zelfs hol-bévers genoend; zy zyn ligtelyk te onderfcheiden; humne vagt is morfig, het hair op ticnl rug is door de vryving van den grond afgeflecten: zy outhouden zig, gelyk de anderen, gaarne anden kant des waters, alwan zommigen zeilfs cene graft van eenige voeten diepte graven, om eene kleine wetering re matken, die tot an de openng van hunne verblyfplaats vloeit, welke verblytilats zig zomtyds tot meer dan honderd vocten in de lengte wititiekt, en fiects hooger en hooger oploopt, op dat zy ge-: legenheid hebben van te wyken, en zig voor het overollige water te beveiligen, narmaate het'hunne verblyfplanten introomt; mar men vindt ook valu die ecnzaame bévers, die viy verre van het water op het land lecven; alle onze Luropifche bévers zyn zo genaande hol-bévers, die eenzaam en op zig zelven woonen; , cn welker vagt op verre na zo fchoon nict is als van de zujken, die cene nuatfchappy opregron; allen verfchillen zy in lileur, nar het klimat daar zy hun verblyf houden: in de vert afgelegen Noordiche landen zyn $\mathrm{zy}$ geheel zwart, cn de vagten van dezen zy'n de belte: onder duz zwar-

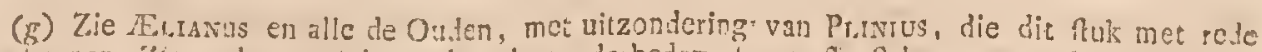
cothenjen. Zie osk over de andere byzonderheder de neefie Schryvers, veikun wy. in de: voorgande noot hobb.n aangetrodksi. 
te bévers worden 'er evenwel zomtyds gevonden, die eene geheel witte of witte met grauw gevlekte, en met ros aan den nek en op her kruis vermengde, kleur hebben $(b)$; naarmate men zig van, het Noorden verwydert heldert de kleur op en vermengt zig; in it Noordelyk gedeelte van Kanada zyn zy hoog kaltanjebruin, in het Zuidelyk gedeelte kaltanjebruin, en geel of ftroo-kleurig by de lllinoifen (i). Men vindt bévers in Amerika van den dertigften grad Noorderbreedte tot an den.zeltigften en hooger, en fteeds in minderen getale, naarmate men naar 't Zuiden nader: oude wereld, zy zyn niet menigvildig das in de Noordelykfte landen, en $z y$ zyn zeer zeldzam in Frankryk, in Spanje, in Italie, in Griekenland, en in Egypte: de. Ouden kenden le11, het ftondt in den Godsdicnft der Magi niet vry hen te dooden; zy waren gemeen asn de oevers van de zwarte Zee, men heeft den béver zelfs Canis.ponticus, of den Pontifchen hond, genoemd: maar wantflnynlyk liebben deze dieren geene geruftheid genoeg aan de oevers van die Zee, dewelke inderdaad van onheugelyke tyden door de menfchen bezogt zyn, gevonden; dewyl nicmand der Ouden van hunne maatfchappy of van hunne werken, fpreekt. AELIANus vooral, die zulk een groot 'Zwak voor het verwonderlyke toont; en die, geloof ik, de earfte gefchreeven heeft, dat de béver zig de zaaclballen afbyt, om die aan den jager ten besten te geeven $(k)$, zou niet gemift hebben van de wonderen hunner Republiek te gewaagen, de fynheid van lun vernuft en hunne zonderlinge bekwaamheden in de bouwkunde met weitiche bcfichryvingen voor te draagen en op te fmulkken. Plinius zelf, Plinius, wiens tierc, droefartige, en verheven geeft, altoos den mentch verugt, om de Natum te verheften, zou zekerlyk niet nagelaten hebben de verrigtingen en werken van Romulus met die van onze bévers te vergelyken; het fchynt derhalven zelser, dat geen der Ouden hunne vernuftige kloekheid in 't bouwen gekend heeft, en fchoon men in de laatfe eeuwen bévers in Noorwegan, en in de andere. Noordelykfte landen van Europa, gevonden heeft, dic in liutten woonden, fchoon het ook waarfchynlyk is, dat de oude bévers zo wel hutten bouwden als de latere, dewyl egter de Romeinen tot zo verre niet waren doorgedrongen, is het niet te verwonderen, dat liunne Schryvers daar geen gewag van maken.

Verfcheiden Auteuren hebben gefchreeven, dat de béver, een water-dier zynde, op het land, en zunder water, niet leeven konde: dat gevoelen is niet waar; want de bever, welken wy hebben, in zyne vroege jeugd in $\mathrm{Ka}$ mada gevangen, cn vervolgens in huis opgevoed, zynde, kcinde het water niet, toen men ons denzelven heeft overgeleverd, hy vreesde en weigerde daar in te gaan, maar toen men hem eens in een bak met water gedompeld, en voor de eerfte reize ntet geweld daar in gehouden hadt, bevondt hy zig, na verloop van cenige ininuuten, zo wel, dat hy daar.niet zogt nit te gaan, el1, toen men hem vryheid gaf, keerde hy van zelven zeer dikwils derwards weder; ook wentelde hy zig in den flyk, en op den natten giond: op zekeren

(b) Cafor albus caudh borizontaliter plandi. Brisson. Regn. Animal. pag. 94. enz.

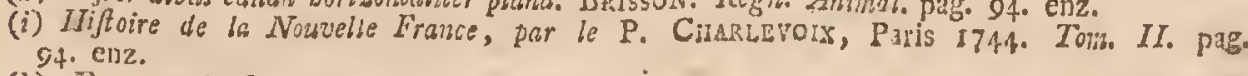

(b) ALlianus Hift. Alimal, Lib. VI. eap. 34. 


\section{$V A N \quad D \quad E \quad N \quad B \quad E^{\prime} \quad V \quad E \quad R$.}

dag ontfnapte hy, en klom langs den keldertrap neder in de gewelven der fteengroeven, die onder den grond van den koninglyken tuin zyn, hy vlugtede vry verre weg, de plaffen-Ivaters, die onder in die fteengroeven zyin, overzwemmende; zodra hy egter het licht der flambouwen, welken ik derwards deed brengen om hem te zoeken, gewar ' wierdt, kwam hy gewillig te rug by hen, die hem riepen, en liet zig ligtelyk krygen: hy is gemeenzaam zonder liefkoozende te zyn; hy vraagt hen, die aan tafel zyn, te ceten; zyne verzoeken beftan in. een zagt klaagend gefchreeuw en eenige beweegingen met de hand, zodra men hem een ftuk geeft, voert hy het wegi en: verbergt zig om het op zyn gemak op te eeten; hy flaapt vry dikwils en ruft. op den buik, hy eet van alles, belalven vleefch, "t welk hy ftandvaftig weigert, 't zy rauw of gaar; hy knabbelt al wat hy vindt, ftoffen, meubelen, hout, en men is verpligt geweeft, de ton, war in hy overgevoerd is, van binnen met blik te bekleeden.

De bévers verkiezen by voorkeur hun verblyf aan de oevers der nieiren, der rivieren, en andere zoete wateren te neemen; men vindt dezelve egter aan den oever der Zee, maar het is voornaamlyk in de Noordfche Zeën, en vooral in de Middellandfche Golven, daar groote rivieren in uitoopen, en welker wateren weinig zout zyn. Zy zyn vyanden van den otter, maken daar jagt op, en vergunnen hem niet te verfchynen in de wateren, daar zy zig onthouden. De vagt van den béver is nog fraaijer en meer gevuld dan die van den otter; zy. beftaat uit twee foortes1 van hair; het een dat kort mar zeer gevuld, zo fyn als dons, en ondoordringbar voor ' $t$ ' water is, bedekt ouniddelyk' het vel; het ander langer, vafter, glanziger, mar yler, ligt over dat eerfte bekleedzel, verltrekt hetzelve, on zo te fpreeken, voor overrok; beveiligt het voor vuil, voor ftof, vonr lyk; dat tweede hair is van weinig warde, het is het eerfte alleen daar men in onze manufacturren gebruik van maalit; de zwartite vagten-zyn gemeenlyk de gevuldite, en bygevolg de meeft geachte; die der land-of hol-bévers zyn veel minker dan die van bévers, die wooningen makken: de bevers zyn des zomers, even als alle andere viervoeerge dieren, ann. 't rujen onderhevig; às is de vagt van die, welke in dat jaargetyde gevangen worden, van weinig waarde: de vagt der witte bévers is, wegens derzelver zeldzannheid, in liooge achting, en de volmankt zwarte zyn byna zo zeldzan als de witte.

Maar behalven de vagt, welle het koftelykf gedeelte is, dat de béver oplevert, verfehaft dit dier ook nog eene ftoffe, daar men in de Geneeskonft veel gebruik van makkt: die ltof waran men den mam van cisforeum heeft gegeeven, is bevat in twee dilkte blasjes, welken de Ouden voor de zaadbal. len van het dier genomen hebben: wy zullen "er de befchryving niet van geeven, noch het gebruik van anwyzen $(b)$, ondat men dit in alle Apothecken vindt $(m)$. De Wilden haalen, aegr men, eene olie uir den tant van densbé-

(b) Zie le Traite du Cafor, par Marius OF. Frinciszus, Paris 1746, in 120.

(m: Men wil dat ce bévers unt hunnen voet vogt uit hunne blacsjes weeten te drukken, sit dit vogt hunnen eetuft opwakkert, als zy walgagtig zyn, en dat de Willen darde fisik. zes mede fmeeren, daar zy hen in zoeken te lokken; zekerer is het, dat de béver zig dar van beditnt on zyu vol vet te houden. 


\section{I76 DE NATUURLYKE H I T T R I E,}

ver, waarvan zy zig, als van een platfelyk middel, tegen verfcheiden kwarlen bedienen: het vleefch van den béver, fchoon vet cn lckker, heef: aitoos een vry onaangenamen bitteren fimak. Men verzekert, dat deszelfs beende. ren ten uiterften hard zyn, marr wy hebben geene gelegenlseid gehad, om die byzonderheid met zekerheid te ontdekken, dewyl wy alleenlyk ecn jongen béver ontleed hebben: zyne tanden zy11 zeer hard, en zo fcherp, dat zy den Wilden voor meffen diencil om het hout te fnyden, wit te holen, en te polyften: ook kleeden zy zig met bévervellen, en drnagen dezelve des winters met het hair nar binnen, en op het nakte lyf; het zyn deze vagtcn, met het zweet der Wilden doortrokken, welken men vette kaftoor noemt, waarvan men zig niet dan voor de ruwfe werken bedient.

De béver gebruikt zyne voorfte pooten als lianden, met eene behendigheid ten minften $z o$ groot als die van den eckhoorn; de vingers dier voorfte voeten zyn wél g'efcheiden, wél verdeeld, terwyl die der agterften met een fterk vlies aan malkanderen verbonden $z y^{\prime 11} ;$ hetzelve verftrekt hem voor vinnen, en het zet zig breed uit gelyk dat aan de pooten van de gans, waar naar de béver in zyll gang op het land ook vry wat gelykt: hy zwemt veel beter dan hy loopt; deivyl zyn voorfte pooten korter zyn dan zyne agterite, zo gaat liy altoos met.een gedooken kop en een geboogden rug; hy heeft zeer gosde zintuigen, een zeer fynen, cn zclfs andoenlyken, reuk; hy fchynt noch de morfigheid, noch de kwade lugten, te kunnen verdragen; zo men hem al te lang opgeflooten houdt, en dus noodzaakt zig binnen zyn verblyfplaats van zyne uitwerpzclen te ontaften, legt hy dezelve ten minften aan den drempel van de deur zyner gevangenis, en werut hen, zolla de deur open gaat, buiten: dic gewoonte valn zinlykheid is hun natuurlyk cigen, en onze jonge béver mifte nooit dus zyn holje fihoon te makken.

Op den ouderdom van een jar heeft hy telionen van ritzigheid gegeeven, het welk filhynt aan te duiken, dat hy te dezer tyd het grootite gedeclte van zyn gioei grekreegen hadt; dus kan zyn leeftyd niet zeer lang zyn, en het is miffchien te veel denzelven tot vyftien of twintig jaaren uit te ftrekken.

Deze bćver was zeer klein naar zyn oudcrdom; cn men kan zigg hierover niet verwonderen, dewyl hy reeds van zyne geboorte af altoos onder dwang geweeft was, en droog, om zo te pprecken, was opgevoed, gecn water kcnnende, voor dat hy negen maanden bereikt hadt: dus heef hy zo wel niet kunnen groeijen of zig.ontwikkelen als andere van zyne foort, die in vryheid leeven en het water genieten, welk element hun byna zo noodzaaklyk fchynt als het gebruik van 't lind.

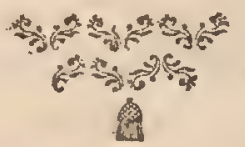




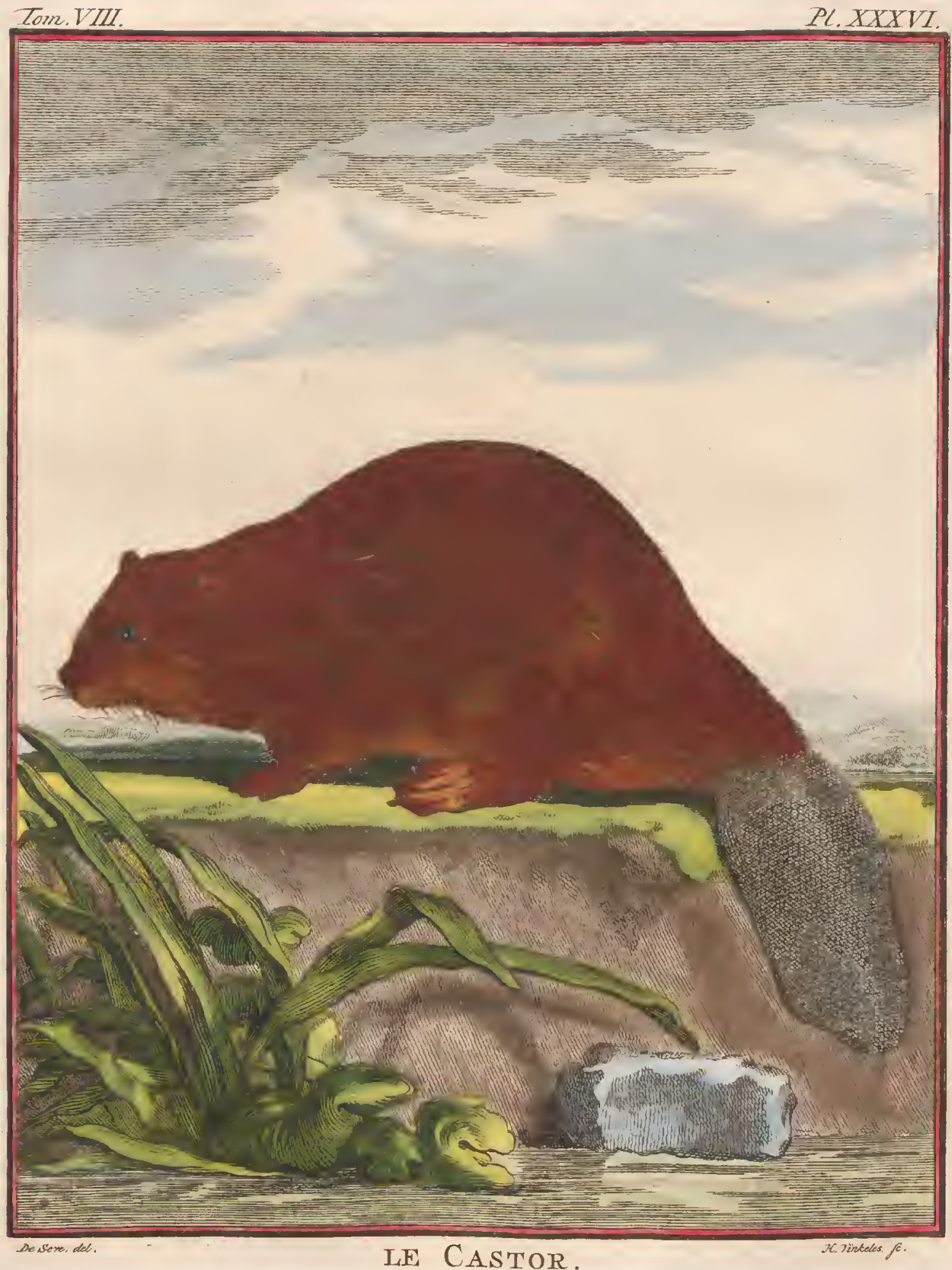






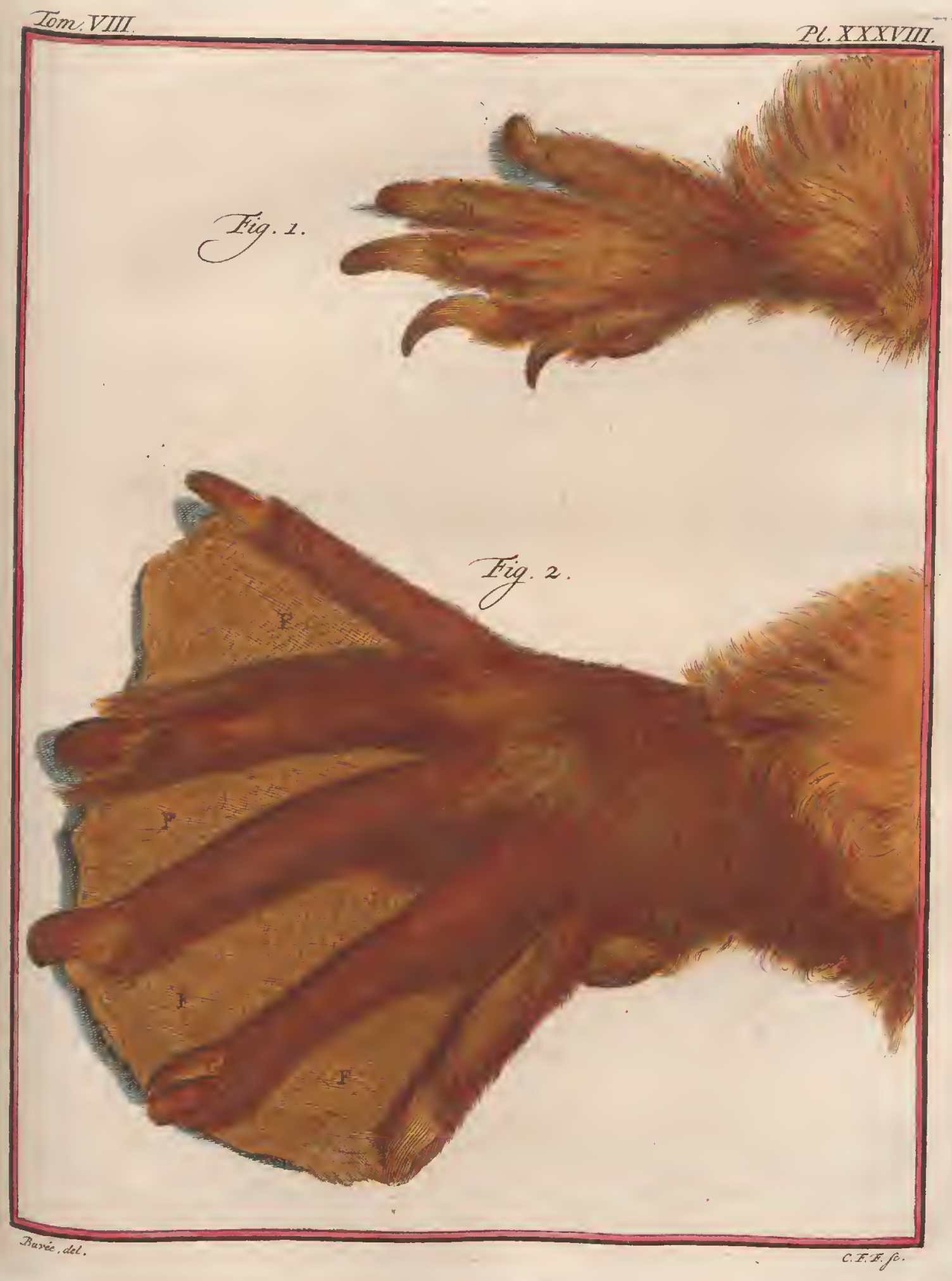





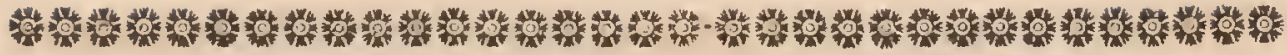

$$
\text { BESCHRYVINGVAN DENB⿺𠃊E VER. }
$$

$\mathrm{D}$

e béver ( $P l . X X X V I)$ gelykt naar de waterrot in de gedaante van den kop, nitgezonderd de ooren, die, naar evenredigheid, korter 2yn; het netsbeen is my meer geboogd, en de kruin van 't hoofd meer plat, voorgekomen; de bek is dik en kort; het hair is zo zwaar op den kop, dat het 'er een gedeelte van verbergt, en dat het gedeeltelyk de oogen bedekr, die reel kleiner zyn dan die van de waterrot; de hals is kort en fchynt zo dik als 't hoofd, het lighaam heeft, naar evenredigheid, meer lengte dan dat van het marmeldier, maar het is even dik, inzonderheid aan ' $t$ agterfte gedeelte; le ponten 7.yn zeer kort, voomaamlyk de voorfte, waarvan de pooten wat binnenwaards gekeerd zyn; de agterfte voeten zyn het veel meer, zodiat men de7elve byna niet ziet, terwyl de béver gaat.

De ftaart ( $p$. XX.Y $/ I I$ ) heeft een zeer ongemeen maakzel; hy is zeer breed en gedeeltelyk met hair bekleed, gedeeltelyk met fchubben bezet; het begin $(A)$ van den ftomp des ftaitrs van den béver, die ten onderwerpe voor deze befchryving gediend heeft, was over de lengte van dric duimen van den aars af mét hair bezet; dit gedeelte van den ftaart hadt ontrent twee en een half duim breedte, en anderhalf duim dikte; het overige $(B C)$ hadt eene sedaante die aan 't eyronde naderde, fchoon het evenwel in een punt $(C)$ uitliep: dit ander gedeelte hadt agt duimen lengte, drie duim en agt lynen breedte in 't midden, en omtrent agt lynen dikte; het was aan de bovenzyde, op de onderzyde, cn aan de randen, met fchubben bezet; de fchubben van het bovenfte waren wat bolrond, die van het onderfte hadclen eene ligte holrondte, en die der zyden waren kleiner; de grootfte hadden in het gedeelte, dat bloot fcheen, drie en een halve lyn breedte, en twee lynen lengte; hat dier draagt zyn ftaart altoos regt op den gezigteinder uitgeftrekt; hy is maar weinig buigzaan, ondertuffchen floeg het 'er de aarde zo hard mede, dat men het geraas van verre hooren kon; het noeg ook het water; zwemmende bediende het 'er zig van als een riem met hem te verhoogen of te verlaagen, of fchuinfch over zyne breedte te draaijen.

De voorfte voeten ( fig. I, Pl. XXXVIII) zyn zeer klein; zy hadden elk vyf vingers, welken het dier onder 't gann zeer verre van malkanderen afhieldt: de twee eerfte $(A B)$ waren, naar evenredigheid, kleiner dan de andere, en hadden lange fmalle en puntige nagels; die der drie andere vingers $(C D E)$ waren breed en zonder prunt; de nagels van den derden en den vierden vinger hadden zo veel lengte als dic van den tweeden, maar de nagel van den vyfden vinger was korter.

De agterite voeten ( fig. 2) waren veel grooter dan de voorfte; zy hadden ook ell vyf vingers $(A B C D E)$ die veel langer waren, en tuffehen welken een fterk vlies ( $F F F F$ ) was: de derde vinger was de langfte, maar hy hadt minder dikte dan de vierde; de magels viln deze twee vingers waren VIII. Deel. 


\section{${ }_{7}^{8} 8$ DE N A T U U R L Y K E H I S T O R I E,}

lang, breed en vierkant, die van den eerften en van den vyfden waren minder breed en puntig; de tweede vinger hadt twee nagels, de een gedeeltelyk. boven en gedeeltelyk ter zyde van de andere; de bovenfte en buitenfte nagel $(G)$ was puntig;, de onderfte en binnenfte nagel $(H)$ was breed en rond aan "t einde.

De gang van den béver is log en gedwongen, ondat zyıle agtcrite pooten beter gemakkt zyn om te zwemmen dan om te gaan; dewyl zy meer lengtehebben dan de voorfte en in een grooten voet eindigen, zo fchynt het dier grooter ftappen te doen met het agterftel dan met het voorftel; en het is indertaad verpligt grooter beweegingen te maaken, waar door het kruis beurtelings ter regter en ter flinkerzyde wordt geworpen, gelyk men in de endvogelen ziet; ondertuffchen laat de béver nict na vry fchiclyk te gaan, fchoon bet niet is naar evenredigheid van de beweegingen die hy makt.

Wanneer de béver greftuit wordt, zo heeft hy een zeer gcboogden l'th en een verlaagd kruis, zodat het agterife gedeelte des lighaams op de aarde draagende een ftempunt makk, het welk gevoegd by dat der agterite voeten, die insgelyks op de aarde draagen, tot aan het cinde van de hiel, eene zeer gemaklyke platifing aan het dier geef, om het voorlte gedeelte des lighaams op te heften, gelyk de eekhoorns en rotten doen; in deze houding bedicnt het dier zig van zyne voorfte pooten als van handen om te voclen, om te vatten om aan zyn mond te brengen, en ook om zig tegen. fteile vlakten op te houden; dan is de rug in eene regte lyn, maar wanneer het dier om zo te fpreeken, overeinde is, zonder eenig fteunzel, dan is de rug zeer geboogd. en het hoofd zeer laag.

De béver hecft tweederleie hair, het een is fteviger en langer dan het an. der, 't welk ecne foort van dons of vlashair is, zo zagt als zyde, en met. vlokken, even als wol, gefchikt; het hadt zig zelfs op den rug van het dier, even als vilt, in malkanderen gekluwend: dit vlashair hadt eene afchgrauwe kleur op den rug en cene grauwe parelkleur op den buik; overal was de punt bruin geelagtig; de lange hairen hadden eene afchgrauwe kleur over omtrent twee derde deelen humner lengte van den wortel af; het ander derde deel was van eene bruine kleur met ros en fchitterend gemengd, het velk verfchillende fchaduwingen aannam narmate men het in verfchillend licht befchouwde, en 't welk zig altoos op verfchillende deelen des lighaams verfchillend vertoonde: dic kleur was ecn zeer vuurig ros boven op het hoofd en den hals, op den rug; op de zyden des lighaams, en op den ftuit; het hair was lchitterend, wanneer men zig voor het dier plaatife om het te bcfchouwen, maar het hadt geen glans en het ros was minder vuurig, wamneer men agter hetzelve geplaatit was: de borit en de agterite beenen waren bruin; de zyden deshoofds hadden eene zeer bleelic ruffe kleur; de vier voeten waren bruin; het grof hair van de knevels was twee en een half duin lang, het was dik en zwart: het fchubagtig gedeclte van den ftaut hade ecne grauwe kleur.

De béver, die ten ondcrwerpe voor de vourgande befchryving gediend heeft, hadt nog alle zyne grontte niet bereikt, waa" toe hy in "t vervolg zout gekomen zyn; hierom heb ik de afmeetingen in de volgende tafel gemeld, gedaan nar een béver van de dierengaarde van Verfanlles, die my voor- 
kwam zyn vollen wasdom te hebben; by is van eene donkerer kleut dan onze béver.

Daar is geen tryfficl aan of de Franfche bidure is het zelfde dier als onze berrer; doch fchoon "er nog bières in languedoc zyn, hebben wy geen derzelven kunnen magtig worden on hem met onzen bever te vergeiyken; zy zyn thans zeer zcldzaam; dalar is evenwel in 't Kabinct een voorite voet on de lange tand der linker\%yde van het onderft kaakbeen van een biovre van GARdon: ik heb deze deelen vergelecken met die, welke daraan in onzen bćver beantwoorden, en ik hel geen verfchil van figuur. bemerkt; de dubbelde nagel des tweeden vingers van den agterften voet, welken ik by voorkeur bybrenge, omdat het een byzonder kenmerk is, was in den voet van den bie. vre even als in dien van den béver, en hadt volkomen hetzelfde maakzel; het hair 't welk aan de twee voeten van den bidure zit, lheeft eene minder bruine kleur dan by den béver en is byna geclagtig; maar dit hair is miffchien ontkleurd geworden door de werking van ' $t$ vuur, daar het aan' blootgefteld is geweeft, toen men deze deelen van den bieure gedroogd heeft.

Lengte des geheelen lighams in een regte lyn gemeeten van het einde van den bok tot aan den ftarit

Hoogte van het voorftel

Hoogte van het midden des ligháans

Hoogte van het agterftel Lengte van den kop vau 't einde van den bek tot aan 't agterhoofd.

Omtret van het einde van den bek

Omtrek van de opening van den mond

Afftand tuffehen de beide neusgaten
Afftand tuflelien het eilld van den bek en den vooriten hoek van 't

Afitand turchen den agterfen hock en 't oor .'

Lengte des oogs van den cenen hock tot den anderen ${ }^{\circ}:$.

Opening van 't oog

Aftand tuffchen de voorfte hoeken der oogen volgens de kromming van het neusbeen gemeeten

Dezelfde aftand in een regte lyn

Lengte der ooren

weten, suimen, Iynen.

Breedte van de bafis op de uitwendipe kromming gemeeten

Afitand tuffehen de beide ooren`om laag genomen ${ }^{*}$. 0 .

Lengte van den hals

Omtrek van den hals

Ontrek des lighaams agter de voorfte pooten gemeeten ${ }^{\circ}$. .

Dezelfue omtrek op de dikfte plaats

Dezelfde ontrek voor de agterfte pooten genomen . :

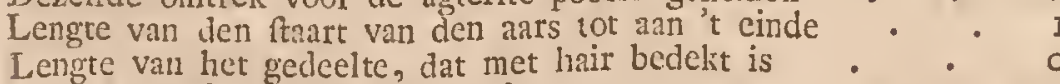

Lungte van het fchubbig gedeelte

Omatek van het gedeclte, dat met hair bedekt is - " O. 9.

Breedte van het ichubbig gedecite . . o. 4. 2.

Lengte van den voorarm van den elleboog as tot aan het gewrigt vin de hand.

$$
z_{2}
$$

o. 4. 0 . 


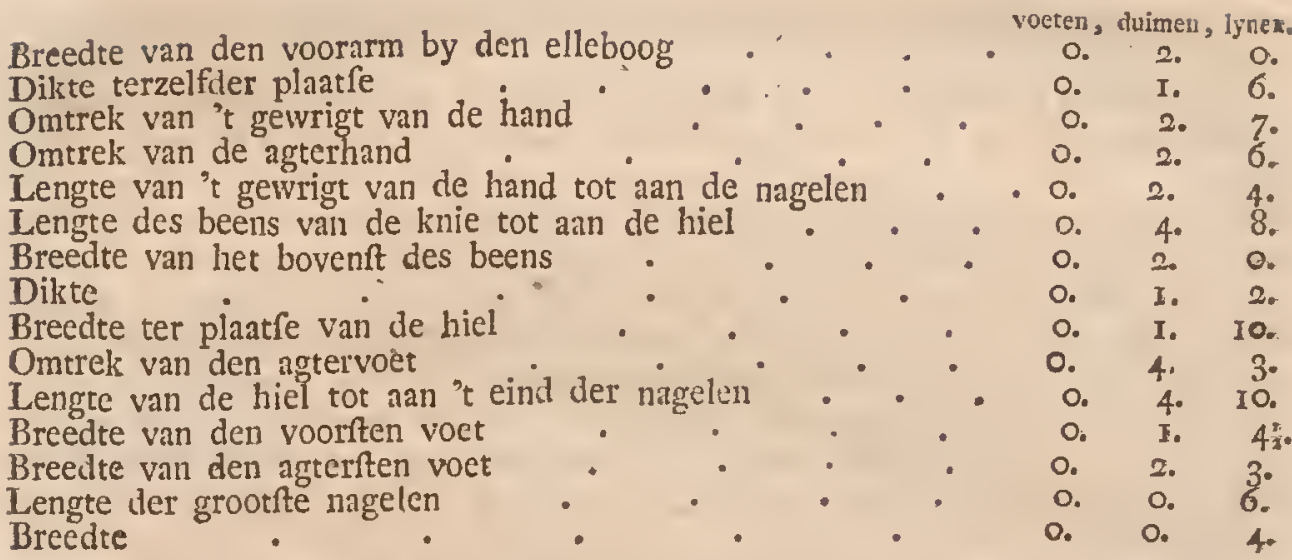

De béver, die ten onderwerpe voor de befchryving der inwendige deelen, en voor die der uitwendige deelen gediend heef, was een voet, elf duim vier lynen lang in een regte lyn gemeeten van het einde van den bek tot aan den aars; hy woog zeventien ponden.

By het openen van den buik vondt men het netvlies over de dunne darmen uitgeftrekt tot in 't midden van de navelftreek; een weinig meer verlengd aan de regter dan an de linkerzyde; het was ten uiterften dun.

De lever ftrekte zig byna zo veel ter regter als ter linkerzyde uit; de maag was in den middel bovenbuik, en het eerfte gedeelte van den blindendarm was in het agterfte gedeclte van de navelitreek, cn makkte daar een boog van de linktr-naar de regterzyde, waar van de holrondte van agteren was; vervolgens verlengde zig de blindedarm linkfch agter de mang, en vouwde zig agterwaards in de linkerzyde tot in de darmbeenftreek.

De twalfvingerigedarm was zeer lang; hy ftrekte zig uit van den portier tot atn de regterzyde van de lever; hy verlengde zig agterwaards van het eene einde tut liet andere van dezelfde regterzyde, en vervolgens in de darmbeenftreek en in den eigenlyk gezegden onderbuik, en hy kwam weder voor. waards langs de regterzyde van den regtendarm tot ann de maag, agter welke hy zig regts af kromde: de twaltvingcrigedarm hieldt aan den regten vaft langs de geheclc nirgeftrelithcid van dit ingewnnd, door cen zeer fmal vlies; de nugteredarm maakte zjne wendingen in den middel bovenbuik, en in het voorlte gedeelte van de regrerzyde; die van den omgeboogendalm waren in de regtiche dambeentlreek, en hy vouwde zig linkfch in de navelftreek voordat hy zig met den blindendarn vereenigde: de kronkeldarm makte eene dubbelde kromming in de gedaante van een roneinfche $S$ in 't midden van de linkerzyde, en vervolgens een boog, die zig in de linker darmbeenftreek, in den eigenlyk gezegden onderbuik en in de regter darmbeenftreek agter den boog van den blindendarm vitthekte; eindelyk makte de kronkeldarm verfcheiden groote omwentelingen tuffchen de twec takken van den twalfvingerigendarm, en op den nugterendarm en den omgeboogendarm, en hy vouwde zig binnenwarids voor dat hy zig met den regtendarm vereenigde. 
.

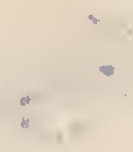




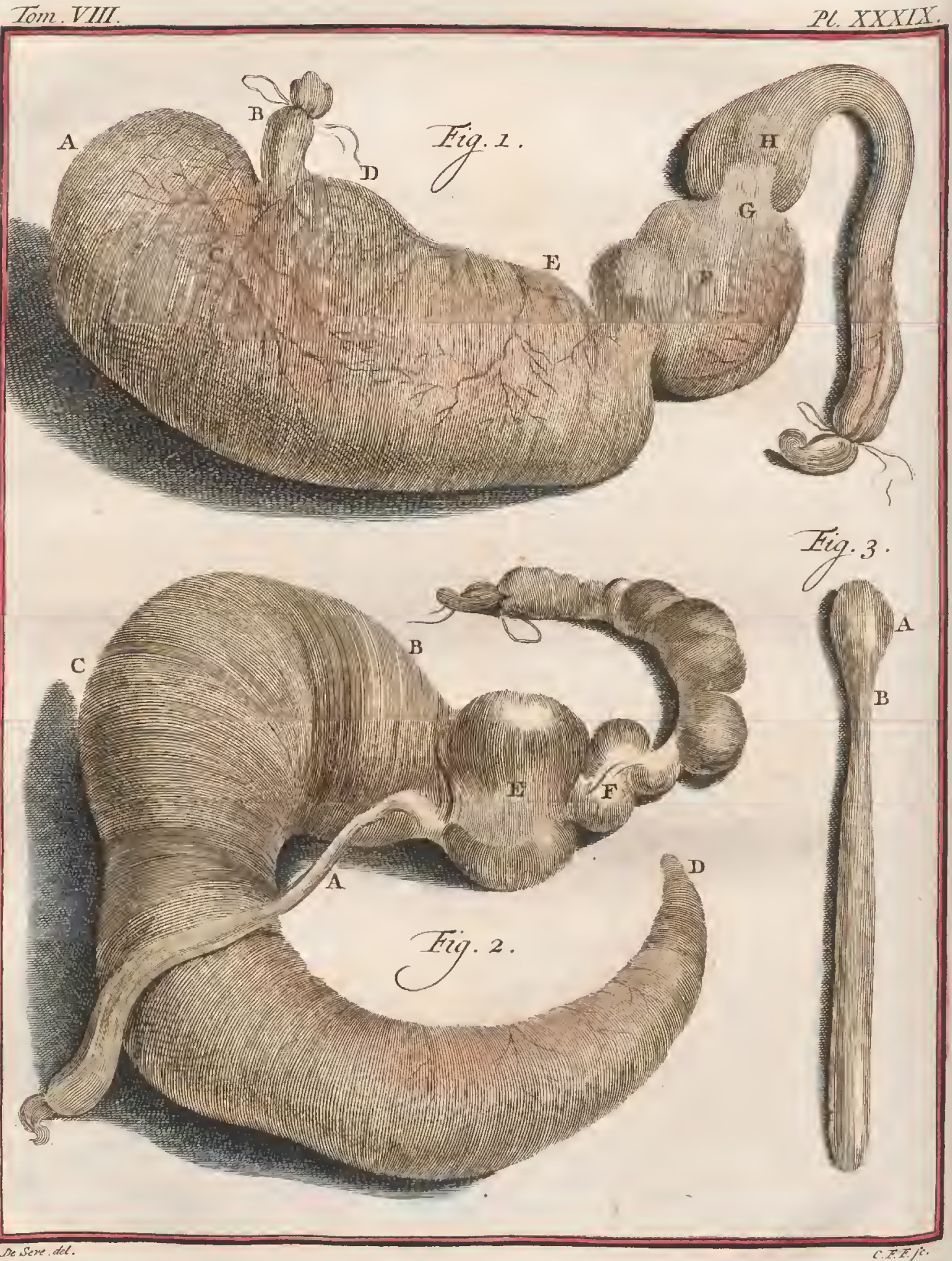




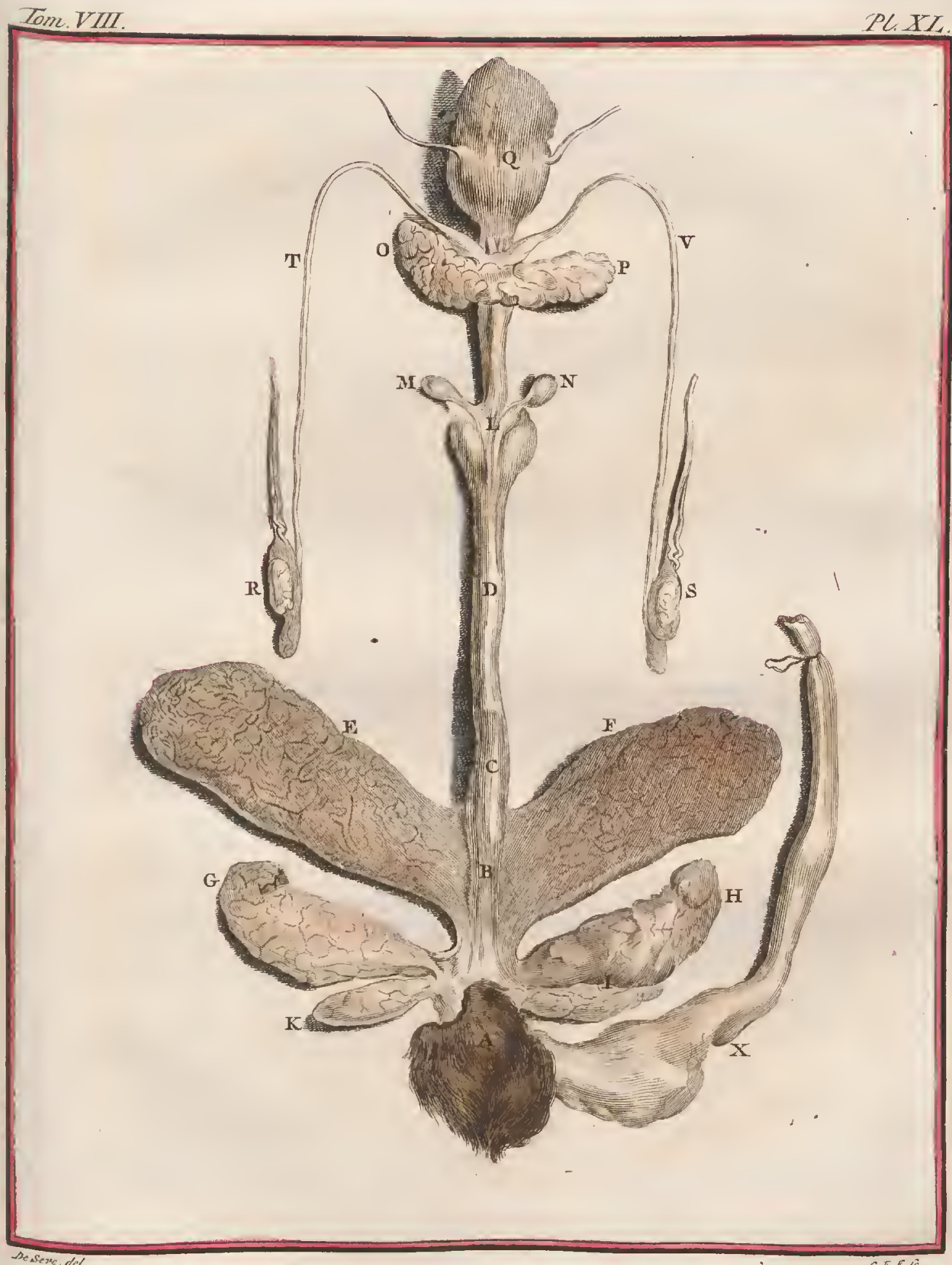



De maag ( fig. I, Pl. XXXIX) hadt eene zeer buitengewoone gedaante; zy liep zeer in $t$ lang; de groote blindezak $(A)$ hadt egter niet veel diepte, ondat de flokdarm (B) zig in het linkergedeelte (C) van ce mang inplantede; daar was aan de regterzyde van den flokdarm een zeer groote klier $(D)$; het regter gedeelte was zeer dun ter plantfe van de plooy $(E)$, en het overige $(F)$ van dit gedeelte, dat zig van de vouw tot aan den porticr $(G)$ uitltrekte, was an de regterzyde gezwollen.

De klier $(D)$ die op de kleine kromming van de maag aan de regterzyde der inplanting van den flokdarm was, hadt veertion lyncn lengte, een duim breedte, en zeven lynen dikte, en beftondt uit verfcheiden kleine klieren, van de grootte van ecn lins; $2 y$ bevatteden alle een dik en witagtig vogt, 't welk in de maag uitfypelde door vyftien groote openingen, geplantlt op drie evenwydige lynen met de kleine kromming van dit ingewand.

De twalfvingerigedarm was veel dikker aan zyn oorfprong ( $H, f i g .1, p$. $X X X I X)$ dan in al het overige zyner uitgeftrektheid, de dunne darmen hadden allen ten naaftenby dezelfide dikte, uitgezonderd het latefte gedeelte ( $A$, $f i g .2)$ van den omgeboogendarm, dat zcer dun was: de blindedarm ( $B C$ $D$ ) was zeer lang en liep in ecn punt uit: de kronkcldarm hadt cene zeer zonderlinge gedaante aan zyn oorjprong $(E)$; hy fcheen ter wederzyden een cyronden zak te maaken, die een duim en zeven lynen lang was, en een duim en twee lynen middellyns hadt; die twee zakien warew an hunne binnenzyde vereenigd, en de verlenging $(F)$ van den kronkeldarm kwam vit de plants hunner vereeniging; daar waren verfcheiden toeknypingen in de uitgeltrektheid van dezen darm, die allengs in dikte verminderde tot ann den regtendarm; die laatfe hadt insgelyks veele vernauwingen, mar hadt minder uniddellyns dan de kronkeldarm.

D. lever beftondt uit vier kwabben; de grootfte was in 't midden, $\mathrm{cn}$ in twee, ten naaftenby, gelyke gedeelten gefcheiden cloor cene fpliting, warin het galblaasje en de draagband geplanteft waren : de Hr. Perrault (a) heeft elk dezer gedeclten voor een afzonderlyke kwab genomen, en dus vyf kwabben geteld in de lever van den béver; maar dewyl deze fplitling zig op verre tha niet tot den wortel van de lever uittrekt, zo befchouw ik de twee gedeeltens, die hier in anmerking liomen, als een enkelde kwabbe; daar warcin twee kieine kwabbstjes op deagterzyde van deze groote middelkwable, het een boven het galblasje, en het ander op het regtergedcelte: datr was an de linkerzyde een kwab byna even groot als die in 't midden, cn ecne andere, die de klcinfte van de vier was en die aan den wortel van de lever bieldt; daar was mar ééne kwab aan de regterzyde, maar zy was door ecne zeer diepe fplyting in twee deelen gchcheiden; de lever hadt vall buiten on vall binnen eenc roodagtig bruine kleur: zy woog agt oncen en vicr gros.

Het galblaasje was groot; het hadt de gedaante van een pecr, en bevattede ecn groenagtig vogt, met een zweenzel van geeligtig, dat twee en cen half gros woog.

De milt (fig. $3, P l . X X X I Y$ ) was in 't lang; $z y$ hadt weinig middelyns

(a) Ménoire pour fervir à l"Hiftoire Naturelle des Alimaux, Part. I. pag. 147. 


\section{DE NATUURLYKE HISTORIE,}

en was byna rolrond uitgezonderd an het boveneinde $(A)$, dat breeder was dan het overig gedceltc, en geplat ten naaftenby gelyk de kop van een flang; want het gedeelte $(B)$, dat by het einde was, hadt minder middellyns dan het overige, en fcheen den hals van de flang te vertoonen; de milt hadt ten naastenby dezelfde kleur als de lever, zy woog een gros en vicr-en-vyftig grein.

Hetalvleefch was zeer verlengd en zeerdun; het ftrekte zig uit van de milt van de linker nar de regterzyde op de maag en langs dentwaalfingerigendarm tot aan de eerfte kromming; het volgde den twaalfvingerigendarm in de regterzyde, tot aan de regtiche dambeenfteek, alwaar het zig met den omgebogendarm vouwde, en eindelyk in het agterft gedeelte van de navelftreek weder nokwam: daar waren eenige kleine takjes evenwydig met zyn lighaan ; én agter de lever, en zes ter platefe van de kromming, die in de darmbeenftreek was; die zes takken ftrekten zig voorwaards uit: het alvleelch, afgefcheiden zynde, was een voet negen duin lang; dus was het veel langer, nar evenredigheid, dan by andere dieren, die in dit Werk rceds befchreeven ZJn.

De nieren hadden ten naftenby eene eyronde gedaante; men zag daar geene uithyding of dieping in, wanneer men har aan de bovenzyde befchouwde, man an de onderzyde was dezelve duidelyk: het voortte gedeelte van de linkernier liep in een kleine punt uit, en daar was een kleine goot, die zig op de buitenzycte van de punt af nittrekte.

De nierklieren waren van cene bruine kleur; zy lagen voor de binnenzyde van ydere nier; zy hadden zes lynen lengte, dric lynen breedte, en twec lynen dikte; de inwendige zelftandigheid was van cene grauwe kleur.

Daar waren in de regtemier vier kwabben, en twee in de linker; zy waren alle geplaatft gelyk in de meefte andere dicren; het hart was dik, weinig verlengd, en byna rond; daar kwamsen drie kleine takken nit de bogt van de groote fiagader; daar bleef nog eene kleine opening in de flagaderbuis, maar die was zeer klein; ik heb de voetlpooren van een eyrond gat gezien, dat door cen dun en doorfchynend vlies geflooten wis, en il heb bemerkt, dat dit gat drie en een half lyn middellyn hadt gehad, maar ik heb 'er geene opes ning in gevonden.

De tcing was dik, gerond aan 't einde, en door cen voor, die zig langs het voorfte gedeclte uitflrckte, in twee gelyke deelen gefcheiden; daar waren twee andere vooren evenwydig met die vall het midden, mar fmaller en korter, zy waren elk maar eene lyn van malkanderen af: het voorfte gedeclte was voorzien van byna onmerkbare tepeltjes, en met ronde vry dikke korrels doorzaid; het agterft gedeelte was gezwollen, en fcheen woder bedekt te zyn met een kleine tong, die ook van zeer kleine vezeltjes en ronde korrels voorzien was; de ftrotklap was puntig.

Het verhenelte was voor de baktanden doorfneeden met vier zeer breede en diepe vooren, welker randen dik waren en in 't midden haarer lengte ecn uiffpring'enden hoek nar agteren makkten: het overige van't verhenselte, tusfeinen de baktanden, was glad; daar was agter de twee voorfte tanden eene zwarte en driekantige vlak, waarvan de balis tegen de tanden was; de pur t verlengde zig in een regte lyn van dezelfde kleur, zy was zeer fmal, en cen 



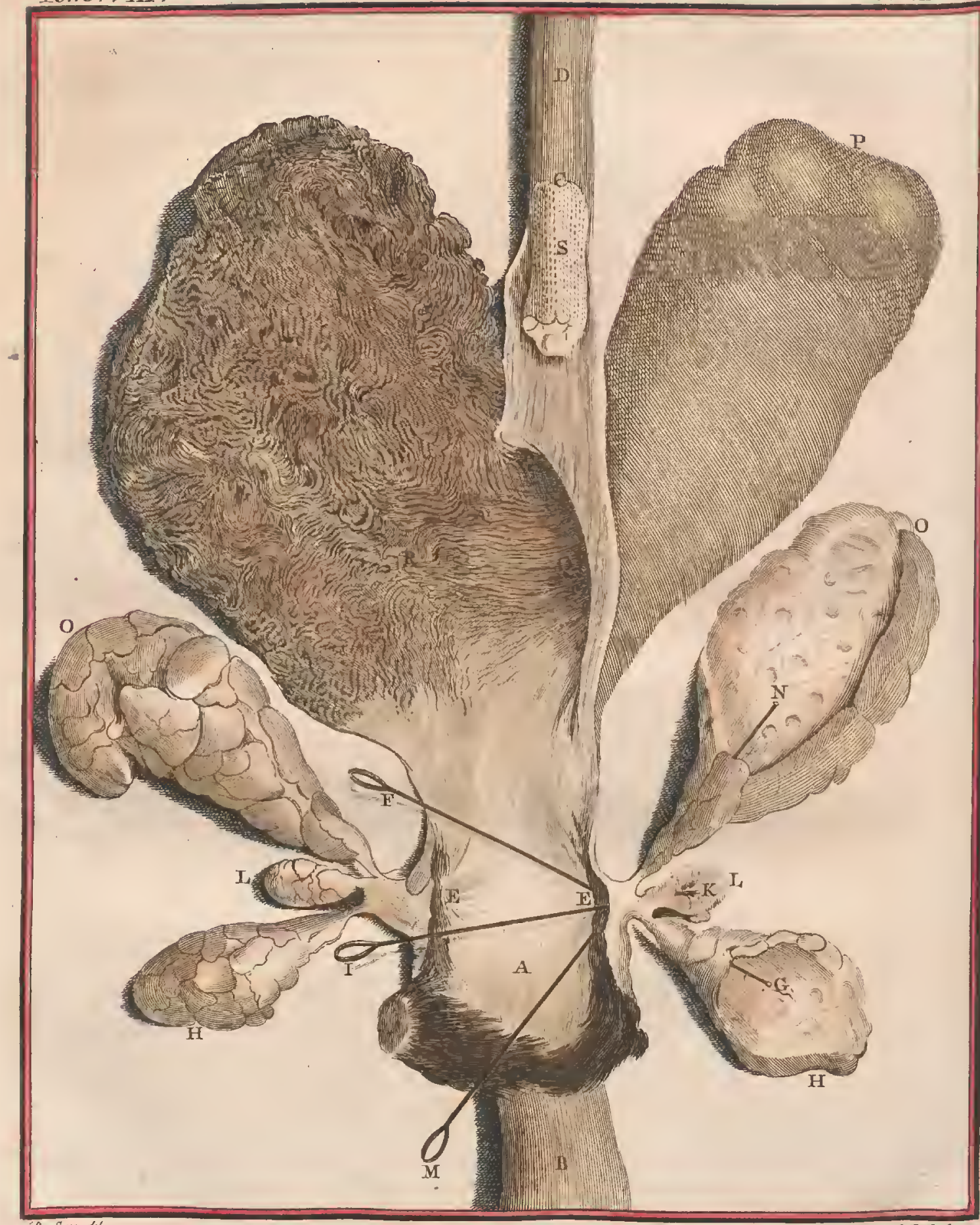


halven duim lang; zy liep uit in "t midden van een lyn, die vcel korter en dwarfch was, by den rand der eerfte voor geplatét: dic kleine lyn hadt flegts een vierde duin lengte, en eindigde aan weerszyde in ecne ronde en zwarte vlak.

De voorherffenen hadden geene holligheden, maar flegts twee kleine groefjes, ecne op het voorfte gedeclte van yder halfrond; zy beantwoordden aan twee knobbelagtigheden van het bekkeneel; de voorherffenen woogen vier en een half gros: de agterherffenen hadden uittandingen, gelyk die der meeste dieren, maar zy waren fmaller, zy woogen een en een half gros.

De pisbuis en de aars hadden maur écne gemeene opening $(A, P l . X L)$ van buiten; zy was op een gelyken afftand vann het agterft gedeelte van het fchaambeen en van het voorfte eind van het fchubbig gedeelte van den ftart ge. plaatft: de voorhuid $(B)$ makte een zeer lange fchede, dic zig uitftrekte van de gemeenc opening $(A)$ tot onder het fchaambeen; het hoofdje $(C)$ van de roede $(D)$ was in het voorfte gedeelte van deze fchede, cn befloeg llegts het derde gedeelte zyner lengte; het middelgedeelte $(B)$ was valt aan twee zeer groote zakken $(E F)$, een aan weerszyde: die zakken waren van een afchgrauwe kleur; zy hadden drie duim en drie lynen lengte, dertien lynen breedte en vier lynen dikte; zy ftrekten zig elk in cene regte lyn uit; maa gelyk die lyn wat fihuinfch naar agteren gerigt was, zo inaakten de twee zakken ten naaftenby een regten hock op de plats hunner vereeniging met de fichede door de voorhuid geformeerd; het einde der zakken was gerond, en daar waren op hunne oppervlakte eenige rimpels van verfchillende bogten, die naar zcer platte knobbelijes geleeken.

Tufichen deze eerfte zalkikn en de opening, die aan de pisbuis en an den regtendarm gemeen is, waren twee groote klieren $(G H)$ die zeer verlengd waren, en twee duim vyf lynen lengte, tien lywen breedte, en zes lynen dikte, hadden; hare rigting was dezelfde als die der twee zakken, daar gewag van gemaakt is; zy hadden eene geelagtige kleur en al het voorkomen van fiamgeloopen klieren; haar einde was binnenwards gekromd, en het gedeclte, dat aan de voorhuid vaft was, hadt flegts vier lynen middellyn.

Men zag ecne voor $(I)$, die zig van het begin van elk dezer klicren tot in "t midden van laare agterfte zyde nitftrekte; door het celagtig weefzel, dar in deze voor gevondell werdt, te doorbouren, heb ik van elk der groote klieren een gedeelte $(K)$ afgcfichilen, hetwelk een kleine klier van ccne eyronde gedante makte, welker groote middellyn ontrent vyftien, en de kleine vyf, lynen lang was.

De roede $(D)$ hadt eene byna rolronde gedaante; daar waren by de fplyting $(L)$ der fponsagtige lighaamen twee klieren $(M N)$ eene aan weerzyde van de pisbuis, die ny voorkwanen de voorfanders te zyn, en die vier lynei lengte hadden, drie lynen breedte, en twee lyuen dikte; zy waren elk valt ann een ftecltje van vier lynen lengte, dat op de pisbuis uitliep.

De zaadvaten $(O P$ ) waren by de blias geplatet $(Q)$ op dertien lynen af1tand van de vooritanders; $z y$ waren in 't lang, en konden elk een duim itr de: lengte, vyf lynen in de breedte, en drie lynen in de dikte, halen; mei bemerkte-dar dikle lnobbeltjes op, zy hadden een geelagtige kleur. 
De zaadballen $(R S)$ waren zeer klein in evenredigheid van de grootte des diers; $2 y$ hadden de gedaante van een olyf, hunne kleur was geelagtig van buiten en witagtig van binnen; de afvoerende buizen $(T V)$ hadden weinis lengte, dus kwanen de zaadballen niet buiten den onderbuik: de middelly'n der afvoerende buizen was veel grooter by de blas dan in al het overig gedeelte harer nitgeftrelktheid.

$\mathrm{Na}$ de voorhuid $(A, P$. XLI, alwar de declen in hunne natuurlyke grootte vertoond worden) geopend te hebben, van den rand der opening, die $z y^{\circ}$ gemeen hadt met den regtendarn $(B, P l . X L I$ en $X, P l . X L$.) tot aan haare inplanting $(C, P l . X L I)$ met de roede $(D)$, vond ik aan weerzyde, zeven of agt lynen boven dezen rand, eene kegelwyze holligheid $(E E)$, die omtrent drie lynen middellyns aan haare opening, endie lynen diepte hadt: de grond dezer holligheid raakte aan het einde der dikke geele en knobbelagtige klieren ( $G \mathrm{H}, \mathrm{P} \% \mathrm{XL}$ ). Deze klieren naar den kant van de voorhuid dryvende, keerden de wanden der holte zig om op het einde van het hoofdje, en maakten een valten kegel, die zo veel hoogte en middellyn hadt als de holte, die'er te voren geweeft was; die klieren in deze platting drukkende, zag men een geelagtig vogt uitfypelen uit drie kleine openingen op éf1e lyn, zeer digt by majkanderen geplatit: ik heb claar drie ftylets ingebragt; het eerfte $(F G, P$ \% $X L I)$ drong in de kleine klier $(K, P l . X L$ en $H H, P l . X L I$. $)$ warvan door den Hr. PERRault in zyne befchryving van den béver gewag is gemaakt: het tweede ftilet $(I K, P l . X L I)$ is in de $\operatorname{nog}$ kleiner klier $(L L)$ die tot heden nog niet was opgemerkt, ingegaan; het derde ftilet $(M N)$ bevondt zig in de dikfte der drie klieren (O O): men zag van buiten de ontlaftunizen, daar de ftilets doorgingen on in 't midden der klieren te dringen; die ontliftingwegen, en derzelver opening in de pisbuis, waren zeer zigtbaar, inzonderheid door de droppels vogt, die daar nitypelden terwyl de klieren gedrukt wierden: ik ben verwonderd dat men dezelve niet heeft opgemerkt! in den béver, warvan de Hr. Perraul' de befchryving heeft gegeeven (b), dewyl die béver grooter was dan de onze; want hy hadt ten naaftenby dezelfde grootte als de béver in de dierengaarde van Verfailles, waar 11aar te manten, in de voorgaande tafel bygebragt, genomcn zyn.

Het celagtig weefzel, dat de klcine klieren in elk der groote $\left(\begin{array}{ll}H & L\end{array}\right.$ ) a an malkanderen hieldt, doorfiydende, heb ik die klcine klieren tot op de diepte van anderhalf lyn afgefeheiden, en ik heb een zak doorgefneeden, die een ydel in "t midden des lighams van elke der drie groote klieren makte: na dezen zak geopend te hebben, heb ik deszelfs binnen-wanden ( $G K N$ ) gezien, die door de monden der kleine klieren doorboord waren; de finede van naby onderzoekende, en dar met een pypje op blazende, heb ik benerkt dat elk der kleine klieren uit andere nog kleiner klieren beftondt, welker uitwerpbuizen op cen gemeene buis uitliepen, war door de binnenwanden van den zak doorboord wierden: ik heb danr eene dikke geelagtige toflic cin van een lelyken reuk in gevonden; die ftof heeft vlam gevat by 't licht

(b) Meinoirs pour Servir d'Hifteire Aaturelle des aumaus, Part. 1, pag. I4I en 544. 
van een kaars, gelyk de Hr. PERrault heeft waargenowen (c); zy wierp vlammende deeltjes uit, die naar alle kanten flikkerden en fprongen; dezelfde ftof, heet gemaakt zynde, gaf cen nog fterkcr en finkerder reuk, die ecnige overeenkonit hadt met dien van gebraden zwitferfche kaas.

De groote zakken van eene afchgrauwe kleur $(E F, P l . X L)$, opgeblazen zynde, zyn zo gefpannen geworden, dat de rimpels en knobbcltjes, die zig eerft vitwendig vertoonden, verdweenen; zy mankten negts cenige zwellngen, die hunne oppervlakte ongelyk maakten: zy hadden in dezcr ftaat ( $P$, $P$ l. $X L I$ ) eene eyronde gedaante, waarvan de groote ontrek van zevell en een lanlf duim, on de kleine yan vyf en een half duim, was: de opening $(Q$. van deze zakken, die in de pisbuis gemeenfchap hadt, was zeer groot; in 's rond uitgeftrekt zynde, hadt zy een duim en vier lynen middellyns; de vliezen dier zelfde zakken waren dun; $2 \mathrm{y}$ maakten op de binnenwanden $(R)$ dikke rimpels, dic belegd warcn met eene klcinc laag diklic ftofie van eene donker grauwe kleur; die ftof hadt cen zeer fterken en zeer onaangenaamen reuk, dic zulks nog mecr wierdt, wanneer men dezelve brandde; $z y$ ging tot koolen over zonder vlammende decltjes uit te werpen, gelyk de ftof der klieren, daar gewag van gemaakt is.

Het hoofdje $(S)$ was rolrond; daxr was een kleine voor in 't lang op de onderfte zyde; de geheele oppervlakte was bedekt met kleine ftyve tepeitjes, die puntig en agterwaards gcrigt waren; het bevattede een been, welks voorfte einde bekleed was met een zwartagtigen champignon, ten naaftenby als in de anpen; daar was beneden dien champignou eene groute opening, die de opening van de pisbuis was.

Lengte der dunne darmen van den portier tot aan den blinden- voeter, duimen, Iyreg. darm

$$
\text { darm }
$$

Omtrek van den twalfvingerigendarm op de dikfte plaatfen $\quad$ I3. 3. 0.

Omtrek op de dunfte plaatfen

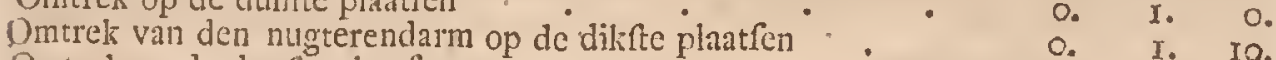

Nmtrek op de dunfte plateften

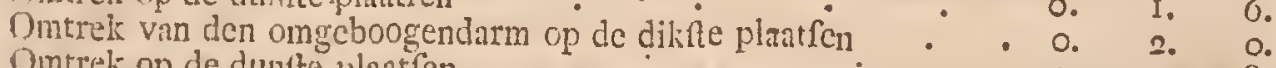

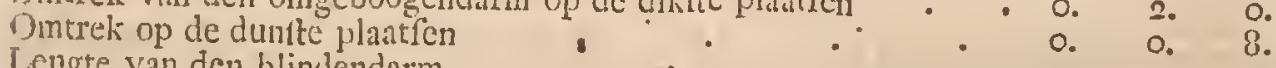

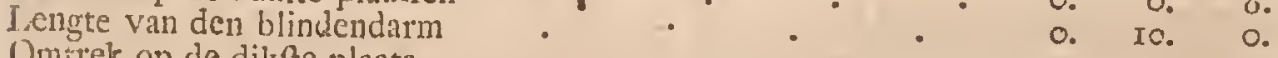

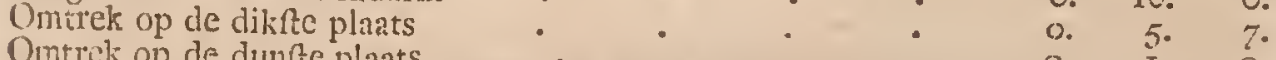

Ointrek op de dunfte plats

Ontrek van den kronkeldarm op de dikfte platfen - . $\quad 0_{0} 3.3$.

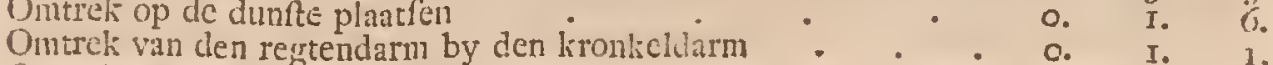

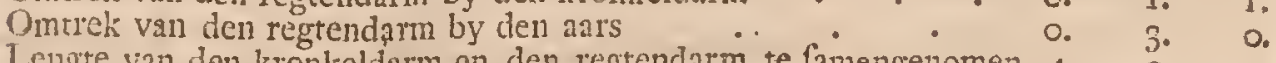

1.engte van den kronkeldarm en den regtendarm te famengenomen. $4 . \quad 0_{0} c_{0}$

Inengte vall de gcheele darmbuis, den blindendarm niet mede begreepen

Groote omtrek van de maa,,$\quad \cdot \cdots+\cdots$

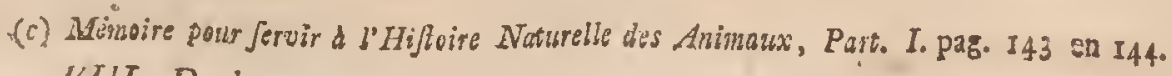
IIIT. Deel. 
Kleine omtrek voeten, duimen, lynct.

Lengte der kleine kromming van den flokdarm af tot aan den hoek, o. 9. dien het regtergedeelte maakt Lengte van den flokdarm af tot aan den grond van den blindenzak. Ontrek van den llokdarm Omtrek van den portier Lengte van de lever Breedte Haare grootfe dikte Lengte van het galblaasje Zyı grootite middellyn

Lengte van de milt
Mliddellyn van het onderfe einde Middellyn by het bovenft cinde Breedte van het bovenfte einde Dikte van het alvleefch.

Lengte der nieren

Breedte

Dikte

Lengte van het zenuwagtig middelpunt van de holle ader af tot aan de punt

Breedte

Breedte van het vieezig gedeclte tuffichen het zenuwagtig middelpunt en het borftbeen

Breedte van ydere zyde van het zenuwagtig middelpunt

०. 3. 8

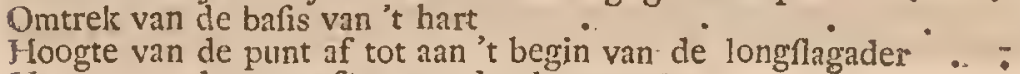

Hoogte van de punt af tot aan den longenzal

Omtrek van de groote flagader van buiten tot buiten gemeeten .

Lengte van de tong

Lellgte van het voorite gedeelte van het toompje af tot aan 't einde.

Breedte van de tong

Breedte der vooren van 't verhemelte

Hoogte van de randen

Lengte der vourherfienen

Preedte

Dikte

Iengte der agterherffenen

Breedte.

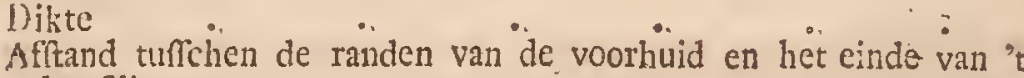
hooflije

J.engte van "t hoofuje.

Dintrek

Lengte van de roeile van de fcheiding der fponsagtige ligliamen af tot aan de inplanting van de voorhuid

Onitrek

lengte der zadballen.

Iiteedte

Dikte

lireedte van den opperibal. 


Dikte
Lengte der anvoerende vaaten
Middellyn van het grootft gedeclte van linune uitgeftrektheid
Middellyn by de blas
Groote omtrek van de blaas

De kop van het geraante $(P l . X L I I)$ geleek naar dien van de waterrot in de voornaame gedaante, maar hy verfchilde daar veel van in de byzondere declen; de béver hadt de tepelwyze uititeekzels grooter; de gehoorbuis meer uitfpringende, het voorhoofd en de eigenlyke neusbeenderen breeder, de openiingen door de jukbeenige boogen bepaald, fmaller, de boogen zelven breeder, de kroonswyze uitfteekzels van het onderft kaakbeen verhevener, enz: daar was geen gat voor de ongputten, noch nitfeekzels ter plaate van de bogt der takken van het onderit kaakbeen, enz.

De béver heeft, gelyk de relmuis, de groote hazelmuis, en de kleine hazclmuis, twintig tanden; te weeten twee lange finytanden voor in yder kaakbeen, en vier baktanden aan elle zyde; die tanden zyn my niet verfchillend vonrgckomen van die der drie andere genoemde dieren, dan voor zo verre de onderfte finytanden minder lang waren met betrekking tot de bovenfte.

De doornagtige uitfteekzels der nekwervelbeenderen waren zeer klein, uitgezonderd dat van het laatfte wervelbeen, dat ling, fmal, en van agteren 1chuinfch gerigt was.

Daar waren vyftien rug-wervelbeenderen, en vyftien ribben; age wäare en zeven valfche; de doornagtige uitfteekzels der twee eerfte wervelbeenderen waren kort en regt; dat van het derde hadt veel meer lengte, en was aan "t einde agterwaards gekrond; ; de doornagtige nittteekzels der agt volgende wervelbeenderen waren agterwaards gebogen, en die der vier lantfle waren regt; daar waren vyf beenderen in het bortitbeen; de twee eerfte ribben, eene aan weerzyde, geledigden zig met de zyden van het voorfte einde van het eerfte been: de geleding der tweede ribbe was tuffchen het ecrfte en tweede been, die der derde tuffchen het tweede en derde been, en zo vervolgens tot de vyfde, zesde, zevende, en agtte ribben, die zig met de zyden van het vierde been geledigden.

De lendenwervelbeenderen waren ten getale van vyf; zy hadden de doorn. agtige viiffeekzels regt en de bykomeinde 1chninfch voorwairds gerigt; de bykomende uitfteekzels van het ecrfte wervelbeen waren de kor:tte, en die van het vierde waren de langfte.

Het voorfte gedeelte van het heupleen had drie holronde zyden, eene bovenfte die de breedite was, en twee onjerfte, waarvan de binnenfte de hol. rondifte was.

Het heiligbeen beftondt uit vyf valfche wervelbeenderen, en de ftaart uit vier-en-twintig; de bykomende ilitfteekzcls der laatte valfehe wervelbeendesen van het heiligbeen waren langer dan die der eerfte, en daarentegen had- 
den die der valfche wervelbeenderen van den ftaart des te minder lengte en breedte als zy nader by deszelfs einde geplaatlt waren; de vier laatfte hadden noch doornagtige noch bykomende nitfteekzels, en het laatfe was byna
rond.

Het fchubagtig vel van den ftart bevattede niet dain een vaft en gedrongen vet met de valfche wervelbeenderen en met peezen, die zig aall weerzyden der doolnagtige uitfteckzels uirftrekten., en die opvolgelyk op de verfchillende valfche wervelbeenderen uitliepen : de ichubben hadden weinig dikte, en fiaken maar zeer weinig over malkanderen heen.

De bovenhoek van " $t$ fchouderblad was gerond, zodat de bovenzyde en de. bafis ten naaftenby een boog van ecn doorloopenden cirkel makten; de doorn. was zeer verheven, en eindigde van voren. in een fchouderbeenshoofd; daar was een klein ravenbeks uitfteekzel.

De fleutelbeenderen waren bolrond van binnen, van boven en van onde. ten platagtig in het gedeelte, 't welk zig met het fchouderblad geledigde, en veel dikker aan 't ander einde.

Her armbeen was zeer kort, en zeer breed aan zyn onderfte gedeelte, omdat 'er een fcherpe verhevenheid was op de buitenzyde; daar was op het bovenft middelgedeelte van de voorfte zyde een dik uitteekzel naar buiten gexigt.

De beenderen van den voorarm geleeken naar die van de waterrot.

Het dijebeen was zeer kort, zeer dik en breed; het hadt een nitfteekzel op het middelft gedeelte van de buitenzyde:

De beenderen van den poot hadden zo veele gelykenis naàr die van de waterrot, als 'er gevonden is tufichen de beenderen van den voorarm van dit dier en den béver, uitgezonderd dat de verhevenheid van het bovenft en voorfte gedeelte van het fcheenbeen minder uitfpringende en minder naar buiten gekromd was; het kuitbeen hadt van voren op zyn bovenft einde een dik uitfteekzel fchuins nar buiten en naar beneden gerigt.

Daar waren vier beenderen in de eerfte ry van de voorhand; het eerfte en het laatftc waren buiten de ry; het tweede was onder het ftraalbeen, en het derde onder de cllepyp: de tweede ry beftondt ook uit vier beentjes; de drie eerfte waren boven de drie eertte beentjes van de agterhand, en het vierde beentje van de voorhand boven het vierde en vyfde van de agterhand; het was het grootfte van de vier en het tweede was het kleinfte: daar was in de voorhand een negende beentje geplaatit tuffchen de twee ryen onder het tweede beentje van de eerfte ry en boven het tweede en derde van de tweede ry; dit negende becn was grooter dan het tweede van de tweede ry.

De voorvoet beftondt unt zeven beercieren, gelyk by de meefte andere dieren; darr was daarenboven een agttle dat verlengd, en an de buitenzyde van het ecrlte wiggrebeen geplaatit, was.

De benderen van den agtervoe:, en der vingeren van de agterfe voeten, waren naar evenredighcid, veel langer en dikker dain die van de agterhand en der vingeren van de voorfte voeten; de vierde vinger van den agterften voet was de dikfle.en.de langite, en de. vyfde. was van cene middel-grootto tas- 
Tom VIII.

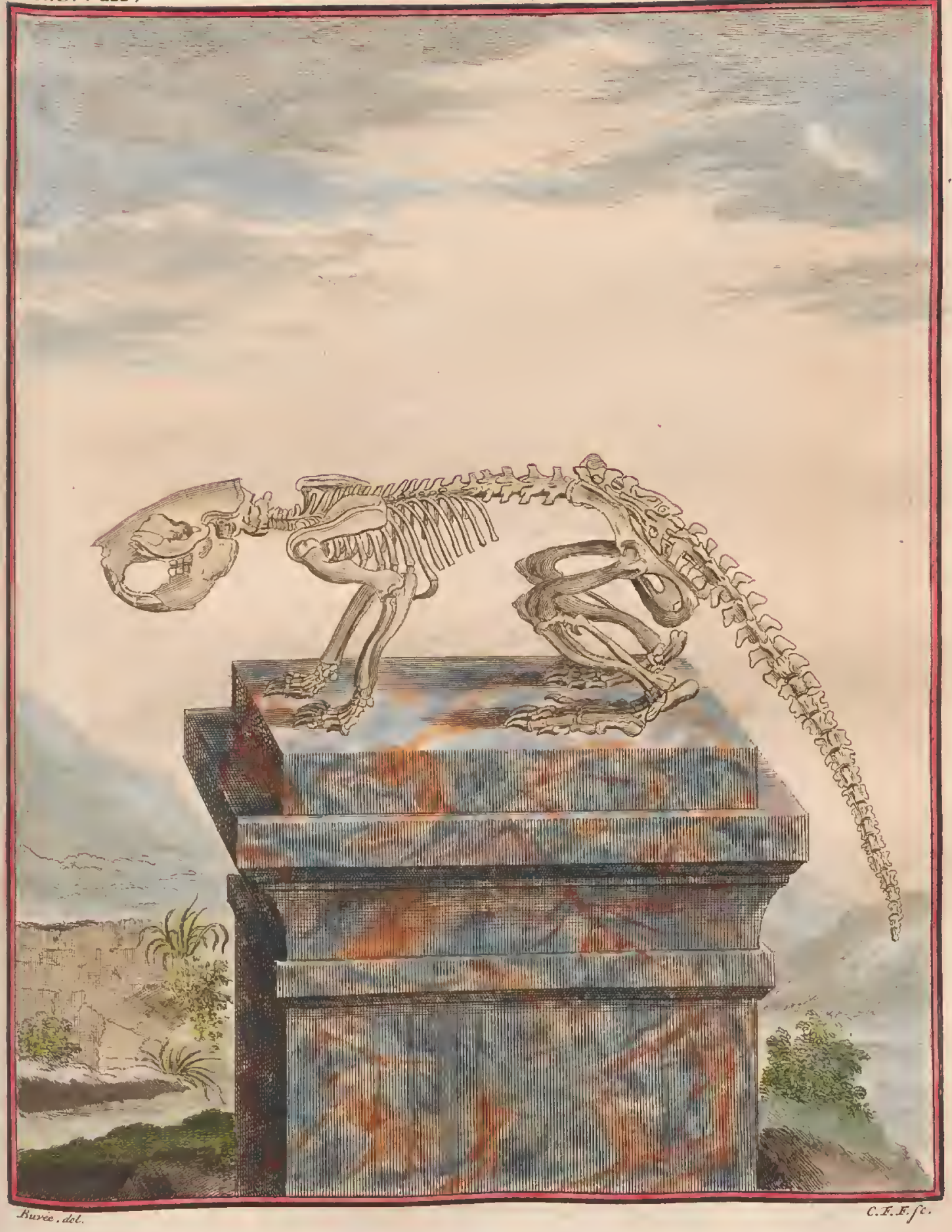



fehen die van den tweeden en den derden vinger; de cerfte was de kleinite van de vyf.

De binnenfte en onderfte magel van den tweeden vinger was niet vaft aan het beentje van den laatfen regel, het was het einde alleen van het kraakbeenige dat verhargt en ftevig geworden was als een waare nagel.

Lengte van den kop van 't einde van de neusbeenderen tot ann 't agduimen, Jynetr. terhoofi

De grootfte hreedte van den kop

Lengte vai het onderft kaakbeen van zyn voorfte einde tot aan den agterften rand van het knokkelwyze uitteelizel

Breedte van het onderf kaakbeen ter plastfe der finytanden

Breedte ter plaatfe van de bogt der takken

Afitand tuftionen de knokkelwyze uirfteekzels

Dikte van het voorfte gedeclte des bovenften laakbeens

Breedte van dit kaakbeea ter plaatfe der fnytanden

Affand tufichen de oogputten en de opening der neusgaten

Lengte van deze opening

Breedte

Lengte der eigeniyke neusbeenderen

Breedte aan de breedfte plaats

Middellyn der oogpitten

Lengte der grootite fnytanden buiten het been

Lengte der grootfte baktanden buiten het been

Breedte

Dikte

Lengte van de bafis van het tongbeen

Lengte der hoornen

Lengte van den hals

Lengte van het gat des eeriten wervelbeens van boven naar beneden.

\begin{tabular}{|c|c|}
\hline $\begin{array}{l}4 . \\
2 .\end{array}$ & $\begin{array}{c}6 . \\
10 .\end{array}$ \\
\hline $2:$ & II. \\
\hline O. & 8. \\
\hline J. & 2. \\
\hline I. & 6. \\
\hline D. & 3. \\
\hline Q. & 9. \\
\hline I. & 4. \\
\hline 0. & 7. \\
\hline ๑. & 7. \\
\hline I. & 7 \\
\hline O. & $5 \frac{t}{2} \cdot$ \\
\hline O. & 9. \\
\hline I. & I. \\
\hline 0. & 4. \\
\hline O. & 380 \\
\hline O. & 3. \\
\hline 0. & 5. \\
\hline $\begin{array}{l}\text { o. } \\
I_{0}\end{array}$ & $8^{\frac{21}{2} \cdot}$ \\
\hline 0. & $5^{\circ} \frac{2}{3}$ \\
\hline 0. & 7 \\
\hline 0. & 4. \\
\hline
\end{tabular}

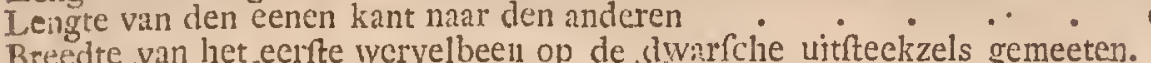

Lengte van het doornagtig uitfteekzel des tweeden wervalbeens . . .

Lengte wan het gedeclte der wervelbeenskolom, die uit de rug-wervel beenderen beftaat

Hoogte van het doornagtig gedeelte van het derde wervelbeen dat het langlt is

Hoogte van dat der latate wervelbeenderen

Lengte des limhams van 't laatife wcirvelbeen, dat het langfte is ... .

Lengte der ecrlte ribben

Afitan der eerfte ribben aan de breedite plaats

Lengte van de tiende ribbe, die de langite is

Lengtc van de laatite der valfche wervelbeendere

Brecdte van de breedfte rib

Lengte van het borfbeen

Lengte van het vyfide been dat het langfte is

Lengte van het tweede been dat het kortite is

Joogta vau laet langite toornagtig uitfeckzel der lendenwervelbeenderen, zynde dat vall het lantfte wervelbecn is 
Lengte van 't lighaam des derden wervelbeens, dat het langfte is duimen, lynea. Lengte van het heiligacen - - - c. $7 \frac{7}{2}$

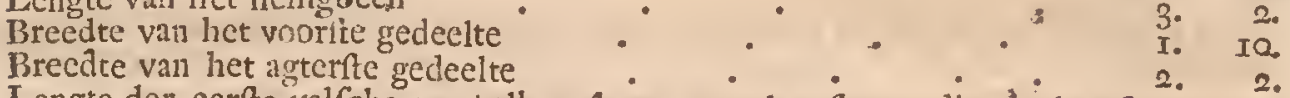

Lengte der eerfte valfche wervelbeenderen van den ftaart, die de langfte zyn

Lelngte der bykomencie doornagtige uitfteekzels van het laatfte wervelbeen des ftarts, die de langfte zyn

Breedte

Breedte van het voorfte gedcelte des heupbeens

Hoogte des beens van "t midden der knokkelwyze holte

Middellyn dicr holte

Lengte van de goot

Breedte in ' $t$ widden

Dicpre

Lengte der cyroinde gaten

Breedte van 't bekken

Hoogtc

Lengte van het fchonderbiad

Brcedtc aan de breedifte plaats

Breedtc aan de fmalfte platats

Hoogte van den doorn aan de verhevenftc plaats

Lengte der 1leutclbecnleren

Lengte des felsouders

Omtrek aan de kleinfte plaats

Middellyn van 't hoold

Breedte van het onderft gelecite

Lengte van de ellepyp

Lengte van de elleboogsknokkel

Lengte van het ftralbeen

Lengte van het dijebcen

Middellyn van 't hoofd

Ontrek van 't midlen des beens

Breedte van het onderft einde

Lengte der kniefchyven

Brecdte

Dikte

Lengte van het fcheenbecn Breedte van 't hoofd

Ontrek vail 't midden des beens

Breedte van lier ouscerft einde

Lengte van her kuitbeen

Ontrek fan de dunfte plats

Brecdte atn her bovenft cinde

Brcedte aan het ondertte einde

Hoogte van de vo.rhand

Lengte van het hielbeen

Huogtc van het eerfe wiggebeen en het fchuitbeen te famengenomen.

o. 8 .

8.

o. IO.

5 .

Lengte van het eerfe becn van de agterhand, cat l.et kortfe is . . 
te van het derde been dat het langfte is yte van het eerfte been van den agtervoet, dat het kortfte is : duimen, lynen: engte van het vierde been dat het langft is

Lengre van den ecrften regel des middelften vingers van den voorften voet

Lengte van den tweeden regel

Lengte van den derden

Lengte van den tweeden

Lengte van den tweeden. regel

Lengte van den derden
Lengte van den cerften regel van den dujm

Lengte van den tweeden $\quad . \quad$ o. 6.

O. 9

O. II

I. II.

o. 5 .

o. 4 .

o. 6.

o. 4 .

I. 0 .

o. $55_{2}^{x}$

0. 7.

0. I0.

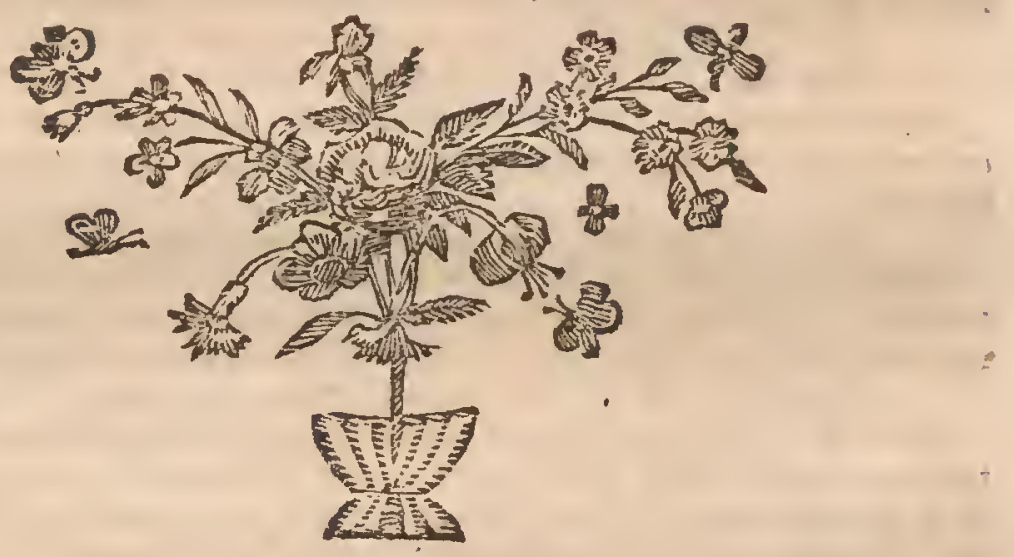


VAN DAT GEDEELTE VAN HET KABINET,

\section{HETWELK BETREKIKING HEEFT TOT DE NATUURLYKE HISTORIE}

\section{VAN DEN BEER EN VAN DEN BEVER.} -

\section{No. DCCCXVI. Een opgezette beer.}

$\checkmark$ Deze beer is groot en van eene gemengde bruin-rosagitige en zwarte of zwartagtige kleur over het gehcele lighaam, uitgezonderd den bck, die ecne veel donkerer vale kleur heeft over zyn boventte gedeelte dan aan de $\mathrm{zy}$ den en van onderen; al het ovcrige des lighaams fchynt zivart of zwartagtig;, omdat het einde der lange hairen van die kleur is; het groottt gedeelte hunner lengte aan de zydc des wortels en van het vlashair is bruin-rosagtig.

No. DCCCXVII. Een voorfte voet van een beer.

Nio. DCCCXVIII. Een agterfte voet van een beer.

Deze twee voeten zyn van de linkerzyde; zy komen van den beer, die teis onderwerpe der:belchryving van dit dier gedicnd heeft; zy zyn in wyngeeft bewaard.

No. DCCCXIX. De nieren van een beer.

Deze nieren zyn van denzelfden beer als de voeten onder de voorgaande nommers bygebragt; zy zyn in wyngect; cen dezer nieren is ontbloot van het bekleedzel, gemeen aan alle de knobbeltjes daar zy uit beftaat.

No. DCCCXX. Hez geraante van een beer.

Dit is het groot geraamte, warvan gewag gemakt is in de befcluryving der tanden van den beer, blz. I 59, cn waarin agt-en-dertig tanden zyn; zyn lengte is van vier voet agt duim van het einde des bovenften laakbeens tot het agterfte einde der heipbeenderen; de kop heeft negen duimen omtreks an de dikite plaats.

No. DCCCXXI. Het geraante van een anderen beer.

Dit gernamte is van den beer, dic ten onderwerpe voor de befchryving van dit dier gediend heef, en 't welk maar vier-en-dcrtig tanden heeft, gelyk reeds geneld is op blz. 159 ; de lengte van dit geramte is van dric voet vy'f duim van het einde des bovenften liakbecns tot an het agterfte einde der heupbeenderen; de kop heeft cen voet en drie lynen omtreks op de dikite plaits gemeetell.

No. DC.CCXXII. Een jonge béver.

Deze béver is maar agt duimen lang van het einde van den néus tot ann den aars; de lengte van den ftart is van drie lynen; het fchubagtig gedeelte is naar twee en een half duim lang; en egter vyfticn lyuen breed an de breed- 
fte plaats; de fchubben zyn zeer onderfcheiden; de dubbelde nagel is reeds wél geformeerd aan den tweeden vinger der agterfte voeten; het hair is van e ene bruin rosagtige kleur over het gelieele lighaam des diers; de fnytanden hebben nog geen zweemzel van oranje kleur; dit dier is in wyngeeft.

No. DCCCXXIII. Het vel van ecn witten béver.

Het bovenft kakbeen, de ftaart, en een gedeeltc der agterfte voeten zyn vaft an dit vel, warvan het hair over het geheele ligham wit is, uitgezonderd het bovenft van den hals, van de fchouderen, van den fnuit, en van den buik, alwaar cen rosigtig zweemzel is.

No. DCCCXXIV. De voorfte voet en de agterfe voet van de linker:yde, en de fnyiand van de reyterzyde van bot onderft kaakbeen van een bidure van Gardun.

Van deze drie ftukken is gewag gemakt in de befchryving van den béver blz. I79. zy zyn gefchonken duor den Hi. Abt DE SAuvagss, Lid van de Kóninglyke Maatchappy van Montyellier.

No. DCCCXYV. Het geraamte ran een béver.

Dit geraamte hecft ten onderwerpe gediend voor de befchryving der beenderen van den béver; deszelfs lengte is van ecn voet vier duim, van liet einde der neusbeenderen tot an het agterfte einde der heupbeenderen; de kop heeft agt en een half duim omtrek, aan de dikfte plaats op 't voorhoofd en op de fcheiding der takken van het onderft kaakbeen genomen.

No. DCCCXXVI. Het tongbeen van een béver.

Dit been is van den béver, die ten onderwerpe gediend heeft voor de be. fchryving der ingewanden en der beenderen van dit dier; het beftaat llegts uit drie ftukken; de bafis heeft een tak, die zig voorwaards uitftrekt, en die zo dik en zo lang is als de twee andere taklien, die zig met de twee hoornen geledigen.

No. DCCCXXVII. Het roede-bien van cen béver.

De lengte van dit been is van een duim; het heeft llegts een lyn middel: lyns over het grootit gedeelte zyner lengte; het is van denzelfden béver al het tongbeen, daar onder het voorgande No. van gewaagil is. 


\title{
194 DE NA T UUR L Y K E H IS TORIE,

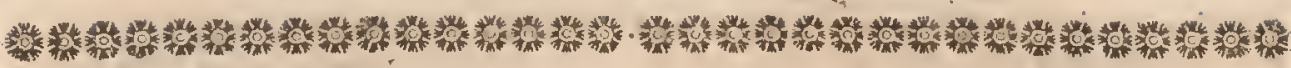

\author{
$D E R \Lambda T O N O F \triangle K O E N *$
}

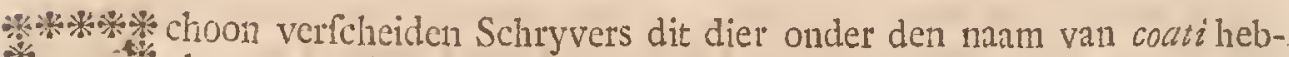
* $\mathrm{N}$ * ben voorgefteld, hebben wy geoordeeld den naam, welken men * ${ }_{*}^{*} * w_{*}^{*}$ het in Engeland heeft gegeeven, te moeten aanneemen, om alle

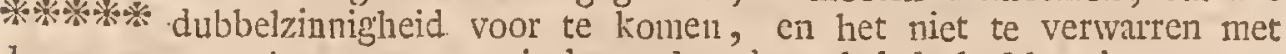
den waren coati, waar van wy in het volgend artykel de befchryving geeven zullen; of ook niet met den coati mondi, die ons evenwel flegts eene verfcheidenheid der foort van de coati fchynt te zyn.

De raton, welken wy leevende gehad, en mecr dan een jaar bewaard hebben, was van de grootte en geftalte als een kleine das; hy is kort en dik van lighaam, heeft zagt, lang, ruig, hair, zwartagtig aan de punt en grauv van onderen; zyn kop is als die van den vos, mar de ooren zyn rond en veel korter; zyne oogen zyn groot, en van eene geelagtig groene kleur; cen zwalrte band loopt dwars onder de oogen; de finuit is uitgehaald, de neus wat opwaards geboogen, de onderite lip kome minder voor uit dan de bovenfte; de tanden zyn als die van den hond; zes finy-en twee hondstanden boven en beneden; de ftart is ruig, ten minten zo lang als "t lighaam, over de geheelc uitgeftrektheid met beurtelingfche zwarte en witte ringen getekend; de voorfte pooten zyn korter dan de agterfte, en duar zyn vyf́ vingers aan alle de vocten, met ftevige en fcherpe nagels gewapend; de agtervoeten draagen genoeg op de hiel, om het dier in ftaat te ftellen van zig overeind te rigten, en om zyn lighaam in eene geftalte naar voren nederhellende, te kunnen houden: het gebruikt zyne voorfte voeten om nar zyn bek te brengen, maar dewyl zyne vingers weinig buigzaam. zyn, zo kan het met ééne hand, om zo te fpreeken, niets aanvatten, het bedient zig van beiden te gelyk, en voegt dezelve famen, om te neemen wat men hen geeft: ichoon hy groot en lyvig is, bcivcegt hy zig egter.zeer vaardig; zyne nagels, zo fcherp als fpelden, ftellen hem in ftaat om gemaklyk op de boomen te klauteren; hy klimt lugtig tot boven in den ftam, en loopt tor op het uiterft der takken; hy gaat alroos met fprongen voort, hy huppelt meer dan hy loopt, en zyne beweegingen, fchoon fchuinfch, zyn alle vardig en los.

Dit dier behoort tot de Zuidelyke declen van Amerika; men vindt het niet in de oude Wereld, ten minften de Reizigers, die van de dieren van Afrika en van de Ooft-Indiën gefprooken hebben, maken. 'er geen gervag valn; het

* De naam Riton komt van 't Engelfch woord Rattoon, of Rackoon; waarmede men dit der in die taal benoeund beeft; in zommige itreeken van Amerika beet het Mapacb.

Tolpi affinis Anericana Ration, feu Ruconz, RaY Synop.. Q:udrup. pag. 179.

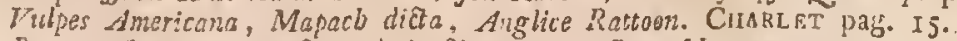

Raccoon Sumare, Hifloire de la Frmazque, Com. II. pag. 329.

U: fus caibli elongatd. LiNNBus.

Cuati Brafilier/iuss. KLeiN de Quadrup. pag. 72.

Urius caudd anwulacin variggati. Le Coati, Brissox. Regu. Animal. pig 261. 


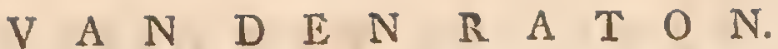

is ondertuffchen zeer gemeen in het heet klimaat van Amerika, en vooral op Jamailka (a), alwaar het zig op de gebcrgtens onthoudt, en van daar nederkomt om fuikerriet te eeten: men vindt het niet in Kanada, noch in de andere deelen van dat vafte land; het is evenwel niet uittermaaten bang voor de koude; de Hr. KLeIN (b) heeft 'er een te Dantzik in 't leevell gehouden, en dat, 't welk wy gehad hebben, was met de voeten in ' $t$ ys bezet, en hadt een geheelen nagt op die wyze doorgebragt, zonder dat het daar ongemak van gchad heeft.

Hy doopte, of liever hy doorweekte, alles wat hy eeten wilde, in 't water; hy wierp zyn brood in zyn waterbak, en haalde het daar niet uit, voordat hy zag, dat het wél doortrokken was, ten zy hy door den honger gedrongen wierdt, want dan nam hy het voedzel droog en zo als men 't hem aanboodt; hy fnuffelde allerwegen, at ook van alles, vleefch, lauw of gebraden, vifch, eijeren, leevend gevogelte, gramen, wortels, ent, hy at ook allerhande fcorten van gekorvenen, en wannecr hy zig in vryheid in ecn tuin bevondt, mam hy flaken, kevers, kormen; hy beninde de fuiker, de mclk, en andere zagte voedzels, boven alles, behalven vrugten, daar hy zo veel werk niet van maakte als van vleefch, en vooral van vifch; hy zogt zig te verbergen, om zyne bchocfte te doen; voor het overige was hy gemeenzanm en zelfs liefkoozende, fpringende op de lieden, daar hy geneigdheid voor hadt, fpeelende gaame en met vry veel bevalligheid, fraay gedofcht, vlug, en alioos in beweeging: het is my voorgekomen, dat hy den aart van de maki voor een grooter-, en de hoedanigheden van den hond in een minder-, gedeelte vereenigde.

(a) Zie tbe Natural Hiftory of Famaika, by H.s SLOANE, Londres 2725 . fol. Tom. II. pag. 329 .

(b) KLEIN, de Quadrup. pag. C2.

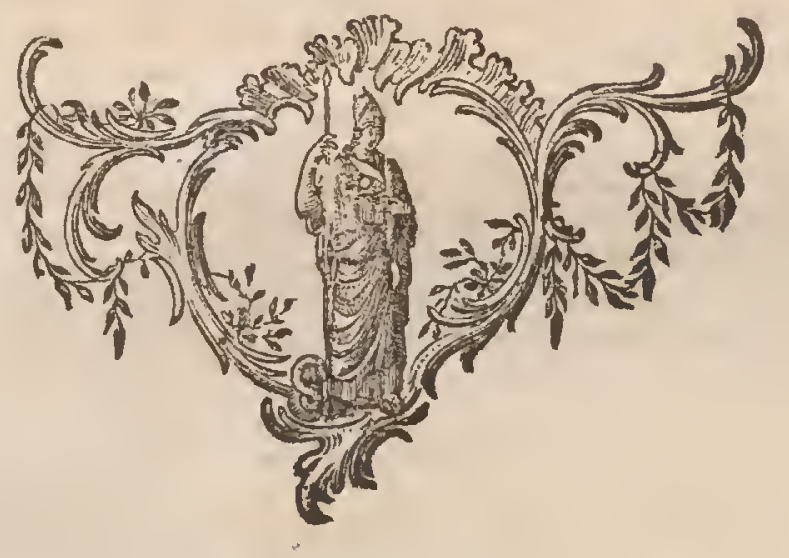

$\mathrm{Bb} 2$ 
I. 6 DE NATUURL Y K E HISTORIE,

\section{BESCIIR YVING VAN DEN RATON.}

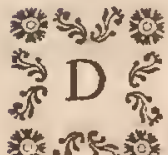

e raton ( $P l . X L I I I)$, die ten onderwerpe van deeze befchryving

gediend heeft, was ten naftenby van de dikte van een das, en geleek zelfs in de geftalte des lighaans vry wat naar dit dier, mar

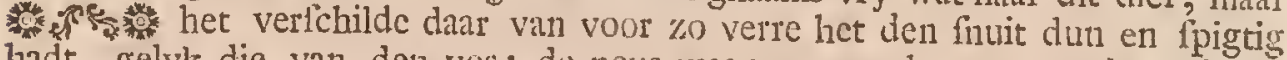
hadt, gelyk dic van den vos; de neus was war omgebogen, en de onderfte lip ftak veel ninder vooruit dan de neus: de kop was van dezelfde dikte als die van den vos, en de ooren hadden dezelfid platefing maar zy waren korter, en aan het cincle gerond; de oogen hadden ook dezelfde grootte als die van den vos, $2 y$ waren van eene blauw gtoenagtige klenl, en daar was op 't linker oog een vlak, die het zelve geheel vcrdonkerde; de ttaart gelcek naar die van de wilde kat, want hy was lang, hairig, en daar waren, van leteen einde tot aan het ander, ringen op van verfehillende kleuren.

De voorfte pooten waren veel korter dan de agterfe, zodat het dicr op zyne vier pooten ftande van agteren veel hooger was dan van voren; en in deze houding was de rug gewelfd of geboogd; wanneer het ging, zettede het flegts de punt der voeten op den grond, gelyk de honden; maar terwyl het mitede, fteunde het ook op de hiel; dat nieuwe fteunpunt gaf het ook gemaklykheid om zig op dc agterfte voeten op te heffen, en om zyn lighaan in eene fchuinfche en zelfs loodregte houding te onderfeunen; die housing was zo gemeenzaam an dit dier als aan de haazen, aan de rotten, aan de eekhoornen, enz, want zo dikwils het at nam het zyn voedzel tuffchen de twee voorfte voeten om het aan zy'11 mond te brengen; het kon dat voedzel niet aanvatten of houden met én voet, zo als wy het zelve in de hand houden, omdat de vingers mar weinig toevouwden; hy hieldr derhalven het ftuk, dar Iny wildc eeten, tuffchen de twee voeten om hoog, hy vieef het terzelfder tyd, de vingers uitgebreid houdende; wanneer hy water vondt, miftedc lyy sooit de voeten dar in te ftecken, zyn brok te lataten vallen, en dien brok vervolgens te vryven, als of hy dien wilde walfchen, mar ' $t$ ' was inderdaad. om denzelven te weeken, want dikwils liet hy dien in 't water, en wreef'hem niet, dan nadat hy het zelve hadt ingtrokken; hy weekte ook allerhande foorten van voedzels, zelfs in het koudite water; nen heeft hem geduurende een fterke vorft met zynie twee veeten in 't ys beklemd gevonden, hetwelk in de kom, daar mon hem zyn water in gaf, was angevroren terwyl hy "er zy. ne voeten inhieldt: wannecr hy door honger geperft wierdt, at hy alles wat hy vondt, zonder het te wryven of in warer te wreken.

Hy was zeer vriatig; wameer hy zig in vryheid bevondt fnuffelde hy in de hoeken der muuren en in de gaten, onder die tzeenen en onder de planten. om gekorvenen te zockin, gelyk als pinnckoppen, nkkken, cnz, en ook kluine dieren, gulyk mollen, muizen, kikvorichen, enz: hy at het vlectici. der viffchem met meer yraigte dan dat der viervoetige dieren en der vogelen; is $r$ algemeen at dit dier allerlande. rauw, gebraden, en zelfs gezouten of 


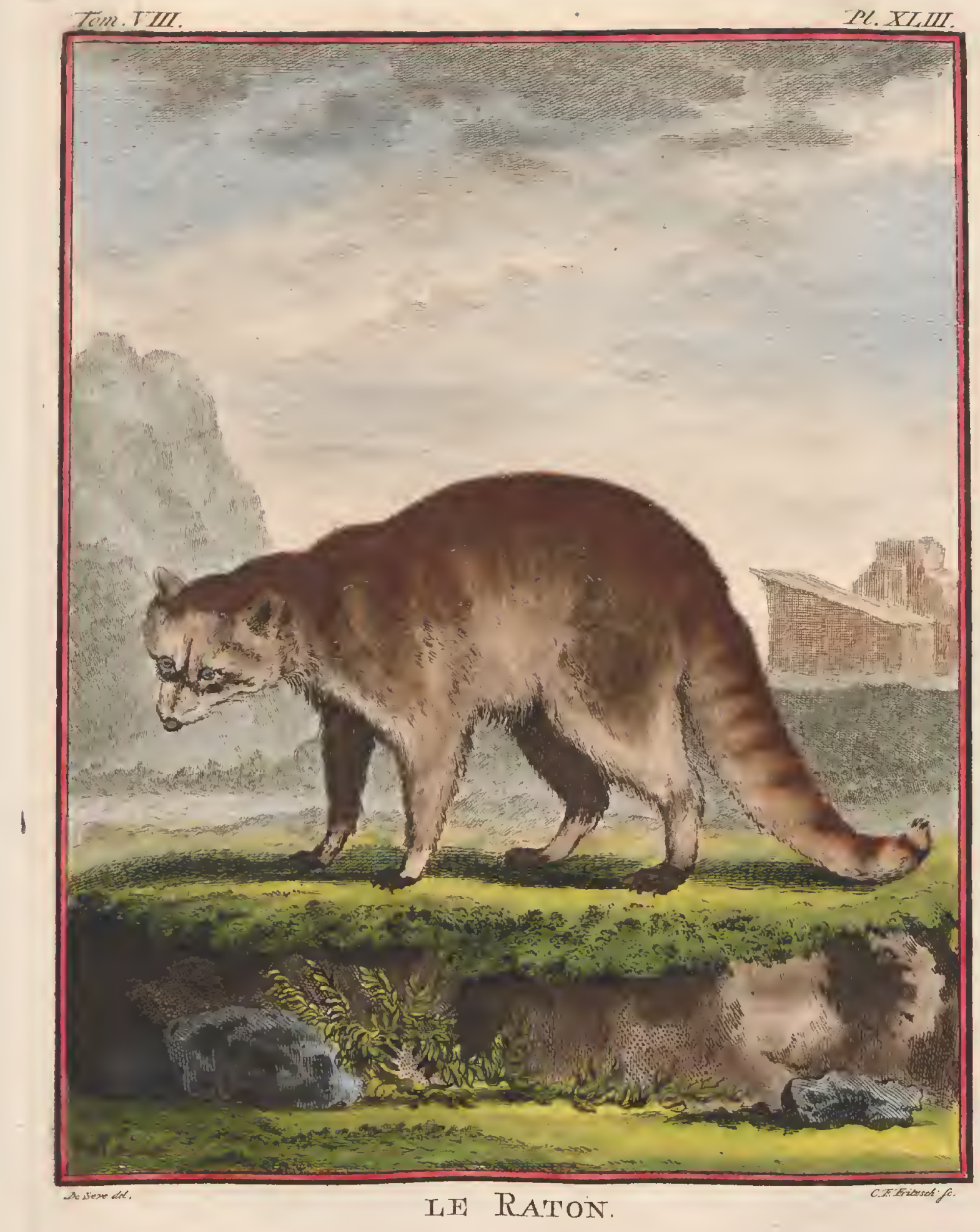



gekruid, vleefch; fterke kaas egter en moltert ftonden hem tegen; hy was zeer greetig naar melk, nar room, fuiker, en alles wat met fiilier ingelegd. was; hy at ook vrugten, maar alleen by gebrek van 't vleefch van dierel1; hy dronk flabbende gelyk de honden en optrekkende gelyk de paarden.

Deze raton was zeer gemeenzalam en zelfs zeer lieflkoozende; hy kende de geenen die hem dikwils naderden, en die hem te eeten gaven, hy fpeclde als de honden en de kitten; hy hadt veele behendigheid, was zeer gauw, en ge beweeging;, en hy hadt, aan de ketting vaft zynde, cen zcer zonderlingen gang; hy belchreef een boog van een cirkel treedende met zyne voorfte pooten niet regt uit mar naar de regterzyde, en wannecr lhy, dus gaande zyn ketting ontmoctede prong hy daar met dc agterfte pooten over; vervolgens kwam hy op dezelfde wyze lingtch af weder te rug, en hy vervolgde dien gang geheele uuren agter een; op "t minite geluid, dat hy hoorde zettede hy zig op zyn agterfte pooteli, en liy hicldi zig overeind om te luifteren en de oorzaali van het geraas te ontdekken; hy hadt veel vernuft en leevendigheid, ik geloof dat deze foort van dieren zig laat temmen gelyk de honden, want deze raton was zeer gezeglyk, en heeft de lieden, die hem al te plotfelyk naderden, of die hem zyn prooy ontncemen wilden, niet gebceten; hy ontweek $20^{\circ}$ verre mogelyk ware eer hy zyn ontlafting wilde doen, en overdekte zyne uitwerpzelen gelyk de katten.

De kleur van dit dier was grauw met zwart en een zwaemzel van val gemengd; en de lippen en de neus viren zwart; daar was een ftreep van eene bruin zwartagtige kleur, die zig van den neus tot bovell het voorhoofa uitftrelite, en eene anderc dwarche 1treep, van dezelfde kleur, die dwarfich ging, veel breeder was, cn an weerszyle onder en op de oogen liep, en zig op. het agtcrft gedeelte van het onderft kaakbecn verlengde; het bovenit van het voorhoofd, de kruin, en het agterft van den kop, het bovenlt van den hals, de fchouder, de ring, het kruis, het borentt gedeclte van de $2 y^{-}$ den des lighams en de buitenite zyde van de dije, hadden eene genengde lileur van grauw, zwart, en een ligt zweemzel vaij valal. Het hai was van twee foorten; het cen korter, zagter, en menigvuldiger dan het ander, maakte ecne foort van vlashair, van eene afchgrnuw-bruine kleur: de lange en ftevige hairen waren vun eene heldere afchgraume tleur by den wortel; $z y$ hadden eene wite of witagtige kieur boven de atchgrauwe, en hun einde was zwart, zodat men, wanneer het bair overcind ftonkt, gelyk het dootgands deedt, het witagtige onder het zwarte, en het zwarte boven hot witagtige, zag: de zyden van den bek de kin, het bovenft der oogen, de zyden van den kop, de ooren, de zyden van den hals, de arm, de voomarm, de roorfte voet, het onderft van de zyien des lighains, de agterfe pont en agterfte voet, waren van ecne witte of witagtige kleur, mar het vlashair dier deelen was kastanjebiun, datzig op cenige platen, voomantyk agter het bunedentt gedeelte rain hat oor; op het agterft gedeelte van het onderit kaakbeen, en op het onderft gedeelte van den poot, vert Jonde; het onderft van den hals, de borft, en de buik, waren van ecne rosagtige kleur me wit gemengd : daar waren op de bovente zyde en op de zyden van den ftart dwaricie

$$
\mathrm{BD} 3
$$




\section{DE N A T UUR L Y K E H I T T R I ,}

ftreepen van ecne zwarte kleur met ros gemengd, en het einde was van dezclfde klcur; de ftrcepen, die by het begin van den ftaart waren, waren fnaller en mincer verre van malkanderen af, dan die, aan het einde; de ruimte, welke deze banden of ftreepen fcheidde, hadt eene grauwe en witagtige kleur.

Het langfte hair van dit dier was op de billen; het hadt omtrent drie duim lengte; de knevels waren wit en twee en een half duim lang; de kop en de voeten hadden flegts een zeer kort hair; dat van het overige des lighaans was lang en opttaande: de plant der voeten en de nagels hadden eene bruine kleur.

Lengte des gehcelen lighaams, in een regte lyn gemeeten van het einde van den bck tot and den aars

Hoogुte van het voorftel

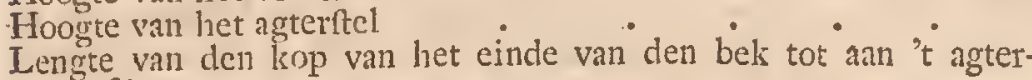
loofd

Ontrek van het cinde van den bek

Omitrek van den bek onder de oogen gemeeten

Omtrek van de opening des monds

Afttand tuffchen de beide neusgaten

Afítand tuffehen liet einde van den bek eil den voorften hoek var

Afitand tuffehen den agterften hoek cin t oor
Lengte des oogs van den cenen hoek tot den anderen

Opening van het nog van het neusbeen geneeten

Dezelfde afitand in een regrte lyn gemeeten . . . .

Omtrek van den kop tuffchen de vogen en de ooren gemeeten.

Lengte der ooren

Brectite van de, bafis volgens de uitwendige kromming gemceten.

Afitand tuflehen de ooren omlang gemecten

Lengte van den hals

Onitrek van den hals

Ontrek des lighaans agter de voorfte pooten

Omtrek aan de dikite plants

Omtreli voor de agrerife pooten gemeeten

I.engte van den fomp des ftaarts

Omtrek van den faart aan 't begin van den ftomp
Lengte van den voorarm van den elleboog af tot aan het gewrigt

van de liand

Breedte van den voorarm by den elleboog

Dikte terzelfuer plats

Omtrek van 't gewrigt van de hand

Omtrck van de agterhand

Jengte van het heen van de linie of tot aan de hiel

13: ante vin het bovent des beens

Jithic 


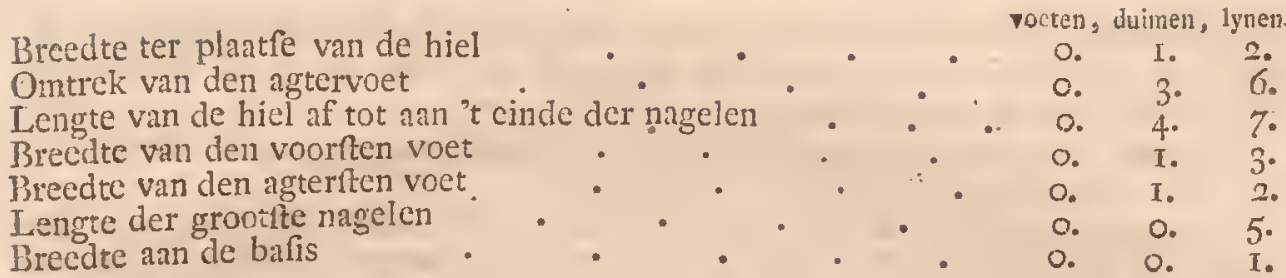

Deze raton (Pl. XLIII) woog vyftien ponden en drie oncen, het netvlics ftrekte zig tot de fchamelhcid uit en vouwde zig boven de dunne darmen; het was zeer dun en bevattede vet op eenige platfen, omdat het dier zeer. vet was: de twaalfvingerigedarm ftrekte zig tot in 't midden van de regterzyde uit, alwaar hy zig binnenwards vouwde; het vervolg van de darmbuis: maakte zyne omwentelingen in de navelftreek, in de zyden, en in de darmbenftrecken en den eigenlyk gezegden onderbuik, vervolgens ftrekte dezelve zig voorwards in de regterzyde uit, liep ter linker in den middel bovenbuik. en verlengde zig naar agteren tot den aars.

Van weerzyde van den aars was een klier, die drie en een halve linic middellyns hadt, zy was bedekt met een 1pier, en bevattede een dik vogt, dat eene: geelngtige kleur, en een zeer onnangenaamen, reuk, hadt; deze klieren openden zig met eene zeer breede opening in den aars.

De lever was meer naar de regter dan naar de linkcrzyde geplaateft, en de maag ( fig. I, Pl. XLIV) was geheel ter linkerzyde; zy was weinig verlengd en zeer klein nar evenredigheid van de dilkte des diers; de groote blindezak $(A)$ hadt weinig diepte, en het gedeelte $(B)$ van het regterdecl, dat zig tusfchen den hoek $(C)$ door dit deel geformcerd, en den portier $(D)$ kevondt was byna niets: daar was geen blindedarm; de wanden der darmbuis waren hard en dik, en zy ladt ten maftenby dezelfde dikte over haare geheele vitgeftrektheid, uitgezondcrd het gedeelte, dat in de middelbovenbuik agter de mang was, en 't welk veel minder dik was dan het overige.

De lever beftondt uit vyf kwablen; de grootfte was in 't midden, en was door twee fplytingen in drie declen verdeeld; de draagband liep door de cene en het galblaasje was in de andere geplaatf: daar was cen kwab, wat minder groot, ter linker, en eene andere ter regterzyde, ten naafteriby van dezelfde dikte als de linker; de regterkwab wwas op verfcheiden plaatfen door verfchillende fplytingen geliliefd: twee klcine kwabbetjes, die miffchien man één maakten, waren and den wortel van de regter kwabbe vaft: de lever hade uit-en inwendig eene vry leevendige roode. kleur; zy woog zes oncen en vier gros.

Het galblaaje was zeer groot, van cene eyronde gedaante, en byna geheel met gal gevuld; het bevaltede van dit vogt de givarte van een gros en tweeen-veertig greinen; het zclve was van eene oranjekleur.

De milt ( fg: $2, F / . X L I V$ ) was langagtig; zy hadt drie zyden gelyk in de meefte andere dicren; har benedeneinde $(A)$ was het breedite gudecite; dit ingewand hadt uiten inwendig eene zeer blecke roode kleur; het woog drie gros ell vier grein.

Het alvleefch was zeer dik; het hadt twee takken, waarvan de kortfte zig 
ter regterzyde langs een gedeelte van den twaalfvingerigendarm uititrekte; de langfte en dikfte tak was op de maag geplaatit en ftrekte zig ter linkerzyde tuffchen de nier en de milt uit.

De regter nier ftak flegts een vierde haarer lengte meer voor uit dar de linker; daar was maar eene tepel in het bekken.

1) regter long beltondt uit vier kwabben en de linker nit twee, die geplaatit, en ten opzigte van de grootte, geëvenredigd waren, gelyk in de meelte andęre viervoetige dieren; die kwabben hadden geene uitfnyding: het hart was byna rond, en in 't midden van de borft geplaatf; de punt een weinig linkfch gekeerd; daar kivanen drie takken uit de bogt van de groote flagader.

De tong was zeer dik in 't midden en dun aan 't einde, daar was eene kleine overlangfche voor in "t midden van 't voorfte gedeelte; dit gedeelte was bedekt met zeer fyne tepeltjes en met kleine witte korrels doorzanid; de tepeltjes van het agterfte gedeelte waren dik, driehoekig, en agterwareds gorigt; daar waren op dit gehleelte zeven kelkklieren, an weerzyde, op een reeks, die fchuinfch van agteren naar voren en van binnen naar buiten was gerigt: de ftrotklap was dik en aan de randen gerond; het verhemelte wierdt dwartch doorfincden met agt vooren, welker bolronde zyde naar voren was.

De agterherffonen waren byna geheel door de herfenen bedekt; de laatfe woogen cen once en drie greinen, en de ngterherfenen twee gros en vier-entwintig grein.

De oogappel hade vier lynen middellyns in "t regter oog, dat gezond was; het kryftallyne vogt hadt dezelfde middelly'n en drie lynen dikte in ' $t$ midden; het was zeer zuiver en zecr doorfchynende: het kryttallyn van 't linker oog was loornagtig, en tot een middellyn van twee lynen verminderd; het hing vaft an het doorfchynend hoornvlies, daar een groote paerel was, ook hadt het dier al in verfcheiden jaaren met dit oog niet gezien.

Het hoofilje $(A, P i . X L V)$ van de roede $(B)$ beftondt uit eene celagtige zelfltandigheid, vry selykende naar die van het roedenhoofdje der honden; fchoon weeker; het zat valt aan een been, welks voorte einde $(C, P ! X L V$ en $A, P l . X L I V$ fig. 3 ), zig byna bloot vertoonde en twee knobbelijes maakte vry veel gelykende inar de heupknoklkcls van een mentch: dit heen ftrckte zig byna tot aan den wortcl van de roede uit, want desseifs agterfte cinde $(B, f g \cdot 3, P \% X / I V)$ was llegts zeven lynen verwyderd van de ficheiding der fponsagtige lighlianuen af, dis zecr wyd waren in deze uitgeftrektheid.

Danar waren onler de roede twee peesagtige vry dikle lioorcien $(D, P l$. $X L V)$ die op den ans $(E)$ uitliegen: de blats ( $\left.F^{*}\right)$ geleek in hame gedanare nar ean cy: de zadballen ( $G H$ ) waren byna ftandigheid hildt cene geelagtige kleur, en een as in " $t$ midden: lk heb mot cen tangetje Jange draden uit deze zelfitandigheid gehaald: de afvoerende buizen $(I K)$ waren zeer klein over het grootfe gedeelte humner uitgeftrelitheid, mar zy waren integendeel zecr dik over de lengte van omtrent anderhalf duim $(L, M)$ by de blas : het fcliynt dat dit gedeelte der afvoerende vaaten de plaats der zandblaasjes vervult, wast het lighaam $(N)$ dat de pisbuis, ter platate ran de inplinting der afvoerende buizen, omvattede, foheen 



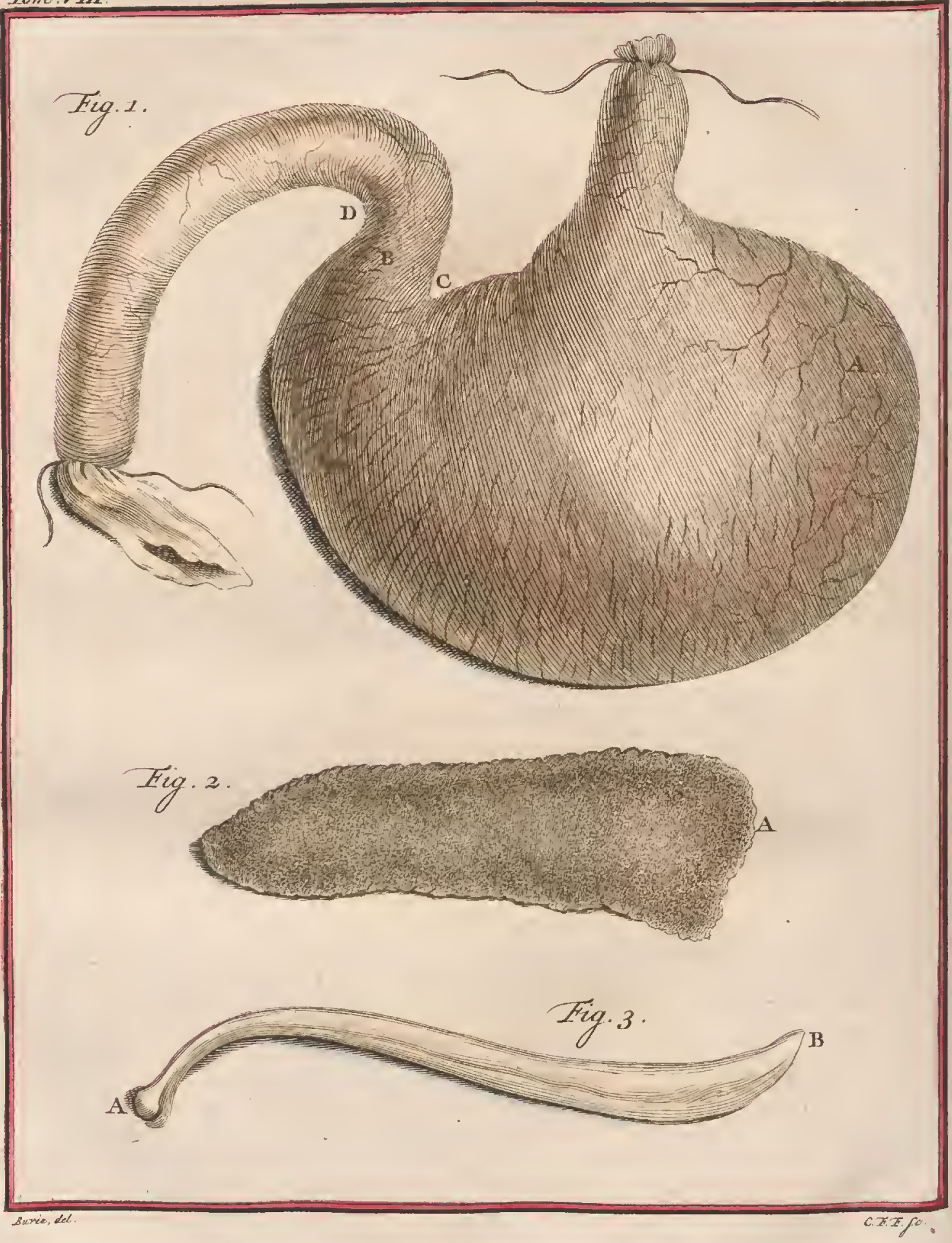




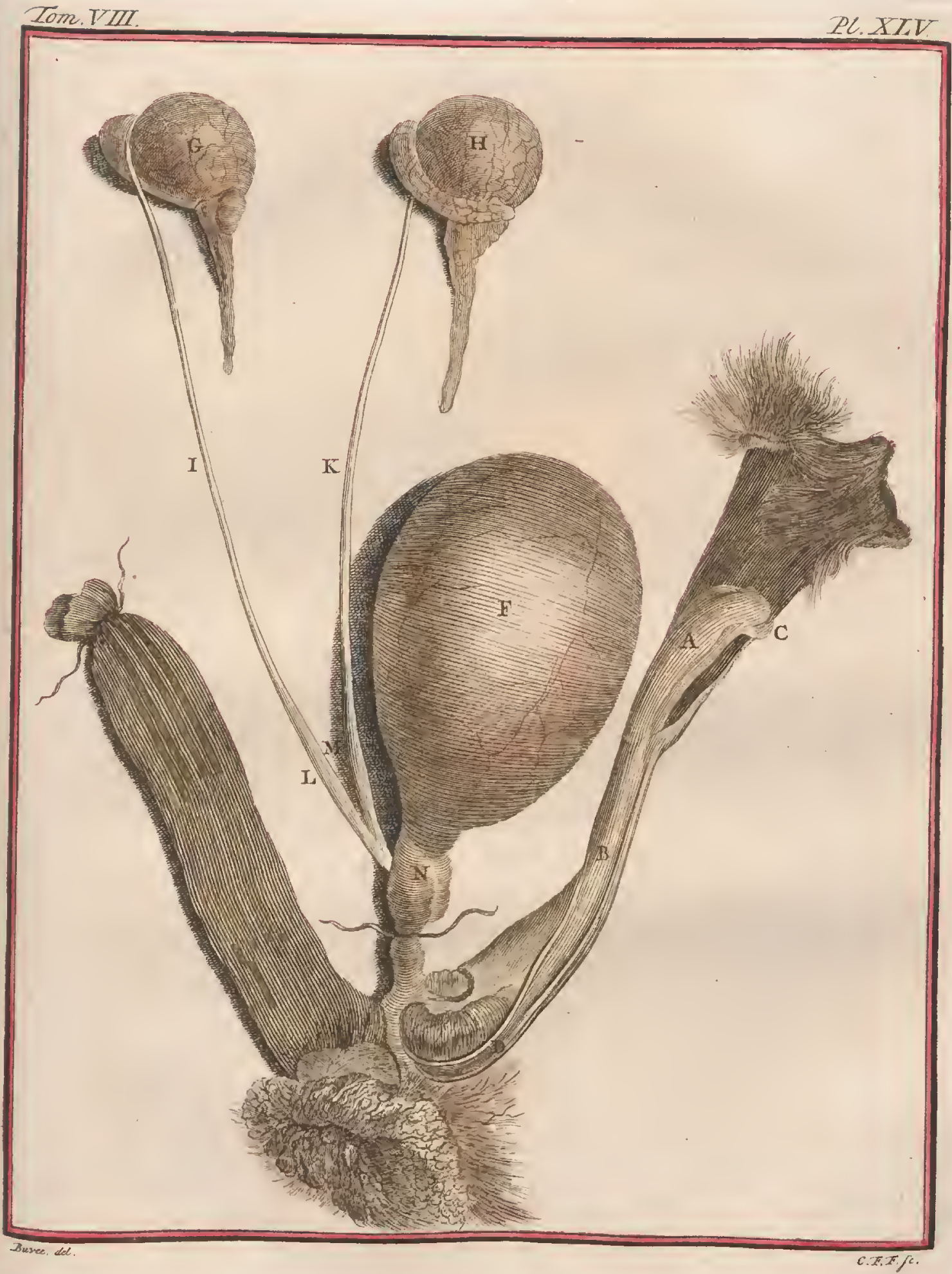



voorftanders te zyn; zyne zelfitandigheid was vaft en gepakt, wanneer men dezelve egter drukte, kivam 'er een dik en geelagtig vogt uit, gelyk aan het zaadvogt van de meefte dieren.

Lengte van de darmbuis van den portier tot aan den aars - . $\quad$ voeten, duimen, lyyen. Omtrek op de dikfte plaatfen

Omtrek op de dunfte platien

Groote omtrck van de maag

Kleine ontrek hoels, dien het regter gedeelre makt

Lengte van den nokdarm af tot op den grooten blindenzak ${ }^{*}$.

Omtrek van den folkdarm

Omtrek van den portier

'Lengte van de lever

Breedte
Haare grootite dilite

Lengte van het galblaasje

Deszelfs grootite middellyn

Lengte van de milt
Brcedte van het ondert eincle

Breedte van het bovenft einde

Dikte in ' $t$ midden

Dikte van het alvleefch

Lengte der nieren

Breedte

Dikte vangte het zenuwagtig middelpunt van de holle ader tot de pint

Breedte
Breedte van het vleezig gedcelte tuffchen het zenuwagtig middel-

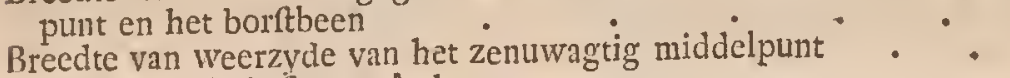

Omtrek van de balis van "t hart

Omtrek van de bafis van "t hart
Hoogte van de punt tot aan 't begin van de longflagader
Hoogte van de punt tot aan den longenzak

Middellyn van de groote flagader van buiten tot buiten gemeeten.

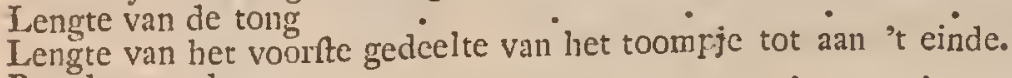

Breedte van de tong

Breedte der vooren van 't verhemelte

Hoogte van de randen

Lengte der voorherffenen

Breedte

Dikte

Lengte der agterherffenen

Breedte

Dikte tuffchen den aars en den balzak
Afitand te van den balzak
Afftand tuffchen den balzak en de opening van de voorhuid

Dikte
Aftand tuffchen den aars en den balzak
Hoogte van den balzak
Aftand tuffchen den balzak en de opening van de voorhuid

Dikte
Aftand tuffchen den aars en den balzak
Hoogte van den balzak
Aftand tuffchen den balzak en de opening van de voorhuid VIII. Deel.

०. 2. 9 .

०. 0.9 .

0. 10. 0.

0. 8.8

o. 1.5 .

o. I. 0.

o. I. 0 .

0. 4. 6 .

o. 5. 0 .

o. I. 2 .

o. 1. 6 .

o. 0.9 .

o. 3. 0 .

o. I. 2.

o. 0.6

o. 0.4 .

o. 0.5 .

o. I. 9

O. I. 2 .

O. I. 0 .

o. 0.10.

o. 2.3 .

o. I. 6 .

0. 2. 3.

5 . 5.

I. 10.

0. 32

0.9.

o. O. II.

o. 0.22 .

o. $0 . \quad \frac{2}{3}$.

o. 2. I.

○. I. 8 .

O. I. I.

o. 0.9 .

o. $x$. 5 .

o. 0.0

o. I. 6 .

o. 0.6 .

0. 4. 3 . 


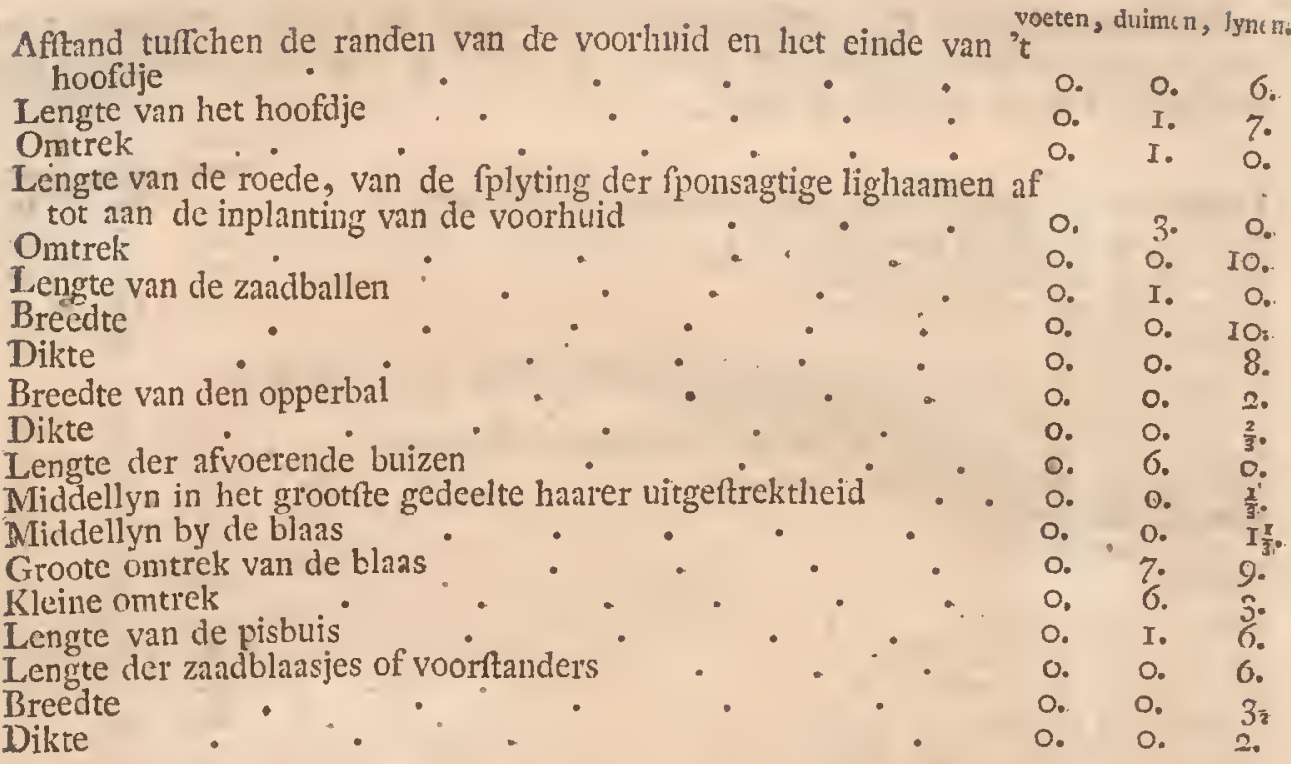

De kop van 't geraamte van den raton (Pl. YLVI) heeft, in de gedaante zyner voornaame deelen, veel overeenkomft met den kop van den das, maar de raton heeft verhevener voorhoofd, breeder en wat, korter fnuit, de oogputten zyn grooter, het agterft gedeelte van den kop dikker, en de verhevenheden van de kruin, en van 't agterhoofd, minder hoog. Daar was een lang beenagtig plaatje, dat uit het agterhoofdsbeen te voorfchyn kwam, en dat zig tufichen de herffenen en de agterherfenen indrong.

Daar zyn veertig tanden, twintig in yder kaakbeen, te weeten zes finytanden, twee hondstanden, en twaalf baktanden; deze tanden gelyken veel mar die van clen das, de latatite der bovenfte baktanden egter is niet de dikfte gelyk in dit dier, en de laatte onderfte byna gelyk met op een na de laatite.

Het doorngtig uitftekzel van het tweede nek-wervelbeen ftrekte zig meernaar agteren dan nar voren: de onderlte tak van het dwarfch uitlteekzel van het zesde wervelbeen wils breed en plat.

Daar waren vyftien rug-wervelbeenderen en vyftien ribben: het agterft gedeelte van het borftbeen verkankerd zynde, konde men het getal der waire ribben en der beenduren van lret borftbeen nict meer herkennen: de doornagtige uititeekzels der tięn eerfte sugwervelbeendere!n helden agterwards, die cier twee volgende wervelbeenderen waren regt, en eindelyk die der drie lantlte helden voormards: de cerfte ribben, éćne an weerzyde, geledigden zig met het voonft middelgedeclte van het eerft der bortbeenderen; de geleding der tweede zibben was tufichen het eerlte en het tweede beentjc van het bortbeen, die der derde ribben tufichen het tweede en het derde beentje, en dus vervolgens tot de agtfte ribben, die zig geledigden met het zevende beentje, wairvan flegts een gedeelte-overbleef: de latfe der valfche 


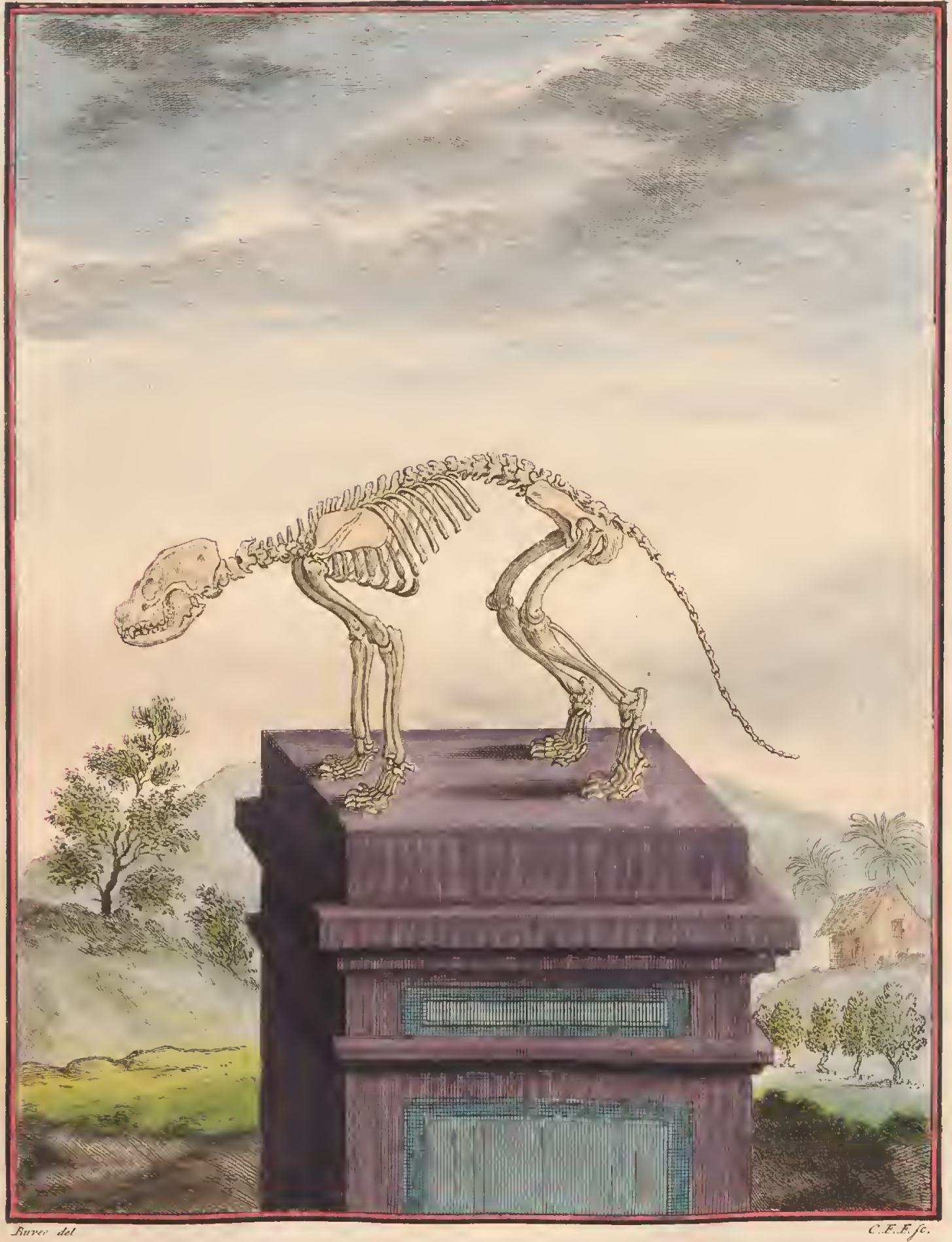


ribben van de regterzyde was veel korter dan de linker, want zy hadt unaar vyf lynen lengte.

De lenden-wervelbeenderen waren flegts ten getale van vyf, gelyk in den das, man: de doornagtige uitlteekzels hadden meer lengte; de bykomende waren voorwaards hellende, en des te langer naarmaate $\mathrm{zy}$ zig digter by het heiligbeen bevondent.

Dit been beftondt flegts uit drie valfche wervelheenderen: daar waren agttien in den ftart; het negende tiende en elfde waren de langfte: het voorfte gedcelte van het heupbecn hadt ten naftenby de gedaante van een lepel: de buitenzyde was zecr holrond.

Het fchouderblad, het armbecn, het been van den voorarm, het dijebeen, en de beenderen van den poot geleeken naar diezelfie deelen in het geraamte van de kat gezien.

Daar waren vier beenderen in de eerife ry van de voorhand, het ecrite was agter het tweede, het vierde agter het derde; het tweede was onder het ftralbeen, en het derde beneden de ellepyp: daar waren vyf beenderen in de tweede ry; het eerfte bevondt zig boven het eerfte been van de agterhand, het tweede gedeeltelyk boven het eerfte en gedeeltelyk boven het tiveede beentje van de agterhand; het derde en vierde been van de voorhand warell boven het tweede en derde been van de agterhand, en cindelyk het vyfde beentje van de voorhand gedecltelyk boven het vierde en gedeeltelyk boven het vyfde van de agterhand.

De voorvoct hadt zeven beenderen, gelyk by de meefte andere dieren; het. tweede wiggebeentje was het kleinfte van de drie: de beenderen van den agtervoet en der vingeren van de agterfte voeten waren grooter dan die van de agterhand en der vingeren vall de voorfte voeten; de nagels hadden, in hunne gedaante, veel overeenkomft met dic van de kat, zy waren van eene zwartagtige kleur.

Lengte van den kop vall het einde der neusbeenderen tot aan 't agterhoofd

De grootite breedte des hoofds

Lengte van het onderft kaakbeen van zyn voorfte einde tot aan den

agterften rand van het knokkelwyze uitfteekzel
Breedte van het onderft kaakbeen ter plaatfe van de hondstanden

Afftand tuffehen de knokkelwyze uitfteekzels
Dikte van het voorfte gedeelte des bovenften kaakbeens

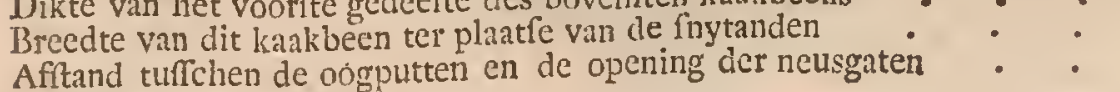

T.engte van deze opening

Breedte

Middellyn der oogputten

Lengte der langfte fnytanden buiten het been

Lengte der langfte, hondstanden buiten het been

Lengte der langfte baktanden buiten het been

Breedte

Dikte dengte twee vooriane deelen van het tongbeen

duimcn, lynen.

$$
\mathrm{Cc} 2
$$

4. 4.

3. $\frac{\pi}{2}$.

3. 8

I. I. I.

o. 2 .

o. $8 \frac{\pi}{2}$.

I. 0 .

0. 7t.

०. $9 \frac{2}{2}$.

o. $\quad 2 \frac{1}{2}$.

o. $5 \frac{5}{2}$.

o. $\therefore$

o. 4 .

o. 5.2 
Lengte der tweede beenderen

Lengte der derde beenderen

Lengte van het been van 't midden der vork

Lengte der takken van de vork

Lengte van den hals

Breedte van het gat des eerfen wervelbeens, van boven naar beneden.

Lengte van de eene zyde naar de andere

Breedte van het eerfte wervelbeen op de dwarfche uitftekzels genomen

Lengte der vyf laatite wervelbeenderen

Lengte van het gedeelte der wervelbeenskolom, die uit de rugtwervelbeenderen beftat

het langh is

Hoogte van dat des dertienden, dat het kortfe is $\dot{0}^{\circ} \cdot 0^{\circ}$

Jengte des lighanms van het laatfie wervelbeen, dat het langfte is ${ }^{\circ} .0^{\circ}$

Lengte der eerfte ribben

Afftand tufichen de eerfte ribben ter breedite plaats

Lengte der negende ribbe die de langfte is

Lengte van de laatfe der valfche ribben

Breedte van de breedife rib

Hoogte van het langfte doornagtig uittteekzeil der lenden-wervelbeen-

deren, zynde dat van op een na het laatite
Lengte van het langfte bykomend uitfteekzel, zynde dat van het laatite

wervelbeen
Lengte des lighaams van op een na het laatfte wervelbeen, dat het. langte is

Lengte van het heiligbeen

Breedte van het vonrfte gedeelte

Breedte van het agterft gedeelte.

Lengte der langfte wervelbeenderen van den itaurt

Breedte van het voorte gedeelte van het heupbeen
Hoogte van het been van het middel der knokkelwyze holligheid.
Middellyn-van die holte

Lengte der eyronde gaten-

Breedte

Breedte van het bekker

Hoogte

Lengte van het fchouderblad

Breedte aan de breedifte plaats

Breedte aan de fmalite plaats

Hoogte van den doorn aan de verhevenfte plaats.
Lengte van den fchoudel

Omtrek aan de lileinfte plats

- Middellyn van het hoofd

Breedte van het onderlt gedeclte

Lengte van de cllepyp

Lengte van den elleboogsknokkel

Eengte van het ftraalbeen

Lengte van het heupbeen

Aiddellyn van deszelfs hoofd

Omtrek van 't midden des beens. 
Breedte van het onderft einde Lengte van de kniefchyven Breedte

Dikte

Lengte van het fcheenbeen Breedte van deszelfs hoofd Omtrek van 't midden des beens Breedte van het onderit einde Lengte van het kuitbeen Omtrek aan de dunfte plaatien Breedte aan het boveneinde Breedte aan het ondereinde. Hoogte van de voorhand Lengte van het hielbeen

Hoogte van het eerfte wiggebeen in fchuitbeen te famengenomen Lengte van het eerfte been der agterhand, dat het kortft is Lengte van het derde been, dat het langft is Lengte van het eerfte been des agtervoets, dat het kortft is Lengte van het vierde been, dat het langft is

Lengte van den eerften regel des middelften vi

Lengte van den tweeden regel

Lengte van den derden

Lengte van den eerften regel van den duim

Lengte van den tweeden regel

Lengte van den cerften regel des vierden vingers der agterfte voeten. Lengte van den tweeden regel

Lengte van den derden

Lengte van den eerften regel van den duim

Lengte van den tweeden regel duinen, lyneu.

\begin{tabular}{|c|c|}
\hline 0. & \\
\hline O. & \\
\hline O. & \\
\hline & \\
\hline o. & \\
\hline I. & \\
\hline o. & \\
\hline $\begin{array}{l}4^{\circ} \\
\text { o. }\end{array}$ & \\
\hline o. & \\
\hline o. & \\
\hline o. & \\
\hline $\begin{array}{l}\text { J.. } \\
\text { o. }\end{array}$ & \\
\hline o. & \\
\hline I. & \\
\hline I. & \\
\hline I. & \\
\hline o. & \\
\hline O. & \\
\hline o. & \\
\hline O. & \\
\hline $\begin{array}{l}\text { O. } \\
\text { O. }\end{array}$ & \\
\hline 0 . & \\
\hline o. & \\
\hline
\end{tabular}

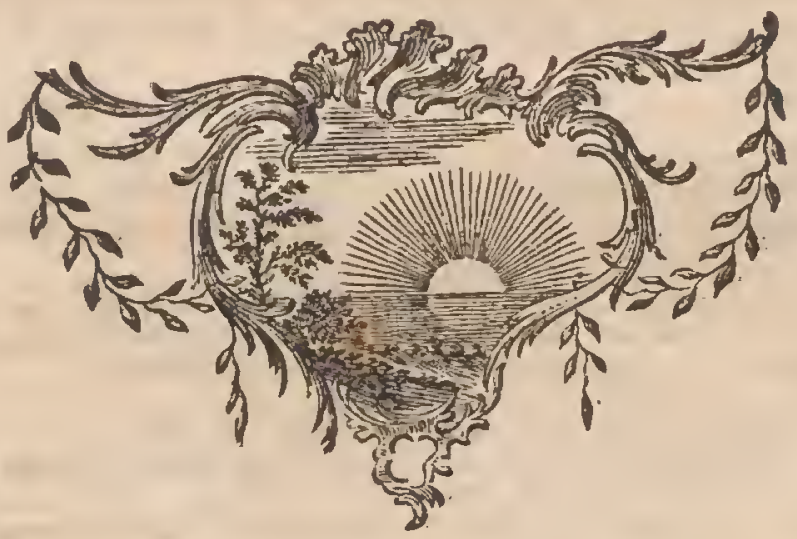


D E C O A T I O F Q U A S J E *.

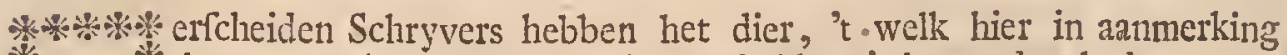
* $V$ * komt, coati-mondi genaamd; wy hebben 't leevend gehad, en wy * * hebben, na het met den coati door THever aangeweezen, en door

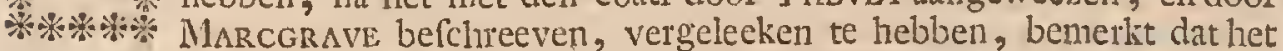
dat zelfde dier is, it welk $z y$ enkel coati gentamd hebben, en dair is alle waarfchynlykheid der wereld, dat de coati-mondi geen dier van eene andere foort, mar eene enkele verlcheid'enheid van deze, is; want MARcGRAVE, na de befchryving van den conti gegeeven te hebben, zegt uitdrukkelyk, dat "er andere coati's zyn, die zwartagrig bruin van kleur vallen, en welken men in brafilién coati-mondi noemt om hen van anderen te onderfcheiden; hy erkent derhalven geen ander verfchil tuffchen den coati en den coati-mondi, dan dạt van de kleur des hairs, en derhalven moet men die twee dieren niet als twee verfchillende foorten, mar alleenlyk als verfcheidenheden in dezclfce foort, befchouwen.

De coati verfchilt ondertuffchen veel van den raton, welken wy in 't voorgaande artikel befchreeven hebben; hy is kleiner, langer van lighaan en hals; het hoofd is ook langer, zo wel als de neus, waarvan hetboventt kaakbeen in een fcort van beweegbaaren varkens-fnuit uitloopr, die een duim of anderhalf duim buiten het onderft kaakbeen nitfteekt: die varkens-fnuit, opwaards geboogen, by de groote lengte der kaakbeenen gevoegd, doet den bek zig vertoonen als krom en naar boven ftaninde: de coati heeft ook veel kleiner oogen dan de raton; gelyk ook korter opan, korter, ruwer, en minder gekamd of geftreeken, hair; de pooten korter, de voeten langer en meer op de hiel ruftende; hy hadt gelyk, de raton, een geringden ftaart $(a)$ en vyf vingers aan alle de voeten.

Zommigen derken dat het das-varken wel de coati zou kumnen zy̆n, en men heeft den Taxus fuillus, waarvan Aldrovandus de figuur geeft, tot dit dier gebragt (b); maar zo men bedenkt, dat het das-zwyin, daar de jagers van fpreeken, onderfteld wordt in Frankryk, en zelfs in de koudite geweften van

* De Coati heet cok Cuati. Singrelarites de la France antarcique, par ANare' Thevet, Paris 155\%. pag. 95, 96. In het Nederduirfel hebben de Natuuronderzoekers bein den naam van Quasje gegeeven, die eene verandering van dien van Cuati is.

Coati. Marcgrav. Hift. Nat. Brafil. pag. 228.

Coati-stondi. Hiftoire de l'Academie, Tom, III. Part. II. pag. 17.

Vulpes minor, roftro fuperiori longiufculo, cauda anmulatin ex nigro EO rufo variegatiz. BARRE38, Hiftr de la France Equinod. pag. 167.

Urjus najo produdto $\mathcal{O}^{\circ}$ mobili, cauda annulatim variegatd. Le Coati-mondi d quete annelée.

Brisson Regn. Animal. pag. 203.

(a) Ditar zyn ook Coatis, welker ffart ecnkleurig is, maar gelyk $2 y$ van de anderen niet dan door dit eenigit kenmerk verfchillen, zo komt ons deze verfcheidenheid niet genoeg voor om 'cr twee foorten van te makken, en wy neemen het llegts voor eene verfcheiden. heid van dezelfde roort.

(b) Bris:oN, Regn. Animal. pag. 263. 


\section{$\begin{array}{llllllllllllllll}V & A & N & D & E & N & C & O & A & T & I\end{array}$}

ons Europa, thuis te hooren, dat integendeel de conti niet dan in de Zuidelyke ftreeken van de nieuwe wereld gevonden wordt, zal men dat denkbeeld., 't welk daarenboven geheel geen grond heeft, ligtelyk verwerpen (c); want de figuur, door Aldorovandus gegeeven, is niet anders dan die van een das, daar men een varkens-fnuit an gemaakt heeft: dic Schryver zegt niet, dat hy dit dier mar 't leeven getekend heeft, cn hy vocgt "cr geene befchryving by: de zeer lange neus en de allezins beweeglyke fnut zyn genoeg om de coati van alle andere dieren te doen onderfcheiden; hy kan zig, even als de beer, zeer gemaklyk overeind houden op zyne agterfte pooten, die voor een groot gedeelte op de hielen dragen, en dezen hebben zelfs groote eeltagtigheden aan de einden, die haar tot naar buiten fchynen te verlengen, en de ruft der voeten te vergrooten.

De coati is onderhevig om zyn ftart te eeten, zo dezelve niet is verminkt, is hy langer dan deszelfs gehecl lighaam; hy houdt dien gemeenlyk om hoog, buigt hem op allerhande wyzen, en draait hem gemaklyk ginds en weêr : die zonderlinge fmaak van den ftaart op te eeten, die tegen de natuur fchynt aan te loopen, is an den coati egter niet byzonder eigen: de aapen, de makis, en eenige andere dieren met lange ftarten, knabbelen het einde van hunnen ftaart, eeten 'er het vleefch en de wervelbeenderen af, en maaken denzelven allengs een vierde, of een derde, gedeelte korter: men wordt door deze byzonderheid tot eene algemeene gevolgtrekking geleid, te, weeten, dat in die zeer verlengde deelen des lighaams, welker niteinden bygevolg zeer verre van de zintuigen, en van het middelpunt des gevoels af zyn, die zelfde gewaarwording zwak, en des te zwakker is, narmate het deel dunner zy; want zo het eind van den thart dezer dieren een zeer gevoelig gedeelte ware, zou de aandoening van pyn fterker zyn dan die van dezen trek, en zy zouden hunnen ftaart even zorgvuldig als de andere deelen van hun lighaan bewaren.

Voor het overige is de coati cen roofdier, dat zig met vleefch en bloed vnedt, even als de vos eil de huis-marter, dat de kleine dieren en het gevogelte om hals brengt (d), de eyers opeet, hunne neften befpiet en overvalt (e); en het is waarfchynlyk wegens deze overeenkomft van imbortt, meer dan wegens de gelyliheid met den huis - marter, dat men den coati als cene fourt van kleinen vos $(f)$, befchouwd heeft $(g)$.

(c) Zie het geen over het das-varken gezcgd is in hec VII Deel van dit Werk; onder het artiticl van den das, blz. 67

(d) Martgrav. Mijz. Brafil. pag. 223.

(e) Singularites de la France Autartique, par Thevet, pag. 96.

(f) Vulpes minor, Éc. BARRERE Hijt. Nat. de la France Equinotiale.

(g) Ik zal by dic berigt van my zelven, nog eenig berigt van eene andere hand hyvoegen: men vindt in het zevende Deel van de Zweedfche Kouinglylie Akademie det IVtetenfciappen eene memorie van den Hr. Liwwaus over de coati-mondi; is ondeel bet wircrekzel, bet welk de Schryver van de Bibliobeque Ras fonnee van dio Memorie gegeeven heed, re moeren mededeelen, zonder tvenwol voor de byzonderheden, die daar in vorgrgedraagen worden, te
willen inftaan: dus.luidt dac uittrelszel.

", De Hr. Linnaius deelt in eene Memorie de Naturlyke Hiftorie van den conti-mondi me. "de". Dit dier wordt eveneens in Zuid-en in Noord-Amerika gevenden : het gely.tit nat " den beer in de lengte zyner agterite beenen, zyn hellenden kop, zya dik hair, en zyne 


\section{DE N A T UURL Y K E H I T ORIE,}

Dewyl dit onderftande nittrekzel zeer gebrekkig van taal, en nog gebrekkiger van zaaken is, zal ik hier een omftandiger berigt uit de Verhandelingen der Koninglyke Zweedfche Akadenie der Weetenfcliappen, VII Deel, voor 't jar 1746 , byvoegen.

"De coati-mondi van den Hr. LinNeus was ongemeen fcherp van reuk, " doch zwak van gehoor en gezigt; als "er icmand by dit dier kwam, die , amandelen of rozynen in den zak hadt, wift hetzelve die aanitonds te vin" den, en ze dien perfoon te ontneemen: het at meeft alles, wat voorkwam, "brood, vleefcl, bry, foupc, zelis kraakbeentjes en ander gebeente, wel"ke het als vleefch kauwde; doch banket, fuiker, eycren, en allerhande " vrugten waren zyne lekkerny; integendeel hadt het geen fmak in iets daar ", azyn in ware, verwerpende ook zuurkool en vilch, die het, rauw of ge"kookt, niet proeven wilde; het dronk weinig, en flurpte niet met de tong ", maar met den mond, zodat het, indien het vat klcin ware, en het den ", fnoet daar nict waterpas in leggen konde, niet in that was, om daar uit te "drinken, dewyl de fuitfilc neus alsdan in "t water dook, en het drinken verhinderde: allerleie foorten van pap of bry fchepte het met de voorpooten, dic het hol makte als een lepel: het hadt veel vermak om alles, wat het te eeten $\mathrm{kreeg}$, als met lianden in water te doopen, terwyl het op de agterpooteir zat, en het hieldt de ljys in 't witer neer; ja wanneer jets op den bodem lag, liaalde het zulks zeer vanrdig, tot de kleinfte brokjes toe, der hetaltede gatarne zyn voedzel, rolde het in de handen om, ,'s nilgts tot den volgenden middag, 't welk te verwonderen is, alzo dit , overecnkont met den tyd, dien de mat duurt in zyn geboorteland. Des "namiddags ging dit dier uit zyn hok en lag zig in de zon neder, vermaa. "kende \%ig, wanneer men het iets gaf dat rond was, met het in de handen " om te rollen; het lag gaarne op den buik, met uitgeftrekte pooten, en

ponten; mar het is ilcin en gemeenzaam, en zyn fasrt is zeer lang, en met verfcheiden " kleurell geftreept of ge.nengd: de Kroonprins van Zwceden hadt een dezer dieren aan den "Hr. l.ınsweus vereerd, die hut vry langen tyd in zyn huis on Jerbouden heeft ten ko?te der " zoctigheden, welle het kon bekomen, en zomtyds van die van zyn baffecour, alwaar de coa. "ti-mondi, in weerwil van 't regt van herbergzambeid, koppen mct een llag zyner tanden " ti-monti, en 't bloed ui!nurpte. Hot dier is opmerkelyk door zyne uiterfe bardnelkigheid "Wegnam, en to byn zin te willen doen; niettegenftaande zyne lsleiuheid verdedigde her zig ", met cene ongemeene terkte, wannecr men hat tegr, zynen dank deedt gaan, en het haak", met cene ongemeere tien geenen, welker zakken hy gemcenzaam ging afoopen, en in " beflag nee nen alles wit hy daar vondt, dat he:n leek; die hardnekkigheid heeft haar hulp. ", midjel; de conti is zeer bing voor varkens-hair; de minfte borftel deedt bem loslaaten; een " watho d beec bem op zekeren dag, toen hy ir een nabumigen tuin gevlugt was, dood, en " de Hr. Linssus geeft "er de outlejing van. Zyne wyze van Ieeven was zonderling; by niep " van miditertagt lot middag, witkte het overige van den dag, en wandelds geregeld van "zes uuren des avonds tot middernagt; welk weder het ook wezen mogt: dit is waarfchynlyk " de tyd, welken de Natuur voor deze foort van dieren in hun Va Jerland gefchikt heeft, om "in humbe bchoeften te voorzicn, om jagt op de rogelen te maaken, en derzelver eyeren

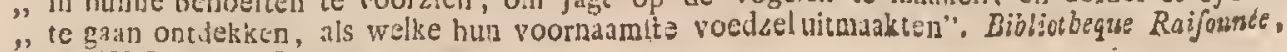
Tome XLI, partie I. pag. 25. 
, niet op zyde; maar in koud weêr ftak het den kop onder de borft, haal" de de pooten by elkander, en kronde den rug naar boven.

"Dit dier zet, onder ' $t$ loopen, de hielen op den grond, met een geboogen rug en den kop nederwaards, kunnende ook een groot end wegs op "de agterpooten alleen gaan gelyk een beer, "t welk het voormamlyk deedt, "Wanneer het icts aangenaams rook. Het klom de menfchen by de beenen " op, en doorzogt zeer nauwkeurig alle de zakken, neemende daar uit, "waar het beliaagen in hadt, ' $t$ welk men niet beletten kon of 't gaf zyn on"genoegen, al knorrende en bytende, te kennen, doende anders niemand leed; "let klom, gelyk de katten, by boomen, paalen, fchuttingen, en alles, op, " doch in ' $t$ afklimmen ging het altoos agter uit: in zyn geboorteland is leet "zulks gewoon, doende dit om de vogelneften op te zoeken, daar het de , eijeren vithaalt, waar in het, $\mathrm{nn}$ hen ecnige maalen in de handen om"gerold te hebben, eindelyk een gat maakte, en dezelve vervolgens uit"zoog.

"Wanneer' de hoenderen het te ma kwamen, greep het dic aan, beet ze den kop af, en zoog 'er her bloed uir, ontziende zelfs geen panwen: het "kon evenwel verdraagen, dat kinderen en honden met hem fpeelden, doch ", niet dat men hem droeg of van den grond opligtte: ook was het dier zeer "eigenzinnig, willende, wanneer aan het touw, daar het aan vaft was, ge" trokken werdt, niet voortgaan, en wanneer men het opneemen wilde, "2 weerde het zig met de tanden en klauwen, knorrende als een beer; men " wift geen raad om het naar zynen zin te dwingen, of iets dat het geroofd " hadt, 't zy leevende of onbezield, te ontneemen, tot dat men eindelyk he" vondt, dat het prikken met varkensborftels hem onverdraagelyk was: dit "werdt gevallig ontdekt, terwyl men bezig was met eene kamer te ftoffen, " en federt hieldt men hem, als hy aan de rokzakken of aan eene lade "kwam, den ftoffer voor den neus; waarop het dier aanitonds, als of hem "se vyand naderde, te rug week".

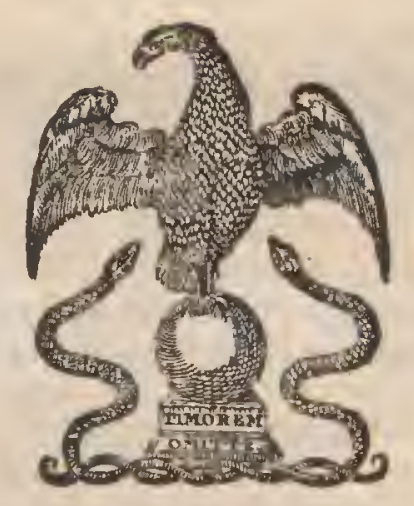

VIII. Deel.

Dd 

Seenen uitftrekte: de lengte en de gedaante van den neus zouden genoeg zyll on den coati van elk ander dier te onderfcheiden; hy hadt eene foort van thuit, wiens bovenft gedeelte cen duim lang was, en op zulk cene wyze gerigt, dat het met het neusbeen cen ftompen hoek maakte, die zig aan 't einde van het bovenft kaakbeen bevondt; de onderzyde van den finuit was flegts negen lynen lang, zy wierdt door de bovenlip geformeerd, en hadt eene evenwydige rigting met de bovenzyde; de voorfte zyde voegde zig met een fcherpen hock by de bovenzyde, en met een ftompen hoek ann de onderzyde; de openingen der neusgaten waren in de voorlte zyde van den fnuit geplatett, en daar was op clk der zydelingfche randen eene diepe kloof, die een gedeelte van de opening van clk der ncusgaten makkte; indien men onderftelt, dat deze neus, in de gedaante van een varkens-fnuit verlengd, wergenomen werde, zou de bek evenwel nog lang en fpigtig zyn gebleeven, gelyk die van dell vos; de coati hadt kleine oogen, ronde en zeer korte ooren; het onderft gedeelte van den agterften rand was dubbeld gelyk in de huis-marter, de bofch-marter, en verfcheiden andere dieren.

De ftant was dik en lang, fchoon hy afgeftompt was geweeft; de vier voeten geleeken veel naar die van den beer, inzonderheid de agterfte, die met hunne geheele uirgeftrektheid tot de hiel op de aarde droegen; daar waren vyf vingers aan yderen voet, en de nagels waren fterk, en van de kleur van hoorn.

Het hair van dit dier hadt verfchillende zweemzcls van bruin, zwartagtig, grauw, geelagtig, en rosagtig, dat van het neusbeen was kort en zwartagtig, zommige hairen hadden eene grautve of rosagtige kleur; die der ooren waren ook zeer kort en bruin; daar was cene grauw-witagtige vlak op eenigen afftand van het oog; de kruin vain den kop, het bovenft van den hals, de rug, het kruis, en het bovenft gedeelte van de zyden des lighaams, waren met ros en zwart gemengd, ondat yder hair eene roffe, of rosagtige, kleur hadt over het grootfte deel zyner lengte van den wortel af, en de punt zwart was: de rand van de bovenlip, het onderit kaakbeen, de keel, het onderft en de zyden van den hals, de bort, de buik, de omtrek van den aars, de oxels, de liezen, en het binnen-gedeclte der vier pooten waren rosagtig, geclagrig, of flegts van eetne grauve kleur, ligtelyk met geel op zommige plat \%en genengd: de buitenzyle van den arm en van den voorarm hadt eene grautw-afchgraulve kleur met bruin gemengd; de buitenzyde van de dij en van den poot badt ten mattenby de zelfde klenren, en daarenboven een zwveemzel van geelagtig: de vier voeten waren van eene gemengde zwartagtige, grauwe en rosagtige kleur: daar was maar weinig hair op den ftaart, 


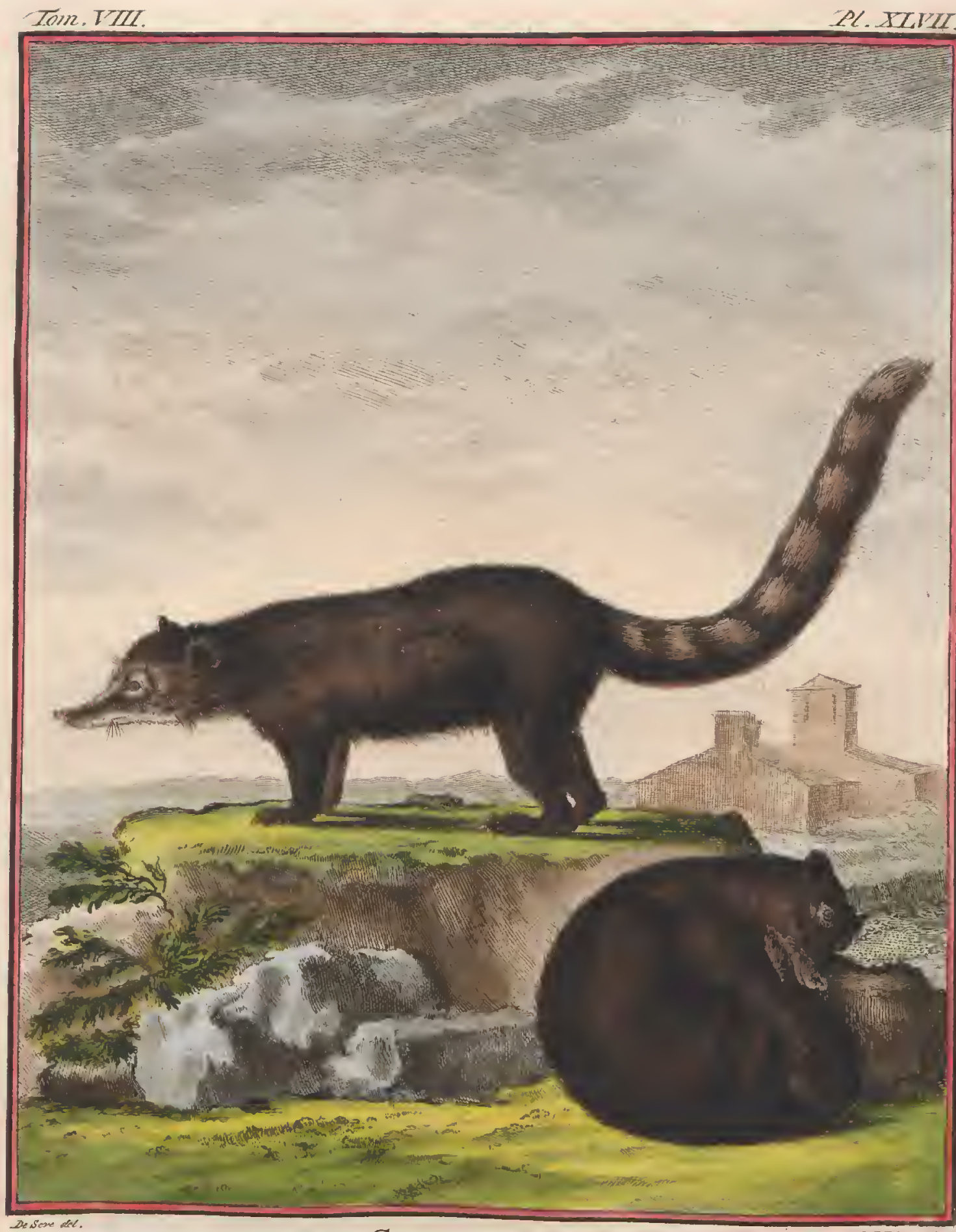

IF COATI NOIRATRE. 


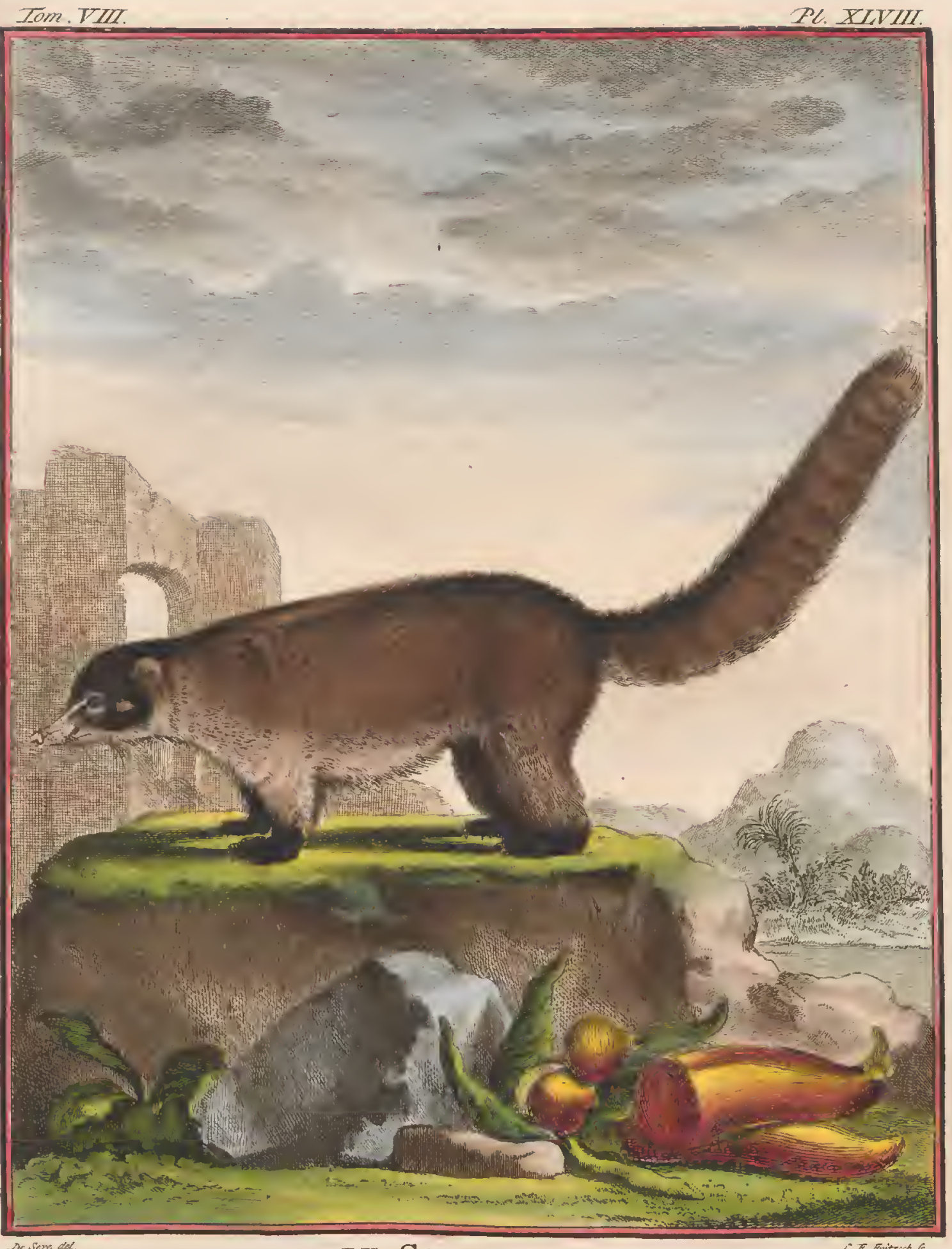

De Sere det?

LE CQATI BRUN. 
men zag daar evenwel fmalle ringen van eene gemengde kleur van grauw en geelagtig en zeer breede ringen van eene zwartagtige kleur; de langite hairen waren op den rug, en konden omtrent een duim in de lengte haalen.

Dit dier rolt zig in malkander om te ruften en zig te verwarmen, in de houding zo als het zelve oncter ann de XLVII Plaat vertoond wordt.

Wy hebben een anderen coati gezien $(P l . X L V I I I)$, die veel grooter was en omtrent twee vocten lengte hadt van het einde van den bek tot aan bet begin van den itaart; het voorhoofd, de flapen des hoofds, de ruimte die zig uitftrekt van de oogen tot ain den hoek van den mond, het onderft gedeelte van den voorarm en de vocten waren zwart of zwartagrig, en daar was een witte vlak op eenigen afftand van den agterften hoek des oogs; het cinde van den bek, de lippen, en de keel waren witagtig; al het overige des lighaams hadt eene gemengde kleur van bruin en val, die donker was op den knp en de buitenfte. zyde der dijen, en helder op de zyden van den hals, en op de buitenfte zyde der armen; die verfchillende zweemzcls van bruin en val maakten op den ftaart ringen, die zig wcinig vertoonden en fmal waren: het hair yan dit dicr was ruiv, en langer dan dat van den eerften coati, waar door zyne ooren zig in de figuur korter vertoonen: de bek was minder verlengd, kleiner an het einde, en in een regte lyn gerigt.

Lengte des geheelen lighaams van het einde van den bek tot aan ten, duimen, Igner. den ars in een regte lyn gemeeten

Hoogte van het voorftel

Hoogte van het agternel

Lengte van den kop van het einde van den neus tot aan'tagterhoofd.

Ontrek van "t einde van den bek

Omtrek van den bek aan liet einde van het onderft kaakbeen ge-

Omtrek van den bek onder de oogen gemeeten : . . $\quad$ o.

Omtrek van de opening des monds . . . : 0 .

Aftand tufichen de twee neusguten

Afitand tuffchen het einde van den bek en den voorften hoek van 't oog

Afitand cuffchen den arterften hoek en "t oor" ${ }^{\circ}$

Lengte van 't 0 og van den eenen hoek tot den anderen' ${ }^{\circ}$.

Opening van 't oog

Afitand tuffehen de voorfte hocken der oogen volgens de kromming van het neusbeen genieeten

Dezelfde afftard in cene regte lyn gemeeten

Omtrek van den kop tufficlien de ougen en de ooren gemeeten.

Lengte der ooren

Breedte van de bafis op de buiten kromming gemeeten : .

Afitand tufrchen de buide ooren om laag gemeeten.$\quad \cdots$

Lengte van den hals

Omtrek van den hals

Omtrek des lighaans agter de voorfte pooten $\cdot{ }^{\circ} \cdot 0_{0}$

Dezelfde omtrek an de dikfte plaats

Dezelfde omtrek voor de agterite pooten

Lengte van den ftomp des itarirts

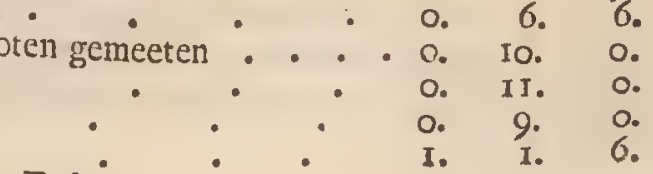

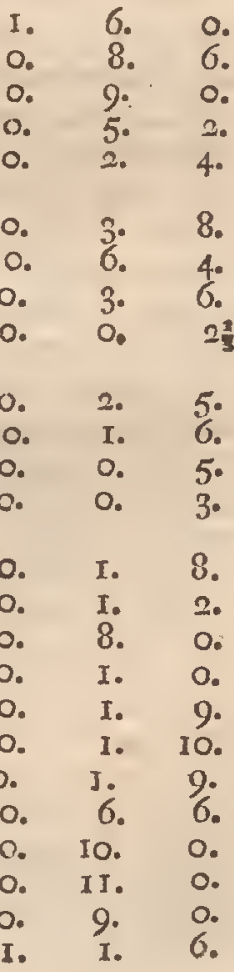




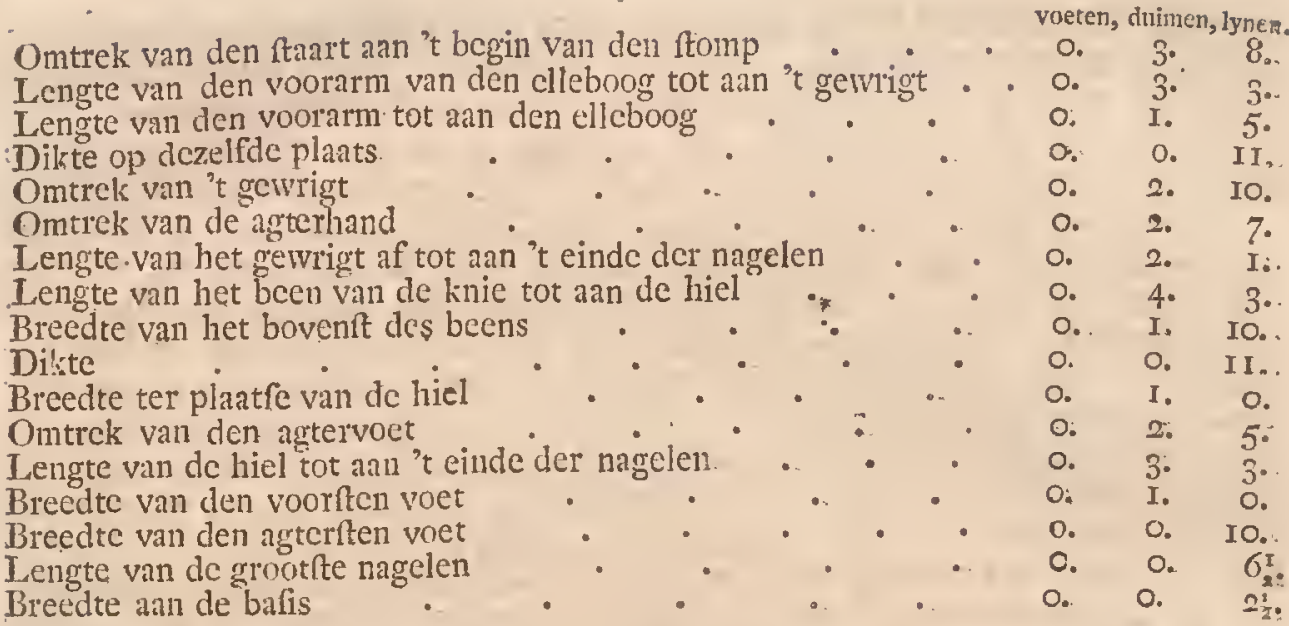

De eerfte coati daar wy gewag van gemakt hebben, en waar op de afmee: tingen, in de voorgaande tafel gemeld, genomen zyn, heeft ook ten anderwerpe gediend voor de befchryving der inwendige deelen; hy was twee maanden in brandewyn beward geweelt.

Daar waren zes nammen, drie aan weerzyde; die van do linkerzyde waren alle op:den buik; de derde-van de regterzyde was geplaatit op de kraakbeenderen der valfche ribben.

Daar was geen blindedarm: de twanlfvingerigedarm ftrekte zig van agteren verder dan de nier uit, hy vouwde zig binnenwards en verlengde zig naar voren om zig aan den nugterendarm te voegen; de draaijingen van het overige der darmbuis waren eerlt in de muelftreek en in de zyden; vervolgens in den-eigenlyk gezegden onderbuik en in de darmbeentreeken; eindelyk. ftrekte zig die buis voorwands en liep agter de mang voor dat $z y$ den legtendarm formeerde.

De maag was dik nar evenredigheid harer lengte; hot regter gedeclte ftrekte zig weinig verder uit dan den hoek daar door gemaakt, en de groote blindezalk hadt weinig diepte: de middellyn der darmen was ten naaftenby dezalfule in de geheele uitgeftrektleid der dambuis, uitgezonderd ter plaatfe vain den regtendarm, die veel dikker was dan het overige; de vliezen van cle maag: cn van de darmen waren heel dik en fterk.

De lever ftrekte zig weining ter linkerzyde nit; zy beftondt uit vyf kwabben, die in 't midden was door twee fplytingen in drie deelen verdeeld; de diaggband ging in de eene, en her galblansje, was in de andere, fplitfing; daar was mar ééne kwab aan de linkerzyde, en zy was ten naaftenby zo groot als de middelfte; de drie andere bevonden zig an de regterzyde, de onderfte was de grootfte van de drie, die van 't midden omvartede de nier, en de derde was de kleinfte van allen; zy zalt vaft aan den wortel van de lever, by de. buvenite opening van de maag; hat galblaasje was groot en hadt de gedante. van een peer. 
De milt was verlengd en hadt drie zyden; haar onderft gedeelte was breeder dan het bovenft.

Het alvlcefch is my voorgekonien zecl lang te zyn; het ftrckte zig agter de maag van den twaalfvingerigendarm tot aan de nilt nit.

De nieren hadden weinig diepte, zy waren dik; daar waren geen tepeltjes in 't bekken; de regtemier ftak de helft haarer lengte meer voor uit dan de linker.

De linkcr-long fcheen flegts uit écnc kwabbe te beftan, en de regter uit twree; ééne groote en ééne kleine; dic laatfte wis geplaatit aan den wortel van de groote by de bafis van 't hart; maar daar waren in de groote kwab twee diepe uitfinydingen, die, zo zy tot den wortel van de long waren doorgegaan, dezclve verdecld zouden hebben in drie kwabben, beantwoordende an die, welke als aangereegen zyn in de regter long van de meefte andere viervoetige dieren: de linker long hadt ook een groote vitfnyding in 't midden, die dezclve byna in twee kwabben verdeelde.

Het hart was ter linkerzyde gerigt; het hadt, om zo te fpreeken, twe punten, want de grond van elke holligheid van ' $t$ hart maakte "er een.

Het einde van de tong was dun en gerond; daur was eene overlangfche voor' in 't milden van het voorfte gedeelte, die met kleine tepeltjes bedekt en met witte korrels bezaaid was; de tepeltjes van het agterfte gedeelte vertoonden zig zeer duidelyk en waren agterwaards gerigt; men zag daar van weer. zyde vyf of zes kelkwyze klieren, geichikt op cen ry welker rigting fchuinfch. was van buiten naar binnen en van voren naar agteren.

De ftrotklap was groot en verlengd; daar waren in het verhemelte negen breede dwarfche vooren, de randen der cerfte makten een hoek voorwaards over "t midden humner lengte, de rigting van de randen der andere vooren was zeer onregelmaatig.

De voorherffenen en de agterherfenen hadden groeven en tandingen gelyk in de meefte andere viervoetige dicren.

De klink maakte eene divarfche kloove; de kittelaar was zcer merkbaar en op.'t midden der onderite lip van de klink gepluatit: het hoofdje eindigde miet een fchyf, die met een rand over deszelfs gcheclen omtrek uititak; daar waren op de wanden van de fchede knobbeltjes, die, ter plaatic van de opening der pisbuis, een ring formeerden; de hoornen van de lyfmoeder waren in cene regte lyn gerigt; de zaadballen hadden eene cyronde gedante.

voeten, duimın, Iynen,

Lengte van de darmbuis van den portier tot aan den aars . - 9. 9. 0.0

Omtick op de dikfte plaatfen

Omtrek op de dunite plats

Groote omtrek van de mang

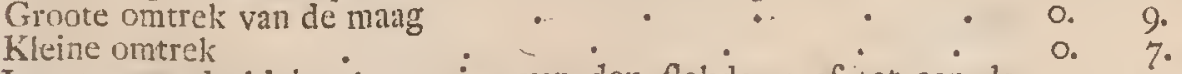

Lengte van de kleine kromming van den flokdarm af tot aan den hoek, dien het regter deel makt denzak

Ontrek van den flokdarm

Ontrek van den porticr:

Lengtc val1 de lever:
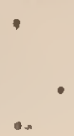

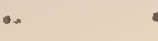

Dd 3
․ I. 3 .

o. o. $\%$

o. 0.5.

c o. 5 . 


\section{4 \\ DE N A T UUREYKE HISTORIE,}

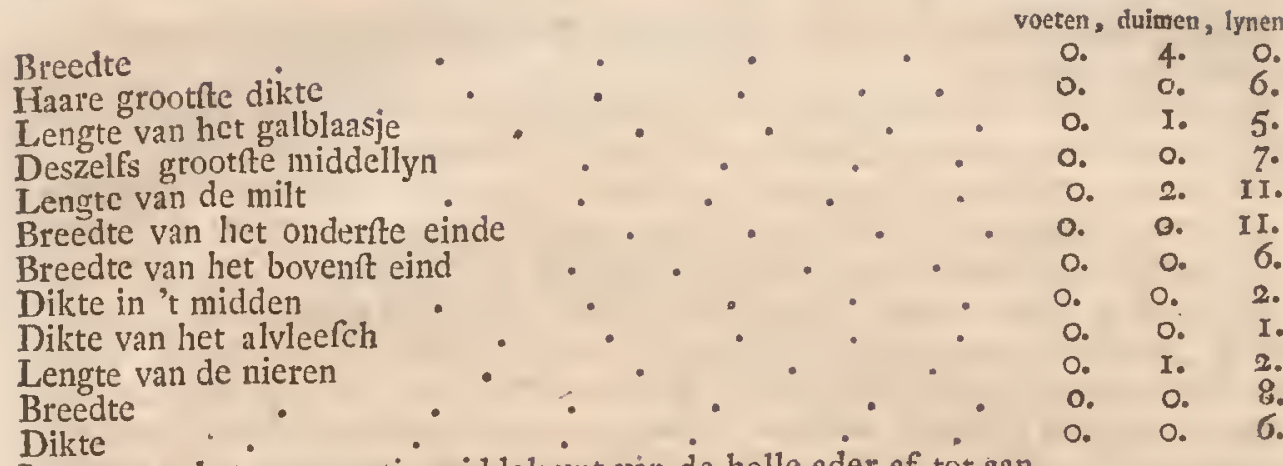

Lengte van het zenuwagtig middelpunt vản de holle ader af tot aan de punt.

Breedte

Breedte van het vleezig gedeelte tuffchen het zenuwagtig middelpunt en het boritbeen

Breedte van ydere zyde van het zenuwagtig middelpunt : .

Omtrek van de bafis van "t hart

Hoogte van de punt af tot an 't begin van de longflagader . . . 0 .

o. $\quad$ o. 9 .

Hoogte van de punt af tot aan den longezak

Middellyn van de groote flagader van buiten tot buiten gemeeten.

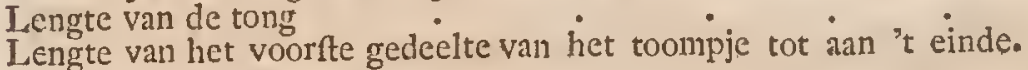

Breed te van de tong

Lengte der voorherffenen

Breedte

Dikte

Lengte der agterherffenen

Breedte

Dikte

Afitand tuffehen den aars en de klink

Lengte van de klink

Lengte van de fchede

Omtrek

Groote omtrek van de blaas

Kleine ontrek

Lengte van de pisbuis

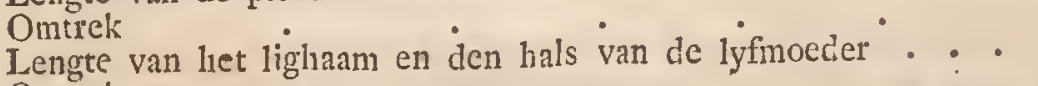

Omtrek

Lengte der hoornen van de lyfmoeder

Omtrek in eene regte lyn tuffchen de zaadbalien en het eind van den

Afitand in eene regte lyn tufchende 0

Lengte van de kromme lyn, die de trompet doorloopt . . . c

Lengte der zaadballen

Breedte

Dikte 


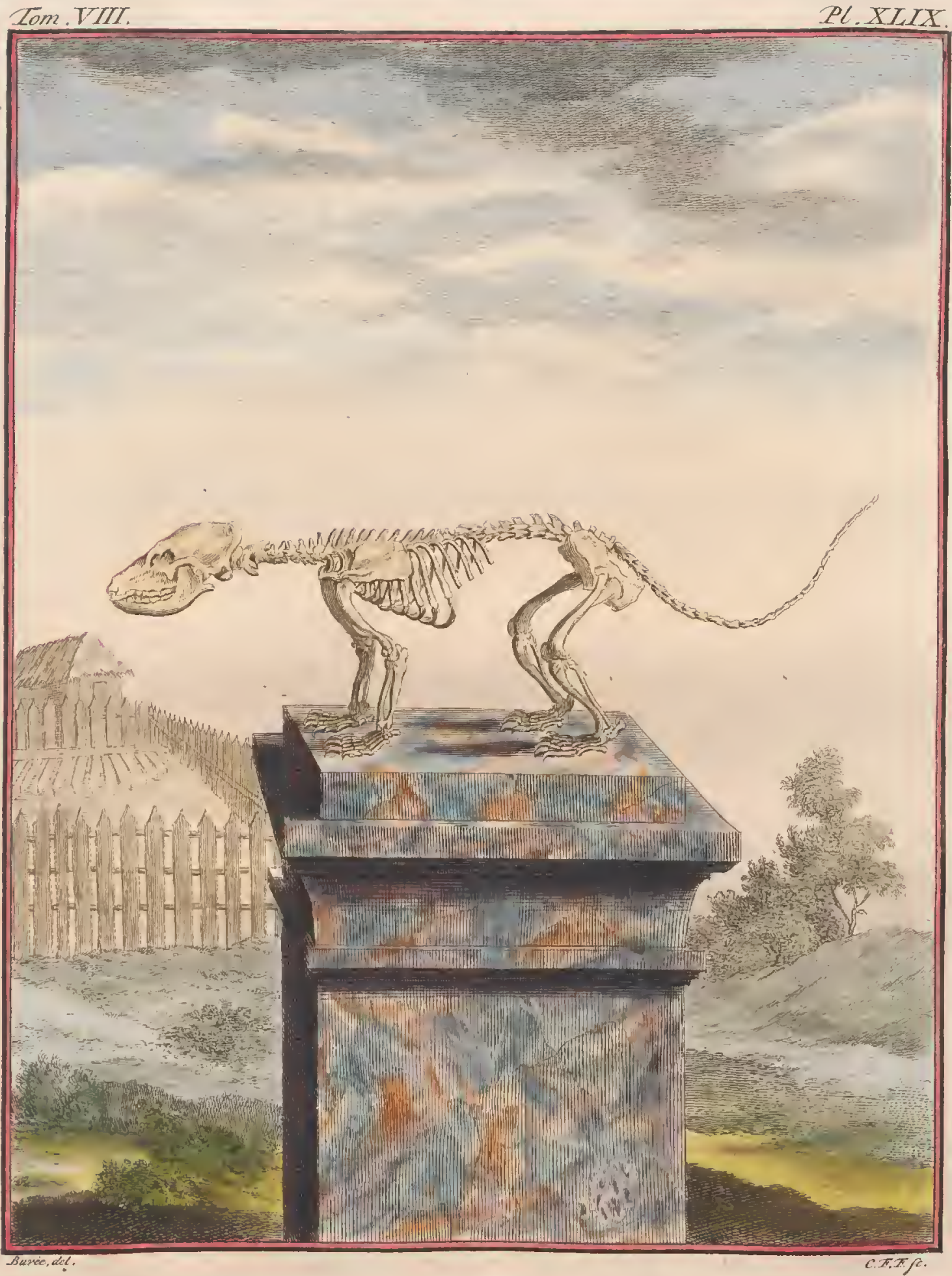



De kop van het geraante van den conti (Pl. XLLX) was, mar evenredigheid, wat fmaller en veel meer vellengd dan die van den raton; de coati hact veel langer en dunner bek, maar hut been-pliatje van het agterhoofitsbeen, dat zig tufichen de voor-en agter-herffenen bevondt, was \%o lang niet; het dnornagtig uititeelizel ran het tweede nck-wervelbeen ftrekte zig ninder naar agtercn dan nar voren uit; de onderfte tak der dwarlche uitfteekzels van het zesde wervelbeen formecrde een punt niar voren en naar agteren.

Daar waren vyftien ribben, gelyk in den raton; het doornagtig nitfteekzel van het elfde rug.wervelbeen was agterwards gebogen, gelyk lie der tien eerfte; het doornagtig uitfteekzel van het twaalfde was regt, en die der drie laatite waren voorwaurds gebogen: daar waren negen beenderen in het boritbeen; het voorfte gedeelte van 't cerfte been was langer en puntiger dan in den raton; de twce cerlte ribben van weerzyde geledigden zig met het middelfte voorfte gedeelte van hetzelve; de geleding der tweede ribben was tuschen het eerlte en tweede been; die der derde ribben tuffchen het tweede en derde, en dus vervolgens tot aan de negende en ticnde ribben, die zig tusfihen het agtite en negende beentje van het borfbeen geledigden; dus wareu er ticn ware ribben en vyf valiche.

Het fchouderblad maakte een uitfjringenden hock aan den wortel van zyn doorn: de beenderen der pooten waren, naar evenredigheid, korter dan in den raton; de beenderen van de voorhand en den voorvoet gelecken naar die van dit dier; daar was in den voorvoet een agtfte beentje, geplatif aan de bimnenzyde van het eerfte wiggebeentje; dit agttte beentje was byna zo dik als het tweede wiggebeentje, en veel dikker dan het beentje, dat daar aan in den raton beantwoordt, en warvan geene melding is gemaakt ter oorzake zyner kleinheid, die het zelve alleenlyk het voorkomen van een zaadbeentje geeft. het overige geleek het geraante van den coati naar dat van den raton

Voor het overige het makzel der beenderen en der tanden.

Lengte van den kop van het einde der beenderen van het bovenft kaak-

duimen, lynen.

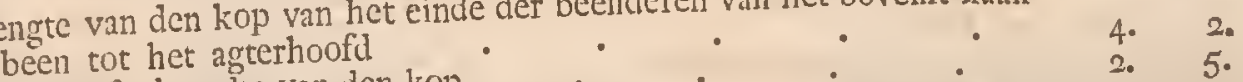

De grootite breedte van den kop a den agterften rand van het knok- ${ }^{2 .} 5$.

Lengte van het onderit kaakbeen tot aan den agterften land van het knok- 3 .

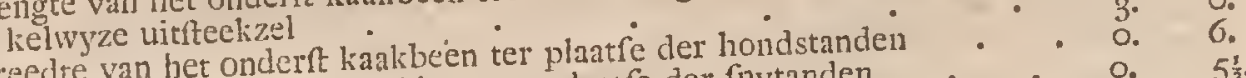

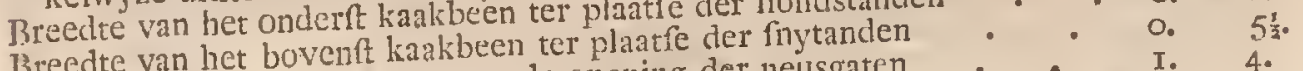

Breedte van het bovent katten en de opening der neusgaten . - I. 4 .

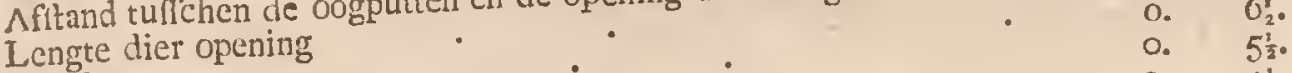

Brecdte der twce voorname dcelen vin het tongbeen $\quad 0.4 \frac{1}{2}$.

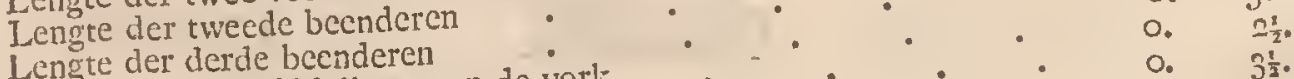

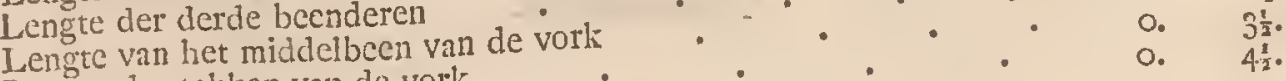

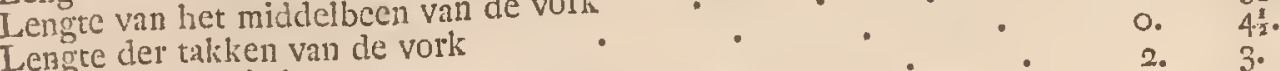

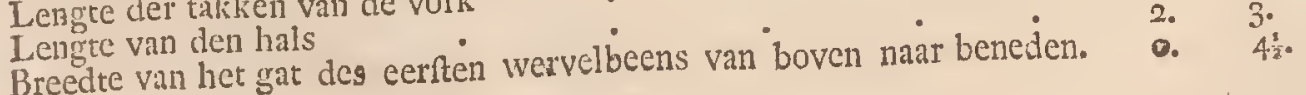


Lengte van de eene naar de andere zyde
Lengte van het gedeelte der wervelbeenkolom die uit de rngwervelbeenderen heftaat

Lengte der cerfte ribben

Afitand tuffchen de eerfte ribben aan de breedfte plaats

Lengte van de negende rib, die de langfte is .

Lengte van het borftbeen

Lengte van de negende rib, die de langfte is .
Lengte van het borftbeen
Lengte van liet ecrfte been dat het langft is
Lengte des lighaams van het vyfde wervelbeen dat het langft is .

Lengte van het lieiligbeen

Breedte van het voorfte gedeeltc

Breedte van het voorte gedeelte
Lengte van het tiende valfelie wervelbeen van den ftart dat het langit is.

Lengte der eyronde gaten

Breedte

Breedte van het bekken.

Hoogte

Lengte van het fchouderbiad

Breedte aan de breedfte plats

Lengte van den fchouder

Lengte van de ellepyp

Lengte van het ftraalbeen

Lengte van het dijebeen

Lengte der kniefchyven

Lengte van het fcheenbeen

Lengte van het kuitbeen

Hongte van de voorhand

Lengte van het hielbeen

Hoogte van het eerfte wiggebeentje en $\dot{f}$ chuitbeentje te famengetiomen.

Lengte van het eerfte heentje van de agterhand dar het kortte is . . . o.

Lengte van het derde beentje, dat het langft is

Lengte van het derde beenje, van den aurtervoet, zynide het kortfte . . . o.

Lengte van het erfte dat het langft is .

Lengte van den eerften regel des niddelften vingers der voorfte voeten.

Lengte van den tweeden regel

Lengte van den derden

Lengte van den eerften regel des duims

Lengte van den tweeden

Lengte van den eerften regel des vierden vingers van den agteriten voct.

Lengte van den tweeden regel

Lengte van den derden

Lengte van den ecrften regel des duinis

iLengte van den tweeden regel

men, lyneti

5 .

II.

o. II.

3. 3.

3. 10.

-. II.

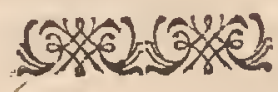




\section{$V \wedge N$ D E N A G $\odot U$ U $I$.

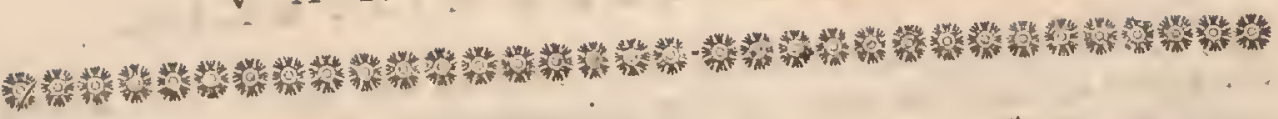

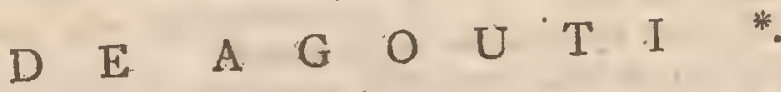

Serterses it dier heeft de grootte van een has, en is door de meefte NaamD Dyft-makers in dc Natumlyke Hiftorie als cen konyn of groote rot

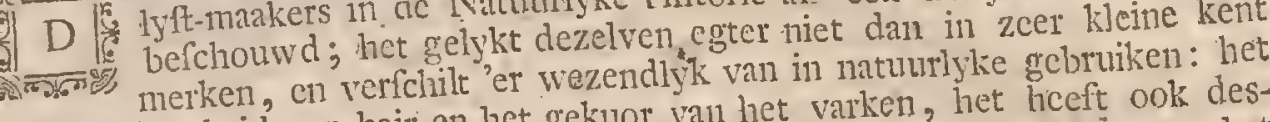
merken, cn verfclint er weznd van het varken, het hiceft ook deshecft de rutwheid het eet vraatig van alles wat men het geeft, en wanneer het verzadigd, of liever opgepropt, is, verbergt het, gelyk de vos, het overfchot zyner fpyzen op verfcheiden platen, om dezelve in tyd van nood wcêr te vinden: het heeft vermaak om tc vernielen, te niryden, te knabbelen, al wat het vindt; wanneer men het tergt roten, fterk op de aarde; over einde, cn het llaat, met zynarig : de Kapucyncr Munnikken van. het byt geweldig, en is zecr kwaadan wion $z y$, in zyne jengd, de tanden Olinde in Brafiliën voedden er een op, wan deze voorzorg, ftrekte het zyne hadden uitgebrooken, man, wanorde 20 vent noch onthoudt rig bloot en open op den grond, gुelyk de hass; hy legert zig gemcenlyk in een hollen boom, of in verrotte ftammen: de vrugten, de patates, de mavioc, zyn het gewoone vocdzel van die, welke rondom de mentchelyke wooningen zwerven; de bladeren en de wortels der planten en der jonge boompjes maken het vocdzel der anderen, die in de boffchen en favanes lecven, nit: de agouti gebruilit, even als de eckhoorn, zyne voorfte voeten, on aan te vatten, en nar zyı bek te brengen : hy loopt zecr fincl op de vlakte en in 't opklimmen van cen hy tnimelen, zo hy zyn voorfte pooten korter zyn dan de agtey is goed van gezigt en zeer fcherp loop in 't afklimmen nict vertuaghe : biy it hy ftan om te luifteren.

van gehoor; wannecr ment hem en in gevoed 25011 , is niet kwaad nm te ee-

Het vleetch van die, welke vet con wh

* De Agouti. 't welk een Indiannche naam is, heet in Brazilie gemeenlyk Cotia, volgens Pisun en Marcgrave. De Nedtritiston.

den niam van Weft-indilch-Konyn genceven. Dortureeich Schryver.ganomen.

dat hy 'er van zegt is ut Nat. dat Brefil. pag. 122.

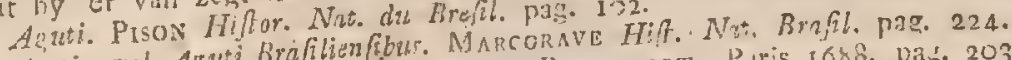

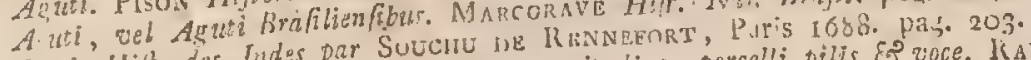

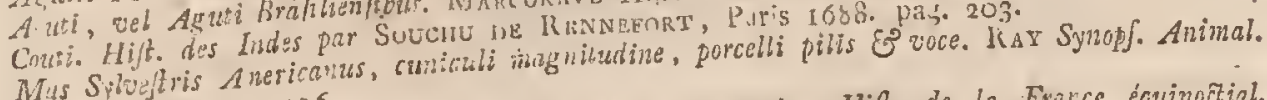
Quadrap. p.b. 226 .

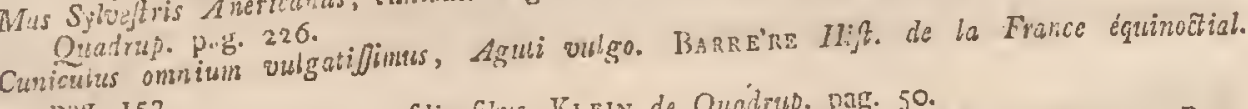
pag. 153.

Cartia, Aguti vel Acuti Brafilis ex rufo Eे Sulco ritixtis, rigidis, vefitus. Brisson Regn

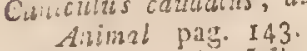

(a) Hiftupte des Iniles, par Souchu DE Ranwerort, pas. 223.

1. II. Deel. 
ten, fchoon het een kleinen wilden fmaak heeft en wat hard is; men zuivert maakt het een on ander op dezelfde wyze gereed.

Men jaagt hem met ho

kan dryven, is hy welhaaft ten einde, omdat hem in afgefneeden fuikerriet 1 troo en bladeren van het fuikerriet op dic grom gemeenlyk een voet hoog fprong, dien hy doet, in deze bedding die gronden ligt, en hy op yderen wils kan-inhaalen, en met een ftok doodil akt, zodat een menfch hem dikfnel voor de honden, en wint vervolgeris kruipt en zig hardnekkig verborgen houdt; daar uit te trekken, vervult dat hol met; de jager, om hem te noodzaaken zyne benuluwdheid door een fmartelyk en rook, het dier, half geitikt, geeft komt nict da1 in den uiterften nood te voorfchend gefehreenw te kennen, en hy dikwils herhitalt, wannecr men hem ontruft of tergt, gefchreeuw, 't welkeen varkentje; jong gevangen laat hy zig ligt of tergt, is gelyk ala dat van

gat. "er alleen uit, en komt van zelf weder.
Deze dieren onthoulen temmen; hy blyft in huis,

wyfjes zocken daar ecne digte plaats om "er in de bofehen en heggen; de reiden; zy makken dat bed van bladeren en hen boor haiare jongen te be. maal 's jaars, ydere dragt, zegt men, is van ; zy werpen twee, of drie, vervoeren haare jongen gelyk de katten, twee of drie digen nan tee $(b) ; z y$ boorte; zy brengen hen nar holle boomitammen, drie dagen na derzelver geten tyd,zoogen; de jonge agouti's zyn wellhate in fwar zy hen maar korvolgen, en hunne kott te zocken: dus is de tyd in ftat on hunne moeder te vry kort, cn him lecven duurt derhalven niet lang.
De agouti fehynt ecn dicr te

wordt in de oucte wereld nict gevonden, en fin Anerika alleen eigen is; het lyke deelen van de nieuwe thuis te hooren fihynt byzonderlyk in de ZuideJiratiliën, in Guiane, op St. Domingo, en opalle de vindt het zeer gemeen in klimaat noodig om te beftatis en voore te tecleis; her kan; het beeft een heet leeven, mits dar men 't voor de koude beveilige, en kan egter in Frankryk plats houdic, vooral in den winter; het bopailige, en op cente drooge warme lyke treeken, en heeft zig niet verfpreid in de zig in amerika tot cle Zuide. gematigde, geweften; op de cilinden vindt nen koude, en zelfs niet in do welke dic is, daar wy de bcfehryving van geeven; mar on com van a gouti, vafte land van Guiane (c) en in Brafiliën, verzekert men dat Cayenas, op "s ryn, en dat die tweede foort, welke men agouchi men dat 'er twee fonten valt dan de eerfe: die, datr wy van fpreeken, is ong, handratig kleiner wy zyn "er van verzekeri door hut getuigenis van liedenetwificld de agont, ne gevoond hebben, en die den agouti en den agouchi, welkeng up Calyeri-

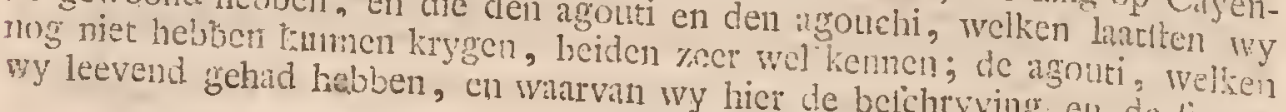

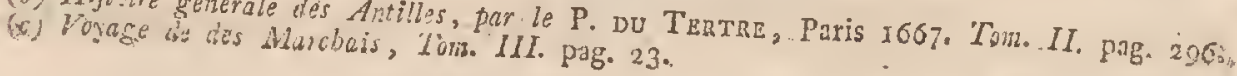




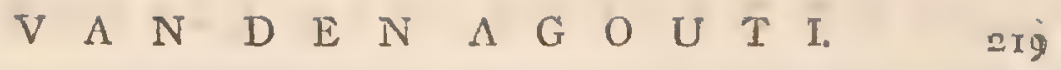

geeven, hadt de grootte van een konyn, zyn vel was ruw en van eene bruine, met ros gemengde, kleur; hy hadt de bovenlip gefpleeten, gelyk de haas, de ftaart was nog korter dan die van het konyn, de ooren zo kort als -breed, het bovenft kaakbeen buiten het onderft uitfpringende, den finuit als de relmuis, de tanden als het marmeldier, een langen hals, fpigtige pooten, vier vingers ann de voorfte voeten, en drie aan de agterfte. Marccrave, en bykans alle de Natuuronderzoekers na hem, hebben gezegd, dat de agouti zes vingers aan de agterlte voeten heeft: Brisson is de eenigfte, die deze dwaaling van MARCGRAvE niet heeft nagefchreeven, zyne befchryving naar het dier zelf makkende heeft hy, even als wy, maar drie vingers aan de ag. terfte voeten gezien.

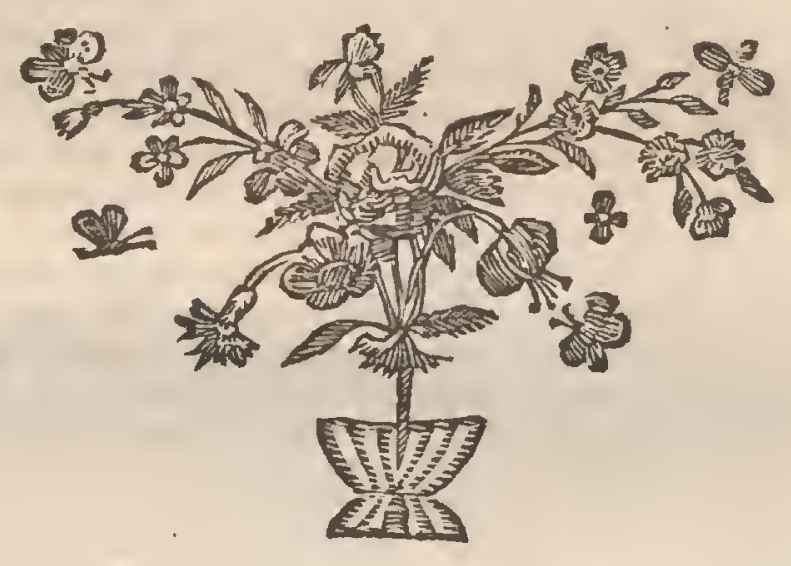

Ee 2 


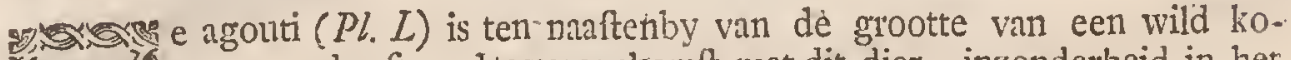

D 10 nyn, en heeft veel overeenkonft met dit dier, inzonderheid in het . gefpleeten gelyk de haas en 't konyn, het heeft het einde van het onderft kakbeen meer agterwaards dan dat van het boventi; en twee groote tancien in yder kaakbeen gelyk de bévers, de rotten, de Indiaanfche vark̄entjes, dé haazen, de konynen, enz: de neus is meer uitfpringende en minder gerond dan die van het konyn, de kruin van den kop is plat, en de ooren zyn zeer breed, zeer kort, en dun gelyk die van de rotten; de agout heeft het lighaam verlengd, de pooten fpigtig, en den ftart zeer kort en kaal; daar zyn vier, wel blykbaare, vingers aan de voorfte voeten, en een vyfde ter platefe van den duim, die met het vel overdekt is, en die zig niet uitwendig vertoont dan door den nagel; de agterfte voeten hebben leggts drie.vingers, maar. zy zjn dikker en langer dan die de:-voorfte voeten; de middelfte vinger is de langfte, die ter zyden zyn allen even lang; de nagels zyn lang, dik, byna rolrond, en van een grauwe kleur; de agterfte voeten dragen op de aarde van het eind der magelen tot aan de hiel; dezclve is darom ook eeltagtig over haare geheele uitgeftrektheid gelyk de agterfte voet van den has en het konyn.

Het einde van den neus, de lippen en het onderfte van het voorfte gedeelte van het onderft kaakbeen van den agouti, dis ten onderwerpe voor deze befchryving gediend heeft, waren van hair ontbloot, en daar was maar zeer weinig op de binnenzyde van den arm en den voorarm, op den onderbuik, de liezen, en de binnen'yde van de dij en den poot: het hair was dik en hard, dat, welk zig ter wederzyde van den aars bevondt, was van eene fraaje oranjekleur; daar, was op "t onderft kankbeen hair van een geele kleur; dat van het onderit der pooten en der voeten. was zwart; liet hair van al het overige des lighams was van eene afchgrauwe of, bruine kleur by den wortel; daar was zwart, of bruin-zwartagtig boven her afchgrauw, en gecel of oranje boven het zwart, en eindelyk was de. punt zwart: men zag de alchgrauwe klemr niet dan door het hair te verwyderen, en de andere lileuren waren nict gelykelyk verdeeld over de verfchillende deelen des lighaans; het zwart hadt de overhand op het agterhoofd, op de bovenzyde van den hals, op de fchoft, op den tichouder, op de buirenzyde van den arm-en van den voorarm, op het agterft gedeelte van dell rug tot an den ftaart; diar was meer oranje din. zwart op het bovent gedeelte van de zyden des lighaams en. meer geel dan bruin op den buik, want daar was een ftreep van geele kleur, die zig van de borlt tot agter den navel nitftekte.

Het langtte hair was van vier duinen, en was op de bovenzyde van den. hals, en op het agterlt gedeelie van den rug; de lengte. van het ander hair. 


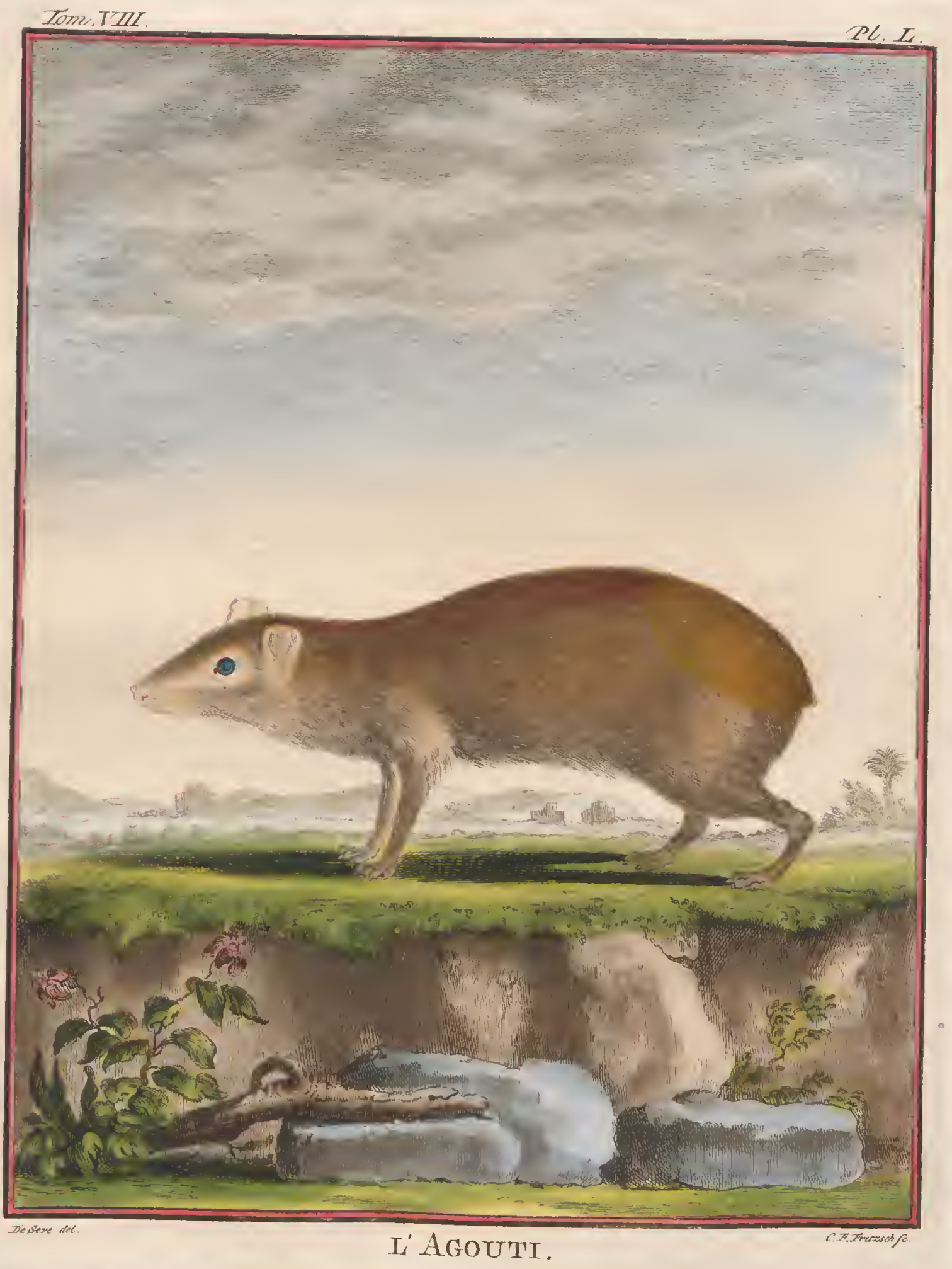



was van een duim of van anderhalven duim, en daar was hair, . dat veel korter was, op den kop en op de pooten: de agouti heeft'knevels gelyk andere dieren; het borftelig hair van denzelven was zwart en byna vier duim lang; daar is ook dergelyk grof hair onder de oogen en onder het onderft kaakbeen by de keel.

voeten, duimen, lyner.

Lengte dès geheelen lighaams, in cen regte lyn gemeeten van het einde van den bek tot aan den aars

Hoogte van het voorftel

Hoogte van het agterfel.
Lengte van den kop van het einde van den bek tot aan het agterhoofd

Omtrek van het einde van den bek

Omtrek van den bek onder de oogen gemeeten $\cdot . \quad \cdot \quad$

Omtrek van de opening van den mond

Afftand tuffchen de beide neusgaten

Afftand tuffchen het einde van den bek en den vooulten hoek van

$$
\text { 't oog }
$$

Aftand tuffchen den agterften hoek en 't oor'

Lengte van het oog. van den eenen hoek tot den anderen $: \quad 0_{0}$

Opening van "t oog
$\Lambda$ fitand tuffchen de voorfte hoeken der oogen volgens de kromming van't neusbeen gemeeten

Dezelfde afftand in eene regte lyn

Omtrek van den kop tuffchen de oogen en ooren gemeeten . - o.

Lengte der ooren

Breedte van de bafis naar de uitwendige kromming gemeeten ... $0_{0}$

Afftand tufichen de beide ooren omlaag gemeeten

Lengte van den hals

Omtrek van den hals

-

Omtrek des lighrams agter de voorfte pooten genomen . . $\quad$ o.

Omtrek aan de dikfte plaats

Omtrek voor de agterite pooten genomen

Lengte van den ftomp des ftaarts.

Omtrek van den ftaart aan 't begin van den ftonip Omtrek van den ftaart aan 't begin van den ftonip
Lengte vall den voorarm van den elleboog tot aan't gewrigt van de.
hand.

Breedte van den voorarm aan den elleboog

Dikte an dezelfde plaats

Omtrek van 't gew rigt van de hand

Omtrek van de agterliand

Lengte van "t gewrigt der hand tot aan "t einde der nageleil .....

Lengte van den poot van de knie tot aan de hiel . . 0

Breedte van het bovenft des beens

Dikte

Omtrek van den agtervoet

Breedte van den voorften voet

$$
\text { E }
$$

0. 5.2.

9. 6.

3. 4.

3. 6.

5. 9.

2. 2.

o. 4.

1. Io.

o. IO.

o. 6.

0. 4.

2. 0

I. 6 .

7. 3

I. 0 .

J. IO.

I. 3.

I. 7.

7.4

7.
10. 4.

9. $\mathrm{o}$.

○. 5 .

i. $\mathrm{O}$

2. II.

c. II.

o. 6 .

r. 6.

I 5 .

I. IO.

3. 9.

I. 9.

o. 10:

o. 10 .

r. 8 .

3. . I0.

०. 6. 
Breedte van den agterften voet

T.engte

Breedte aan de bafis

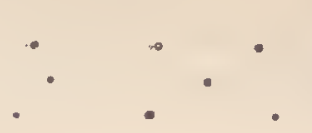

Deze agouti woog dric pond derticn en een half once; het netvlies was mer vet belaaden en zcer ruim; het ftrekte zig tot het fchaambeen uit; de mag lag geheel an de linkcrzydc, en de twaalfvingerigedarm hadt weinig lengte; de nugteredarm makte zyne wendingen in het voorfte gedeelte van de navelftreck, en de omgebogendarm in het agterft gedeelte van die zelfde ftreek: de blindedarm ftrekte zig fchuinfch van de linker tot de regter weeke buikzyde; de kronkchlarm volgde dezelfde rigting, en maakte eenige kleine geftrengelde omwentelingen die in de regter weeke buikzyde by het einde van den blindendarm, aan malkanderen vaft waren; vervolgens vouwde hy zig weder op de matg, en makte eenige bogtigheden onder de wervelbeenskolom voor dat hy zig aan den regtendarm voegde.

De grnote kromming van de mang was zeer bollond, en bygevolg blecf het midden van dit ingewand gefpannen; de groote blindezal hadt veel diepte; het regtergedeclte van de mag, "t welk zig tuffichen den hoek van 't midden vall dit gedeclte el1 den portiei bevindt, was zeer hort: de dunne darnicn haddon allen ten naaftenby dezelfde diktc; het cerfte gedeelte egter van den twaalfvingerigendar'm was de dikfte plats, die 'er in de darmbuis was van den poltier af tot an den blindendarm: het latite gedeelte $(A, P l, L I)$ van den omgeboogendarm was het kleinfte: de blindedarm $(B C)$ was zeer lang en dik naar evenredigheid; het begin (D) van den kronkeldarm hadt ten naaftenby dezelfde dikte als de blindedorm, over de lengte van twee of drie dnimen; vervolgens verminderde deze darm langzanmerhand in dikte tot in "t midden zyner lengte, en wierdt eindelyk weder wat dikker den regtendarm naderende; de vliezen van de maag en de darmen waren zeer dun en zeer zwak.

De lever ftrekte zig zo veel ter linkel als ter regterzyde uit; zy beftondt uit drie groote kwabben en éne kleine; de grootite van allen was geheel aan de linkerzydc, die van 't midden hadt wat minder uitgebreidheid; de draagband en "t gaiblas we waren in "t midden van die kwabbe digt by malkander; de derde der groote kwabben was de kleinfte, en in har gehcel aan de regterzyde geplanft; de vierde kwabbbe, dic de kleinfte van allen was, zat ann den wortel van de derde, en was in twee langagtige deelen gefcheiden: de lever hadt uit-en inwendig eene roodagtige kleur; zy woog twee oncen zeven en cen half gros; het galblasje hadt de figuur van een peer, het bevattede cene zeer kleine hocveelheid verdikte gal.

De milt was zeer klein; haar oncerft einde was vecl breeder dan het bovenft ciudc; hare kleur was roodagtig bruin, zo wel lit-als inwendig; $z y$
woog een half gros en zeven grein.

He milv af tot an den twanlfvingerigendarm uit. 


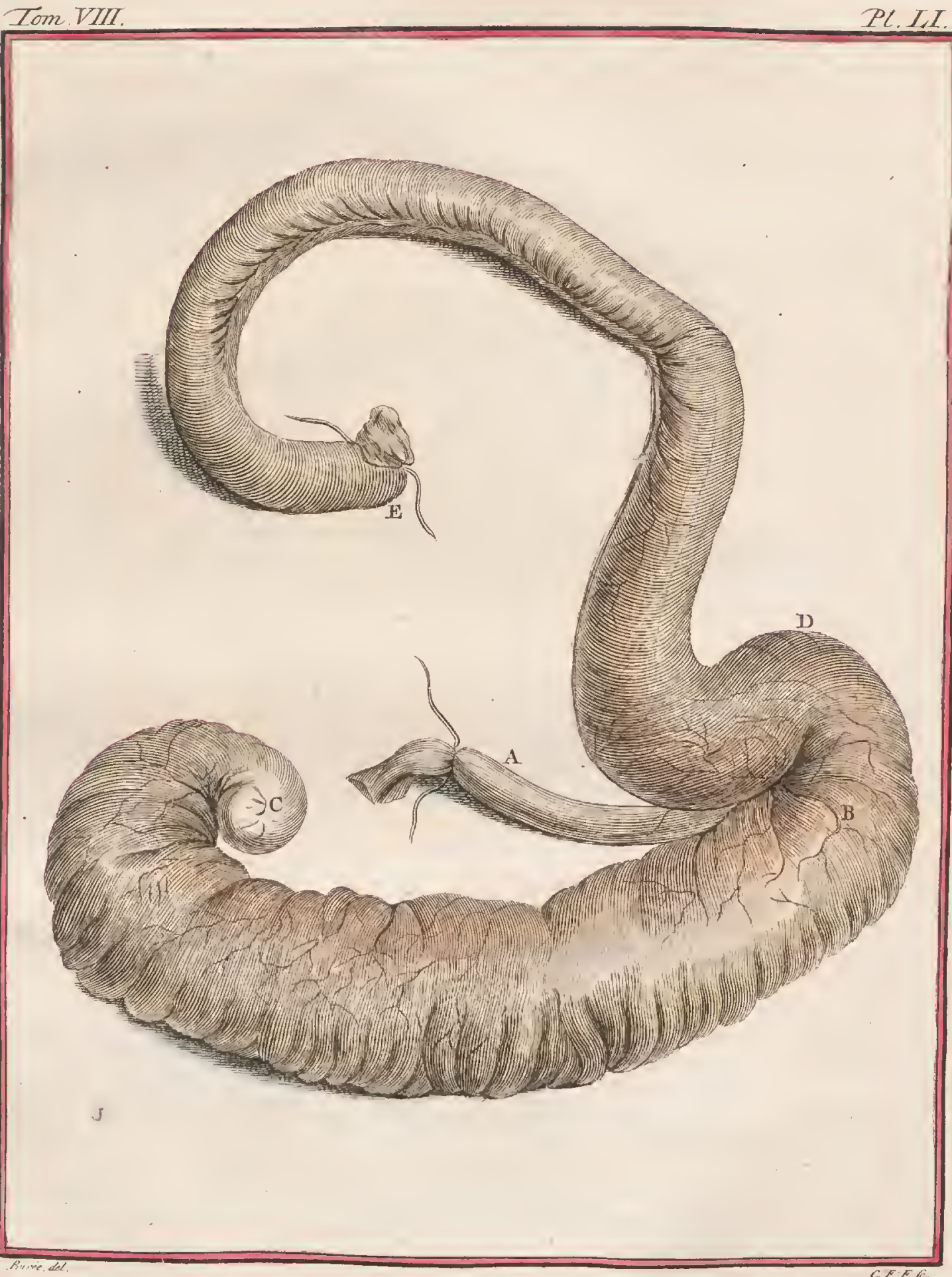


$\longrightarrow$

1 
De nieren hadden weinig diepte; het bekken was weinig: uitgeftrekt, en de tepeltjes waren door malkanderen verward; de regter nier ftak meer voor uit dan de linker.

Het zenuwagtig middelpunt van het middelrif was zeer dun en zeer groot; het hart was in ' $t$ midden vitn de bortt geplaatift, de punt een weinig linkfch gedraaid; zy was kort en byna rond: de.groote flagader verdeelde zig enkelyk in de op en nedergaande.

Daar waren vier kwabben in de regter long en twee in de linker, geplaatit en van makzel zo als in den hond en in de meefte andere dieren.

De'tong was lang, fmal, dik, en met zeer kleine tepeltjes bedekt; daar was eene overlangfche voor over 't midden van haar voorftestyedeelte, en twee kelkklieren op het agterfte: deze klieren waren weinig verheven en op een lyn afitands van malkanderen geplaatft; zy hadden omtrent een lyn middellyns: de ftrotklap liep in een punt uit.

Daar waren op het voorfte gedeelte van het verhemelte, tuffchen de voorfte tanden en de ecrite baktanden, twee breede vooren, welker randen zeer verheven waren, want zy hadden eene lyn hoogte: daar waren tufichen de drie eerfte baktanden van weerzyde vyf andere, weinig diepe en zeer fmalle, vooren; haare randen maakten twee bolrondheden naar voren, en waren in 't midden harer lengte afgebrooken.

De voorherffenen hadden weinig groevingen; haar agterft gedeelte was veel breeder dan het voorfte, en daar waren flegts twee kwabben aan weerzyde: de agterherffenen waren in har geheel agter de voorherffenen geplatit; $\mathrm{zy}$ waren fmaller en langer dan in de dieren, dic in dit Werk reeds befchrecven zyn; de voorherffenen woogen drie gros en de agterherfenen vier-en zeftig greinen.

Het is my voorgekomen, dat dit dier twaalf tepels hadt; zeven op de bort', dric aan de regter, en vier aan de linkerzyde, en vyf op den buik, dric aan de regter en twee aan de linkerzyde; maar ik lieb my niet kunnen verzckeren, dat alle de knobbeltjes, welken ik voor tepels heb genomen, inderdaad wezendlyke tepels waren, of dat "er nog geene andere waren, welken ik niet heb kunnen onderfcheiden van de knobbeitjes, die zig aan den wortel van elk hair bevonden; het fchynt uit de plantfing der twalf tepels, daar ik van gewaigd heb, te volgen, dat "er nog twee meer hadden mocten $z \mathrm{yn}$, eene op de regterzy'de van de borlt en eene op de linkerzyde van den buik.

De agouti hadt geen balzak, daar was maar cen lyn afitands tumchen den aars en de opening van de voorhuid, die op eene verinevenheid geplatatl was; men voelde de rocile en het hoofitje onder het vel langs het fohambeen, zodat $z y$ in den gewoonen ftat agterwaards gerigt waren; maar wanneer men het hoofdje deedt uitkomen, gelyk in de opiegting gebeurt, dan veriengde zigg het vel van de bilnaad, en fitrekte zig tot het voorlte gedeelte van het fchambeen uit, en alsdan rigtede de roede zig voorwalds.

Het hoofdje $(A, f i g . I, H l$. LII, on fig. 2. alwaar hee in zyn naturulyke grootte vertuond wordt), was van eene roodagtige kleur, het hadt eene by- 
na rolronde gedaante, en het was holrond aan 't einde; de opening van de pis-

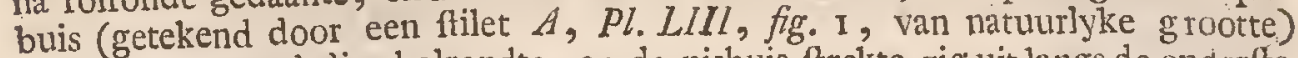
was op den grond dier holrondte, en de pisbuis ftrekte, zig uit langs de onderfte zyde van een been waar van men het einde zag op den rand van de holrondte van het hoofdje, en 't welk men van binnen voelde: daar was een voor, die zig-langs de onderfte zyde van het hoofije uititrekte; de geheele buitenfte oppervlakte was bezct met kleine witte, ftyve, fteekende, en agterwaards gerigte, tepeltjes: daar waren daarenboven aan weerzyde van het honfdje cen beenagtig platje in de" gedaante van een vleugel ( $B$, fig. I., en $A A$, fig. $\mathrm{I}, P l$. LII en $B$, fig. I, $P l$. LIII) elk dezer platijes was vyf lynen lang en drie-vierde lyn breed; zy waren dun en lunne uiterlte rand eindigde in kleine tanden, gelyk die van een zaag; deze platjes zaten met hunne binnenzyde an het hoofdje vaft;-ik heb hen verlangd gevonden tegen het hoofdje; ik weet niet of zy zig in de opregting van de roede verheffen; in dit geval zouden de tanden van humen buitenften rand cen hinderparl zyn voor ' $t$ inbrengen van het hoofdje in de fchecie van het wyfje.

De afvoercnde buizen (C. C, fig. I, Pl. LII en LIII) waren dun en kort; ik heb de zaadballen $(D D$, fig. $I, P l .: L I I)$ in den onderbuik by de liezen gevonden; zy waren van eene weeke zelfitandigheid, en hadden eene verlengde eyronde figuur; men onderfcheidde de vaaten van hunne binnenfte zelffandigheid, die roodagtig was, en men zag cen kleinen as in de rigting van hunne groote middellyn; men. zag ook de gekluwende vaaten, die het knobbeltje van den: opperbal maakten.

De roede $(E, f i g$. I,$P l$. LLI en $D$, fig. I, Pl. LIIII) beftondt uit twee fponsagtige lighanmen en hadt twee kocrden; de . blaas ( $F$, fig. I, Pl. LII) was klein en hadt de gedaante van een peer, hate vliezen waren zecr dun en .doorfchynende.

De vooritanders ( $G \cdot G, f i g . I, P l . L I I$ en $E E, f i g . I, P l . L I M)$ ivaren gedeeltelyk klieragtig en.gedeeltelyk vaatıgtig; men zag humue klcine vaaten, die verfcheiden bogten makten; daar kwam een vloeibaar vogt uit, zy had. den gemeenfchap met de pisbuis $(F, f g . I, P l . L .111)$ door eene opening, ge-tekend met een ftilet $G$ H.

De zandblaasjes ( $H \mathrm{H}, \mathrm{fig} . \mathrm{I}, P l$. LII en $I I$, fir. I, $P l . L l l I$ ) waren zeer lang cn beftonden vit vaten, die anderhalf lyn middellyns hadden; zy - svaren met groote omwendingen gekluwend en liepen uit op cen lang fteelyje ( $K K$, fig. I, $p l$. LIII), dat geneenfchap hadt met de pisbuis by de openin:gen der afvoerende vaaten en cler voorftanders: de zaadblaasjes bevatteden cene witte en verdilste ftofie, die in de pisbuis $(F)$ doorging door.eene opening, door het ftilet $L M$ aangewezen: ik heb nit de pisbuis eene zelf-ftandigheid $(f / g .2, P l . L I I I)$ gehalald, die my is voorgekomen van dezelfde natuur te z.5n ; en die zig daar gefatzoeneerd hadt; zy brak gelyk hard lym, en hadt 'er de glinftering van op de gebroken plants.

Daar waren op omtrent anderhalf duim afftands van de voorftanders by den ans ( $I$, fig. I, $l l$. LIl en $N, f i g$. I, Pl. LIII), twce klieren ( $K K$, fig. I, Wl. LI. $6.7 \mathrm{O} O$. fig. $\mathrm{I}, \mathrm{Pl} . \mathrm{LIII})$, dic elk zeven lynen lengte en breedte en 


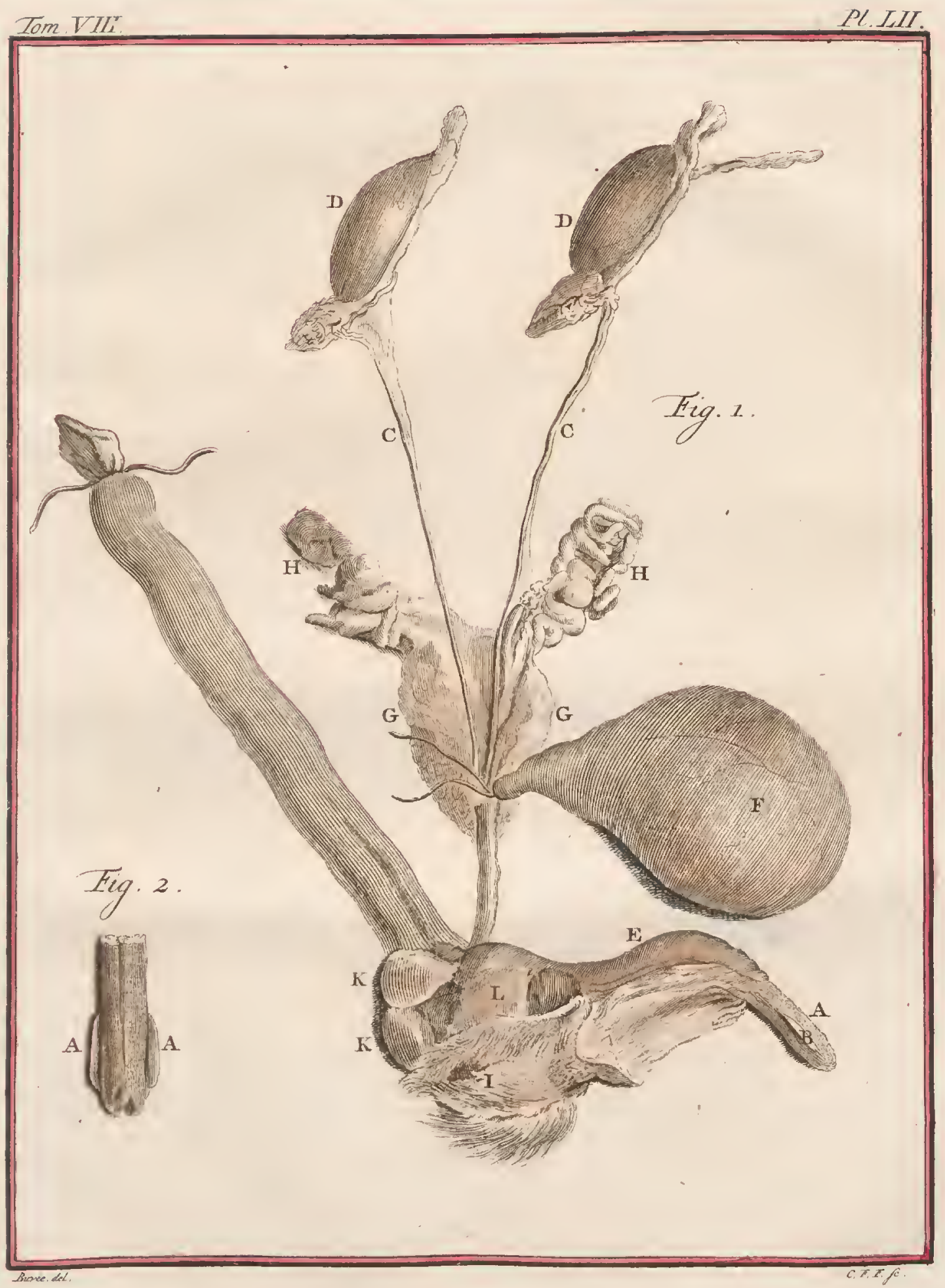






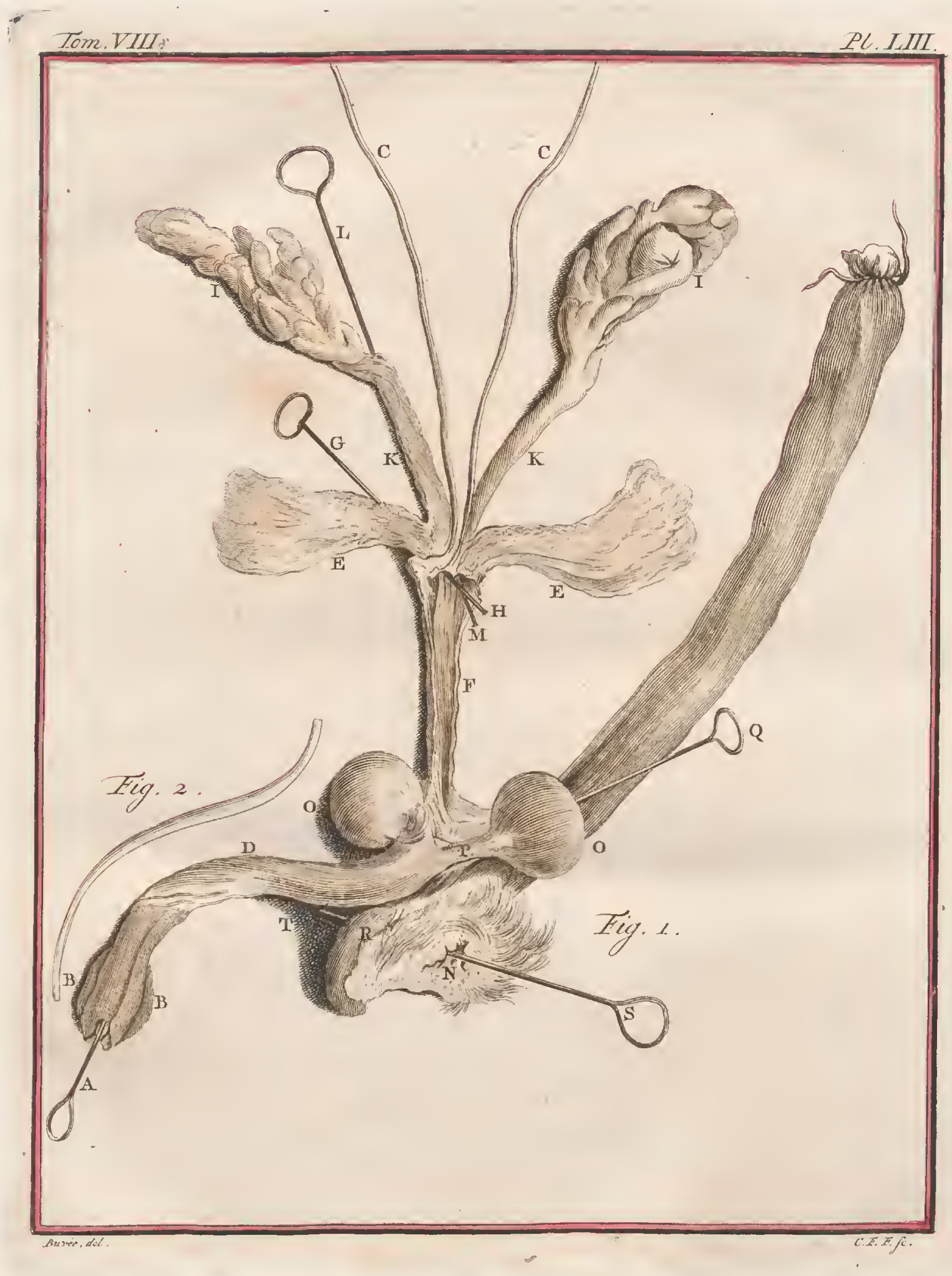


vier.lynen dikte hadden; zy hadden gemeenfchap met de pisblis door een foort van voetje $(P, f g$. I, $P l$. LIII) getekend door een ftilet $(Q)$, en daar fypelde een vloeibaar vogt uit.

Daar was aan weerzyde van den aars nog een kleine zak ( $L$, fig. I, Pl. LII en $R$, fig. I, $P l . L I I I)$, die negen lynen lengte, zes lynen breedte, en vier lynen dikte, hadt; die zakken openden zig in den aars $(N, f i g .1, P l . L I I I)$ door eene opening, met een 1tilet $S T$ aangeweezen; zy bevatteden eene fnotagtige, kruimelige zelfftandigheid van een zeer flegten reuk en eene geelagtige kleur.

voeten, duimen, lyned.

Lengte der dunne darmen van den portier tot aan den blin-

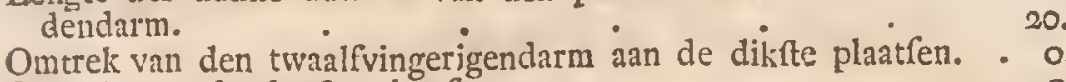

Omtrek aan de dunfte plaatfen

Omtrek van den nugterendarm aan de dikfte plaatfen ..$\cdot$. o. I.

Omtrek aan de dunfte plaatfen . . . . I. I.

Omtrek van den omgeboogendarm aan de dikfte plaatfen . . . o. r. 0.

Omtrek aan de dunfte plaatfen - . - o. o. Io.

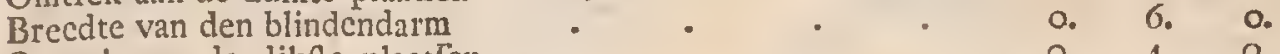

Omtrek aan de dikifte plaatien . . . . . o. 4.00

Omtrek aan de dunfte plaatfen $\quad$ o. 2. 3.

Omtrek van den kronkeldarm op de dilifte plaatfen . . o. 4. c.

Omtrck op de dunfte platfen

Omtrek van den regtendarm by den kronkeldarm - $\quad$ o. I. 6 .

Omtrek van den regtendarm by den aars
Lengte van den kronlieldarm en dẹn regtendarm te famen ge-
o. nomen onder begreepen

Groote omtrek van de maag

Kileine ontrek kn kleine kromming tot aan den hoek, dien het regter
gedelte maakt gedeelte maakt
Lengtc van den flokdarm af tot aan den grond van den grooten

\section{blindenzak}

Omtrek van den nokdarm

Omtrek van den portier

Lengte van de lever

Breedte

Haare grootife dilite

Lengte van het galblaasje

Zyn grootfe middcllyn

Lengte van de milt
lireedte van liet onderite einde

Brcedtc van het bovenite einde

Dikte in " $t$ midden

Dilste van hot alvleefch

Lengte der nieren

Breedte VIII. Deel. 
Dikte vangte liet zenuwagtig middelpunt van de holle ader tot an

de punt

Breedte . I. 2

Breedte van het vleczig gedeelte tuffchen het zenuwagtig middelpunt en het borftbeen

Breedte van ydere zyde van het zenuwagtig middelpunt $\cdot$.

Omtrek van de bafis van 't hart

Hoogte van de punt af tot aan het begin van de longflagader.

Hoogte van de punt af tot aan den longenzak

voeten, duimen, lyner.

Middellyn van de groote flagader van buiten naar buiten gemee-

ten

Lengte van de tong

Lengtc van het voorfte gedeelte van het toompje tot aan 't einde.

Breedte van de tong

Lengte der voorherifenen

Breedtc

Dikte

Lengte der agterhorficnen

Tircedte

Dikte

Afftand tuffehen de randen der voorhuid en het einde van " $t$ hoofdje

I.ngte van het hoofdje

Omtrek

Lengte van de roede van de fplitfing der fponsagtige lighaamen af tot aan de inplanting der voorhuid

Omtrek Lengte der zaadballen

Breedte

Dikte

Breedte vall den opperbal

Dikte Iengte aer afvocrende buizen

Middellyn

Groote omtrek van de blais "

Kleine omtrck

Omtrek van de pisbuis

Lengte der zaadblaasjes

Brecdte

Dikte

Lengte der voorftanders

Brcedte

Dikte

Het geraamte van den agouti $(P l . L I V)$, heeft vecl overeenkomft met dat van het Indiaanfch varkentje; de agouti heeft egter veel breeder voorhoofd en wat langer bek; het uititeekzel van de bogt der takken van het onderft kaakbeen is veel minder verlengd; daar zyn geene uitfteckzels aan weerzyde van 


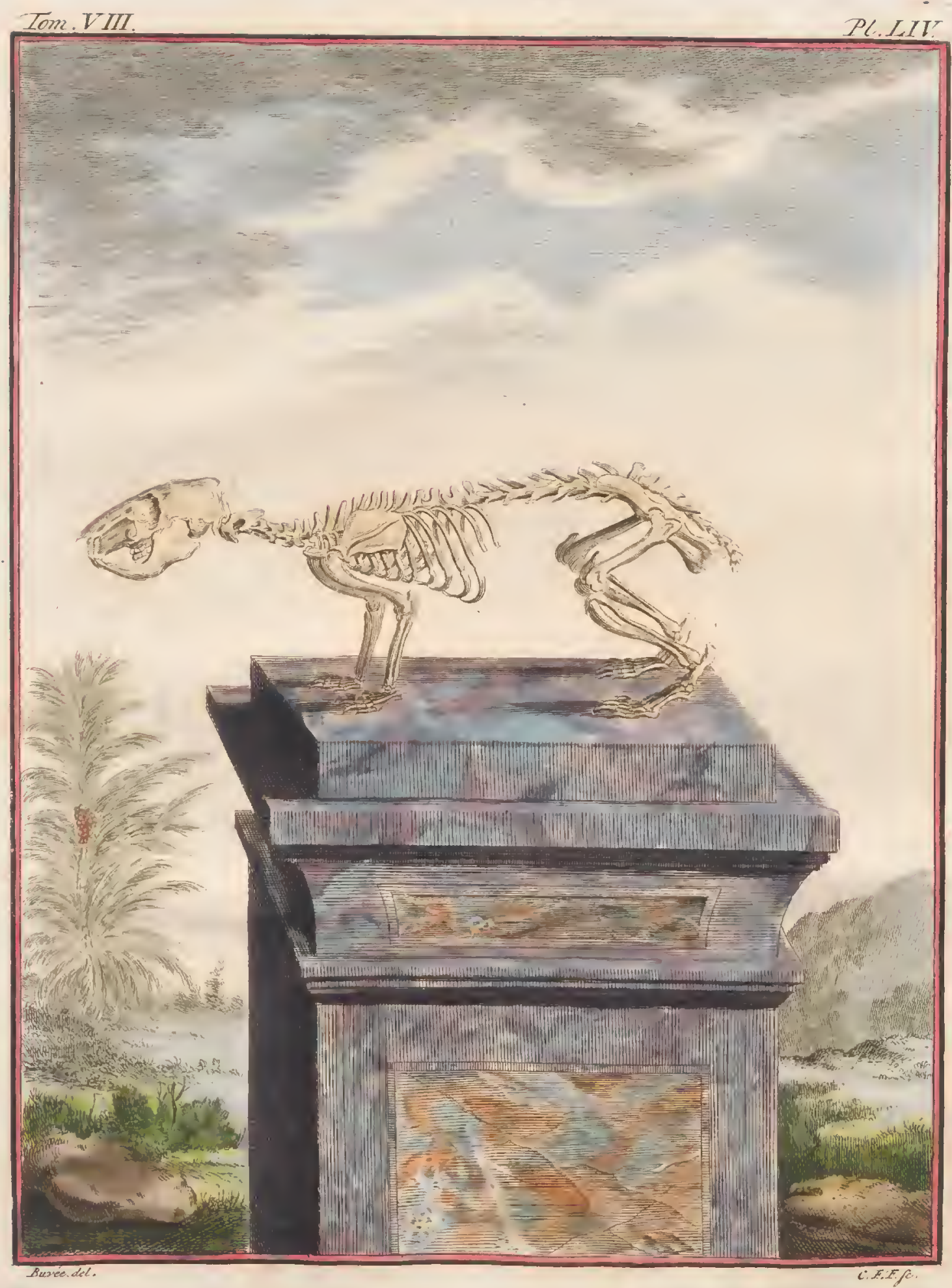



dit kaakbeen op deszelfs buitenzyde onder de baktandent, en het jukbeen makt maar zes kleine tandingen op den rand van de oogput.

De tanden zyn ten getale van twintig, gelyk die van het Indiaanfch varkentje , de finytanden hebben eene oranjeagtige kleur op hunne buitenfte $z y$. de; de baktanden zyn byna nict getand op hunne binnenzyde, en hebben llegts zeer weinig diepe infinydingen op humne buitenzyde.

Daar zyn dertien rugwervelbeenderen en dertien ribben, agt waare en vyf valfche; het doornagtig uitfteekzel van het eerfte rugwervelbeen was regt, die der negen volgende wervelbeenderen waren agterwaards hellende: het doornagtig uitfeekzel van het elfde wervelbeen was regt, en eindelyk die der twee laatite waren voorwards hellende: daar waren zeven beenderen in hei borftbeen; de twee ecrfte ribben, aan weerzyde een, geledigden zig met het voorfte middelfte gedeelte van het eerfte beentje; de geleding der tweede ribben was tuffchen het eerfte en tweede, die van de derde ribben tufichen het tweede en derde becntje, en dus vervolgens tot de zevende en agtite ribben, die zig geledigden tufichen het zesde en zevende beentje.

De bykomende uitfteekzels der zes lenden-wervelbeenderen hadden, naar evenredigheid, minder breedte dan in het Indianfth varkentje; het heiligbeen beftondt uit vier valfche wervelbeenderen, en de ftaart uit zeven, waarvan de laatlte famengroeijingen hadden, die hen mismaakten; daar was op het agtcrit en bovenft gedeelte van yder heup-been een groot uitfeckzel agterwaards gerigt.

De bovenzyde van het fchouderblad was weinig bolrond naar buiten over zyne lengte; de beenderen van den arm, van den voorarm, van de dije, en van het been, verfchilden niet van die van het lndianfeh varkentje, dan voor zo verre $z y$, naar evenredigheid, langer waren; de kniefchyven had. den nog meer lengte ten opzigte van die van 't Indiannfeh varkentice.

Daar waren maar dric beenderci in de cerfte ry van de voorliand; het eerit dat het grootfte was, bevondt zig onder het ftraalbeen, het tweede onder de ellepyp, cn het derde agter het tweede been van de voorhand; de tweede ry beftondt uit vier beenderen; het ecrfte bevondt zig geplaatit ge. deeltelyk boven het eerfte been van de agterhand, en gedeeltelyk boven het tweede; het tweede been van de voorhand boven het tweede been van de agterhand; liet derde been van de voorhand gedeeltelyk boven het tweede been van de agterhand en gedeeitelyk boven het derde; het vierde been van de voorhand gedeeltelyk boven het derde van dc agterhand, boven het vierde, en gedeeltelyk boven het vyfde.

De voorvoet hadt negen beenderen, te weeten een kootbeen, een fchuitbeen, geplatift tuffehen het kootbeen en twee wiggebeentjes, die vór de twee cerftc beenderen van den agtervoet waren, een hielbeen, cn een tcerlingsbeen, van voren geplaatt; het zevende beentje bevondt zig aan de binnenzyde van het voorfte gedeelte van het hielbeen, het agttte aan de binnerzyde van het eerfte wiggebeentje van den agouti, ter plaatfe alwar het ee1fte wiggebeentje is der dieren, dic 'er drie hebben; en eindelyk was het negende been van den voorvoet onder het agterft gedeelte van hact derde been van den agtervoet.

Ff 2 


\section{DE NATUURLYKE HISTORIE,}

Daar waren vyf beenderen in de agterhand; het eerfte was, naar evenredigheid, veel kleiner dan de andere; de twee regels van den duin waren, naar evenredigheid, ook kleiner dan die der andere vingeren; in ' $t$ algemeen waren alle de beenderen van de agterhand en van de vingeren der voorife voeten veel kleiner, dan de drie beenderen van den agtervoet, en die der drie vingeren van de agterfte voeten.

Lengte van den kop van het einde der neusbeenderen tot aan het agterhoof

De grootfte breedte van den kop

Lengte van het onderft kakbeen, van deszelfs voorfte einde, tot aan den agterften rand van 't knokkelwyze uitfteekzel

Breedte van het onderft kaakbeen ter plaatfe der fnytanden ${ }^{*} \cdot$

Aftand tuffchen het knokkelvyze uitfteekzel

Dikte van het voorfte gedeelte van het bovent kaakbeen

Breedte van dit kaakbeen ter plaatfe der fnytanden

Lengte van de bovenfte zycle

Affand tuffchen de oogutten en de opening der neusgaten

Lengte dier opening

Breedte

Lengte der eigenlyke neusbeenderen

Breedte aan de breedfte plaats

Middellyu der oogputten

Lengte der langite finytanden buiten ' $t$ been

Lengte der dikfte baktanden buiten 't been

Breedte

Dikte Lengte van de twee voorname deelen van het tongbeen

Lengte der tweede beenderen

Leingte der derde beenderen

Lengte van 't middelbeen van de vork

Lengte der takken van de vork

Lengte van den hols

Breedte van het gat des eerften wervelbeens van boven naar beneden.

Lengte van de cene naar de andere zyde

Breedte van het cerfte wervelbeen op het dwarfche uititeckzel ge-

mengte van het gedeelte der wervelbeenskolom; die uit de rugtvervel-

beenderen beftat
Hogte van het doornagtig uitfteckzel des derden wervelbeens, dat het

langft is

Lengte des lighaams van het laatfe wervelbeen, dat het langfte is.

Lengte der eerfte ribben

Afftand tufichen de ecrite ribben aan de brcedite plaats

Lengte van de negende rib, die de langfte is

Lengte viln de latifte der valfche ribben.

Breecite van de breedte rib

Lengte van het burftbeen

Lengte van deszelfs eerfte been, dat het langft is

daimen, lynen.

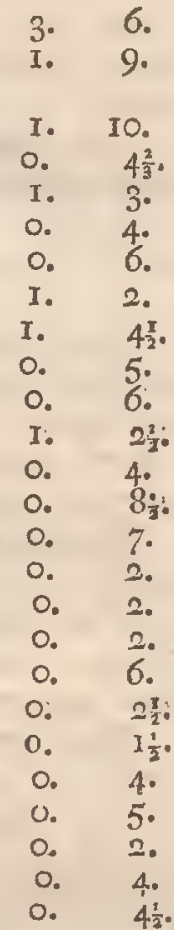

I. 0.

$5 \cdot$

o. 9 .

o. $3 \frac{1}{3}$

o. $5 \frac{1}{2}$.

O. $\quad 9 \frac{2}{2}$

o. $7 \frac{1}{2}$.

2. 9

2. I.

0. 2.

o. 3. 
Lengte van het zesde, dat het kortft is - duimen, lyuen. Hoogte van het langfte doornagtig uitteekzel van de lenden-wervelbeende- 0 . $3 i^{\text {: }}$

ren, - zynde dat van het vyfde
Lengte van het langfte bykomend uitfeckzel zynde dat van het laatite

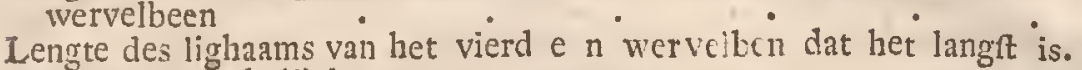

Lengte van het heiligbeen

Breedte van het voorite gedeel te

Breedte van het agterfte gedeelte
Lengte van het eerfte valfche wervelbeen van den itaart dat het langft is.

Breedte van liet voorfte gedeelte van het heupbeen

Hoogte van het been van het midden van de knokkel holte

Middellyn van deze holte

Lengte van de goot

Breedte in 't midden

Diepte

Lengte der cyronde gaten

Breedte

Breedte van het bekken

Lengte van het fichouderblad

Breedte aan de breedife plaats

Breedte ann de fmalfte plaats

Hoogte van den doorn aan de verhevenfte plaats

Lengte van den fchouder

Omtrek an de klcinfte plats

Middellyn van den kop

Breedte van het onderfte deel

Lengte van het halsheen

Lengte van den elleboogsknokkel

liengte van het fraalbeen

Lengte van de heup

Middellyn van deszelfs hoofd

Omrtek van 't midden des beens

Breedte van het onderfte einde

Lengte der kujefchyven

Breedte

Dikte

Jengte van het fcheenbeen

Breedte van het hoofd

Omtrek van ' $t$ midden des beens

Bredite van het onderfte einde

Iiengte van het kuitbeen

Breedte van het bovent einde

Breedte van het onderfte einde

Hoogte van de voorhand

Iengte van het hielbeen
Hoogte van het tweede wiggebeen en het fchuitbeen te famenge-

nomen
Lengte van het eerfte been van de agterhand dat het kortft is

o. 7 .

7.

o. $\quad 7$.

I. II.

$2 \frac{1}{2}$.

o. 32.

: 5 .

2. 0.

o.. 4 .

.. 8.

o. $6 \frac{2}{2}$.

I. 0.

○. $5 \frac{2}{2}$.

O. IO 1 :

II.

2. I,

I. 0 .

If 3 
Lengte van het derde been dat het langit is
Lengte van het derde been van den agtervoet, dat het kortit is . .

Lengte van het tweede been dat het langft is ${ }^{\circ}$ van den voorften

Lengte van den tweeden regel des eerften vingers van den voorften

voet van den tweeden regel

Lengte van den tweeden regel
Lengte van den eerften regel van den middeliten vinger

Lengte van den tweeden regel .. $.{ }_{0}, \ldots$

Lengte van den derden
Lengte van den eerften regel van den middelften vinger der agterfte voeten

Lengte van den tweeden regel

Lengte van den derden

duimen, Jyner.

o. $\quad 9 \frac{\pi}{2}$.

I. 3 .

I. 4 .

○. $3 \frac{\pi}{4}$

o. I!

o. $3 \frac{1}{3}$

o. $3 \frac{1}{2}$

o. 6 .

o. $3 \frac{1}{5}$

o. 5 .

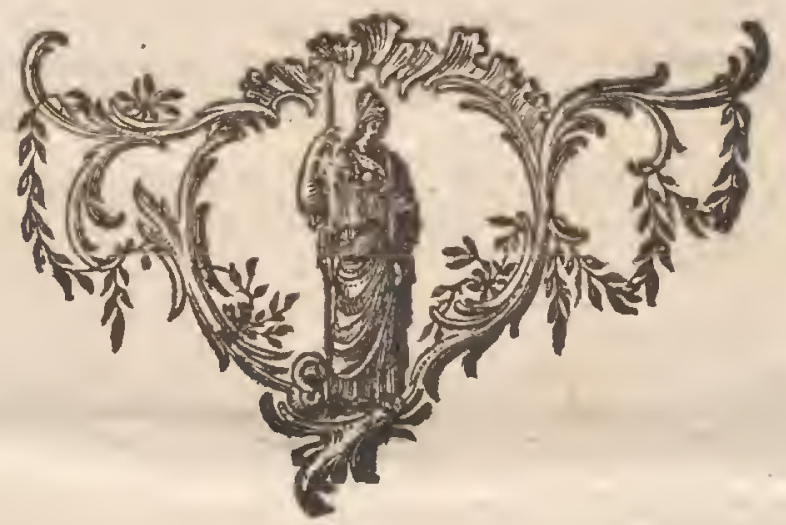




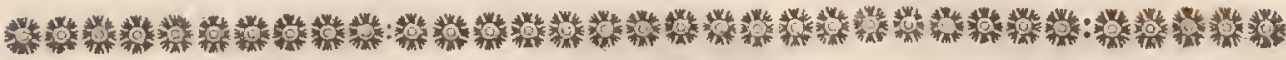

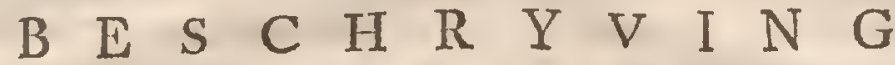

\section{VAN DAT GEDEELTE VAN HET KABINET,}

\author{
HETWELK BETREKKING HEEFT TOT DE NATUURLYKE HISTORIE
}

\section{VAN DEN RATON, DEN COATI EN DEN AGOUTI.}

No. DCCCXXVIII. Een gonge raton.

Dit diertje is maar zes duim drie lynen lang van het einde van den bek tot, aan 't begin van den ftart, die én duim negen lynen lang is. Schoon hy, naar evenredigheid des lighaams, minder lengte heeft dan in den volwaffen ftant, het blykt egter dat dit jonge dier een raton is, zo door de geftalte des lighanms als de kleur des hairs; illzonderheid door twee zwarte vlakken; die onder de oogen zyn, en door ringen, beurtelings grauw en bruin, die op den ftaart zyn.

No. DCCCXX1X. Het vel van een raton.

Het is dat van het dier, dat ten onderwerpe voor onze befchryving gediend heeft.

No. DCCCXXX. Het geraamite van een raton.

Dit geraamte is van het zelfde dier, als het gemelde vel; het is anderhalf voet lang, van het einde des bovenften kaakbeens tot het agterfte gedeclte der heupbeenderen; de omtrek van den kop, aan de dikfte plaats gemeeten, is van agt duim.

No. DCCCXXXI. Het tongbeen van een raton.

Het beftant uit negen beentjes; de tweede zyn van dezelfite lengte als de takken van de vork, en de derde zyn de kleinfte van allen.

No. DCCCXXXII. Het ruedebeen van een ratut.

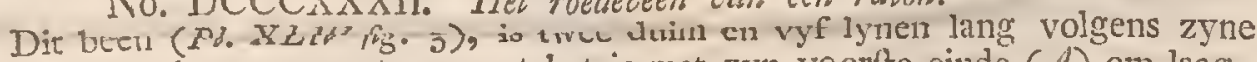
twee krommingen gemeeten, want het is met zyn voorfte einde $(A)$ om lang, en met $7 y+1$ agterfte einde $(B)$ om hoog gekromd; het heeft tien lynen omtreks aan de dikfte plaats $(C)$.

No. 1)CCCXXXIII. De buid van een coati.

Het is deze, warvan op blz. eIo van dit Deel gewag gemaakt iș.

No. DCCCXXXIV. Een coati in royngeft.

Deze coati is een wyfje en fchynt van dezelfde foort te zyn als die, welke ten onderwerpe voor de befchryving van dit dier gediend heeft $(a)$, het is ten naaftenby van dezelfde grootte, want het heeft een voet vyf en een haif duim lengte van het einde van den bek tot aan 't begin van den ftart; het

(s) Zie blz. 2 II van dit Deel. 
varfchilt 'er alleenlyk van in eenige fchaduwingen van dekleur des hairs; want het neusbeen heeft een zwartagtige kleur, en eenige zweemzels van graur zonder cenige vertooning van rosagtig: de rand van de bovenfte lip, het onderft kaakbeen, de keel, het bovenit en de zyden van den hals, de borft, de buik, de omtrek van den aars, de oxels, de liezen, en de binnenzyde der vier pooten zyn rosagtig, geelagtig, of llegts van eene grauwe, ligtelyk met geel gemengde, kleur, gelyk in het wyfje, dat reeds befchreeven is $(b)$; maar dit heeft daarenboven nog eene donkere dageraad-en zelfs roodagtige, kleur op den hals, op het voorfte gedeclte van de borft, en op de oxels; men ziet geen geelagtig op het binnenft gedeelte van de dije en vanden poot, noch rosagtig op de vier voeten; de ftaart van dit wyfje is geknot en gedeeltelyk kaal, gelyk die van het ander; het hair dat overgebleeven is, heeft dezelfde kleuren by deze twee dieren, en zy gelyken malkanderen volmaakt in figuir en makzel van alle de deelen des lighaams.

No. DCCCXXXV. Het geraamte van een coati.

Dit geraamte is van den coati, die ten onderwerpe voor de befchryving van dit dier gediend heeft; deszelfs lengte is van een voet vier en een half duim - van het einde des bovenften kaakbeens tot het agterft einde der heupbeenderen; de kop heeft zes duim drie lynen omtreks op de dikfte plats genomen.

No. DCCCXXXVI. Het tongbeen van een coati.

Het beftant uit negen beenderen; de eerfte zyn byna zo lang als de takken van de vork, en langer dan de tweede beenderen.

No. DCCCXXXVII. Een jonge agouti in wyngecft.

Dit diertje is mar zeven duimen lang vain het einde van den bek tot aan 't begin des ltatarts, die maar vicr lynen lang is; men bemerkt reeds op 't hair van dezen jongen agouti de eerfte zweemzels van alle de kleuren van den volwaffen ttaat.

No. DCCCXXXVIII. Een jonge agouti gedroogd.

Deze agouti is wat kleiner dande voorgande, maar ly heeft reeds dezelfde kleuren.

No. DCCCXXXIX. Het vel van een agouti.

Dit is het vel van den agouti, die ten onderwerpe voor de befchryving van dit dier gediend heeft.

No. DCCCXL. Hes geraamte van een agouti.

Dit geraamte is van " $t$ zelfie dier als het ftraks gemelde vel; het is een voet drie en een half duim lang van het einde der neusbeenderen tot het agterft einde der heupbeenderen; de omtrek van den kop, ain de dikfte plaats genomen, is van zes duimen.

No. DCCCXLT. Het tongbeen van een agousi.

Het beftat uit negen beenderen; de eerfte zyn de langfte van allen; de tweede zy'll byna even lang als de derde; het middelfte been van de vork is zeer breed, en heeft eene verlenging die zig voorwaards uitftrekt.

No. DCCCXLII.

(b) Zie weder blz. 2 It van dit Deel, 
No. DCCCXLII. Het roedebeen van een agouti.

Dit been is negen lynen lang, drie on een half lyn breed aan ' $t$ een einde, en flegts anderhalf lyn aan ' $t$ ander einde; dit breede gedeelte is holrond aan zyne onderite zyde, en bolrond an de bovenfte. No. DCCCXLIII. Een geraamie, dat veel overeenkomft beeft met
dat van den agouti.

Dit gernante was in 't Kabinet onder den naam van Indifche rot; het is grooter dan dat van den agouti onder No. DCCCXL gemeld, want het is een voet agt en een half duim lang van het einde der neusbeenderen tot aan het einde der heupbeenderen: voor het overige heb ik in deze twee geraamten, met malkanderen vergeleeken, niet dan al te geringe verfcheidenheden opgemerkt, om te vermoeden dat $z y$ van dieren van verfchillende foorten zyn.

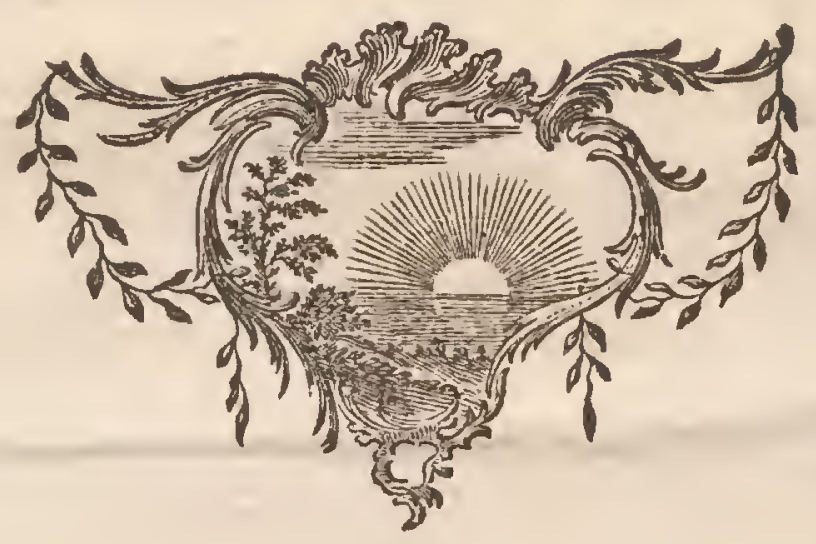

VIII. Deel. 
In dit agtfte Deel zyn LIV Plaaten, die op de volgende wyze noeten ingezet rvorden.

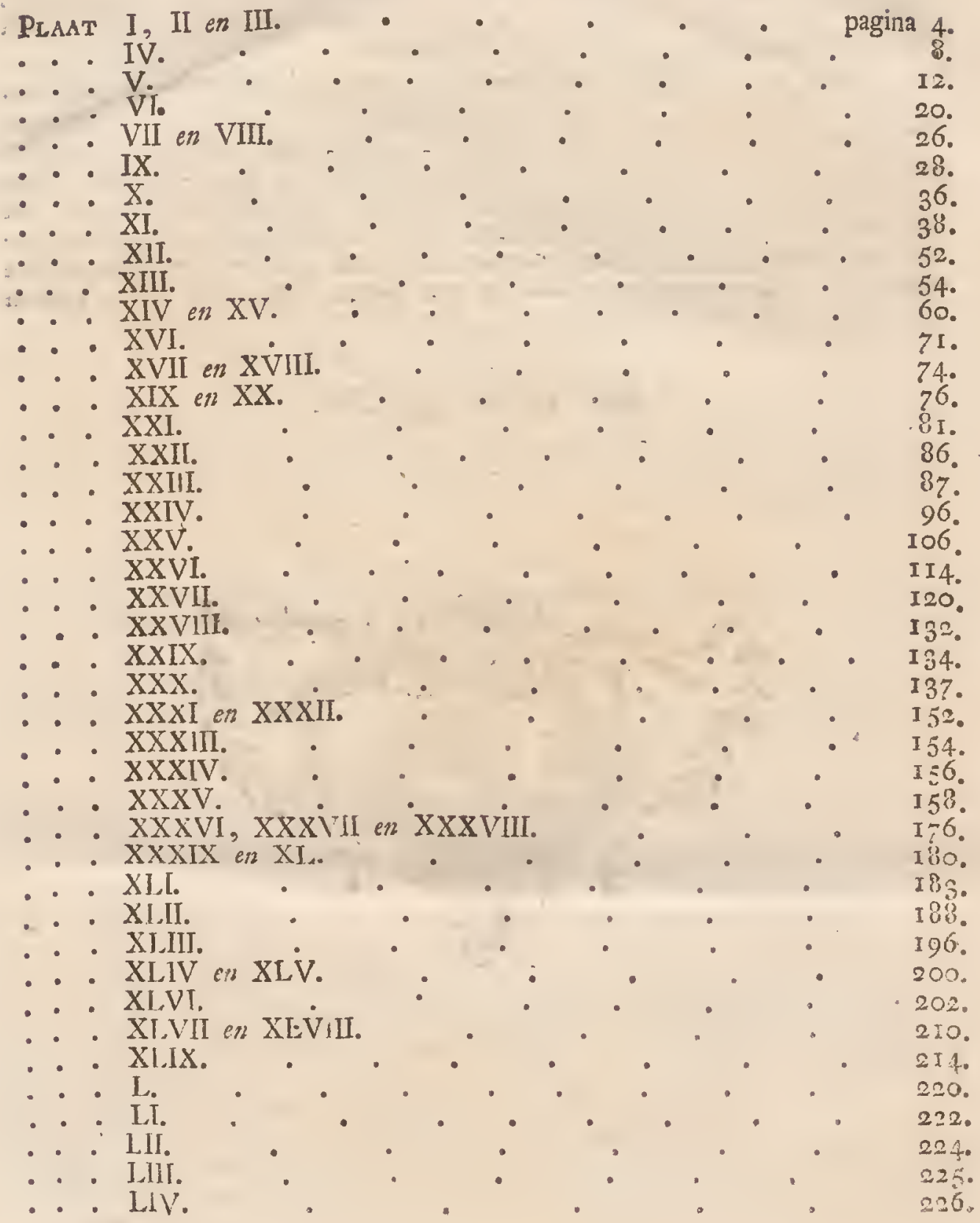









